(6-

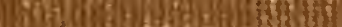

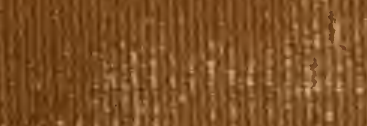
15. Afy

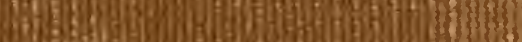
(150) for E.

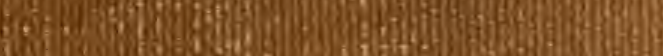

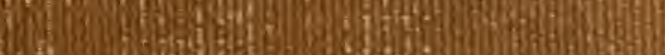

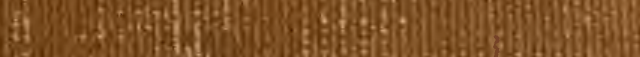

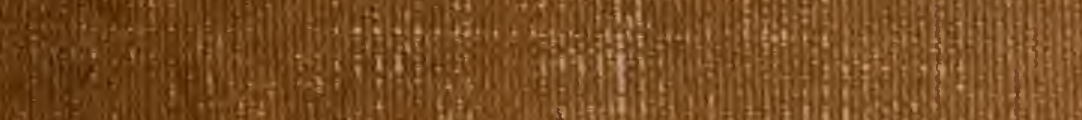

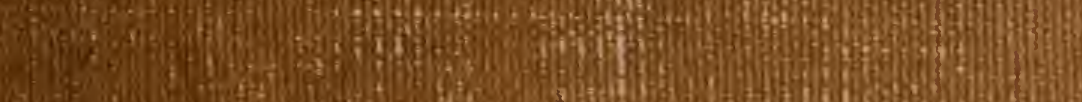
(2)

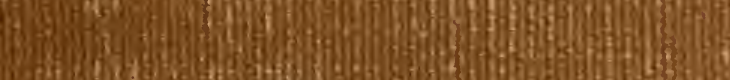
I.t.

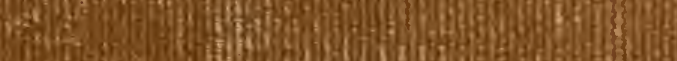

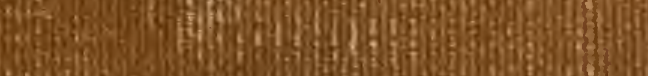
Fof (3) 3.

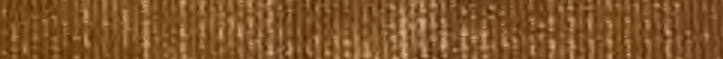
s.

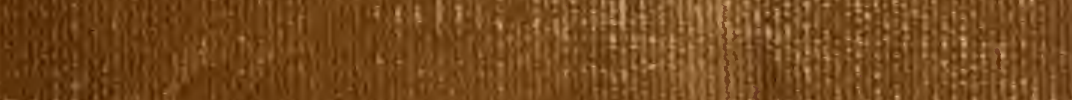
H. M

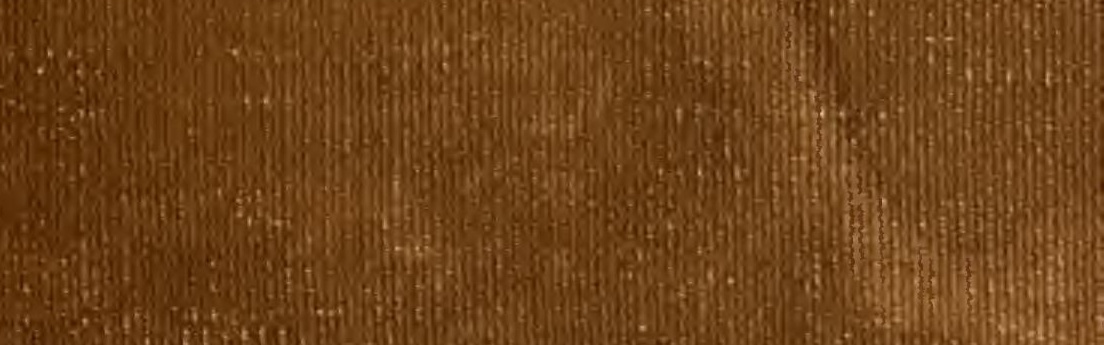
3.

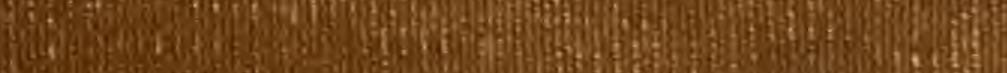

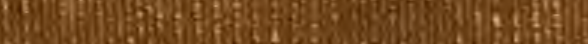

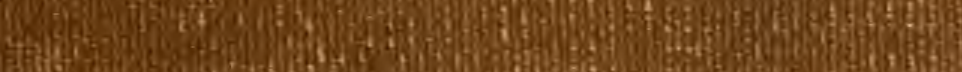

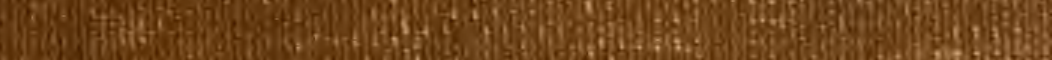
mow 7.

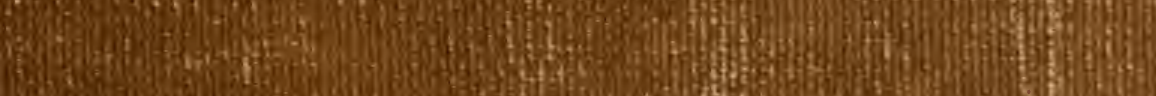
(3)

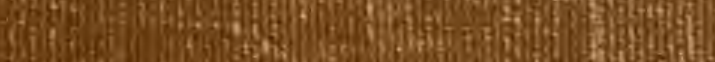

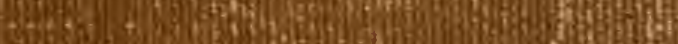




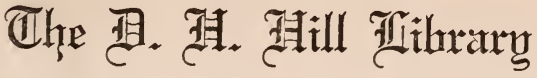

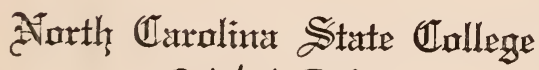
QK475 B6
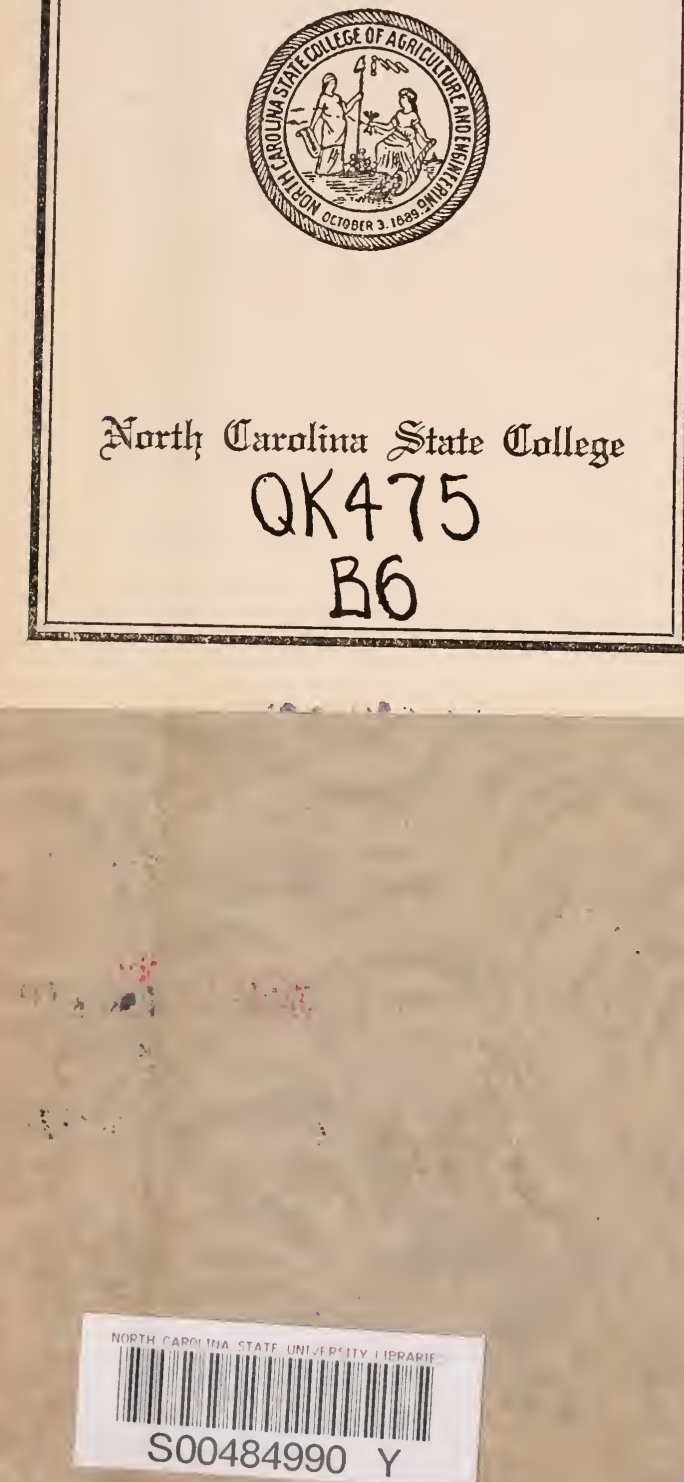
This book may be kept out TWO WEEKS ONLY, and is subject to a fine of FIVE CENTS a day thereafter. It is due on the day indicated below:

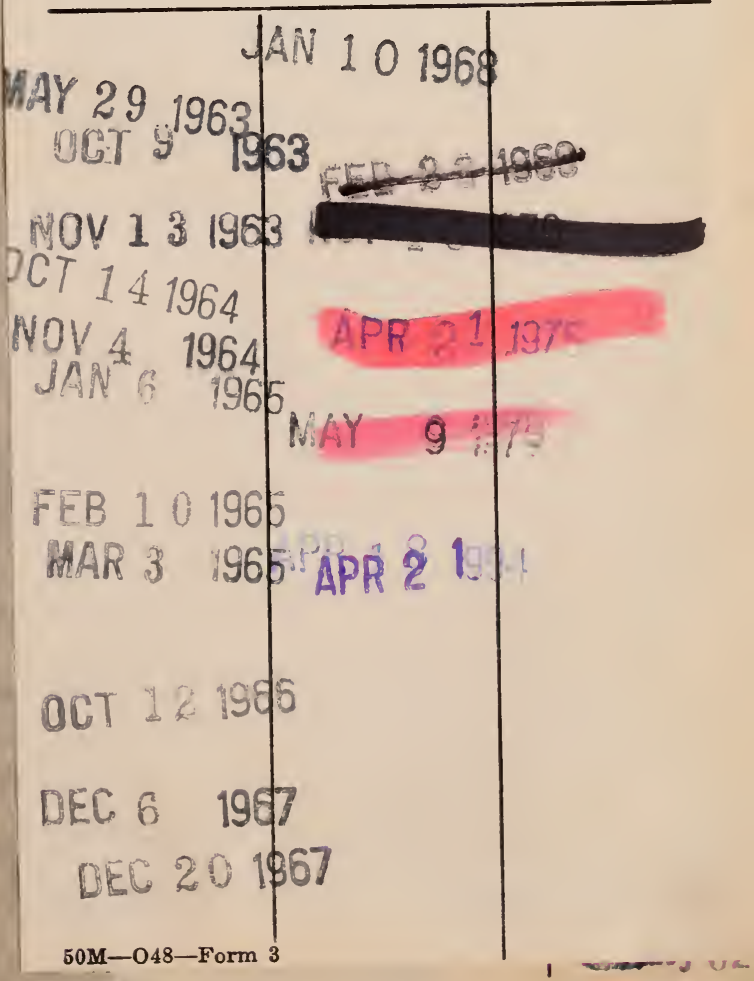




TREES IN WINTER 


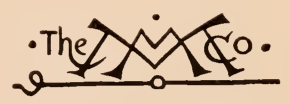

THE MACMILLAN COMPANY

NEW YORK - BOSTON - CHICAGO

DALI.AS - SAN FRANCISCO

MACMILLAN \& CO., Limited

LONDON - BOMBAY - CALCUTTA

MELBOURNE

THE MACMILLAN CO. OF CANADA, LTD. TORONTO 


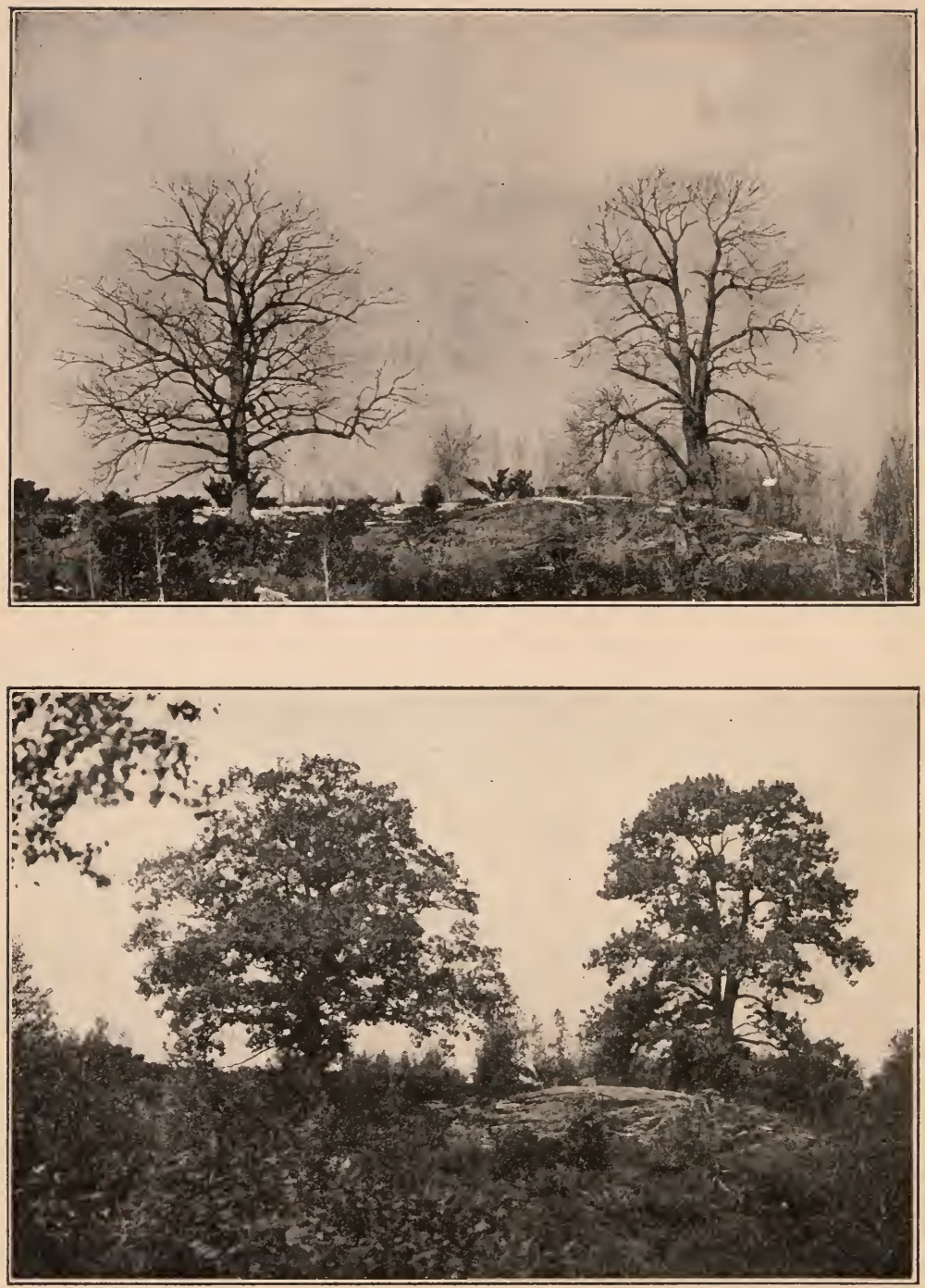

OAK AND CHESTNUT IN WINTER AND IN SUMMER • 


\title{
TREES IN WINTER
}

\author{
THEIR STUDY \\ PLANTING, CARE AND \\ IDENTIFICATION
}

\begin{abstract}
BY
ALBERT FRANCIS BLAKESLEE, Ph. D.,

PROFESSOR OF BOTANY A N D

DIRECTOR OF SUMMER SCHOOL CONNECTICUT AGRICULTURAL COLLEGE

AND

ChESTER DEACON JARVIS, Ph. D.,

HORTICULTURIST, STORRS

EXPERIMENT STATION
\end{abstract}

ILLUSTRATED

Nirrur 21ork

THE MACMILLAN COMPANY

1913

All rights reserved 
Copyright, 1913,

BY THE MACMILLAN COMPANY.

Set up and electrotyped. Published January, x913. 


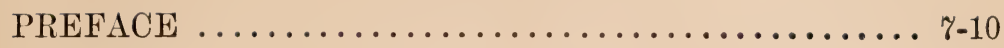

\section{INTRODUCTION}

TFE STUDY OF TREES

Tree identification-Tree study in relation to poetry and art-tree photography-tree ecology-tree measurement - tree collections-tree study in high schools and colleges-field work-students' collections-tree study in graded schools.

\section{PART I., PLANTING AND GARE OF TREES}

CHAPTER I

STRUCTURE, LIFE AND GROWTH OF A TREE .... 31-45

The parts of a tree-the root-the leaf-the stemreproduction.

\section{CHAPTER II}

THE PROPAGATION OF TREES ............. 46-60

Propagation from seeds-nature's way- the forest nursery - collecting seeds for planting-storing seeds-testing the vitality of seeds-planting seeds-care of seedlingstransplanting — propagation by cuttings—making cuttings — setting cuttings-propagation by graftage-graftingbudding.

\section{CHAPTER III}

TREE PLANTING IN RURAL DISTRICTS ........ 61-74 The conservation of good scenery - a national park system — sign boards must go-arousing interest-the problem of the country roads-making the best use of existing conditions-roadside planting - the use of trees around the home-adaptation-the function of trees in home decoration-shrubs-planting for winter effect-the planting plan-the finished picture.
6022 
TREE PLANTING IN TOWNS AND CITIES ..... . 75-95

Trees in relation to city life-suggestions for street planting-arrangement of trees on the street-parking strips-permanent and temporary planting-the best species for city streets-trees of rapid growth-municipal control of shade trees-parks and public squares-the natural type-the artificial style-planting suggestions for city homes-types of city homes-the suburban lot-back yard planting.

\section{CHAPTER V}

\section{THE SELECTION OF TREES FOR SPECIAL PUR-} POSES ........................... 96-101

Trees with showy flowers-blooming before or with the leaves-blooming after the leaves - trees with showy fruits -trees with strikingly-colored foliage-trees with brilliant autumnal tints-deciduous trees valued for their winter effects-very tall trees-columnar or narrow pyramidal trees-weeping trees-trees resistant to smoke-desirable shade and avenue trees-trees for seaside planting-trees for dry situations and dry climates-trees best adapted to wet soils-trees best adapted to calcareous or limestone soils-varieties of fruit trees for home planting-apples, pears, quinces, peaches, plums, cherries.

\section{CHAPTER VI}

HOW TREES ARE PLANTED . . . . . . . . . . 102-113

Preliminary considerations-prune before plantingpreparing the ground-staking the ground-setting the trees-time to plant-making the holes and filling inmoving large trees-staking and guarding young treesstakes-guards-grills. 
THE CARE OF TREES . ................ 114-123

Improving soil conditions-the need of humus in the soil - fertilizers for trees-cultivation-pruning shade treeshow to cut off a limb-time to prune-pruning toolstaking care of the wounds.

\section{CHAPTER VIII}

COMMON INJURIES TO SHADE TREES ........ 124-145

Sources of injury-injuries cansed by gas and smokeinjuries from overhead wires-injuries from regrading streets-injuries from improper pruning-injuries from horse bites and careless driving-injuries from wind and ice-injuries from improper soil conditions-renovation of trees-the natural age limit-tree surgery-dehorning trees-taking care of recent injuries-filling cavitiesbolting and chaining.

\section{CHAPTER IX}

\section{THE CONTROL OF PARASITES ............ 146-173}

Fungus troubles-insect troubles-how insects injure trees -methods of combating insects-spraying for insectshand-picking of insects-banding and trapping-preventive measures-natural enemies of insects-some common shade tree insects-leaf-eating insects-bag worm, brown-tail moth, canker worm, elm-leaf beetle, gypsy moth, slugs, spiney elm caterpillar, tent caterpillar and fall webworm, tussock moth-sucking-insects-aphis or plant louse, spruce gall louse-scale insects-borers.

\section{CHAPTER X}

INSECTICIDES, FUNGICIDES AND SPRAYING . . 1\%4-182 Insecticides-stomach poisons-contact insecticidesfungicides-spraying-spraying machinery. 


\section{PART II., IDENTIFICATION OF TREES}

EXPLANATION OF TERMS ............... 185

ANALYTICAL KEY ..................... 192

METHOD OF USE, KEY TO GENERA AND SPECIES.

DESCRIPTION OF SPECIES ................. 210

The Pines (p. 210-221) -the Larch (p. 222)-the Spruces (p. 224-233) - the Douglas Fir (p. 234)-the Balsam Fir (p. 236) - the Hemlock (p. 238)-the Coast White Cedar (p. 240) - the Arbor Vitae (p. 242)-the Junipers and Red Cedar (p. 244-24\%) - the Ginkgo (p. 248) -the Willows (p. 250)-the Poplars (p. 252263)-the Walnuts and Hickories (p. 264-275)-the Hornbeams (p. 276-279) - the Birches (p. 280-291) - the Alders (p. 292) - the Beech (p. 294) - the Chestnut (p. 296) - the Oaks (p. 298-321)-the Elms (p. 322329 ) - the Hackberry (p. 330)-the Mulberries (p. 332335) - the Magnolias (p. 336-339)-the Tulip Tree (p. 340)-the Sassafras (p. 342)-the Witch Hazel (p. 344)-the Sweet Gum (p. 346) - the Sycamore (p. 348)-the Pear (p. 350)-the Apple (p. 352)-the Mountain Ash (p. 354)-the Quince (p. 356)-the Shadbush (p. 358) - the Hawthorns (p. 360)-the Cherries (p. 362-3\%1) 一the Plums (p. 3\%2-3\%\%) 一the Peach (p. 378)-the Kentucky Coffee Tree (p. 380)-the Honey Locust (p. 382) - the Redbud (p. 384)-the Yellow IVood (p. 386) - the Locusts (p. 388) - the Ailanthus (p. 390) - the Sumachs (p. 392-395) - the Holly (p. 396) — the Maples (p. 398-413) - the Horse-chestnut (p. 414) -the Linden (p. 416)-the Dogwoods (p. 418)-the the Tupelo (p. 420)-the Ashes (p. 422-42\%)-the Catalpas (p. 428). 


\section{PREFACE}

The title, Trees in Winter, might seem to one unacquainted with the subject to confine the usefulness of this book to the months December, January and February. Winter, as we shall use the term, is not defined by the human calendar. It is that period when the tree is in its resting condition, and may be considered to extend from the shedding of the leaves in the fall to the bursting of buds in the spring. The period is different for different trees and in different localities, but in the northeastern United States it may begin as early as the latter part of September, with such forms as the Butternut, and may extend even into the middle of May with the Catalpa. The title would further emphasize the general rule brought out in Part I that the buying, planting, and care of trees should take place only in their dormant condition. Such exceptional treatment as spraying for leaf diseases will be discussed for the sake of completeness but it still remains true that a tree generally would better be left untouched during its growing season. The material in Part II, first appeared in pamphlet form as a bulletin of the Storrs Agricultural Experiment Station. The demand for the bulletin, especially for use in the schools, has proven so great throughout the state that it seems desirable to publish the information in book form and thus render it more widely available than could be the case in a state publication of necessarily limited distribution.

Part I, on the planting and care of trees, has been added in carrying out the suggestion of the publishers and many of our correspondents who have thought that such an introductory part would broaden the usefulness of the book, especially among those who possess trees of their own. The section is written primarily for the individual and his home grounds rather than for a municipal street planting commission. The viewpoint, therefore, will be more that of the country and of the home than that of the city. No especial originality is claimed for the material in this part, a considerable number of publications including government bulletins have been consulted in its preparation. If the arrangement of the subject matter renders nceded information easily obtainable, it will have served its purpose.

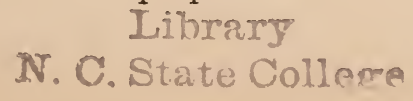


Part II is intended as a guide to the indentification of our common trees in winter. Although lumbering and the commercial handling of trees is chiefly carried on in the leafless season and their identification at this period consequently is of the greatest importance, still there has been up to the present time little assistance accessible in this country to one who has wished to be able to distinguish the trees in their interesting winter condition.

The text with keys in Part II, is an outgrowth of outlines that one of the authors has developed and used with various modifications for the last five years in his college classes in Botany and Forestry. The photographic illustrations are all originals, most of them by the other author. In Part II, one of us is responsible for the text and for the selection of the material photographed, and the other for the majority of the photographs, while in Part I, one of us has written the introductory chapter on the study of trees and the chapter on the structure, life and growth of a tree, and the other the subsequent chapters. We have, however, frequently consulted throughout in the preparation of the book.

The order of arrangement of the species in the text and the scientific names follow the usage of the seventh edition of Gray's Manual, and the latter are in accord with the rules laid down in the Vienna Congress. The figures and descriptions given are of trees for the most part growing wild in the northeastern portion of North America, including as its center New England, and the neighboring regions. A few rarer species which occur only very locally or in isolated instances within this region have been omitted from illustration. In their places, however, some of the more frequently cultivated trees have been included because of their value for forestry purposes or because of their familiarity in ornamental plantings. The varieties of cultivated forms are so numerous that it is obviously possible to take account of only the most common types. Their inclusion, it is believed, will add to the value of the publication especially for its use in cities. The keys can be absolutely relied upon only for the species just mentioned from New England and the neighboring regions. New England, including as it does the meeting ground between the northern and southern floras, is extremely rich in the species of trees represented. Part II, therefore, especially in its descriptive text and illustrations 
should prove of service outside of the geographically restricted region described.

The photographs of the twigs and of the fruit of the deciduous trees are very nearly natural size. They have been slightly reduced in production but all of them to same scale, except the fruits of the Catalpa, the Chestnut and the Honey Locust as indicated under these species. Line drawings or touched-up photographs would no doubt show important details more clearly by emphasizing certain of the minute markings. Since, however, these details are often obscure, and moreover receive full recognition in the accompanying text, it has been thought that a truer idea of the twigs would be gained if they were left as they appeared in the photographs. Accordingly, they have not been "doctored" in preparation or reproduction. The leafy twigs of the cone-bearing evergreens have been more or less reduced as indicated under the descriptions of the genera in the key. All the twigs of a single genus, however, are on the same scale.

Part II follows the same general plan as in the bulletin. Another winter's study has made possible a number of additions, especially among the habit characters and some minor corrections have been made in the text. New habit photographs are given of the Red Mulberry, the Sassafras, the Swamp White Oak and the Chinquapin Oak and bark photographs of the Carolina Poplar and the Chinquapin Oak. Last winter's classes in Botany and Forestry made use of galley proofs of the keys and descriptive text, and the present year's classes have used the finished bulletin. The keys especially have in consequence been considerably modified since their first arrangement. Many of the explanatory phrases which may appear to be unnecessary have been inserted at the demand of the students. Where possible the most obvious characters have been employed and though the keys in consequence have become somewhat more cumbersome it is hoped they will prove more usable. Errors and omissions have no doubt crept in despite the efforts to avoid them. We would be grateful for any additions or corrections that may be suggested in the descriptions or keys in view of a possible further revision of the text

Acnowledgements are due to the Storrs Agricultural Experiment Station for the use of the half tone plates of figures $34,3 \%, 38,45$, 48, 49, and 50 in Part I, and for most of those in Part II; to 
the Connecticut Agricultural Experiment Station for the use of illustrations represented by figures $30,44,46,47,5 \%, 75,76,7 \%$, $78,79,80,81,82,83,84,85,86,87,88,89,90,91,92,93$ and 95 ; to the Cornell Experiment Station for the use of figures $41,42,51,52,53,55,62,68$ and 69 ; to the U. S. Department of Agriculture for the use of figures $71,72, \gamma 3,74$ and 98 ; to Messrs. Isaac Hicks and Son for the use of figures 39 and 40 ; to the Newark Shade Tree Commission for the use of figure 54; to the Frost Bartlett Company for the use of figures 61, 63, 70, and 96 ; to Mr. A. D. Taylor for the use of figure 23; to Mr. George A. Cromie for the drawing represented by figure 36 ; to $\mathrm{P}$. B. Mann for taking one of the habit photographs of the Sassafras on page 342 ; to Mr. J. M. Johnson for taking the habit photograph of the Red Mulberry on page 332, to Mr. C. C. Laney for the habit and bark photographs of the Chinquapin Oak on page 306 ; to Mr. A. F. Schulze for compiling the index; to many other people for assistance in various ways; and especially to the students whose interest in trees in winter first suggested this publication and whose cooperation in its production has helped to give it its finished form.

Albert Francis Blakeslee. Chester Deacon Jarvis.

Storrs, Conn., March 1912. 


\section{INTRODUCTION.}

\section{THE STUDY OF TREES.}

It is frequently the practice in an introductory chapter to show the importance of the subject to be discussed and to attempt to prove that it, of all subjects for study, is most worthy of the 'eader's consideration. Many words could thus be used in describing the misfortune to civilization, literature and art had our world been devoid of trees and the product of trees. The forester and the lumberman bear testimony to the utilitarian value of trees and the landscape architect to their use in making our surroundings more beautiful. It is not necessary, therefore, to justify the interest in our subject.

Although the botanical specialist and the student of tree diseases, may, it is hoped, find in the present volume added means of identifying their tree specimens, the book is not intended primarily for the indoor laboratory. It is meant to serve as an introduction to the study and appreciation of one phase of outdoor life. The present chapter will suggest some of the ways in which the study of trees may be carried on.

Tree Identification - In the early stages of knowledge come names. If one objects that so large a part of the book is given over to the means of distinguishing one tree from anotherin other words to learning their names-it must be remembered that the natural approach toward knowing a person is learning his name. It is not otherwise with trees. We who are teachers know the difficulties in learning the names in a new class of students. Some of us may have devised temporary expedients as jotting down in our roll book such distinguishing facial characteristics of the students as the color of the eyes or of the hair. No doubt, if it were worth while, a satisfactory key to the identification of a class of students could be worked out by the use of such characters. We have never tried it with our students because we have soon come to know them less by such detailed marks of distinction than by the whole face and we finally learn to recognize them even at a distance by some indefinable peculiarity of form or habit of gait.

The more minute characters of the twig used in the keys and descriptive text are to be used as we use the color of the hair and 
eyes in learning our new students. The ideal toward which identificational studies should tend is the ability to recognize a tree at a distance. Unfortunately the general appearance or "habit" of a tree as well as the character of its bark is difficult of precise description, but if the markings on the twigs are considered chiefly as first aids to the uninitiated, progress toward this ideal will be more surely made.

Winter is the best time in which to acquire this ability to recognize trees at a distance. They are individually more conspicuous at this season. Try watching them from a car window in their winter aspect and you will be surprised to find how many can be thus recognized after a little practice. A tree in winter 'is far from being the characterless object many believe. Freed from its covering of leaves, the skeleton of the tree is revealed and with the method of branching thus clearly discernible, the species may generally be more readily identified at a distance than when in its summer garb. There are many forms, moreover, that are difficult to distinguish by summer features alone, but which in winter have twig, bud, or other characters which make their separation comparatively easy.

We have suggested as the goal of identificational study the power to recognize trees by the more general features of "habit" and bark. The present volume can be considered only as an introduction toward this study. Extreme care has been taken in the attempt to obtain photographs that will represent the most typical appearance of these features. It must be remembered, however, that no two trees are absolutely alike but that they vary more or less as shown on page $18+$ in response to difference in external conditions as, for example, age, soil, light (figs. 18 and $19 \mathrm{p}$. 39 ), and locality as well as to innate differences in the individual trees themselves. Considerations of space forbid usually the illustration of more than a single type and this in general, in connection with the descriptive text, will suffice. It is hoped, however, that the present volume will stimulate similar illustrative work on other more limited areas or on more limited groups where the restrictions of space for illustrations need not be so keenly felt.

When once we have begun to acquire a resonable familiarity with trees, numerous ways in which the study may be advanced will occur to the reader. The possibilities in Forestry and Landscape 
Architecture need not be discussed, although some knowiedge of these professional subjects will be of special interest to anyone who owns a woodlot or landed home, and will be of general interest to all citizens to whom national conservation of our resources in natural beanty as well as in natural wealth is a matter of concern.

Tree Study in Relation to Poetry and Art-Trees to most people are of interest aside from their scientific or utilitarian value. It is surprising to many to learn that only a small proportion of the large number of books on trees have been written primarily from the botanical or the utilitarian point of view. The marjority view trees as elements in the world of beauty out of doors. The highest expression of an appeciation of this beauty appears in the form of poetry or art. It will accordingly be well to consider trees for a moment from this viewpoint before further discussing their study.

Poetry is not an unintelligible ebullition of enthusiasm for the good, the true, the beautiful. Poetry demands sympathy. Sympathy entails familiarity, knowledge; and knowledge is power in poetry as in business. It is no accident that before a winter book on trees was ever thought of and the color of the bud used to distinguish the European Ash from some of its American relatives, Tennyson was able to characterize a lock of hair as "black as ash buds in the front of March," and was able to see "a thousand emeralds burst from the ruby-budded lime." Few can have a productive appreciation for poetry, but if we learn to see clearly and with sympathy the natural beauty around us we have learned the foundations upon which poetry is based.

Trees are the most conspicuous living elements in the landscape, especially in winter, and as such must appeal strongly to the student of outcloor life. To the landscape artist they are more than canvas or pigments, for they are themselves the picture which on canvas with his pigments he tries to reproduce. If we study art we are led to visit the museums of art. We learn how in different times and in different countries men have seen and interpreted beauty. Some, for example, find beauty in the single form, others in groups. The result is as varied as the personality of the artists. Although an advance can be discerned in the method of expression and, by the process of evolution, such guid- 
ing principles as simplicity and unity have become generally accepted, still it can be readily seen that art has its styles as well as dress. Landscape architecture has undergone a development and is subject to changes like other forms of art.

The landscape is a gallery of art always open. The pictures are many, varied, and ever changing. Trees are the principal figures. They are interesting for their individual beauty and for their effect in harmonious groups. It is for us to find these pictures, to discover what in form or composition or situation makes them interesting. The student of art does the same for the gallery masterpieces and opens his eyes to new worlds of beauty. We also may have our eyes opened, for the landscape is always with us.

Profitable indeed in this connection will be a study of the landscape artists. In what way do trees appeal to them? What part do trees play in their compositions? Is it the individual tree or trees in groups that interest them most? Is it in the foreground, the background or the middle distance that we find them most frequently represented? What species are preferred? Compare Ruysdael, Corot, Constable and other landscape artists. Are they alike in their preference?

Claude Monet has given us a wonderful series of pictures of the Thames Bridge in varying moods. We may find for ourselves as interesting a series of even a single tree (figs. 1 to 11). Along a sloping roadside by a farm house stands a Sugar Maple of some eighty winters. Looked at from east or west the tree is narrowperhaps from crowding in its youth by neighbors now no longer present. From north or south the crown shows the broad, eggshaped outline more typical of the species. On the eastern side are several ragged limbs broken some four or five years since by an ice storm that blew in a too heavy load of sleet from the east. On the western side the tree seems perfect. From above on the north its outlines are partially blocked by buildings and obscured by the background of the fields below. From the south it seems to raise its head and shows the limbs clear-cut above the sky line. From a distance it is a conspicuous landmark and always interesting. We can picture the tree from different viewpoints. We can see it in different lights and shadows. We can follow the changes in the background of the picture-the bare ground, the snow, the green fields; the mists, the rain, the full sunlight, the long shadows and

Fig. 1. (Upper right hand figure) the tree viewed from the south. Fig. 2. (Middle right hand figure) the tree viewed from the west. Fig. 3. (Lower right hand figure) the tree viewed from the east.

Fig. 4. (Upper left hand figure) the tree from the north.

Fig. 5. (Middle left hand figure) the tree in an ice storm.

Fig. 6. (Lower left hand figure) the tree in summer foliage. 


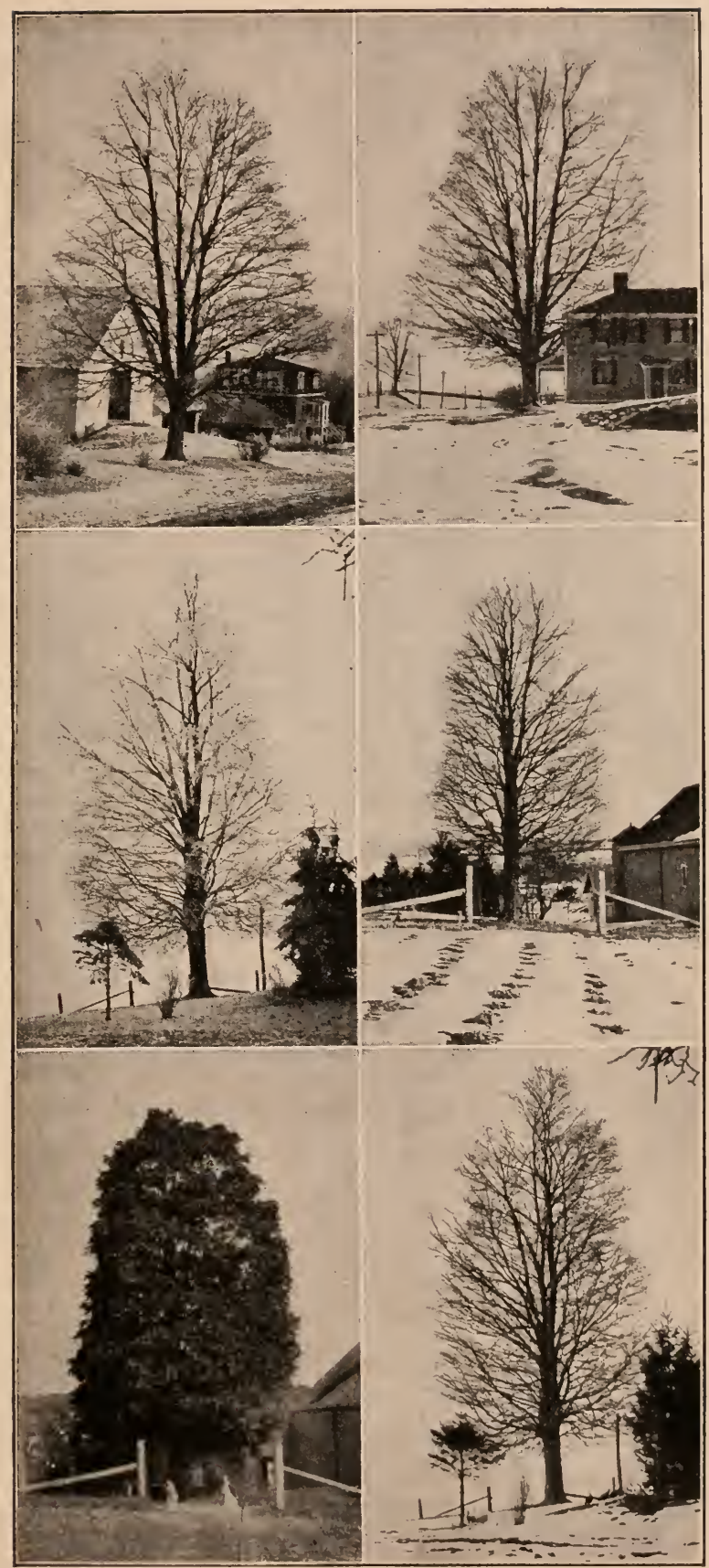

Figures 1-6. A Sugar Maple. See footnote page 14. 


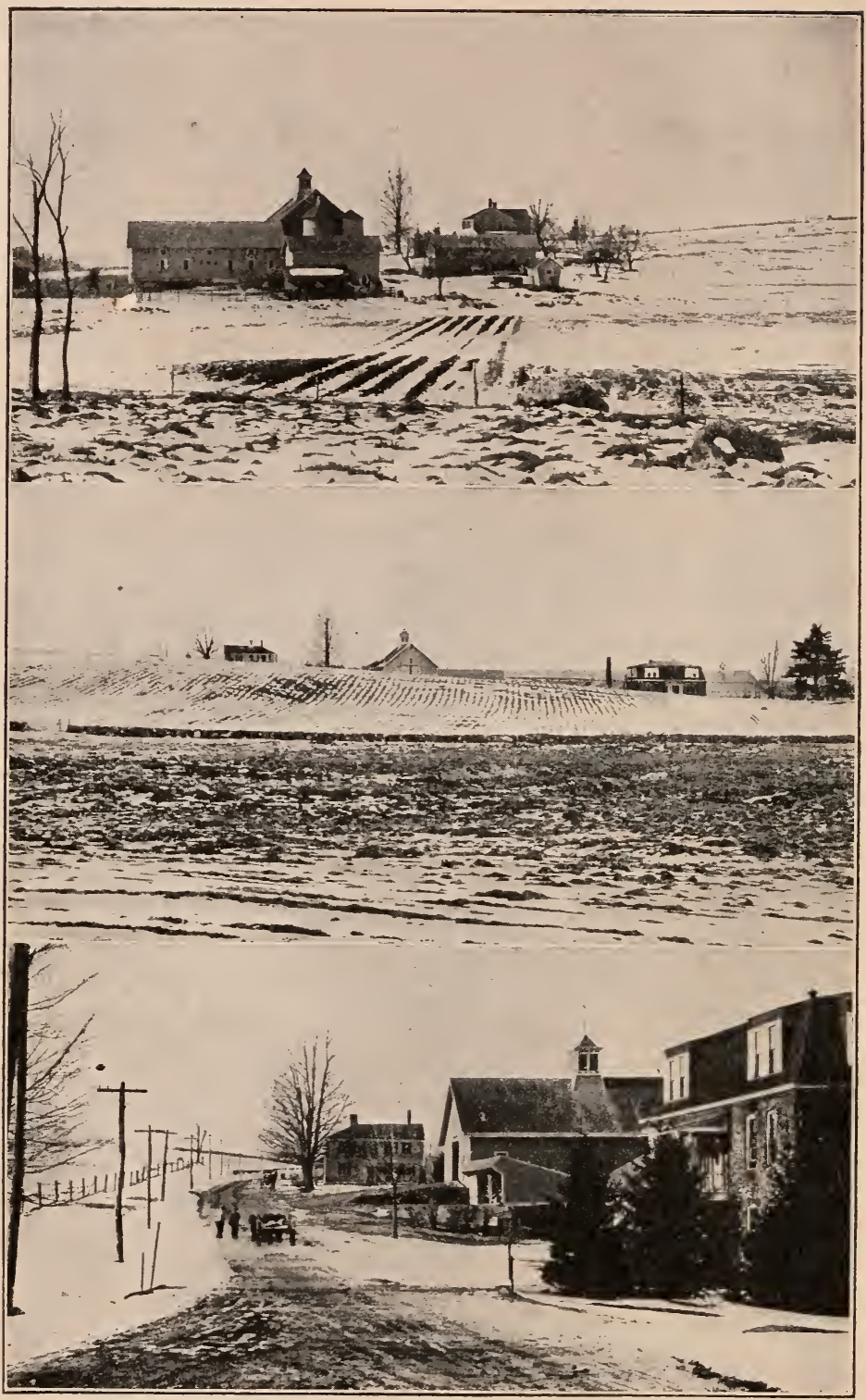

THE SAME MAPLE SEEN FROM A DISTANCE

Fig. 7. (Upper figure) across the meadow.

Fig. 8. (Middle figure) beyond the cornfield.

Fig. 9. (Lower figure) up the road. 


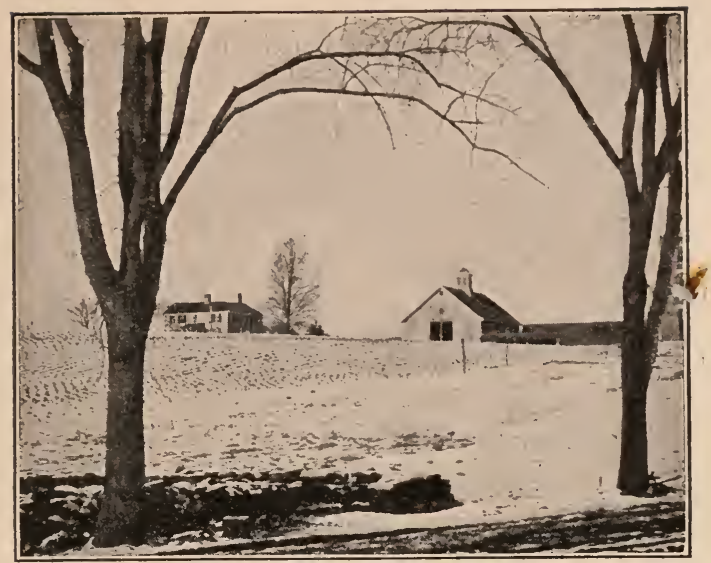

Fig. 10. The Maple framed in by Elms.

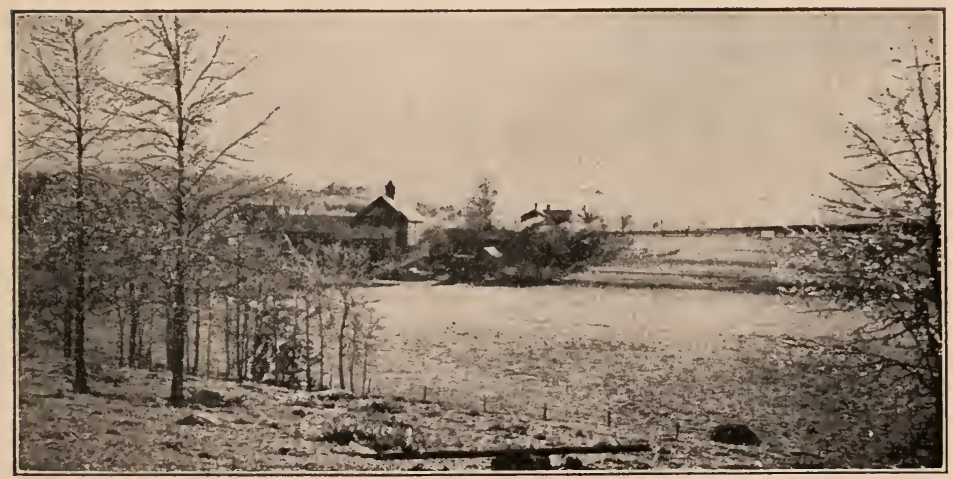

Fig. 11. The Maple in sunlight and shadow.

the bright tints at sunset or at dawn. We can watch the changes in the tree itself, can note in winter its type of branching and the fine penciling of its twigs against the sky, in spring the opening of its buds and the rapid growth of flower and leaf, in summer the full foliage, in autumn the rich leaf coloring and the fall of leaf and fruit.

A swing hangs from a broad spreading lower limb. Children play about it. Robins have built their nests in its branches and here they rear their young. Throughout the long, hot summer days its dense covering of leares gives a grateful shade below. To 
the sleepy child the moonlight casts weird fairy shadows of the limbs upon the bedroom floor and the soft rustle of its leaves lulls him to sleep. Is there great wonder then that in after years this same child holds the old family tree dear-an inseparable part of his youth. The tree has helped to make the house a home. We have been viewing a tree in its human relations. Such a view may not be botany, but whoever has had a home with a tree, knows that it is life.

Tree Photography - It is fortunate for us who are not painters that the photographic camera offers a means of recording the pictures as we find them. The ground glass or the "finder" on the camera or even an empty frame held at varying distances from the eye will separate for us the view from its surroundings. Only experience however, will show what results to expect in the developed picture. In general better effects will be obtained from near views or from distant views with prominent features in the foreground.

The condition and position of the sunlight are matters of prime importance in the photographing of trees. Full light is desirable and the sun should be somewhat behind and considerably to one side of the camera. If light comes from behind the tree a mere silhouette of the branching is obtained, while if the light is directly back of the camera the trunk and crown appear flat from lack of contrast. When one side of the trunk, as viewed from the camera, appears dark and the other side in direct sunlight, all the branches of the tree in the finished picture, as well as the trunk, will appear solid. The position of the light is of even more importance in photographing the bark. Depressions and ridges seem to disappear when the light shines directly against them and a somewhat lateral illumination is therefore necessary to bring out the details of the bark sculpturing.

The position of the camera must also be considered. A tree viewed from below appears different from what it would if viewed on the level and from a distance. Habit views are often taken too near the trees. Moreover, the camera is generally placed below the usual eye level and this position tends to give the tree an unnatural appearance. It is generally useless to attempt to show much detail in the method of branching of an individual tree if the crown cannot be seen clear above the sky line. A cover- 
ing of snow, however, may offer as good a background as the sky and allow a tree to be photographed against a hillside where otherwise a satisfactory photograph would not be possible (p. 35\%). A white sheet held behind the trunk may afford an artificial background for a bark photograph. Generally this is not necessary since bark photographs are taken at close range and the surrounding objects are mostly out of focus. If need be, the background can be painted out on the negative. For habit pictures in sunlight we have found a No. 16 stop and 1/25-1/20 second exposure to give good results when the wind will allow so long an exposure. For bark pictures the smallest stop and a proportionately longer exposure, say $1 / 2$ to 1 second, will give the greater detail desired in such pictures.

To one interested in botany as an avocation, trees furnish an especially available subject for outdoor study. They are accessible in city or in country, in winter or in summer. Their size renders them conspicuous. They can accordingly be studied from a carriage, an automobile, or a rapidly moving train, and in this way much learned that would be impossible to discover if the study were confined to a single locality or if the student were dealing with smaller forms.

Tree Ecology - Ecology, the study of plants in relation to their environment, finds in trees a most convenient group in which to carry on investigations. The subject is comparatively new and many problems are as yet unsolved. After some familiarity has been gained with the trees that grow in one's own locality, it will be possible to discover something about their distribution. A list of the local tree flora of one's state, county or town or even of a more restricted area has a distinct value if carefully made, but it is far from being the end of tree study. What trees are usually found growing together and what are the causes that bring them to be thus associated? Is there a swamp "association," a dry hillside association or other associations of more or less well marked character? What is the influence exerted upon the various species by differences in character of the soil and its chemical composition - the presence or absence of lime for example-the amount of available moisture, the altitude, the exposure to the sun and wind on different sides of a hill or mountain, the climate and other such 
factors and how do they become effective? What influence do they have upon the growth of the individual tree?

If a woods is cut down or burned over or if a pasture is neglected, what are the first trees most likely to grow up? How have they come there? Are these the trees that will prevail after fifty or one hundred years? What is the character of the "climax forests" in the region investigated? In the northeastern part of the United States there is no lack of deserted pastures in all stages of return to the forest condition and old, gnarled apple trees even, the remnant of some forgotten orchard, may be found still living in the midst of the woods and completely surrounded by forest trees. These various stages of development may be pieced together and may enable us to make out the order of "forest succession."

The climate of a given locality is the resultant of such diverse factors as latitude, altitude, rainfall and exposure to wind and sun. It is expressed by the character of the regetation. The length of the growing season, from the gradual awakening of growth in the spring till its cessation in the fall, is of prime importance to agriculture. Are the springs and falls early or late in a given locality? The progress of the seasons can best be measured in terms of tree activities, such as the appearance of the leares and flowers, the ripening of the fruit and the falling of the leaves in different species. Observations of these points in the yearly history of different species of trees is of so much importance in measuring general and local climate, that the Forest Service, Washington, D. C., is attempting to obtain records on this subject from as many different places as possible. They will gladly send record blanks to anyone willing to co-operate with them in making observations. The time of opening of the bud, of flowering and of leaf fall if accurately recorded, especially for a series of years, although for only a single species, will be information of value.

The life of the individual tree will well repay our study. What are the problems that it must solve in order to lead a successful existence, and how are these problems solved by different kinds of trees? These questions are discussed in Chapter II. The effect of external conditions upon the habit is touched upon in Part II.

Tree Measurement - The information regarding the dimensions of a tree are of minor importance for purposes of identification, but are of considerable value to the woodsman. The diameter of the 
trunk may be best measured directly by calipers at breast height from the ground or indirectly obtained by dividing the circumference by 3 (more accurately by $\pi=3.1416$ ). A number of rough methods of estimating height are given in books on forestry. For example, from a distance equal to several times the length of the tree, the height of a $10 \mathrm{ft}$. pole beside the trunk or a mark on the trunk of known height may be compared with the height of the whe tree.

The height to which one can reach may be determined by trial and this kept in mind as a unit of measure. A piece of paper is fastened to the trunk at this height from the ground. From a distance, with arm fully extended, we measure off with the finger on a lead pencil the height of the paper from the ground which we will imagine to be 7 feet. Using this distance on the pencil as a scale, we continue sighting upward and find that the top of the tree is $81 / 2$ units, let us say, from its base. Each unit being 7 feet the total height is, therefore, approximately $591 / 2$ feet. Experience has shown that if the distance from which the sights are made is at least three or four times the height of the tree and the arm is kept fully extended during the process of sighting, the results show a fair degree of accuracy.

The shadow of the tree may be compared with the shadow of an erect pole of known height and the height of the tree computed by the rule of three. A right angle triangle constructed of wood or cardboard with two sides equal may be used as a measure. One of the equal sides is kept vertical by an attached plumb line and sights are made along the long edge from different distances till the top of the tree is just seen above the line of sight. The distance paced to the tree gives the height of its top abore the eye. Instead of using a triangle to find the point from which to pace to the tree, German foresters are said to sometimes use a cruder method which consists in bending over with the back to the tree and finding the distance where the top is just visible when viewed with the head between the knees. This method, however, has natural limitations. The last three methods are conditional upon the tree standing upon approximately level ground.

Instruments for more accurate measurement are on the market under the name of hypsometers. A home-made instrument may readily be constructed which has been found to compare faror- 
ably in accuracy with the expensive Faustmann hypsometer of which it is a modification. A rectangular board about a foot in length is ruled in squares or more conveniently has squared co-

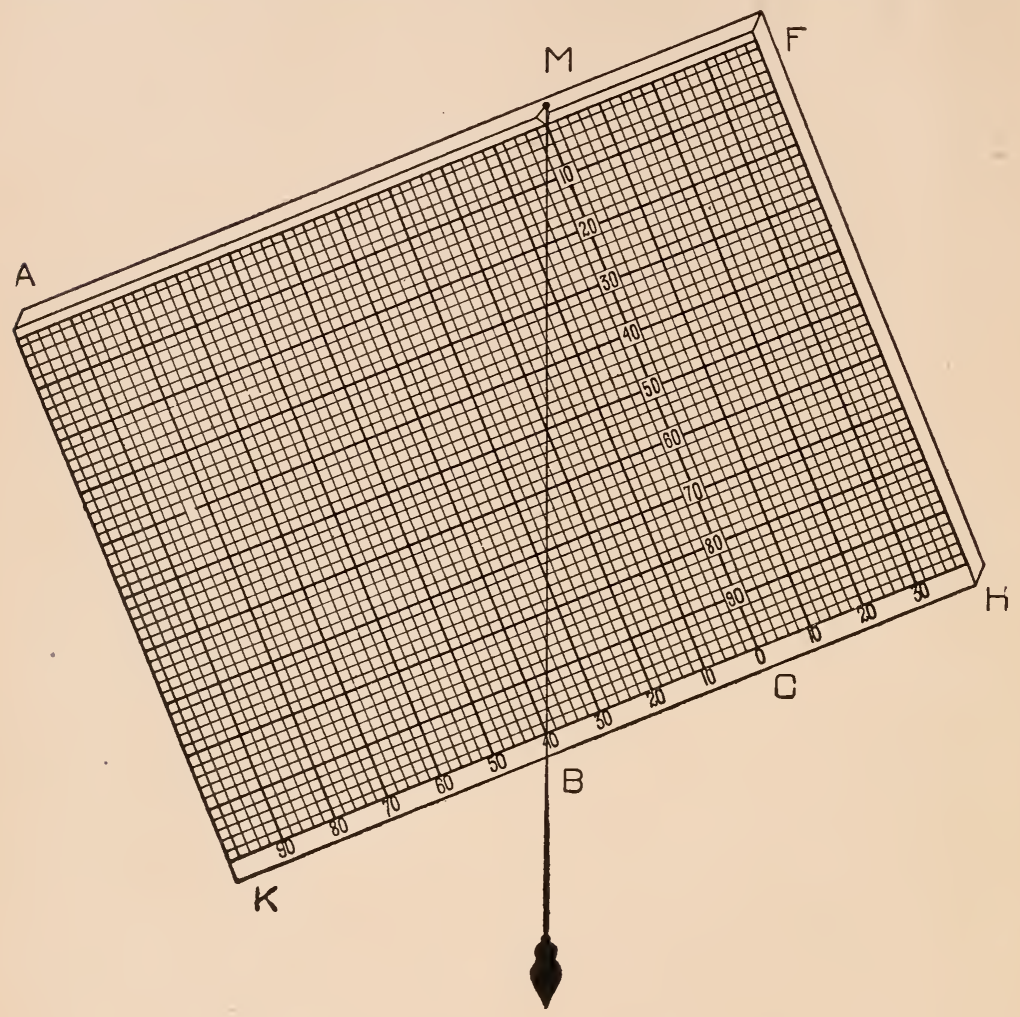

Fig. 12. Home-made Height Measurer.

ordinate paper pasted on one side (fig. 12). Care should be observed that the top of the board AF is straight and accurately parallel to the lines running lengthwise of the paper. The line $\mathrm{MC}$ is numbered from $\mathrm{M}$ in any convenient unit, say up to 100 , and using the same unit, the line $\mathrm{HK}$ is numbered in both directions beginning at $\mathrm{C}$. A thread with a weight is attached at M and hangs free from the zero point at the top of MC. In use a convenient distance, say $100 \mathrm{ft}$. from the tree, is first measured off as a base line, and upon this measurement largely depends the accuracy of the height estimation. At the $100 \mathrm{ft}$. mark the 
top of the tree is sighted along the straight edge AF which may more conveniently be fitted with some simple form of sights. At the point $\mathrm{B}$, where the plumb line crosses the line CK the height of the tree above the eye is indicated in feet. The height of the eye above the ground is added to this reading if the measurement is on the level, or a second sight may be made to the base of the tree and the reading noted on $\mathrm{CH}$ added or subtracted, according to whether the base of the tree is below or above the eye level. If in the instrument as figured, the base line had been $100 \mathrm{ft}$. as suggested, the height of the tree above the eye is given as $40 \mathrm{ft}$. If, however, the base line had been $50 \mathrm{ft}$. the height is given at 20 ft., the reading being taken at the intersection of the thread with the line running lengthwise through whatever number on MC has been used to represent the base line. The two smaller diagrams show the instrument in position for sighting to top and base of tree respectively. In figure 13 the eye is assumed to be on the level

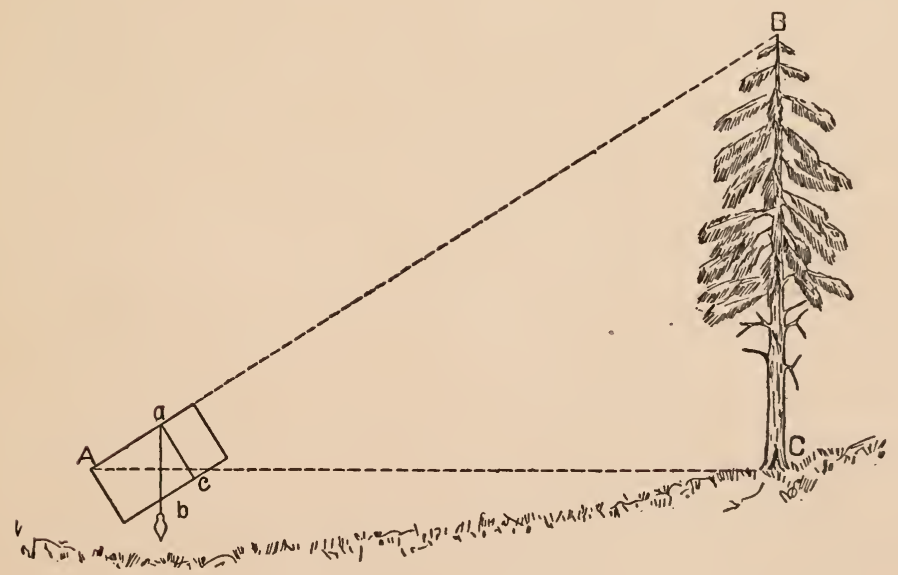

Fig. 13. Height Measurer in position for sighting to top of tree.

with the base of the tree and only a single sight is necessary. In figure 14, the base of tree is below eye level and the distance CD must be found by a downward sight and added to the reading obtained for BC. It can be readily seen from inspection of the figures that the method is based upon the similarity of the triangles $\mathrm{ABC}$ and $\mathrm{ACD}$ with the smaller triangles abe and acd. 


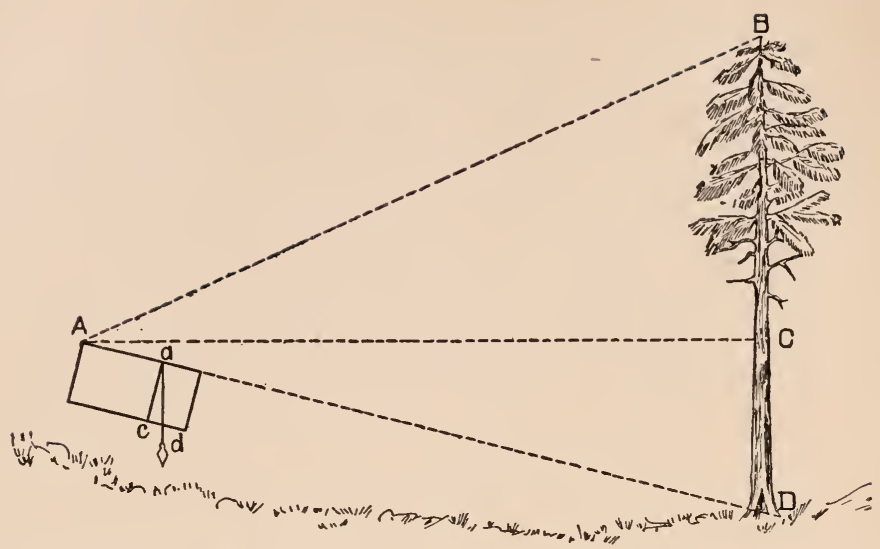

Fig. 14. Height Measurer in position for sighting to base of tree.

Tree Collections - The collecting instinct is said to be one of the early marks of a naturalist. Whether this is true or not, it is certain that the gathering and arranging of a collection is a sure means of becoming familiar with objects of natural history. For many it has an irresistable fascination. To the specialist in systematic botany, a well ordered collection is indispensable. In any large herbarium it will be found that a considerable part of the collections have been contributed by amateurs. It is not enough to have a species represented by a single specimen. All parts of the plant should be collected in different stages of development. It is surprising, therefore, that even the best herbaria are strongly in need of material illustrating the winter condition of woody plants, although the winter twigs form one of the best means of identifying tree species. Plants vary so much, whatever mark of distinction is considered, that specimens are desired from different situations and from different geographical regions in order to show how widely the individual species may vary. The possibilities of collecting, therefore, are practically limitless to those who are interested in this form of study.

In the preceding paragraphs, some of the methods of tree study that it has been thought might prove suggestive to the amateur individual student of the subject have been outlined. In the remaining sections of the chapter, the subject of tree study in schools will be briefly considered. Forestry schools and for- 
estry classes nee not be discussed in this connection. An intimate practical knowledge of trees is the goal of their existence.

Tree Study in High Schools and Colleges - Botany in colleges and in high schools under college influences gives in general little encouragement for outdoor work. This is due in part to the relative ease of handling students indoors, but more perhaps to a reaction against the somewhat narrow botany of the earlier naturalists which consisted largely in becoming familiar with the mere names of the individual plant species. In consequence, students after taking an elementary course in the subject sometimes complain that of the common forms they meet every day they are no better able to tell one plant from another.

Botany, aside from the subject matter it may offer to the botanical specialist, to the horticulturist, or to the forester, may reasonably be included with other sciences in a general college course upon two grounds: - First, the power it may be expected to give the student to observe accurately, to form correct conclusions from the facts in hand and to express his thoughts with clearness: Second, the accumulation of a body of facts that will tend to make the world about us more intelligible and life, therefore, more interesting. Too frequently we forget that the student and the student's viewpoint are of more importance than botany and the botanist's viewpoint. True a certain amount of knowledge of the internal structure and physiology of plants is necessary to an understanding of their life activities and rightly forms a prominent part of the result obtained from a general course in botany. To make anatomy and physiology the total result is to take somewhat the viewpoint of those books on systematic botany which refuse to consider a plant that has acquired enough human interest to be brought into cultivation, unless the form in question is also found growing wild.

The questions of a layman will often give us a clue as to what parts of our subject are of most general interest. The inner mechanisms and functions of a bird may be nearly of as much interest to the laboratcry specialist as they are of value to the bird itself, yet they are of minor interest to the general public. In the writer's experience, Bird Study and Tree Study form two of the most popular summer school courses, and largely it is believed because their air has been an out-of-doors acquaintance with common forms 
of wide familiarity. If, in our general course, we should teach our plant forms more from the standpoint of the human interest they arouse, and less from that of their evolutionary relationships. we need not thereby suffer in either of our ideals of training for power or of acquiring a stock of useful information. Even the much-maligned analysis work, the identification of plants by an artificial key, has certain peculiar educational advantages too often neglected. The use of a key demands accurate observation and careful judgment. If these are not given, the student discovers his mistake by failure to find the correct species and is automatically led to repeat his observations.

Field Work - Field work to be successful must be fully as carefully planned as indoor laboratory work. In order to prevent the exercise from degenerating into a mere picnic, the purpose of the trip should be definite and the objects to be observed or the problems to be studied not too numerous. It is as important to decide what to leave out as what to include. The ground to be visited should be gone over by the teacher before each excursion for the same reason that demonstration experiments in physics or chemistry must be tried in private in order to insure their successful performance before a class.

Experience has shown that some form of report, though but brief, is as necessary with students out of doors as their records made within the laboratory. Further, the number of students that can be successfully handled on a field trip is a matter to be considered. It will differ with the character of the work and the skill of the teacher. Lack of proper regard for some of the requirements of outdoor work with students has often foreordained well-meaning efforts to failure, but such failures do not detract from the education value of the work when properly planned and executed.

The writer has conducted his identificational tree study in the following manner. A squad of students provided with writing material is brought to the first tree to be investigated and without being told its name they are asked to write down independently, each for himself, what they think the tree is. After they have made their guess, its correct name is given and they are led to work out the distinguishing characteristics of the tree taking with them for later comparison specimens of leaves, twigs or fruit ac- 
cording to the season. Each tree on the trip is first guessed by the student before it is discussed by the instructor. A correct guess counts 1 for such forms as the Tulip Tree, which is the only one of its genus in the region. Sugar Maple if correctly guessed would score 2, since there are several Maples to be distinguished. The guess, Maple or Red Maple for the Sugar Maple, would score 1, or one-half the value given the full correct name. At the end of the trip the trees are reviewed from the specimens collected and the individual scores of the students calculated and reported. Naturally these scores are not counted at all as marks in making up the class standing, but the scoring game has been found to add a decided zest to the exercises. The report called for consists of a list of the trees studied with a very brief characterization of the distinguishing features of each. At the beginning of each new trip, the trees of the previous exercises are reviewed from specimens. These frequent reviews are essential. Occasionally, quizzes consisting in identifying actual specimens on exhibition or the trees themselves are of value. In summer the distinguishing characters have been taken from the leaves, in winter from the twigs. The latter from reasons of convenience have been studied largely in the laboratory.

Ability to distinguish trees from a distance by habit and bark characters has been much more readily acquired by students than was at first thought possible. On account of weather considerations, this work has been carried on chiefly in March and April, before the opening of the buds and while the method of branching in consequence is still discernible. The process has been the same as in the field exercises already described, except that the student's guess must be made before coming near enough to see the detailed marks of distinction. A closer approach determines the correctness of his first impression. In review, unfamiliar photographs, respectively of the habit and the bark of the tree in question are exposed together and slowly carried from one end of a row of students to the other. This method is in imitation of the car window identification of trees, and it is surprising how readily photographs can be thus recognized when once a familiarity with the distinguishing habit and bark characters has been acquired. Lantern slides would doubtless be of much service in this connection. 
Students' Collections - Students' collections formed a prominent part in the older courses in botany. To identify, collect, press and mount a hundred specimens, as was frequently required, gave certainly an added familiarity with plants, but the amount of mechanical labor involved is unduly large in proportion to the results obtained.

With trees the flowers are of minor interest, leaves and winter twigs furnishing the chief identificational features available for collections. Individual leaves can be easily pressed, placing them between the pages of a book being frequently sufficient. Winter twigs need no preparation before being sewed or otherwise fastened to mounting paper. It has been the writer's practice to require of students a small collection of leaves in the fall and a similar collection of twigs in the winter or early spring. Accompanying each leaf or twig is given a short characterization emphasizing its chief marks of distinction. 'The specimens may be largely collected on the field trips and the mechanical labor of preparation is not excessive.

More elaborate individual work ean be done by the student if time is available. Keys can be worked out for various groups of trees. A tree book may be made including some of the commonest forms within a limited area and representing them by specimens, by drawings, by photographs or by half-tone pictures. Such a tree book may be with or without written matter on each tree represented, but its preparation would assuredly give one knowledge of the trees studied. In the writer's experience the most effective way to learn about trees is to write a book on the subject.

A school collection for permanent exhibition is desirable and warrants a greater outlay of time and labor than could be given to the work by the individual students. Each tree should be repsented by at least a leaf, a winter twig, a picture of the bark and one of the habit. The fruit is also generally desirable. Among the things that can be added to advantage are the flowers, a seedling, an outline map with shaded areas showing the distribution of the species, and a series of wood sections such as may be obtained of R. B. Hough, Lowville, N. Y. These specimens of each species may be mounted together on cotton in shallow, glass-front boxes such as the Riker cases, or conveniently exhibited behind glass which is passepartouted to a firm back in the manner in which pic- 
tures are frequently mounted. Kirkwood in Nature Study Review for January, 1912, describes a method of mounting specimens in large wooden frames, but if many cases are to be stored or exhibited the surface dimensions as also the thickness of the mounts must be kept within limits.

Tree Study in Graded Schools - On account of their conspicuousness, accessibility, beauty and utility, trees have formed an important element in outlines of nature study courses recommended for elementary schools. Coulter \& Patterson in their Practical Nature Study, to mention but a single book, give valuable suggestions on tree study with typical lesson plans and topical outlines by grades and seasons. Farmer's Bulletin No. 468, entitled "Forestry in Nature Study," may be obtained free by addressing The Department of Agriculture, Washington, D. C., and should be in the hands of every teacher interested in nature work. This bulletin gives outlines for courses of study for the different grades and a valuable list of supplementary reading and reference books for nature study teachers together with a key to the more common genera of trees based on leaf characters. In view of the accessibility of this publication and the literature therein cited, it would be inappropriate to enter into an extended discussion of the place of tree study in the elementary schools. The present book would draw attention to the fact that trees in winter are more available for purposes of study than most have believed. The interest shown by classes of summer school teachers in identifying specimens of twigs collected the previous winter indicates that the winter study of trees can be taken up with enthusiasm by teachers in their schools. In our experience, the winter identification of trees has proven to students one of the most interesting subjects of their course. It is of decided value for its training in the power of accurate observation. The work comes at a time when material for natural history study seems scanty and might therefore be used to bridge over the period between fall and spring which are unfortunately considered by many the only seasons when study of outdoor life is possible in the schools.

The markings on a branchlet enable us to read a tree's name. They may also give us a chapter in the tree's past history as is shown on page 38 . By placing twigs in water in the late winter the bud may be forced and we may learn the future possibilities 
that lie bound up in a winter twig. The name of a tree and its past and future life, however, form but an introduction to the study of a tree. What are its relations to utility and to human enjoyment, are questions that should not be neglected. The skillful teacher will be able to correlate tree study with other work and so direct the natural enthusiasm of children for outdoor observation that it may not become a burden to the daily program.

An appreciation of natural beauty is a recognized object of nature study. It must in general, however, remain a valuable by-product rather than the immediate object of pursuit. An unreasoning appeal to mere wonder and admiration at the beauties of nature is likely to have an effect opposite to that desired. The appeal must come in the way of observations and problems and the problems must be definite. What is the most beautiful single tree, individual group of trees, the most beautiful street or the most beautiful home with tree surroundings in the neighborhood? What are the elements that make them interesting? From what points of view are they most pleasing, and what is it that gives these viewpoints an advantage over others? Such questions, modified to suit the grade of the pupils, have been suggested by Professor Waugh of Amherst, and the writer can confirm their usability with students. 


\section{PAR'T I. \\ PLANTING AND CARE OF TREES.} CHAPTER I

\section{STRUCTURE, LIFE AND GROTTH OF A TREE.}

Before discussing the planting and care of trees, it is well to consider briefly the structure, life and growth of the individual tree itself. For a fuller treatment of the subject the reader may be referred to the current text books on botany and forestry.

A tree is a living thing and as such has the same great problems to meet that face all living organisms - plants as well as animals. It must have food in order to live and grow and it must provide for a continuation of its kind. Animals are able to move about in search for their food which they obtain ready made from other animals or from plants. The tree, however, like other green plants is deprived not only of the power of locomotion but also of the power of using food made by other organisms. It has, therefore, to manufacture its own food. This it does by combining food constituents from the soil with that from the air and is therefore a manufacturer as well as a consumer of its own products. In Chapter I, we shall consider the different organs of the tree in relation to the manufacture of plant food, to growth and to production.

The Parts of a Tree-There are three main parts to a tree -roots, leares and stem. The roots obtain water with dissolved mineral water from the soil and anchor the tree in place. The leaves have a double function. They gather carbonic acid gas from the air and they combine this gaseous food constituent from the air with the food constituents from the soil in the manufacture of plant food. The stem connects the roots with the leares and raises the latter to a position favorable for carrying on their work. The three main parts of a tree may now be considered more in detail. The diagram in figure 15 may serve to make the explanations clearer. 


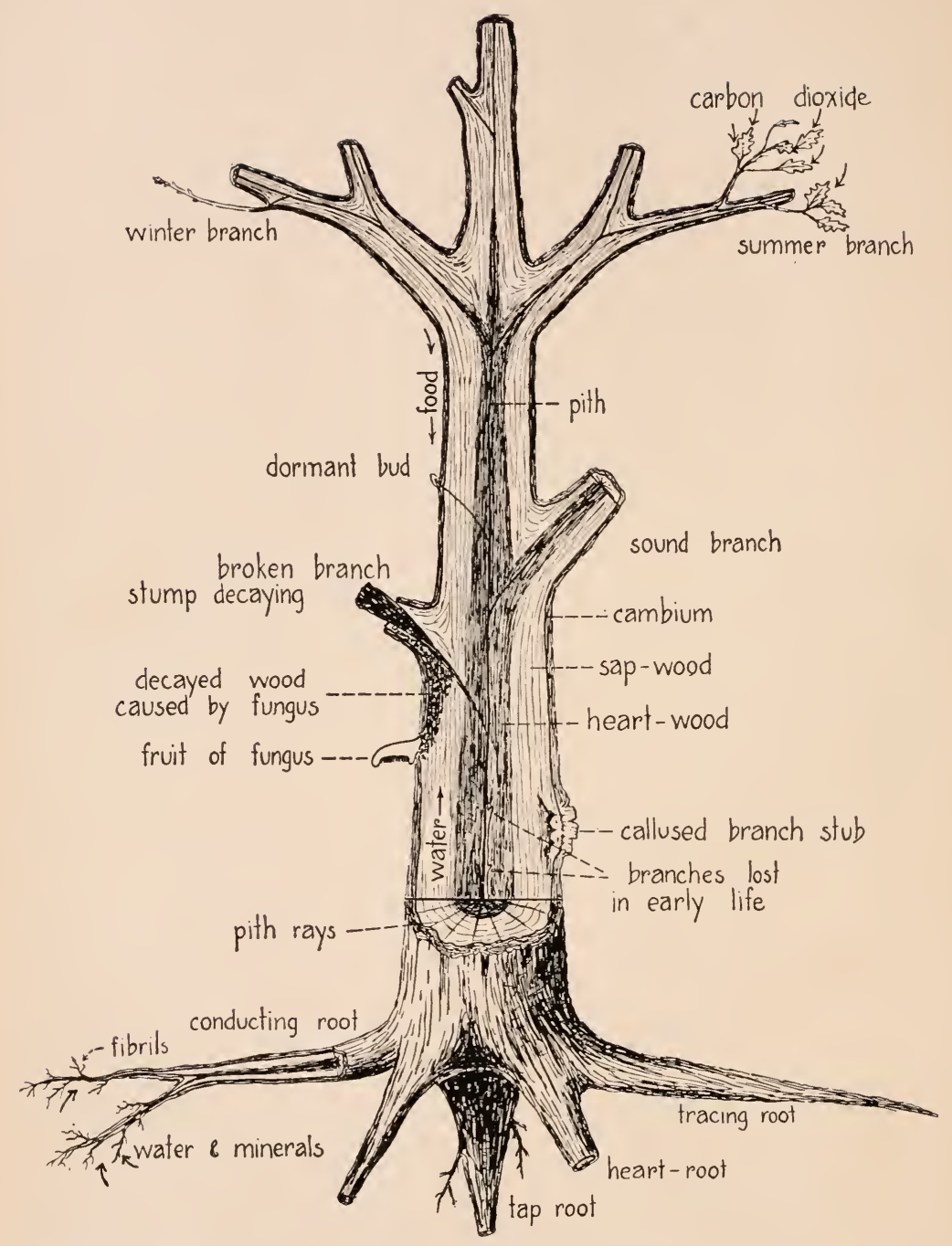

Fig. 15. Diagram to illustrate parts and functions of a tree. (Modified after Fernow). 
The Root-According to their position, the roots of a tree may be classified into tap-roots which grow directly downward, surface or tracing roots which occupy a shallow layer just below ground, and roots which take a position intermediate between these two types. Some trees like the Hickory, the Bur Oak and the White Oak regularly develop a strong deep-seated tap-root and in consequence are able to draw water from the lower levels but are difficult to transplant; others like the Birches and Spruces have only surface roots and are therefore dependent upon the supply of moisture in the shallow upper layers. Most of our trees, like the Maple and Ash, are found to have a combination of both kinds. Many forms, moreover, in which one of these two root types predominates are able to adapt themselves to the condition of the soil in which they grow. Thus at the Minnesota Experiment Station, a small Bur Oak growing on dry, gravelly soil is reported to have developed a tap-root 20 feet long,

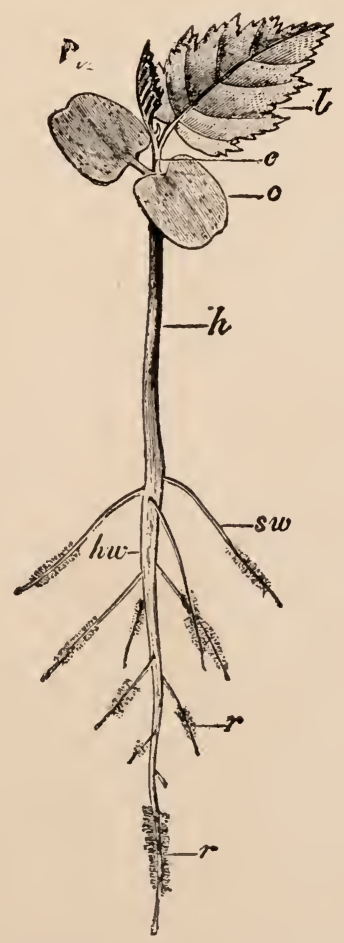

Fig. 16. Seedling of Hornbeam, after Strasburger. $r$ zone of roothairs near root-tip; hw, main roots; sw, lateral roots; 1,1, foliage leaves; c, seed-leaves. 
while on moist, fertile clay land in the same section such trees are believed to have tap-roots seldom more than six feet long.

Absorption of water and minerals in solution is the great service of roots, but it is only their smallest branchlets - the root fibrils — that are capable of taking in water. The older parts are soon covered with a waterproof layer of bark and are of service only in conducting fluids to the stem and in holding the tree in place. The fibrils, moreover, do not take in fluids throughout their whole extent but almost exclusively throngh fine root-hairs, which in the shape of minute tabular cells form a velvety covering on their younger portions (fig. 16). These root-hairs are short-lived, enduring only for a few days or at most weeks. New hairs, however, are constanly being formed toward the root tips as those further back die and shrivel up. In some trees it has been 'shown that fine threads of various species of moulds growing in the soil surround the root fibrils and take the place of root-hairs, but it still remains true that only the youngest parts of roots are capable of absorbing water. It can be readily understood, therefore, how serious the damage may be to the tree when its almost invisible root fibrils are injured in any way as by transplanting. Fortunately roots can rapidly regenerate lost parts and, if the need of water is lessened by judicious pruning of the crown, the new rootlets formed will be able to absorb enough water to keep the tree from withering.

How far roots extend from the trunk is not easy to observe. Roots of the Elm have been found clogging up drain pipes 150 feet from the tree, but such a distance must be exceptional. Garden-. ers claim that the parts underground extend laterally as far as those above ground and such a condition would bring the young feeding rootlets directly under the edges of the leafy crown. While this is far from being strictly true, it should be remembered that the absorbing fibrils are in a circle at some distance from the trunk. In consequence, any such treatment of the soil, as adding water or food constituents, should take place at some distance from the trunk rather than at its base, in order to benefit the tree.

In order to live and grow, roots must have food. This is made for them in the leaves and handed down through the stem and older roots. If the supply of food is diminished by a partial loss of leaves, some of the roots die. If the supply of water and food constituents from the soil is lessened by root injury a part of the leafy crown will die. A rather definite balance exists between the extent of the root system and that of the crown. 


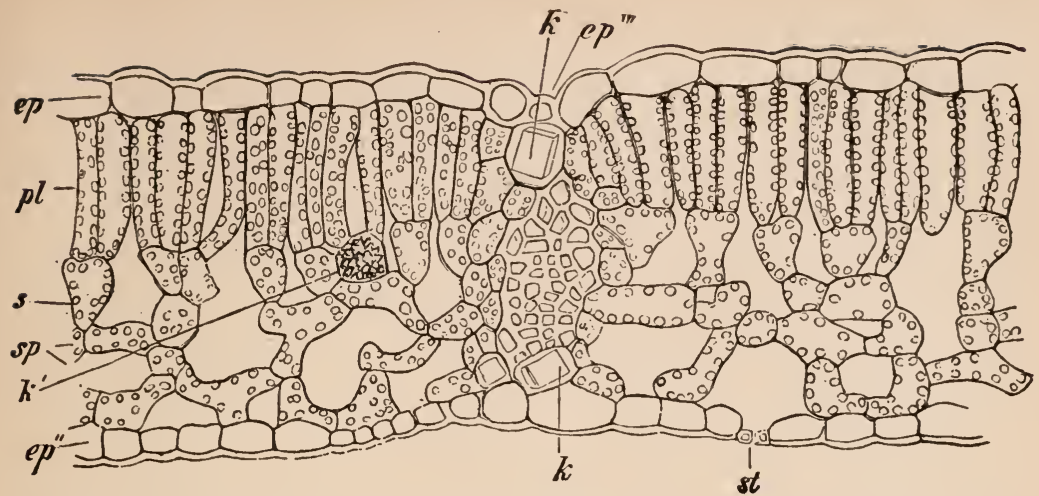

Fig. 17. Cross section through a Beech leaf, after Strasburger. ep, ep", epidermis, the protective covering of upper and lower surface of leaf; pl, $s$ and $\mathrm{sp}$, cells containing little granules of leaf-green or chlorophyll-the places where plant food is made; st, opening through the epidermis connecting the air passages in the leaf with the free air outside.

All parts of plants need oxygen. Roots obtain it from the air in the soil. If the roots are too deeply covered, as when the ground is filled in above them in changing the gradé, or if the air in the soil is driven out by an excess of water, most trees are likely to suffer. Some forms like the Elm, however, are naturally able to endure such unfavorable conditions.

The Leaf - It has been already said that trees are like animals in their general food requirements, but that they have the added characteristic of being able to make out of elements obtained from the soil and from the air the complex food which they require. This manufacture of plant food takes place within the leaf in minute granules of leaf-green or chlorophyll (fig. 1\%). Sunlight is necessary and furnishes the energy for the process. Carbonic acid gas from the air enters through small openings into the leaf and is there broken down into oxygen and carbon. The oxygen is returned to the air in the pure state, while the carbon is united with the water and minerals from the soil. The complex plant food which is thus built up, is transported to all the growing parts of the tree and is used in the construction of new leaves, roots and wood. Carbon is the conspicuous element in wood, comprising one-half of its dry weight, and in the production of charcoal is left in nearly a pure state. When wood is completely burned, the process observed in the leaves is reversed. The water passes off as vapor, the mineral matter is left in the form of ashes, while the carbon reunites with the oxygen of the air in the formation of cabonic acid gas. The leaf may be compared to a factory. Carbonic acid gas, water and dissolved minerals are the raw materials. Plant food 
is the finished product. Sunlight is the energy which runs the machinery.

The fact that sunlight is necessary for the formation of plant food in the leaves, explains the poor development of branches that are partially shaded. The Post Oak, shown on page 101, was interfered with by a neighboring tree on the right. The scant growth of limbs on this side is the result. The lower branches of trees in the woods die and are "self-pruned" when their leaves are so shaded that they are no longer able to make sufficient food for a continuation of growth. It is for this reason. that all forest-grown trees tend to produce tall trunks with but little branching (fig. 19) while trees in the open (fig. 18) branch more freely and are therefore better able to express the habit characters peculiar to the species.

Species of trees differ in their ability to tolerate shading. There are "tolerant" forms like the Hemlock, the Beech and the Sugar Maple that are able to grow under the shade of other trees, and "intolerant" forms like the Poplars and Birches that are killed by a relatively small amount of shading. In planting groups the relative tolerance of the forms represented should be taken into consideration.

Although the leaves are arranged in a position favorable to illumination, they are at the same time exposed to conditions favorable to evaporation. It has been estimated that a Beech 110 years old "transpired" through its leaves approximately 2,250 gallons of water during a single summer and that an Oak with some 700,000 leaves transpired about 180 gallons daily. Such a considerable amount of water lost by the leaves must be made good by the roots or the tree will perish from thirst. A diminished root absorption, brought about by injury during transplanting or caused in any other way, can be neutralized by pruning the crown and thus reducing the amount of leaf surface exposed to evaporation.

- Trees that drop their leaves all at once are called "diciduous" in distinction to our Evergreens which retain their foliage throughout the winter. The latter, however, are not stictly evergreen. In the White Pine for example (page 211), leaf scare can be iound in increasing numbers on second and third year's growth and show that in this species the fall of the foliage is gradual and that its individual leaves usually do not remain on the tree more than three years. The evergreen character is generally associated with conebearing forms. The Holly is the only broad-leaved tree of the 


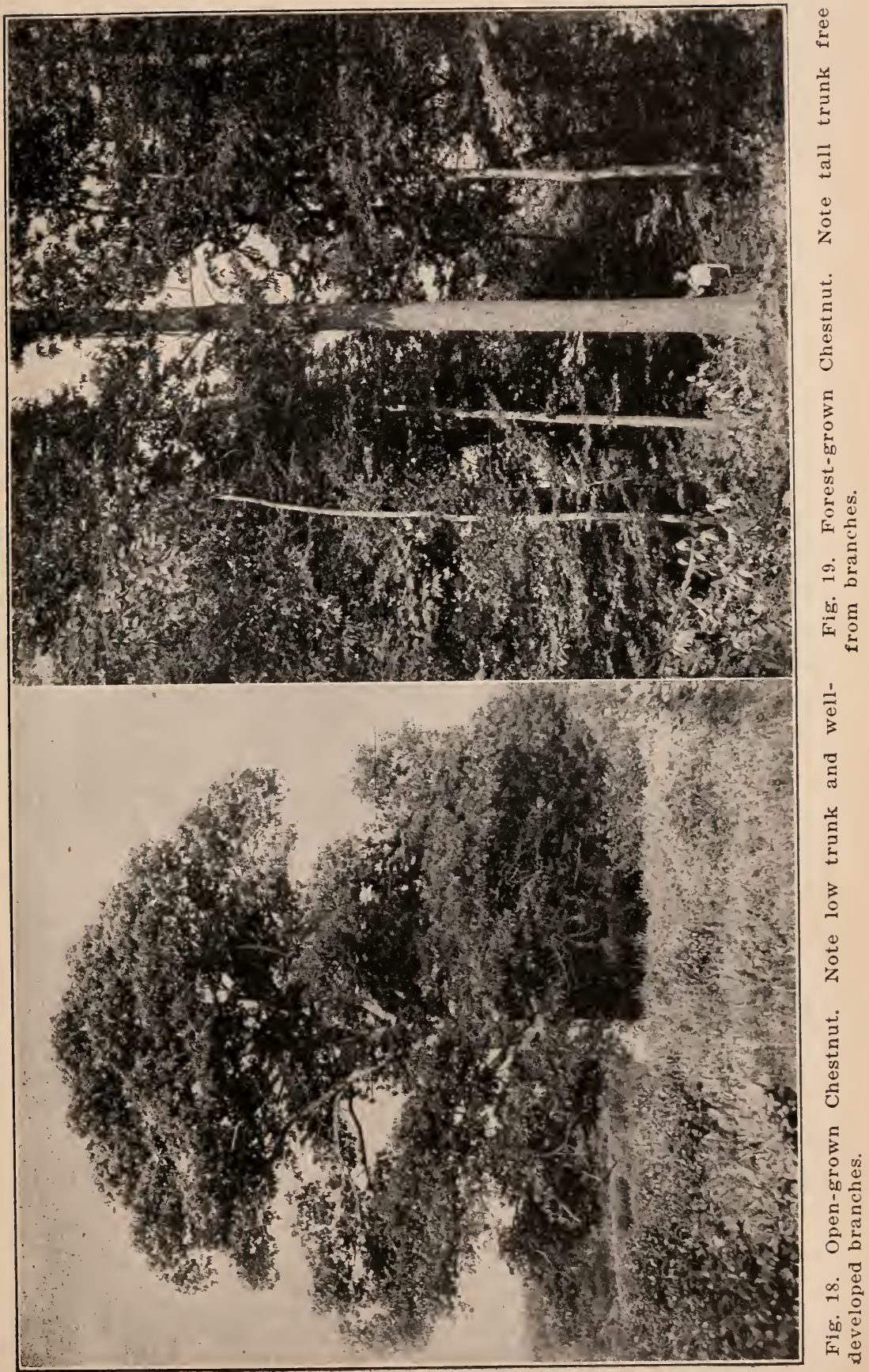


northeastern United States that is evergreen, and the Larch is our only conifer that is deciduous. Some trees, however, like certain species of Magnolia, are deciduous in New England and evergreen in the southern states.

The bare-twigged condition prevents the tree from suffering a more rapid loss of water than its roots could suppply in the winter season if the broad, thin leaves were left exposed to evaporation. In the autumn the living substance of the leaf is broken up and with all the food remaining is withdrawn into the branches. Only the framework remains and the colors left by the disintegration of the green chlorophyll. The leaf has served its function as a machine for the manufacture of plant food and is now ready for the scrap heap. Before it dies, however, a separating layer forms at the base of the leaf stalk and heals the wound before the leaf is abstricted. Cold or dryness may hasten the process, but an early frost may kill the leaves and prevent their falling in the normal fashion.

Not only the fall of leaves but also their autumn coloring is generally independent of frost and may at times occur even in midsummer. The trees of the northeastern United States show a more brilliant coloring than those in the more humid climate of Europe, and even our native species are said to have duller foliage when grown abroad.

The Stem - The stem of a tree has the function of connecting the roots with the leafy crown and of raising the latter above the shade of competing forms. A branchlet of the Horse-chestnut (fig. 20) may be taken as a convenient form to illustrate the various markings found on a young stem. The large triangular patches resembling somewhat closed horse-shoes in shape are the leaf-scars showing where the bases of the leaf-stalks were attached to the twig before their fall. The little dots corresponding to the nail holes in a horse-shoe are the bundle-scars and mark the location of the so-called fibro-vascular bundles that run through the leaf-stalks and connect with the veins of the leaf acting thus as the channels for the transference of raw material and manufactured food to and from the leaf. The leaf-scars are located at the nodes and the portion between the nodes is called the internode. Scattered along the twig are little dots, the lenticels, which are openings that function to a certain extent like breathing pores. 


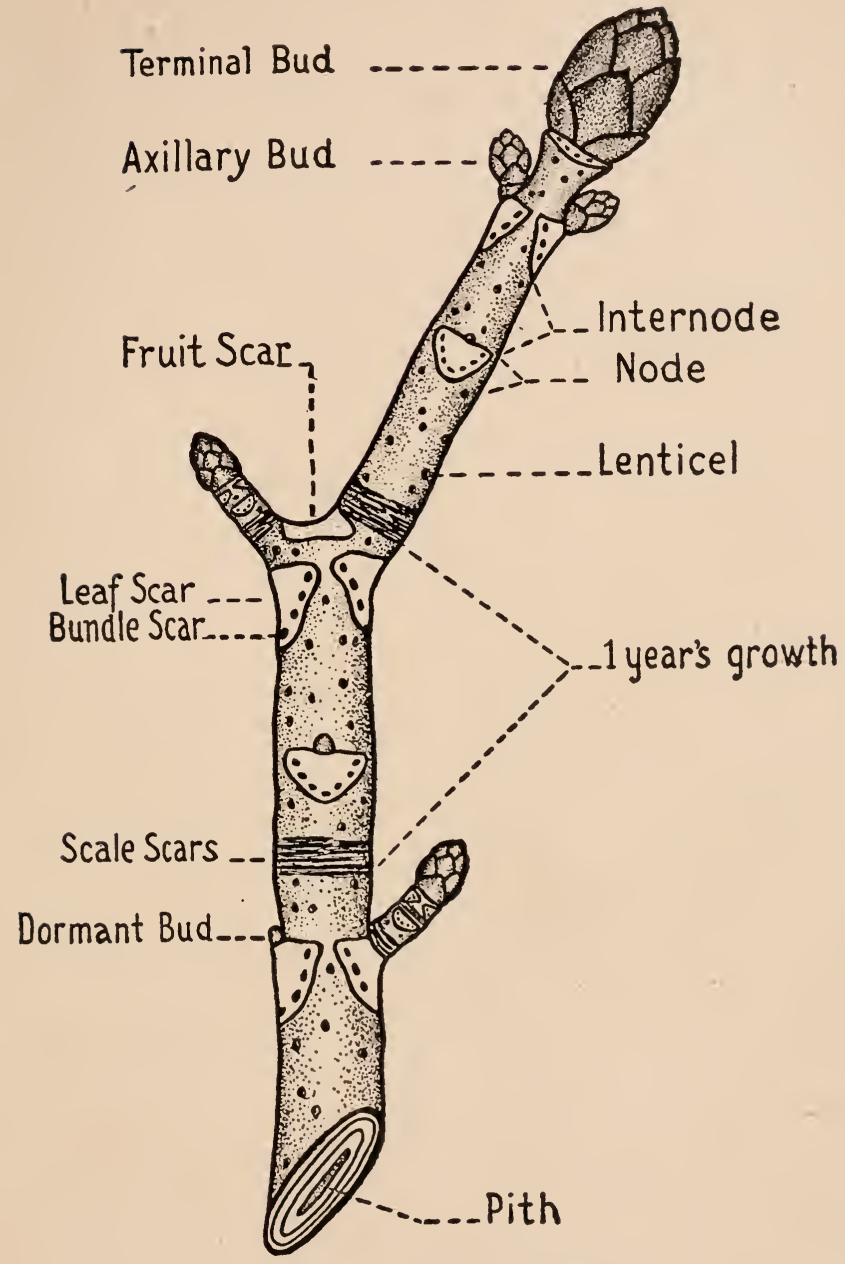

Fig. 20. Twig of Horse-chestnut.

Above each leaf-scar is normally produced an axillary-bud so called because located in the axil or angle made between the twig and the leaf-stalk when the latter was present. The lateral buds are in distinction to the terminal buds at the ends of the twigs.

Buds that produce shoots with leaves are called leaf buds. Certain of the buds - the flower buds - do not continue the growth of the twig but form the flowers which develop into fruit. Where the individual fruit (in the Horse-chestnut the fruit cluster) was 
attached, a fruit-scar is left, and these fruit scars furnish evidence of the amount of fruit produced in previous years.

Each bud contains the rudiments of next year's growth with shortened internodes and minute leaves folded together like a fan and packed away within the protective covering of the bud-scales. Buds begin to form by May or June, but remain during winter in a condensed condition. Growth in the spring consists, for the most part, of a rapid elongation of the internodes and an enlargement of the parts which are, already formed in the bud, and may be completed in a few days. For most trees, the number of leaves and

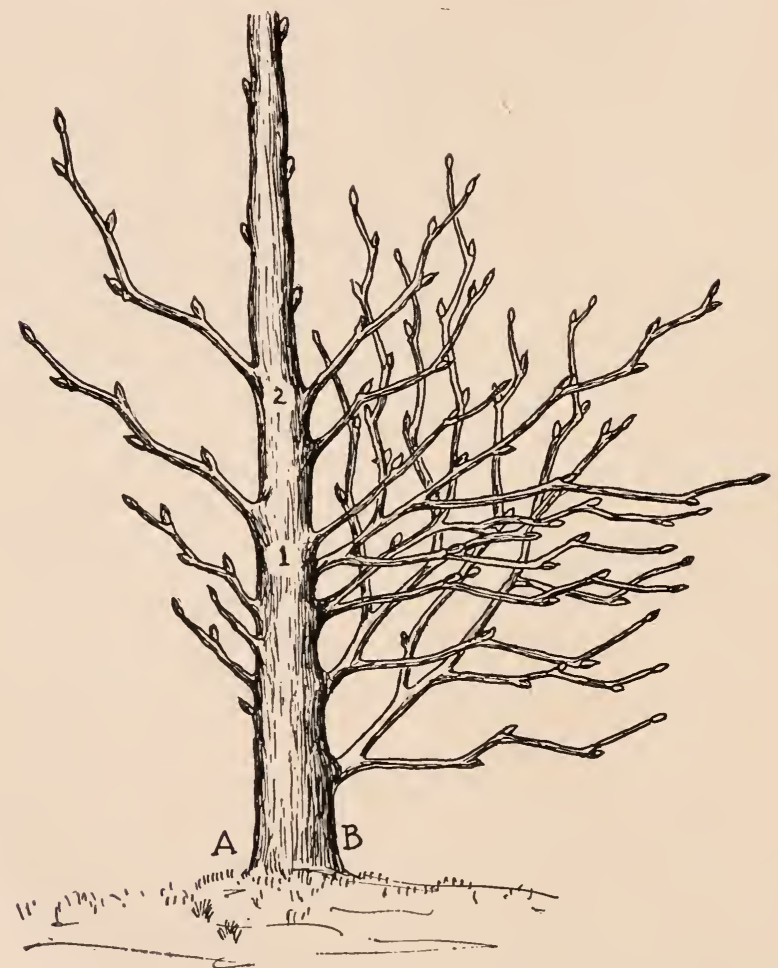

Fig. 21. Diagram of three-year-old tree after Mueller, to show, on side $B$, the number of branches theoretically possible if all the buds develop and, on side $\mathrm{A}$, the number actually produced. 1 and 2 mark the end of the first and second year's growth respectively. The branches have developed from axillary buds such as are seen on the last year's growth above 2 . 
flowers a bud is capable of producing is determined not during the spring elongation of the bud but during its formation the previous year. At least a single bud is usually formed above each leaf. Of all the buds produced in a season only a very small number ever start and grow into branchlets, and the great majority of these branchlets eventually die and are pruned off by the tree. There is a struggle for existence among buds and branchlets as well as among seedlings, and the strongest alone survive. The accompanying diagram (fig. 21) shows the condition that might result from a free development of buds and branches in contrast with the condition that usually exists. Dormant buds frequently retain their vitality for many years and may be forced into derelopment if the growth above them is injured. Adventitious buds are those that form outside of their regular position at the nodes. They are responsible for the sprouts that regularly form on the cut stump of Chestnut and many other of our deciduous trees. Poplars and Willows (p. 251) produce them in abundance when the limbs are cut back or "pollarded."

The bud-scales are modified leaves which protect the parts within from mechanical injury and from loss of moisture, but except for the prevention of sudden changes of temperature, they are of little value as a protection against cold as is so often supposed. At falling they leave a ring or band of scale-scars marking the limit of each year's growth. These bands often remain distinct for many years (see twig of Beech p. 295) and by counting their number the age of the branchlet may be estimated. Thus it can be readily seen that the figure of the Horse-chestnut represents growth made during three years. Each year a ring of new wood is formed just underneath the bark, and a count of the number of these annual rings between the central pith and the bark, as seen in a cross section of a branch or trunk, will likewise give the age of the part investigated. The uppermost buds of a year's growth are gen. erally the largest and most likely to develop into branches the following spring. In some species, as many of the Evergreens, and the Carolina Poplar (p. 261) for example, the branches coming from these more vigorous buds form regular whorls along the trunk at the upper part of each year's growth and afford for such species a third means of estimating the age. 
By aid of the markings just discussed on the stem the past history of the tree can be deciphered often for a considerable num-

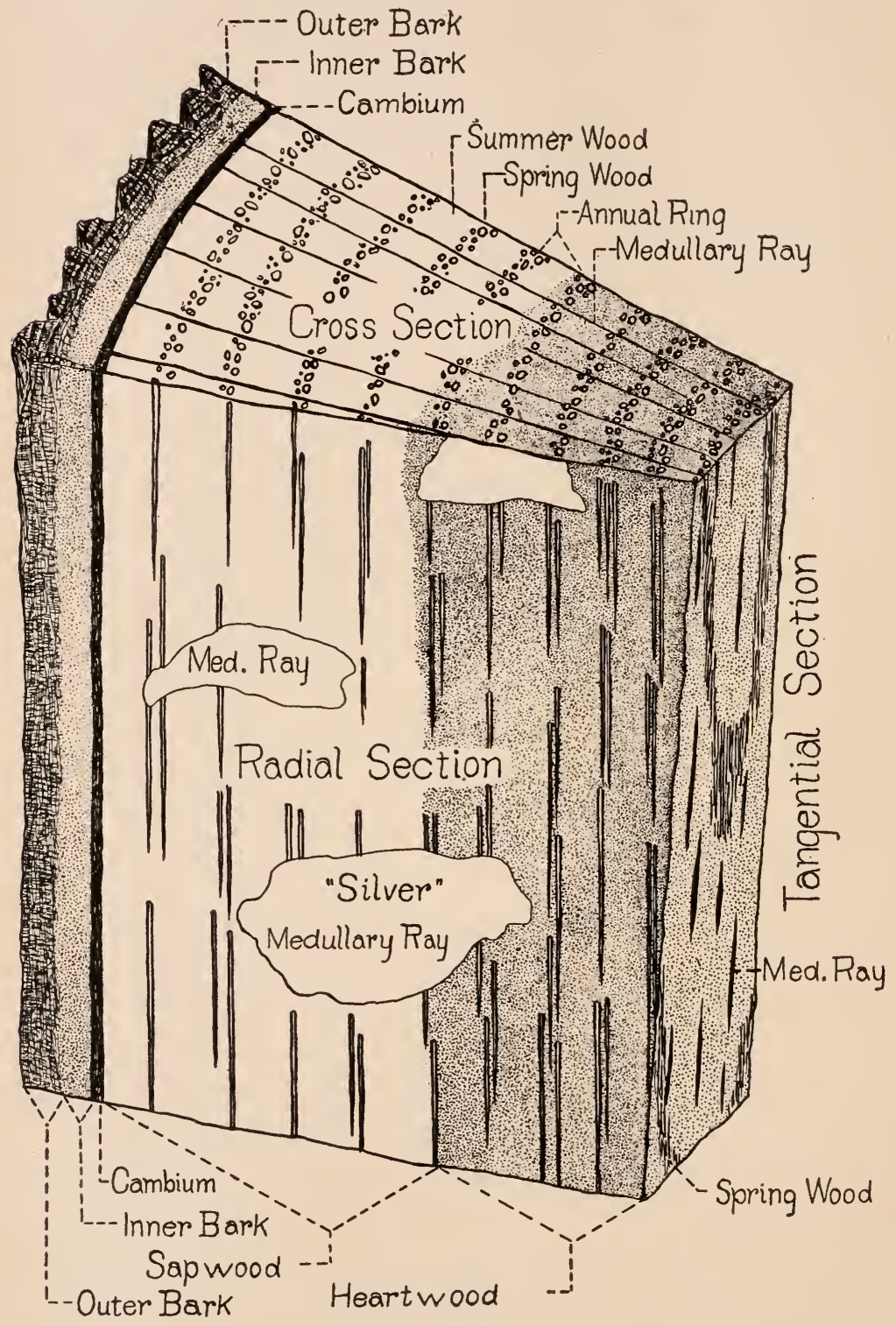

Fig. 22. Diagram to illustrate structure of a block of Oak wood. 
ber of years. The parts of a twig as furnishing a means of identification is further discussed in Part II.

A general idea of the internal structure of an older stem may be obtained by the study of a block of Oak wood (fig. 22). Aside from the relatively narrow pith in the center, the trunk of a tree is made up of three general regions: - the protective covering of bark outside, the thick cylinder of wood within and the thin sheet of delicate tissue forming the cambium between these two regions. The cambium layer is of special interest since it is the only part that remains alive throughout the growth of the trees. In making a whistle, the boy finds in this layer an easy place of separation of wood from the bark. Each year its outer surface forms a new layer of the bark and its inner surface a new layer of wood. By adding an annual ring of wood the cambium itself is pushed out by just so much each season away from the center of the tree but always remains a narrow layer. The bark, as well as the wood, is thus increased in thickness each year, but unlike the wood, it is subjected to the pressure of growth from within and in most species eventually dies, cracks and wears away on the outside as rapidly as it is renewed on its inner surface.

The annual rings usually give an accurate record of the age and rapidity of growth of a tree, since defoliation by insect injury or other influences that would cause a double period of growth in a single year are of rare occurrence. Trees like the Oak and Ash produce in the early part of the growing season large tubular cells which extend vertically up and down the trunk and later form cells of smaller dimensions. In such trees, therefore, the porous spring wood can be readily distinguished from the denser summer wood.

At the end of a $\log$ a cross section of the trunk is exposed, and on it can be seen fine lines radiating out from the center. These are cut edges of the medullary rays or pith rays, as these narrow sheets of tissue are sometimes called. A section cut lengthwise of the $\log$ and parallel to the annual rings is called a tangential section and shows the extent up and down of the medullary rays as seen in end view. The radial section is made lengthwise of the $\log$ and parallel to the medullary rays. If extended, it would pass through the center of the tree. This is the direction in which lumber is sawed in making "quartered oak." The shiny streaks " Oak wood cut in this fashion are called the "silver" and are in 
fact medullary rays seen in surface view. In the radial section the annual rings are evident and the spring wood is seen to be made up of hollow tubes. In the tangential section the rings, if they show at all, form V's or ellipses due to the saw failing to cut exactly parallel to the grain. Boards are generally sawed off from parallel sides of a $\log$ so that, although the outer cut is tangential and the median cut is radial most of the boards will be sections intermediate between these two. The markings on the finished lumber will accordingly vary in appearance.

To many it is a surprise to learn that the large bulk of a tree is dead, literally with no more life than the proverbial barn door. Hollow trees are not infrequently found alive and flourishing. Except for their liability to be blown over, they often do not seem to be greatly handicapped by the loss of inner.wood. The older wood, therefore, is mainly of service as a mechanical means of support and has no part in the life activities of the tree. In some forms the inner wood as it dies, takes on a darker color and under the name of heartwood is easily distinguished from the younger, lighter colored sapwood toward the outside. The outer layers of the bark also are dead. There remains, therefore, as the essential living portion of the stem, the cambium layer with the inner bark on its outer side, and the saprood just within.

Experiments have shown that the ascending currents which carry water and dissolved minerals up to the leaves are located in the sapwood. The inner bark transports the manufactured food from the leares. If the inner bark is serered, as by "ringing," the descending sap is interrupted and the roots ultimately will die of starration. Portions above the ring are still able to obtain water and raw material through the channels in the sapwood so that injury brought about by girdling may not make itself shown till the succeeding season.

The cambium layer is responsible not only for the regular formation of wood and bark but also for their regeneration. An injury which exposes the cambium will excite this layer to increased growth and a formation of wound tissue or callus will result. Callus spreads gradually in all directions from the exposed cambium where it first makes its appearance. Bark forms on its outer surface as it slowly seals over the wound. Unless destructive wood fungi gain entrance through the wound, the healing pro- 
cess may be completed without injury to the tree. Scars, more or less entirely covered by callus, are familiar objects on trees that have been pruned. They are shown in figures 44 and $4 \%$ The process of grafting depends upon the growing together of this wound tissue found on two different twigs when their cambium layers are held in contact.

Reproduction-- A tree is a flowering plant. Except for a few forms like our fruit trees, Magnolias, Horse-chestnut, Catalpa, Locust and Tulip Tree, the flowers are generally inconspicuous and consequently often overlooked. From perfect flowers come seed, and seeds are the natural means of reproduction in flowering plants. Most species have both sexes upon the same individual, with male and female organs in the same flower, or in separate blossoms on the same tree. The Willows, Poplars, and Ashes, however, have the different sexes on separate individuals, and are called, therefore, dioecious. A single tree of a dioecious species will bear flowers of only a single sex. Cuttings carry the sex of the tree from which they were made. Forms like the Lombardy Poplar which produce only male flowers never set seed and can be multiplied, therefore, only by nonsexual methods such as by cuttings.

Trees do not bear with equal abundance every year. Thus, although a few cones may be produced each season, the White Pine in the northeastern states has a good, seed year but once in about six years. Reproduction in relation to propagation is further discussed in the following chapter. 


\section{CHAPTER II \\ THE PROPAGATION OF TREES.}

PROPAGATION FROM SEEDS.

Nature's Way - The natural way for trees to reproduce their kind is by seeds. The trees in the virgin forest have been produced from seeds and without the aid of man. The moist floor of the forest offers favorable conditions for the germination of seed and the growth of the seedlings. There is not room for the development of all the trees that commence growth. Only the strongest and most favorably situated individuals survive and the less fortunate ones are overshadowed and are lost in the struggle.

Since there is room in the forest for the development of only a limited number of trees, nature has adopted wonderful methods for the desemination of seeds far beyond the limits of the forest. Some specimens that commonly grow along streams make use of the water to carry their seeds to distant places down stream. This probably accounts for the rows of Carolina Poplars and Sycamores along certain river banks and on areas that are usually flooded in the spring. The seeds of many other species are scattered by animals. Is it not probable that the Hickories and other nut trees commonly found growing along stone walls have come from the nuts accidentally dropped by squirrels on their way to their nesting places? Birds are often responsible for the desemination of fleshy or berry-like seeds of such species as the Mulberry, Hackberry, Sassafras, Dogwood, Mountain Ash, Hawthorn, Shadbush, Holly, Juniper, Cedar and the Cherries.

The most common agency for the desemination of seeds is the wind. The seeds of many species are equipped with peculiar devices by which they may be carried various distances from the parent trees. The Hop Hornbeam seeds carry balloons (see p. 27\%) and the Sycamore seeds parachutes. The seeds of the Catalpa fly in a monoplane (see p. 429) and those of the Elm and Ailanthus sail through the air on flimsy rafts, (see p. 391). The seeds of the Birches are constructed in the form of tiny birds (see p. 28\%), while those of the Maples (see p. 403) are supplied with wings resem- 
bling those of certain insects. The Ashes have dart-like seeds that shoot through the air in great profusion (see p. 423), and the Basswood sceds (see p. 41\%), are suspended from a leafy shield by means of which they are carricd long distances.

While nature's method of seeding is truly unique, it is also remarkably extravagant. A very small percentage of the seeds that are formed ever germinate and develop into trees. Many of them after falling to the ground are destroyed by forest fires. A large number are eaten by insects and other animals. Many more fail to find suitable locations for their germination and growth. To allow for this great waste and to keep up the supply of the various species, tree seeds are bourn in great profusion. It is interesting. to estimate the number of seeds bourn by a single tree of the more prolific species like the Mulberry, the Catalpa, the Sycamore, the Poplars, the Birches, and some of the Evergreens.

It may be plainly seen that in the economic production of timber, natural seeding is not to be depended upon. Although in the hands of an expert forester the natural seeding of cleared land from adjacent forests, may often produce satisfactory results. Direct planting with nursery-grown trees is likely to give quicker and more certain results and furnish only the desired kinds of timber.

The Forest Nursery - While it is possible to obtain seedlings for forest planting at a reasonable price, there is no reason why the farmer or forest planter cannot grow his own trees from seed. To encourage the planting of forest trees some states are furnishing young trees at prices but slightly in excess of the cost of production. Even at these low rates the planter would find it more satisfactory to grow his own trees. To do this successfully he needs to know only a few general principles. The method employed in the growing of some species may differ slightly from that used in others, but the principles are very much the same with all. The work now is largely in the hands of specialists, but when farmers and others come to realize the ease with which trees may be grown and to appreciate the saving in money, there will be nrore planting done.

Collecting Seeds for Planting - On account of the difficulty of collecting and the exacting requirements in the 
handling and storing of tree seeds, the price usually is very high. According to the reports of the United States Bureau of Forestry, a pound of Larch seed costs from $\$ 12.00$ to $\$ 16.00$, White Pine from $\$ 1.50$ to $\$ 3.00$, Sugar Maple .75c to $\$ 1.00$, and White Oak from $10 \mathrm{c}$. to $25 \mathrm{c}$. The forest planter, therefore, would do well to collect his own seed and thus obviate this unnecessary expense.

In the collecting of seeds it is usually necessary to climb the trees. The seeds are either picked by hand or are shaken or beaten off and collected in large sheets on the ground. The practice of cutting down trees for the purpose of obtaining their seed should be discouraged. Some species, like the Chestnut, the Beech, the Hickories, the Oaks, the Walnuts, and the Butternut, are more easily gathered after severe frosts. The work of gathering seed, however, extends from April to November, according to the species. The season for some species, like the Birches, the Maples, the Elms, the Poplars and the Willows, is very short, while that for others, like the Common and Honey Locusts, the Catalpa, the Box Elder, the Kentucky Coffee Tree, the Sycamore, and the Ashes, is more extended and may stretch far into the winter. It is difficult to state definitely the exact time when seeds of the various species should be collected. Of course they should not be gathered until they are ripe, and to avoid loss it is usually advisable to collect them as promptly as possible after they reach this condition. Some species must be gathered promptly after reaching maturity if they are to be saved at all. Others if left either on the tree or on the ground are likely to be carried away by squirrels.

Storing Seeds - As a rule, seeds that mature before mid-summer should be sown when gathered. Those that mature later than August first should be stored until spring. Large seeds like the nuts and acorns may be stored in earth outside or in a cold cellar. The smaller seeds, except those of Evergreens, may be stored in boxes in thin layers between layers of sand. The boxes should be buried outside in the ground or placed in a cold cellar. The seed of Evergreens requires a cool, dry place and is usually placed in sacks and hung in cold sheds or barns. Some seeds need to be subjected to frost before they will germinate and develop properly. Others require two or more years contact with the soil before they will germinate. These cases are exceptions, 
however, and are mentioned here to show that all kinds of seed cannot be treated in exactly the same manner.

Some seeds require special treatment before storing for the winter. During the early fall most kinds should be spread out in thin layers in some cool, airy place, such as under a shed on the north side of other buildings or on the upper shelves of a cool, dry cellar. Nuts and acorns are best kept on the ground in a cool shed. Most kinds require close attention to keep them from heating and moulding. If the layers are too deep the seed is likely to mould, and if too shallow it is likely to dry out. The more succulent seeds should be in thinner layers than the dryer kinds. With some of the quickly drying sorts it is sometimes necessary to cover them with straw, chaff, or a thin cloth. Some of the Evergreen cones require excessive drying before they will open and release their seeds. The fleshy fruits of the Mulberry, the Cherry, the Hawthorn, and the Plum, require macerating in water until the seeds can be separated readily from the pulp. The shucks of Black Walnuts, Butternuts and Hickory nuts should be removed within a few days after gathering. The most important point to be observed in the storing of seeds of any kind is to keep them in a cool, dry place to prevent germination and at the same time avoid excessive drying.

Testing the Vitality of Seeds - Some seeds will remain viable for many years while others must be planted within a few weeks to insure a good growth. Seedsmen frequently mix their "left-over" seed with their fresh stock and this sometimes accounts for the low degree of germination of some samples. It is well, therefore, to test a sample of seed before buying large quantities. The only strictly reliable test to determine the vitality of seeds is germination, but this often requires many days or weeks for results. With a little experience in examining fresh and stale seed, one may expect to determine fairly accurately whether a given sample will grow. The examination consists in cutting open about fifty seeds of a sample and in observing whether the kernels are decayed, moldy, abnormally shrunken or completely dried out. If a large percentage of those examined are firm, plump, and normally moist, the sample probably may be relied upon. The seeds of some species, like the Ashes and Locusts, may be extremely dry and yet be reliable. 
The seed of a large proportion of the species will germinate within ten to thirty days and the vitality of these may be definitely determined by germination tests. A definite number of seeds of any sample may be covered with sand or moss at a depth equivalent to the diameter of the seed. The box containing the sample under test should be kept in a place where the temperature ranges from 60 degrees to 70 degrees F., and the soil or moss kept in a moist condition. For the smaller seeds the use of sand will give the best results and for the larger kinds either moss alone or a mixture of moss and sand is recommended.

Planting Seeds - Seed beds should be located on moderately light, well-drained soil. Whenever possible, it is also well to locate the bed on the north or east side of a building, forest, or other windbreak. A common and convenient width for seed beds is four feet. The length may be extended according to the amount of seed to be planted. The rows run crosswise of the bed. In very large plantations it is usually advisable to sow the seed in long rows or drills clear across the field, in much the same way that vegetable seed is planted. This arrangement admits of horse cultivation and lessens the hand work.

The soil should be well prepared by previous cultivation. Its physical and chemical condition may be greatly improved by the addition of well rotted stable manure. Ground that has been under cultivation for at least one year is not so likely to be infested with injurious insects and will give better results than newly broken land.

The best time for planting most species is early spring. Some species, like Red and Silver Maple, River Birch, Elms, Poplars and Willows, mature their seeds in June and these must be planted immediately, but most species are carried over winter and planted as soon as the soil can be properly worked. If the soil is too wet the seeds are likely to rot, while if it is too dry the seeds will not germinate until late in the season and may possibly remain in the ground until the following season.

The seed of the species that make a small growth during the first season, like Conifers, Birches, Elms, and Sugar Maple, may be planted in rows about eight or twelve inches apart. It is sometimes sown broadcast in well prepared seed-beds and the seedlings transplanted in nursery rows the first or second year following. The 
seed of the rapid-growing species, like the Soft Maples, Hickories, Oaks, Black Walnut, Butternut, Ashes, Elms, Locusts and Catalpas, should be given more room and should be planted in rows two to three feet apart. The seeds should be so spaced in the row that the seedlings will not require thinning. Medium sized seeds and those that have tested high in germination may be planted from one to two inches apart, while the smaller ones and those that have proven to be low in vitality should be spaced somewhat closer. The larger seeds like nuts and acorns may be spaced about three inches apart. For very small seeds it is customary to use a board on which to stand and thus aroid trampling the soil. The rows in which the seed is to be planted may be marked off by running a hoe handle along the edge of the board.

The amount of covering that should be given seeds depends upon their size and upon the character of soil. Large seeds should be planted deeper than smaller kinds. A common rule is to cover all seeds about three or four times their own depth. On light soil, and especially during dry weather, they should be covered more deeply, while on heavy soil twice their own depth would be sufficient. In order to bring the soil moisture up to the level of the seeds and to prevent the seed from being washed out by rain it is well to roll the ground or firm it by walking on a board placed along the row. The loss of moisture and the baking of the surface may be prevented by scattering chaff on the seed bed after planting.

Care of Seedlings - The young seedlings of most species will require shade for the first season and of the conifers for the first two seasons. The necessary shade may sometimes be supplied by the use of evergreen boughs, but the common practice is to use frames made of lath. (See fig. 28.) The latter are placed about their own width apart and nailed on end strips about two inches in thickness and five to six fect in length, The frames are supported eighteen inches above ground for conifers, and from two to three feet for other seedlings. The screens are removed only on cloudy days and during gentle rains. When the soil is sufficiently moist the frames serve a useful purpose by shedding part of the water that falls. With broad leaved seellings it is usually unnecessary to keep the shades on after the first of August.

When it is necessary to water seedlings the water should be applied gently, allowing it to soak in. When good cultivation is 
supplied it is seldom necessary to apply water. The cultivation should be so frequent and thorough that no weeds will develop and that a loose soil mulch will be maintained on the surface.

Transplanting - Most trees are large enough to be taken from the seed bed after one year's growth. Conifers and a few other species make a very slow growth and should be left in the seed bed for two years. The seedlings of some of the most rapidgrowing species are occasionally planted in their permanent locations at the end of the first season, but the usual practice is to transplant them in the nursery for at least one season. The transplant-

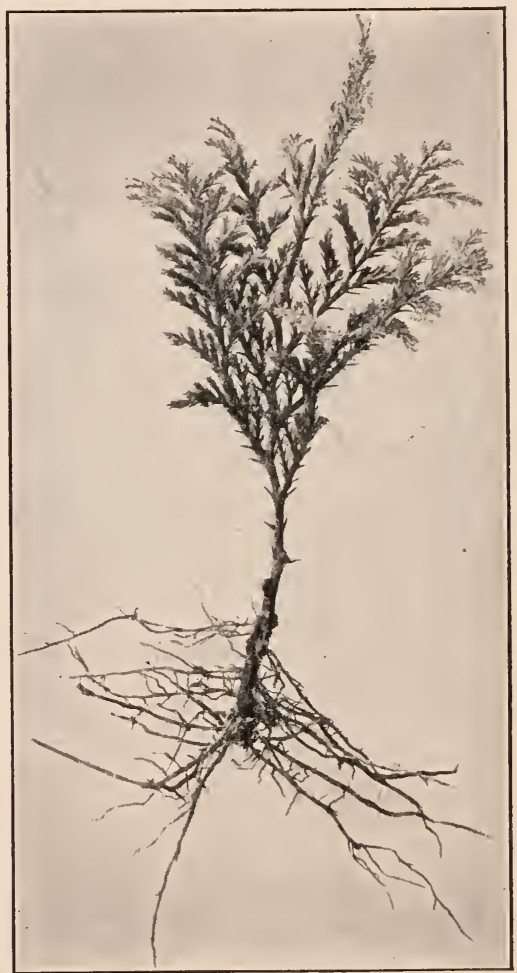

Fig. 23. A one-year-old Cedar cutting.

ing is usually done in the spring, from the first of April till the middle of May. The length of time that they remain in the nursery depends upon the growth and this is largely influenced by the 
character of the soil and the kind of treatment. In the moving of young trees from one position to another, great care should be exercised in preventing the roots from drying out. This precaution is especially necessary in the handling of conifers.

\section{PROPAGATION BY CUTTINGS}

It is a common thing to find willow twigs that have fallen from trees and taken root. The branches of some species of willow are so brittle that they are broken off by the wind. Some of these fall in the water and are carried down stream for many miles and are finally washed ashore, where they find conditions favorable for rooting.

From nature, therefore, man has learned that trees may be propagated by cuttings. Most woody plants when given proper conditions may be propagated in this way. Species differ greatly in respect to their amenability to this method of propagation. Poplars and Willows are very easily propagated from cuttings, and the desired result often may be attained more readily by this means than by the collecting and planting of seed. Some species, on the other hand, are quite difficult to propagate in this way, and with such the practice is to grow them from seed. The chief advantage in propagation by cuttings is the saving of time. Many trees started from cuttings are large enough at the end of the second or third season for planting in their permanent positions on lawns or along roadsides. Furthermore, there are many horticultural varieties, like the weeping forms, that do not come true from seed and these must be propagated either from cuttings or grafted on seedlings of the same or some closely-related species.

Making Cuttings - Cuttings from woody plants are usually gathered in the late fall or early winter. There are three distinct kinds employed in the propagation of trees, namely: simple, heel, and mallet. (See fig. 24).

The simple cutting is employed generally with such trees as the Willow and Poplar. It consists of a straight portion of a shoot from six to twelve inches in length, nearly uniform in size throughout, and containing two or more buds. At the lower end it is usually cut off just below a bud, because roots develop more readily at the joints. Some species, like the Apple, Pear, Plum, Cherry, Hawthorn, Mountain Ash, Elm and Ailanthus, are more 
easily propagated from root cuttings than from cuttings taken from above ground. These are also of a simple type and are obtained from young trees that have been grown from seeds. The

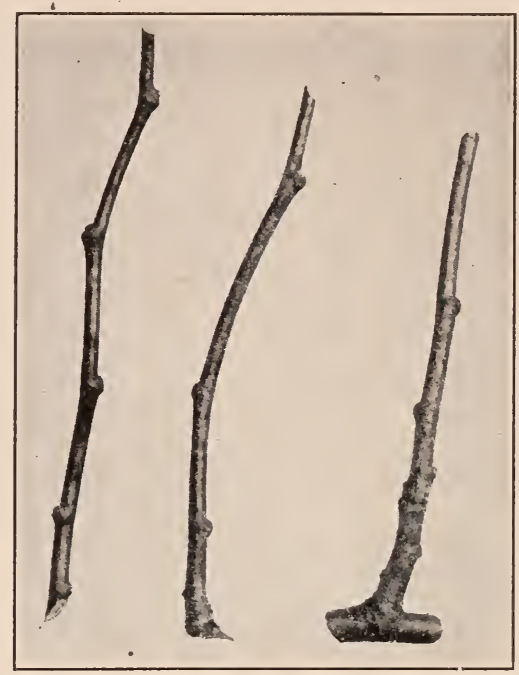

Fig. 24. Hard wood cuttings. A simple cutting on the left; a heal cutting in the center and a mallet cutting on the right.

root from one of these trees may often be divided into from three to twelve pieces.

Heel cuttings are made by severing twigs close to their bases and in such a manner as to carry with them portions of the parent branch, forming the so-called heel. Heel cuttings are usually not more than six inches in length and are frequently used for the propagation of spruces and firs.

Mallet cuttings are made by severing the parent branch above and below a short side-branch so as to leave a mallet-like piece of the former at the base of the latter. They are usually from five to eight inches in length and are commonly used in the propagation of Junipers and Arbor Vitaes.

Setting Cuttings - The various kinds of cuttings are handled in much the same way. After being cut they are usually tied in bundles of fifty, or more, with all the tops pointing in the same direction. The bundles are packed in sand or soil and 
either buried on the north side of a building or stored in a cool cellar until spring, when they are ready for planting. During the winter the lower ends of the cuttings should become callused. Callusing is the first step toward root formation. The cuttings are planted usually in rows eighteen to thirty-six inches apart and about six inches apart in the row. They are placed in the ground either on the slant or in a vertical position and set so that one or two buds remain above the. surface. 'The soil always should be packed firmly about the cuttings. The after treatment is about the same as for seedlings.

\section{PROPAGATION BY GRAFTAGE}

According to Bailey's Cyclopedia of Horticulture, "Graftage comprises the process and operation of inserting a part of one plant into another, with the intention that the part shall grow on the foster root, together with all the questions which arise in relation to the practice." It is a comprehensive term, embracing all questions relating to the operations of both grafting and budding.

This method of propagation is employed when it is necessary to perpetuate varieties that do not come true from seed, as is the case with all varieties of our cultivated fruit trees, like apples, pears, plums, cherries, peaches, lemons and oranges, and with many horticultural varieties of ornamental trees. It is employed also with trees that do not bear seeds freely and with those whose seeds are difficult to germinate and that do not propagate well by cuttings. The practice is also useful in dwarfing tall-growing species; for example, the standard pear is made dwarf by grafting it upon the quince. Furthermore the practice may be useful in adapting certain kinds of trees to adverse conditions of soil and climate. For example on account of the difficulty of growing the plum on light soil, it is sometimes grafted on the peach, which is better adapted to sandy soil.

As a rule, grafting must be done with plants of close relationship, but frequently success follows grafting of one species on another, as in the case of plums, and occasionally of one genus or another, as is the case of the pear and quince. It is not enough, however, that the graft should unite, but it should form a good union that is not likely to be parted by wind storms or by heavy loads of fruit. The limits within which grafting can succeed, therefore, are to be determined only by experiment. 
Grafting - There are many methods of grafting, differing mainly in the position of the union and in the method with which the scion and stock are joined. Space here will permit only of a discussion of general principles and for the technique of the various methods the reader is referred to Bailey's Nursery Book.

That portion of a plant that is mechanically inserted upon another plant with the expectation that it shall grow, is called the scion. The plant or the part of a plant upon which the scion is set is called the stock. The most important point in the whole operation of grafting is the necessity for inserting the scion in such a way that its cambium layer or inner bark will come in close contact with that of the stock. When this condition is fulfilled all that remains is to prevent the access of moisture and disease spores and to prevent the parts from drying out before union is affected. This is accomplished by the use of grafting wax which may be purchased at small cost or made of the following: resin, 4 parts; beeswax, 2 parts; tallow or linseed oil, 1 part (by weight). The resin and beeswax are broken finely and melted together with the tallow. When thoroughly melted the mixture should be poured into a pail of cold water and left there till it becomes just hard enough to handle, when it should be taken out and pulled like taffy until it becomes light brown or fawn in color. In the pulling and subsequent handling the hands should be well greased to prevent sticking. If the wax hardens before the time for using, it must be slightly warmed and softened so that it may be applied expeditiously and effectively.

Scions for grafting are usually collected in November, just after the leaves have fallen, but they may be collected any time during the dormant season. The scions are tied in bundles, packed in moist sand or soil and stored in a cool place in the same way as described for cuttings.

Cleft Grafting is the method commoniy employed when it is desired to change the variety of mature fruit trees. The process in brief is described here and will serve to illustrate more clearly the essential features of all grafting methods.

A branch, usually less than two inches in diameter is sawed off squarely and smoothly. The stub is split down through the center to a distance of about two or three inches. For this purpose a special kind of knife is used and a mallet is often used to drive the 
knife into the stock. The knife is equipped with a short wedge on the back of the extreme end of the blade. This wedge is used to hold the slit open while the scion is adjusted. The slit may be widened by simply pressing on the knife handle and after the

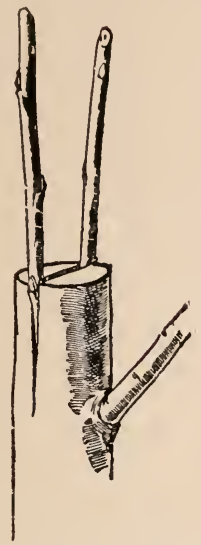

Fig. 25. A Cleft Graft, before and after waxing.

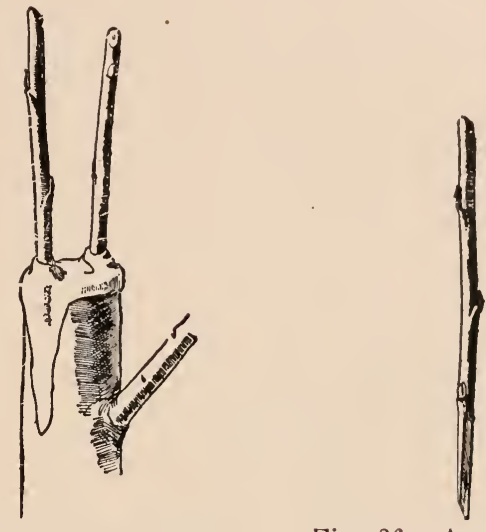

Fig. 26. A scion for cleft-grafting.

scion has been placed the pressure on the handle may be relieved and the wedge withdrawn. The pressure of the stock should be sufficient to hold the scion in position. (See fig. 25.)

The scion is cut in a sloping fashion at the base, or in the form of a very thin wedge. The sloping part should be thicker on one side than on the other. The shaping is usually done so that the lowest bud will come on the thicker side and at a point about opposite the upper part of the wedge. The upper part is cut off squarely and at a point slightly above the third bud. (See fig. 26). If scion wood is scarce two buds are sufficient to each scion. The scion is adjusted so that the inner bark on the thicker side comes in contact with the inner bark of the stock. The lower bud comes about level or just below the surface of the stock and is usually covered in the waxing process. The task is completed by covering with wax all exposed cut surfaces.

It is customary, with branches that are large enough, to insert two scions. They shotild be set so that their thicker margins will be on the outer side of the stock. The second graft affords a double chance for success and it assists in healing up the wound. 
If both scions grow, the weaker one, about midsummer, is sawed off in a sloping fashion, taking with it part of the stock. When the scion and stock are about equal in diameter, as is usually the case in root grafting, the process known as whip grafting is usually employed. Figure $2 \%$ will serve to illustrate the process.

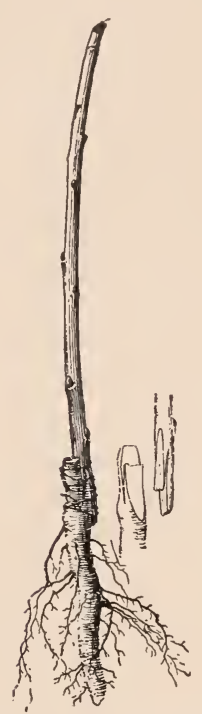

Fig. 27. A root-graft.

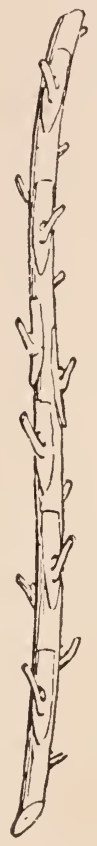

Fig. 28. A "stick" of buds.

Budding - The practice of budding has become a more common means of perpetuating varieties than that of grafting. It is habitually employed on the trees of most stone fruits and frequently on those of apples and pears. The operation is simple and consists of inserting a single detached bud under the bark of the stock. In the hands of experts it can be done with great speed. The usual plan is for a man to set the buds and a boy to follow closely and do the tying. The practice is employed chiefly on stocks of small diameter and preferably on those not more than one year old.

The work is done whenever the bark will peel readily, which 
is either in early spring or late summer. As commonly practiced the work is done in August or early September.

When everything is in readiness the buds are at once taken from a tree of the desired variety. Long shoots of the past season's growth are collected for spring budding and of the present season's growth for summer budding. If the shoots are collected in the summer the leaves will be on, but these should be cut off promptly, leaving about a fourth of an inch of the leaf-stalk to serve as a handle to the bud. This shoot is called a "stick of buds." (See fig. 28). Each stick contains several buds, al of which are cut, but not serered, before any of them are inserted. The cutting consists in taking a slice out of the bark about an inch in length and extending above and below the bud. A small amount of the wood from just beneath the bud is likely to be taken, and this may either be removed or left. When finally severed by making a straight cut across the top, the result will be a shield-shaped piece of bark with a bud in the center. A sharp thin-bladed knife is necessary for clean and rapid work.
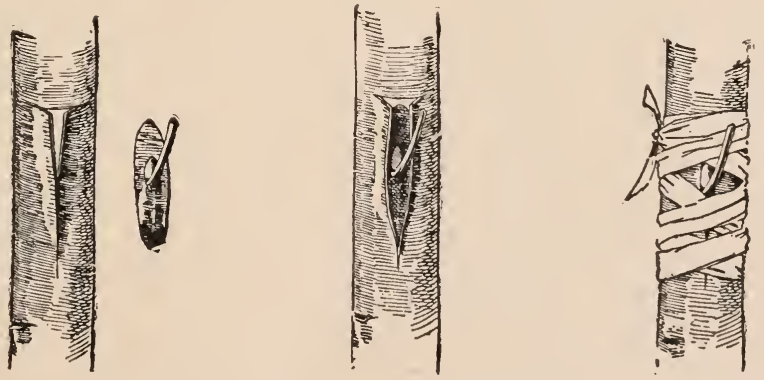

Fig. 29. The three stages in the process of shield-budding.

Before inserting the buds the leaves are remored from that portion of the stock where the operation is performed. A 'T-shaped incision is made and, if the bark peels nicely, the bud may be pushed down under the bark until its abrupt top fits snugly against the transverse part of the T. The operation is completed by tying with rafia or some kind of soft cord. The tying material is usually cut in suitable lengths of about one foot. It should not be wound over the bud itself. (See fig. 2!).

Budding is usually done on seedlings and at a point rery near the ground. With larger trees the various branches should be 
budded at positions somewhere near their junction with the nain stem.

In about two or three weeks the bud will have "stuck" or united to the stock. The bandage then should be cut to allow for the growth of the stem. The summer-set bud should remain perfectly dormant until the following spring when the stock should be cut off just above the bud. This will throw the entire force of the plant into the shoot that will spring from the bud. Sometimes a growth of three or four feet will be made the first season and the following spring the tree may be set out in its permanent location. 


\section{CHAPTER III}

\section{TREE PLANTING IN RURAL, DISTRICTS. THE CONSERVATION OF GOOD SCENERY.}

Every citizen in every country is interested, or should be interested, in good scenery. Of the various elements that constitute good scenery or that go to make up our landscape there are none so ornamental nor so indispensable as trees. During the early settlement and development of the country the problem was to get rid of the trees and undoubtedly there was a great waste of timber. The necessarily wasteful methods of the early settlers were handed down to the later generations and the wholesale destruction of forests was thoughtlessly continued until about fifty years ago. At this time we first began to realize that for the benefit of the coming generation and for the future prosperity of the country, something must be done to stop or mitigate the unnecessary waste.

The problem of today then is much different from that of the early days and we hear a great deal now about the conservation of forests and the necessity for planting trees. It is an important problem from the standpoint of economy and almost equally important from the standpoint of esthetics. This country is noted for its fine scenery and our beautiful landscape is regarded by foreigners as one of the country's greatest assets. Undoubtedly there are many sections of the country that are worth more for the scenery they possess than for agriculture or forestry. In discussions relating to the conservation of our natural resources, therefore, the element of good scenery should always be considered. Since good forests, good farms, and good waterways contribute largely to the landscape, the element of good scenery cannot easily be separated from many of the commonly recognized natural resources.

Trees have become so much a part of our civilization that it would seem almost impossible to get along without them. What would our homes, our country roads, our city streets, our parks, and our landscape be without them? We all know that trees are beautiful and even necessary in such places, but we cannot fully appreciate their value till we have seen the desert. The settlers 
in the prairie section of the West have many times declared that the longing to see the trees and the hills of New England caused more distress than the desire to see old friends and relatives.

The value of trees from the economic or commercial standpoint is well understood and can be estimated on the basis of dollars and cents. Their esthetic value and their value from the standpoint of health is not so generally appreciated nor is it so amenable to calculation. We hear a great deal these days about surveysforest surveys, agricultural surveys, and the like. A survey in this sense means an inventory or a stock-taking. It would be interesting to make a survey based upon the landscape wealth of any section or of the whole country. It would be interesting also to compare in such a survey the relative value of the various elements of the landscape. It seems safe to predict that in most sections trees would be credited with a very large proportion of the total wealth.

\section{A NATIONAL PARK SYSTEM}

There is a tendency nowadays on the part of the cities to extend their park systems far into the country. In Massachusetts a reservation scheme known as the Metropolitan Park System, embracing the whole state is well under way. Immense tracts of land possessing admirable landscape features have been acquired and improved. Roads and boulevards, connecting the various holdings with one another and with the Boston Park System have been constructed. The trees have been protected from injury and many new plantings have been made. The aim of the whole scheme is to preserve the natural scenery and to make it accessible to the appreciative people of the commonwealth. The project does not interfere with the utilization of the surrounding land for agricultural purposes. It has had a marked influence upon land values and has developed among the people a local patriotism and a greater appreciation for natural scenery.

The movement in Massachusetts is sure to exert a wide influence. At the present time there is a movement on foot that will connect Montreal and New York by the use of a great scenic boulevard. Other states and districts are bound to see the wisdom of such a policy and to enact similar laws for the conservation of natural scenery. The next step should bring together the park reserva- 
tions of the various states and the ultimate result should be what may be called a national park system. Such a system would unite the great natural wonders of America, with Niagara Falls as the central figure. Among the hundreds of special features of this great national park may be mentioned the gigantic forests of California, Yellow Stone geysers of Wyoming, the Grand cañon of Colorado, the wheat fields of Kansas, the Mammoth Cave of Kentucky, the vineyards of New York and Pennsylvania, the Green Mountains of Vermont, the famous elms and peach orchards of Connecticut, the apple orchards of Virginia, and the palm groves of Florida. The railway companies must necessarily take an active part in such a movement, and many of them have already made a start in this direction. The traveling public has done much to encourage development in this respect and can do much more by patronizing the companies that offer the most attractive routes.

The Sign-Boards Must Go - There will be no place in the great national park system for the hideous sign-board so commonly found along railway lines and public highways. This method of advertising shculd be discouraged. How to get rid of this objectionable feature of the landscape seems like a difficult problem, but it is believed that the offenders will eventually realize the advisability of protecting the welfare of the public. There is a growing sentiment in opposition to the sign-board nuisance. Many people, by their refusal to use any of the products that they know to be advertised in this way, have asserted their feelings in a most effective manner. If their children should "cry for Castoria" they will endeavor to soothe them with some brand that has been advertised in a more legitimate fashion.

Arousing Interest - The greatest progress and the most enduring results in any direction must come through education. We hear a great deal in these days about the necessity for some kind of instruction that will fit the child to his environment. The study of the landscape, of which trees form the chief element, will go a long way toward developing in the child a love for the beautiful and eventually bring him in harmony with his surroundings. It seems advisable, therefore, that a campaign for the conservation and improvement of rural scenery should start with the schools. 
Village improvement societies, of which there are a great many, are doing a splendid work by way of stimulating greater effort among property holders and municipal officials. Their influence, however, is too often restricted to the limits of their own little village and their attitude toward neighboring villages too often savors of rivalry. If every organization of this sort should reach out and co-operate with similar organizations in neighboring villages the result would be almost beyond comprehension. The influence of such organizations should also be felt on the surrounding farms, and farmers should be encouraged to take an active part in the movement. Many of the more thickly populated rural sections should have societies of their own. Since wellkept farms contribute largely to the general appearance of the country, prizes are sometimes offered either by the state or by some agricultural association for the best kept farms. This practice sometimes results in better farms, but the principle is all wrong. When farmers get the proper spirit they will improve their farms for the added pleasure and profit to be derived.

The granges, farmers' clubs, women's clubs, and the various organizations connected with the church, may all share in the movement for better scenery in the country. Every section' has its own special scenery and it should be the business of some organization to protect it. If there is no organization in the community that may be intrusted with the responsibility, one should be formed for this express purpose.

\section{THE PROBLEM OF THE COUNTRY ROADS.}

The Location of Country Roads - The country road primarily is for the purpose of communication and transportation. The first consideration, therefore, should be efficiency. Many of the country roads to reach their maximum of efficiency should not only be rebuilt, but should be relocated. It is remarkable that in hilly sections so many roads follow the shortest route, like the Indian trails, rather than the natural contours of the land. Roads that follow the valleys and the streams are usually more efficient and decidedly more picturesque. Where the streams are tortuous, of course, it is possible to orerdo such an undertaking. In flat countries, on the other hand, there is much waste of time in following the straight concession and crossroad routes. Some 
cities have realized the necessity for abandoning this rectangular or checkerboard arrangement of streets and are now planning some diagonal routes between important points. Road builders should keep in mind that often there is a saving of almost a third of the distance between two points by traveling in a direct line. Farmers who live in a checkerboard section would be astonished if they should figure out the waste involved in traveling over indirect routes for a period of ten or twenty years. Some farmers would find that during their lives they have traveled thousands of unnecessary miles. It is not an easy matter, however, to change the location of a road and usually we must take them as we find them.

Although somewhat foreign to the subject under discussion, it seems advisable to digress just long enough to make a suggestion for the improvement of country road-beds in sections where stones are abundant. There are many such locations where the farmers could build permanent roads in front of their farms by using the stone from their fields instead of piling up huge walls that not only occupy valuable space but furnish the best protection for injurious insects and obnoxious creatures of various kinds. On some farms the non-productive area on account of stone walls often amounts to one-fifth of the total acreage. It would seem like a feasible thing for the farmers in a certain community to "get together" on a road improvement proposition of this kind. The removal of the stone walls could be accomplished during the winter months and most of the work done during slack seasons. Some communities undoubtedly could afford to invest in a stone crusher with which to grind stone for dressing their roads. If nothing but the native soil is used on top of the rocks the result will be quite satisfactory, for, on account of the drainage afforded by the stone foundation, such roads dry out quickly in wet seasons. For economic reasons alone, the ridding of the farm of the scattercel and piled stones would be worth while. Furthermore, improved roads in any community reduce the cost of transportation and tend to increase land values.

Making the Best Use of Existing Conditions - In many secuons of the East the problem is to keep down the brush along the roadside. The custom in such places is to periodically mow and burn everything within the highway limits. An able- 
bodied man, armed with a brush scythe, is capable of destroying more good scenery within a few weeks than can be developed on the same area within several years. Much of this, of course, is necessary to keep the road clear, but it seems strange that country and town officials implicated in such wholesale destruction cannot see the folly of this practice. If it should become necessary to widen the thoroughfare it would seem unnecessary to have the cutting extend clear to the limits. By leaving a strip along the fences, with occasional interruptions for a more extended view, the effect would be decidedly more pleasing. Within a few years the larger-growing species may be expected to arch over the road in such a way as to furnish shelter from the hot rays of the sun during the summer and cold winds of the winter.

A still better plan would be to retain only a few of the largest and most desirable specimens to furnish the needed protection and to contribute to the beauty of the wayside scenery. More trees may be reserved than will ultimately be required, but some of them should be cut out as soon as the trees begin to crowd. No attempt should be made to select trees that are in line, but it is well to choose only those that are at some distance from the road bed. Whenever possible, it is well to restrict the selection in a certain stretch of road to one or two species, but it is better to have a great variety of species than to have none at all. For this purpose it is well to select long-lived species, like the Oak, some of the Maples, the Hickories, the White Elm, the Chestnut, the White Pine, the Linden, the White Ash, the Tulip, the Sycamore, and others. The brush around the selected trees will need to be kept cut for ten or fifteen years, but after that it is not likely to make much headway in the shade of the larger trees, as may be seen along country roads that pass through the forest. By allowing some of the trees to develop, therefore, the municipality is eventually relieved of the necessity for annually or bienially mowing the brush along the roadside.

It is not an uncommon thing when traveling through rural communities to find men engaged in cutting down fine roadside trees. There are various reasons given for such action and on investigation it is often found to be petty grafting on the part of one or more of the town officials. Occasionally the men who are found doing the work will excuse themselves on the ground 
that in wet weather the trees prevent the road from drying out. Such an argument carries little weight, for expert road builders claim that on account of the roots holding the soil in place it is an advantage to have trees along the roadside. Other offenders will say that they get the wood as their remuneration for the work

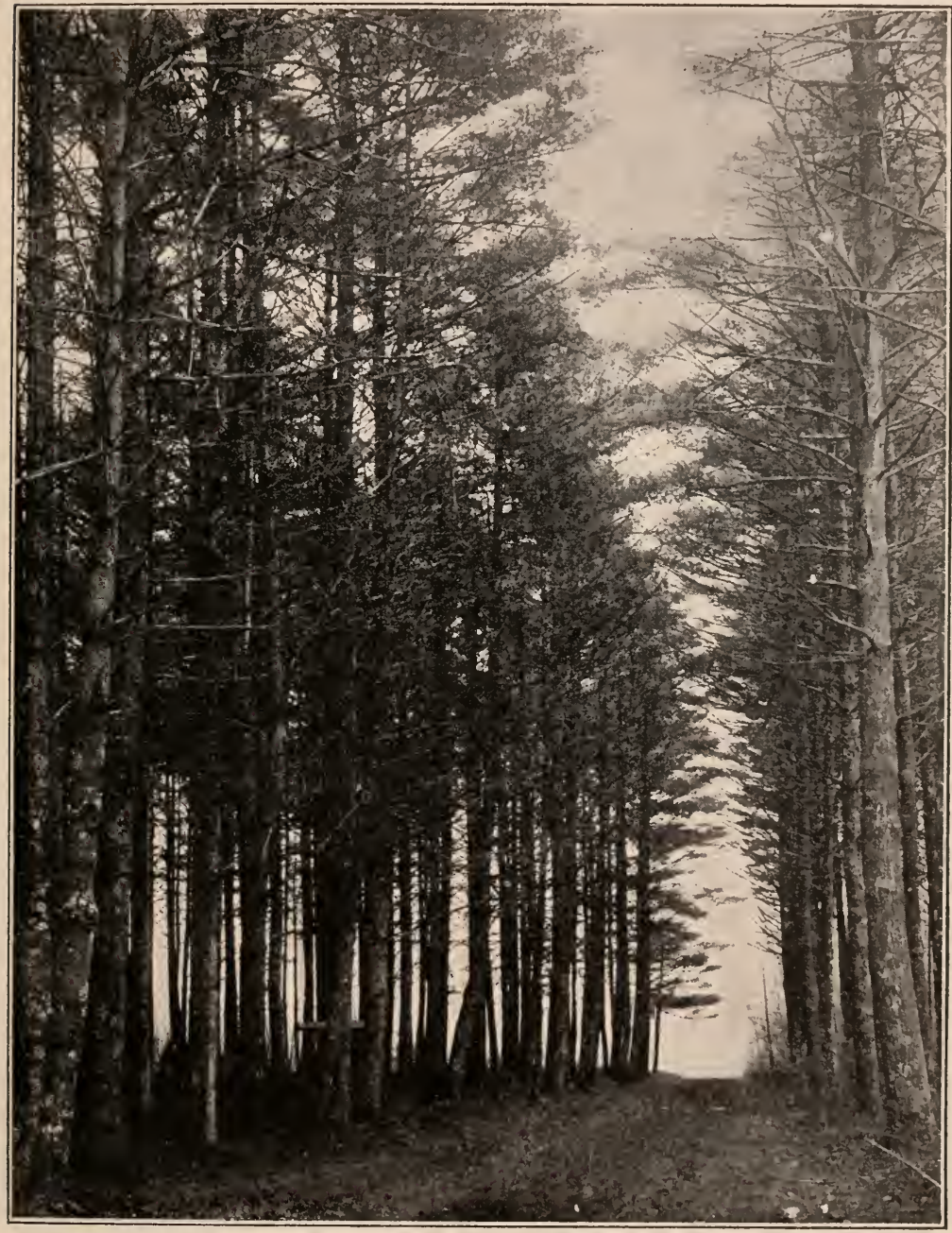

Fig. 30. A country road through a White Pine grove, 50 years old, at Windsor, Connecticut. 
of cutting the brush. On the whole, the apparent inexcusable destruction of roadside trees is largely the result of ignorance. Until the town or county officials in rural communities come to realize the real value of trees, or until public sentiment becomes much keener than at present, this shameful practice is likely to continue.

It is unfortunate that the farmer's woodlot is so often located at the rear of the farm, instead of along the roadside. Everyone appreciates the short stretches of wooded road in the country and it is hoped that the few remaining roadside forests will not be disturbed for many years. If it should be necessary to remove them at some time it is further hoped that the owners will see the wisdom of leaving a strip of from one to two hundred feet along the roadside. This strip would make an excellent place for the farm woodlot, and for the practice of modern methods of forest management.

Roadside Planting - In most places there seems to be no reason for the absence of trees along the country roadside. When we consider how easily trees may be obtained and how little trouble and expense tree planting envolves we wonder why we should not have them along all country roads. Suitable trees usually may be obtained in neighboring forests without expense. If each farmer would occasionally spend a few hours in the planting of trees, it would not be long before the desired result would be attained. While the planting of a row of trees along the front of a farm may greatly enhance its value, the result is largely a public benefit and bears the same relation to the community as sidewalks and improved roads. For this reason it would be worth while for every country town to take up the work of roadside planting.

It is always well to select species that are common to the neighborhood. Exotic forms when found in the country seem out of place and are not recommended for roadside planting. For the sake of uniformity it is well to plant only one species on a single stretch of road. With a view to securing early results, trees of a rapid growing species are sometimes planted alternately with the permanent trees. This practice is always attended with the danger of leaving the temporary trees so long that they are likely to affect the permanent planting. In order that trees may 
show up at their best they must have plenty of room for derelopment.

In the selection of species for roadside planting it is well to avoid forms that are especially susceptible to injury from insects and diseases. The Elm in many respects is admirably suited to roadside planting, but on account of its susceptibility to injury from the leaf beetle it is not generally recommended. At the present time it would be unwise to plant the common Chestnut in the northeastern states on account of the prevalence of the chestnut bark disease, for which no remedy has yet been devised.

Those who have traveled through the Niagara district of Ontario or the Annapolis valley in Nova Scotia have been surprised at the splendid effects obtained from the planting of fruit trees along the roadside. There is great economy in this practice, but fruit trees as commercially grown do not offer sufficient protection from sun and wind. The sweet cherry is probably one of the best kinds of fruit trees for this purpose. It is a large-growing tree and is useful in attracting the birds. Farmers can well afford to grow some fruit especially for this purpose. The birds, in rendering useful service, more than pay for the fruit they eat. In some sections of Europe the municipal authorities are accustomed to plant fruit trees along the public highways for the sake of ornament and economy. The common custom being to offer the fruit for sale on the trees and to sell it to the highest bidder. In many cases the revenue from the sale of fruit is sufficient to pay for the work expended on the road.

The custom when planting trees on country roadsides, is to plant in straight rows. Uniformity of arrangement is not so important for country roads as for city streets, and it is possible with certain species to produce an effect so formal that it will not be in keeping with the natural surroundings. The important point is to avoid in country plantings everything of an artificial nature.

On narrow roads it is advisable to set the trees rery near the fence, but on roads that are forty fect or more in width, they may better be set about six or eight feet from the highway limits. 'This will allow for a sidewalk on the outer side of the rows of trees. If the farmer is planting the trees at his own expense it is usually advisable to set them on his own land, probably four or fire feet from the fence, except where the road is very wide. The 
permanent trees on one side of the road should be set opposite the spaces on the opposite side. This will allow more room for the spreading tops and at the same time avoid the appearance of formality. Where the roads are narrow and where the trees must be planted within the highway limits, it is well to avoid the larger-growing species.

\section{THE USE OF TREES AROUND THE HOME}

The Location of the Home - It is remarkable that so many country residences are located on the hill-tops, fully exposed to the cold winter winds. Such locations usually are not only unattractive, but are decidedly inconvenient. It is true that the higher elevations offer better views of the landscape, but, as Mr. Manning has remarked, "One soon tires of a fine view, if it is secured at the expense of a daily climb up a long hill." It would seem more desirable to select for the residence a less elevated site and reserve the hill-top for an occasional view of the distant landscape. More pleasing planting effects also may be produced on a gently sloping hill-side. The matter of convenience is of greatest importance and, of course, should be given precedence over esthetic considerations.

Adaptation - Volumes may be written on the subject of rural adlaptation. The present discussion, however, must be limited to that phase which relates to trees. It is hard, however, to refrain from expressing disapproval of the type of residence usually found in the rural districts of America. Too many of them give the impression that they have been lifted from the crowded city block and accidentally dropped in the country. The modest frame or stone cottage with its low sloping roof and graceful dormer windows seems decidedly more pleasing and appropriate than the erect red brick house with its white mortar, its bright colored trimmings, and its painfully-symetric outline. While good planting will go a long way toward covering up deficiencies in the make-up of the house, the best results can be attained only when the building harmonizes with the surroundings.

Oftentimes there is just as much lack of harmony in the choice of species and the planting arrangement as in the stiff and formal dwelling house. The formal style as applied to landscape art seems entirely out of place "amid the green fields, and beside the wanton gracefulness of luxuriant nature." In the past there has been a great tendency to follow European styles and to use 
foreign species of trees and shrubs. The attempts at formal gardening in rural districts are becoming less frequent and it is encouraging to note that there are fewer people nowadays who believe that it is necessary to trim trees in a variety of fantastic shapes to bring out their beauty. The tendency at the present time is to use fewer of the exotic forms and to depend more upon the native flora, especially in respect to trees. As suggested for roadside planting, the rural home builder would do well to go to a neighboring forest for his trees. The foreign species are not so well suited to the soil and climate, and this is an additional reason for choosing native forms.

On the small or medium-sized place it is not always practicable to engage a trained landscape gardner. The owner will probably get more pleasure from the home surroundings if he can claim some credit for their creation. The style may not be correct in all its details, but it is likely to supply the needs of the family and to increase the knowledge and interest of the owner. For the planning and planting of large estates it is usually advisable to engage a landscape architect of ability and reputation. There are many so-called landscape gardeners soliciting contracts of this kind who are wholly unreliable and who are likely to do more harm than good.

The Function of Trees in Home Decoration - The fundamental uses of trees around the home are to furnish the great masses of regetation with which to frame the home picture, to direct and restrict the views along desirable lines, to screen objectionable objects, to emphasize the elevations of the ground, to vary the sky-line, to furnish shade and shelter, and to give to the surroundings the expression of comfort and homliness. Trees contribute to these purposes mainly by their foliage which varies not only with the species, but with the changes in season. Their flowers and their fruit, while largely incidental, are valuable attributes and should receive careful consideration. Even in their winter condition, trees possess great beauty, although of a different kind.

Shrubs - It is difficult to discuss home planting without taking into consideration the use of woody shrubs. In conjunction with trees they are useful in the production of great banks of foliage. As a rule, trees require much less attention than do shrubs, and by the careful selection of species very satisfactory results may be produced by their exclusive use. It is always well, however, to include a few shrubs. even in the most unpretentious plantings. 
Shrubs are largely used in groups and belts and not as individual specimens. Few shrubs are sufficiently graceful and characteristic in habit to make pleasing objects when planted singly, but by their great variety, a group becomes very attractive. Their place is largely in borders with trees or buildings as back grounds and in clumps in the open lawn or in the bends of walks and drives. On small lots the shrubs and small trees should predominate, while the larger areas will stand a greater proportion of large trees.

Planting for Winter Effect - It is remarkable in view of the volumes that have been written on subjects relating to landscape architecture, that so little attention has been given to the matter of planting for winter effect. Most trees in the northern sections are dormant or in their winter condition for at least six months in every year. Although people do not use their gardens and grounds so much at this season of the year as in the summer, the appearance of the home surroundings in winter may be greatly improved by the careful selection of species and by their proper grouping. The evergreens, of course, are indispensable for winter effect, but some of them are decidedly more desirable than others. The spruces, unless used with discretion, are likely to be too formal for rural planting, but when interspersed with pines and hemlocks are very useful for backgrounds. The hemlock is the most graceful of evergreens and should be more generally planted around rural homes. It thrives well in shaded locations where other species fail. There is a great variation in color among evergreens and the somber effect produced by some kinds may be greatly diminished by planting with them one of the brighter colored species. The same result may be attained by using some of the contrasty deciduous trees, like the white or gray birch. The value of the birches also may be greatly enhanced by being located in front of an evergreen background as shown on page 231 .

The Planting Plan - The work of planning the home ground is greatly facilitated by the use of a plan. (See figs. 32 and 33). This should be drawn to a scale and should show in the beginning all the landscape fixtures or those features that must remain unchanged. Such fixtures include the buildings, the irregularities of the surface of the ground, the valuable shade trees, the orchard, the highway and anything else that it is impracticable to move. The next step after locating the fixtures, is to indicate on the plan the position of the trees and shrubs to produce the desired effect.

Of course, anyone who attempts to make such a plan, must have 
in his mind a fairly clear conception as to how the place should look when finished. In other words, he must be somewhat of an artist. The required conception on the part of the landscape gardener is not unike that of the artist who paints pictures on canvas. Many people are better artists than they suppose, and it does not take much ability to make a pleasing landscape picture from the ordinary country home.

The landscape gardener, whether amateur or professional, before locating his trees should study the surroundings with a view of ascertaining the direction of the most pleasing views. In this connection he will consider the views from the various windows of the house, from the veranda, and from various points on the lawn. In locating the trees, then, it is necessary to keep constantly in mind these desirable views. The next problem will be to block out any objectionable views, either on the home grounds or on adjacent lands. The farm buildings may usually be screened from the house and from the highway without seriously affecting their convenience. In some cases the desired effect may be produced by a belt of trees and shrubs separating the front lawn from the back yard. This arrangement is not always the most desirable for it is often possible to give expanse to a small lawn by leaving a vista that extends far in rear of the house. One or more clumps of trees or shrubs carefully arranged may effectively block out objectionable views without completely closing the view in that direction. Furthermore, skillful gardeners often appropriate views through neighboring grounds in order to give expanse to a place that would otherwise appear crampt. This is accomplished by blocking out the neighboring houses and by maintaining vistas through the adjacent grounds. Similar results may be attained by opening vistas into adjoining meadows or pasture fields.

With larger areas it is often advisable to separate the grounds in such a way as to provide for secluded nooks, and this is very casily accomplished by planting. Such seclnded areas, however, should be relatively small and should not detract from the unity of the whole scheme. There is not the necessity for seclusion in rural districts as in the cities, but when the grounds are large cnough it is advisable to arrange the shrubbery so as to separate a portion of the rear lawn for the purpose of a home playground. It may include accommodations for pleasure and recreation, such as tennis courts, hammocks and the like. 
A common mistake in dividing the grounds into two or more parts is in making use of a hedge or solid belt of trees. A much more pleasing way is to use clumps of shrubbery. These may be a considerable distance apart, but so arranged that they will block the view from the street and at the same time maintain an expression of expanse. It is sometimes desirable, for quick results, to

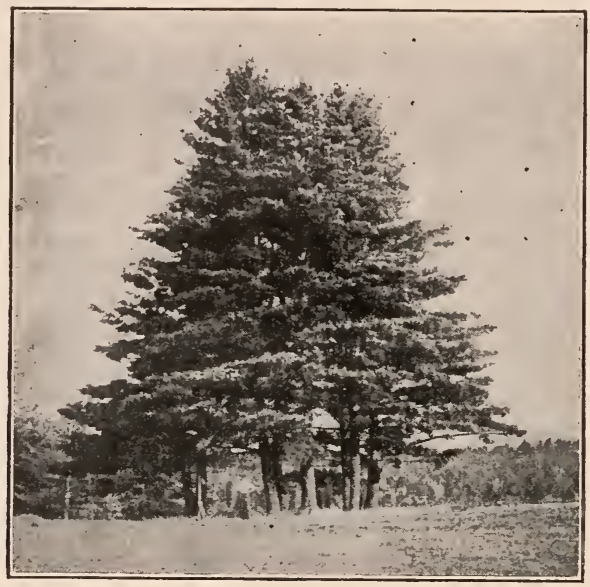

Fig. 31. A group of White Pines that retain the character of an individual

plant trees close together, and a clump of trees of the same species often produces a pleasing effect. Although the trees in a clump lose some of their character as they mature, the group as a whole often assumes the character of an individual tree of the species as shown in figure 31.

The Finished Picture - Where trees and shrubs have been properly grouped the result should present a pleasing picture. The house will naturally be the central figure and any planting scheme that will detract attention from the house is not considered good taste. The vistas from the highway should lead to the central figure - the house. The shrubbery, if well planned, will form an appropriate frame to the landscape picture. The shrubbery that is not located in the border or frame of the picture should contribute somewhat to the picture itself. Such trees and shrubs, therefore, should be attractive and should be closely related to the house. If many trees are scattered over the ground one is likely to lose sight of the central figure and the result is likely to present the appearance of a tree museum rather than a home picture. 


\section{CHAPTER IV}

\section{TREE PLANTING IN TOWNS AND CITIES.}

\section{TREES IN RELATION TO CITY LIFE.}

When we think of the open country we are reminded of the cool and shady roads, although some country roads are not so alluring as they ought to be. The thought is comforting. On the other hand, when we think of conditions in the city, the hot and dazzling parements present themselves vividly to our memory. The thought is anything but comforting. Blessed is the city that is well supplied with trees. An occasional city has been so well blessed in this respect that it has become famous the country over, and such a city is often designated as the Forest City, the Elm City, or the City of Parks.

The attractiveness of a city depends largely upon its trees. A city without trees cannot be attractive, and the more trees within the city limits, the more attractive is the city likely to be. Most cities are anxious to attract visitors and permanent settlers, and the success of cities in this direction will depend largely upon their supply of trees. Trees, therfore, by making a city more attractive, tend to increase the value of real estate. The value of trees to any particular property is manifested by comparing the selling price of property with and without trees. In some cases a lot with two or three trees along its front boundary will sell at a price fifty per cent. higher than a similar adjacent lot without trees.

The real value of shade trees to abutting property has also been shown by court decisions, although in the past judges have usually underestimated their true worth. The following is an extract from an editorial in the Newark Evening News, under date of July 20, 1911:-

"The Appellate Division of the New York Supreme Court has confirmed a judgment of the lower court, fixing what may be called a good round value on trees in the city. 
"A construction company doing some work on a street, found that the trees hindered their progress. They thereupon cut down the trees without so much as considering for a moment their value to the owner's property.

"Suit was at once brought against the company, the damages being laid at $\$ 500$, for each tree cut down. The Plaintiff recovered for the full amount as the value of the trees, and the court added $\$ 1,000$, more for punitive damages. It was this verdict that was carried to the Appellate Court and has been sustained."

Five hundred dollars may seem a large sum for a tree in the city, but it must be remembered that the value of the trees as kindling wood or as lumber, or even as the material for house trimmings or furniture, is not the thing to be considered. The tree required many years to grow. It not only adorned the property but it afforded health, comfort, enjoyment and protection to its owners. Its place, when destroyed, could not be filled by another tree inside of fifteen, twenty, or thirty years, and all this time the owners of the property are deprived of its benefits.

Municipalities have just come to recognize the value of trees from the standpoint of health. Since trees absorb the carbonic acid gas from the air it is believed that they help to purify the air. Health authorities are now recommending the planting of trees in the cities with a view of mitigating the intense heat during the summer months and of diminishing the death-rate among chil-

\section{SUGGESTIONS FOR STREET PLANTING}

Although at the present time much attention is being given to the planting and care of trees in cities, it is remarkable that the matter has not receired more attention in the past. The cost of setting out trees is so small compared with the lasting benefits derived from them, that it is hard to understand why cities and towns should not take up the work on an extensive basis. The smaller towns should profit from the experience of the larger and older cities. The problem is decidedly less difficult with small towns, for they can plan their streets with a view of having them lined with trees. Trees that get a good start when the town is young are more likely to thrive well and to administer to the needs of the mature city, than those that are planted later, when they are subjected to all the hardships of the crowded city streets. 
The principles involved in the planting of city streets are entirely different from those involved in the planting of country roads. In the eity the treatment necessarily must be of a formal nature to harmonize with the geometric lines of eity streets. City planting is done amid artificial surroundings and in this respect it differs radically from country planting, which is always associated with natural objects. It is important, therefore, that the trees on a city street should be uniform in character and should be planted in straight lines.

Arrangement of Trees on the Street - It is essential for the best results that streets be sufficiently wide to admit of a strip of ground between the sidewalk and the curb for the exclusive use of the trees. This strip need not be more than four or five feet in width, but twice this width would give the street a better appearance and would facilitate the growth of the trees. On some streets there is no strip left for this purpose, and the trees necessarily must grow through openings in the sidewalk. Trees in such positions do not look so well and are not likely to thrive so well. In some cases, where the roots may extend beneath the walk to the open spaces in front of the residences, the trees are not likely to be seriously handicapped. Where the street is too narrow for a suitable planting strip and where there is an open space on the abutting property, it would seem advisable to place the sidewalk near the curb and to plant the trees along the inside of the walk. When the buildings are close to the street and when there is no room for a planting strip, the conditions are unfarorable for the development of trees. Oftentimes the roadways are wider than is necessary to accommodate the traffic. In such cases they should be reduced in order to make room for planting.

When the planting strip is narrow the trees are usually set in the center, but with wider strips their position will depend upon the width of the street and the proximity to tall buildings. Where the street is wide the trees may be set near the curb. There is danger, of course, in getting the trees too near the curl, where they are likely to be injured by horses and rehicles. On the other hand, where the buildings are tall and near the street, it is necessary to place the trees as near the curb as possible, except where the streets are very wide. 
Parking Strips - With very wide streets it is customary to reserve "parking strips" down through the center for the planting of one or more rows of trees. Such reservations are not recommended for streets less than one hundred feet in width. Where two rows of trees are required on this strip, and this is always advisable, the street should be at least 130 feet in width. The parking. strip when narrow is often used for the planting of shrubbery alone. Wider strips are often used for walks, bicycle paths, and street railway tracks.

Very pleasing planting effects may be produced on wide streets or arenues with parking strips to accommodate two additional rows of trees. While it is customary to plant but one species on ordinary streets, the appearance of avenues or boulevards may be greatly enhanced by planting a strikingly different species along the parking strip. On some of the widest streets we frequently find two rows along each side of the street. This arrangement is seldom satisfactory for the reason that the trees are likely to become too crowded. Streets that are wide enough to accommodate four rows of trees are usually wide enough for a parking strip which would accommodate two rows of trees and thus give a better distribution.

Distance Between Trees - It is well to adopt a uniform system of spacing the various varieties of street trees. The individuals should be so spaced that they may develop into perfect specimens. The distance between the trees should be slightly in excess of the natural spread of the species when mature. Of course, such factors as environmental conditions, the character of the soil, the severity of the climate, and the amount of protection the trees receive, will exert considerable influence upon the ultimate development. The distance at which the commonly planted street trees should be spaced is about as follows:-

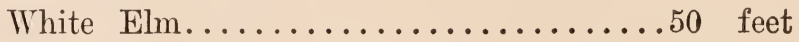

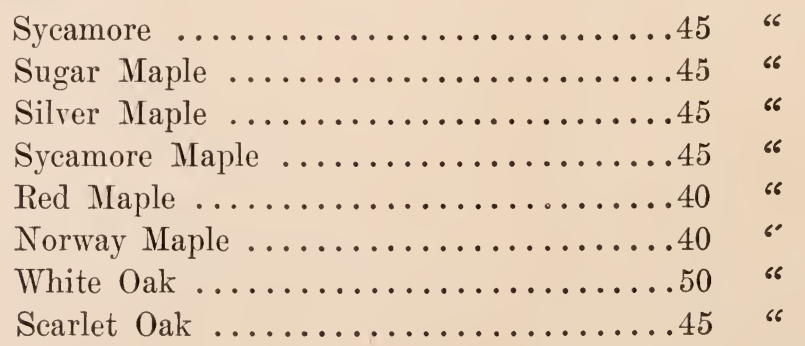


Red Oak ....................45 "

Chestnut Oak ...................45 "

Pin Oak ......................

Tulip ......................... "

Common Locust ................45 " "

Honey Locust ..................40 "

White Ash .....................45 "

Linden .....................40"

Horse Chestnut ..................... "

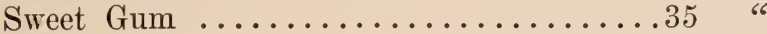

Ginkgo ........................ "

Hackberry .......................... "

Ailanthus ......................... "

Carolina Poplar ..................... "

Lombardy Poplar .................. "

Hardy Catalpa ......................... "

Kentucky Coffee .................. " "

It is not always practicable to place trees at regular distances, for they must be made to fit in a given stretch between cross streets. In some places the trees are arranged along the street in relation to the abutting property. This is not right, for such an arrangement is likely to lack uniformity. It is usually best to have the trees regularly spaced and where the street is wide enough for their full development they should be planted opposite one another. On narrow streets, for the sake of giving them more room, the trees on one side of the street may be planted opposite the spaces on the other side. The chief objection to this method of arrangement is the uneven appearance that it presents at the street intersections. Whether planted opposite or alternately the rows should not extend exactly to the corner, for in such positions they are more likely to be injured and are also likely to interfere with the illumination of the streets.

Permanent and Temporary Planting - It is always advisable to plant long-lived trees on city streets. There is always a temptation, for the sake of getting early results, to plant rapid-growing species. The rapid-growing species are usually short-lived, and for this reason are objectionable. While it is usually best to plant only one species on a given street it is sometimes permissible to alternate the permanent trees with trees of a quick-growing spe- 
cies. The prevailing objections to such a practice are that it breaks up the uniformity and that the temporary trees are likely to be left too long, in this way injuring the permanent planting. Trees radically different in form and coloring, like the Red Oak and Carolina Poplar, should present a pleasing effect when regularly and alternately spaced. When the temporary trees begin to restrict the supply of sunlight and the supply of plant food and moisture, they should be promptly cut down.

The Best Species for City Streets - In the selection of species it is well to keep in mind the width of the street, the height and proximity of buildings, the character of soil, and the relative susceptibility to injury from the effects of insects, diseases, smoke, impure air, escaping gas, high and low temperatures, ice storms, and general neglect. The ornamental value of the various species should also be considered. Some trees are peculiar for their flowers, others for their summer or autumn foliage, and still others for their symmetry. Furthermore, a street tree should furnish the required shade, and species differ greatly in this respect. Again, some trees like the staminate Ailanthus are offensive on account of their odor, and others like the Horse-chestnut and the Locusts are objectionable on account of unclean habits.

The White or American Elm is probably the most commonly planted street tree. It makes a tall, graceful growth and has many commendable points. Unfortunately it is subject while young to the attacks of borers and to the ravages of the leaf-beetle and other insects throughout its whole existence. It is still largely planted, especially in suburban sections where there is a desire to produce a natural effect.

The tendency at the present time is to use for city street planting the species that present a more formal appearance. The following are likely to give good results under varying conditions: Red Oak, Pin Oak, Scarlet Oak, Red Maple, Norway Maple, Sycamore Maple, American and European Linden, Sycamore, Ginkgo, Ailanthus, Hackberry, Sweetgum.

Trees of Rapid Growth - Where early results are necessary, such varieties as the Carolina Poplar, Box Elder, Hardy Catalpa, Silver Maple, Linden, and Sycamore may be employed. The following' table prepared by the late William F. Fox, superintendent of forests for the state of New York, gives the relative growth-rate of 
a number of native species. The table is based upon the behavior of saplings which in the beginning were three inches in diameter. It is estimated that in 20 years they should attain the diameter indicated in the table:-

\begin{tabular}{|c|c|}
\hline Silver Maple ................ & \\
\hline White Elm ................... 19 & 66 \\
\hline Sycamore ......................18 & 66 \\
\hline Tulip 'Tree $\ldots . \ldots \ldots \ldots \ldots \ldots \ldots \ldots$. . . . . . & "6 \\
\hline Linden .................... & 66 \\
\hline Catalpa $\ldots \ldots \ldots \ldots \ldots \ldots \ldots \ldots \ldots \ldots \ldots \ldots \ldots$ & 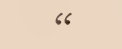 \\
\hline Red Maple ...................16 & " \\
\hline Ailanthus $\ldots \ldots \ldots \ldots \ldots \ldots \ldots \ldots$ & " \\
\hline Cucumber Tree ..................15 & "6 \\
\hline Chestnut .....................14 & “ \\
\hline Common Locust ................14 & “ \\
\hline Sugar Maple ...................13 & “ \\
\hline Horse-chestnut $\ldots \ldots \ldots \ldots \ldots \ldots \ldots$. . . . . & “6 \\
\hline Honey Locust . . . . . . . . ...........13 & “ \\
\hline Red Oak ........................ & " \\
\hline Pin Oak ..................... & "6 \\
\hline Scarlet Oak ................... & " \\
\hline 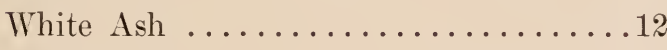 & “ \\
\hline White Oak ..................12 & " \\
\hline Hackberry $\ldots \ldots \ldots \ldots \ldots \ldots \ldots$........ & "6 \\
\hline
\end{tabular}

\section{MUNICIPAL CONTROL OF SHADE TREES}

There are many reasons why the planting and care of shade trees should be placed in the hands of municipal authorities. If the work is left to the property holders the streets will lack uniformity and the result is usually a jumble of trees of various species, of various ages, and planted at various distances and in various ways, in line and out of line, continuous and interrupted. Examples of the result of such methods may be seen in almost any city.

Municipal control is not a new idea as applied to shade trees, but only during the past ten or fifteen years has its adoption been at all general. The laws of Massachusetts require each town and city to appoint some one or more officials whose duty shall be the planting and care of shade trees. Such officials are designated by various titles, the more common being: Tree Warden, ritr For- 
ester and Street Commissioner. Many states have in their statute books laws relating to shade trees in towns and cities. The most progressive legislation along this line is found in the laws of New Jersey, Pennsylvania and Massachusetts. Each of these states leaves the towns and cities free to supplement the statutes by local ordinances. For the guidance of municipalities that are contemplating the problem of municipal control, the shade tree ordinance of the city of Newark, N. J., is here given in full:-

BE IT ORDAINED by the Shade Tree Commission of the City of Newark, New Jersey, as follows:

1. It shall be unlawful for any person, firm or corporation, without the written permit of the Shade Tree Commission, to cut, break, climb or injure any tree or portion of tree planted or growing in any public highway within the City of Newark, or cause, authorize or procure any person to cut, break, climb or injure any such tree or any portion thereof; or to cut, break, climb or injure any tree or plant, or any portion of any tree or plant, planted or growing in any city park or parking strip within the City of Newark, or cause or authorize or procure any person to cut, break, climb or injure any such tree or plant or any portion of such tree or plant; or to injure, misuse or remove, or cause, authorize or procure any person to injure, misuse or remove any device set for the protection of any tree or plant in any public highway or eity park of said City. Any person, firm or corporation desiring for any lawful purpose to cut, prune or trim any tree in any public highway of said City of Newark may apply to the Shade Tree Commission; and if in the judgment of said Commission the desired cutting, pruning or trimming shall appear necessary, and the proposed method and workmanship thereof such as said Commission approves, the Shade Tree Commission may thereupon issue a written permit for such work. Any work done under such written permit must be performed in strict accordance with the terms thereof.

Any person, firm or corporation which shall violate or authorize or procure a violation of any provision of this section or of any permission given as aforesaid shall, upon conviction thereof, forfeit and pay a penalty of Five Dollars $(\$ 5)$ for each and every such offense.

2. It shall be unlawful for any person, firm or corporation to kill or remove, or cause, authorize or procure the death or removal of, any tree planted or growing in any public highway, or any tree or plant planted or growing in any city park, within the said City of Newark. Any person, firm or corporation desiring for any lawful purpose to take down or remove any tree in any public highway of said City of Newark may apply to the Shade Tree Commission; and if in the judgment of the said Commission the desired taking down or removal shall appear necessary, the Shade Tree Commission may thereupon issue a written permit therefor. Any work done under such written permit must be performed in strict accordance with the terms thereof.

Any person, firm or corporation which shall violate or authorize or procure a violation of any provision of this section shall, upon con- 
viction thereof, forfeit and pay a penalty of Fifty Dollars (\$50) for each and every such offense.

3. It shall be unlawful for any person, firm or corporation owning, or using, or having control or charge of gas or other substance deleterious to tree life to allow such gas or other substance to come into contact with the soil surrounding the roots of any tree in any public highway or of any tree or plant in any city park in the City of Newark in such manner as may injure such tree or plant.

Any person, firm or corporation which shall violate or authorize or procure a violation of any provision of this section shall, upon conviction thereof, forfeit and pay a penalty of Ten Dollars $(\$ 10)$ for each and every such offense.

4. It shall be unlawful for any person, firm or corporation owning, or using, or having control or charge of gas or other substance deleterious to tree life, to allow such gas or other substance to come in contact with the soil surrounding the roots of any tree in any public highway or any tree or plant in any city park in the City of Nerark in such manner as shall kill or destroy such tree or plant.

Any person, firm or corporation which shall violate or authorize or procure a violation of any provision of this section shall, upon conviction thereof, forfeit and pay a penalty of Fifty Dollars ( $\$ 50$ ) for each and every such offense.

5. It shall be unlawful for any person, firm or corporation to cause, authorize or procure any brine water, oil, liquid dye or other substance deleterious to tree life to lie, leak, pour, flow or drip on or into the soil about the base of a tree in any public highway or eity park in the City of Newark, or onto a sidewalk, road or pavement therein at a point whence such substance may by lying on, or by flowing, dripping or seeping into such soil, or in any other manner whatever, injure such tree; or to cause or procure such lying, leaking, flowing, dripping, seeping or injuring.

Any person, firm or corporation which shall violate or authorize or procure a violation of any provision of this section shall, upon conviction thereof, forfeit and pay a penalty of Five Dollars (\$5) for each and every such offense.

6. It shall be unlawful for any person, firm or corporation, except with the written permit of the Shade Tree Commission, to place or maintâin upon the ground in any public highway or city park within the City of Newark any stone, cement or other material or substance in such manner as may obstruct the free access of air and water to the roots of any tree in any such highway or park. Unless otherwise provided for in such written permit as above provided for there must be maintained about the base of the trunk of each shade tree in the public highways and city parks of the eity at least six square feet of open ground for a tree of three inches in diameter, and for every two inches of increase of such diameter there must be an increase of at least one square foot of open ground.

Any person, firm or corporation which shall violate or authorize or procure a violation of any provision of this section shall, upon conviction thereof, forfeit and pay a penalty of Ten Dollars $(\$ 10)$ for each and every such offense. 
7. It shall be unlawful for any person, firm or corporation to interfere or cause or authorize or procure any interference with the Shade Tree Cornmission or any of its employees, agents or servants while they are engaged in and about the planting, cultivating, mulching, pruning, spraying or removing of any tree in any public highway or city park within the said City, or in the removing of any device attached to said tree or in such removing of stone, cement, sidewalk or other material or substance as may be necessary for the protection and care of any such tree in accordance with the requirements set forth in Section 6 hereof as to the area of open ground to be maintained about the base of the trunk of each shade tree in the public highways and city parks of the City.

Any person, firm or corporation which shall violate or authorize or procure a violation of any provision of this section shall, upon conviction thereof, forfeit and pay a penalty of Ten Dollars (\$10) for each and every such offense.

8. It shall be unlawful for any person, firm or corporation to cause, authorize or procure a wire or other conductor, charged with electricity, to come into contact with any tree in a public highway or with any tree or plant in a city park in the City of Newark in such manner as may injure or abrade such tree or plant.

Any person, firm or corporation which shall violate or authorize or procure a violation of any provision of this section shall, upon conviction thereof, forfeit and pay a penalty of Five Dollars (\$5) for each and every such offense.

9. It shall be unlawful for any person, firm or corporation to cause or authorize or procure a wire or other conductor, charged with electricity, to come into contact with any tree in a public highway or any tree or plant in a city park in the City of Newark in such manner as shall destroy or kill such tree or plant.

Any person, firm or corporation which shall violate or authorize or procure a violation of any provision of this section shall, upon conviction thereof, forfeit and pay a penalty of Fifty Dollars $(\$ 50)$ for each and every such offense.

10. It shall be unlawful for any person, firm or corporation to attach or keep attached to any tree in any public highway or city park in the City of Newark, or to the guard or stake intended for the protection of such tree, any rope, wire, sign or any other device whatsoever.

Any person, firm or corporation which shall violate or authorize or procure a violation of any provision of this section shall, upon conviction thereof, forfeit and pay a penalty of Five Dollars (\$5) for each and every such offense.

11. It shall be unlawful for any person, firm or corporation to tie any horse or other animal to any tree in any public highway or city park within said City of Newark; or, having charge of such horse or other animal, to allow or cause or procure it to injure any such tree; or for any person in charge of such horse or other animal to cause or allow it to stand so that it can injure such tree.

Any person, firm or corporation which shall violate or authorize or procure a violation of any provision of this section shall, upon con- 
viction thereof, forfeit and pay a penalty of Ten Dollars ( $\$ 10)$ for each and every such offense.

12. It shall be unlawful for any person, firm or corporation to plant or set out any shade tree, or cause or authorize or procure any person to plant or set out any shade tree, in or on any part of any public highway or city park within the said City of Newark without first obtaining from the Shade Tree Commission a written permit so to do or without complying in all respects with the conditions set forth in such written permit.

Any person, firm or corporation which shall violate or authorize or procure a violation of any provision of this section shall, upon conviction thereof, forfeit and pay a penalty of Five Dollars (\$5) for each and every such offense.

13. During the erection, repair, alteration or removal of any building or structure within the City of Newark it shall be unlawful for the person or persons in charge of such erection, repair, alteration or removal, to leave any street tree in the vicinity of such building or structure without such good and sufficient guards or protectors as shall prevent injury to said tree, arising out of or by reason of said erection, repair, alteration or removal.

Any person, firm or corporation which shall violate or authorize or procure a violation of any provision of this section shall, upon conviction thereof, forfeit and pay a penalty of Ten Dollars $(\$ 10)$ for each and every such offense.

14. It shall be unlawful for any person, firm or corporation to enter upon any portion of lawn or other cultivated ground in any eity park within the said City of Newark when forbidden so to do by an official sign or other official notification.

Any person, firm or corporation which shall violate or authorize or procure a violation of any provision of this section shall, upon conviction thereof, forfeit and pay a penalty of Five Dollars ( $\$ 5$ ) for each and every such offense.

15. It shall be unlawful for any person, firm or corporation to throw, deposit or leave any paper or waste material whatsoever in or upon any part of the surface of any city park within said City of Newark or in or upon any park property or appurtenance therein except in the receptacles provided in such park for that purpose.

Any person, firm or corporation which shall violate or authorize or procure a violation of any provision of this section shall, upon conviction thereof, forfeit and pay a penalty of Five Dollars (\$5) for each and every such offense.

16. It shall be unlawful for any person above the age of fourteen years to play at any game in a city park in the City of Newark, except at such times and in such places and under such regulations as may be designated in writing by the Shade Tree Commission.

Any person, firm or corporation which shall violate or authorize or procure a violation of any provision of this section shall, upon conviction thereof, forfeit and pay a penalty of Ten Dollars (\$10) for each and every such offence. 
17. It shall be unlawful for any person, firm or corporation to place or erect any booth, stand or other structure, or to place any wagon or other vehicle, except such as may be propelled by hand and adapted for the carrying of children, invalids or dolls, on or in any city park of the City of Newark, without the written permission of the Shade Tree Commission.

Any person, firm or corporation which shall violate or authorize or procure a violation of any provision of this section shall, upon conviction thereof, forfeit and pay a penalty of Ten Dollars $(\$ 10)$ for each and every such offense.

18. It shall be unlawful for any person, firm or corporation to sell or offer for sale within any city park of the City of Newark any goods, wares or merchandise whatsoever, or to display or distribute any advertising device, circular or card in any such park.

Any person, firm or corporation which shall violate or authorize or procure a violation of any provision of this section shall, upon conviction thereof, forfeit and pay a penalty of Five Dollars (\$5) for each and every such offense.

19. It shall be unlawful for any person, firm or corporation to deface, damage, or in any wise injure any statuary or pedestal, or other structure or park appurtenance whatsoever, in a city park in the City of Newark.

Any person, firm or corporation which shall violate or authorize or procure a violation of any provision of this section shall, upon conviction thereof, forfeit and pay a penalty of Five Dollars (\$5) for each and every such offense.

20. It shall be unlawful for any person, firm or corporation to hunt, molest, injure, eapture or in any way interfere with the freedom of any bird, being free and undomesticated, in any city park in the City of Newark; or to hunt, molest, injure, capture, or in any way interfere with the freedom of any squirrel, fish or other animal, being the property of the City, in any such park.

Any person, firm or corporation which shall violate or authorize or procure a violation of any provision of this section shall, upon conviction thereof, forfeit and pay a penalty of Five Dollars(\$5) for each and every such offense.

21. It shall be unlawful for any person to utter any profane, threatening or abusive language or loud outcry, or perform any obscene or indecent act, commit any nuisance, solicit any contribution or subscription, or to play any game of chance, in any city park within the City of Newark, or to bring into such park any instrument of chance or gambling whatsoever.

Any person, firm or corporation which shall violate or authorize or procure a violation of any provision of this section shall, upon conviction thereof, forfeit and pay a penalty of Ten Dollars $(\$ 10)$ for each and every such offense.

22. Every violation by the same person, firm or corporation, of any provision of any section of this Ordinance, which continues on any day or days succeeding the first violation thereof, shall constitute an additional violation for each of such succeeding days. 
23. All Ordinances and parts of Ordinances heretofore ordained which are inconsistent with this Ordinance are hereby repealed.

24. This Ordinance shall take effect immediately.

The Newark Shade Tree Commission is invested by statute with "exclusive and absolute control and power to plant, set out, maintain, protect and care for shade trees in any of the public highways of the city of Newark; and with exclusive control of the public parks belonging to or under control of the city of Newark, or any department in the government thereof, with full power and authority to improve, repair, manage and control the same."

\section{PARKS AND PUBLIC SQUARES}

In the early stages of the development of most of the older cities there was little expectation that such settlements would ever develop into such enormous centers of population. Little attention, therefore, was given to the matter of making provision for future needs, and as a result some of the cities have suddenly realized the need of parks and have expended vast sums of money in acquiring land for this purpose. Some cities early realized the necessity for setting aside large tracts of land for public use and others have had lands donated or bequeathed to them with the stipulation that they be used for parks or play-grounds. The smaller towns have profited by the experience of the older cities and many of them are making reservations for park purposes. There is, therefore, a demand on the part of the smaller municipalities for information relating to the selection and planting of trees for parks and public squares.

The Natural Type - In the making of parks the tendency at the present time is to maintain or develop some natural landseape. Most of the largest and best known parks of this country are of the natural type. The designers of the large city parks have realized the need of a large and secluded strolling ground. Only the larger tracts of land are suited to the natural type of park. In some instances, like Keney Park, Hartford: Mount Royal Park, Montreal; and many others, the native forest has been preserved. The making of a natural park from an existing forest is a simple matter, consisting chiefly in the planning and constructing of the walks and drives. Many of our large natural parks, hewever, had in the beginning very little, if any, woodland, and 
most of the trees that are now found growing in them have been planted. In the planting of these parks the landscape gardeners have freely copied from nature. In some, like Central Park, New York, certain sections have been set aside for formal or semi-artificial gardening.

In the department of a park of the natural type, it is advisable, as far as possible, to arrange the trees in groups according to species. In this connection it is always well to study the special adaptation of the various species. Some prefer a light soil, while others thrive best on heavy or moist soil. Some must have an abundance of light, while others require some protection from the direct rays of the sun. It is hoped that the lists given in the following chapter may be of some assistance in the way of locating the trees in their most comfortable environment.

The planting in a natural city park should be so arranged that nothing can be seen that suggests the city. With this in mind the borders should be supplied with a fairly dense growth of trees and shrubs. Some of the large growing evergreens will be found useful for this purpose, using some brighter colored species, of course, to enliven the effect.

The making of a natural park is not unlike the work of planning the home grounds. The principles are the same. While it is true that most natural parks are larger than the ordinary home ground, the element of size is not such an important factor after all. The modest home ground is considered a unit while the large natural park is usually a collection of units, each one of which may be developed along much the same line as suggested for the country home. It must not be understood, however, that a well-planned natural park lacks unity, although this is the prevailing weakness of many parks.

Many cities have made the great mistake in creating formal parks when they might just as well have had natural ones. The chief function of a park is to furnish rest and recreation to the inhabitants of the city. Those who live in the smaller cities may readily avail themselves of the refreshing rural scenery which is the best antidote for the wearing influences of city life. To the residents of the larger cities the rural scenery is inaccessible. The city that best serves its inhabitants from the standpoint of parks 
is the one that furnishes a good supply of rural seenery within its limits.

The Artificial Style - With small areas it is difficult to follow the natural style, except at a great loss of space. The artificial style, therefore, is followed usually on the small city square or "green." In these the walks follow straight lines and the trees are usually disposed in such a way as to shade the walks and to contribute beauty to the surroundings. The arrangement of trees along the walks should be much the same as suggested for street planting. Furthermore, the varieties best suited to this purpose, as a rule, are those that are generally recommended for eity streets.

Since the trees in the "green" are usually grown under more favorable conditions than those on the street, it is possible to select varieties that are somewhat more exacting in their requirements. Some of the varieties that are especially valuable for their showy flowers or for their attractive autumn foliage may be used. A common error in the planting of formal parks is the tendency to seatter the trees evenly over the whole area, producing the "nursery" effect. In order to show the individual beauty of the trees and to furnish sufficient light for the growth of shrubs and herbaceous plants, a few open areas should be maintained.

\section{PLANTING SUGGESTIONS FOR CITY HOMES}

Types of City Homes - The main factor to be considered in the preparation of planting plans for the eity lot is the size. For convenience in this discussion it seems advisable then to classify city homes according to their dimensions. In the first place there are the pretentious homes of the men of wealth where the grounds occupy from half an acre to several acres. On such places the planting need not be unlike that recommended for country homes. Sometimes the owners of such homes prefer to adopt the formal or artificial style, but in most cases the demand is for the natural style, and in such cases the object is to imitate rural conditions and as much as possible to exclude the urban scenery.

Secondly, there is the common suburban home with its detached house and its small front and back yards. This is the type of home usually found on the residential streets of the smaller cities and in the popular suburbs of the larger eities. The people who occupy such homes are frequently owners and are anxious to make their homes as comfortable and attractive as possible. 
The third type of city home is the one which consists of a house in a solid row of similar units and which is so near the street that there is no room for planting. Such homes are dependent upon the street trees for shade. Some of them, however, have some room in the rear where planting may be done to good advantage.

There are all gradations between these three groups and there are probably many other types of city homes that cannot well be classified. The planting for the first group of homes has been

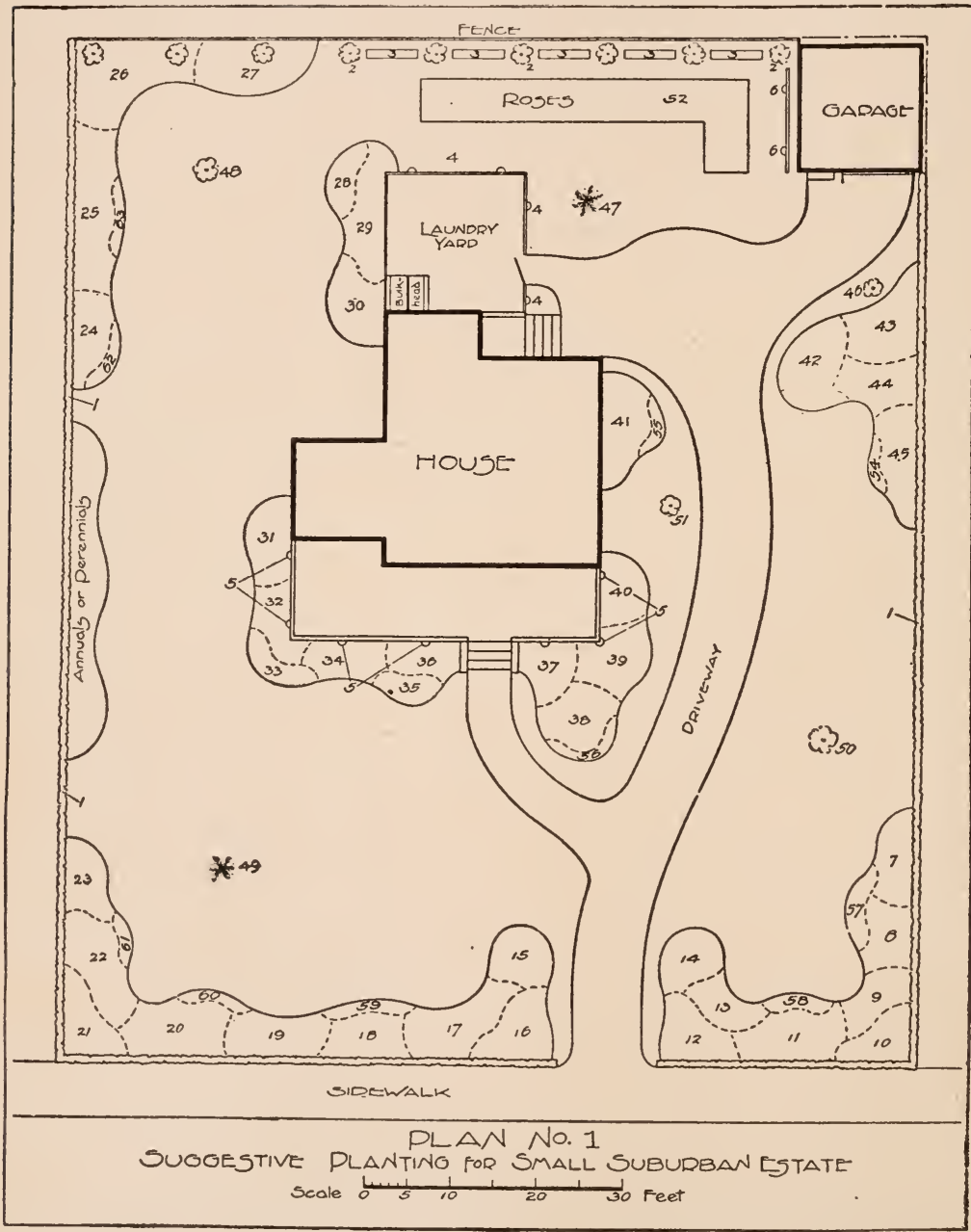

Fig. 32. A planting plan for a small suburban home after Kirkegaard. 
List No. of No. Plants.

\section{PLANTING LIST FOR PLAN NUMBER ONE}

Berberis Thunbergii. Japanese Barberries. Or Ligustrum ovalifolium. California Privets to be planted I foot apart. Populus nigra var, italica. Lombardy Poplars.

Althaea Rosea. Hollyhocks, to be planted 1 foot apart.

VINES As FolLows:-

1 Lonicera japonica var. Halliana. Hall's Honeysuckle.

1 Clematis paniculata. Panicle-flowered Clematis.

1 Ampelopsis quinquefolia. Virginia Creeper.

1 Lycium halimifolium. Matrimony Vine.

VINES As Follows:-

1 Wistaria chinensis. Chinese Wistaria.

1 Tecoma radicans. Trumpet Honeysuckle.

1 Clematis Jackmanni. Jackman's Hybrid Clematis.

1 Actinidia polygama. Japanese Actinida.

1 Dorothy Perkins Rose.

1 Crimson Rambler Rose.

1 Aristolochia macrophylla. Dutchman's Pipe.

Early Ripening Grapes.

Spiraea bumalda, var. A. Waterer. Anthony Waterer Spiraea.

Cydonia japonica. Japanese Quince.

Hydrangea paniculata. Fall-flowering Hydrangea.

Lespedea bicolor. Bush Clover.

Forsythia suspensa var. fortunei. Drooping Golden Bell.

Kerria japonica. Shrubby Globe-flower.

Rosa rugosa. Japanese Rose.

Spiraea Thunbergii. Thunberg's Spiraea.

Stephanandra flexuosa. Stephanandra.

Rosa rugosa. Japanese Rose.

Hydrangea paniculata var. glandiflora. Large-flowered Fall Hydrangea.

Calycanthus floridus. Carolina Allspice.

Lonicera tatarica. Tartarian Honeysuckle.

Elaegnus longipes. Oleaster.

Diervilla florida. Weigelia.

Prunus japonica. Flowering Almond.

Myrica cerifera. Bay-berry.

Rosa rugosa var. alba. White Japanese Rose.

Amorpha fruticosa. False Indigo.

Philadelphus Coronarius. Sweet-scented Syringa.

Syringa vulgaris and persica. Tarious varieties. Mixed Lilacs.

Spiraea japonica var. alba. White-flowered Japanese Spiraea. Viburnum opulus. Mountain Cranberry.

Spiraea prunifolium. Bridal Wreath.

Spiraea bracteata. Round-leaved Spiraea.

Sambucus nigra var. aurea. Golden-Leaved Elder.

Ribes alpinum. Alpine or Mountain Currant.

Euonymus alatus. Winged Burning-bush.

Spiraea Thunbergii. Thunberg's Spiraea.

Acanthopanax pentaphylla. Five-leaved Aralia.

Acanthopanax pentaphylla. Five-leaved Aralia.

Prairie Rcses.

Forsythia suspensa. Drooping Golden Bell.

Viburnum tomentosum var. plicatum. Japanese Snowball.

Rhodotypus kerrioides. White Kerria.

Deutzia scabra crencita. Roughed-leaved Deutzia.

Rhus cotinus. Smoke-bush.

Chionanthus virginica. White Fringe.

Cornus alba. Red-barked Ozier.

Catcilpa speciosa. Southern Catalpa.

Picea alba. White Spruce.

Apple Tree.

Picea pungens. Blue Spruce.

Fagus sylvatica var. purpurea Riversi. Rivers' Purple Beech. Betula alba var. pendula laciniata. Cut-leaved Birch.

Best Hybrid Perpetual Roses.

Hardy Asters.

Achillae ptarmica var. The Pearl.

Coreopsis lanceolata. Lanced-leaved Tickseed.

Sedum spectabile. Showy Sedum.

Scarlet Phlox paniculata. Panicled Hardy Phlox.

Delphiniums. Various species. Perennial Larkspurs.

Paeonia officinalis. Paeonias.

White Phlox paniculata.

Veronica longifolia var. subsessilis. Speedwell.

Chrysantheum lwucanthemum var. hybrida. Shasta Daisies.

Aquilegia chrysantha and various species of tall Columbines.

TALL ColumBines.

Tulips, Narcissuses, Hyacinths, Scillas and Snowdrops may

be planted among shrubs and near edge of beds. 
discussed under the head of Rural Homes. The planting for the second group will be discussed under the head of The Suburban Lot, and that for the third group under the head of Back Yard Planting.

The Suburban Lot - The size and shape of city and suburban lots varies so greatly that it is difficult to generalize on matters pertaining to its planting. A large proportion of them, however, are about $50 \times 100$ feet, and have the house located in the center. On a lot of this size it is not easy to follow any particular style. Since prevailing custom is the rule in matters of dress and since trees and shrubs may be regarded as the garb with which we clothe our homes, it seems safe to take custom as our guide in the matter of home planting.

The main objects of planting, of course, are to furnish protection from the sun, to soften the harsh lines of the buildings, and to furnish ornament. The planting necessarily must be simple, and matters of conrenience and sanitation should overrule considerations of beauty. Where trees are planted along the street it is doubtful whether there will be room for any on the lawn. Probably a single specimen of a small-growing variety may be admitted. A white or gray birch may often be so located that it will give diversity to the sky-line and relieve the harsh lines of the buildings.

On larger lots, two or three trees may be planted, but these should be located in the extreme corners. For sanitary reasons, also, there should be no large trees planted so near the house as to prevent the free circulation of air and the admission of sunlight. The most common mistake is in getting too many trees around the house. Evergreens especially should be avoided, except on very large places. They produce a shut-in effect that is objectionable on small places.

The dweller in the small city or in the suburbs of the large city, therefore, must depend largely upon shrubs and herbaceous plants for his home ornamentation. These are usually grouped in borders along the boundaries and around the buildings. Small chmps are often used also in the curves and junctures of the walks. Occasionally a single specimen or a group may be located in the open lawn, but as a rule an unbroken greensward will produce more pleasing results. When the house is located at one side 
of the lot an open space may be left along the other side, connecting the front and back yards, and in this way giving the expression of expanse.

Back Yard Planting - By the planting of a few shrubs or small growing trees the back yard may easily be transformed from a repository for all kinds of rubbish to a beautiful secluded spot where the family may obtain much enjoyment. The back yard of the common city residence is usually a piece of ground measuring not more than fifty or sixty feet in each direction and is oftentimes much smaller. It is generally surrounded by a high board fence. In an enclosure of this kind it is well to form a border of shrubbery around the whole area and preserve an open center. (See fig. $33)$. The unsightly fence may be covered by the use of climbers or tall-growing shrubs. Grape vines, Raspberry and Blackberry bushes may be used for this purpose. These often thrive better in shaded locations than the purely ornamental vines and hsrubs. If preferred some of the ornamentals, like Virginia Creeper, Dutchman's Pipe, Philadelphus, Wegelia, and Spirea, may be used. A space of three or four feet in front of the shrubs may be devoted to herbaceous perennials or annuals.

The number of trees in a back yard necessarily must be small. As a rule where other plants must be grown there is not room for more than one tree, and this should not be especially large. It should be located in the most convenient place to furnish shade, but should not be too near the house. For this purpose there is probably nothing better than the pear or the apple. There are longerlived species, but, under favorable conditions, they may be expected to attain an age of at least one hundred years. With a little care in the way of pruning and spraying, a single apple tree may be expected to furnish all the apples the ordinary family can use during the winter. For the sake of giving greater variety and to furnish fruit over a wider period, the tree may be grafted to two or more. varieties. Cherry trees, although shorter lived, are also very useful for back-yard planting.

Some species, like the Red and Norway Maple or the Pin and Chestnut Oaks, are not so likely to be affected by insects and disease, and for this reason are generally preferred, especially when the trees are not likely to receive the proper attention. Where no shrubs 


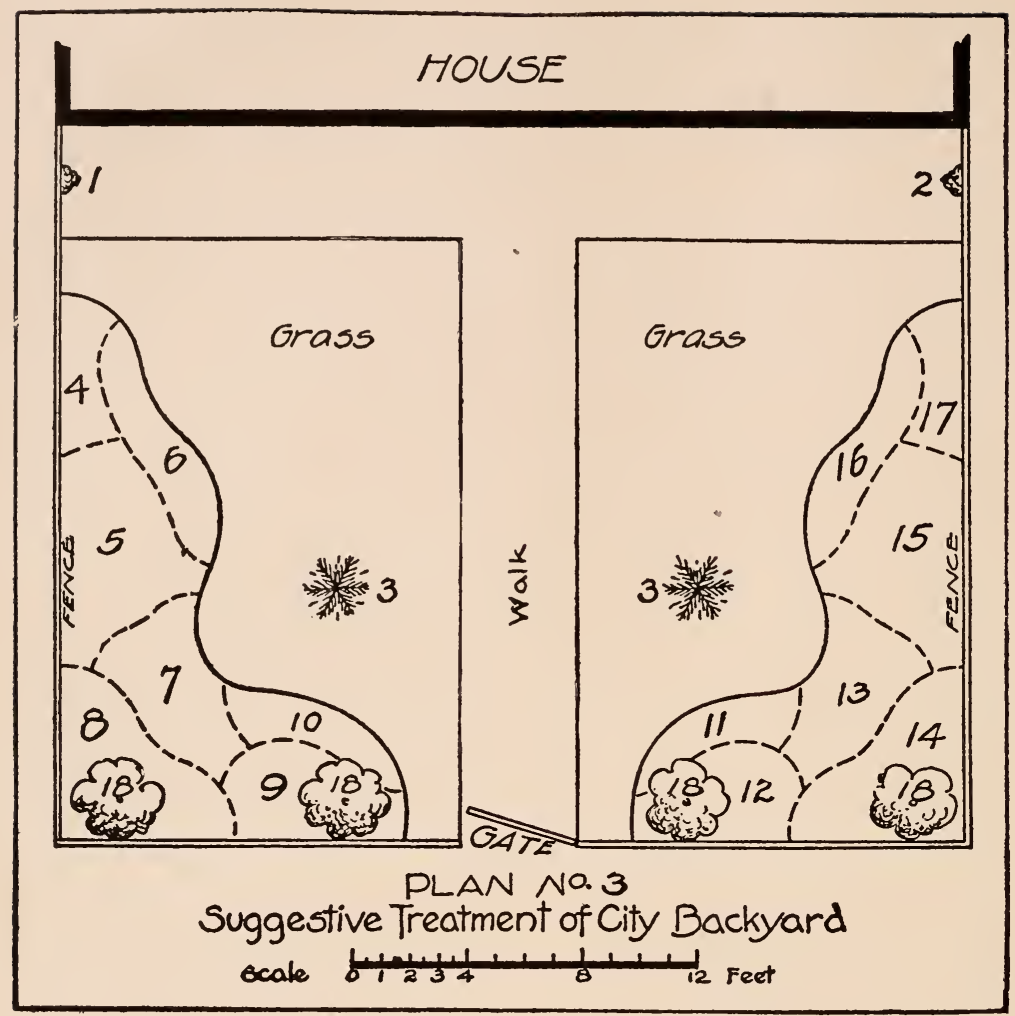

Fig. 33. Suggestive planting plan for a city back yard after Kirkegaard.

List No. of

PLANTING LIST FOR PLAN NUMBER THREE

No. Plants.

11

21

32

43

54

$6 \quad 6$

$7 \quad 3$

$8 \quad 3$

$9 \quad 3$

Wistaria multijuga. Loose-clustered Wistaria.

Tecoma radicans. Trumpet Honeysuckle.

Juniperus communis var. hibernica. Irish Juniper.

Berberis Thunbergii. Japanese Barberry.

Ligustrum ovalifolium. California Privets.

Phlox paniculata. In variety. Perennial Phlox.

Rhododendron catawbiense hybridum. Hybrid Rhododendrons.

Euonymus europaeus. Strawberry Tree.

Forsythia suspensa var. fortunei. Fortune's Golden Bell.

Coreopsis lanceolata. Tickseed.

Iris germanica. Germian Iris in variety.

Rosa rugosa. Japanese Rose.

Kalmia latifolia. Mountain Laurel.

Viburnum opulus. Mountain Cranberry.

Symphoricarpos racemosus. Snowberry.

Paecnia officinalis. In variety. Garden Paeonies.

Kerria japonica. Globe-flower.

Populus nigra var. italica. Lombardy Poplar. 
or other plants are grown, the number of trees in the back yard sometimes may be increased, but they should not be planted so closely that they will interfere with one another's natural development and prevent the growth of grass. 


\section{CHAPTER V}

\section{THE SELECTION OF TREES FOR SPECIAL PURPOSES.}

As has been shown in previous chapters, there are many factors that determine the choice of species. The fundamental question to be decided is whether a particular type of tree is suited to the purpose from the esthetic standpoint. Usually the choice of species for the production of a given effect is subject to a wide range. After considering all of the forms that seem to answer the purpose in an ornamental way, it is well in the final selection to choose those having few objectionable features.

Some species are better adapted to a certain set of conditions than others, and certain conditions beyond our control often restrict the selection of species to a very narrow range. Some trees will not grow on dry soil, others fail to thrive on wet soil. Some fail to develop properly unless there is an abundance of lime in the soil, and others fail on calcarous soils. Some cannot stand the smoke and gas common to city streets. Some require plenty of sun while others, to reach their highest degree of perfection, must be somewhat protected from the hot rays of the sun. Some will not stand the seashore climate and others will fail at high altitudes.

The relative susceptibility of species to insect and fungus attack is a subject too often overlooked. Certain species, like the White or American Elm, are well adapted to ornamental planting, for both city and country, but cannot be recommended except for places where they are likely to be taken care of. And again there are some species that have many desirable qualities and yet are objectionable in one or more respects. The Horse-chestnut, for example, is an attractive and effective shade tree, but it is objectionable on account of the litter it produces on the ground. The Silver Maple is attractive, graceful, and quick-growing, but it is short-lived and easily broken by wind and ice. The sex of trees is an important consideration in some cases. For example, the pistilate or female Carolina Poplar is very objectionale on account of its cottony seeds that literally fill the surrounding atmosphere and attach themselves to buildings, to other trees, and to people's clothing. The male trees of the Ailanthus, also, are exceedingly objectionable on account of the odor produced by the staminate flowers. 
The following lists are furnished with the hope that they may be of service in the selection of species for special purposes and conditions. They have been modified after liehder', and Fernow ${ }^{2}$ They are not intended to be complete, but are fairly reliable for northeastern conditions. The common names are used, but their corresponding botanic name generally may be obtained by referring to Part II.

\section{TREES WITH SHOWY FLOWERS.}

BLOOMING BEFORE OR WITH THE LEAVES.

Apple (fls. white or pinkish).

Cherries, several species (fls. white).

Flowering Dogwood (fls. white).

Peach (fls. pink).

Plums, several species (fls. white).

Red Bud (fls. rosy pink).

Red Maple (fls. blood red) .

Shad Bush (fls. white).

Willow (fls. yellow).

BLOOMING AFTER THE LEAVES.

Basswood (fls. white).

Catalpa (fls. white or yellow).

Chestnut (fls. white or yellowish, blooms in July).

Common Locust (fls. white or light pink).

Cucumber Tree (fls. yellow) and other Magnolias.

Hawthorn (fls. white).

Horse-chestnut (fls. white or red).

Mountain Ash (fls. white).

Tulip Tree (fls. yellow).

Yellow IVood (fls. white).

TREES WITH SHOWY FRUITS.

Apple (fr. red or yellow).

Ailanthus var. erythrocarpa (fr. red).

Cherries (fr. red, black or yellow).

Flowering Dogwood (fr. scarlet).

Hawthorns (fr. red or yellow).

Holly (fr. red).

Mountain Ash (fr. red).

1-Rehder, Alfred, in Bailey's Cyclopedia of American Horticulture, IV., pp. $1835-6,1906$.

2-Fernow, B. E., The Care of Trees, pp. 364-373, 1911. 
Plums (fr. red, dark blue, or yellow).

Red Maple (fr. red in May and June).

Sassafras (fr. dark blue).

Magnolias (fr. pink).

TREES WITH STRIKINGLY COLORED FOLIAGE.

Beech, var. purpurea (lvs. purple).

Blue Spruce (lvs. silvery or bluish white).

Box Elder, var. argenteo-variegatum (lvs. white and green).

Carolina Poplar, va. aurea (lvs. yellow).

Norway Maple (lvs. light or yellowish green in early spring) var.

Reitenbachi (lvs. becoming dark red in summer); var. Schwedleri (lvs. bright red in spring).

Silver Poplar, (lvs. white beneath) var. nivea (especially conspicuous.

Sycamore Maple, var. Worleei (lvs. yellowish).

White Birch (lvs. light green); var. purpurea (lvs. purple).

White Fir, Abies concolor (lvs. silvery or bluish-white).

White Willow, var. argentea (lvs. silvery white).

TREES WITH BRILLIANT AUTUMNAL TINTS.

Black Oak (scarlet).

Flowering Dogwood (scarlet).

Ginkgo (yellow).

Hawthorn (scarlet and orange).

Pin Oak (scarlet).

Red Oak (dull red).

Red Maple (scarlet).

Sassafras (red and yellow).

Scarlet Oak (scarlet).

Shad Bush (red).

Sugar Maple (scarlet and orange).

Sumachs (bright scarlet).

Sweet Gum (red).

Tupelo (scarlet).

White Ash (yellow and purple).

White Birch (yellow).

White Oak (purplish).

DECIDUOUS TREES VALUED FOR THEIR WINTER EFFECTS.

Beech (steel-gray bark; frequently retains its leaves).

Box Elder (light green and purplish branches). 
Bur Oak (corky branches).

Cork Elm (corky branches).

Gray Birch (grayish white bark).

Hawthorn (Crategus viridis and some others, red fruit).

Kentucky Coffee Tree (picturesque, nude branches).

Liquidambar (corky branches).

Mountain Ash (scarlet fruit).

Red Birch (flaky reddish-brown bark).

Sassafras (green twigs).

Striped Maple (striped bark).

Sumachs ( scarlet fruit).

White Birch (silvery-white bark).

White Oak (retains its dead leaves).

Yellow Birch (silvery-yellow flaky bark).

Yellow Willow (yellow branches).

VERY TALL TREES.

Bald Cypress.

Black Oak.

Pin Oak.

Black Walnut. Red Oak

Carolina Poplar. Sycamore.

Common Locust. Tulip Tree.

Honey Locust. White Elm

Norway Spruce. White Pine.

COLUMIAAR OR NARROW PYRAMIDAL TREES.

Arbor Vitae.

Bald Cypress.

Black Maple, var. monumentale.

Coast White Cedar.

Firs (most species).

Juniper, var. Suecica and pyramidalis.

Larch.

Lombardy Poplar.

Red Cedar.

Silver Poplar, var. Bolleana.

Spruces (most species).

Tulip Tree, var. pyramidalis.

WEEPING TREES.

Ash (Fraxinus Excelsior, var. pendula).

Basswood (Tilia petiolaris). 
Beech (Fagus sylvatica, var. pendula).

Cherry (Prunus serotina, var. pendula).

Elm (Ulmus scabra, var. pendula).

Maple (Acer saccharinum, var. Wieri).

Oak (Quercus pedunculata, var. pendula).

Plum (Prunus pendula).

White Birch (Betula alba, var. pendula).

Willow (Salix Babylonica).

TREES RESISTANT TO SMOKE.

Ailanthus.

American Hornbeam.

Horse-Chestnut.

Balsam Poplar.

Carolina Poplar.

Flowering Dogwood.

Hawthorns.

Linden

Honey Locust.

Maples (most species).

Shad Bush.

Sycamore.

White Oak.

White Elm.

DESIRABLE SHADE AND AVENUE TREES.

Black Oak.

Black Walnut.

Red Oak.

Chestnut.

Scarlet Oak.

Chestnut Oak.

Ginkgo.

Honey Locust.

Horse-chestnut.

Linden.

Norway Maple.

Pin Oak.

Silver Maple.

Sweet Gum.

Sycamore.

Sycamore Maple.

Tulip Tree.

White EIm.

White Oak

TREES FOR SEASIDE PLANTING

Arbor Vitae.

Ailanthus.

Austrian Pine.

Carolina Poplar.

Common Juniper.

Pitch Pine.

Red Oak.

Sassafras.

Scotch Pine.

Small-toothed Aspen.

'Tupelo.

White Spruce.

Yellow Willow.

TREES FOR DRY SITUATIONS AND DRY CLIMATES.

Black Oak.

Chestnut Oak.

Common Juniper.

Scarlet Oak.

Scotch Pine.

Shad Bush. 
Pitch Pine

Red Cedar.

Red Oak.
Smooth Alder.

White Birch.

TREES BEST ADAPTED TO WET SOILS.

Alders.

Bald Cypress.

Balsam Fir.

Black Oak.

Black Spruce.

Coast White Cedar.

Larch.

Linden.

Pin Oak.

Pitch Pine.

Poplars (most species).

TREES BEST SUITED TO CALCAREOUS OR LIMESTONE SOILS.

Austrian Pine.

Beech.

Coast White Cedar.

Flowering Dogwood.

Hawthorns.

Juniper.
Red Birch.

Red Oak.

Red Maple.

Silver Maple.

Swamp White Oak.

Sweet Gum.

Sycamore.

Tupelo.

White Birch.

White Spruce.

Willows (most species).

VARIETIES OF FRUIT TREES FOR HOME PLANTING.

Apples:- Yellow Transparent, Red Astrachan, Williams, Oldenberg, Gravenstein, Chenango, Wealthy, McIntosh, Fameuse, Fall Pippin, Wagener, Jonathan, Sutton, Tolman, Grimes, King, Hubbardston, Northern Spy, Red Canada, Golden Russet, Delicious, Ontario, Roxbury, Baldwin.

Pears:-Summer Doyenne, Giffard, Bartlett, Flemish Beauty, Sheldon, Seckel, Bose, Anjon, Lawrence, Winter Nelis.

Quinces:-Orapge, Champion.

Peaches:- Rivers, Greensboro, St. John, Carmen, Mountain Rose, Early Crawford, Crosby, Champion, Late Crawford, Elberta, Sterens, Smock.

Plums:-Red June, Abundance, Burbank, Bradshaw, Imeprial Gage, Lombard, Yellow Egg. Reine Claude.

Cherries:-May Duke, Wood, Knight, Tartarian, Hortense, Montmorency, Morello. 


\section{CHAPTER VI \\ HOW TREES ARE PLANTED. \\ PRELIMINARY CONSIDERATIONS.}

Ordering Trees - It is always well to procure catalogues from several reputable nursery concerns. Other things being equal, it is advisable to order trees from a local nursery. The so-called ' 'tree agent' is not always reliable and, for this reason, best results will follow the practice of ordering directly from the nursery. Since there is so much confusion in names of trees, it is well to make sure that the nurseryman knows what trees are required. The Latin name should always accompany the common name. Even then there is danger of confusion, and to be absolutely sure of getting the required species, it is desirable to go to the nursery and personally examine the trees.

Nurserymen carry usually two or more grades of trees. As a rule the difference between first and second grade trees is in size or "caliper." If this is the case a second grade tree is likely to give satisfactory results. It may be a little later in maturing, but since a small tree suffers less from "shock" in transplanting, it is likely to catch up to the larger-sized tree within a few years. It is not advisable to buy third grade or "cull" trees for they are likely to be weak growers or ill-shaped specimens. The price of nursery stock will depend upon the grade and upon the age of the trees. Where quick results are demanded it is advisable to buy trees two or three inches in diameter or those that are five to ten years of age, or to plant mature trees as described later.

Where trees are grown on the place they may be moved with large balls of earth attached and in this way the shock and risk of moving may be lessened.

"Puddling" and "Heeling In" - Trees come from the nursery in boxes or bundles. To prevent them from drying out the roots are usually packed in moist straw or other material. If they should arrive before planting time the roots should be "puddled" and the trees "heeled in." Puddling consists in dipping the roots in a semi-liquid mixture of clay and water. This forms a coating of clay over the roots and prevents them from drying out. Heeling in consists in digging a trench from one to two feet in depth, 
depending upon the size of the tree, into which the bundles of trees are placed and their roots covered with soil. In order to make sure of having the trees on hand at planting time, it is

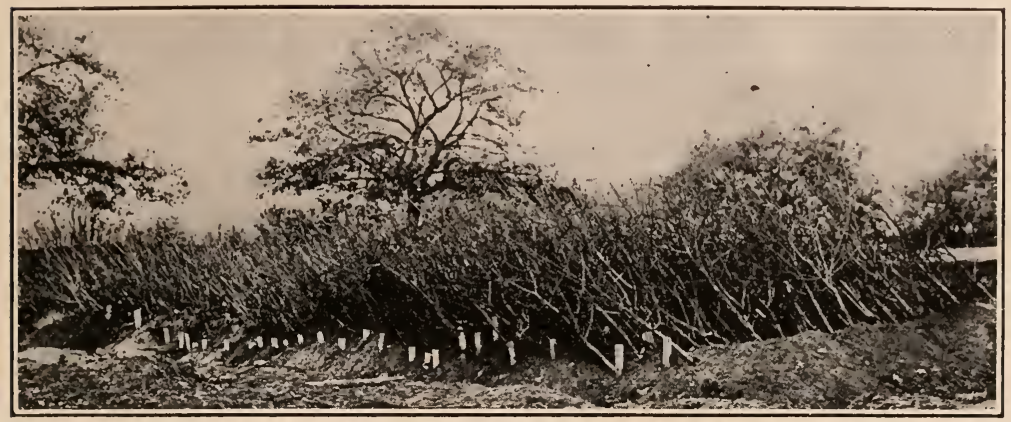

Fig. 34. Nursery stock "healed in."

sometimes necessary to order them shipped in the fall. When they arrive they may be heeled in until ready for use in the spring.

Prune Before Planting - In the process of digging, no matter how carefully done, many of the roots are sure to be broken off or injured in some way. To balance up for this loss of roots the tree should have its top greatly reduced. This is done by cutting out superfluous branches and by heading in the remainder. This practive is not necessary nor desirable for Evergreens. Trees with abundant root systems will not need to be headed in so severely as those deficient in roots. The older the tree when moved the greater the danger in losing its roots, and the greater the necessity for heading in. With trees not more than three or four years of age, the remoral of most of the past season's growth will be sufficient, but with older trees it is usually necessary to remove two or more years' growth. With some trees, like the Pin Oak, Ginkgo, Poplars and Evergreens, whose reculiar beauty is dependent upon a single stem or central leader, it is necessary to do the pruning on the side branches. This pruning and heading-in greatly reduces the chances of failure and yet does not seriously effect the rate of development. The more severe the pruning the greater the growth during the first few seasons. 
It is therefore better to ere by over pruning than by not pruning enough.
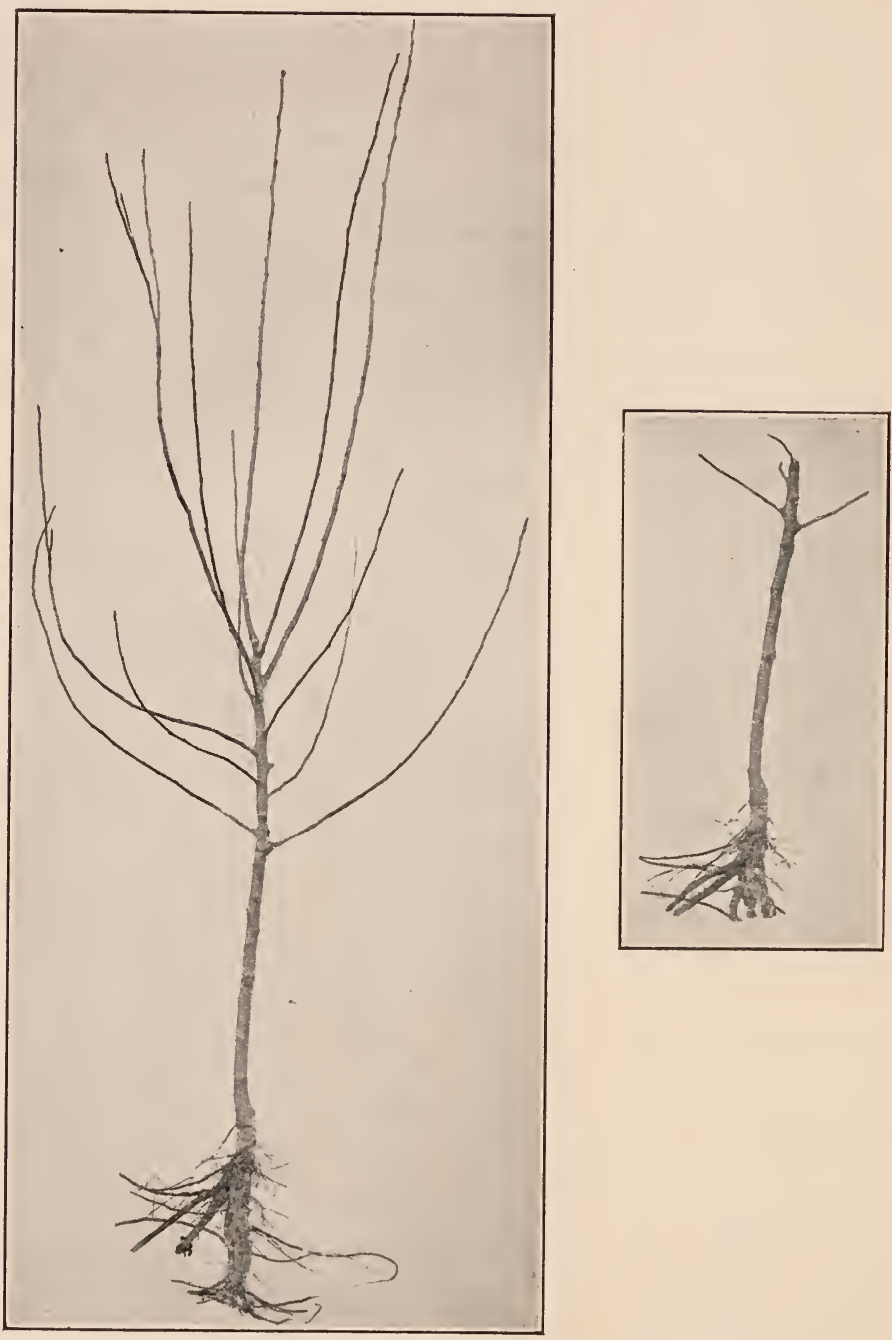

Fig. 35. A fruit tree before and after pruning, showing proper treatment preparatory to planting.

The roots also will require some pruning. All mangled roots should be removed, making a fresh, smooth cut. Long, sprawling roots may also be shortened in to accommodate a smaller hole. 
Preparing the Ground - Too much cannot be said with regard to the necessity for making the tree comfortable in its new

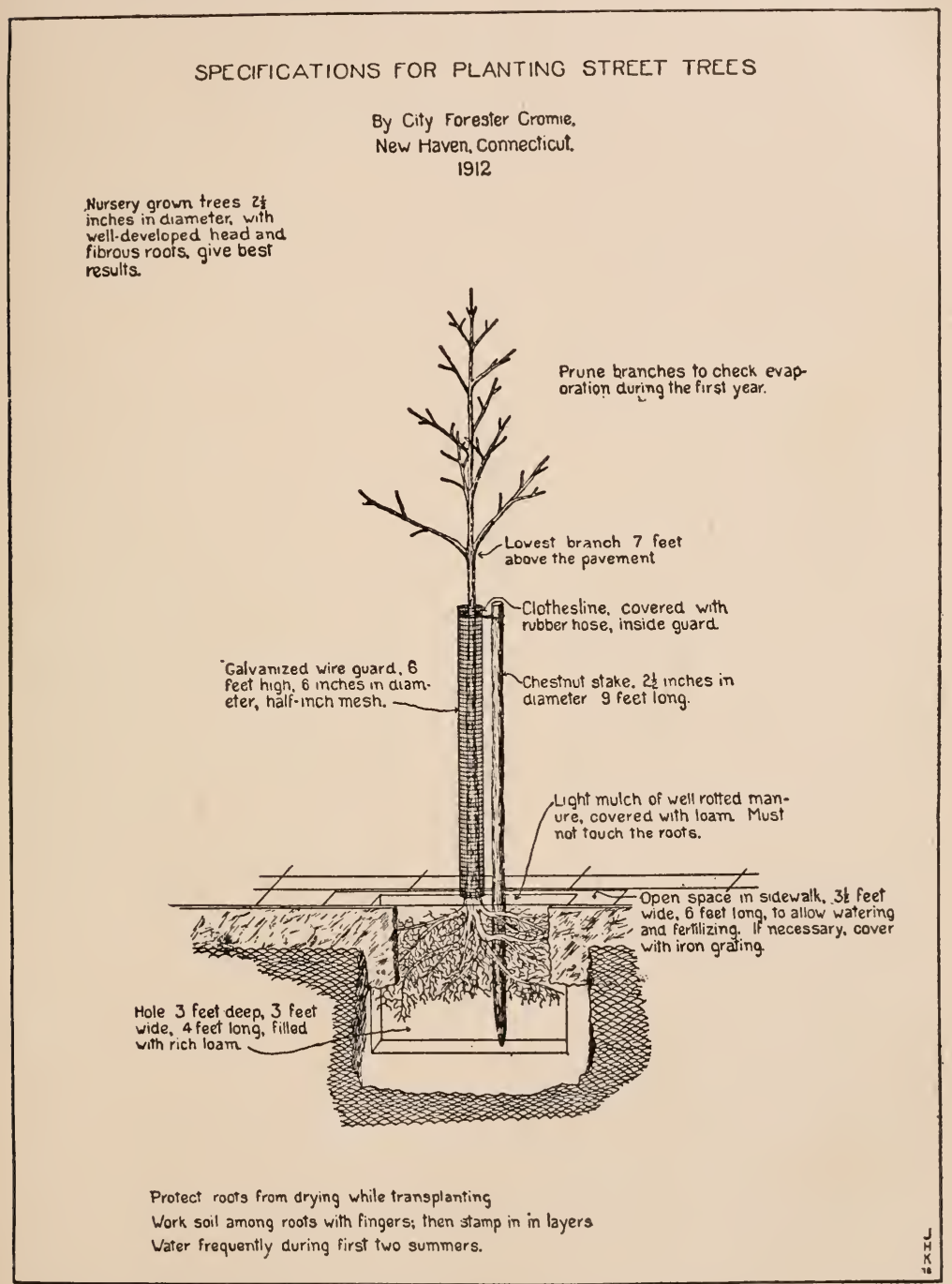

Fig. 36. Diagramatic specifications for tree planting. A scheme followed by many municipalities.

position. Wherever practicable, the ground should be plowed deeply and subsoiled, and in this way the feeding area for the 
roots will be enlarged. In low places, where water is likely to stand during wet seasons, it will be necessary to underdrain, for few trees will thrive in wet soil. Tile underdrains should be placed about four feet below the surface. If nearer the surface they are likely to be stopped up by the roots of the trees. Where there is an impervious hard-pan near the surface it may be broken up by the use of dynamite.

On city streets it is usually impracticable to plow, except when planting newly-formed streets and avenues. When it is not practicable to break up the whole area where trees are to be planted, larger holes and greater care in their preparation will be necessary.

Most soils are deficient in both plant food and vegetable matter and are greatly benefited by heavy applications of stable manure. Where the young trees are widely separated it is well to restrict the application to a radius of about six feet around each tree. It should be thoroughly mixed up with the soil. On city streets where the application must be restricted to a small area the manure is usually mixed with the soil that is placed around the roots of the tree. For this purpose only very fine, or well-rotted, manure should be used.

Staking the Ground - The setting of stakes where the trees are to be planted is recommended for most kinds of plantations. Where trees are to be planted in a straight line along a roadside or on a city street, the problem is a simple one. When trees are planted for definite effects about the home or in parks, the work is often perplexing and the correct location of the stakes often necessitates much shifting. A stake is much easier shifted than a tree, and the location of trees may be decided upon before the approach of the planting season.

\section{SETTING THE TREES}

Time to Plant - Spring planting usually gives better results than fall planting, although with care trees may be planted in the fall with much assurance of their surviving. The spring is the natural growing season and trees planted at this time commence to send out new roots immediately, so that if they were somewhat carelessly planted they would stand a better show than those planted in the fall and allowed to remain over winter in an unfavorable condition. If it is desired to plant in the fall it 
is of the utmost importance to get the soil well packed around the roots and to apply on the surface a liberal amount of stable manure or other coarse material to prevent the tree from being heaved by frost. Those trees having succulent roots, like the magnolias, should always be planted in the spring. Spring planting is usually done as soon as the ground warms up and before the buds begin to swell.

Making the IIoles and Filling In - Where the ground has been well prepared, it is only necessary to make the holes large enough to accommodate the root system. Where it is impracticable to cultivate the whole area where trees are to be planted, it is well to dig the holes much broader and deeper than is necessary to accommodate the roots. With ordinary sized trees the holes should be about two feet deep. Before setting the tree, however, the hole should be partly filled with surface soil with which some well-

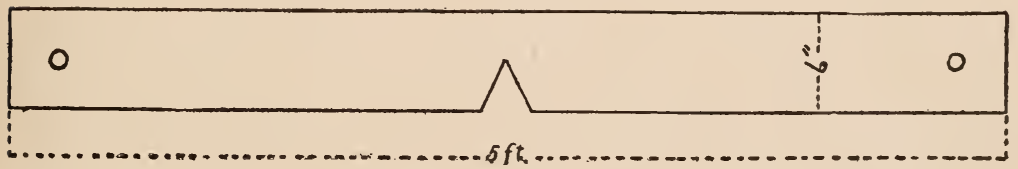

Fig. 37. The Planting-board. A useful device for locating trees in their correct positions.
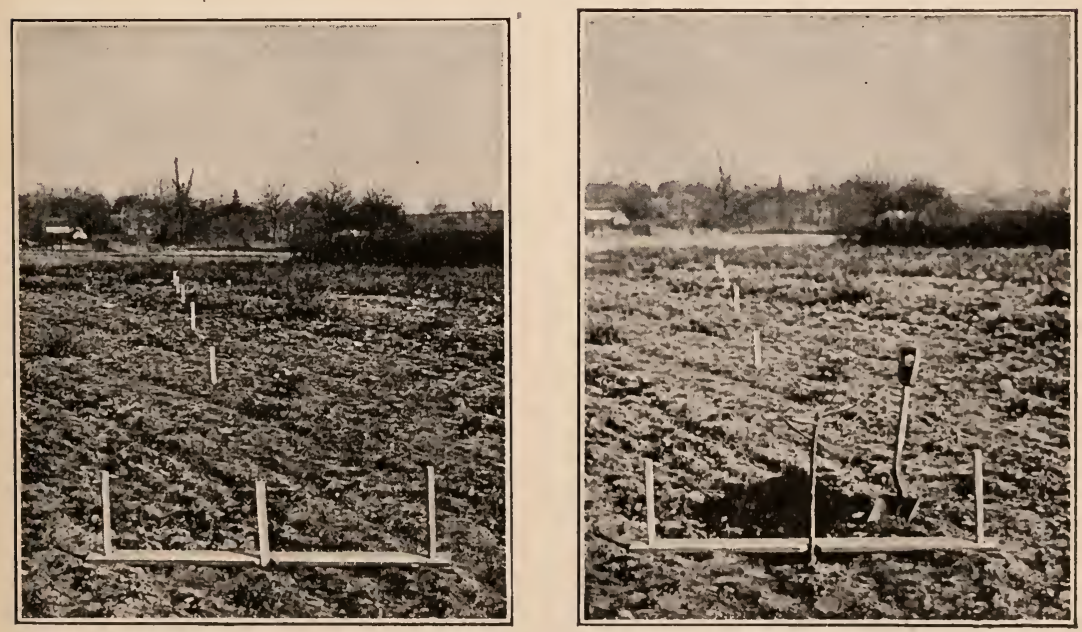

Fig. 38. How the Planting-board is used. 
rotted manure has been mixed. The tree should be set at just about the same depth at which it grew in the nursery. The roots are spread out naturally and the fine surface soil thrown or sifted in about them. Only a small amount of soil should be thrown in at a time and it should be well tamped, avoiding any open spaces beneath or about the roots. A pointed stake will be found serviceable in tamping the soil about the roots. The last few shovels-full should be thrown loosely about the tree to act as a mulch.

Where it is necessary to get the tree in the exact position where the stake stood, a device called a planting-board will be found useful. Such a contrirance may be readily made from a board, eight to ten feet in length, by making a notch in the center and a hole at each end, as shown in figure 3\%. Before digging the hole the board is placed on the ground with the notch adjusted to the stake that marks the position of the tree. A guide stake is then driven in the ground through each of the holes at the end of the board. The board may then be removed while the hole is being dug, after which it is placed back on the guide stakes and the tree adjusted to the notch in the center.

Moving Large Trees - The demand for quick results in tree planting often necessitates the moving of very large trees. Trees from twelve to eighteen inches in diameter are often successfully moved. Very large specimens require the services of expert tree movers, who have the proper equipment for the purpose. Frequently, however, it is desirable to go to a neighboring forest for moderately-sized trees for home planting. Trees from six to eight inches in diameter may be moved with a fair degree of certainty and without an elaborate equipment. Since trees grown in the open are usually more shapely and have better root systems, they are likely to give better results when transplanted, than forest-grown trees.

The principles involved in transplanting large trees are the same as for small trees, but the work is performed at greater risk. Experts, however, seldom lose a tree.

Where trees are to be carried short distances it is well to preserve a large ball of earth around the roots. If a large proportion of the roots are kept intact, it will not be necessary to cut back the top so severely. Where trees must be transported 
long distances it is usually necessary to wash the soil from the roots and to carefully wrap the latter with moist straw and burlap. Most trees will need to be severely headed-in or dehorned, but those with many branches may be safely moved after being severely

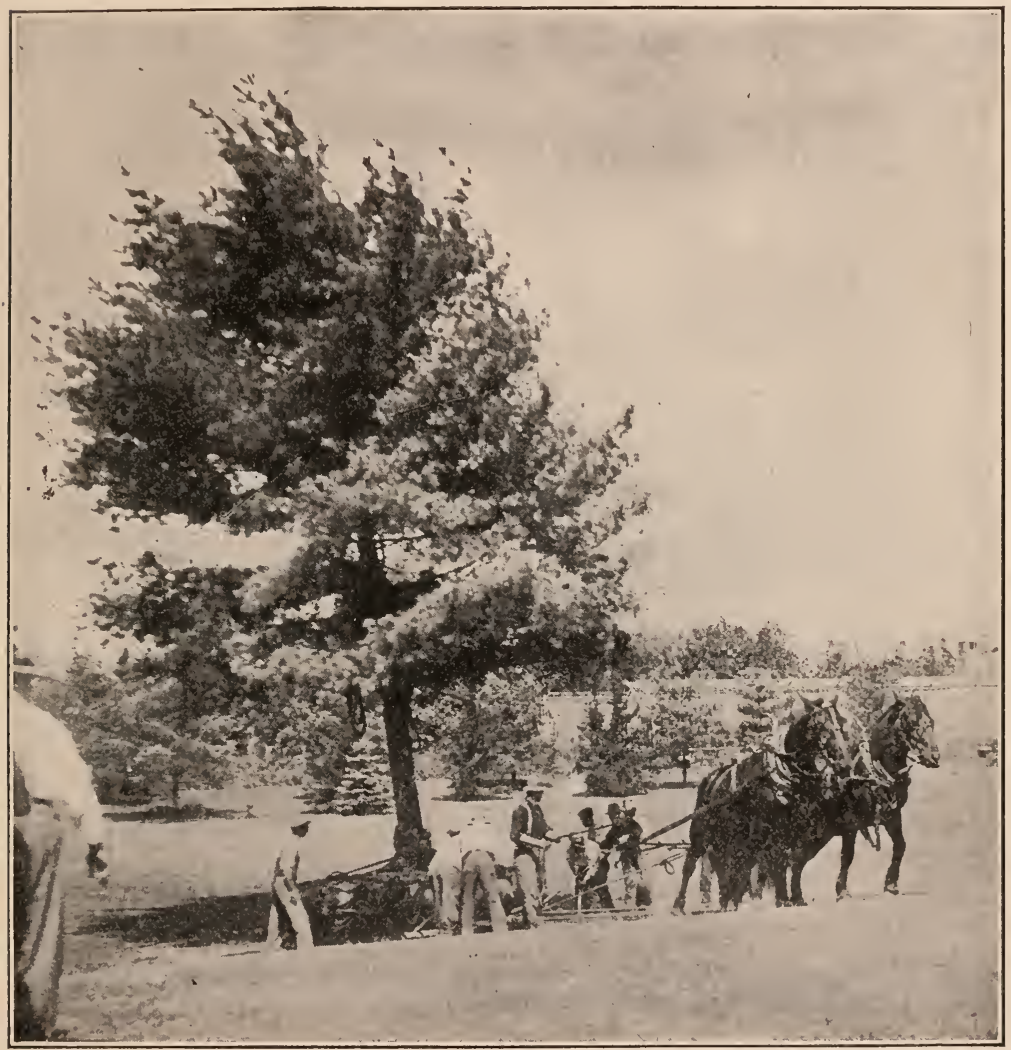

Fig. 39. A large Evergreen being transplanted. A large ball of ${ }^{\prime}$ earth is being retained on the roots.

pruned throughout the whole top. This treatment obviates the necessity for changing their natural habit. Some trees, of course, may be greatly improved in form by a severe heading-in. As in the planting of small trees, the important point with large trees is in getting the soil well filled in and packed around the roots of the newly set tree. By directing a stream of water about the roots the soil may be forced well under the base of the tree. 
Newly set trees should be securely guyed for at least one season, or until their roots become firmly established in their new position.

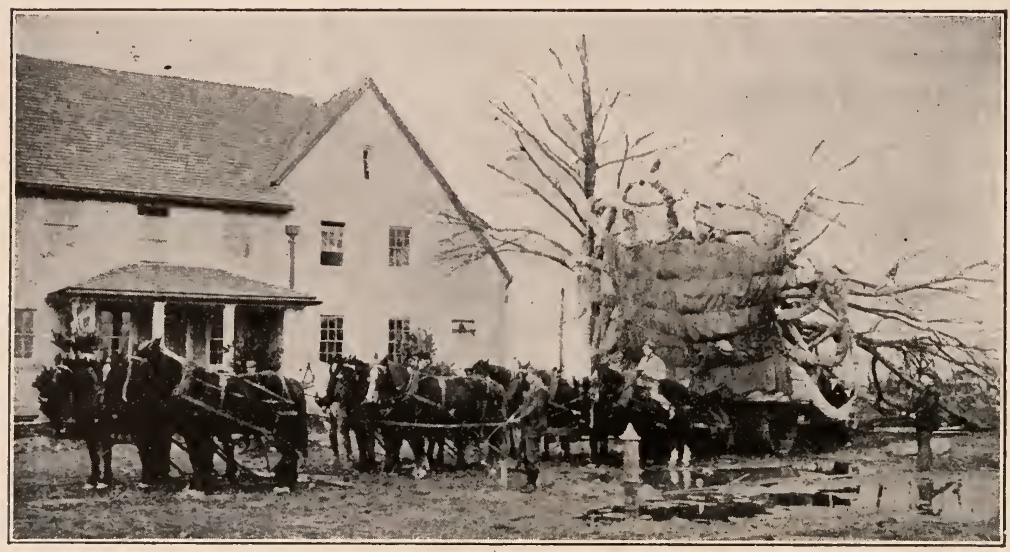

Fig. 40. Transplanting a large tree, showing the method of binding up the roots, when it is necessary to transport long distances.

Trees with an abundance of small roots are more likely to survive the process of transplanting. The species that are more commonly and successfully moved are the Maples, Elms, White Ash, Basswood, Catalpa, Horse-chestnut, Pin Oak, Poplars, and Willows. Trees with tap roots and few fibrous roots, like the Hickories and most Oaks, are moved with less certanity. The very soft and tender rooted trees, like the Tulip and the Magnolias, are also difficult to move without loss.

\section{STAKING AND GUARDING YOUNG TREES}

Newly-set trees are likely to become ill-shaped and badly damaged if not properly supported and guarded during the first few years of their life. 'This applies especially to street trees, but lawn trees, although they many not require guards, should be supported in some simple and inconspicuous manner.

Stakes - A single stake, painted green, and long enough to reach almost to the top of the tree and to extend into the ground at least two feet is the simplest method of supporting young trees. It is made pointed at the lower end and, after a hole is made with a crowbar, it is driven into position. Sometimes 
two stakes are used, one on each side of the tree, but there is no special need for this additional expense. (See fig. 41). A common method of attaching the tree to the stake, which should be done at two or three places, is by means of a manila rope run

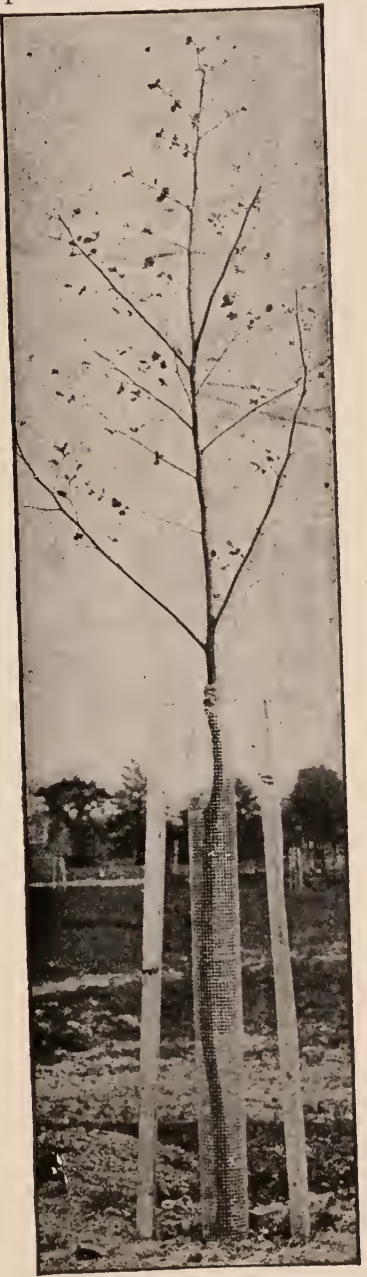

Fig. 41. A simple and effective method of staking and guarding young trees.

through a piece of rubber hose. This is tied around the tree, using an ordinary double knot, and then the ends are tied around the stake. The knot between the ree a id the stake prevents 
chafing. This is all the protection needed for trees on the lawn or in positions along the street and roadside where there is little danger of injury from passing vehicles and thoughtless people.

Guards - Street trees, being subject to various forms of injury, require guarding as well as supporting and for this purpose a combination tree-guard and support has been successfully used in Washington and other cities. These are four-sided wooden boxes attached to four stakes driven into the ground. The trees are held firmly in the center of the box by means of leather straps attached to the corners. Although cumbersome and unsightly in appearance, they are very effective and remain in position for several years.

A simple and inexpensive guard may be made of heavy wire mesh and used in combination with the single stake. The cylinder of wire should be about six feet high and should be attached to the stake. Wire cloth made of number 16 wire and with oneinch meshes comes in rolls twenty inches wide. Twenty inches is just about the right width to encircle the tree and the cloth, therefore, may be cut in six-foot lengths. The upper edge of the cylinder may be bound with a piece of rubber hose to prevent chafing. There are many types of iron guards on the market, but they are quite expensive and are of very little support to the tree unless they are set deeply into the soil. They are commonly used in connection with grills, where they are very useful. They are less conspicuous and take up less room than the wooden box.

Grills - Where trees are set in openings in the pavement or sidewalk, the space around the base of each tree is often covered with iron grating to prevent the soil from becoming packed so hard as to make it impervious to water. Such devices, of which

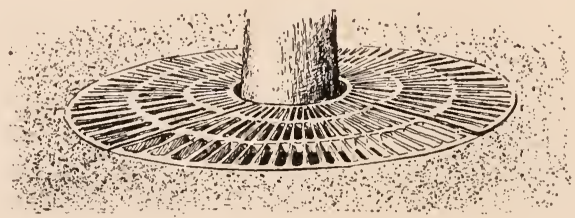

Fig. 42. A good type of Grill.

there are many styles, are known as grills. They are usually cast in sections and are adjusted so as to come flush with the side- 
walk. They are supported on stakes driven into the ground. It is well to leave a slight depression in the ground under the grill for the purpose of holding some of the water that may run into it. The earth immediately around the tree, however, should be somewhat elevated to prevent the water from coming in contact with the trunk. 


\section{CHAPTER VII THE CARE OF TREES.}

There are many people who believe that a tree after being properly planted requires no further treatment. While many trees growing wild have attained a perfect development, it should be remembered that these are the exceptions and that many of their youthful companions either have died or have been seriously affected in form and vitality. When trees become well established and are allowed to develop under normal conditions they require very little attention. On the other hand, young trees and trees growing under abnormal or adverse conditions are less able to take care of themselves. The growing of trees on narrow streets, where the ground is almost completely covered with pavement and where the trees are smothered with smoke and poisoned with coal gas, is decidedly an abnormal condition and it is a wonder that there are not more failures.

\section{IMPROVING SOIL CONDITIONS}

The Need of Humus in the Soil - The failure of trees to develop is more often due to an unfavorable physical condition of the soil than to any other cause. When the physical condition is not right the tree roots cannot develop properly and the tree cannot get an adequate supply of water. Since plant food must be dissolved in water before the tree can make use of it, a shortage of water means a shortage of nutrition. Moreover, the soil must be in a good, physical condition for the development of certain useful micro-organisms and to facilitate favorable chemical action. The constituent most necessary to keep the soil in a good mechanical condition and the one most commonly deficient is humus, or decayed vegetable matter. In nature this is supplied by the continual decay of leares and other herbage on the surface. It is not practicable in our streets and on our lawns to allow the leaves to remain where they fall and the grass to develop and to contribute regetable matter when it dies. When lawns are made and when new streets are being planted it is a feasible thing to apply a good dressing of vegetable matter in the form of stable manure or other coarse material. The turning under of a good crop of herbage is the easiest way to increase the humus content of 
the soil. In farm practice it is a common thing to grow a crop of clover, rye, or buckwheat for the purpose of ploughing under.

The water-holding capacity of a soil is dependent largely upon its humus content. 'Trees growing in soil that is well supplied with humus are not likely to suffer from drought during dry seasons. It is not necessary here to enumerate the many other functions of humus in the soil, but it is enough to say that it should be supplied whenever practicable.

Fertilizers for Trees - Most soils contain a sufficient supply of the various elements of plant food - nitrogen, potash, and phosphoric acid - and when the soil is in a good mechanical condition the tree is able to obtain without difficulty these elements, and it is seldom necessary to make additional applications. But since the soil where our shade trees are supposed to grow is not usually in a suitable mechanical condition and since it is often impracticable to improve it in this respect; the application of chemical fertilizers often proves beneficial.

Inasmuch as soils differ so widely with regard to their manurial requirements, it is always difficult to make any general recommendations. The following formula is suggested as an annual dressing for each full grown tree. A very large tree should receive a slightly heavier dressing and a smaller one proportionately less:-

Nitrate of soda (15\% nitrogen or its equiralent) 6 pounds

Muriate or sulphate of potash $(50 \%$ potash $) \ldots \ldots 6$ "

Acid phosphate (18\% phosphoric acid) ....... " 8

This is a light dressing and may be greatly increased without fear or injury. The three compounds may be mixed together and scattered over the surface of the ground, extending considerably beyond the spread of the branches. The application should be made in the spring, just as the leaves are appearing, and during a heary rain, or just before watering the ground from a hose. If these directions are followed and if the lumps are well mashed there will be no injury to the grass. The practice of spreading stable manure on the ground beneath the trees in the fall and in raking it off in the spring, is a commendable one, but many people object to it on account of the odor and appearance.

Cultivation - Whenever it is feasible, the ground beneath and around the trees should be cultivated. Cultivation acriates the soil and increases chemical action, making more plant food arail- 
able. It also assists in conserving the moisture of the soil by forming a loose mulch on the surface that lessens evaporation. The turf around the trees would be better broken up every few years and a good supply of vegetable matter added before reseeding. Such a practice, however, is not always practicable, but where the trees are located along borders, it may be followed without seriously affecting the appearance of the surroundings.

\section{PRUNING SHADE TREES}

Trees on the lawn will require very little pruning, the work consisting mainly in the removal of dead or diseased branches. Strect trees, on the other hand, require careful training to insure a symmetrical development and to prevent their branches from interfering with the traffic. A well-developed street tree should have a compact and symmetrical head and the branching should commence at a point eigth or ten feet from the ground. The beauty in a row of street trees is largely dependent upon uniformity in size and shape. The individual trees, therefore, should be as nearly alike as possible. Some will require encouraging to keep them up to the average in size, while others will need to be cut back to keep them down to the average. It should be remembered in this connection that pruning while the tree is dormant stimulates regetative growth and that pruning during the growing season tends to counteract an excessive growth.

The branching should start at the same height on each tree. The lower branches need not be cut off until they begin to interfere with traffic, and these should be removed gradually. One or two of the lower branches may be removed at intervals of two or three years until the proper height is reached. The base of the head should not project horizontally, but should ascend obliquely, producing an arched effect and giving more room in the center of the street.

How to Cut Off a Limb - When it is necessary to head back branches, the cut should be made just beyond a side branch that points in the desired direction. Such a cut, if a large one, should be made on a slant to prevent the accumulation of moisture on the surface. In ordinary pruning a whole branch is removed, and when this is done the cut is made close to the parent branch. Great care should be exercised in preventing the branch from splitting down during the process. This trouble may be avoided 
by cutting about half way through the branch from beneath at a point marked $\mathrm{A}$ in figure 43, which may be about six or eight inches beyond the junction. The final cut is then made from above and close to the parent branch as shown at $B$ in the diagram. By the time the saw reaches the center, the branch will split horizontally at $\mathrm{X}$ and drop off, when the cut may be con-

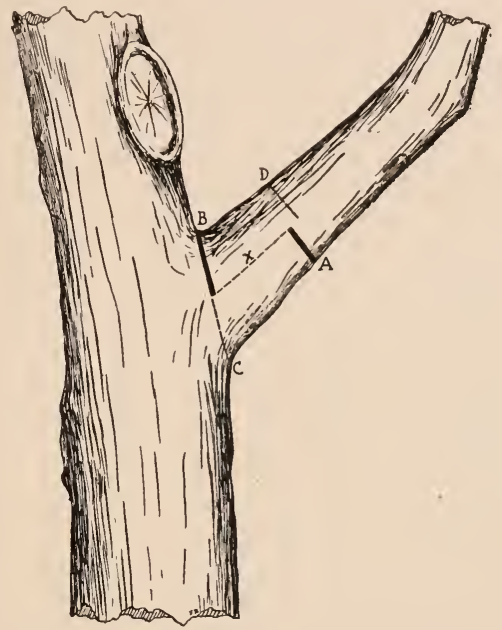

Fig. 43. Diagram to illustrate the method of sawing off a large limb to prevent it from splitting down the trunk. Cut first at $\mathrm{A}$ and then at $B$, when the branch should split along the dotted line $\mathrm{X}$, and drop off. If the limb does not drop off when the second cut reaches the half-way point, a third cut should be made at the point $D$. After the limb has dropped off the final cut may be made through to $C$.

tinued through to C. Sometimes with tough-wooded trees and when there is a large shoulder at the base, the branch may not split readily when the second cut reaches the half-way point or the level of the ending of the first cut. In such cases a third cut should be made from above at the point $\mathrm{D}$, just beyond the first cut. When these two cuts meet on the same level the limb will drop off, when the final cut may be finished.

All cuts should be made smooth and close to the parent branch, which forms the callus to heal the wound. When there is a large shoulder at the base of the limb to be removed, there is always a temptation to make the cut beyond the shoulder and at right-angles with the branch. Wounds made by cutting in this direction, although much smaller, will not heal over as readily 
as those made by cutting parallel with and close to the parent branch. (See figs. 44, 45, 46, and 47 ).

Time to Prune - In general, pruning should be done while the tree is dormant. Most people prefer to prune in early spring, believing that the wounds heal over better when made just before the tree starts its growth. There are cases, as pointed out before,

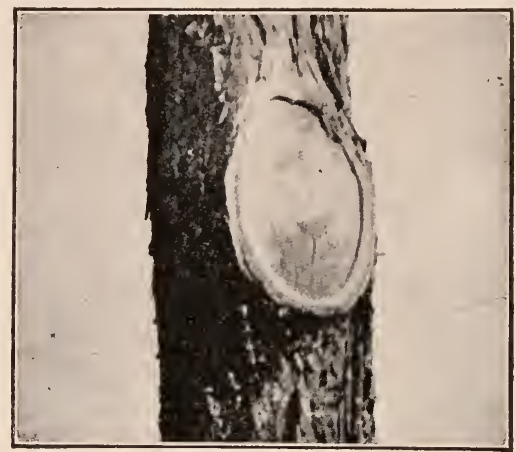

Fig. 44. A cut properly made, observe that the wound has already commenced to heal.

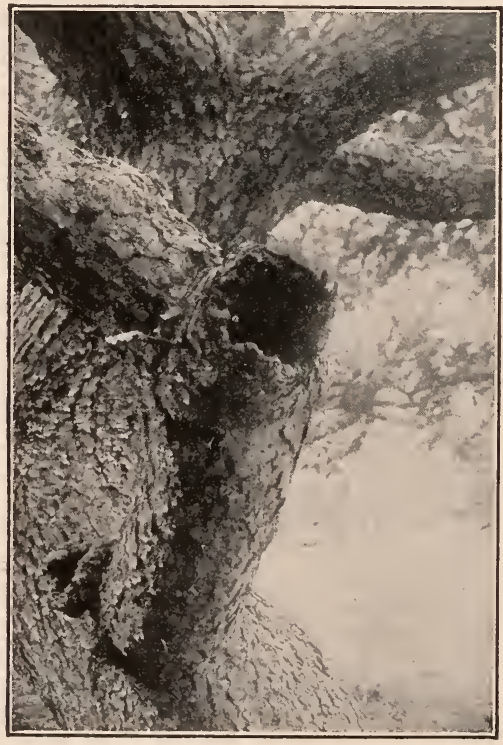

Fig. 45. The result of bad Pruning. 
where certain trees may be making too much growth, and where pruning during the growing season is recommended. While the practice of summer pruning is useful in the way of reducing vegetable growth and in encouraging the development of blossoms and fruit, it tends to weaken the tree. It produces the same effect as a partial defoliation by insects. Pruning during the

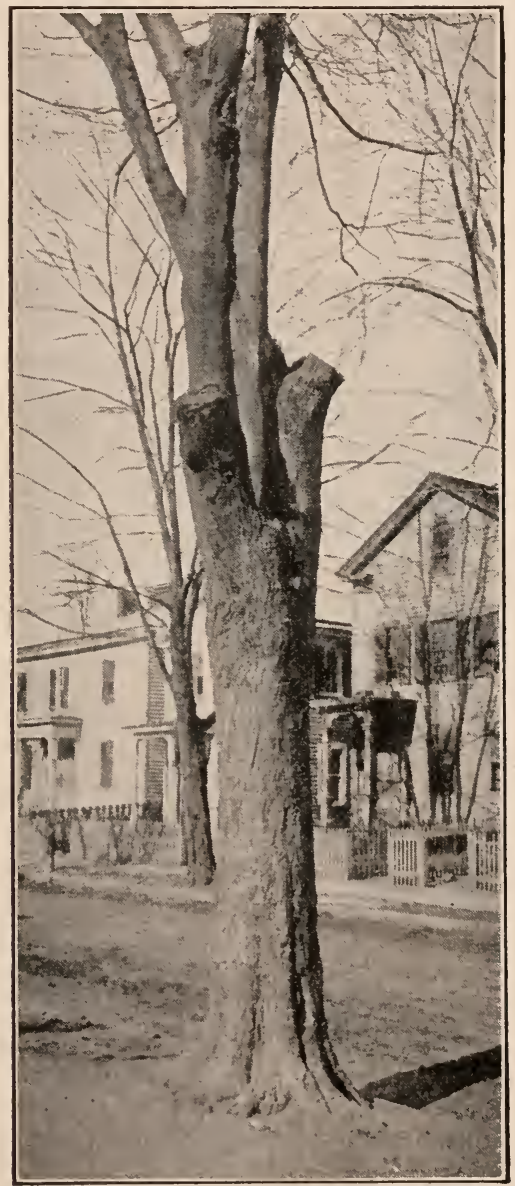

Fig. 46. An example of bad Pruning. Compare with Fig. 45.

summer, therefore, always should be sparingly done. It is practiced mostly on fruit trees to encourage fruit development. It should 
be remembered that the buds from which the blossoms and fruit come during any season have been formed during the previous summer. To have any influence upon the supply of blossoms and fruit for the following year, therefore, the pruning should be done early in the summer, before the fruit buds are formed. With most species the best time is about the first of July. The removal

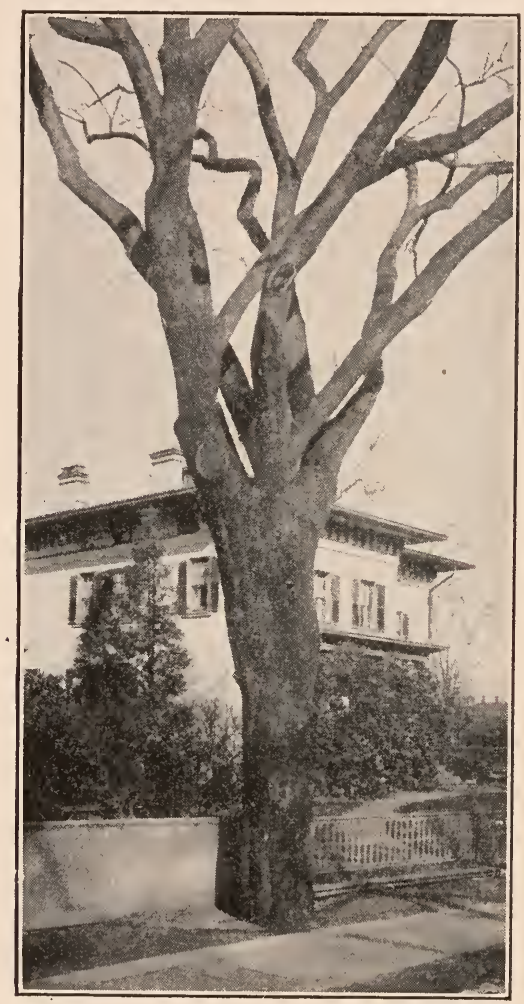

Fig. 47. An example of good Pruning. The cuts have been made close and smooth and the wounds properly dressed.

of foliage, only, will produce the same effect as removing branches with leaves attached. Since trees rarely grow too rapidly the practice of summer pruning is seldom necessary. The rule, however, is to prune in winter for more wood growth and in summer for more blossoms and fruit.

Pruning should never be done when the sap is moving freely in 
the spring, for some trees are likely to suffer seriously from the loss of sap. Should any dead or diseased branches be observed during the summer it is always well, for the sake of appearance, to remove them immediately.

Pruning Tools - The tools actually necessary for pruning are few in number, but good workmen are very particular with regard to the character of their tools. There are saws specially designed for the purpose, but a large proportion of them are useless. Some workmen prefer one type and some another. A small but very convenient saw is shown in figure 48. This is called the California Pruning Saw and comes in three sizes based upon the length of

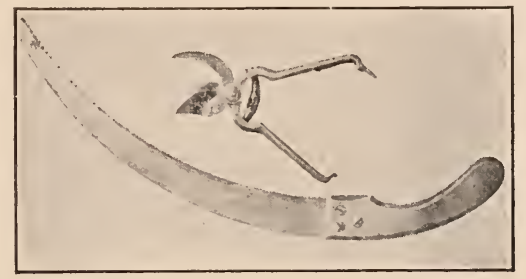

Fig. 48. Pruning Tools. A 14-inch California Pruning Saw and a good type of Pruning Shears.

the blade as follows: 12, 14 and 18-inch. This saw is too small for work where there are many large limbs to be cut, but it should be included in every pruner's kit. A larger saw also will be necessary. A saw of good size and with large teeth, known as Atkins' Universal Saw, No. 83, is a farorite with many people. A oneman saw, which is a small cross-cut saw, will be found useful for the eutting of very large limbs.

The pruner will also require a good set of pruning shears like those shown in figure 48. These are especially useful in pruning young trees. There is a knack in using hand shears that when acquired will greatly facilitate their use. The cutting blade should be placed on the upper side of the branch so that the weight of the latter will relieve the binding. It is advisable also to have the non-cutting blade toward the side to be removed to avoid injuring the part that is to remain.

Long-handled loppers are useful in "lopping" off the ends of branches. These are similar to hand shears but are attached to a twelve or fifgteen-foot pole. The shears are operated by the 
use of a long rope or steel rod that passes through screw-eyes on the pole. This tool may also be used as a hook with which to pull loose branches out of a tree. If a similar instrument

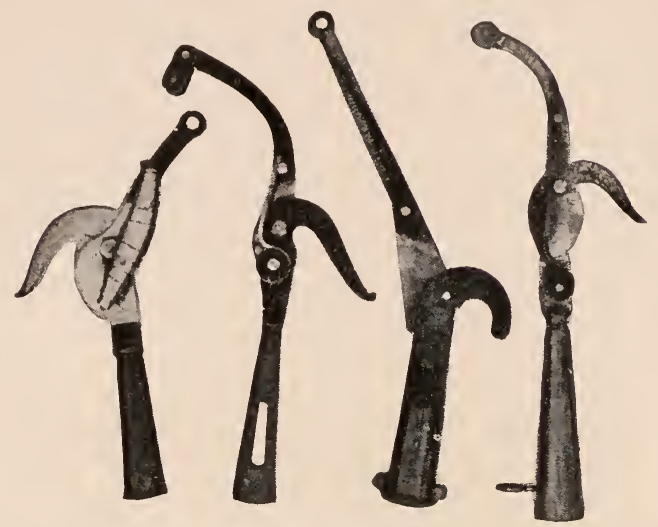

Fig. 49. Four types of "loppers" from which the handles have been removed for photographing.

could be made with the cutting blade working from above, it would be a decided improvement. Among the other tools and accessories that are likely to prove useful may be mentioned, a small one-handed axe; a piece of rope; tree climbers; a pruner's belt for the carrying of tools and for supporting the operator.

Taking Care of the Wounds - The wounds made by pruning must be protected to prevent the access of fungi. ' Small wounds, or those less than two inches in diameter are likely to heal over before danger of infection. I This depends largely upon the species and the vigor of the tree.I The wounds of Poplars and Willows heal over quickly, while those of the White Oak or Sugar Maple heal very slowly. A As a rule, all wounds two inches or more in diameter should be dressed with some preparation./ When the pruning is done in the fall or winter the dressing should be delayed till spring. This will give the cut surface a chance to dry out and the wood to become "checked." If the dressing is applied when the wood is in such condition it will be decidedly more effective in sealing up the cracks. Thick paint made from white lead and raw linseed oil will answer the purpose. A little green or black coloring matter may be added to make the wounds less 
conspicuous. Most experts use coal tar for dressing wounds. This material makes an excellent dressing, but occasional samples containing an excess of creosote or carbolic acid have caused serious damage to the living bark around the wounds. When care is exercised in preventing it from running down on the healthy bark, it may be safely used.

The larger wounds will require later applications every two or three years unless they are permanently sealed up in some way. Wounds six inches or more in diameter are sometimes covered with zine. When the work of "tinning," as it is commonly called, is properly done it is a very effective means of taking care of large wounds. The zinc plates should be cut out so as to fit

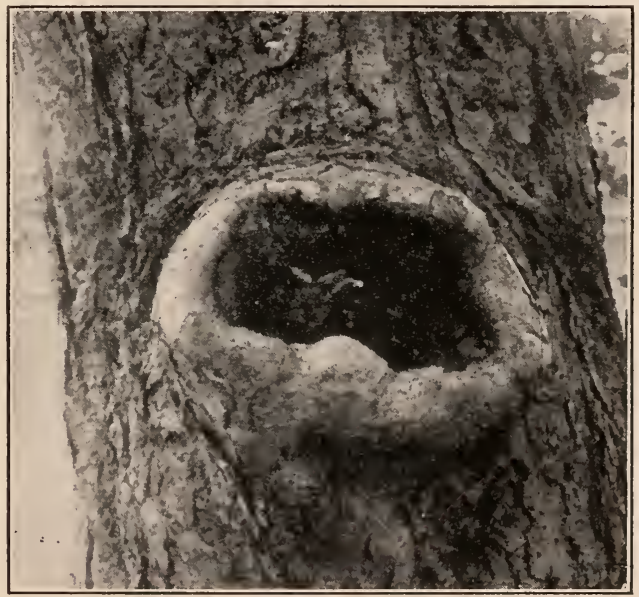

Fig. 50. The failure to protect the wound with some kind of dressing has allowed the entrance of wood-destroying fungi

exactly inside of the cambium layer or inner bark. It is applied immediatelyạafter painting and should be tacked down with largeheaded brads. The brads should completely encircle the plate and should not be more than one inch apart. When put on in this way, and before the paint has dried, there will be no danger of moisture or disease spores getting beneath it. Within a year or two the callous will form over the edge of the plate making a permanently tight covering. 


\section{CHAPTER VIII \\ COMMON INJURIES TO SHADE TREES.}

\section{SOURCES OF INJURY.}

Trees in the city and sometimes those in the country are subjected to many forms of injury. Many of the common injuries are the result of either ignorance or indifference and may easily be prevented. A large proportion of them, however, may be attributed to the unfavorable conditions under which the trees are grown. Many injuries, also, are caused by insects and fungi, but these are discussed in the following chapter.

-Injuries Caused by Gas and Smoke-It is a common occurrence in towns and cities to find trees dying or dead from the effects of gas. The injury may be caused from the presence of gas either in the soil about the roots or in the air about the foliage. Gas in the soil comes from leaking pipes and this trouble may be avoided by the careful laying of gas mains. Municipalities should see that gas pipes are properly laid and corporations should be held responsible for injuries caused by leaking gas pipes. On account of the impervious layer of soil or pavement on the surface, a very small leak will often cause much injury. Sometimes the trees will die gradually, one or two branches at a time, and may survive for several years. On the other hand, cases have been recorded where a whole row of trees has been killed in a single season and from a single leak in a gas main.

Affected trees will take on a sickly appearance. The foliage turns yellow and finally falls. The presence of gas in the soil may usually be detected by boring in several places to a depth of three or four feet. A soil auger is a useful tool for this purpose, but where this is not available, a crowbar may be used. The odor of gas in these holes indicates with certainty its presence in the soil. Where gas is found it is well to dig a trench around the trees and to loosen up the soil as much as possible to get rid of the gas. The leak, of course, should be promptly located and repaired.

Many trees are injured by the coal gas in the air that comes from smoke stacks. Trees in the neighborhood of railway yards 
and manufacturing plants may be found in various stages of decreptitude. The only remedies for this trouble are the passing of city ordinances that aim to regulate the smoke nuisance and the avoiding of species like the Elm, the Sugar Maple, and others, that are especially susceptible to gas poisoning.

Injuries From Overhead Wires - The construction and operation of overhead telephone and electric lines is responsible for

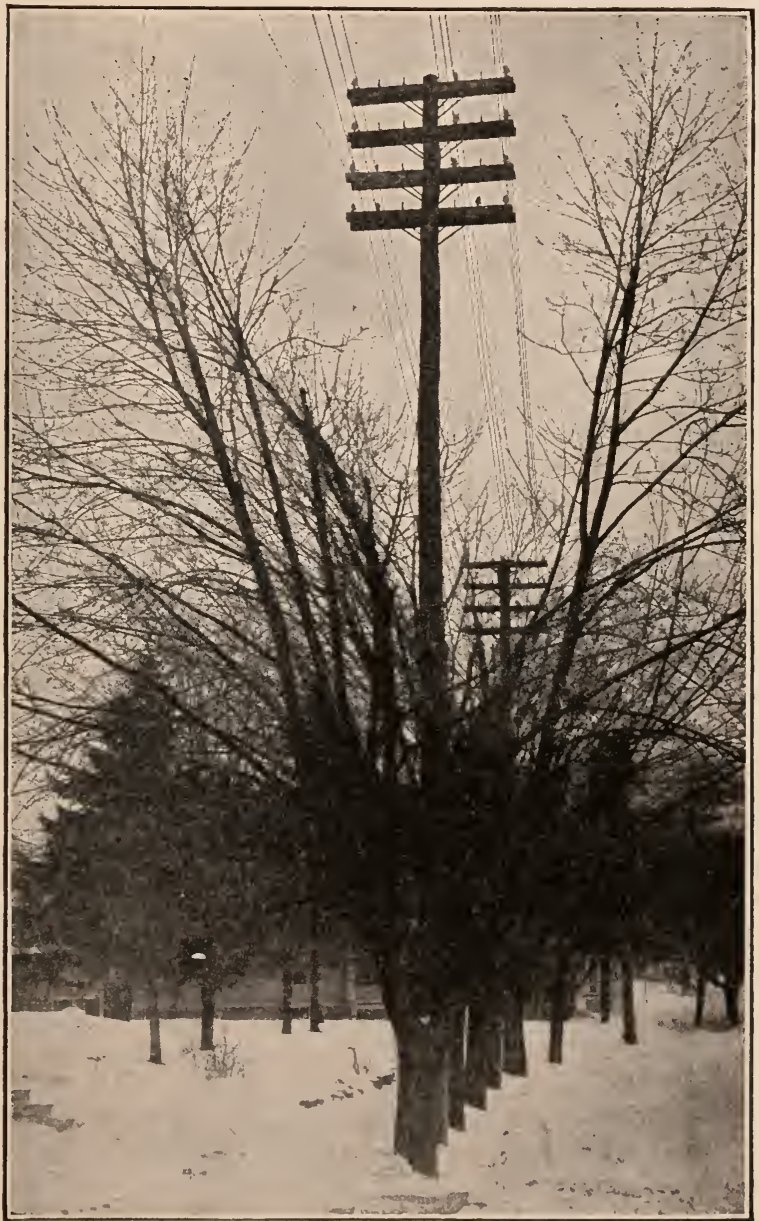

Fig. 51. A row of trees that have been butchered by electric linemen.

much serious injury to shade trees. The careless chopping out of branches to admit of the free passage of wires may be seen almost 
everywhere. Sometimes the whole center of a tree has been removed and sometimes a large notch has been cut out from one side of the tree. In either case the general symmetry of the tree has been spoiled. Occasionally trees have been injured by escaping

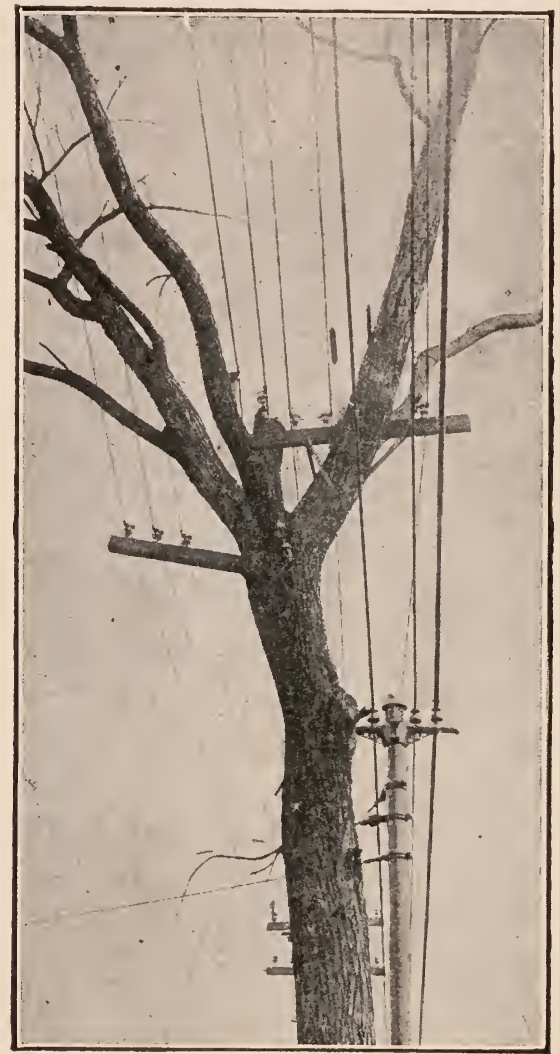

Fig. 52. An illegitimate use of trees.

electrical currents. This trouble comes from having the wires so near that the branches touch them during a wind storm. Even though the trees are not burned by the current, the constant wearing of the bark by the wires causes large abrasions that weaken the branches to such an extent that they are soon broken down by the wind.

Telephone and Electric Light Companies should not be allowed to mutilate valuable shade trees. Where the trees interfere with 
the free passage of the wires overhead, the companies should be required to adopt the underground system. If it should be necessary to run a line through street trees the company should be required to protect such trees from abrasion.

Electric linemen are not the only offenders, but much damage has been done by building contractors in the use of trees as anchors for guy wires. A wire tightly wound around a tree soon interferes with the circulation of sap. (See fig. 53). If trees must be used for this purpose, care should be observed in protecting them from injury by the use of wooden strips, as shown in figure 53 .
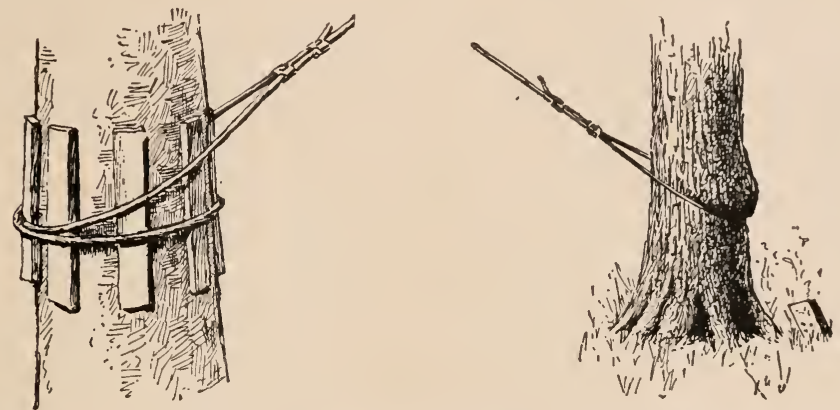

Fig. 53. The right and wrong methods of attaching guy wires.

Injuries From Regrading Streets - Workmen engaged in repairing, widening, or regrading streets often destroy valuable trees without regard to the effect upon the appearance of the street. This reckless destruction of trees is usually unnecessary. If a street should be widened to such an extent that a few trees are likely to stand in the roadway it is not always necessary that they should be removed. It is sometimes practicable to project the curbing at intervals so as to protect the trees, or it may be advisable to construct a curbing around a tree and allow the traffic to pass on either side.

In the changing of grade on city streets and country roads many trees are sacrificed that might be saved by exercising a little care. If soil is removed around the base of a tree the roots dry out and if the soil is filled in around the trunk, to the depth of a foot or more, the roots are deprived of air and the bark is injured by coming in contact with the soil. Where the grade is lowered it is possible oftentimes to leave a mound of 
earth about the tree and the mound may be encircled by curbing from six inches to a foot or more in height. (See fig. 54). In case of fills, a tree may often be saved by building up a well

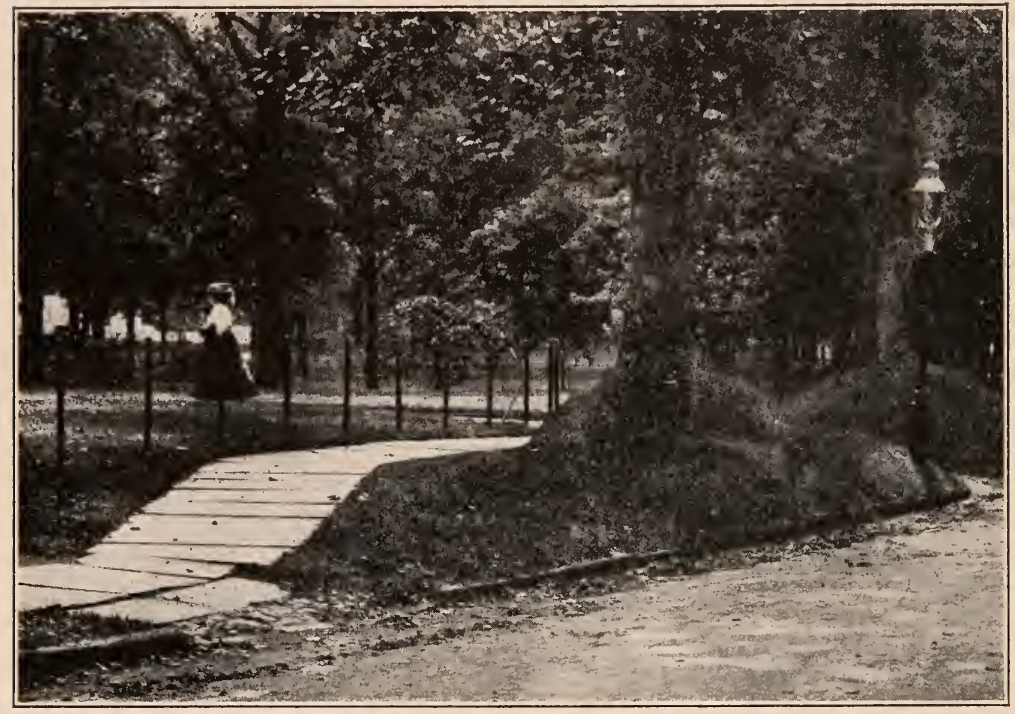

Fig. 54. A method of saving trees where the street grade is being lowered.

around it, as shown in figure 55. Unless the fill is too deep, the tree may be saved by filling in around the base with large stones. On lawns this is by far the better practice. By the time the soil becomes filled in about the stones the tree will have thrown out new roots nearer the surface.

Injuries From Improper Pruning - The commonest and probably the greatest injury to shade trees comes from improper pruning and the failure to properly care for the wounds. (See

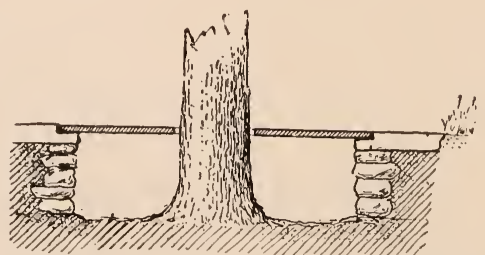

Fig. 55. Where the grade must be raised about trees they may be saved by the making of a "well" about each tree. 
figs. 45 and 46 . The importance of making close, smooth cuts and the necessity for protecting the wounds has been discussed under the head of Pruning, and the work of repairing damage from this cause will be discussed under the head of Renovation of Trees.

Injury From Horse Bites and Careless Driving - Where trees hare been used for hitching posts much injury has been the result. Horses gnaw the bark and cause large wounds on mature trees. (See fig. 56). Trees affected in this way are much weakened and are liable to be blown down by wind. Unprotected young trees are often girdled and killed by gnawing horses. Trees may be protected from horse bites by using wire netting, but on account of its unsightly appearance some cities prefer to deal with the problem by passing and enforeing ordinances. In some cities the teamsters and drivers who have been responsible for injury in this respect

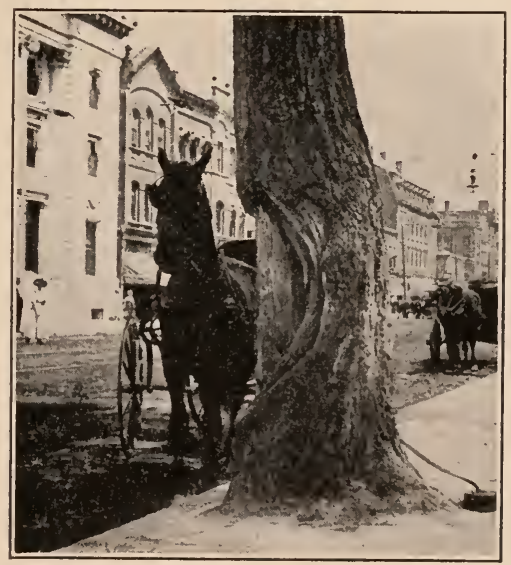

Fig. 56. "Cause and Effect." A familiar sight along city streets.

have been heavily fined and as a result the trees are seldom injured. A heavy fine, of course, will not restore an injured tree and since there is likely to be some who are not familiar with the law and who do not realize the danger, all trees near the curb should be protected. In Washington, wire poultry-netting is used for this purpose. It may be obtained in two-yard widths and just enough may be cut off to reach around the tree. Sometimes it is wound twice around. In either case the ends are fastened with light wire 
that will break before causing serious pressure on the bark. A safer way, and one sometimes followed, consists in using a heavier grade of netting and attaching it on the exposed side of the tree,

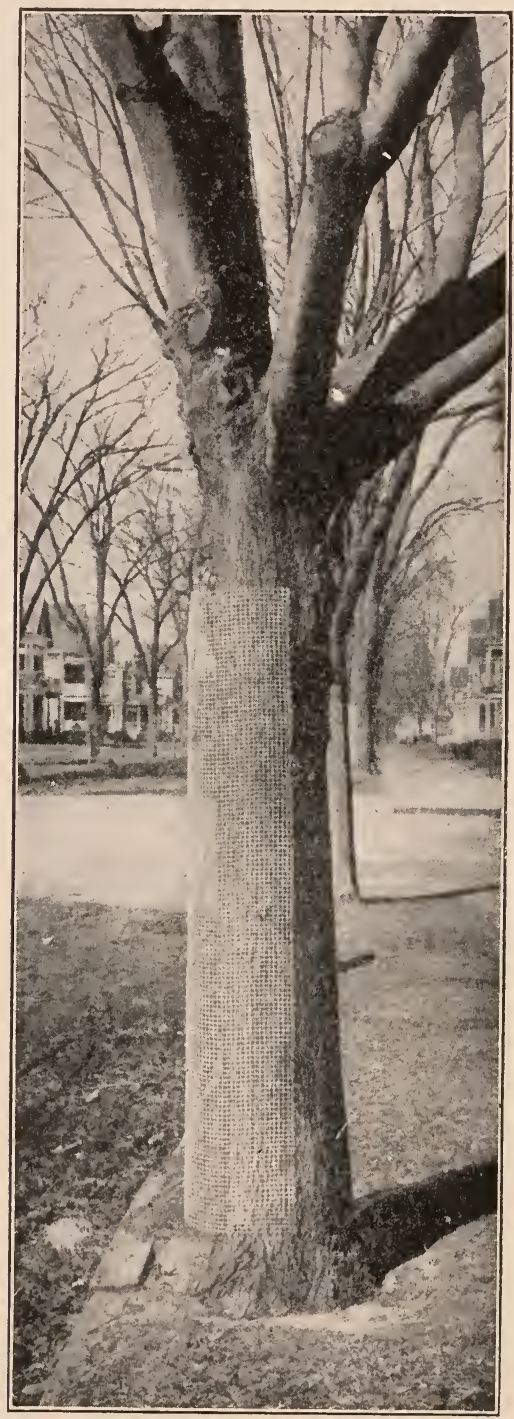

Fig. 57. An excellent method of protecting Shade Trees from injury by horses. 
only, as shown in figure 5\%. The netting is fastened on with staples and as the tree trunk enlarges, the wire is drawn through the staples.

Many trees are injured also by passing vehicles. Where the trunks project out beyond the curb it is difficult to avoid injury.

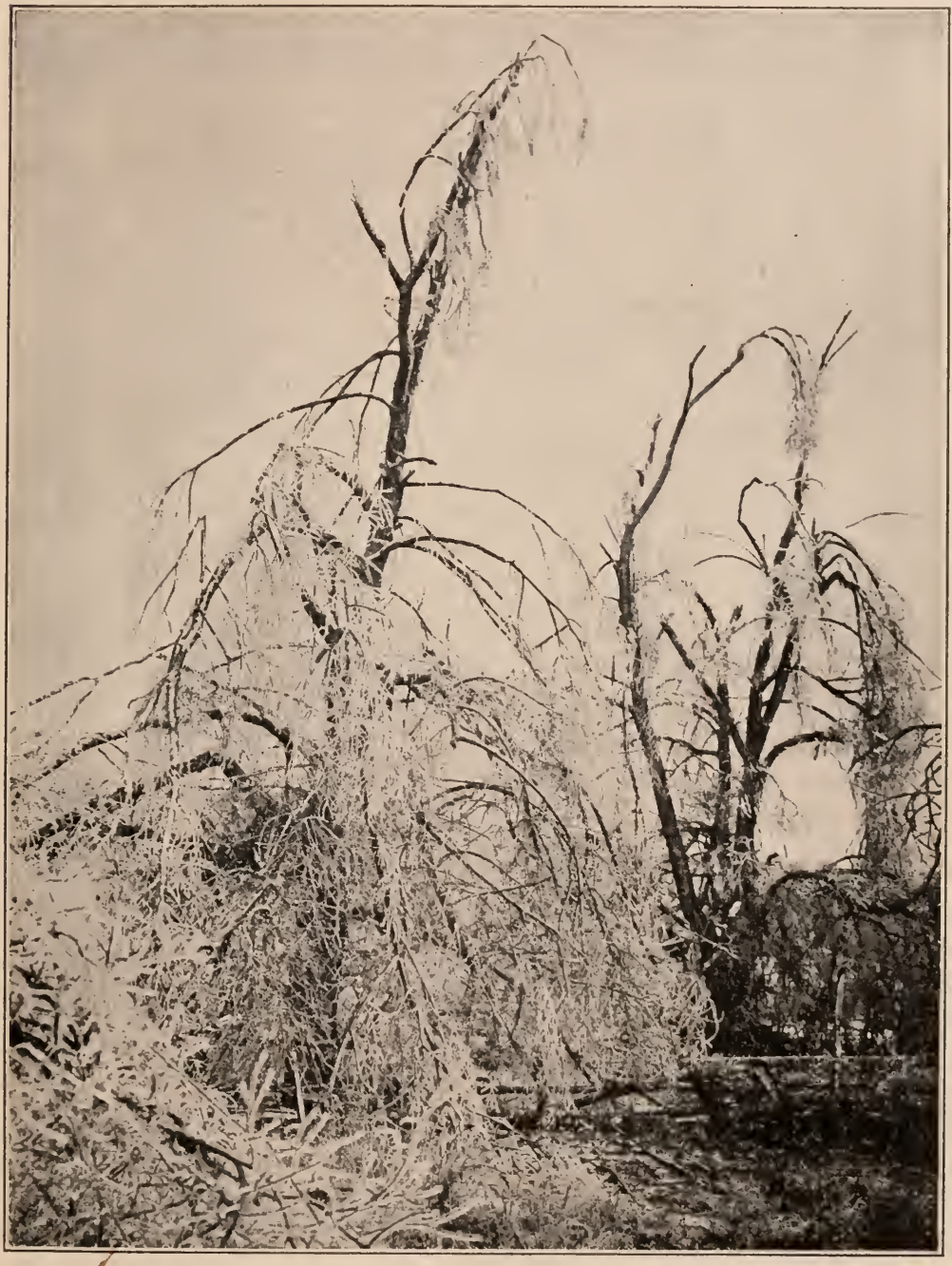

Fig. 58. Willow Trees after an ice storm. 
On city streets a slight projection of the curbing will often prevent much injury. On country roads and in places where there is no curbing, the injury may be prevented by the placing of a large stone in a sloping fashion in front of the tree.

Injuries From Wind and Ice - Much damage to trees is done by severe wind storms. The wind, of course, cannot be prevented, but much trouble may be aroided by the proper selection of species. Species differ greatly in their ability to withstand wind. Trees that suffer most are those with brittle wood, like the Willows, Poplars, Ashes, and Silver Maple.

Evergreens are often injured by the accumulation of soft snow on their branches. Valuable specimens should be closely watched and relieved of their heavy burdens during snow storms. Sleet or ice storms when followed by strong winds are very destructive to trees. Serious injury to small-growing trees usually may be avoided by knocking off the ice as it accumulates. Most danger occurs when the temperature falls after the storm and the ice becomes firmly set on the branches and twigs. It is necessary, therefore, to shake the ice off before it sets. A long slender pole, padded with burlap, may be used to remove the ice. As a rule, it is only necessary to remove that near the ends of the branches where the leverage is greatest. When broken branches are promptly removed and the wounds properly treated, trees soon recover from the effects of ice and wind storms. Poplars with excurrent stems often lose all of their side branches, but new branches soon take their place.

Injuries From Improper Soil Conditions - The soil along city strects is often very deficient in plant food and is often in a very poor mechanical condition. The macadamized and paved streets shut off the natural water supply and many trees are slowly dying for the want of water. Since the elements of plant food must be dissolved in water before the trees can make use of them, much of the injury may be attributed to starvation. Poor soil and the lack of moisture produce what is known as "stag-head," the symptoms of which are a stunted and sickly appearance of the tree, an imperceptible annual growth, sparsely scattered yellow foliage, and dead branches at the top of the tree. The only remedy for such a condition, of course, is to remove the cause of the trouble. An open space of at least three feet in diameter must 
be left unpaved around each tree unless the roots may extend beneath the sidewalk and make use of the adjacent lawn or yard as a feeding ground. Sometimes trees have been planted in soil that has-come from excavations and the only means of correcting such a condition is to remove as much of the soil as possible from around the roots and substitute for it some rich garden soil, or a liberal supply of well-rotted stable manure may be mixed with the soil already about the roots.

Poor drainage is often responsible for much injury. Where the soil-water comes near the surface, the roots are prevented from entering deeply into the soil. Trees that have been blown down and those having crooked and leaning trunks, usally have been grown under such conditions. Such trouble can be avoided only by proper under-draining.

\section{RENOVATION OF TREES}

The natural age limit - Knowing that some trees have reached the age of several thousand years, it is surprising that so many of our shade trees should die so young. The age of a dragon tree (Dracaena Draco) on one of the Canary Islands is said to be over 6,000 years; that of a Bald Cypress (Taxodium mucronatum) in Mexico is believed to be over 4,000 years; and that of an English Oak (Quercus pedunculata) in Europe and a "big tree" (Sequoia gigantea) in California is known to be over 2,000 years. Many trees also have attained an enormous size, both in height and diameter. The Eucalyptus in Australia is known to reach a height of 470 feet and the "Big Tree," the Redwood, and the Douglas Fir of California often grow to a height of 300 feet. The Sycamore and the Tulip Tree in the eastern states sometimes reach a height of 150 feet. The tree of largest diameter is found at the base of Mt. Etna in Sicily. It is a species of Chestnut (Castanea vesca) and its trunk is over 60 feet in diameter. Some people claim that this remarkable tree is the result of the union of several individuals. The Oriental Sycamore comes next with a diameter of about 40 feet.

These remarkable measurements are attained by trees growing under favorable conditions. The most of our shade trees are not growing under conditions most favorable to their development. It is easy to find something wrong with the environment of almost every tree, and this accounts for the failure or weakening of so 
many trees before they reach their maximum development. Although a definite age limit for the various species of trees cannot be fixed as with animals, we frequently classify them as long-lived trees and short-lived trees. The Oaks, the White Pine and the Sycamore are regarded as long-lived trees, and the Poplars, Willows and most of the Birches as short-lived. Most other species are intermediate between these two extremes.

Tree Surgery - Property holders and those who have charge of the tree work in cities, are frequently confronted with the necessity for renovating trees that have been neglected in the past. The demand for the improvement of neglected trees has brought into existence a class of men variously known as "professional foresters," "tree doctors," and "tree surgeons" and their business is known as tree surgery. On the whole these people are reliable and are doing a good work. Some of them, however, are not so dependable and their work not only is of little value, but is sometimes accompanied by real injury to the trees. It is well to avoid those who claim that by injecting into the trunk some magic concoction the tree is thereafter immune to the attacks of insects and disease.

The reputable tree surgeons are in the habit of making contracts for the renovation of trees. Towns and cities frequently engage these experts to treat all or a part of their trees that require attention. Their work usually consists in the removal of all dead wood from the trees, the dressing of the wounds, the filling of the cavities, and the necessary chaining and bolting. Sometimes they are engaged either by the same or a separate contract, to spray the trees and to treat them in other ways. They may contract to do the whole job for a stipulated amount, or they may fix a charge for each tree that requires treatment or for each day that they work.

Dehorning Trees - A few years ago in the city of Boston and other New England cities, many of the park and street trees were sererely headed-in or "dehorned." The practice was limited mostly to the very tall specimens. Many fine old elms were treated in this way. The objects seem to have been to encourage a denser growth and to lessen the danger from falling branches. The desired objects were accomplished, but at a great sacrifice to the appearance of the trees for many years. After a lapse of about fifteen years many of the trees have outgrown the effects of such harsh treat- 
ment and are beginning to regain their natural habit. 'There are few people who approve of the promiscuous dehorning of shade trees and the practice now is largely restricted to the work of rejurenating weak and neglected trees.

'There is probably no better way of putting new life into weak trees than by severely pruning during the dormant season. The weaker the tree the more severe should the treatment be. A tree that is making a very small annual growth and that has put out a scanty supply of foliage should be severely cut back. The removal of three-fourths of the top during the following winter would tend to awaken new activities. When we consider that the new growth and the development of the foliage and blossoms must come

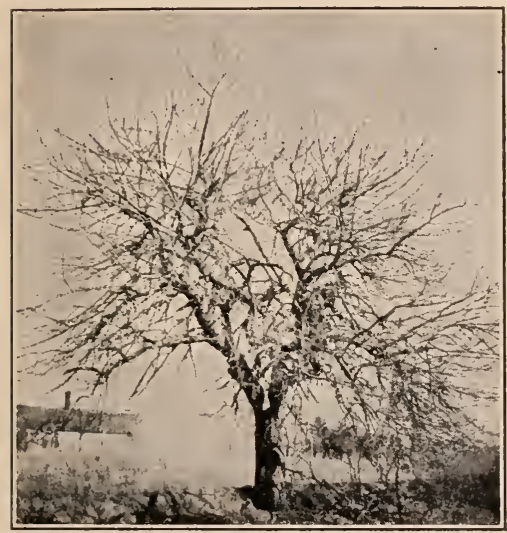

BEFORE PRUNING.

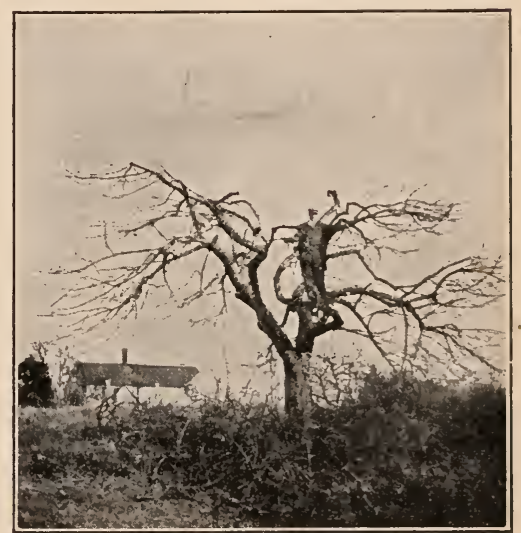

AFTER PRUNING.

Fig. 59. Heading-in neglected Apple Trees to render them more easily sprayed and to facilitate the harvesting of the fruit. A common practice in New England.

from the energy stored up in the lower part of the tree and in the roots, it is not surprising that there is sometimes a feeble growth. By removing a part of the top, all of the stored-up energy is forced into the remaining part with the result that the tree, during the following season, carries fewer leaves, but these are of a better color and appearance. A tree sometimes becomes constitutionally unbalanced from the effects of an inadequate supply of food or water or from the effects of insect attack, fungus disease, or mechanical injury. A tree in this condition has not sufficient energy stored up 
to put out the required foliage to properly nourish the tree and to store up enough reserve food material for the following year's growth. As a result the tree becomes weaker and weaker and, unless it receives help, finally dies. A severe pruning, while dormant, tends to throw the tree back into proper balance.

Except in serious cases, it is not necessary to completely dehorn the tree, many weakened trees require only a severe general pruning to put them into proper balance, and with such it would be unwise to spoil their shape by dehorning. Some ill-formed trees, on the other hand, are improved in shape by a moderate headingin. Neglected apple trees for example, are being severely dehorned

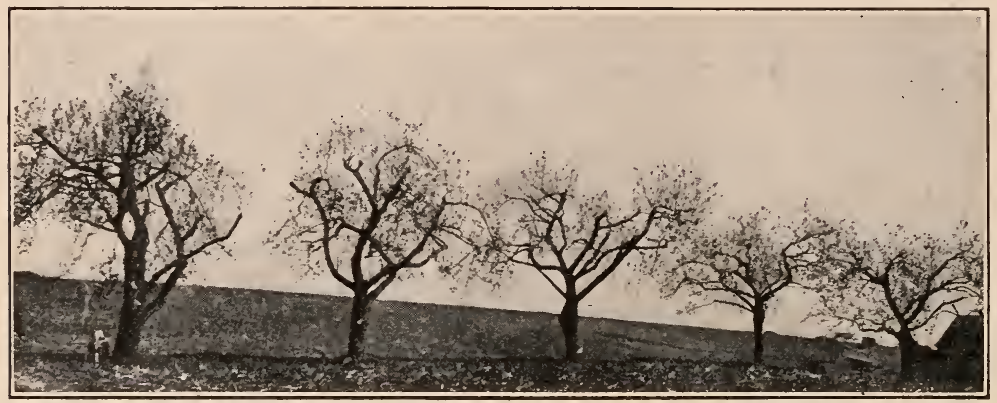

Fig. 60. Old Apple Trees one year after being "dehorned."

by many growers in New England and New York for the purpose of reducing the height of the trees and of developing new heads nearer the ground. In the most severe cases the whole top is removed, leaving nothing but stubs from which sprouts readily develop, and these when properly trained, form the new head. (See figs. 59 and 60$)$.

When weakened trees are dehorned or severely pruned they should be given good eare in every respect. The breaking up of the turf and the application of fertilizers in the spring and the supplying of water during dry seasons, will go a long way toward rejuvenating old and weakened trees.

Taking Care of Recent Injuries - Fresh wounds are frequently found on the trunk or main branches of trees. These are usually the result of accident, of carelessness, or of wilful destruction. In some cases trees become girdled from leaving wire labels attached, from guy wires in construction work, or by mischievous boys. In 


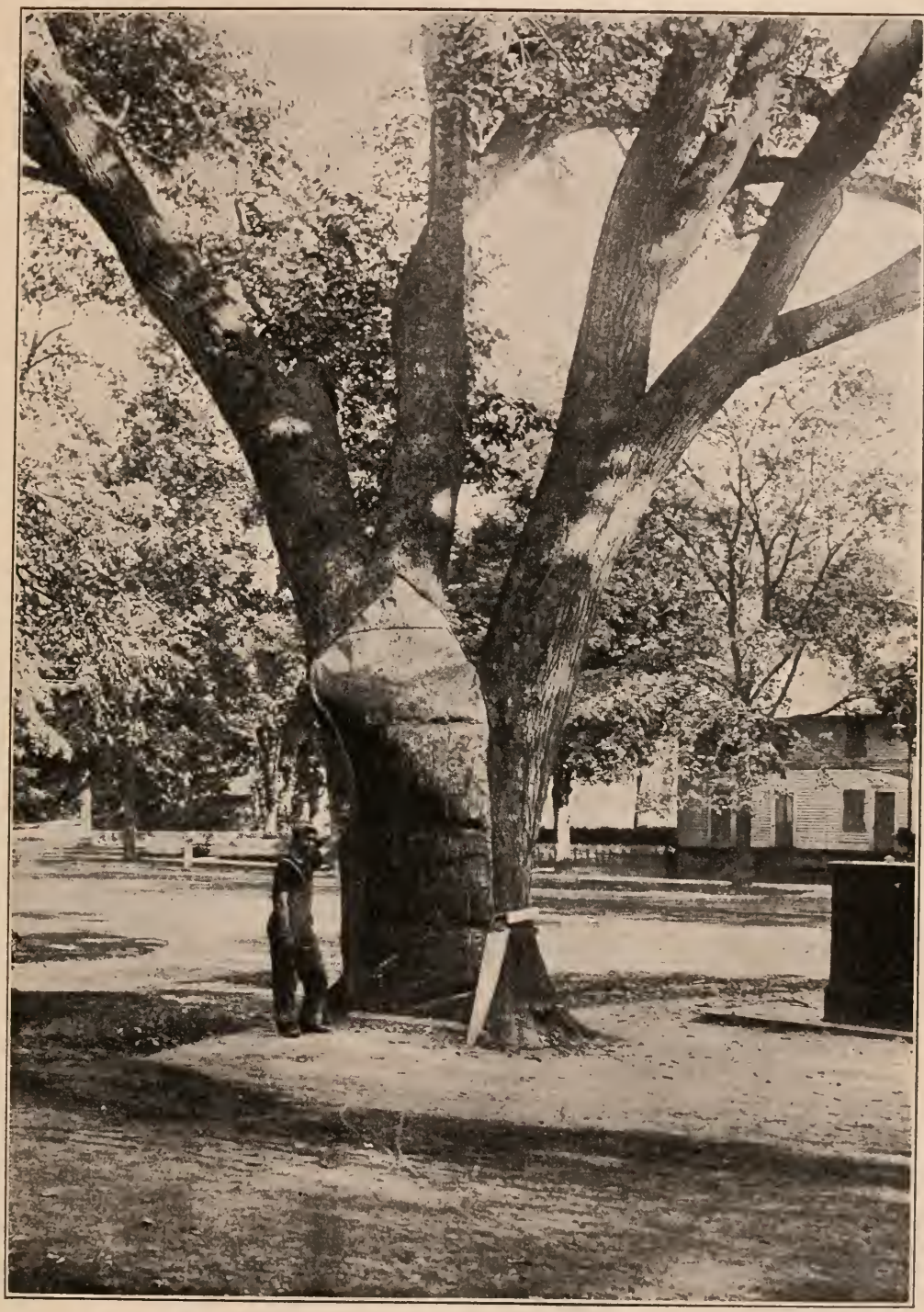

Fig. 61. A good example of the use of zinc in covering a surface wound. Observe that the zinc is fitted closely to the freshly cut edges of the bark and it is applied in pieces that overlap like shingles on a roof. 
other cases the trees are injured by horses or passing vehicles. Wounds made from any such causes may be easily and quickly healed if treated before the wound has had a chance to dry out. They should have their edges trimmed up with a sharp knife, always cutting back to firm bark. The whole surface should then be covered with grafting wax and bandaged with cloth. If done in the early part of the summer a new bark will develop over the whole surface. This method of healing is different from that associated with old wounds.

Where a portion of the bark has been removed all around the trunk, the trouble is more serious, but if the wound is not more than three or four inches in width and if the injury occurred in the early part of the summer when the cambium is active, the tree may be saved by protecting the wound with wax as just described. If the wound has become somewhat dried, or if it is a wide one, it will be necessary to resort to bridge-grafting.

For "bridging" a wound it is necessary to smoothly cut back the edges of the wound to sound bark and connect the two edges with freshly-cut scions. The scions should be of the past season's growth

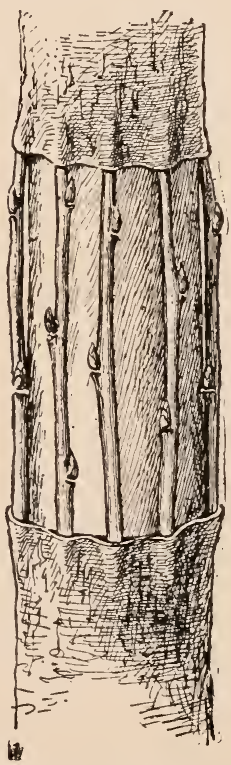

Fig. 62. Bridge Grafting. A process used in healing over wounds that extend clear around the trunk or a large branch. 
and may be taken from the same tree or some other tree of the same species. The scions should have their leaves removed, their ends ent werlge-shaped, and should be just long enough to extend under the bark about an inch at each end. 'The whole wound, scions and all, should be covered with soft grafting wax and cloth bandages. The scions, when they become united to the bark at both ends, serve to conduct the elaborated food material down to the lower part of the tree. In time the wound will heal over completely. (See fig. $62)$.

Wounds of the previous season, or those that have been allowed to dry out, will require different treatment. A girdled tree, if not treated soon after the accident, will die, but so long as there is a strip of bark remaining there is hope for the tree. In such cases, the edges of the wound should be cut back to living cambium and the wound thoroughly sterilized with copper sulphate, one pound to ten gallons of water. The whole wound, as soon as dry enough, should be painted with ordinary white lead paint, or with coal tar, and then covered with zine. The zine should be eut so that it will fit exactly inside of the wound, and in this way allow the bark or margin of the wound to heal over the edge of the zine. The edge of the zine should be firmly nailed down, using large-headed nails not more than an inch apart. The zine may be painted any color that will be inconspicuous. If the zinc should become broken so that water may enter, it should be promptly removed and replaced with whole strips.

Filling Cavities - Many trees whose trunks have been completely hollowed out, have been saved from breaking down by the use of cement filling. Cement is used largely for support and acts as a reinforcement. In order that there should be no further decay the work must be carefully done. The accompanying illustration, figure 63 , shows the various stages in filling a knothole cavity. Briefly stated the work consists in eleaning out all the decayed material, sterilizing with copper sulphate solution, and filling with concrete. The edges of the wound should be trimmed back to living bark. Knot-hole wounds are usually prepared by sawing off the projection or lip around the wound. If the decayed area has not extended far enough to weaken the tree, the cavity need not be filled. It should be cleaned and 

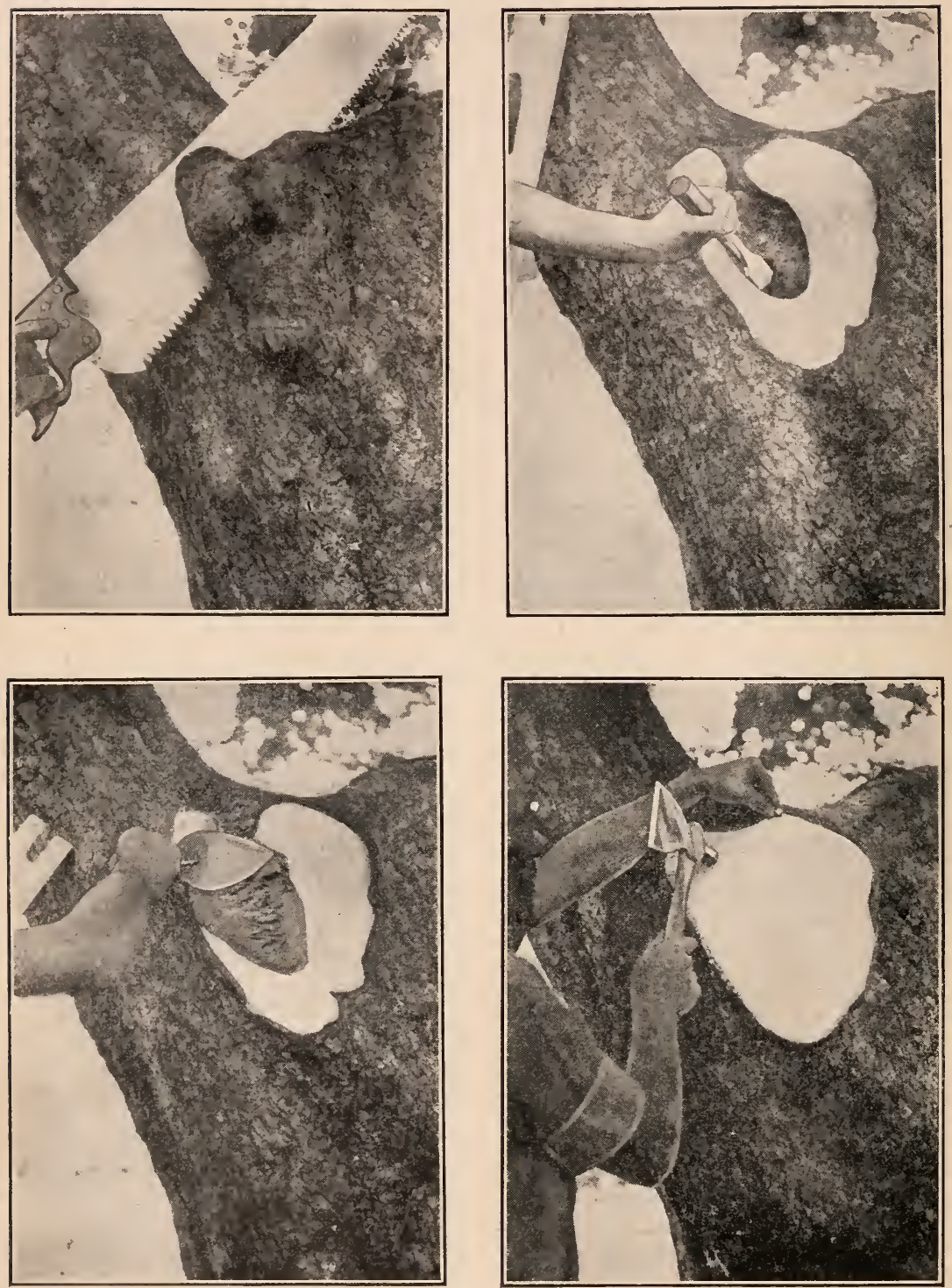

Fig. 63. Tree Surgery, Various stages in the treatment of knot-hole cavities. 
sterilized, however, and the opening covered with zine as described, for large wounds made by pruning.

In slender cavities where there is a small opening, it is necessary to make some additional holes through the living bark and wood to facilitate the work of cleaning (see fig. 6t), and it is often necessary to enlarge the opening to give more room for working. In such cases it is also necessary to make up the cement mixture in a semi-liquid form, so that it will flow into all crevices.

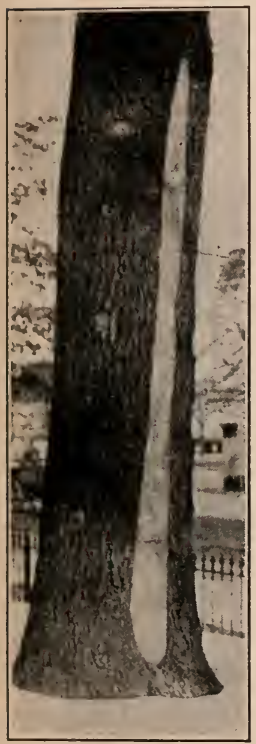

Fig. 64: A wellfilled cavity showing the three holes that were made through the living bark to facilitate the work of cleaning out and afterward filled with concrete.

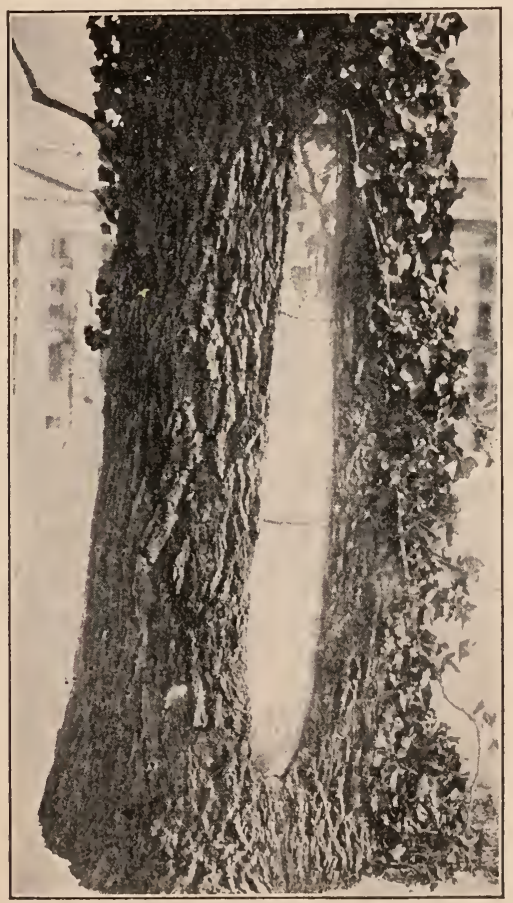

Fig. 65. This kind of cavity work does not detract from the appearance of the tree and is a permanent improvement. Observe that the cement is molded to form a convex surface.

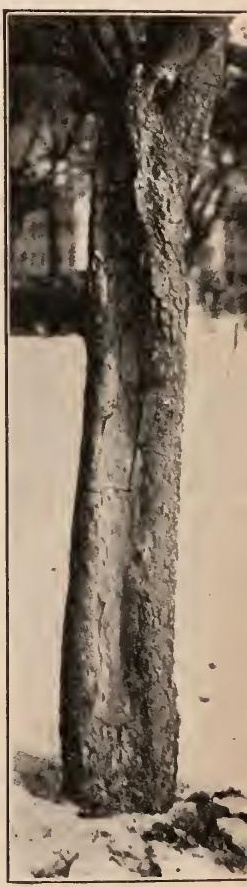

Fig. 66. A poor ly-filled cavity Observe that th concrete has concave surfac and is badl cracked. It als projects over th edge of the barl preventing it healing. 
Very large openings will need to be bricked up to hold the concrete in position. The proportions used in making up concrete varies, but most experts use one part cement, two parts sand, and four parts crushed stone for the main filling. Just enough water is added to make a mixture that will settle well into all crevices without much tamping. The finishing is done with a stiffer mixture made up of one part cement to two parts of fine sand and just enough water to make a good mortar. Sometimes nails are partly driven into the main filling to assist in holding the finishing material in position until it has hardened.

The finishing of the surface is one of the most important features of the work. The filling should be left with a convex surface and the edge of the concrete should be beveled off so that it comes just beneath the cambium layer or inner bark. If the finishing is properly done the callous will form over the edge of the filling. In long cavities that extend far up the trunk, it is customary to divide

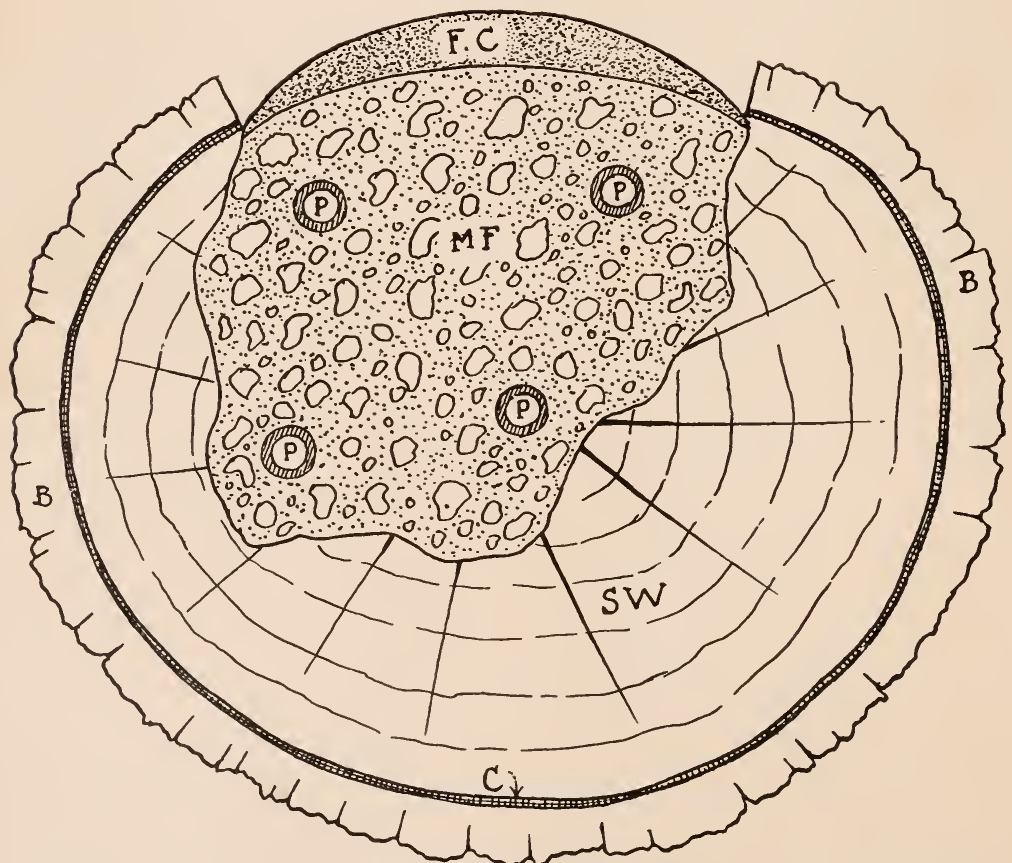

Fig. 67. Cross-section of a filled cavity, showing the correct position of the concrete in relation to the bark and cambium. B-bark; Ccambium or inner bark; SW-sound wood; MF-main filling of concrete; P-iron pipes for reinforcement; F.C.-finishing concrete. 
the filling into two or more sections by cutting into it with a knife in about the same way that sidewalk builders section off their concrete walks. (See figs. 64 and 65). This precaution obviates the irregular cracking of the concrete due to the swaying of the tree by the wind. By reinforcing the concrete, also, with two or more steel uprights, by numerous steel rods, or by iron pipes, the danger from cracking the filling is greatly reduced. Even though no cracks are made in the concrete there is likely to be a crack between the wood and the filling, where water is likely to enter. For this reason some prefer to cover the concrete with zinc, tacking it down on a freshly-painted surface as previously described.

Bolting and Chaining - Some trees with bad crotches, like the Elm and Silver Maple, are very liable to split down, unless protected in some way. Any tree with a cavity in its trunk, no matter how small, is likely to split open, due to the freezing of the accumulated water. Trees affected in this way, of course, should first have their cavities filled and the water prevented from accumulating. Any tree that shows a tendency to split should be supported by bolting or chaining. It is also well to preclude damage by bracing all trees with bad crotches, even when there is no indication of splitting. A sudden storm often tears large branches from the trees that are least suspected of being injured. When the branch is completely severed there is no hope, and all that can

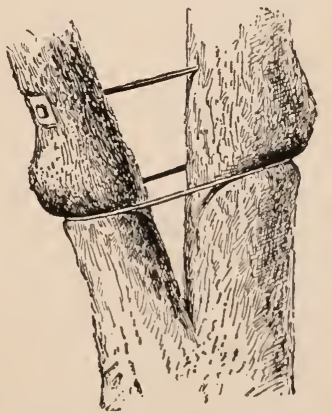

Fig. 68. The result of improper methods of supporting a weak crotch.

be done is to trim up and dress the wound. If the branch is not completely severed and if it may be readjusted without injuring the connecting tissue, the chances are favorable for saving the limb. 
There are many mistakes made in attempting to support a tree prone to splitting. Sometimes more harm than good is done, and frequently good trees are seriously injured by the good intentions

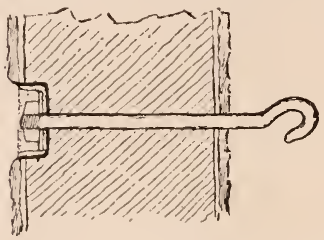

Fig. 69. The proper method of inserting a bolt.

of the owner or the poor judgment of the so-called "tree-doctor." The use of chains, wires, or iron bands around two or more branches is sure to cause injury. When trees are supported in this way there is no opportunity for expansion or growth without bringing much pressure on the bark, and, as a result, the branches affected are partially girdled and either killed or greatly weakened. (See fig. $68)$.

When the branches are far apart, the best method of bracing is in the use of bolts with a hook on one end and a large washer and

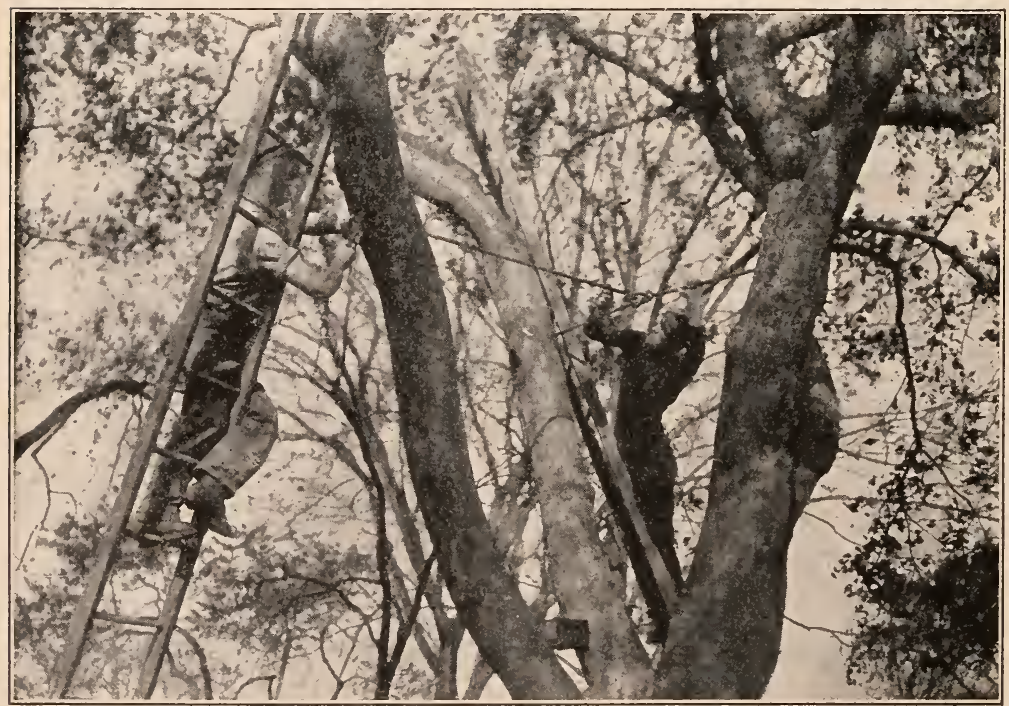

Fig. 70. Method of bolting a tree possessing three or more main branches. 
nut on the other. These are inserted by boring a hole clear through the branch and by counter sinking the washer and nut as shown in figure 69 . T'wo or more of the bolts may be inserted and connected by wires or chains. The nuts soon become imbedded in the wood and the result is a very efficient and inconspicuous method of bracing.

Where the branches are near together, as is usually the case with Elms and Silver Maples, the bolt may be made long enough to extend through both branches and threaded at both ends. The nuts and washers in this case, also, may be countersunk. The nearer the crotch the stronger should the bolt be to stand the great strain during wind storms. A one-inch bolt at a distance of three or four feet from the crotch is sufficient except for the larger trees. When the bolting is done at a distance of four or more feet from the crotch there is more or less swaying motion that tends to weaken the bolt. For this reason, bolts connected by chains are preferable to solid bolts, except at points very near the crotch. 


\section{CHAPTER IX \\ THE CONTROL OF PARASITES. \\ FUNGUS TROUBLES.}

Trees are subject to a great many kinds of disease. Few diseases, however, are so serious as to require treatment. 'Tree diseases are caused mostly by parasitic fungi, which are low forms of vegetable life that live upon and within the tissue of the host plants. The most serious forms, from the shade-tree standpoint, are those causing the decay of the trunk and main branches. Since such forms are not capable of entering the uninjured bark these troubles usually

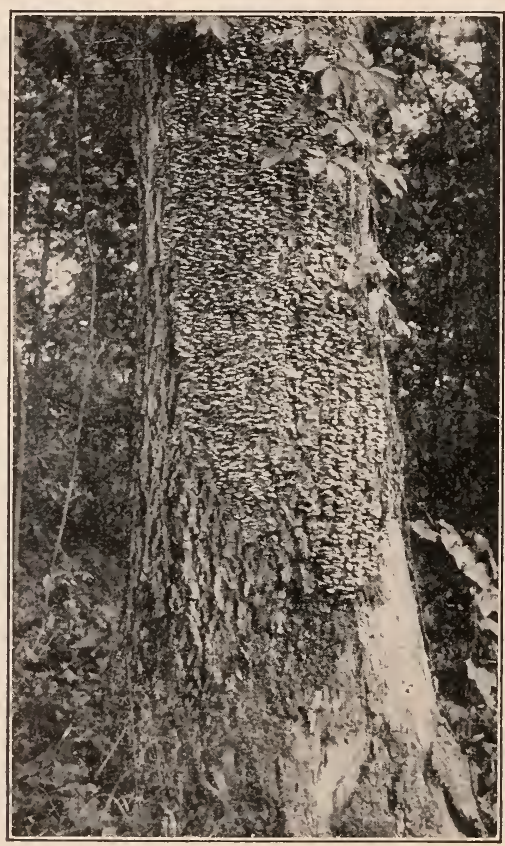

Fig. 71. A Red Oak tree injured at the base by fire. A fungus gained access through the wound and is rapidly rotting the sapwood beneath.

may be prevented by taking proper care of the wounds. It should not be assumed that the mere removal of the toadstool-like growths 
on the trunk or branches of a tree will have any beneficial effect, for these are the result of disease and not the real trouble. These familiar fungus growths are found only on wood that has become diseased as a result of some mechanical injury, which may have occurred several years before. The treatment for such troubles, as mentioned elsewhere, consists in removing the decayed wood containing the fungus, sterilizing the wound, and protecting the tree from further infection.

There are some leaf diseases, like the black-spot or "tar-spot" on the Maple, that sometimes cause injury, but are seldom so serious as to kill the tree. There are other tree troubles that affect the leaves and which frequently cause serious alarm on the part of the owner of the trees. A branch here and there and sometimes onehalf or more of the tree will show colored and dying leaves, many of which fall about mid-summer. This trouble is especially common on the Sugar Maple, and it is sometimes very difficult to determine the cause. It is probably caused many times by an unbalanced condition of the tree. The Sugar Maple develops a large growth of foliage in the spring, and during the dry months of July and August the roots seem to have trouble in supplying enough moisture to take care of the evaporation from the leares. As a result, some of the less favored branches lose their leaves. Trees

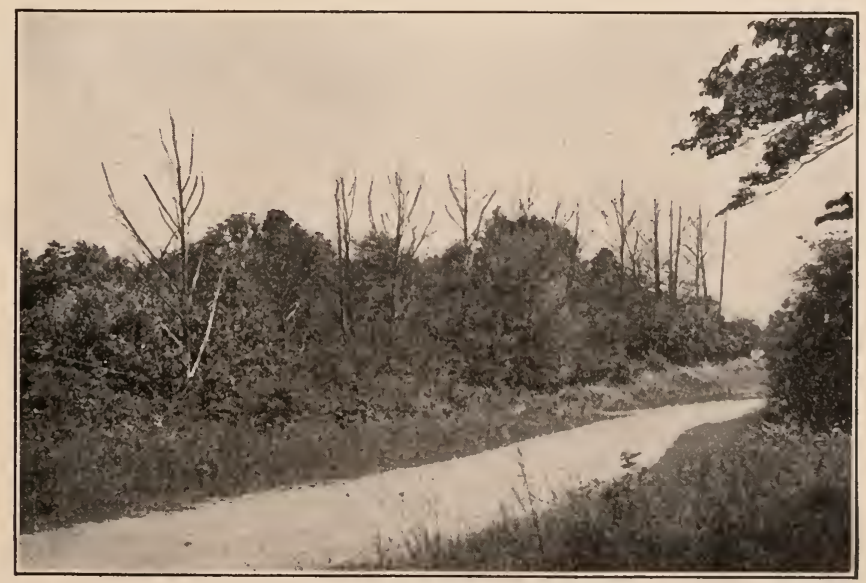

Fig. 72. Chestnut trees killed by the bark disease. 
affected in this way usually leaf out again the following spring and show no ill effects.

The most serious fungus pest of shade trees in the northeastern states is the Chestnut-bark disease. Enormous tracts of chestnut timber have been rendered worthless except for firewood. Ornamental chestnuts in parks and on private grounds also have been killed in many sections. The total financial loss from the disease is estimated now at $\$ 25,000,000$. The spores of the fungus probably enter the bark through small wounds caused by birds, insects, or abrasions. They commence growth in the cambium

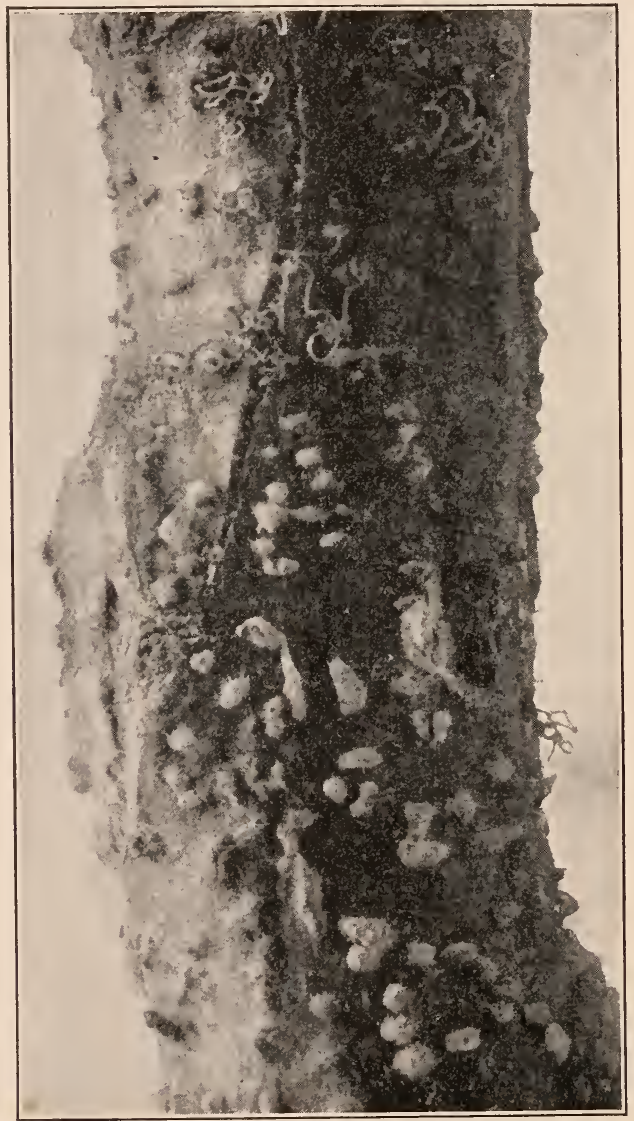

Fig. 73. Diseased Chestnut bark showing pustules and form of discharge of summer spores in damp weather. (Magnified 3 diameters.) 
layer and the disease soon encircles the trunk of the tree, or a single branch, as the case may be. All parts of the tree above the infection dies, and if the infection starts on the main stem or trunk, the whole tree is killed.

So far, no means has been devised for the prevention or control of the disease. When valuable shade trees become affected in one or more branches, the remainder of the tree possibly may be saved by promptly cutting out the diseased portion. It is import-

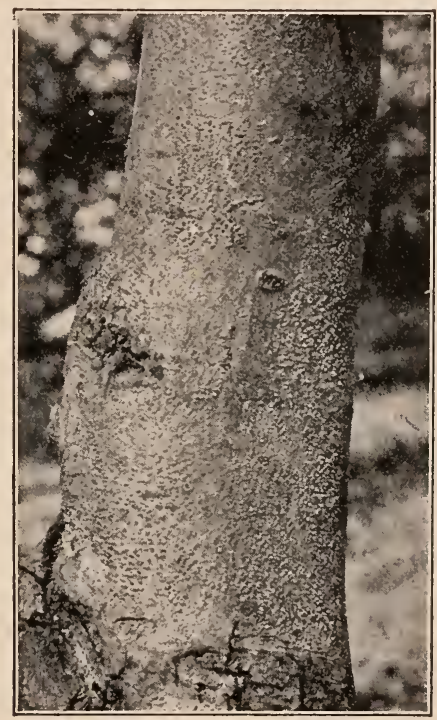

Fig. 74. Diseased Chestnut bark showing pustules of the parasitic fungus bearing winter spore

int that the cut be made many feet below the point of infection to aroid carrying the spores on the pruning saw. Great care also should be exercised in avoiding injuries to the bark of the remaining portion of the tree. The wounds made in cutting out the diseased branches should be promptly painted with tar to prevent further infection.

\section{INSECT TROUBLES}

How Insects Injure Trees - The caterpillars, as well as some beetles, injure the trees by devouring the leaves. A tree may be 
completely defoliated without being killed. When the foliage is destroyed early in the season a second crop of leaves usually appear's. The necessity for furnishing a second supply of leaves in one season weakens the tree, and if it is repeated for three or four years, is likely to prove fatal. The condition becomes more serious when the second crop of foliage is also destroyed. Without foliage the tree cannot store up the necessary reserve material to supply its needs the following spring.

Anothar class of insects, mostly grubs, cause injury by burrowing under the bark and into the wood of trees. These are the so-called borers. Occasionally one of these insects, like the Maple borer, will completely girdle and cause the death of a tree in one season, but usually they will work in a tree for many years before it dies. The insects so weaken the trees that they are finally blown over or broken down. To this class of insects belong some of our more serious pests. Their destructiveness is because of their habit of attacking a tree at its most vital point - the cambium and because their presence is not often detected until much damage has been done. Even when they are known to be present they are destroyed with great difficulty.

A third class of insects, including the bugs, scales, and plant lice, injure the trees by piercing the tissue and sucking the juices. The affected foliage becomes pale in color, curls up, and sometimes dies. The bark also becomes infested and often large pits or indentations are formed. With most members of this class, their great power for destruction lies in their appearing in such enormous numbers and in their power to reproduce so abundantly. Of the San Jose scale, for example, there are three or four broods in a season, and one pair of insects surviving the winter may by fall have progeny numbering into the billions.

Methods of Combatting Insects - In the control of insect pests it is necessary to know something about their feeding habits. The failure to get satisfactory results from spraying may usually be attributed to the use of the wrong remedy. In the control of insects that obtain their food by sucking, no benefit would be derived from the application of stomach poisons, for it would be impossible to get any of the poison into the insects' food. It is necessary, therefore, to first determine to which class the pest belongs whether it is a chewing-insect or a sucking-insect. 
It is well to determine also whether the insect causing the injury is in the larval or adult form. As a rule, injury is caused by insects in the larval form only, but some species, like the Elm-leaf beetle, feed during both the larval and adult stages. With insects of the latter type it is always advisal)le when possible to destroy them in the adult form before they have had a chance to deposit their eggs, and in this way prevent the ravages of the second generation.

Spraying for Insects - The most common and the most satisfactory method of controlling insects is by spraying. There are many instances, however, where spraying is not practicable, and there are many kinds of insects that cannot be controlled in this way. The preparation and application of insecticides and the appliances used in the work will be discussed under the heading of "Insecticides, Fungicides, and Spraying."

Hand-Picking of Insects - The large and conspicuous caterpillars often may be controlled by hand-picking. Their presence usually may be indicated by their droppings on the ground. Caterpillars that live in colonies or that build tents like the fall webworm and the tent-caterpillar, may be destroyed either by burning with a torch or by cutting or brushing them ont and dipping them in kerosene. Conspicuous nests and egg masses like those of the gypsy, tussock, and brown-tail moths, may be destroyed either on or off the tree during the dormant season. Where small bounties have been offered to school children, serious pests have been kept under control without further expense.

Borers also are usually controlled by hand-picking. - ne sawdust-like castings around the base of the tree is an indication of their presence. A sharp pocket knife, with which to dig the insects out, will be found useful. A flexible wire or an old-fashioned knitting needle sometimes may be used to kill the insect without cutting into the bark.

Banding and Trapping - Many ways have been derised for trapping insects and thus preventing them from reaching their feeding and breeding places. These methods of control are especially useful on forest lands and other places where it is impracticable to spray. Sticky bands and other obstacles tied around trees make it possible to destroy many insects that congregate beneath the band in their efforts to reach the foliage. This method is especially 
useful with certain wingless moths that may be prevented from depositing their eggs. The important point regarding their use is to have them in position when the insects commence to crawl up the tree.

The simplest band is made by using a strip of cotton batting, about eight inches in width and long enough to reach around the

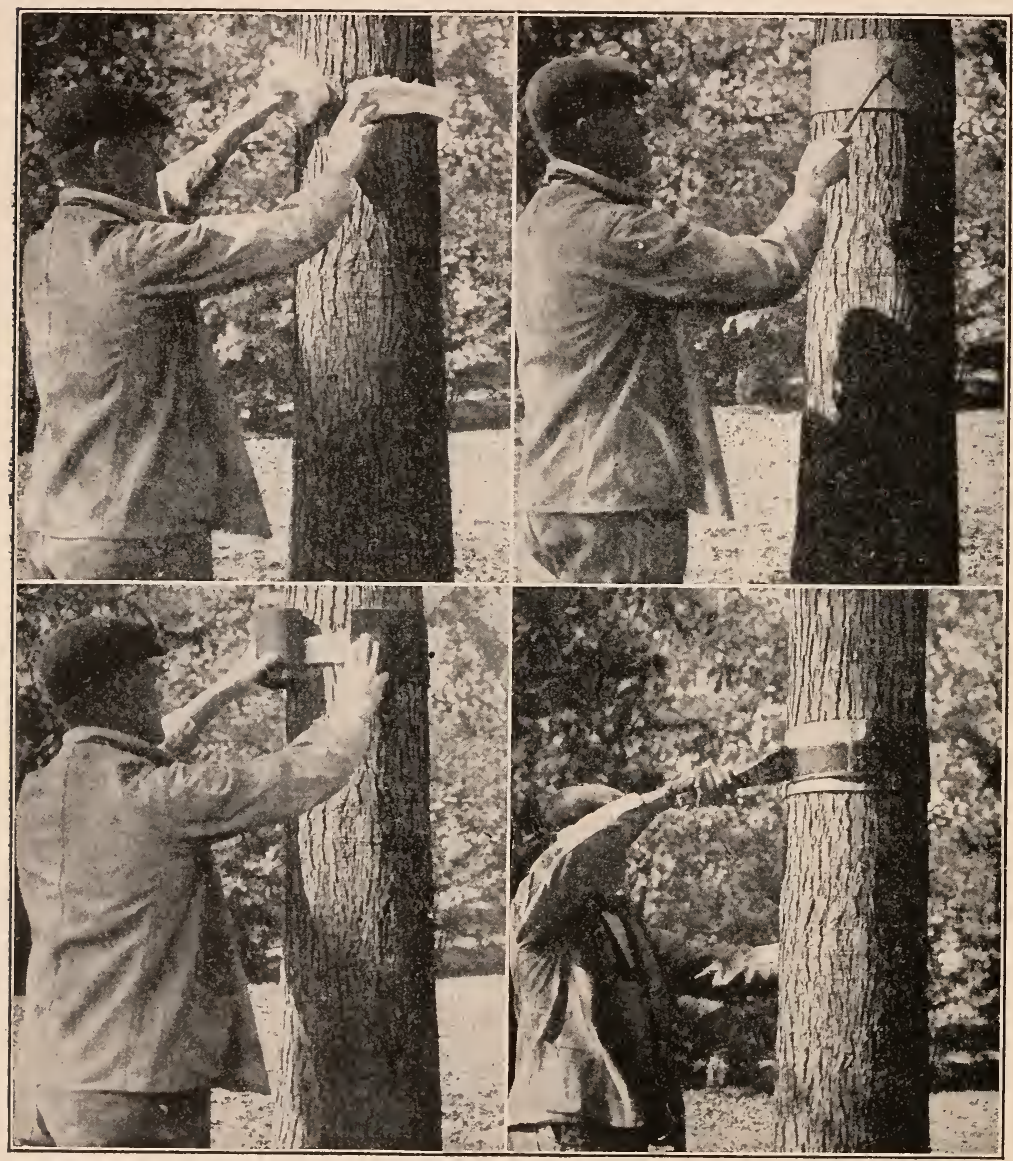

Fig. 75. Method of applying sticky bands to protect trees from Canker-worms.

tree and to lap over an inch or more. The batting is firmly tied around the tree trunk at a point about six feet from the ground. 
The twine used for the purpose should pass around the lower border of the batting so that the upper border may be turned down, forming an umbrella-like barrier.

The most satisfactory band is one made of sticky material like "Tree Tanglefoot," a commercial preparation, which may be obtained for about thirty cents per pound. After smoothing off the bark it may be applied directly to the tree. Young, thin-'barked trees may be injured by direct contact and for this reason the "Tanglefoot" may be applied to a strip of tarred roofing paper, which may be attached to the tree. For ornamental trees it is usually advisable to use the roofing paper, for this may be removed after the trapping season is over. Where the bark is rough a narrow strip of cotton batting may be placed beneath the paper to prerent the insects from crawling beneath. (See fig. 75). Where it is desirable to leave these bands on for more than one season they should be recoated. Where the paper is tacked only at the lap it will stretch sufficiently to accommodate at least one year's growth. Bands put on in this way have been successfully used for three or four seasons.

Night-flying moths are often trapped around electric lights. Some insects, like the leopard moth, are hard to destroy in any other way. The simplest way is to suspend beneath the light a shallow ressel containing water with a layer of oil on the surface. The moths are attracted to the light and accidentally drop in the liquid and are killed.

Preventive Measures - The careful selection of species for planting is undoubtedly the best way of handling the insect problem with respect to shade trees. Some trees are remarkably free from insect troubles, but none are absolutely immune. The species in the following list of commonly planted trees are arranged in order of least susceptibly to insect attack: Ailanthus, Ginkgo, Sweet Gum, Basswood, Tulip Tree, Carolina Poplar, Horse-chestnut, Sycamore, Hackberry, the Oaks, the Maples, the Elms, the Locusts. The least susceptible species, of course, are not always the most desirable for planting, for they may not possess the other qualifications of a good shade tree.

Since a large proportion of the shade trees in use belong to susceptible species, the recommendation concerning the selection of species applies only to new plantations. Much may be done in 
the way of preventing injury by keeping trees growing vigorously. A strong-growing tree is better able to withstand the attack of insects than a decrepit one. Some insects, like the bark-beetles, cause serious injury to weakened trees, while they seldom affect vigorous specimens. The burning of infested branches, leaves, fruit or other rubbish where insects are likely to hibernate will destroy many pests and lessen the severity of the attack in succeeding seasons.

Natural Enemies of Insects - Much may be done, also, to guard against insect depradations by protecting the natural enemies of the insects. In sections where birds are allowed to collect and are encouraged to nest, the excessive development of insect pests is prevented. Injurious insects also have many enemies among their own kind. It is a common occurrence to see a large caterpillar almost completely covered with small white bodies. These are the cocoons of a parasitic insect, the earlier stages of which have been spent within the host insect. Caterpillars thus. affected sometimes survive, but are usually too weak to complete their development. Insects affected in this way should not be destroyed by man, for in doing so he also destroys many useful parasites.

Some insects are attacked also by certain fungus diseases that exert a marked influence on keeping the pest under control. Owing to the influence of a fungus parasite, the gypsy moth in its native home is not a serious pest. When the insect was accidentally imported the fungus parasite was left behind, hence the seriousness of the pest in this country. A representative of the United States Department of Agriculture, a short time ago went to Japan and brought back come cultures of the parasitic fungus. Efforts are now being made to encourage the development of the disease amidst the gypsy moths of Maasschusetts.

There are many other examples of insects having been imported without their natural enemies, and among these are the most serious pests of trees, such as the San Jose scale, the leopard moth, the brown-tail moth, and the elm-leaf beetle. Such serious pests as these and some fungus pests, also, have been imported on nursery stock and might have been avoided by an adequate system of inspection. Some form of legislation is badly needed for the prevention of infested nursery stock coming into this country.

\section{SOME COMMON SHADE TREE INSECTS}

To prescribe the proper treatment for the control of any particular pest, it is necessary to be able to identify the species causing 
the trouble and to know something about its feeding habits. Many of the failures in spraying may be attributed to the application of the wrong remedy. Since there are many books and Experiment Station bulletins relating to specific shade tree pests, it is necessary here to describe only the most destructive forms. Every state has its experiment station where insects may be sent for identification and where adrice may be obtained regarding the control of insects and diseases and other subjects. In the descriptions that follow no attempt is made at completeness. To call attention to the more striking character's and habits is the object. 'The character of the injury is emphasized because this is usually the most available means of identification.

\section{LEAF-EATING INSECTS.}

Bag Worm - This insect gets its name from the fact that the larva carries a sort of bag that protects its body. The forepart of the caterpillar's body projects through the mouth of the bag. These bags are very conspicuous on trees in winter and contain the eggs from which the caterpillars hatch during the month of May. Each young caterpillar immediately after hatching commences to build a sack for itself, using small pieces of leaves and fastening them together with threads of silk. The bags increase in size as the insect develops and are from one to two inches in length when the larva is full grown. The larva feeds on a great variety of trees, including the evergreens. When the insect is ready to pupate it attaches the bag to a branch or twig and reverses its position in the bag. In about three weeks the mature insect emerges in the form of an inconspicuous moth. The male moth flies away, but the female moth is wingless and legless and remains in the bag until she has deposited her eggs, when she wriggles out and dies.

The pest may be controlled by collecting the nests during the winter or by spraying with arsenate of lead as soon as the caterpillars appear.

Brown-tail Moth - This pest was introduced into Massachusetts about twenty years ago and is now spreading rapidly throughout the neighboring states and Canada. It feeds on a great variety of plants and is especially destructive on the Maples. Elms, and Oaks. The adult moth is snowy-white and is distinguished readily 
by the conspicuous brown ending of the body. The female lays her eggs in July and in the form of an oblong cluster on the under side of the leares. The eggs hatch in early August, and the young

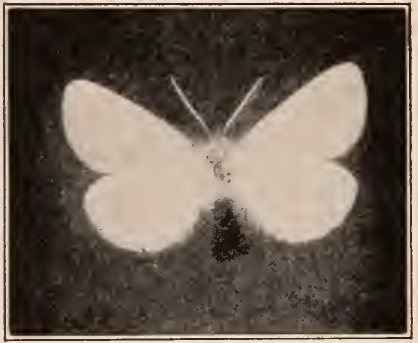

Fig. 76. Adult female (natural size.)

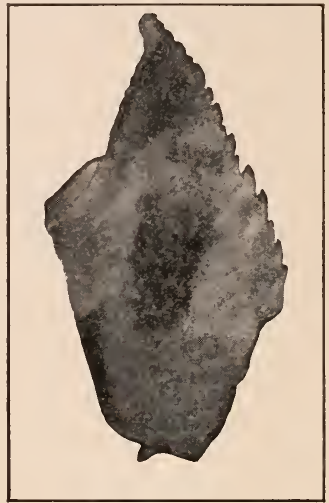

Fig. 77. Egg-mass on a leaf. (Natural size.)

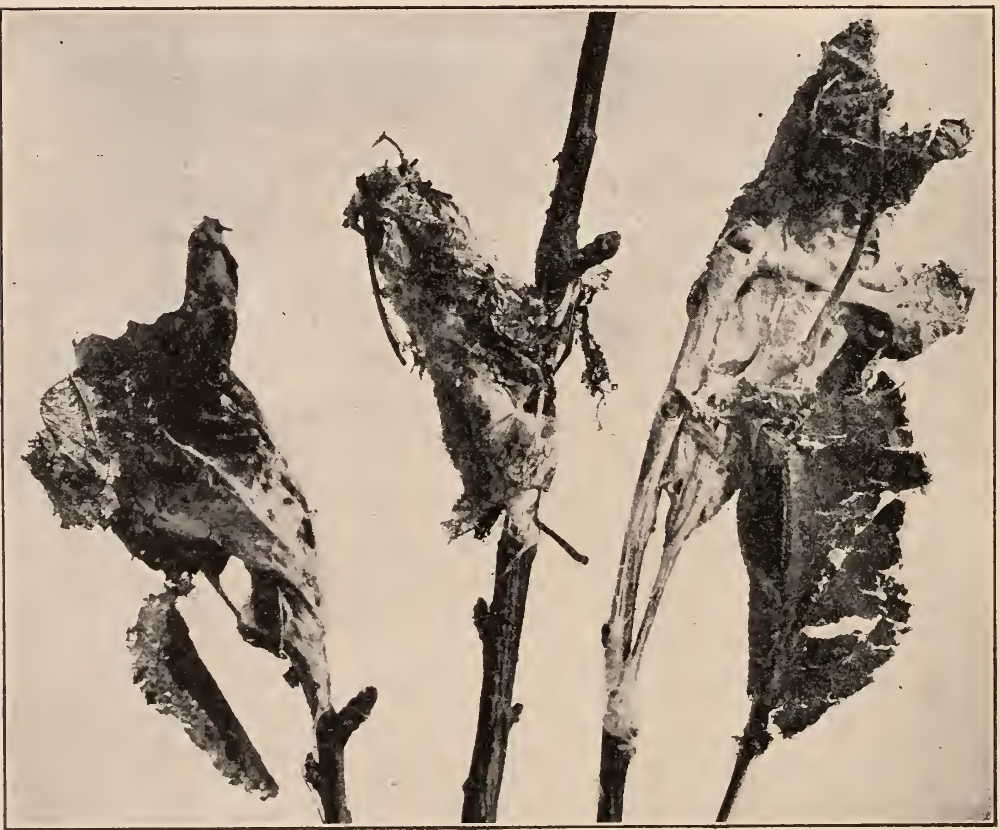

Fig. 78. The Brown-tail Moth. Tinter nests. (Natural size.) 
caterpillars commence feeding on the upper surface of the leares. A little later, using leaves and silken threads, they build large nests at the ends of the branches, and as cold weather approaches the undeveloped caterpillar's enter these nests where they spend the winter. From two to three hundred enter the same nest. They come out in April, feed upon the buds and leaves, finish their growth and about the end of June become pupae. They remain in this condition for about two weeks, when the adult moths appear. The caterpillars when they appear are about one and a half inches in length and are abundantly clothed with hairs which often become broken and fill the atmosphere with fragments. These hairs coming into contact with the human skin cause a serious irritation.

This pest may be controlled by collecting and destroying the winter nests, and this is probably the most satisfactory method. Long-handled "loppers" (fig. 49) may be used for this purpose. Spraying early in May with arsenate of lead, 10 pounds to 100 gallons of water, may also be depended upon to keep the insect under control.

Canker Worms - These are the familiar measuring worms or loopers. They are often observed hanging from a tree by a slender

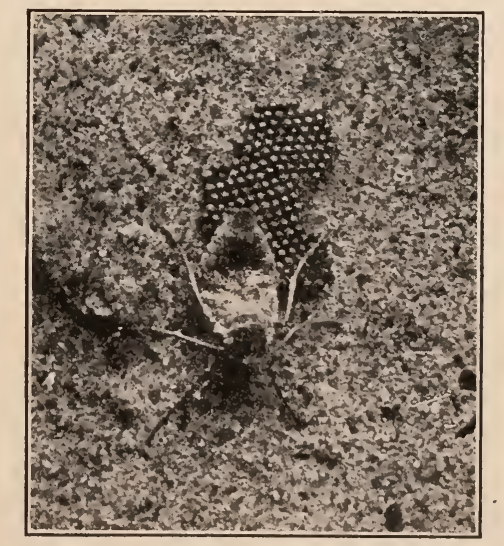

Fig. 79. Adult Female CankerWorm depositing her eggs.

thread. There are two closely related species, the fall canker worm and the spring canker worm. They feed upon many kinds of trees, but seem to prefer the Apple, Pear, Chestnut, Elm, Hickory, Box 
Elder and Maple. The eggs are deposited either in late fall or early spring, and hatch about May first. Usually the young caterpillars completely devour the tissue of the leaves, leaving nothing but the veins. About the first of June they become full grown and are almost an inch in length. They let themselves down by means of a silken thread and go into the ground where they remain in the pupal state until fall. The adults of the fall species emerge in November and the wingless females may be seen crawling up the trunks of trees to deposit their eggs on the branches. The adults of the spring species emerge in March or April.

Since the females cannot fly, they must crawl up the trees to lay their eggs, and this suggests the method of control. The pest may be kept completely under control by banding the trees. (See fig. 75). Spraying with arsenate of lead (ten pounds to 100 gallons of water) will destroy all insects that hatch from the eggs already on the trees.

Elm-Leaf Beetle - This is another imported insect and is one of the worst pests of the Elms. Fortunately its rarages are restricted to the Elms. The adult beetles are a fourth of an inch in length and are yellowish, grayish, or dull olive-green in color with an indistinct dark line along each side of their back. They usually spend the winter in the attics of houses or other sheltered places. They appear early in May and commence feeding on the newlyformed leares, making characteristic round holes. During the latter part of May or early in June the beetles deposit the familiar orange-colored eggs on the under side of the leaves. These hatch in about a week and the young grubs commence feeding on the under side of the leaf. The grubs mature in about three weeks and descend to the base of the tree, where they change to pupae. A second brood sometimes occurs.

Spraying the newly-formed foliage in May with arsenate of lead will usually be sufficient to control the pest, but occasionally a second application as soon as the grubs appear, will be necessary. The pupae around the base of the tree may be killed by spraying with strong kerosene emulsion.

Gypsy Moth - This destructive insect was imported accidentally about forty years ago. Its larva feeds on almost any kind of vegegation, including all kinds of shade trees and ornamental shrubs. The eggs are laid usually on the trunks and brauches of 
trees, but sometimes on fences and buildings, in July or August. They are arranged in oval masses and are covered with short hairs. The whole mass presents a creamy or yellowish appearance. They remain in this condition until the following May, when the young caterpillars appear and begin feeding upon the expanding foliage.

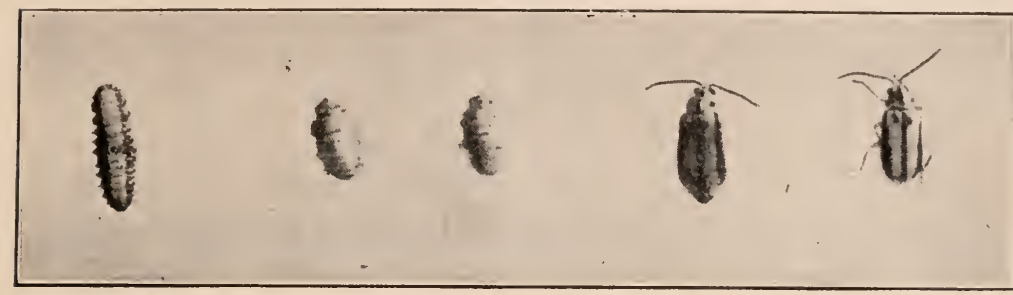

Larva

Papae

- Adults

Fig. 80. The Elm-Leaf Beetle in its various stages.

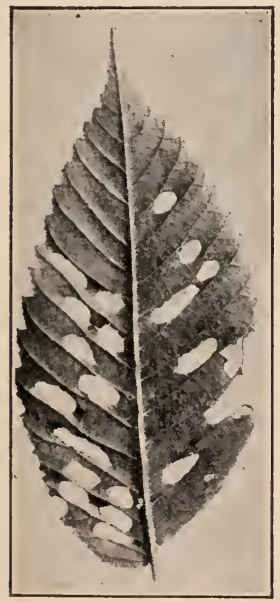

Fig. 81. Holes made by the adult Elm-Leaf Beetles.

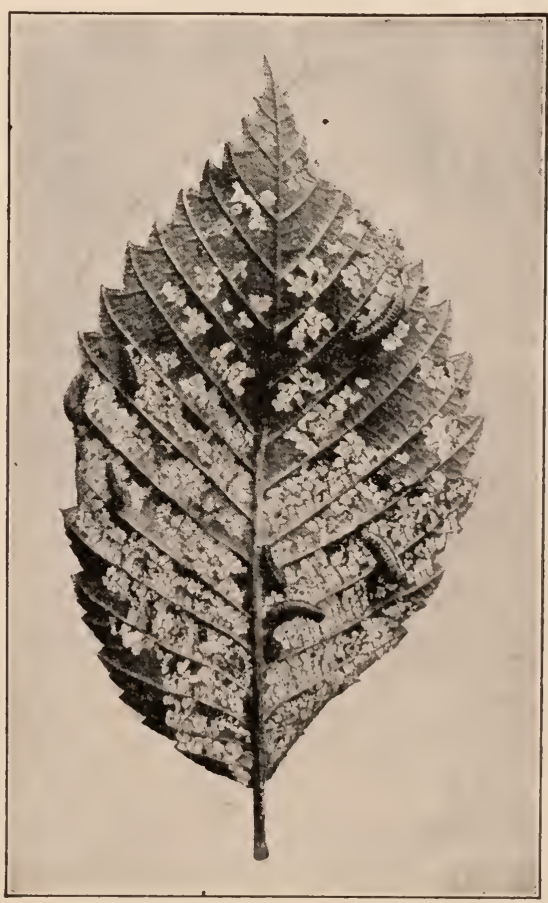

Fig. 82. Elm-Leaf Beetle Larvae working on the under side of a leaf. (Natural size.) 
The caterpillars when mature are somewhat over two inches in length, and are covered with long hairs. In color they are dark brown with a pair of blue spots on each of the first five segments and a pair of red spots on each of the remaining six segments. In early July they change to pupae, and in late July develop into adult

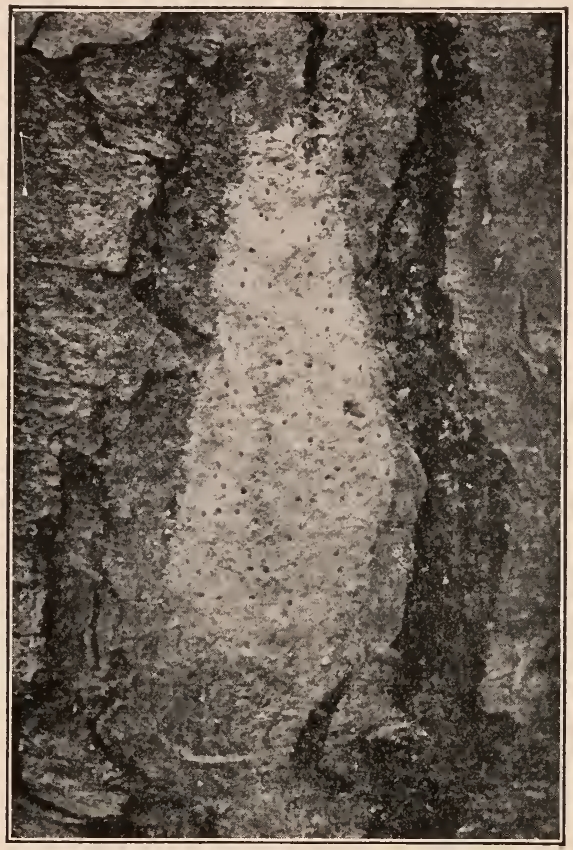

Fig. 83. A Gypsy Moth egg-mass, natural size, after the larvae have emerged through the small holes.

moths. The moths measure about fire inches across the expanded wings. The male is smaller than the female and is brown in color. The female is almost white with dark markings. They are heavybodied insects and, for this reason, do not fly long distances.

One of the most effective means of controlling the pest is by destroying the egg masses during the fall and winter. A sponge saturated with creosote and attached to the end of a long pole is used for this purpose. A little lamp-black is added to the creosote to color the egg masses. In Massachusetts, the following creosote mixture is used: Creosote oil 50 parts, carbolic acid 20 parts, tur- 


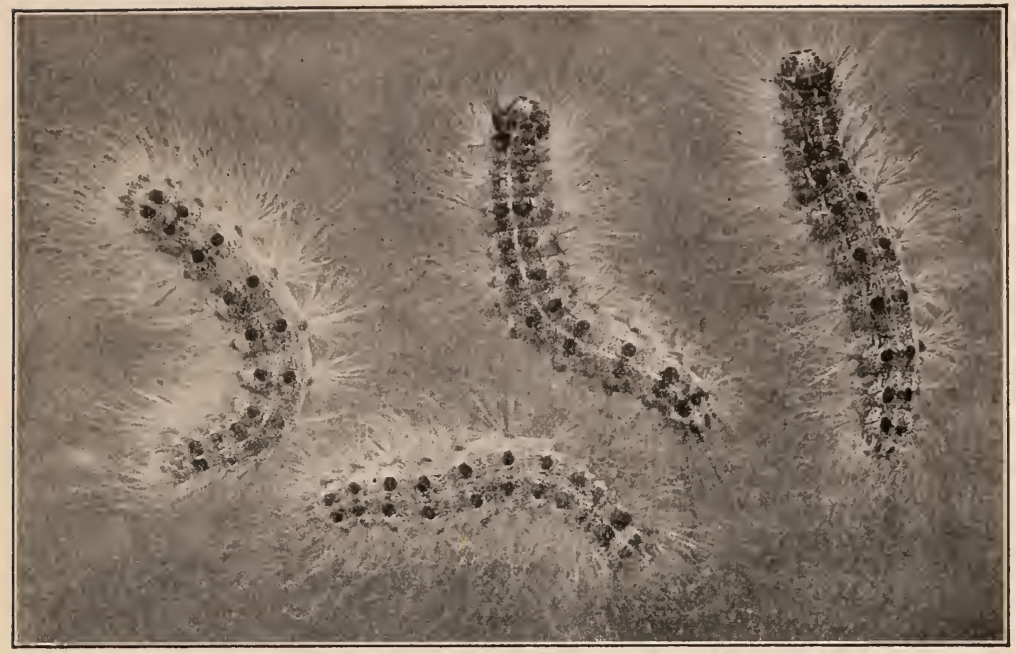

Fig. 84. Full-grown Gypsy Moth Larvae.

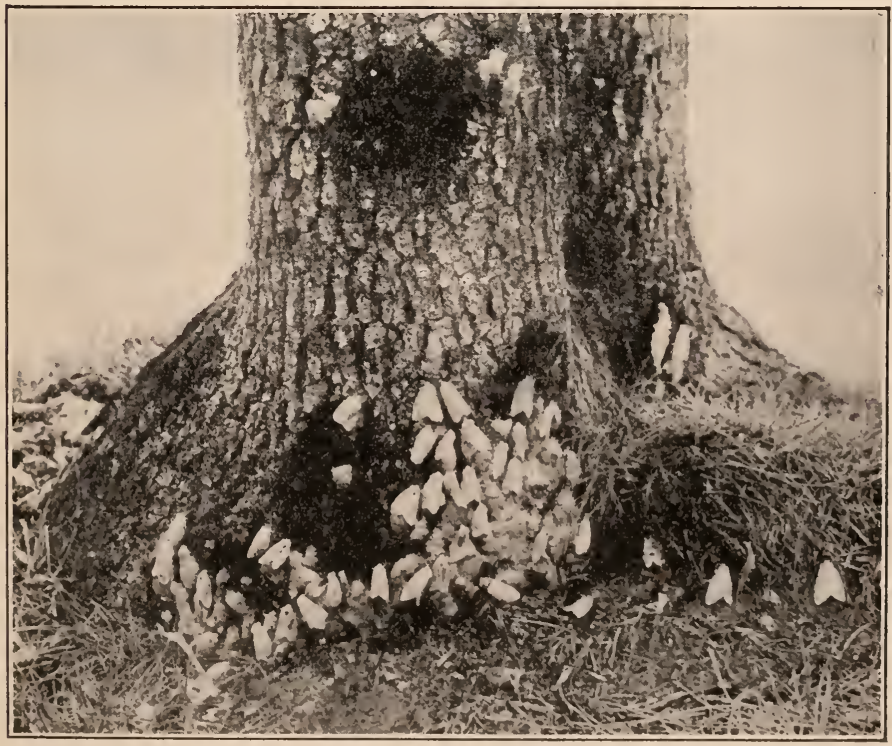

Fig. 85. Adult female Gypsy Moths depositing egg-masses at the foot of an Oak Tree. 
pentine 20 parts, coal tar 10 parts. With tall trees it is usually necessary to get up among the branches.

Since the caterpillars feed mostly at night and congregate on the trunk of the tree during the day, it is possible to trap many of them under burlap bands. A simple band may be made up by tying a piece of cheap burlap, eight inches in width, around the trunk and turning the upper edge down over the string. The bands should be examined every afternoon and the trapped insects brushed off into a pail of kerosene and water.

When infested trees have been sprayed with arsenate of lead (12 pounds to 100 gallons of water) soon after the leaves appear, and while the insects are small, good results have followed. The fullgrown caterpillars are more resistant to arsenical poisons and may feed upon the sprayed foliage for a long while before they get enough to kill them.

Slugs - The larvae of certain insects known as saw-flies, are slimy-looking creatures and are called slugs. One species is quite troublesome on the Pear, another on the Willow, and the most destructive of all on the Larch. The slugs vary in size according to the species; the species affecting the Willow being over an inch in length, while that on the Pear is less than a half inch. The slugs appear in the spring and lavishly feed upon the developing foliage. They are readily controlled by spraying with arsenate of lead at ordinary strength.

Another insect belonging to this class is known as the Maple leafstem borer. It has entirely different habits from those just described. The adult lays its eggs in the leaf-stalk at the base of the blade of the leaf. The young larva tunnels inside the stem, eating out the tissue. The affected blades break off and fall to the ground about June first. The stems containing the insects remain attached to the ground where they pupate and emerge the following spring as adult saw-flies.

The insect attacks the Sugar, Norway and Sycamore Maples. It is not widely distributed and seldom causes serious injury. Spraying the ground well with kerosene emulsion about June 15th when the larvae are going into the soil, has been suggested.

Spiney Elm Caterpillar-This is the name applied to the larva of the common "mourning cloak" butterfly. Besides the Elm, it feeds on the Poplar and Willow. In some seasons it be- 
comes a serious pest, but on Elms is controlled readily at the same time that trees are sprayed for the leaf-beetle. The eggs are laid early in May and are in cylindrical clusters around the twigs. They hatch in alout two weeks and the caterpillars arrange themselves in rows facing the edge of the leaf. They completely skeletonize the leaf, leaving only the reins, and later in the season, only the mid-rib. When the caterpillars reach maturity, about the first of July, they are nearly two inches in length, black with white and red dots, and covered with black branched spines. About this time they enter the pupal state which lasts about two weeks, when the adults appear. The butterflies soon commence depositing eggs which, when hatched, form the second brood of caterpillars.

It is seldom necessary to spray especially for this pest. If found on young trees they may be jarred off or the affected twigs may be cut off and the insects destroyed.

The Tent Caterpillar and Fall Web-worm - It is a common occurrence to find unsightly looking webs in trees. These are caused by tent caterpillars or fall web-worms. The larvae feed on the foliage, but their chief injury is in giving the tree an unsightly appearance. A species closely related to the ordinary tent caterpillar that is commonly found on Apple Trees, is called the forest tent caterpillar. This insect does not build a tent, but spins a silky web along the branches and the caterpillars congregate in clusters in much the same way as the other species.

The best method of controlling these pests is to cut off and burn the webs with the insects. Spraying with arsenate of lead will kill the young caterpillars, but does not get rid of the unsightly web.

Tussock Moth - The handsome larvae of this insect is a common shade tree pest in towns and eities. It feeds on the foliage of almost all ornamental trees except the evergreens. The insect passes the winter in the egg stage. The young caterpillars appear in May and commence to feed on the under side of the leaves, eating the green portion and leaving the framework. When they become larger they eat holes through the leaf and when full grown they eat the entire leaf except the mid-rib.

The full grown larva is very striking in appearance, of yellow color beneath, with gray stripes along the sides, and a black stripe between two yellow ones along the back. Along the sides are a 
number of tubercles, each bearing white hairs. Four large tufts of hair are borne along the back and following these are two

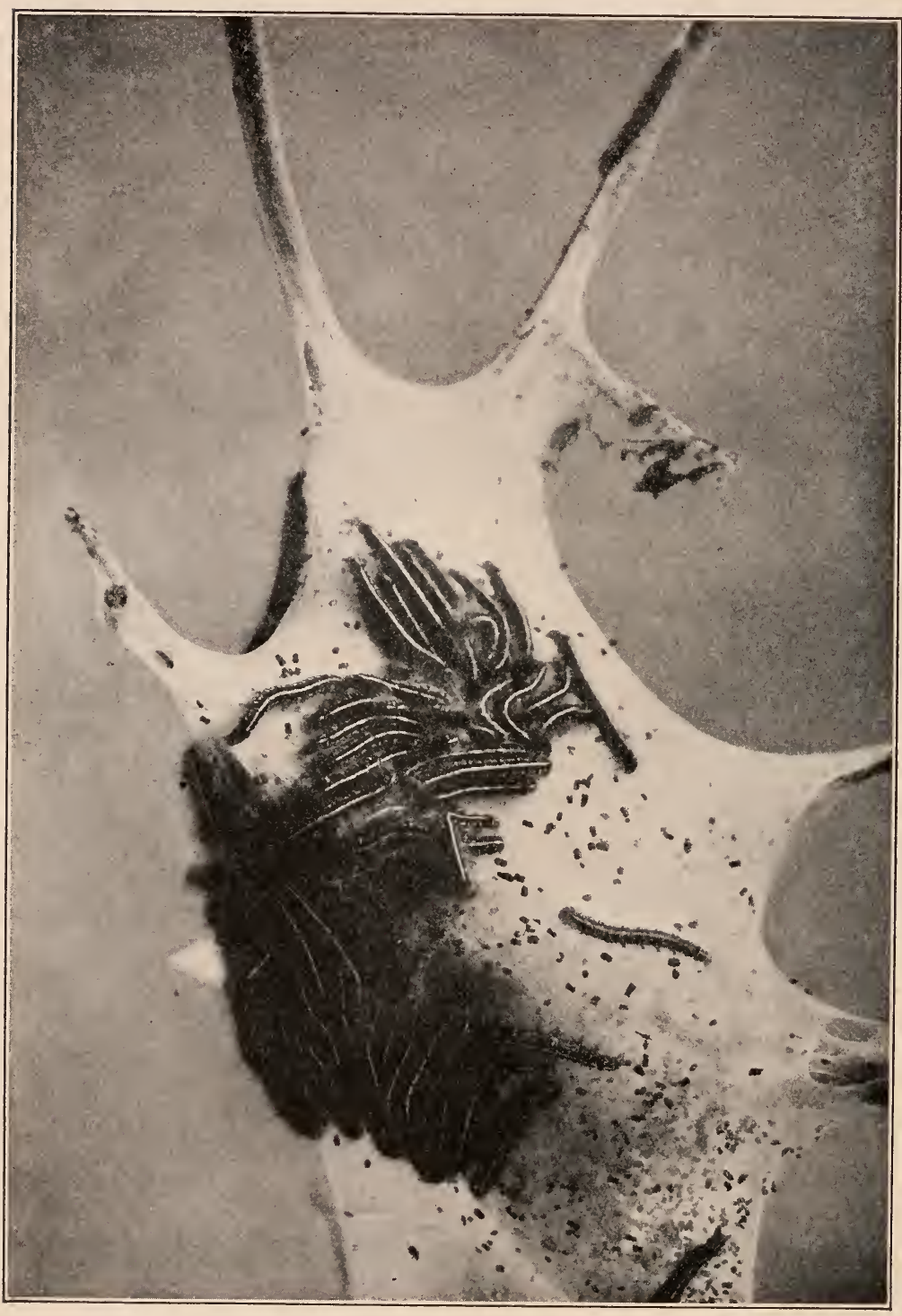

Fig. 86. Tent Caterpillars resting on the outside of their nest. 
bright red tubercles. The head is bright red and is supplied with two tufts of long black hairs. A single long tuft is borne on the posterior extremity.

About the first of July the larva spins a silken cocoon, gray in color and attached to the rough bark of the tree. It remains in this condition about two weeks when the adult moth emerges. The female moth which is without wings, about a half inch in

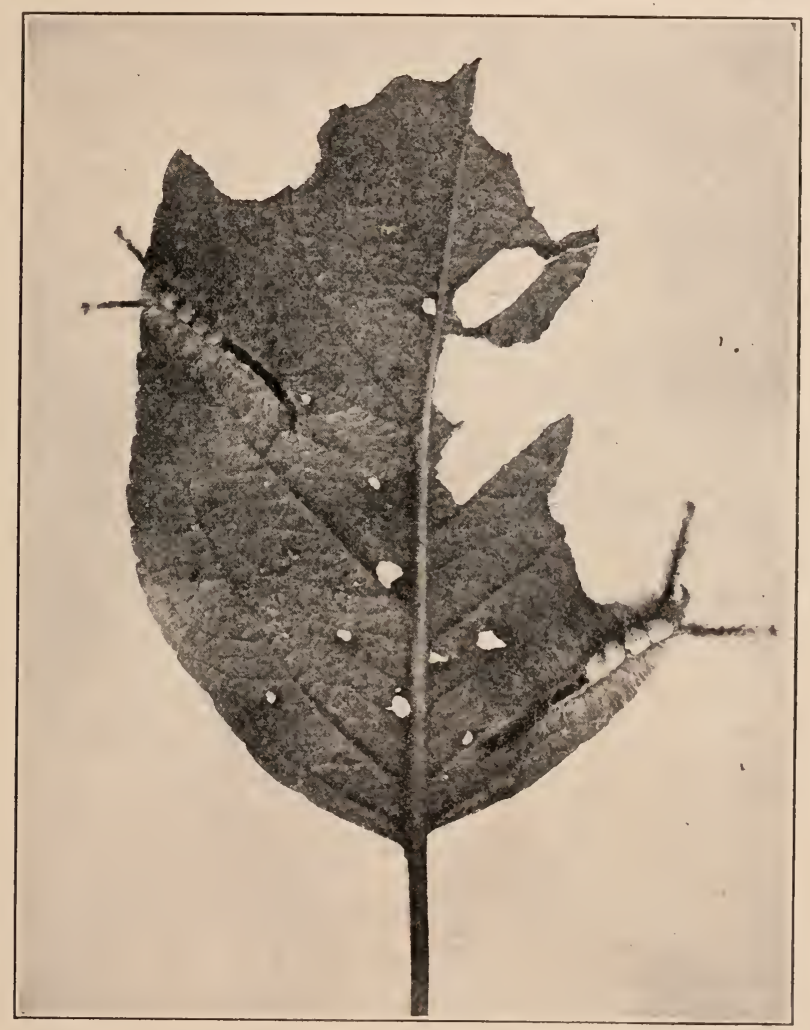

Fig. 87. White-marked Tussock Moth Larvae on under side of leaf. (Natural size.)

length, and gray in color, soon commences to deposit her eggs. The eggs are laid on the outside of the abandoned pupal case or cocoon. These soon hatch forming the second brood which goes through the same transformations. 
The best way of controlling this pest is in the destruction of the egg-masses during the winter. This may be done either by scraping them off and burning them or by treating them with creosote in the same way as described for gypsy moth eggs. The pest may be controlled also by spraying in June with arsenate of lead at the rate of six pounds to one hundred gallons of water. By destroying the first brood in June there should be no trouble from the second brood later in the season.

\section{SUCKING-INSECTS.}

Aphis or Plant Lice - There are many species of aphis affecting shade trees. As a rule different species attack different kinds of trees. They are very much alike except in color. The green, brown, black, and woolly forms are the most common. 'The insects pass the winter in the egg stage and often in early spring the newly hatched lice may be seen in large cluster's on the swollen buds and newly formed leaves. A little later the leaves curl up and the insects remain inside sucking the juice from the tissue of the leaf. The insects multiply very rapidly and often cause much injury to ornamental trees. They secrete a sort of honeydew that collects on the foliage and often drops to the ground. A fungus often develops on this sweet secretion giving it a black, unsightly appearance.

This pest seldom becomes so serious as to require treatment, but may be controlled, if remedial measures are necessary, by spraying with kerosene emulsion as soon as the young lice appear and before the leaves begin to curl. Fine tobacco powder blown on the trees after the leaves have curled will be found helpful in controlling the pest. The use of whale-oil soap, at the rate of one pound to five gallons of water, is recommended where only a small amount of spray material is required. It costs a little more than kerosene emulsion, but is more conveniently prepared.

The Spruce Gall Louse is different from the other species of this class in that it builds galls on the growing twigs. In some sections it has become a serious pest of the Norway Spruce. The Black, White, and Blue Spruces are also subject to attack. The eggs are laid about May first, the young lice appearing about a week later and settling at the base of the new shoots. By some peculiar form of irritation produced by the insects, a gall-like swelling is produced. Concealed within these galls the insects 
feed upon the juices of the plant. There are two broods in a season and infested trees soon present an unsightly appearance.

Spraying with kerosene emulsion late in April to kill the adult insects, is usually recommended. Some claim that spraying with whale-oil soap, one pound to two gallons of water, gives better

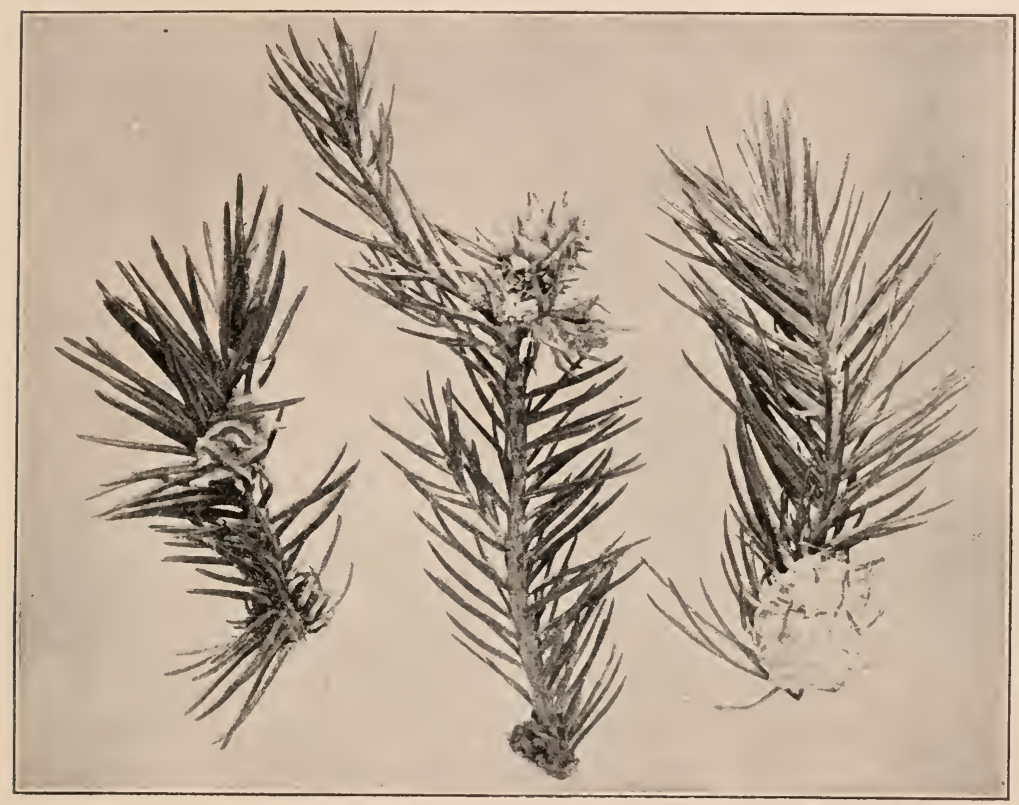

Fig. 88. The work of the Spruce Gall-louse.

results. Whatever is used it should be applied before the galls are formed. On small trees the pest may be kept under control by cutting out and burning the galls as soon as they are formed and while the insects are within.

Scale Insects - The most destructive forms of scale insects are the cottony maple scale, the woolly maple scale, the San Jose scale, the oyster-shell scale, the scurfy scale, and the tulip scale. They are all small and some of them are so inconspicuous as to go unnoticed until much damage has been done. The young insects, as a rule, are active only during the first few days of their life, after which they settle down. project their beak into the bark, leaf, or fruit and remain there for the rest of their lives. 
As a class, they secrete a waxy or scaly covering to their body and for this reason are called scale insects. The scaly covering of the San Jose species is circular in outline, either black or gray in color, and about half the size of the head of a pin. That of the oyster shell species is elongated, pointed at one end, either

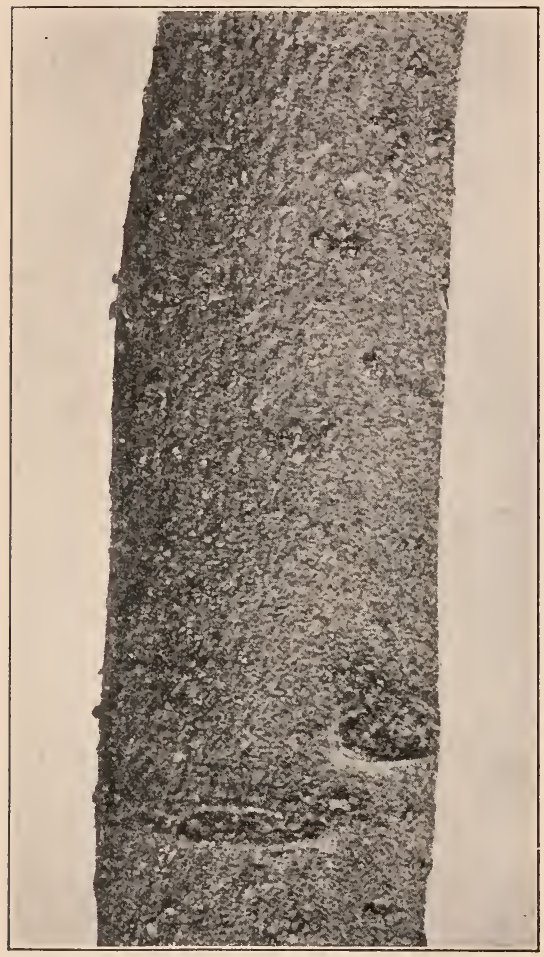

Fig. 89. The San Jose Scale.

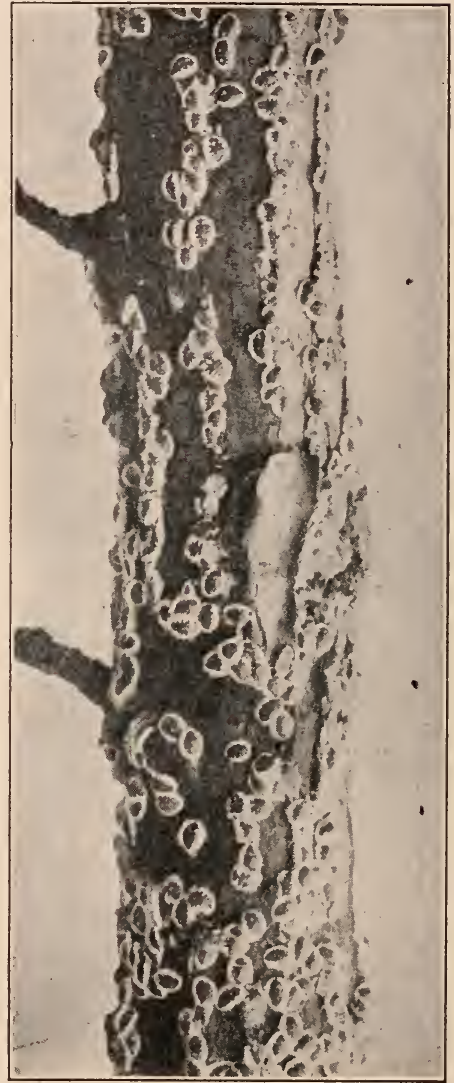

Fig. 90. The Elm Scale.

brown or black in color, and about one-eighth of an inch in length. The scurfy scale is somewhat fan-shaped, of a pale gray color, parchment-like, and about one-eighth of an inch in length. The tulip scale is much larger and more conspicuous, being about a quarter of an inch in diameter, hemispherical in shape, and dark brown in color. The cottony maple scale also is a large and con- 
spicuous form. Attached to the posterior part of the female is a large cottony mass, containing the eggs. As the egg mass increases in size, the posterior end of the body becomes more elevated. When full grown, the brown female with the egg-mass protruding is about a half inch in length. Another species attacking the maple is known as the woolly maple scale and differs from the above in that the woolly mass completely covers the female and her eggs.
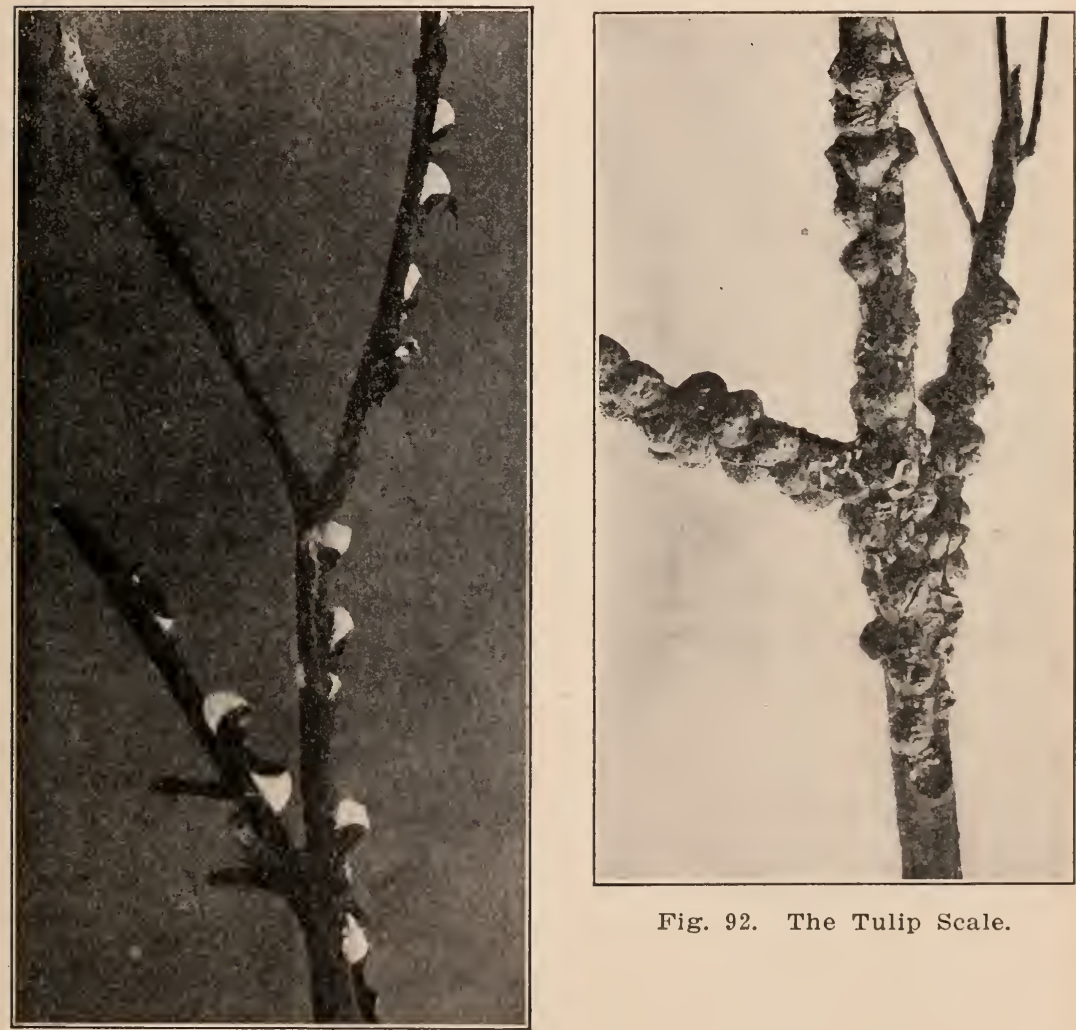

Fig. 92. The Tulip Scale.

Fig.91. The Cottony Maple Scale.

Most scale insects may be controlled by spraying with either miscible oil or the lime-sulphur wash during the dormant season. The former will give better results on old and rough-barked trees. The important point is to completely cover the surface of the 
bark with the spray. Most of the insects, and especially the San Jose species, multiply very rapidly, there being several broods in a season. The fruit trees, like the Apple, Pear, Plum, Peach, Hawthorn, and Mountain Ash are especially susceptible to the attack of scale insects. Young trees should be closely watched, for they are often killed or severely injured before the pest is observed.

BORERS.

On account of their habit of feeding about the cambium. layer, the insects belonging to this class are very destructive and are very difficult to control. There are many different kinds of

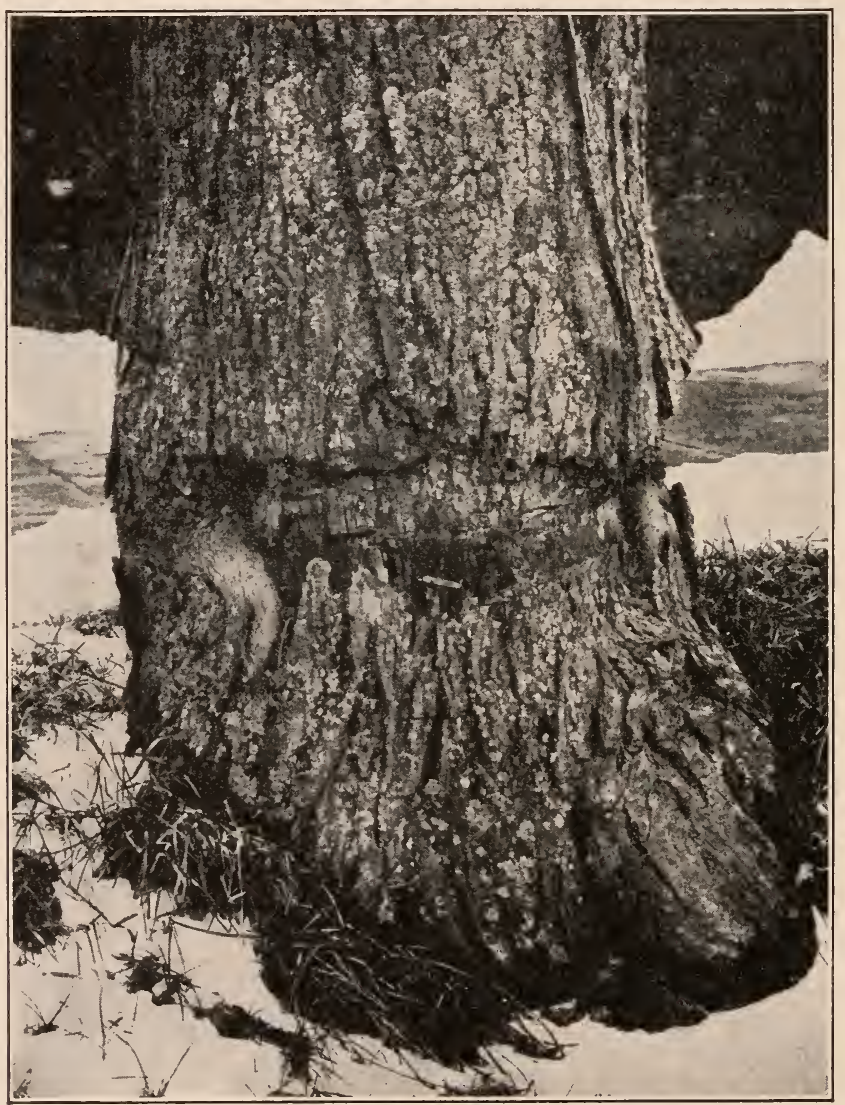

Fig. 93. The work of the Maple Borer. 
borers, each having its favorite species or family of trees for its feeding ground. The Maples, Poplars, Locusts, Elms, and fruit trees are most susceptible to the attack of some form of borer. As a rule, their presence is indicated by sunken areas on the bark and sometimes by sawdust-like castings on the ground, just below the point of attack. It is well to carefully examine the trunks of susceptible trees twice a year, in April and October, and dig out the borers with a sharp pocket knife. A flexible wire or a common knitting needle may be used where the insect is located far into the wood.

The larva of the Leopard Moth sometimes called the Imported Elm-tree-borer, is one of the most destructive shade tree pests. Around New York, Boston and other cities along the northeastern coast it is becoming very troublesome. Its habits are somewhat different from other borers in that it attacks the smaller

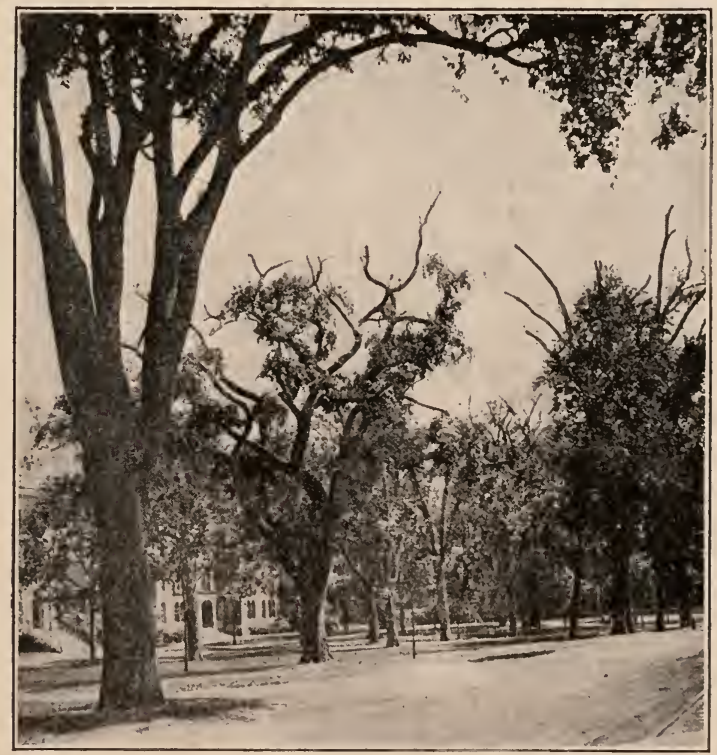

Fig. 94. Trees injured by the Leopard Moth or the Imported Elm Borer.

branches at the top of the tree, where its presence is not usually detected until the affected branches have been killed. 'The infested area of a tree gradually extends downward until the main 
branches and even the trunk become affected. TL borer often completely girdles the branch and consequently that part of the branch beyond the injury soon dies. Trees affected with leopard moth borers are strikingly characteristic by their dead branches at the top of the tree. Most kinds of deciduous trees are subjcet to the attack of this pest, but the White or American Elm has suffered most.

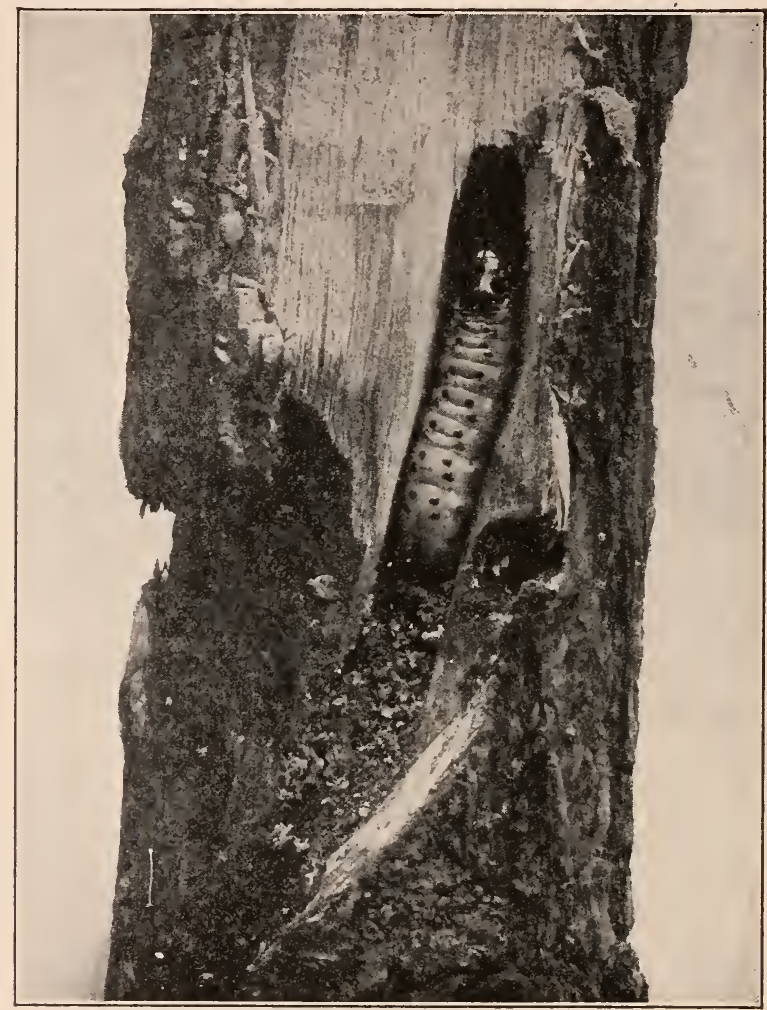

Fig. 95. The Leopard Moth Larva in its burrow. (Natural size.) The following paragraphs are copied from the authors' summary of a valuable bulletin by Britton and Cromie*:-

"The moths appear about July first, the males being very common around electric lights, and the females lay eggs singly or

\footnotetext{
*Britton, W. E. and Cromie, G. A. The Leopard Moth. Conn. Agr. Exp.
} Sta. Bul. $169,1911$. 
in groups of two, three or four, in the crevices of the bark or near the buds. The larvae, hatching in a few days, begin to tunnel in the twigs, and by the end of the season are about one inch in length. They leave the small branches and crawi over the bark to enter larger ones, cutting large galleries into them and expelling the frass through round holes, which they soon close with silk webs. During October the borers go deeper into the wood, and remain through the winter two inches or more beneath the bark. They pupate in their burrows the second spring, and before the moth emerges the pupa works itself partly out of the opening, and the adult flies away, leaving the empty case protruding from the burrow.

"There are few natural checks, only one parasite being known in this country and four in Europe. It is believed, howerer, that certain birds, especially woodpeckers, prevent the spread of the leopard moth in the open country. Many larvae are doubtless killed by the breaking off of the branches, which in cities are carted away and destroyed.

"Removing infested branches; injecting carbon disulphide (bisulphide) into the burrows, and stopping the opening; probing with hooked wire for the larva; are some of the methods of control.

"Planting species of trees not badly infested, like Oaks, Honey Locusts and Sycamore, and especially those kinds that do not grow very large, and have a smooth bark; placing trees further apart, so that the larvae cannot easily crawl from one to the other; and keeping the trees well nourished and vigorous, are the chief preventive measures." 


\section{CHAPTER X \\ INSECTICIDES, FUNGICIDES, AND SPRAYING.}

INSECTICIDES.

The reader will understand by this time that there must be two distinct types of insecticides: stomach poisons and contact insecticides. There are a great many belonging to each class. A large number of them are superfluous, and to avoid confusion, only those that are necessary and in common use are discussed here.

Stomach Poisons - The stomach poisons are those that kill by being eaten, and are used for the control of insects that chew their food. The most common stomach poisons are arsenate of lead and Paris green. The latter sometimes causes injury to the foliage unless used in combination with lime. It is generally used in the following proportion:

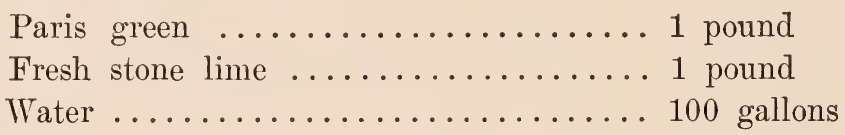

The Paris green should be mixed first in a small quantity of water to form a thin paste. The lime also should be slaked in a small quantity of water. Both materials may then be strained into the spray tank and the required amount of water added.

Arsenate of lead, on account of its safeness, its sticking qualities, and its general efficiency, has become the standard insecticide for insects that chew their food. It may be made up at home, but generally it is better to buy it ready prepared. It comes in either paste or powder form. Most people prefer to buy the paste. To prevent it from drying out, the paste should be kept covered with water. It is generally used in the following proportion:

Arsenate of lead paste .......6 to 10 gallons

Water ................. 100 gallons

The paste should be mixed up with about two quarts of water and then strained into the tank. Some insects are harder to kill than others and should receive the maximum amount. Most forms, however, are readily killed by using six pounds to one humdred gallons. 
Contact Insecticides - Insects that obtain their food by piercing the epidermis and sucking the juices from the plant tissue, must be killed by contact and the preparations used for the purpose are called contact insecticides. Such preparations are usually caustic in character and kill by irritation or by clogging the breathing pores of the insect.

Common hard soap at the rate of one pound to six gallons of water, is commonly used for plant lice. Whale-oil soap which comes in paste form, is usually preferred for this purpose and is used in the proportion of one pound to five gallons of water. It is also used to some extent as a dormant spray for scale insects. For this purpose it is used in the following proportion:

Whale-oil soap $\ldots \ldots \ldots \ldots \ldots \ldots \ldots \ldots 2$ pounds

Water .................. 1 gallon

Either kind of soap is more easily dissolved in hot water.

This preparation is too expensive to be used where there are many trees to be sprayed, but when only one or two trees or a few bushes are affected with scale insects, it is a convenient remedy and is not so disagreeable to apply as some of the other preparations.

Kerosene emulsion is probably the best remedy for the control of sucking-insects when the spraying must be done while the tree is in foliage. A stock solution may be made up and used when required and at any strength:

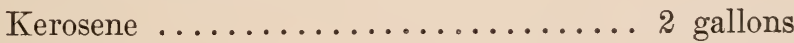

Hard soap ................ 1/2 pound

Hot water $\ldots \ldots \ldots \ldots \ldots \ldots \ldots \ldots \ldots$ gallon

Cut the soap into thin slices, dissolve in the hot water, remove from the fire and pour it into the kerosene while hot. Churn thoroughly, or pump into itself with a force pump, until a creamy emulsion is formed, which will mix readily with cold water. For use on foliage, dilute at the rate of one to twelve. Some plants with tender foliage require a weaker solution. For use on dormant trees, dilute at the rate of one to three.

Tobacco decoction, made by steeping one pound of tobacco stems or waste in two gallons of water, is a safe remedy for plant lice on tender-foliaged plants. 
The lime-sulphur wash is the standard remedy for the control of scale insects on fruit trees. It may be made up at home, but it is disagreeable and exacting work. It may be purchased in consentrated form at from twenty to thirty cents per gallon and is ready for spraying after diluting it with eight parts of water. In this proportion it is used only while the trees are dormant. It has extremely caustic properties and corrodes and discolors everything with which it comes in contact. For this reason it should not be used in proximity to painted buildings.

Miscible or "soluble" oils of which there are many brands on the market, are useful and convenient preparations for the control of scale insects. Compared with the lime sulphur-wash, they are less corrosive, not so disagreeable to handle, and may be safely used about buildings. They may be purchased at thirty cents to one dollar per gallon, depending upon the quantity required. They should be diluted with water in the proportion of one to fifteen and should be used only during the dormant season. The container should be shaken well before drawing off the oil. A few drops of oil in a glass of water should produce a milky solution. If the oil does not mix readily with water as indicated by this test, it should not be used.

Carbon bisulphide is a heavy volatile liquid and is sometimes used for the control of borers affecting the trunk, and of other insects affecting the roots of trees. It readily evaporates when exposed to the air. The fumes are poisonous and very inflamable. A teaspoonful poured into the burrow of a wood boring insect, and the opening stopped up with wax, will usually kill the pest. The fumes being heavier than air, settle to the lower places and it is well, therefore, to get the chemical into the top of the burrow. If a tree trunk is badly infested it is sometimes advisable to arrange an oil-cloth jacket around the trunk, tying it tightly above and below the affected area. A saturated sponge holding about a cupful of the liquid may be hung beneath the jacket and at the upper part of the trunk. The fumes will penetrate into all crevices, and within twenty-four hours the inclosed insects will be suffocated.

\section{FUNGICIDES}

The use of fungicides is to kill fungus spores and to prevent their access into the tissues of the plant. The standard fungicide is Bordeaux mixture which may be made up as follows: 


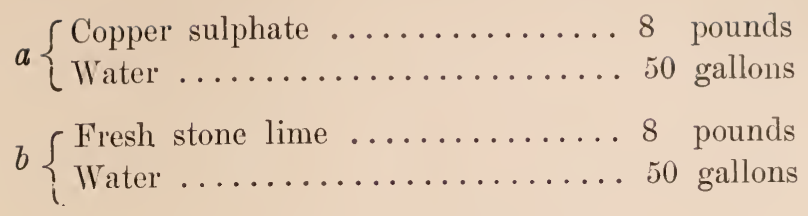

The copper sulphate may be dissolved either by the use of hot water or by suspending it in a burlap sack at the top of a barrel. of cold water. The lime should be slowly slaked, using a little water at a time. When both solutions, $a$ and $b$, are ready, they should be poured simultaneously into the spray tank. When large quantities are required it is customary to make up stock solutions of copper sulphate and of lime, using two pounds of each to a gallon of water. To make a hundred gallons of Bordeaux mixture from these stock solutions it will be necessary simply to measure out four gallons of each, dilute each with 46 gallons of water $(50-1=46)$, and strain into the spray tank.

When a tree needs to be sprayed for some leaf-eating insect as well as for some disease, six to ten pounds of arsenate of lead may be added to every hundred gallons of Bordeaux mixture. There are many brands of prepared Bordeaux mixture on the market and some of them contain arsenic, either in the form of arsenate of lead or Paris green. Pyrox and Bordeaux-lead are common examples of such preparations. They are convenient remedies and are very efficient, but cost more than the home-made mixture.

The commercial lime-sulphur wash which has been discussed under the heading of Insecticides, is also a good fungicide. When used on Peach trees in the dormant condition, it may be depended upon to kill scale insects and at the same time to control the disease known as leaf-curl. It is also being recommended as a sulbstitute for Bordeaux mixture for spraying during the summer. For spraying foliage, however, it should be diluted at the rate of two gallons of the wash to one hundred gallons of water.

\section{SPRAYING}

Most people fail to spray for the reason that they believe it to be a difficult and exacting operation. 'Those who have had experience have gained confidence and now regard the operation as a necessary item in their yearly routine. There are many professional 
sprayers going around the country soliciting contracts for this kind of work. Most of them are reliable, yet there are some who do not know the first principles of spraying and who have not the proper equipment for the kind of work they undertake. When reliable people may be engaged to do the work at the proper time, it often would be advisable for the property-holder to have his spraying done by contract. 'The property-holder, even though he should not do his own spraying, should know something about the subject so that he may know whether his work is being properly done.

When spraying with arsenate of lead for the control of insects that chew their food, the spray should be applied until it commences to drip from the foliage. Even though the foliage is not completely covered, the insects, if they continue to eat, are sure to find some poison. In the spraying for sucking-insects, on the other hand, greater care must be exercised, for the spray actually must touch the insect. In the application of fungicides, also, the whole surface of the leaves must be covered to prevent the access of the disease spores.

It is always desirable to spray with the wind. To do this it is necessary to make a second application after the direction of the wind has changed. With nozzles that make a fine spray, it is impossible to spray against even the lightest breeze. It sometimes happens that the work must be finished at one time and it is possible to do so by selecting a still day and by using a nozzle of the Bordeaux type that will produce a coarse spray. A coarse spray will carry farther, but is more wasteful of material.

Spraying Machinery - For the private owner who has only a few trees to spray, a barrel outfit operated by hand and costing about twenty to twenty-five dollars, will answer the purpose. By the use of extension ladders, extension rods, and long leads of hose, it is possible to spray the tallest trees. Barrel outfits mounted on two-wheel trucks may be purchased at a small additional cost and are very handy on small places. The small bucket and knap-sack outfits are useful for bushes and young trees, but are unsuited to spraying mature trees.

On large estates a power outfit of some kind will be found very useful. When fine nozzles are used, a three horse-power gasoline outfit may supply as many as six leads of hose. Such an 
outfit will supply sufficient pressure for the spraying of the tallest trees. Where it is desirable to reach the top of tall trees without

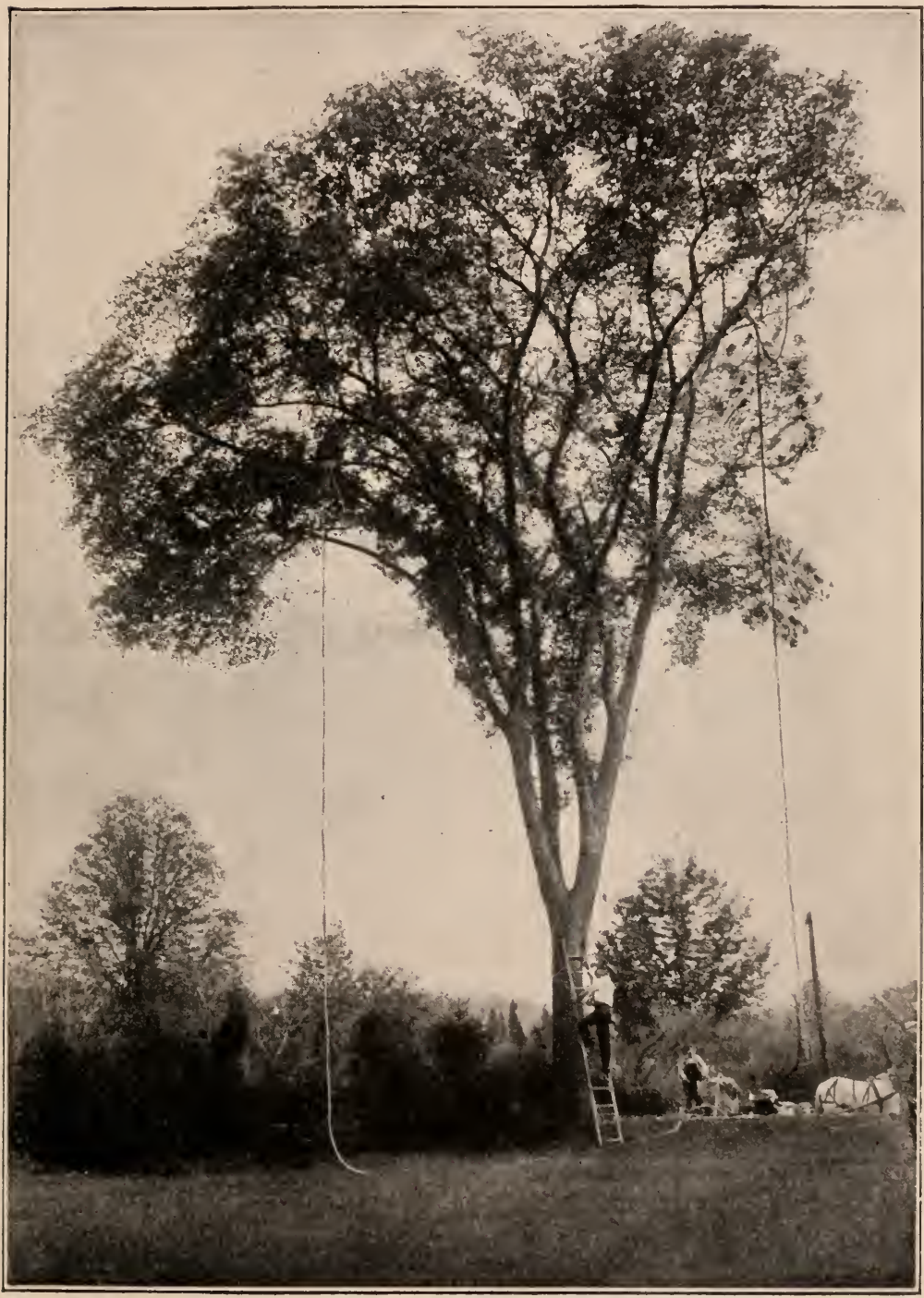

Fig. 96. Spraying a large Elm Tree using a hand pump and two long leads of hose. A very satisfactory outfit where there is danger of disfiguring buildings and where a high-pressure outfit cannot be used conveniently. 
climbing, a more powerful outfit will be necessary. A ten horsepower outfit will do the work and is very suitable for towns and cities. Most municipalities have many trees in the open that may be sprayed from the ground without fear of disfiguring buildings. Spraying in this way is decidedly less expensive and less dangerous, than where it is necessary to climb the trees. A powerful outfit

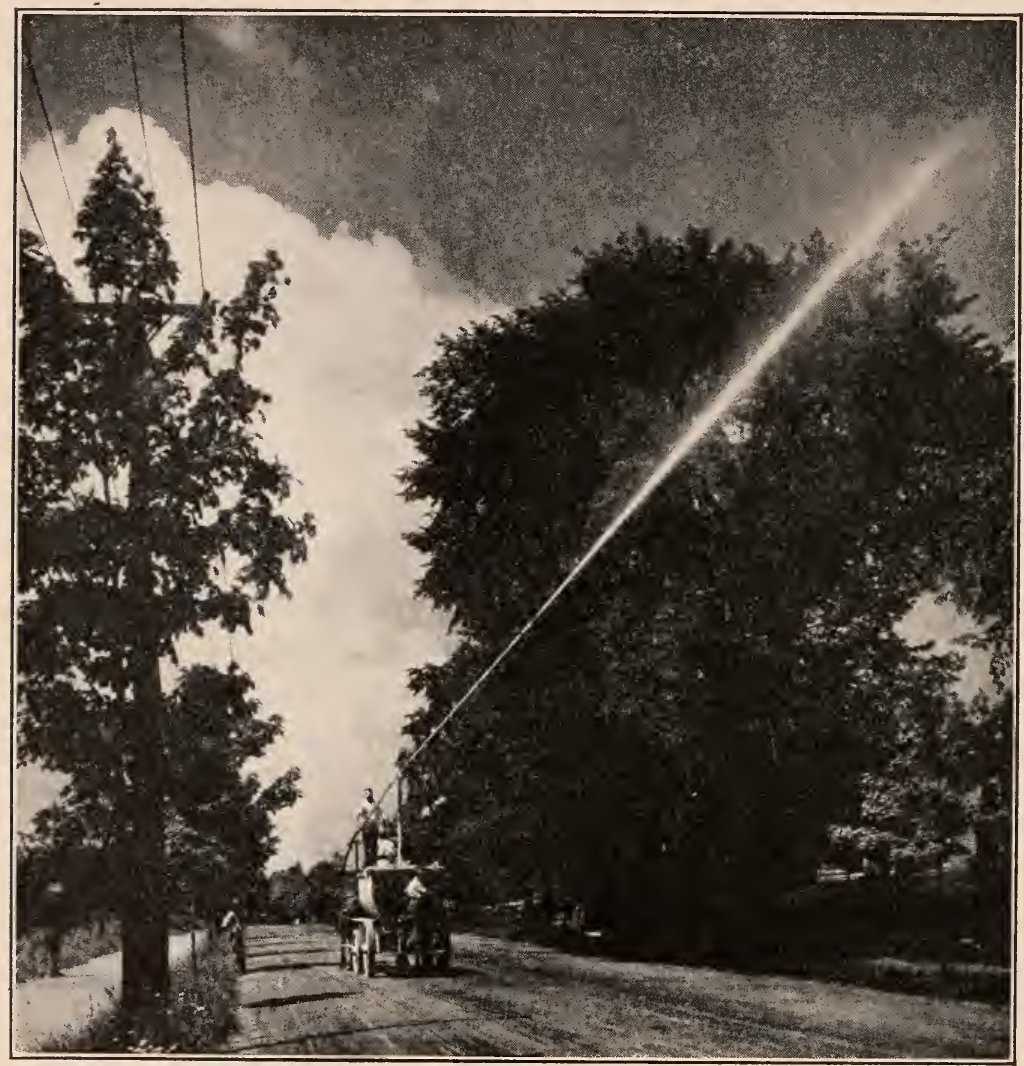

Fig. 97. The use of a high pressure pump in spraying tall trees.

may be used for both purposes. When wanted for working in the vicinity of buildings, it may be adapted simply by changing the nozzles.

Nozzles vary greatly in structure and adaptability. When spraying at close range a nozzle that will make a fine mist or "fog" is 
desirable. Those of the disc type are best suited to the purpose. When it is required to throw a stream high into the air a nozzle of either the "Long Distance" or the Bordeaux type will be found most useful. The "Long Distance" nozzle may be adjusted so

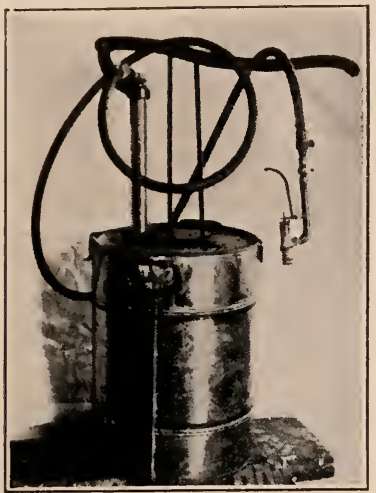

Fig. 98 An inexpensive Spraying Outfit for small trees and shrubs.

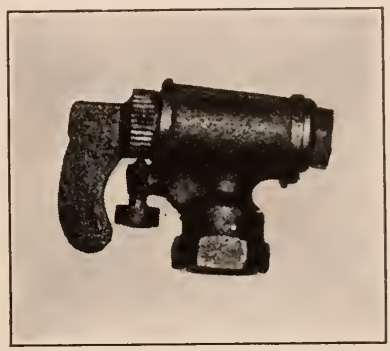

Fig. 99. The Bordeaux Nozzle commonly used in spraying shade trees. It may be adjusted to trow either a straight stream or a fan-shaped spray.

as to regulate the size of the stream. The Bordeaux type (fig. 99) may be regulated so as to produce either a straight stream or a fan-shaped spray.

To aroid troublesome "blow-outs" it is well to use long shank couplings and two clamps on each section of the coupling.

Rubber hose of the best quality is necessary for high-pressure work. The half-inch size is sufficient for close work, but for long distance work it is better to use a larger size. It should be strong enough to stand a pressure of at least two hundred pounds, although for close work it is seldom necessary to maintain a pressure of more than one hundred and twenty-five pounds.

Most spraying outfits are supplied with mechanical agitators to insure the discharge of the mixture at uniform strength. On hand outfits they are usually attached to and operated with the handle of the pump. Such agitators seldom furnish sufficient agitation. especially when there is only one nozzle in operation and the handle is necessarily moving slowly. For the spraying of aresnate of lead that quickly settles, it is safer to use an old garden hoe with which the man who operates the pump may keep the mixture 
thoroughly agitated. The best power outfits are supplied with propellor agitators. These consist of shafts on which are fixed two or three propellers like those used on small boats. 


\section{PART II.-THE IDENTIFICATION OF TREES}

\section{EXPLANATION OF TERIIS}

Before considering the individual trees in detail it seems desirable to give a general discussion of the different terms used as headings in the description of the species.

Name - A common English name heads the description of each tree and this name is used throughout the book as the designation of a particular species. The same form may be known in different localities by several entirely different common names. Thus the Tupelo in some places is called only Pepperidge, in others, Sour Gum or Black Gum. After consultation with the 'literature the name Tupelo was chosen as being somewhat more desirable for the whole of New England than the other names given in smaller type as synonyms. Often several common names may be in about equally frequent use. There is in general, only one scientific name at present sanctioned by botanical authorities and this is placed first, followed by the Latin synonyms in italics.

Habit - By the word habit, we denote the general appearance of a tree seen as a whole. A tree strictly speaking is generally considered as a woody growth having an undivided trunk at the base and rising to at least twice the height of a man. A shrub on the other hand is low-growing and may branch from the very base. No hard and fast line, however, can be drawn between a tree and a shrub. Many trees at the limit of their range or under unfavorable conditions are reduced to the form and dimensions of a shrub and some forms growing as shrubs in New England become trees in states outside this group. A young tree sometimes resembles a shrub, but is more rapid in growth and generally does not bear fruit until it has reached a considerable size. Of the forms on the borderline between trees and shrubs only those have been treated that have demanded recognition on account of their commonness or their relationship with other forms. 
Two general habit types are recognized - the spreading and the erect - often termed deliquescent and excurrent respectively. The former is well represented by the Apple (p. 353) and White Elm (p. 32\%) and the latter by the Evergreens and those of the Poplars that form narrow conical heads (p. 261-263). By its more erect habit of growth the Sweet Cherry (p. 369) is readily distinguished from the Sour Cherry (p. 3\%1) and in like manner the Pear (p. 351) from the Apple (p. 353). It is these habit differences that form the most ready means of separating the contrasted trees just mentioned which may closely resemble each other in twig characters. The angle which the branches make with the trunk is frequently a diagnostic character of considerable value. For example, the ascending and gracefully outward curving limbs of the American White Elm (p. 32\%) stand in contrast with the sharply divergent limbs of the English Elm (p. 325). Likewise the horizontal branches of the Tupelo (p. 421) and the strongly pendant lower limbs of the Swamp White Oak (p. 305) are characteristic of these species. The relative thickness of the branchlets contrasted in the Sweet Cherry (p. 369) and the Black Birch (p. 281) and the arrangement of the branchlets whether opposite or alternate and whether erect or drooping, may further be mentioned as habit characters.

As one becomes more familiar with trees in their winter aspect, the number that cannot be recognized at a distance becomes greatly diminished. We come to know trees by hardly definable traits, much as we recognize our friends at a distance by some peculiarity of form or gait. Watching the trees from a car window is a great help in acquiring this familiarity with the habit characters. The method of branching and other features included in the habit do not furnish such precise marks as do the twigs, and cannot therefore be of much value in a descriptive key. In fact the habit varies considerably among individual trees of the same species, no two trees having exactly the same method of branching. Moreover trees grown in woods in company with other trees are prevented by lateral shading from developing their normal form and produce tall trunks with but little branching. On the other hand trees apart from other trees have usually been planted for 
ornament or have originally grown in woods but have been left isolated by the cutting down of their neighbors. In the latter case the habit will be more or less that of a forest-grown tree dependent upon the age at which the conditions of light and shade were altered (see lower habit picture p. 329). In the former case the top of the young tree may have been cut in the process of transplanting causing an increased branching at the point of cutting and the lower limbs may have been trimmed off, giving a greater show of trunk. These mutilations, however, have less influence upon the outline of the head or crown than might be imagined since the tree is generally able to accommodate itself to such accidents as those mentioned and express its individuality despite them. The age of the tree is also an important factor in the outline, young specimens being in general narrower and more conical than in later life while those in old age may have lost shape through ice storms, high winds and the attacks of fungi.

So far as possible the photographs may have been taken from mature specimens growing in the open and only those have been chosen which have been considered to present an appearance typical of the species. They will help one to form a mental picture of those generalized features of a tree in the landscape which may be recognized at a distance, but which are difficult of analysis.

Bark - Although it is upon the appearance of the bark more than upon any other character that the woodsman depends in his recognition of timber trees, the bark shares with the habit the misfortune of being difficult of precise description. A study of the photographs, however, in connection with the description of the color and texture will enable one to recognize a large proportion of our trees by the appearance of the bark alone. They have been taken from mature trees of moderate size which have developed the characteristic sculpturing of the bark rather than from those of larger size which are less frequently seen. A tape measure surrounding the trunk or in some instances a penknife stuck into the bark may serve to give an idea of the relative size of the markings on the trunk. The heading "Bark" is used throughout the descriptions in reference to the trunk and larger limbs and not to the twigs which are described under another heading. 
The color of the outer bark is an important mark of distinction and is the chief means of separating the different species of the Birches (p. 281-291). The color and taste of the inner layers of the bark are in some cases also characteristic. The Black Oak for example is best distinguished from other Oaks by the yellow and intensely bitter inner bark. Similarly, the Black Birch, the Sassafras and the genus Prunus including the Cherries have barks with characteristic flavors. The swamp-loving Poison Sumach (p. 395) is the only poisonous tree in New England so that after this shrubby form is known there need be no fear of tasting bark and twigs of any unknown tree-like species.

The bark varies in character according to the age of the tree. In the young tree the bark is smooth, but, as the trunk expands from the growth of the wood within, the covering of dead bark outside is forced to crack in a variety of ways giving rise to characteristic fissures and ridges which become more prominent as the tree grows older. The bark of few trees such as the Beech (p. 295) and the American Hornbeam (p. 279) remain smooth, their outer layers expanding with the growth of the tree. The barks of others as the Paper and Yellow Birch (p. 283) stretch and peel off in thin papery layers. In the Birches (p. 289) and Cherries (p. 369) the breathing pores (lenticels) become horizontally elongated to form narrow transverse streaks which are characteristic for these forms. When ridges or scales are formed they may be close and firm and with difficulty removed from the trunk as is the case with the bark in the Black Oak group or, on the other hand, they may be easily rubbed off as are the scales of the bark of the White Oak and of most members of the White Oak group. Bark of this latter type is called flaky in our descriptions and this distinction between barks that are flaky and those that are not flaky is of considerable importance in classification. 'To avoid confusion little notice is taken of the minute scales that are likely to occur on the surface of both types of bark. The bark may come off in large sheets as in the Shag-bark Hickory (p. 269) and the Sycamore (p. 349), and the ridges may be long as in the Chestnut ( $p .29 \%$ ) or short and run together to form more or less perfect diamond-shaped areas as in the White Ash (p. 423) 
but these as well as other differences in the sculpturing are shown in the photographs and to not require further discussion.

Twigs - The unqualified word twig refers in the descriptions to the growth of the past season only. Older twigs and branchlets are the designations employed for the small growth of several seasons. The Horse-chestnut (fig. 20) has been taken as a convenient form to illustrate the various markings found on the twig and is discussed on page 39 .

In some species, such as the Black Birch (p. 281) and the cultivated Cherry (p. 369), a sharp distinction can be drawn between rapidly-grown long shoots which have elongated internodes and continue the growth of the twig and slowly grown short spurs which have greatly abbreviated internodes and crowded leaf-scars. The fruit-spurs of the Apple (p. 353) and Pear (p. 351) are of this latter type.

Of the distinctive characters giren under the heading twigs may be mentioned the relative thickness, whether stout or slender, the presence or absence of thorns or prickles, the color, the taste as indicated under the discussion of the bark, and the character of the surface, whether smooth or more or less covered with hairs. Twigs are called hairy when the hairs are individually distinct, downy when they are fine and numerous, and woolly or cottony when they are twisted together into a more or less felt-like mass, but these distinctions cannot be always sharply drawn. A twig if smooth may be dull or shiny in appearance. The lenticels are of most distinctive value in those forms like the Birches (p. 289), in which they become horizontally elongated with age. 'The color, size and shape of the pith are often characteristic as seen in the wide salmon-colored pith of the Kentucky Coffee Tree (p. 381) and the star-shaped pith in the Oaks and to a less degree in the Poplars (fig. 100). The pith, however, frequently varies considerably in color in a given species. Some few trees have their pith separated by hollow chambers such as the Hackberry and the Butternut (fig. 101) or have solid pith but with woody cross partitions such as the Tupelo.

Leaf-scars - The arrangement of the leaf-scars form primary divisions in the classification. They may be opposite with two 
scars at a node as in the Horse-chestnut, or alternate with only one scar at the node as in the majority of species. Alternate leafscars may be arranged along the twig in two longitudinal rows when they are said to be 2-ranked, as in the Mulberry (fig. 103), or in several rows when they are more than 2-ranked as in the Poplars (fig. 100). Twigs sometimes if rapidly grown have the leaf-scars which are normally opposite pulled apart to appear alternate, but the typical condition will be found on other parts of the tree. A few species like the Chestnut sometimes take the 2-ranked, and sometimes the more than 2-ranked position, and the number of ranks in other forms may be at times somewhat obscured by a twisting of the twig. The distinctions in the main, however, hold good and where a doubt is likely to occur in regard to the arrangement, a place has been made in the key for the species in both the 2-ranked and the more than 2-ranked groups.

The size and shape of leaf-scars are important factors in identification. They may be very narrow as in the Pear and their upper margins may be flat or convex as in the Black Ash (p. 42\%) or deeply notched as in the White Ash (p.423) or form a band nearly surrounding the bud as in the Sycamore (p. 349). They may become dingy and inconspicuous or be sharply distinct by color contrast with the rest of the twig. Thus the Elms and the Poplars have their leaf-scars covered with a light-colored corklike layer which makes them conspicuous irrespective of their size. Leaf-scars may be level with the twig or more or less raised with their surfaces parallel with the twig or making various angles with it up to a right angle. Ridges in some cases run down the twig from the base and corners of the leaf-scar.

At the bases of the leaves of some species a pair of small leaflets called stipules are regularly formed and leave, at the fall of the leaf, more or less definite stipule-scars at either side of the leafscar as, shown in the Carolina Poplar (fig. 100).

The number, the size, the relation to the surface of the leafscar whether sunken or projecting, and the distribution of the bundle-scars form important points of distinction. When they are 


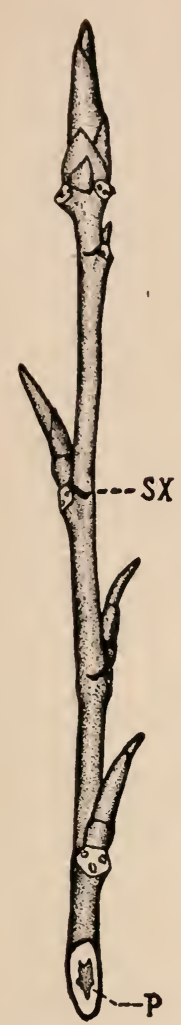

indistinct, as is frequently the case, they may be revealed if a thin slice is taken off the surface of the leaf-scar. This surface section must be very thin, however, since the number of bundle-scars exposed by a deep cut is often different from that on the surface, and this latter number is the one used in the keys and descriptions. A distinction is made between a group in which the bundle-scars form a single line and a second group in which they are variously scattered and grouped or in a double line.

Buds - In regard to their position buds are terminal or lateral. Buds produced at or near the nodes but not in the axil of a leaf-scar are called accessory buds. Of these there are two kinds: superposed buds located above the axillary buds and collateral buds located at either side of the axillary buds. The former are shown in the Butternut (fig. 101) and the latter in the Red Maple (fig. 102). Classified according to what they produce there are flower buds which contain the rudiments of flowers, leaf buds which contain rudiments of leaves, and mixed buds which produce both flowers and leaves. Flower buds are generally stouter than leaf buds.

Most species by the end of the growing season have Fig. 100. Twig formed terminal buds which remain through the winter
of Carolina Poplar.

sx $\div$ Stipule and are destined to continue the growth the following Scar. spring. In some species, however, such as the Mulberry p-Starshaped Pith(fig. 103)the terminal bud together with the tip of the twig dies away and drops off before the beginning of winter leaving a small scar at the end of the twig. The presence or absence of the terminal bud is a very valuable point of distinction and is used throughout in the keys. Unfortunately it is not always possible at a cursory glance to say whether the terminal bud is present or absent and a hand-lens must generally be used for an accurate determination of this point. In the Mulberry figured, the self-pruning sear formed by the dropping off of the terminal bud is perched on the tip of the twig with the topmost lateral bud obviously in the axil of the last leaf-scar. Frequently, however, 
the self-pruning scar may be nearer the lateral bud which bends in and gives the appearance of being terminal. The presence of a

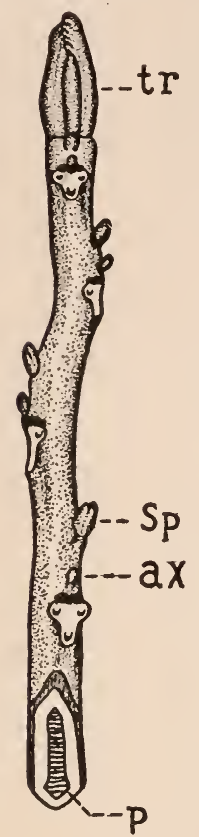

Fig. 101. Twig scar.

of Butternut. tr-terminal

ax-axillary bud. sp-Superposed p-chambered leaf-scar below it shows that it is in fact axillary, but since leaf-scars are sometimes present toward the end of twigs withont buds in their axils the presence of the self-pruning scar at the twig end must be used as the decisive sign that the terminal bud is really absent.

Aside from the color, the presence or absence of hairs, stickiness, fragrance and other such surface characters, the position of the buds in relation to the twig may be of importance. Buds that lie close up against the twig as those of the Small-toothed Aspen (p. 255) are called appressed, while those that project more or less away from the twig as those of the Carolina Poplar (fig. 100 )are called divergent. In the Common Locust and a few other forms the buds are sunken below the surface of the twig, and can be found only by cutting the twig lengthwise through the leaf-

\section{(1he}

The characters of the bud-scales Fig. 102. Twig of of most importance are the shape, Red Maple.

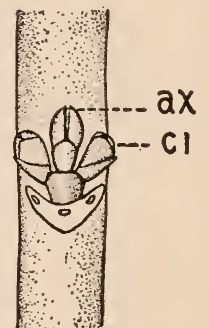

ax-axillary bud. the number visible in the unmutil-cl一 collateral arrangement - whether alternate or opposite - and the number of ranks they form on the bud.

Fruit - The fruit generally forms a good means of identification when it can be found. Unfortunately there are a number of limitations to its use for this purpose. In the first place many species of trees do not fruit every year, and it may happen that the species under examination is not in its fruiting period and consequently all the trees of the region will fail to show fruit. Again, in some species such as the Ash the sexes are separate and consequently only female trees can ever be expected to bear fruit. The fruit generally does not remain on the tree throughout the winter but if the tree is sufficiently isolated from other species, 
a careful search on the ground will often be rewarded by the finding of specimens of fruit that one can feel sure came from the tree in question. However, some species such as the Poplars and the Red and Silver Maples scatter their fruit early in spring, and fruiting material of such forms in consecpuence is not to be looked for in winter. The immature fruit of some species may be found on the tree in winter and be of value in identification. Thus the presence of young acorns on an Oak in winter shows that it belongs to the Black Oak group.

ax--8 --SC. The staminate flowering clusters are of similar diagnostic value in certain groups, their presence or absence, for example, separating the American Hornbeam from the Hop Hornbeam.

Comparisons - Under this heading are contrasted the different species that are considered likely to be confused. It is believed that the information in this section will prove more valuable to one with some knowledge of trees than the more detailed descriptions first given.

Distribution - The habitat first discussed under

Fig. 103. ' 1 wig of this heading shows in what kind of locations Mulberry.

ax-last axillary bud often mis- normally grows. The information may be of identaken for a ter- tificational value by elimination. Thus if one finds sc $\rightarrow$ self-pruning scar left by fall a cedar-like tree on a hillside pasture one can be bud and tip of sure it is not a Coast White Cedar since this latter twig.

species grows only in swamps. In like manner the geographical limits may assist in identification; a Pine found growing wild in Rhode Island or Connecticut, for example, could not be the Jack Pine since this is a northern form found native only in the northern New England states. Although some cultivated trees have escaped from cultivation, an introduced tree is generally characterized by the places in which it is found growing.

Wood - Under this heading the information given in regard to the characters of the wood and the economic value of the species is of practically no value for purposes of identification of standing timber, but may prove of general interest to the student of trees. 


\section{ANALYTICAL KEY \\ METHOD OF USE}

Despite the fact that the appearance of the bark and the method of branching are almost exclusively depended upon by the experienced woodsman in recognition of species, these characters are difficult of precise description and not adapted to use in a key. The twigs therefore with the scaly buds and leaf-scars are used, as a basis of the following keys. The word "twig" in the sense here used, it should be remembered, denotes the growth of the past season only, and the word "bark" refers to the bark of the trunk and older limbs and not of the twigs or branchlets. The student should read the foregoing section and note the limitation of terms and characters used in the following pages.

Before attempting to identify an unknown tree it is necessary to have good material to work with. Care should be taken that the twigs selected are normal in appearance, being neither abnormally stunted in growth nor unusually elongated as are twigs on young sprouts. Frequently the species may be determined by an inspection of the twigs alone but notes on the character of the bark and the habit of growth as well as specimens of the fruit will generally be found useful and sometimes necessary.

In the key a choice is given between two paragraphs preceded by the same number. This choice leads to a new number or to the name of the species followed by the page where a detailed description of the tree may be found. The White Ash may be used to show the method of procedure. Starting with No. 1 we have the choice between trees with "leaves persistent and green throughout winter" and trees with "leaves not persistent and green throughout winter." We choose the latter and this takes us to No. 11 where the decision must be made between "leaf-scars opposite or in 3's" and "leaf-scars alternate." The leaf-scars on the Ash are opposite and we take the first 11 and are led to No. 12. At 12 we have the alternative between "leaf-scars, or some of them, 3 at a node" and "leaf-scars always 2 at a node." The first pair of contrasting characters mentioned are always the most important. The constant presence in the Ash of two leaf-scars at a node is sufficient to cause us to choose the second 12, and our choice is corroborated by the position of the bundle-scars and by the presence of a terminal bud, so we pass to 13 . The upper lateral buds of 
the Ash are not covered by persistent bases of leaf-stalks and there are 2 or more pairs of scales to the leaf buds, we therefore pass to 14 . The relatively small size of the buds and their freedom from stickiness takes us to 15 where the number of the bundlescars and the other characters given show us that we have in hand a twig of one of the Ashes. We now turn to No. 165 and confirm our determination of the genus by reading the general description of the Ashes. To find out which Ash we are dealing with we procede with the key of the Ashes and, knowing that the leaf-scars in our specimens are deeply concave on their upper margins, we conclude that we have the White Ash (Fraxinus americana). At page 422 we find a detailed description with photographic illustrations of this species and may learn the winter characters of the tree not already given in the key. If the description and photographs do not correspond to the tree under investigation, we know that we have gone astray at some point in the key, and turning back we repeat the analysis taking if need be the other alternative of a pair where the choice had been doubtful.

The meaning of unfamiliar terms may generally be found in the glossary. Often, however, the photograph offers a better explanation. Thus in distinguishing the Carolina from the Lombardy Poplar, the word "spire-shaped" as applied to the habit, can best be understood by reference to the picture of the latter species. When a choice within a number seems impossible from the information available, trial should be made of both contrasting paragraphs. In the key to the Oaks, for example, the character of the bark - whether flaky or not flaky - is used as a distinguishing mark. With only the twig at hand, it may still be possible to trace the name by trying the tree first under "bark flaky" and if this does not lead to the correct name, then under "bark not flaky." It might seem needless to suggest that both the contrasted parts of each number encountered should be read but work with students has shown that such a suggestion may be useful.

Sometimes a tree is variable in the characters used in the key. Thus the Chestnut has terminal buds sometimes present on the twigs though they are generally absent. In such cases, however, and where there is a legitimate doubt as to whether the tree should be placed in the first or the second group, it has generally been placed in both so that either of the two choices should lead to the correct 
name. The determination of the presence or absence of the terminal bud is perhaps the greatest pitfall likely to be fourd in the use of the key, but should give little difficulty if the discussion in the introduction is understond and the terminal scar is looked for with the aid of a hand-Iens. 


\section{KEY TO GENERA AND SPECIES}

1. Leaves persistent and green throughout winter (Evergreens) ...2

1. Leaves not persistent and green throughout winter (dead leaves

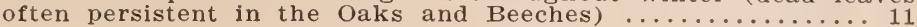

2. Leaves broad, prominently spiny-margined. Holly (Ilex opaca) p.396

2. Leaves narrow, often minute and scale-like; Conifers (i.e. cone-

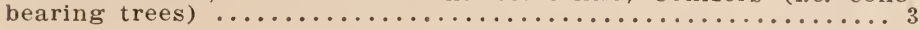

3. Leaves, except scale-leaves, needle-shaped, in definite, generally sheathed clusters on the sides of the branches..... Pine (Pinus) 85

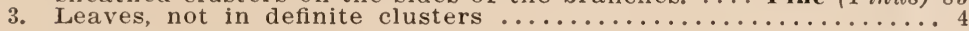

4. Leaves opposite or in 3 's, therefore 2 or 3 at a node .........5

4. Leares alternate, scattered, therefore only 1 at a node .......8

5. Leaves whorled in 3's, all alike, whitened above and green below, awl-shaped, sharp-pointed and spreading; fruit bluish, berry-like; a shrub or low tree. (See also juvenile condition of Red Cedar)

5.

5. Leaves opposite in 4 ranks, minute, scale-like, closely overlapping 6

6. Young twigs prominently flattened and forming a flat, 2-ranked, fan-shaped spray often mistaken for the true leaves which are minute and of two shapes, those on edges of twig being narrower, those on flat sides being broader and more abruptly pointed with each leaf generally showing a conspicuous raised glandular dot;

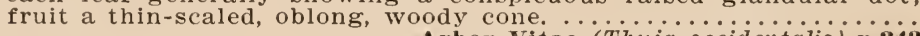

6. Young twigs not prominenti Arom flatened; fruit spherical ...... 7

7. Spray somewhat fan-shaped; young twigs not prominently 4-angled; leaves all alike in shape, some of them with prominent raised glandular dot on back; fruit a spherical woody cone. ..........

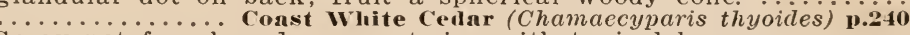

7. Spray not fan-shaped; young twigs with typical leaves are prominently 4-angled; leaves without conspicuous glandular dots, of two kinds; (a) the juvenile form - awl-shaped, spiny-pointed and spreading, in 2's or 3's at a node and resembling leaves of Common Juniper, the usual leaf form on young trees but generally to be found on some parts of older trees; (b) the typical form - smaller, scale-like and closely appressed; fruit bluish, berry-like. ........ ...................... Red Cedar (Juniperus virginiana) $\mathbf{1} .2 \mathbf{2}$

8. Leaves distinctly flattened ......................... 9

8. Leaves not distinctly flattened, needle-shaped, 4 -angled, sessile on projections of the bark. ............................. (Picea) 91

9. Leaf about $1 \mathrm{~cm}$. long with definite leaf-stalk, leaving prominently projecting scar when detached. Hemlock (Tsuga canadensis) p.235

9. Leaf about $2 \mathrm{~cm}$. or more long, without leaf-stalk, leaving a flat or only slightly raised scar when detached ................ 10

10. Buds small, nearly spherical to broadly ovate, their scales covered and glued together by resinous coating; leaf-scars flat. ..........

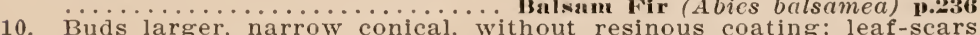
slightly raised ........... Douglas Fir (Pseudotsuga taxifolia) p.234

11. Leaf-scars opposite or in 3 's, therefore 2 or 3 at a node ......12

11. Leaf-scars alternate, therefore only 1 at a node $\ldots . . . \ldots . .16$

12. Leaf-scars or some of them 3 at a node; bundle-scars in an ellipse; terminal bud absent.............. Catalpa (Catalpa) p.42s

12. Leaf-scars always 2 at a node; bundle-scars not in an ellipse;

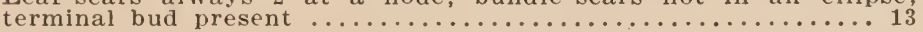

13. Leaf buds with only a single pair of scales; lateral buds, at least the upper ones, covered by persistent bases of leaf-stalks $\ldots \ldots \ldots$.

13. Leaf buds with 2 or more palrs of scales; lateral buds not covered by persistent bases of leaf-stalks ........................ 
14. Terminal buds large, over $1.5 \mathrm{~cm}$. long, sticky or varnished; leafscar large, inversely triangular; bundle-scars $3-9$, conspicuous. ....

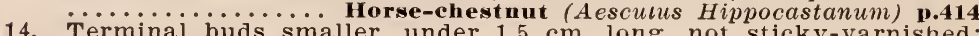
Terminal buds smaller, under $1.5 \mathrm{~cm}$. long, not sticky-varnished;

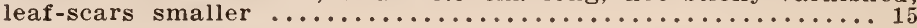

15. Bundle-scars, minute, numerous in a U-shaped line often more or less confluent; bud-scales scurfy (i.e. rough-downy). ..............

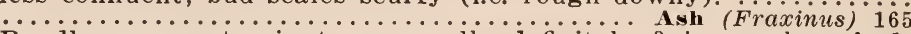

15. Bundie-scars not minute, generaily definitely 3 in number; bud-

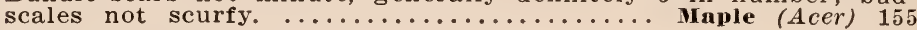

16. Stipule-scars entirely encircling the twig ............... 17

16. Stipule-scars absent or if present not encircling the twig ...... 19

17. Leaf-scar almost completely surrounding the bud; terminal bud absent; (the last lateral bud may appear to be terminal but absence of terminal bud is shown by small scar at end of twig). ...........

17. Leaf-scar not surrounding the bud; terminal bud present ..... 18

18. Buds ovate to conical, hairy at least within; scar of rudimentary

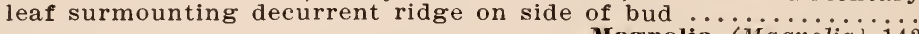

18. Buds flattened oblong, smooth without and within; scar of rudi-

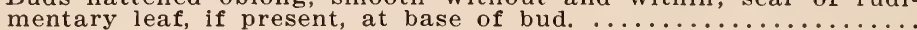
..................... Tulip Tree (Liriodendron Tulipifera) p.340

19. Twigs with thorns, spines, or prickles, or branches ending in

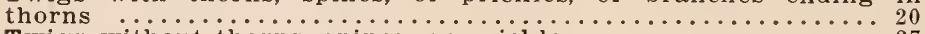

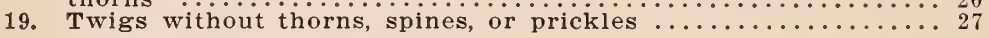

20. Spines in pairs at the nodes, or twigs covered with weak hair-

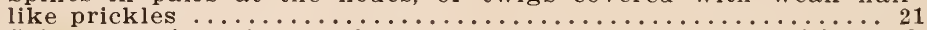

20. Spines not in pairs at the nodes, twigs not covered with weak

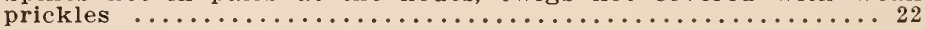

21. Buds rusty-hairy, more or less covered by bark; terminal bud

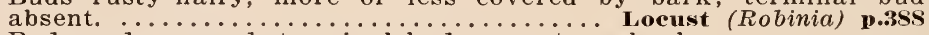

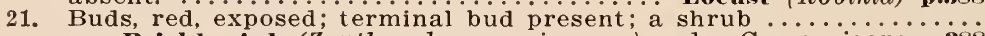
....Prickly Ash (Zanthoxylon americanum) under Comparisons p.3ss

22. Thorns lateral, regularly placed on the twig at or near the

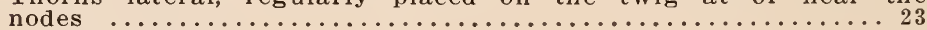

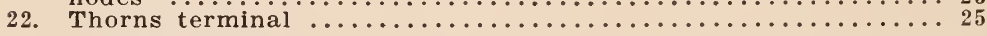

23. Thorns generally branched, situated above the nodes; buds several in a longitudinal row, the lower ones covered by the bark. ........

....................... Honer Locust (Gleditsia triacanthus) p.3s2

23. Thorns generally unbranched on twigs, situated at the nodes; sometimes branched thorns on trunk; buds exposed ..........24

24. Thorns generally present at all the nodes; bundle-scar single.

....... Osage Orange (Maclura pomifera) under Comparisons p.360

24. Thorns generally absent from many of the nodes; bundle-scars 3 .

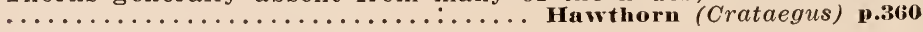

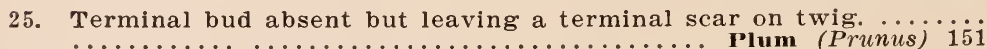

25. Terminal bud present, at least on spineless branches ......... 26

26. Tree with bushy habit of growth; twigs with characteristic licorice-like taste, generally reddish-brown, more or less palewoolly at least toward apex; lateral buds blunt, flattish, appressed and more or less pale-woolly ........... Apple (Pyrus Malus) p.352

26. Tree with upright habit of growth; twigs without characteristic taste, generally yellowish green and generally smooth; lateral buds sharp-pointed, smooth or sometimes slightly downy, generally not flattened nor appressed. ............. Pear (Pyrus communis) p.350

27. Pith in section lengthwise of twig seen to be interrupted by hollow chambers or by thin woody partitions (the partitions are fre-

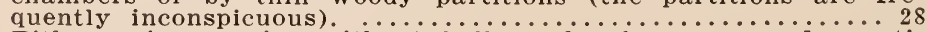

27. Pith continuous; i.e. without hollow chambers or woody parti-

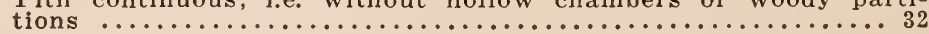


28. Pith chambered but with chambers confined to the nodes......... 28. Pith when chambered with chambers not confined to the nodes 29

29. Pith brown, wide, with hollow chambers; fruit a nut ......... 30

29 . Pith light colored, narrow; fruit a small stone-fruit ........ 31

30. Downy patch present above leaf-scar; nut elongated.

30. Downy patch absent from leaf-scar; nut round. (Juglans nigia) p.2.

31. Pith with hollow chambers; buds brown, terminal bud absent, lateral buds appressed........ Haekberry (Celtis occidentalis) p.330 31. Pith with woody partitions in the solid ground-mass; buds reddish, terminal bud present, lateral buds divergent.

Tupelo (Nyssa sylvatica) p.4zo

32 Leaf-scars regularly 2 -ranked, i.e. arranged in 2 longitudinal rows

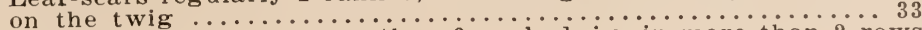

32. Leaf-scars reguiarly more than 2 -ranked, i.e. in more than 2 rows

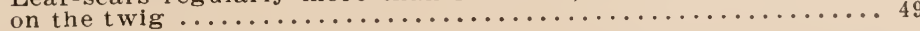

33. Terminal bud absent (the last lateral bud may appear to be terminal but absence of terminal bud is shown by small scar at

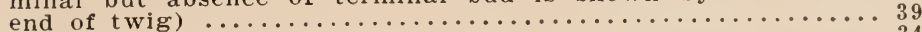

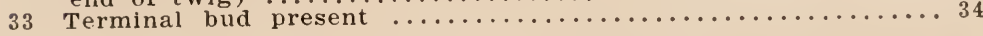

34. Stipule-scars nearly encircling twig; buds long and narrow, generally over 5 times as long as wide, divergent; bud-scales in pairs, 4-ranked, 10 or more scales visible. ..... Beech (Fagus) p.294 Stipule-scars when present relatively short; buds stouter, generally not over 4 times as long as wide; bud-scales less numerous ... 35

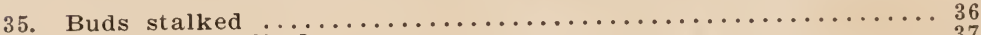

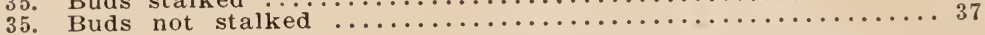

36. Buds, for the most part naked, i.e. with undeveloped leaves serving the function of scales; woody, 4-parted fruits and the remains of last season's nowers generally present $\ldots \ldots \ldots \ldots \ldots \ldots \ldots \ldots$

36. Buds covered with bud-scales; fruit a woody cone-like catkin

37. Leaf-scars very narrow, V-shaped, swollen at the 3 bundle-scars; buds long, appressed; bud-scale tipped with dark point; stipulebuds long, appressed; bud-scale sush (Amelanchier canadcnsis) p.35s

37. Leaf-scars relatively broad; buds shorter; bud-scale without conspicuous dark point: stipule-scars present though often incon-

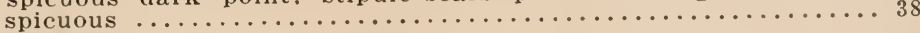

3.8. Bundle-scars 3; bark of young stem and branches with horizontally elongated lenticels. often peeling into papery layers; pith generally elliptical often with irregularly toothed edges; fruit a catkin, immature catkins generally present on tree in winter. 10.

3s. Bundie-scars several; lenticels not horizontally elongated; bark Bever peeling in papery layers; pith more or less 5-pointed, starshaped; fruit a bur. .......... Chestnut (Castanea dentata) p.296

39. Leaf-scar almost entirely surrounding the buds; buds brown, hairy, several massed together to form a bud-like cone; bundle-scars raised, generally 5 in a single curved line.

Yellow wood (cladrastis lutea) p.3si

39. Leaf-scar not more than half surrounding the bud; buds not massed

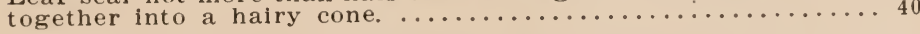

40. Bundle-scars 3 or more in a single curved line. . . . . . . . 43

40. Bundle-scars more than 3 in a closed ellipse, double line, variously clustered or irregularly scattered. ................. 41

41. 2-3 scales visible to a bud; bundle-scars not prominently pro-

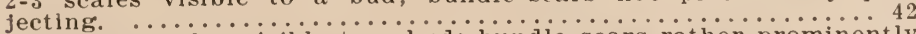

41. 4 or more scales visible to a bud; bundle-scars rather prominently projecting. ......................... Mulberry (Morus) 141 
42. Twigs usually zigzag; pith roundish; buds and twigs mucilaginous when chewed; fruit spherical, woody, about size of pea, at tached to a leafy bract. ................................... (Tilia) p.416

42. Twigs nearly straight; pith more or buds and twigs not mucilaginous when chewed; fruit a large bur

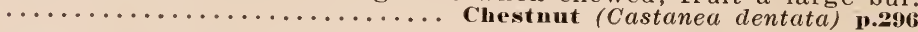

43. Buds superposed, at least at some of the nodes; stipule-scars

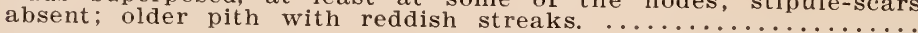

43. $\ldots \ldots \ldots \ldots \ldots \ldots \ldots \ldots \ldots \ldots \ldots \ldots \ldots$ Redbud (Cercis canadensis) p.3s4

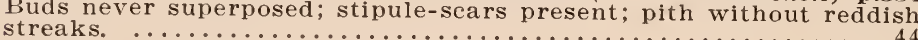

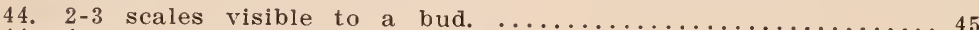

44. 4 or more scales visible to a bud $\ldots \ldots \ldots \ldots \ldots \ldots \ldots \ldots \ldots \ldots \ldots \ldots \ldots \ldots \ldots$

45. Buds stout; buds and twigs mucilaginous when chewed; lenticels not horizontally elongated; fruit spherical, woody, about size of pea, attached to leafy bract. ......................... (Tilia) p.416

45. Buds narrower, buds and twigs not mucilaginous when chewed; lenticels on stems and branches horizontally elongated; bark often peeling in papery layers; fruit a winged seed-like body borne in

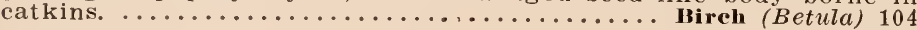

46. Bud-scales 2-ranked (i.e. arranged on the bud in 2 longitudinal rows); leaf-scars covered with a smooth corky layer; bundle-scars typically sunken; bark ridged; catkins absent.

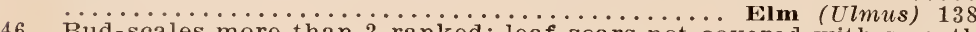
Bud-scales more than 2-ranked; leaf-scars not covered with smooth corky layer; bundle-scars not sunken; fruit borne in catkins. . . 47

47 Lenticels horizontally elongated with age; bark on young trunks and branches smooth, not becoming fluted, often peeling into papery layers but not flaky; fruit a flat seed-like body borne in catkins; catkins generally present on tree in winter.

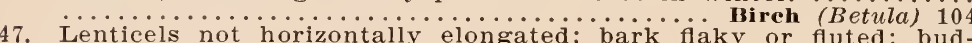
Lenticels not horizontally elongated; bark flaky or fluted; budscales 4-ranked; fruit a nutlet attached to a bract. ........48

48. Bark flaky; twigs 1-2 mm. thick; buds usvally $3-7 \mathrm{~mm}$. long; nutlet enclosed by a sac-like bract; staminate catkins generally abundantly present in winter.

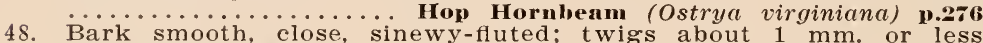
thick; buds usually $2-4 \mathrm{~mm}$. long; nutlet attached to flattish, toothed bract; staminate catkins enclosed in enlarged scaly buds, therefore no catkins visible on tree in winter.

................. American Hornbenm (Carpinus caroliniana) p.2̈̈s

49. Buds clustered at tips of vigorous shoots; terminal bud not greatly

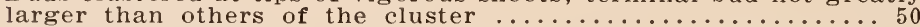

49. Buds not clustered at tips of vigorous shoots, or if slightly clustered, then terminal bud much larger than others of the cluster 53

50. Bundle-scars numerous, scattered; pith regularly 5-pointed, star-

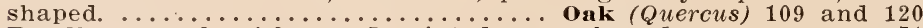

50. Bundle-scars 3 ; pith not 5 -pointed, star-shaped ...........51

51. Terminal bud absent, but leaving a terminal scar on twig. ......

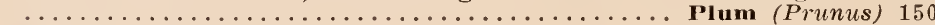

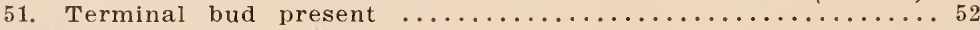

52. Buds woolly at least at tip; collateral buds generally present. .... 52 Buds smooth; collateral buds generally absent ............. 145

53. Buds stalked ............................... 54

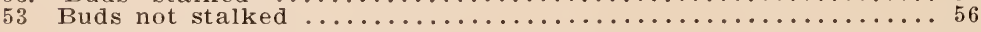

54. Buds bright yellow dotted, often superposed.

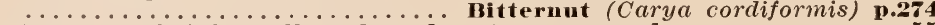

54. Buds not bright yellow dotted, not superposed ...........55

55 Buds always stalked, blunt; stipule-scars present; catkins present

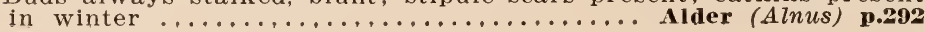


55. Buds, except occasionally on rapidly grown twigs, generally not stalked, pointed; corky ridges generally present on branchlets; stipule-scars and catkins absent. ....................

56. Buds sunken (i.e. partially or completely covered by the bark) for the most part minute and superposed; best seen in a section lengthwise of the twig, through the node at right angles to the

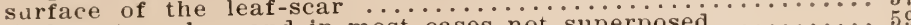

56. Buds not sunken and in most cases not superposed ........ 59

57. Twigs very stout, generally $1 \mathrm{~cm}$. or more thick; pith salmoncolored: buds bronze-silky, exposed but surrounded by an incurved downy rim of the bark; bundle-scars generally more than 3 .

Kentucky Cofree Tree (Gymnocladus dioica) p.3so Twigs rather slender generally less than $5 \mathrm{~mm}$. thick; pith whitish not salmon-colored; bundle-scars $3 \ldots \ldots \ldots \ldots \ldots \ldots$

58. Buds smooth, distant, the uppermost breaking through the bark above the leaf-scar, the lower ones submerged, appearing in sec-

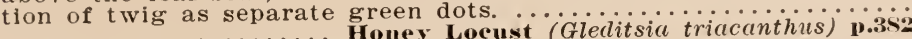

58. Buds downy, clustered together in cavity below leaf-scar $\ldots \ldots \ldots$ Buds downy, clustered together in cav......................... (Robinia) p.3si

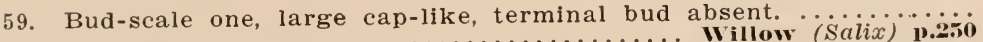
Bud-scales more than one or bud-scales absent; terminal bud

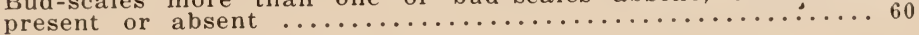

60. First or lowest scale of lateral bud directly in front (i.e. facing directly out away from twig; see fig. 100); leaf-scar covered with a light-corky layer, large inversely triangular; bundle-scars 3 , often compound; pith more or less 5 -pointed star-shaped. $\ddot{3} \ddot{3} \dot{6}$

60. First or lowest scale of lateral bud not directly in front ..... 61

61. Twigs branching freely the first season, therefore branches showing on last season's growth, the branches surpassing the main

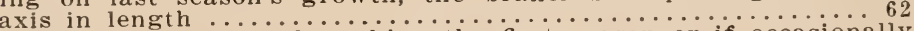

61. Twigs generally not branching the first season or if occasionally branching then branches not surpassing main axis in length 63

62. Bundle-scar one; twigs greenish, spicy, mucilaginous when chewed.

..... Sussarra. (sassafras varifolium) 1).34:2 Bundie-scars 3 twigs not mucilaginous. .............. Itternute-leuved Dogwood (Cornus alternifolia) under Comparisons p.41s

63. Bundle-scars 1 or 2; leaf-scars, except on young shoots, mainly densely clustered on short, stout, wart-like branches ........64

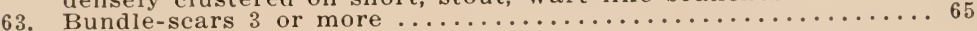

64. Bundle-scar single; leaf-scars minute, scattered leaf-scars also present on twigs, very numerous and strongly decurrent; twigs slender; fruit a cone, generally present. ........ Larch (Larix) 90

64. Bundle-scars 2; leaf-scars larger, scattered leaf-scars if present relatively far apart and not decurrent; twigs stouter; fruit a stonefruit generally absent. ................ Ginkgo (Ginkgo biloba) p.24s

65. Bundle-scars 3 or if more than 3 then in a single curved line (bundle-scars of Bitternut p. 275 occasionally in single line) 69 65. Bundle-scars more than 3, variously grouped or scattered, but not

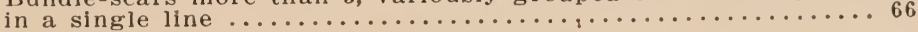

66. Stipule-scars absent; terminal bud present ..............6s

66. Stipule-scars present; terminal bud present or absent ........67

67. 2-3 bud-scales visible; bundle-scars not projecting; terminal bud present or generally absent. Chestuut (Castanea dentata) p.2:(i

67. 4 or more bud-scales visible; bundle-scars projecting; terminal

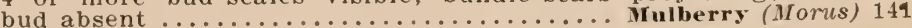

68. Buds large; twigs without resinous juice; fruit a nut; a tree. . . .

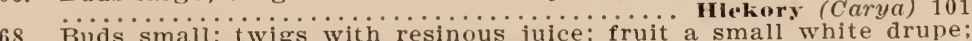
a shrub growing in swamps. Poison sumnch (Rhus Vernix) p.394 


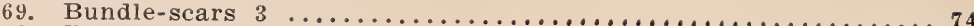

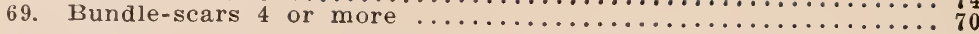

70 Terminal bud absent, but leaving a terminal scar on twig ..... 72

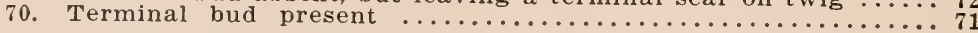

71. Lateral buds mostly large, twig without resinous juice; fruit red, berry-like; a small tree. ............. Mountuin Ash (Pyrus) p.35-

71. Lateral buds small, cut $t$ wig exuding watery, resinous juice; fruit small, whitish drupes; a shrub growing in swamps.

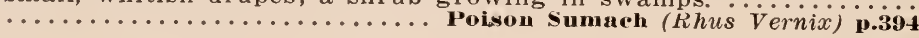

72. Leaf-scars deeply $\mathrm{V}$-shaped, almost entirely surrounding the

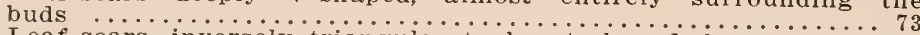

72. Leaf-scars, inversely triangular to heart-shaped, large, not more than half surrounding the bud; twigs stout; pith chocolate-brown.

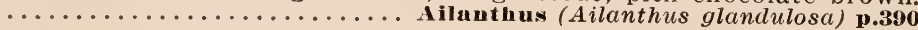

73. Pith yellowish-brown; twigs stout, exuding a milky juice when

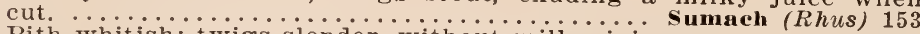

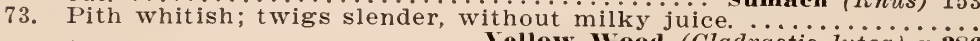

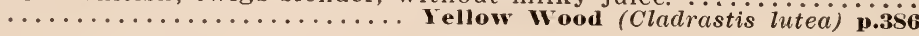

74. Terminal buds on rapidly grown shoots absent, but leaving a ter-

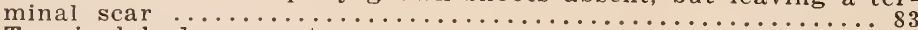

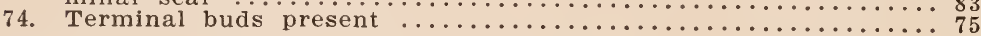

75. Lateral buds flattened, appressed, about as broad as long ..... 76

75. Lateral buds not distinctly flattened and appressed, in most cases

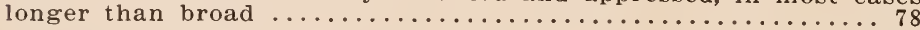

76. Terminal bud large, generally $12 \mathrm{~mm}$. or more long; some of the lateral buds generally long, nearly equalling terminal bud; leafscars raised on dark red, polished ridges of the bark.

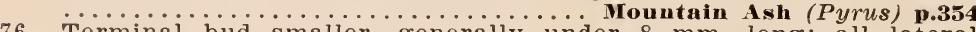
Terminal bud smaller, generally under $8 \mathrm{~mm}$. long; all lateral buds small; leaf-scars not on specially colored ridges of the bark 77

77. Tree with bushy habit of growth; twigs with characteristic licoricelike taste, generally reddish-brown, more or less pale-woolly at least toward apex; lateral buds blunt, more or less pale-woolly.

77.......................... Aple (Pyrus Malus) p.35: Tree with upright habit of growth; twigs without characteristic taste, generally yellowish-green and generally smooth; lateral buds sharp-pointed, smooth or sometimes slightly downy.

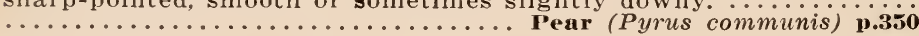

78. Buds spherical or nearly so, seldom pointed; bud-scales thick, shining; leaf-scars narrow; twigs more or less zigzag, branches generally thorny; fruit a small pome; small trees or shrubs.

$\ldots \ldots \ldots \ldots \ldots \ldots \ldots \ldots \ldots \ldots \ldots \ldots \ldots \ldots \ldots$ Hawhorn (Crataegus) p.360

78. Buds not spherical; bud-scales thinner .................. 79

79. Leaf-scars narrow crescent-shaped, generally several times as

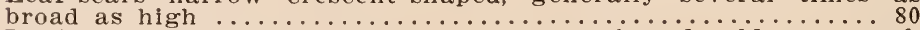

79. Leaf-scars semicircular to broadiy crescent-shaped, seldom as much

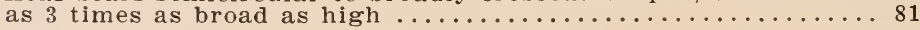

80. Buds long, narrow, elliptical, 3-4 times as long as wide.

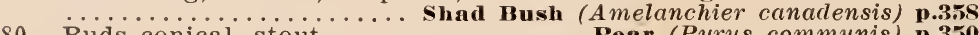

80. Buds conical, stout................. Pear (Pyrus communis) p.350

81. Twigs densely speckled with very minute pale dots, brightly colored, generally green-yellow below ard more or less reddish above and highly polished; buds generally densely downy at least toward apex; collateral buds usually present.

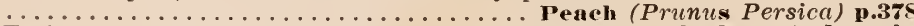
Twigs not densely speckled with minute dots; buds not densely downy, collateral buds generally not present .............. 82

82. Twigs without bitter taste; branchlets generally becoming corkyridged; bud-scales downy-margined; leaf-scars large with conspicuous bundle-scars; fruit a spherical bur-like head generally present in winter. ...... Sweet Gum (Liquidambar Styracifua) p.346

82. Twigs with bitter taste often resembling bitter almonds; branches without corky ridges; bud-scales not downy-margined; fruit a drupe.................................... or Plum (Prunus) 145 
83. Buds spherical or nearly so; bud-scales thick, shining; twigs more

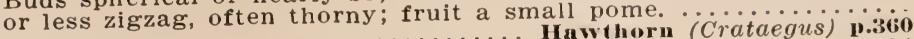

83. Buds not spherical, ionger than broad .............. 84

84. Twigs generally gray-woolly toward apex; buds blunt, brown-hairy at tip; stipule-scars at the sides of leaf-scar. ….............

84. Twigs smooth or downy but not woolly; buds pointed, generally smooth or somewhat downy; stipule-scars more or less behind Plum (Prunus) 150 leaf-scar.

\section{THE PINES}

\section{Pinus.}

Needle-shaped leaves in many small clusters of 5 or less, each cluster surrounded by a persistent or deciduous sheath and borne on a rudimentary branch which is subtended by a scale-like primary leaf; fruit a cone with woody scales, maturing at the end of the second or third season: seeds winged. The position of the resin-ducts in the leaves is a distinctive character of some value and may be observed if a thin cross section is made with a sharp knife and viewed toward the light with a hand-lens. Twig photographs are about $1 / 4$ natural size.

85.' 5 needles in a cluster. .........White Pine (Pinus Strobus) p.210

85. Less than 5 needles in a cluster .................. 86

86. 3 needles in a cluster. ........... Piteh Pine (Pinus rigida) p.212

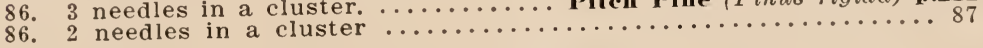

87. Needles 3-6 in. long, cones at right angles to branch ......... 88

87. Needles $1 / 2-3 \frac{1}{2}$ in. long, cones pointing either backward or forward

88. Twigs reddish-brown, leaves slender and flexible, resin-ducts peripheral; native species ..... Red Pine (Pinus resinosa) p.216 Twigs yellowish-brown. leaves thicker and stiff, resin-ducts between periphery and bundle; European species. ............... ................ Anstrinn Pine (Pinus Laricio, var. austriaca) p.21s

89. Cones pointing forward, leaves $1 / 2-1 \frac{1}{2}$ in. long, dark yellowishgreen resin-ducts between periphery and bundle; native species. ......................... Jane (Pinus Banksiana) p.214 89. Cones pointing backward, leaves $1 \frac{1 / 2-31 / 2}{1 n}$. long, bluish-green,

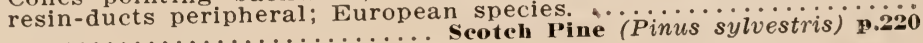

\section{THE LARCHES}

\section{Larix.}

Pyramidal deciduous-leaved cone-bearing trees; twigs with resinous taste; rapidy-grown shoots with numerous scattered strongly decurrent leaf-scars with single bundle-scars; short stout wart-like branches with densely clustered leaf-scars abundant.

90. Cones $1 / 2-3 / 4$ inch long with few scales; twigs pale reddish-brown;

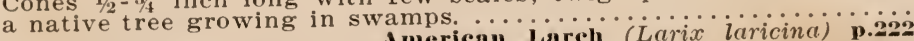

90. Cones 1 inch or more long with many scales; twigs yellowish, stouter; a European tree $\ldots \ldots \ldots$ iecidia) under Comparisons p.2.2.

\section{THE SPRUCES}

\section{Picea.}

Evergreen pyramidal trees with 'scaly bark, alternate scattered, 4angled leaves without proper leaf-stalks but perched on persistent decurrent projections from the bark and ovate to cylindrical pendant cones which fall off the tree entire. The Spruces are distinguished from the Balsam Fir by the 4-sided scattered leaves, the projecting leaf-scars and the scaly bark. Twig photographs are about $1 / 3$ natural size. 
91. Twigs hairy $\ldots \ldots \ldots \ldots \ldots \ldots \ldots \ldots \ldots \ldots \ldots \ldots \ldots \ldots \ldots \ldots \ldots \ldots \ldots \ldots \ldots$

91. Twigs smooth or nearly so, cones cylindrical $\ldots \ldots \ldots \ldots \ldots \ldots \ldots \ldots \ldots . . \ldots$

92. Cones cylindrical, more than 3 inches long; cultivated species ....

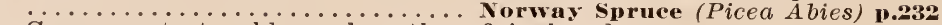

93. Leaves dark yellowish green, $1 / 2-3 / 4$ inch long. Cones ovate-oblong 11/4-2 inches long; a tree growing on uplands, rarely in wet places, reaching $40 \mathrm{ft}$. or more in height. . Red Spruce (Picea rubra) p.226

93. Leaves bluish green, $1 / 4-1 / 2$ inch long, cones ovate, $1 / 2-11 / 2$ inches long, persistent on tree for more than a year; a tree growing chiefly in swamps or lowlands, generally under $30 \mathrm{ft}$. in height, sometimes fruiting when less than $5 \mathrm{ft}$. high.

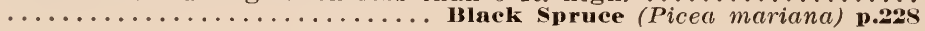

94. Leaves green, cones 4-7 inches long, cultivated species.

94.

95. Cones $21 / 2-4$ inches long, cone scales distinctly longer than broad with narrowed, ragged, blunt apex; cultivated western. species.

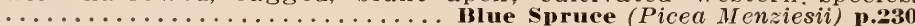

95. Cones $1 \frac{1}{2}-2$ inches long, cone scales rounded, not ragged; leaves generally with unpleasant odor, native in northern New England but cultivated further south. White Spruce (Picea canadensis) p.224

\section{THE POPLARS}

\section{Populus.}

Rapidly growing trees generally with erect more or less continuous trunk forming distinct whorls of branches at top of each year's growth by which the age of the tree may be estimated; branchlets brittle easily separating at point of attachment; young bark smooth, generally light colored; pith, 5-pointed star-shaped, upon drying generally turning brown or black; leaf-scars large, 3-lobed, inverted triangular, covered with a light colored corky layer; stipule-scars generally distinct, narrow; bundle-scars 3, simple or compound in 3 groups; buds with the first scale anterior (facing outward), the first pair of scales small and opposite; scale-scars marking annual growth persisting for several years; seeds downy, produced from catkins in spring, the tree often spreading widely by formation of root suckers. The Poplars are dioecious. They resemble the Willows but are easily distinguished by the numerous scales to the bud. In addition to the native species here described a rare form, the Downy Poplar [Populus heterophylla L.] occurs locally in swamps in southern New England.

96. Twigs covered at least at apex with white cottony felt which may be readily rubbed off exposing the greenish bark below. .......

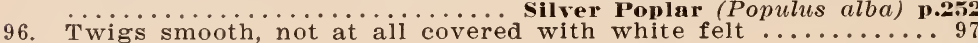

97. Twigs yellowish $\ldots \ldots \ldots \ldots \ldots \ldots \ldots \ldots \ldots \ldots \ldots \ldots \ldots \ldots \ldots \ldots$

97. Twigs not yellowish (generally reddish-brown) $\ldots \ldots \ldots \ldots . . .99$

98. Lateral buds for the most part divergent, large, about $10 \mathrm{~mm}$. or more in length, tree with more or less pyramidal head, but not narrowly spire-shaped. .... Carolina Poplar (Populus deltoides) p.260

98. Lateral buds for the most part appressed, smaller, generally under

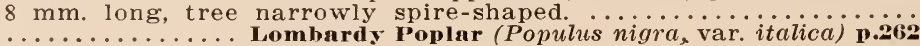

99. Buds more or less pale dusty-downy.

............... Large-toothed Aspen (Populus grandidentata) p.25t

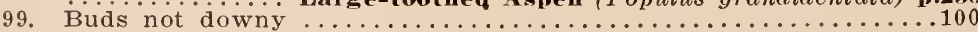

100. Buds large, over $15 \mathrm{~mm}$. long, covered with fragrant sticky gum.

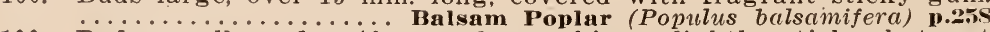
100. Buds small, under $10 \mathrm{~mm}$. long, shiny, slightly sticky but not fragrant. ......... Small-toothed Aspen' (Populus tremuloides) p.254 


\section{THE HICKORIES}

\section{Carya.}

Trees with smooth gray tough bark in young trees, becoming roughened with age; twigs in the main stout, tough, flexible, but with difficulty broken, dark, sharply outlined against the sky; buds more or less naked to evidently scaly, frequently superposed, the lateral sometimes enclosed in a sac soon splitting at the top and often stalked; leaf-scars alternate, more than 2-ranked, large, conspicuous, more or less 3-lobed inversely triangular; bundle-scars conspicuous, more than 3 , irregularly scattered or collected in 3 more or less regular groups, rarely in a straight line; pith not chambered except at nodes, sometimes somewhat star-shaped in cross section; lenticels oblong, conspicuous; fruit an unsculptured nut, inclosed in a husk which splits into four valves at least at the apex.

101. Buds conspicuously bright yellow with minute glandular dots; terminal buds elongated, flattened; bud-scales 4-6, valvate in

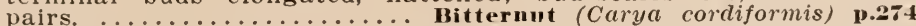

101. Buds not conspicuously bright yellow-dotted; terminal buds ovate; bud-scales, 10 or more, overlapping, or the outermost on lateral buds usually forming a closed sac soon splitting from the top;

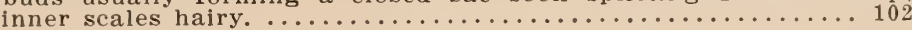

102. Buds small, terminal buds 5-10 mm. long, their outer darker scales generally somewhat glandular dotted, but not conspicuously yellow; outer scales often falling and exposing downy scales beneath; twigs smooth, comparatively slender; bark not at all or but slightly shaggy. ................. Pignut' (Carya glabra) p.272

102. Buds large, the terminal buds $8-15 \mathrm{~mm}$. long, ovate, nearly or quite glandless; twigs stout, often downy toward tip .........103

103. Bark not shaggy; terminal buds broadly ovate to spherical, outer scales soon falling off entire, exposing pale yellowish-gray silky scales beneath. ................. Moekernut (Carya alba) p.270

103. Bark distinctly shaggy; terminal buds elongated ovate, dark outer scales persisting through winter but shagging off in pieces from their apex downward. Shag-bark Hickory (Carya ovata) p.268

\section{THE BIRCHES}

\section{Betula.}

Bark smooth, in some species peeling into papery layers but not flaky; lenticels becoming conspicuously horizontally elongated with age; leafscars alternate, 2-ranked, semi-oval to crescent-shaped; stipule-scars narrow, often inconspicuous; bundle-scars 3 rather inconspicuous; fruit a flat seed-like body borne in catkins, staminate catkins generally present on the tree in winter.

104. Bark close, not easily separated into thin papery layers . . . . 105 104. Bark easily separated into thin papery layers and generally peeling spontaneously .............................. 106

105. Bark dark reddish brown; twigs with strong wintergreen taste.

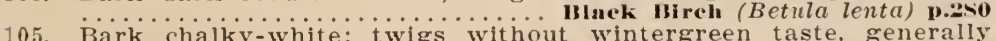
roughened with resinous dots. (iruy Bireh (Betula populifolia) p.2si

106. Outer layers of bark chalky-white ............... 107

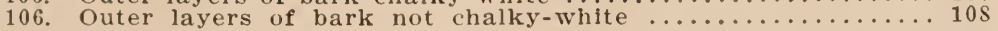

107. Native species. ...... Puper Hireh (Betula alba var. papyrifera) p.2ss 107. European species. .... Europenn White Hreh (Betula alba) p.290

108. Bark reddish-brown to light pink; rare and local in New Hampshire and Massachusetts, occasionally cultivated.

Red Hirch (Betulä nigra) is.asi

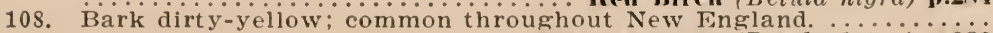

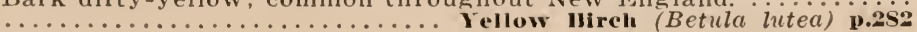




\section{THE OAKS \\ Quercus.}

The Oaks form a large genus, of which 52 are North American. Of these, 12 are native to New England. Buds clustered at ends of twigs, more or less 5-sided pyramidal, covered with 5 rows of closely overlapping brownish scales. Leaf-scars concave to rounded above, rounded at base, generally broader than high and raised with a ridge more or less well marked, decurrent from lower edge, the ridges from the 5 ranks of leaf-scars causing twig to be more or less 5 -angled especially when dried. Bundle-scars irregularly scattered, inconspicuous. Stipule-scars inconspicuous. Pith of cut twig 5-pointed, star-shaped. Cross-section of branch or trunk showing layers of large, porous spring wood alternating with dense layers of summer wood. Medullary rays of wood very prominent, showing as radial lines in cross section of a log, also generally showing prominently, especially through a handlens, on cut end of stout branchlet of several years growth. Fruit an acorn inclosed in a scaly cup. Dead leaves often persistent on the tree during winter.

\section{Key to Oaks based upon fruiting material.}

109. Fruit maturing in autumn of second year, ripe acorns therefore borne upon parts of twig two years old; immature acorns to be found in winter on twigs of the past season's growth; shell of nut hairy inside; abortive ovules at the top of the nut; scales of acorn-cup broad and thin; lobes of leaves bristle-pointed. ......

109. Fruit maturing in one year, ripe acorns therefore borne upon past season's growth; no immature acorns to be found upon twigs in winter; shell of nut smooth inside; abortive ovules at base of nut; lower scales at least of acorn cup more or less thickened at base giving a knobby appearance to surface of cup; scales more or less densely woolly; kernel commonly sweetish; lobes of leaves not

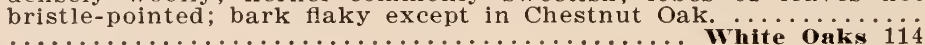

110. Cup of acorn shallow saucer-shaped $\ldots \ldots \ldots \ldots \ldots \ldots \ldots \ldots \ldots \ldots$

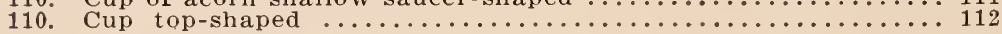

111. Cup thin, $15 \mathrm{~mm}$. or less wide; buds $4 \mathrm{~mm}$. or less long. .........

111. Cup thick, $20 \mathrm{~mm}$. or more wide; buds over $4 \mathrm{~mm}$. palustris) p.314 Red Oak (Quercus rubra) p.3iz

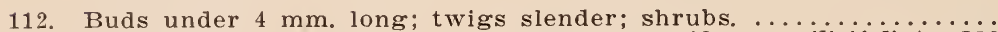

112. Buds over 4.5 mm. long; twigs rather stout; trees ................. 113

113. Upper scales of cup loosely overlapping; buds pointed, whole

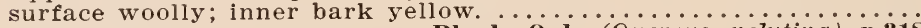
....................... Black onk (Quercus velutina) p.31s

113. Upper scales of cup closely overlapping; buds blunt, downy above middle; inner bark pale red. Searlet Oak (Quercus coccinea) p.316

114. Upper scales of cup with thread-like outgrowths forming a fringe to cup; branchlets often with corky ridges; lateral buds frequently appressed. ........ Bur Oak (Quercus macrocarpa) p.302

114. Cup without distinct fringe; branchlets without corky ridges:

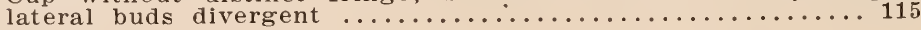

115. Bark on branchlets peeling back in dark stiff-papery layers: marginal scales of cup narrow awn-pointed; acorns long-stalked. . . . ....... Swamp White Oak' (Quercus bicolor) p.304

115. Bark on branchlets not peeling back in dark stiff-papery layers; acorns sessile or short-stalked (at times long-stalked in White

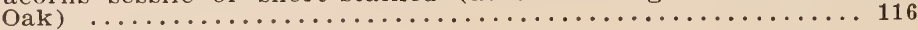

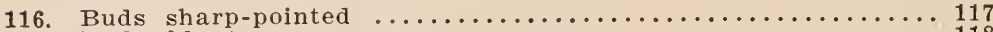

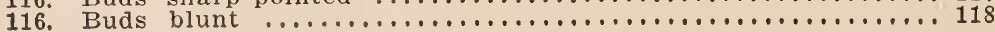


117. Nut 20-35 mm. long; buds 4-10 mm. long; bark thick, furrowed,

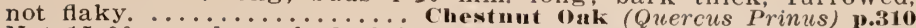

117. Nut 15-20 mm. long; buds $3-6 \mathrm{~mm}$. long; bark thin, flaky. .....

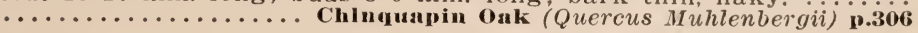

118. Twigs slender, generally not over $2 \mathrm{~mm}$. thick; shrubs.

118. .............. Dwarf Chinquapin Onk (Quercus prinoides) p.30s

118. Twigs relatively stout, generally over $2 \mathrm{~mm}$. thick; trees ... 119

119. Twigs, at least in part, covered with very fine close olive-green down; buds, generally nearly hemispherical, about as broad as long; scales of cup only slightly knobby, apex of nut generally

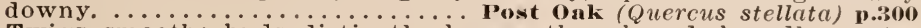
119. Twigs smooth; buds distinctiy longer than broad, broadly ovate; scales of cup thick-knobby at base, apex of nut generally smooth.

White Oak (Quercus alba) p.29s

\section{Key to Oaks without fruit.}

NOTE. (W) after name indicates that. the tree belongs to the White Oak Group.

(B) after name indicates that the tree belongs to the Black Oak Group.

Immature acorns therefore may often be found on winter twigs of species marked with (B) but not on those marked with (W).

120. Buds large, those at tip of twig $4.5 \mathrm{~mm}$. or more long ...... 121

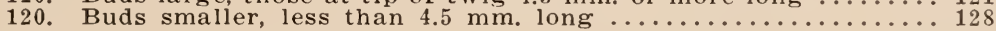

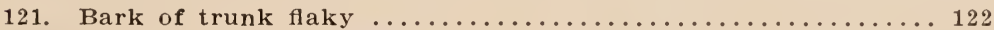

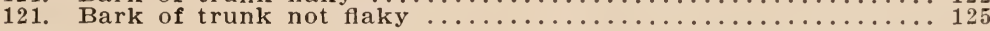

122. Lateral buds generally appressed, buds downy; older twigs often with corky ridges. ...... Bur Oak (W) (Querrus macrocarpa) p.302

122. Lateral buds divergent, buds smooth; twigs without corky ridges

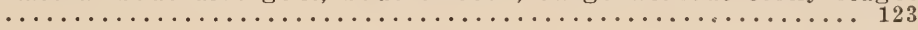

123. Buds narrow conical, pointed.

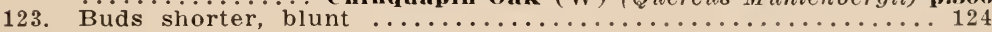

124. Twigs at least in part covered with very fine close orange-brown

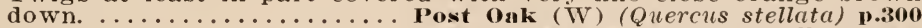

124. Twigs smooth. .............. White Oak (IV) (Quercus alba) p.29s

125. Surface of buds pale-woolly ..................... 126

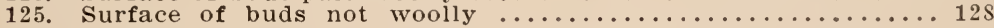

126. Inner bark of trunk orange-yellow; twigs bitter, coloring saliva yellow when chewed; whole surface of bud woolly; buds large, ovate-conical. ............ Black Oak (B) (Quercus velutina) p.31s

126. Inner bark of trunk not yellow; twigs neither bitter nor coloring saliva when chewed; not more than upper half of bud woolly 127

127. Buds sharp-pointed; ovate, the widest part about $1 / 1-1 / 3$ above base;

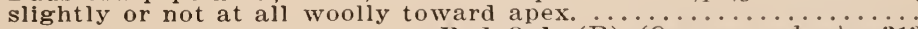

127. Buds blunt-pointed; oval-ovate the widest part at or slightly below

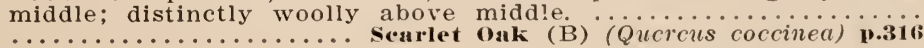

128. Fissures of bark separated by long flat ridges; buds orate, more

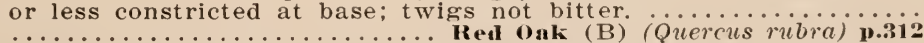

128. Fissures of bark separated by long rounded ridges; buds narrower conical, seldom constricted at base; twigs more or less bitter when

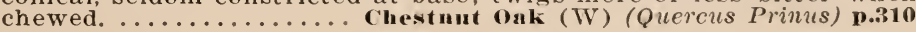

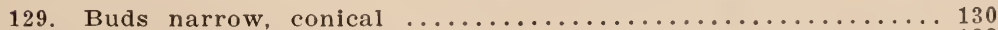

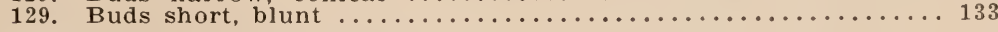

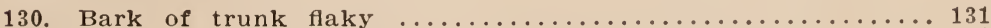

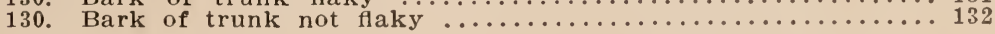


131. Buds downy, lateral buds generally appressed; older twigs often with corky ridges. ..... Bur Oak (W) (Quercus macrocarpa) p.30: 131. Buds smooth, laterai buds divergent, twigs without corky ridges

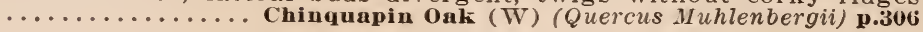

132. Twigs of past season dull, finely downy; shrubs.

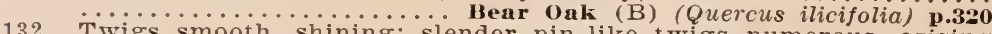
Twigs smooth, shining; slender pin-like twigs numerous, arising at nearly a right angle with the branchlets; trees.

$\ldots \ldots \ldots \ldots \ldots \ldots \ldots \ldots \ldots$ Pin Oak (B) (Quercus palustris)

133. Bark on branchlets peeling into long, dark, stiff-papery layers. $\ldots \ldots \ldots \ldots \ldots \ldots$ Swamp White Oak (W) (Quercus bicolor) p.304 133. Bark on branchlets not peeling into long, dark, stiff-papery lay-

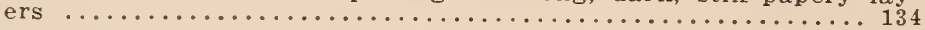

134. Twigs slender, generally not over $2 \mathrm{~mm}$. thick; shrubs ...... 135

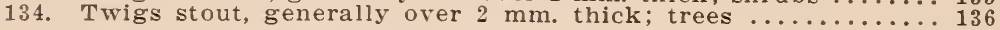

135. Bark of trunk smooth; young acorns generally found on winter twigs; buds more generally conical.

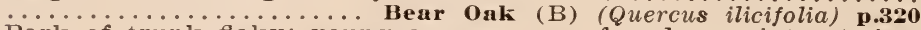

135. Bark of trunk flaky; young acorns never found on winter twigs. ........... Dwarf Chinquapin Oak ( $W^{r}$ ) (Quercus prinoides) p.3os

136. Lateral buds generally appressed; buds densely downy; older twigs often with corky rides. Bur Oak (W) (Quercus macrocarpa) p.302

136. Lateral buds divergent; buds not densely downy; twigs without

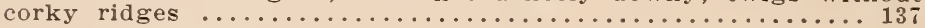

137. Twigs at least in part covered with very fine close orange-brown down; buds generally nearly hemispherical and about as broad as long. ................ Post Oak (W) (Quercus stellata) p.300 137. Twigs smooth; buds broadly ovate, distinctly longer than broad. ......................White Oak (W) (Quercus alba) p.29s

\section{THE ELMS}

\section{Ulmus.}

Leaf-scars alternate, 2-ranked, semi-circular, small, but conspicuous, covered with a light corky layer; bindle-scars prominent, 3 to several, sunken; terminal bud absent, lateral buds medium sized with 2 ranks of over-lapping bud-scales; twigs slender; bark ridged; fruit small, flat, winged, ripening in spring.

138. Twigs gray and rough and strongly mucilaginous if chewed; tips of buds conspicuous with long rusty hairs.

138. Twigs neither gray and rough slippery Elm (Ulmus fulva) p.322

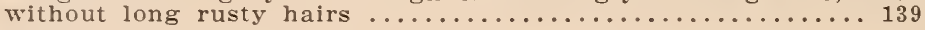

139. Buds chestnut brown; bud-scales with darker margins; bark ridged; native species ............................... 140

139. Buds smoky brown to almost black; bud-scales nearly uniform in color, bark. firmer, roughened into dark oblong blocks; trunk mostly continuous into crown with stout limbs arising at a broad angle; head, "Oak-like;" European species.

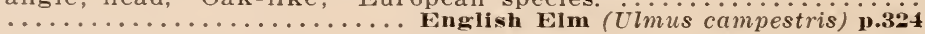

140. Twigs often with corky ridges; trunk generally continuous into crown with stiff dependent lower branches; head narrow, "Hickorylike." ............................ Elm (Ulmus racemosa) p.32s 140. Twigs without corky ridges; trunk dividing into several limbs, spreading gradually upward and gracefully recurving; head broad, "Elm-like." ............... White Elm (Ulmus americana) p.326

\section{THE MULBERRIES Morus.}

Leaf-scars alternate, 2-ranked, nearly circular; stipule-scars narrow; bundle-scars projecting in a closed ring or irregularly scattered; terminal bud absent; bud-scales 2-ranked; twigs with milky juice. 
141. Buds about as broad as long, more or less flattened and appressed, generally under $4 \mathrm{~mm}$. long; bud-scales reddish brown without darker margins. .............. White Mulberry (Morus alba) w.334

141. Buds longer than broad, not at all or but slightly flattened, divergent, generally over $5 \mathrm{~mm}$. long; bud-scales greenish brown with darker margins. .............. Red Mulberry (Morus rubra) p.332

\section{THE MAGNOLIAS}

Magnolia.

Terminal bud much larger than lateral buds; bud-scales valvate, united in pairs to form a cap, corresponding to stipules, each pair enclosing in succession an erect folded leaf connected with the next inner pair of scales; the unmatured leaf which belongs to the outer pair of stipular scales falling off in autumn and leaving a scar on side of bud with a decurrent ridge below, representing its leaf stalk; stipule-scar narrow, encircling the twig; leaf-scars alternate, more than 2-ranked, broad, oval to narrow crescent-shaped, bundle-scais numerous, irregularly scattered or in a double row; twigs aromatic; fruit a cone made up of numerous follicles which split open in the autumn and let out the large flattish seeds.

142. Buds large 25-50 mm. long; twigs stout; leaf-scars large ... 143 142. Buds small 10-20 mm. long; twigs slender; leaf-scars small ... 144

143. Buds densely pale-downy; twigs light yellowish to bluish-green, more or less downy, fruit nearly spherical. Large-leaved Magnolia. Large-leaved Cucumber Tree, Large-leaved Umbrella Tree....... ............ (Magnolia macrophylla Michx.) under Comparisons $\mathbf{1} .336$

143. Buds smooth; twigs brown; fruit elongated. ...................... Umbrella Tree (Magnolia tripetaia)

144. Twigs brown; leaf-scars narrow, crescent to U-shaped; buds blunt, densely downy; bark flaky; a tree; in New England found only in cultivation. ........ Cucumber Tree (Magnolia acuminata) p.336

144. Twigs and buds bright green; leaf-scars oval to broadly crescentshaped; buds pointed, with long, silky hairs, often nearly smooth; pith with more or less distinct transverse woody partitions in the ground mass; bark smooth; in New England usually a shrub, growing wild in deep swamps in Eastern Massachusetts, also extensively cultivated. Sweet IBay, Swamp Bay, Laurel Magnolia, Beaver Tree. (Magnolia virginiana L.; M. glauca L.) .............

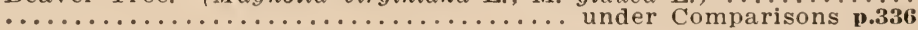

\section{THE CHERRIES, PLUMS AND PEACH}

\section{Prunus.}

Leaf-scars alternate, more than 2-ranked; bundle-scars 3 ; stipule-scars present, inconspicuous, or absent; buds with scales overlapping in several rows; terminal bud present or absent; fruit a drupe.

145. Terminal bud present ........................ 146

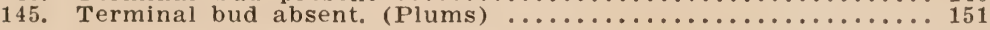

146. Twigs densely speckled with very minute pale dots, brightly colored, generally green-yellow below and more or less reddish above and highly polished; buds generally densely downy at least toward apex; collateral buds usually present.

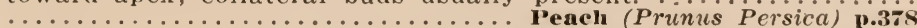

146. Twigs not densely speckled with very minute dots; buds not densely downy; collateral buds absent (occasionally present in Wild Red Cherry) $\ldots \ldots \ldots \ldots \ldots \ldots \ldots \ldots \ldots \ldots \ldots \ldots \ldots \ldots \ldots$

147. Buds clustered at tips of all shoots; twigs under $2 \mathrm{~mm}$. thick.

147. ……......... Wll Red Cherry (Prunus pennsylvanica) p.366 (1) or clustered only on short fruit spurs; twigs generally over $2.5 \mathrm{~mm}$. thick ..........................

148. Short stout slow-growing fruit spurs present with buds clustered

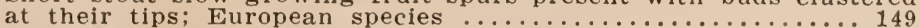

148. Short fruit spurs absent; native species $\ldots \ldots \ldots \ldots \ldots \ldots \ldots \ldots \ldots 150$ 
149. Habit erect, generally with a central leader 149. Habit spreading, without central leader; buds smaller; twigs more slender. ................... Sour Cherry (Prunus Cerasus) p.370

150. Bud-scales gray-margined; buds generally over $5 \mathrm{~mm}$. long; bark

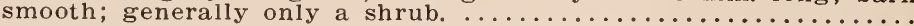

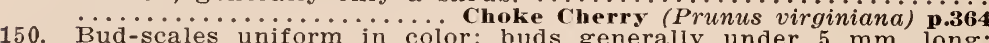
Bud-scales uniform in color; buds generally under $5 \mathrm{~mm}$. long; bark becoming rough-scaly; a small to large tree. .............. ................. Wild Black Cherry (Prunus serotina) p.362

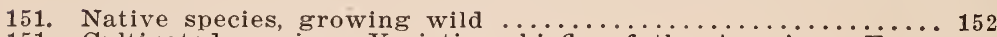
151. Cultivated species. Varieties chiefiy of the American, European, $\ldots \ldots \ldots \ldots \ldots \ldots \ldots$ or Japanese type of Plum. p.374

152. Buds generally under $4 \mathrm{~mm}$. long

152. .............. American Wild Plum (Prunus americanaj p.374 152. Buds generally over $4 \mathrm{~mm}$. long. Canada Plum (Prunus niyra) p.372

\section{THE SUMACHS}

\section{Rhus.}

Shrubs or small trees with pithy twigs and milky or watery juice; leaf-scars alternate, more than 2-ranked; bundle-scars numerous scattered or in a single curved line; stipule-scars absent; terminal bud present or absent; fruit a small drupe borne on erect or drooping clusters.

153. Terminal bud present; fruit smooth white in loose drooping clusters. ..................... Poison Sumach (Rhus Vernix) p.394

153. Terminal bud absent; fruit more or less hairy, red, in dense erect

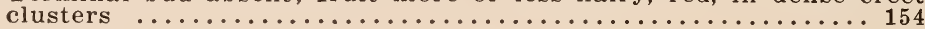

154. Leaf-scars narrow, V-shaped, nearly encircling the buds; cut twig

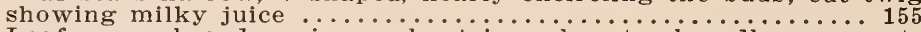

154. Leaf-scars broader; inversely triangular to broadiy crescentshaped; twig with watery juice and resinous taste. ............... ........ Dwarf Sumach (Rhus copallina) under Comparisons p.392

155. Twigs densely hairy. ..... Staghorn Sumach (Rhus typhina) p.392

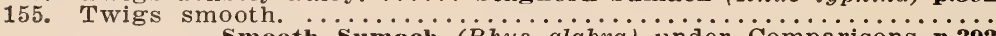
........ Smooth sumach (Rhus glabra) under Comparisons p.392

\section{THE MAPLES}

Acer.

Leaf-scars opposite, narrow $\bar{U}$ or V-shaped; bundle-scars conspicuous, equidistant, typically 3 , though sometimes each of these becomes compounded; fruit winged, in pairs.

156. Conspicuous, narrow tooth present between leaf-scars ..... 157

156. Conspicuous tooth absent from between leaf-scars ............ 159

157. Buds white-downy, collateral buds generally present, twigs generally with a bloom. .............. Box Elder (Acer Negundo) p.412

157. Buds smooth, collateral buds never present, twigs without bloom

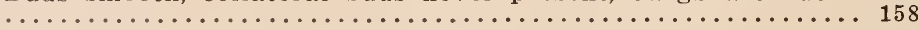

158. Buds with only one pair of scales visible, older branchlets whitestreaked. ............. Striped Maple (Acer pennsylvanicum) p.398

158. Buds with several pairs of scales visible, branchlets not whitestreaked. ............... Norway Maple (Acer platanoides) p.408

159. Outer single pair of bud-scales equalling the bud in length, their edges meeting and enclosing the bud, therefore generally only one pair of scales visible; pith brown; shrubs or at the most

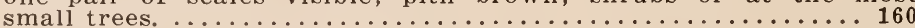

159. Outer pair of scales shorter than bud, their edges not meeting. therefore several pairs of scales visible; trees .............. 161

160. Buds and twigs stout, smooth; young bark with longitudinal white lines. ................. Striped Maple (Acer pennsylvanicum) p.398 
160. Buds and twigs more slender, both buds and twigs (at least toward tip) white-downy, white lines absent from bark. ..............

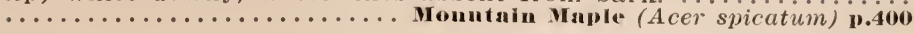

161. Buds brown, narrow, sharp-pointed, generally 4-8 pairs of closely

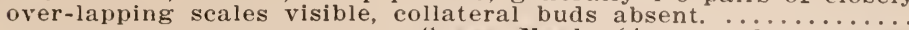

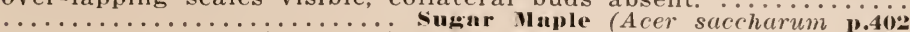

161. Buds red or green, broader, blunt-pointed, fewer scales visible 162

162. Terminal buds small, red, generally under $5 \mathrm{~mm}$. long and not distinctly larger than lateral buds; collateral buds generally

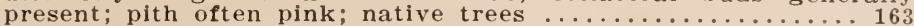

162. Terminal buds large, stout, generally over $5 \mathrm{~mm}$. iong and generally distinctly larger than lateral buds; collateral buds never present; European trees ......................... 164

163. Broken twigs with rank odor, bark falling away in large, thin flakes on old trees, branchlets strongly tending to grow downward and curve upward at their tips.

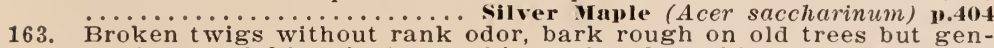
erally not flaking in large thin scales, branchlets less markedly curved. ....................... Red Maple (Acer rubrum) p.406

164. Buds red, inner scales covered with rusty wool; adjacent edges of leaf-scars meeting and forming a slight projection; bark closeridged, not flaky. ........ Norway Maple (Acer platanoides) p.40s

164. Buds green, inner scales white-woolly, edges of leaf-scars not

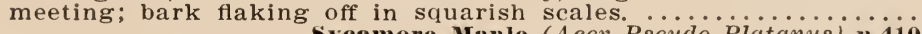

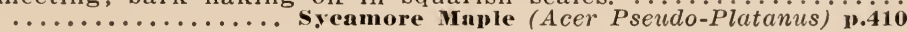

\section{THE ASHES Fraxinus.}

Leaf-scars opposite, large, conspicuous; bundle-scars numerous, minute, forming a curved line often more or less confluent; buds stout, scurfy, brown or black with ovate bud-scales opposite in pairs; twigs stout and brittle; fruit winged.

165. Leaf-scars deeply concave on upper margin.

..................... White Ish (Fraxinus ainericana) p.422

165. Leaf-scars not deeply concave on upper margin, semicircular to

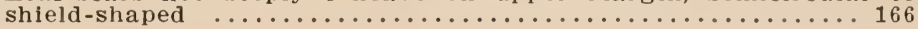

166. Bark soft-scaly; buds generally black; last pair of leaf-scars generally some distance below end of twig giving a stalked-like

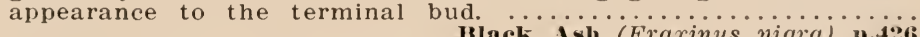

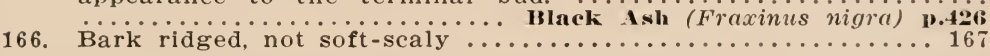

167. Buds black; trees found only in cultivation. ...................

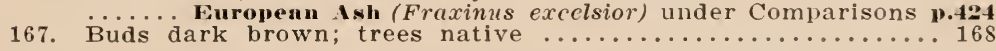

168. Twigs downy. ........... Red Ish (Fraxinus pennsylvanica) p.424

168. Twigs smooth. Green ish (Fraxinus pennsylvanica, var. lanceolata)

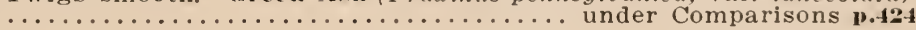




\section{WHITE PINE \\ Soft Pine, Weymouth Pine.}

Pinus Strobus L.

HABIT-The tallest conifer of New England, 50-80 ft. high with a trunk diameter of 2-4 ft., in virgin forests of northern New England trees have been found over $150 \mathrm{ft}$. in height with a trunk diameter of 7 ft.; trunk straight, tapering gradually, normally continuous into the crown, with wide-spreading, horizontal limbs, in young trees generally arising in whorls of five, and with secondary branches in the same plane, producing characteristic horizontal layers; head broadly conical, spray delicate, bluish-green.

BAIK-On young trunks and branches, smooth, greenish-brown, becoming fissured into comparatively shallow, broad, flat-topped, longitudinal ridges.

TWIGS-Slender, light brown, smooth or slightly hairy, resinous.

LEAVES-In clusters of 5 , without sheaths in winter, soft, bluishgreen, flexible, 3-5 inches long, slender, 3-sided. MICROSCOPIC SECTION-showing a single fibro-vascular bundle, 1 or 2 peripheral resin-ducts, a single layer of strengthening cells only beneath the epidermis, stomata only on the two inner sides.

HUDS-Ovate to oblong, about $1 \mathrm{~cm}$. long, sharp-pointed, bud-scales long, pointed, yellowish-brown.

FRUI'T-Cones, 4-10 inches long, stalked, arooping, cylindrical and more or less curved. SCALES-thin, not thickened at apex and without spines. Seeds winged.

COMPARISONS-The White Pine is the only Pine of New England that has 5 needles in a cluster. The layered arrangement of its secondary branches enables it to be recognized as far as it can be seen. Young trees can be further distinguished from the Pitch or Red Pines by the greater delicacy and bluer color of the leafage. Frequently the terminal bud of the central leader is killed by an insect, the Pine Weevil, thus interrupting the growth and causing one or more of the young lateral branches to grow erect to take its place. Gnarled old specimens which have many times in their lifetime suffered these insect injuries may present a rather picturesque appearance but are of little value for lumber. The tree photographed perhaps had its leader killed when young, but despite the three erect limbs which have taken the place of the single leader it still shows the outline characteristic of the species.

DISTRIBUTION-In fertile soils; moist woodlands or dry uplands; often planted for ornament, wind-breaks and for reforestation. Newfoundland and Nova Scotia, through Quebec and Ontario to Lake Winnipeg; south along the mountains to Georgia, ascending to 2,500 feet in the Adirondacks and to 4,300 feet in North Carolina; west to Minnesota and Iowa.

IN NEW ENGLAND-Common, from the vicinity of the sea coast to altitudes of 2,500 feet, forming extensive forests.

WOOD-Light, not strong, straight-grained, easily worked, light brown often slightly tinged with red, largely manufactured into lumber, shingles and laths, used in construction, for cabinet-making, the interior finish of buildings, woodenware, matches and the masts of vessels. 

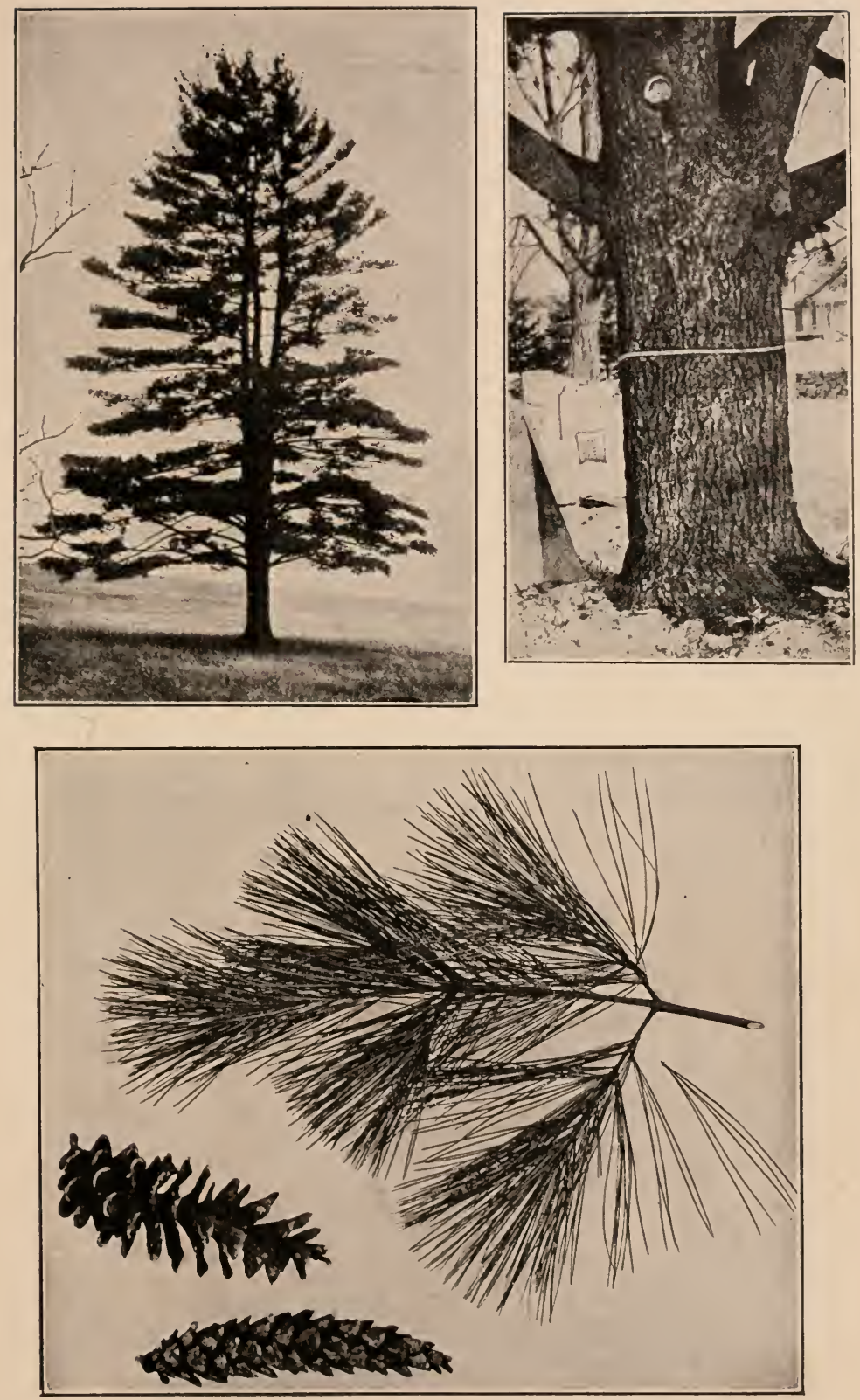

White Pine 


\section{PITCH PINE Hard Pine, Yellow Pine.}

Pinus rigida Mill.

HABIT-Generally a low tree 30-50 ft. in height with a trunk diameter of 1-2 ft. occasionally 70-80 ft, in height with trunk diameter of 2-4 ft.; trunk more or less tapering, branches thick, gnarled, often drooping, forming an open pyramidal or oblong head; foliage in coarse rigid, yellowish-green tufts. Dead branches and old persistent cones are frequent and the tree has generally a decidedly scraggly appearance.

BIIK-On young trunks and branches rough, broken into reddish brown scales, with age becoming deeply furrowed into broad flattopped ridges separating on the surface into rather loose dark reddishbrown scales. Clusters of leaves and short branches are not infrequently formed directly from the old trunk (see in photograph above the tape measure.)

TWIGS-Stout, light brown, not downy, roughened especially after the fall of the leaves by the decurrent bases of scales subtending the leafclusters.

LEAVES-In clusters of 3 , with persistent sheaths, yellowishgreen, 2-5 inches long, stout, stiff, spreading with pointed tips. MICROSCOPIC SECTION-3-sided, showing 2 fibro-vascular bundles, resin-ducts located intermediate between bundles and periphery, strengthening cells beneath the epidermis in patches several layers thick, generally surrounding the resin-ducts and at one side of the vascular bundles, stomata on all three sides.

BLDS-Cylindrical to ovate, pointed, resin-coated, scales reddishbrown.

FRIIT-Cones $1 \frac{1}{2}-4$ inches long, without stalks, ovate becoming more or less spherical when opened, borne laterally, singly or in clusters at about a right angle to the twig, often remaining on the branches for ten or a dozen years and frequently found on trees only a few feet high. SCALES-thickened at tip and with a stiff recurved prickle.

COMPARIsons-The Pitch Pine is the only native Pine in New England that has three needles in a cluster. Its ragged appearance with frequent dead branches, persistent cones, and yellowish-green, stiff foliage renders it easily distinguished from the White and Red Pines without examination of the needles.

DISTRIBITIOV-Most common in dry, sterile soils, occasional in swamps. New Brunswick to Lake Ontario; south to Virginia and along the mountains to northern Georgia; west to western New York, Ohio, Kentucky and Tennessee.

IN NEW ENGLAND-Maine-mostly in the southwestern section near the seacost; as far north as Chesterville, Franklin county; scarcely more than a shrub near its northern limits; New Hampshire-most common along the Merrimac valley to the White Mountains and up the Connecticut valley to the mouth of the Passumpsic, reaching an altitude of 1,000 feet above the sea level; Vermont-common in the northern Champlain valley, less frequent in the Connecticut valley; Connecticut-rare or local in Litchfield county, frequent elsewhere; common in the other New England states, often forming large tracts of voodland, sometimes exclusively occupying extensive areas.

WOOD-Light, soft, not strong, brittle, coarse-grained, very durable, light brown or red, with thick yellow or often white sapwood; largely used for fuel and in the manufacture of charcoal; occasionally sawed into lumber. 


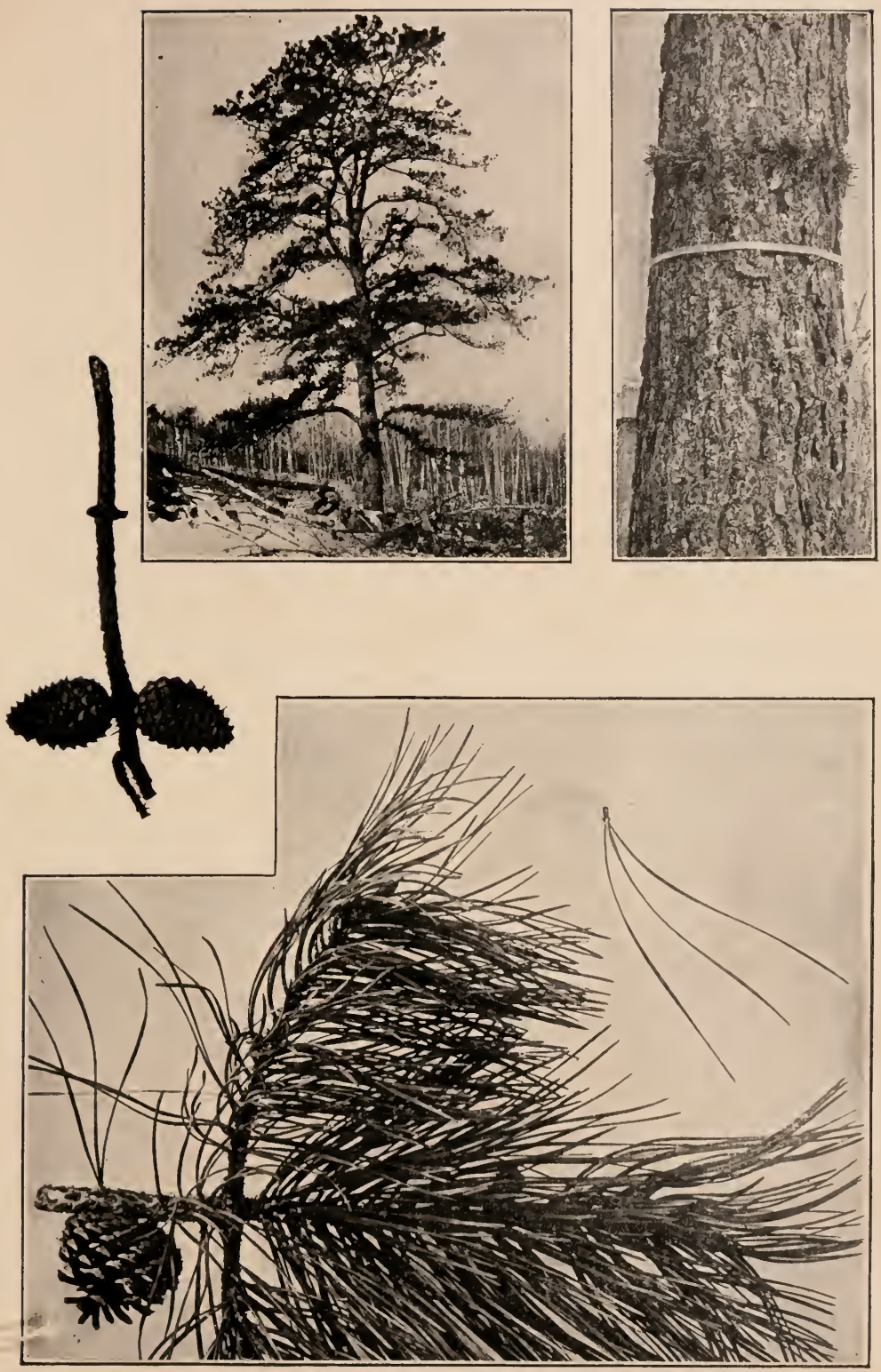

Pitch Pine 


\section{JACK PINE \\ Northern Scrub Pine, Gray Pine, Spruce Pine. \\ Pinus Banksiana Lamb.}

$P$. divaricata auth.

HABIT-Usually a low tree, 15-30 ft. in height with a trunk diameter of 6-8 inches, under favorable conditions becoming 50-60 ft. high with a trunk diameter of 10-15 inches; with large spreading branches forming an open symmetrical head resembling somewhat the Spruce in regularity of outline or on exposed windy situations and in poor soil becoming stunted with gnarled stem and irregular scraggly distorted head.

BARK-Dark reddish-brown with irregular rounded edges roughened with close scales.

TWIGS-Rather slender, reddish to purplish brown, not downy, roughened by scales subtending leaf-clusters.

LEAVES-In clusters of 2 with short persistent sheaths, dark yellowish-green, $1 / 2-1 \frac{1}{2}$ inches long, stout, stiff, generally curved and twisted, flatened or concave on one side, rounded on the other, tip pointed. MISCROSCOPIC SECTION-showing 2 widely separated fibro-vascular bundles, resin-ducts located intermediate between bundles and periphery, a single layer of strengthening cells around the resinducts and one or more layers beneath the epidermis.

BLDS-Ovate, short-pointed, coated more or less thickly with resin.

FRUIT-Cones 1-2 inches long, without stalks, conic-oblong usually curved and pointed forward, appearing between or sometimes at the whorls of lateral branches, more or less distorted, remaining closed for several years, persisting on the tree often for a dozen years. SCALES-in young cones with an incurved prickle, when mature thickened at the apex without spines or prickles.

COMPARISONS-The short yellowish-green needles of the Jack Pine will distinguish this species from other Pines. The longest needles sometimes approach in size short needles of the Scotch Pine, but those of the Scotch Pine are of a bluish-green color and moreover their cones point backward instead of forward as in the Jack Pine.

DISTRIBUTION-Sterile, sandy soil; lowlands, boggy plains, rocky slopes. Nova Scotia, northwesterly to the Athabasca river, and northerly down the Mackenzie to the Arctic circle; west through northern New York, northern Illinois and Michigan to Minnesota.

IN NEW ENGLAND-Maine-Traveller Mountain ' and Grand Lake; Beal's Island on Washington county coast, Harrington, Orland and Cape Rosier; Schoodic peninsula in Gouldsboro, a forest $30 \mathrm{ft}$. high; Flagstaff; east branch of Penobscot; the Forks; Lake Umbagog; New Hampshire-around the shores of Lake Umbagog, on points extending into the lake rare: Welch mountains; Vermont-rare, but few trees at each station; Monkton in Addison county; Fairfax, Franklin county; Starkesboro.

wOOD-Light, soft, not strong, close-grained, clear pale brown or rarely orange color with a thick nearly white sapwood; used for fuel and occasionally for railroad ties and posts; occasionally manufactured into lumber. 

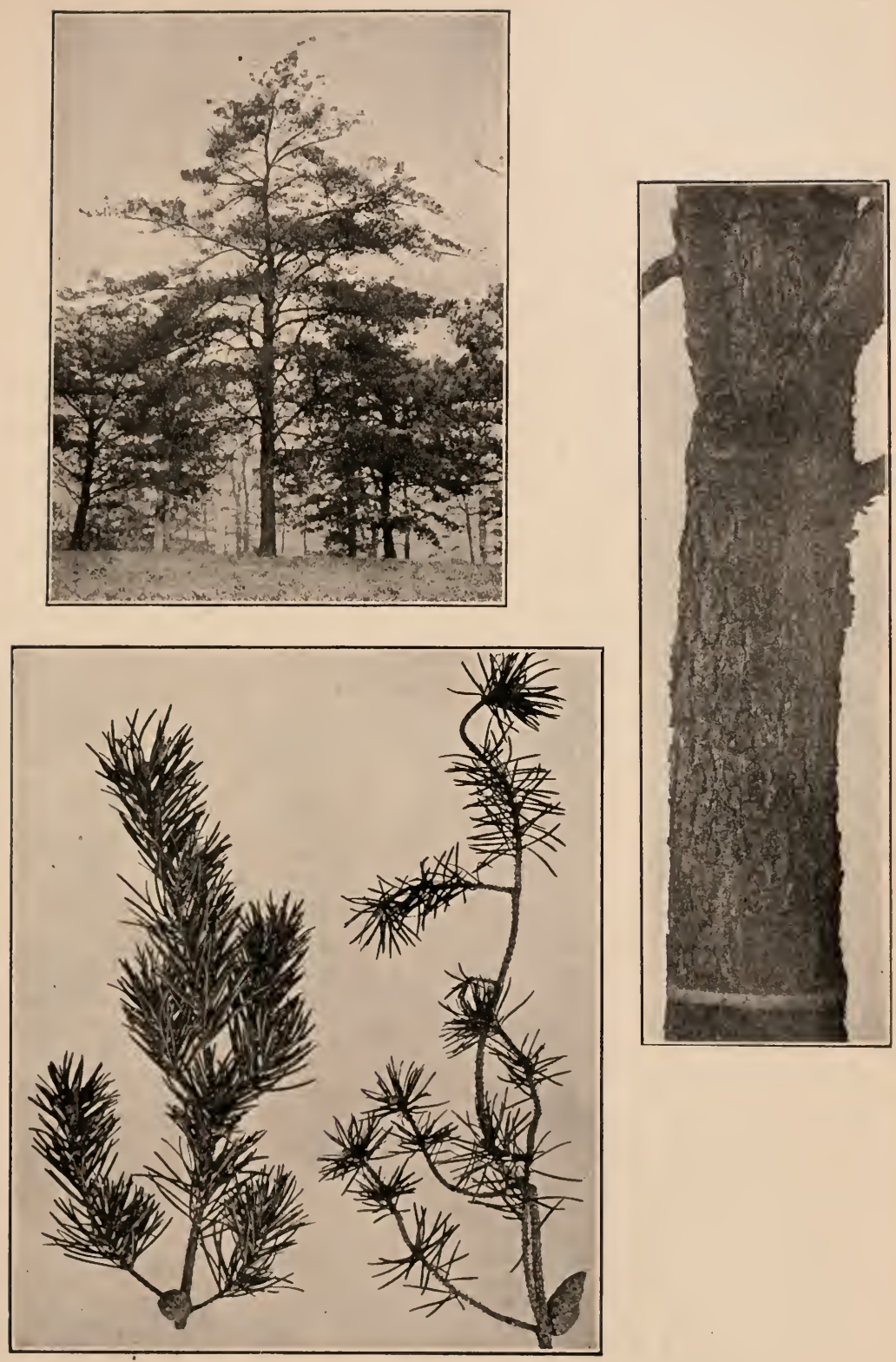

JACK PINE 


\section{RED PINE \\ Norway Pine.}

Pinus resinosa Ait.

НА ВIT-A tree 50-75 ft. in height with a trunk diameter of 2-3 $\mathrm{ft}$., in Maine, reaching a height of over $100 \mathrm{ft}$; trunk erect, continuous into the crown with stout spreading branches often dependent and ascending at their tips, more distinctly whorled than in the Pitch Pine, in young trees clothing the trunk to the ground, forming a broadly pyramidal head becoming irregularly round-topped with age. Foliage in long flexible dark green tufts.

B.IRI- - Reddish-brown, with shallow flat ridges, separating off in irregular thin flaky scales.

TWIGs-Stout, light reddish-brown, not downy, roughened by decurrent scales subtending leaf clusters especially toward base of each year's growth.

LEAVES-In clusters of 2, with long persistent sheaths, dark green, shining, 3-6 inches long, slender, soft flexible, flattened on one side, rounded on the other, with pointed tip. MICROSCOPIC SECTION - showing 2 fibro-vascular bundles, peripheral resin-ducts, a single layer of strengthening cells beneath the epidermis and around the resin-ducts, stomata all around.

BUDS-Oblong to conical, pointed; scales reddish-brown.

FRUIT-Cones about 2 inches long, without stalks, ovate-conical, when opened more or less spherical, making a right angle with the stem, ripened cones remaining on the tree during winter. SCALES-thickened at apex but without spines or prickers.

COMPIRISONS-The Red Pine with two long needles in a cluster should not be confused with our other native New England Pines. It resembles, however, the Austrian Pine, but may be distinguished from this species by its more slender flexible needles (see under Austrian Pine).

DISTRIIITION-In poor soils; sandy plains, dry woods. Newfoundland and New Brunswick, throughout Quebec and Ontario, to the southern end of Lake Winnipeg; south to Pennsylvania; west through Michigan and Wisconsin to Minnesota.

IN NEW ENGLAND-Maine-common, plains, Brunswick, (Cumberland county;) woods, Bristol (Lincoln county;) from Amherst (western part of Hancock county) and Clifton (southeastern part of Penobscot county) northward just east of the Penobscot river, the predominant tree, generally on dry ridges and eskers, but in Greenbush, and Passadunkeag growing abundantly on peat bogs with Black Spruce; hillsides and lower mountains about Moosehead, scattered; New Hampshire-ranges with the Pitch Pine as far north as the White Mountains, but is less common, usually in groves of a few to several hundred acres in extent; Termont-less common than the White or the Pitch Pine, but not rare; Massachusetts-still more local, in stations widely separated, single trees or small groups; Connecticut-rare or local; Granby, Salisbury; Rhode Island-occasional.

WOOD-Light, hard, very close-grained, pale red, with thin yellow often nearly white sapwood; largely used in the construction of bridges and buildings, for piles, masts and spars. The bark is occasionally used for tanning leather. 

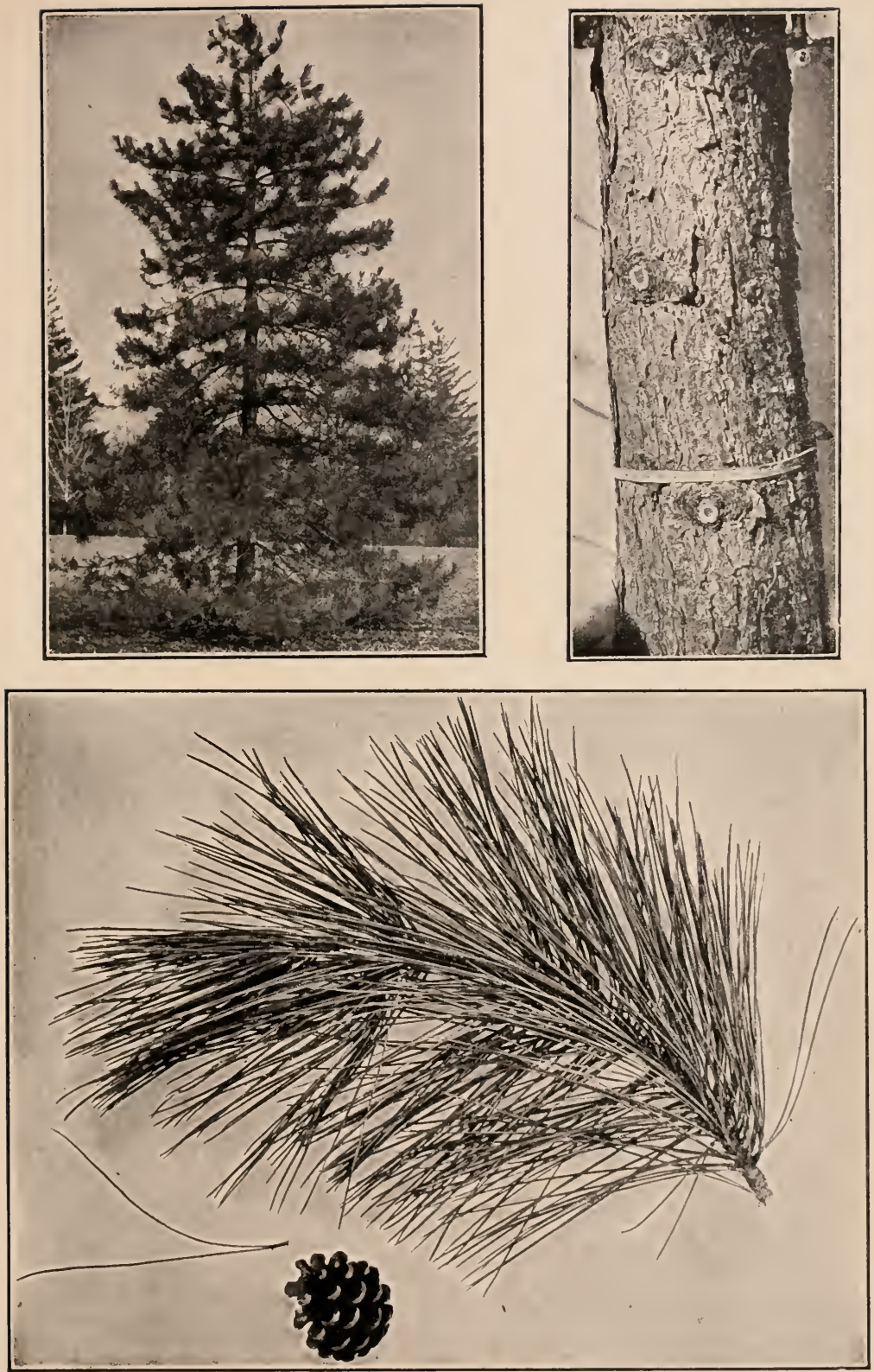

Red Pine 


\section{AUSTRIAN PINE} Black Pine.

Pinus Laricio, var. austriaca Endl.

HABIT-A tall tree reaching $60-80^{\circ} \mathrm{ft}$. in height; trunk erect continuous into the crown, branches in young trees regularly whorled, foliage in rigid dark green tufts.

BARK-Grayish-brown, roughened with scaly ridges, reddish-brown within.

TWIGS-Stout, yellowish-brown, not downy, roughened by decurrent scales subtending leaf-clusters especially toward base of each year's growth.

LEAVES-In ciusters of 2, with relatively short persistent sheaths, dark dullish green, 3-5 inches long, rigid, flattened on one side, rounded on the other, sharp-pointed. MICROSCOPIC SECTION-showing 2 fibro-vascular bundles, resin-ducts located intermediate between bundles and periphery, strengthening cells beneath the epidermis in patches several layers thick also surrounding the resin-ducts and on one side of the fibro-vascular bundles, stomata all around.

BUDS-Oblong-conical, pointed, sometimes covered with a white resin.

FRUIT-Cones 21/4-3 inches long, without stalks, ovate-conical, becoming broadly ovate when opened, making about a right angle with the stem. SCALES-thickened at apex, generally with a short dull spine.

COMPARISONS-The Austrian Pine resembles most closely the Red Pine among our New England species. The stiff character of its sharp-pointed leaves in distinction to the soft flexible leaves of the Red Pine may be observed by striking the open hand against a tuft of the needles. The winter twigs of the Austrian Pine are yellowishbrown, those of the Red Pine are bright reddish-brown. The microscopic sections of the leaves of the two species are very distinct.

DISTRIBUTION-A native of Europe but frequently cultivated in this country as an ornamental tree and to some extent used in forest planting.

wOOD-Light, soft, rich in turpentine and very durable. In Europe the wood is used as a building timber and turpentine is obtained from the tree. 

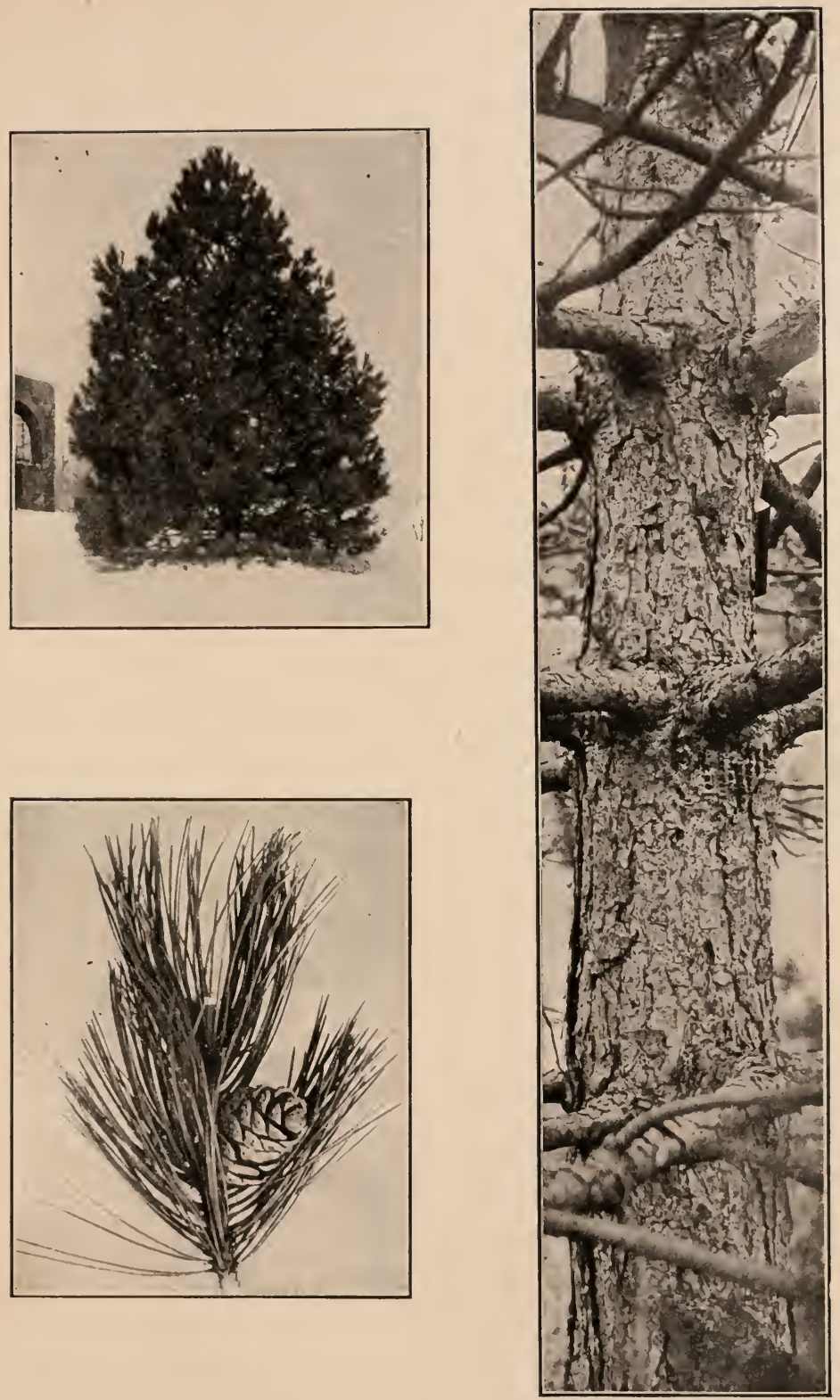

Austrian Pine 


\section{SCOTCH PINE}

Scotch "Fir."

Pinus Sylvestris L.

HABIT-A tree up to 70 feet or occasionally $120 \mathrm{ft}$. in height; as cultivated in this country in the open, often a low branching tree with more or less pendant limbs and inclined trunk presenting a rather straggling or unkempt appearance; frequently of more erect habit, especially in company with other trees.

BARK-Grayish-brown, scaly, upper part of trunk and branches characteristically smoothish in appearance by flaking off of the outer bark in thin papery light-reddish layered scales.

TWIGS-Of medium thickness, dull grayish-yellow, not downy, roughened by scales subtending leaf clusters.

LEAVES-In clusters of 2, persistent, sheaths becoming lacerated, dull bluish-green $1 \frac{1}{2}-3 \frac{1}{2}$ inches long, stiff, generally twisted, flat or concave on one side, rounded on the other, pointed. MICROSCOPIC SECTION-showing 2 fibro-vascular bundles, peripheral resin-ducts, strengthening cells around resin-ducts, at one side of the bundles and benath the epidermis, stomata all around.

BUDS-Oblong-conical, brown, often somewhat resinous-coated.

FRUIT-Cones $1 \frac{1}{2}-2 \frac{1}{2}$ inches long, short-stalked, grayish or reddish brown, conic-oblong, generally appearing with the whorls of lateral branches, usually pointing backward. SCALES-in young cones with a short projection which when mature may persist as a short weak inconspicuous point or is deciduous, apex of scale thickened with a more or less prominent four-sided boss often recurved especially toward base of cone.

COMPARISONS-The Scotch Pine often improperly called Scotch "Fir" may be distinguished from the other Pines native or cultivated in New England by the bald reddish appearance of the upper part of trunk and branches, the short bluish-green leaves and the backward-pointing cones.

DISTRIBUTION-A European tree cultivated abroad in extensive forests for its timber. In this country more or less planted as an ornamental tree, and sparingly escaped from cultivation. In Connecticut rare or local as an escape; New London, Lyme, Southington, Bridgeport.

woOD-Light, soft, reddish-brown, with thick light yellowish or reddish sapwood, easily split and durable, corresponding in importance abroad to the White Pine in this country. 

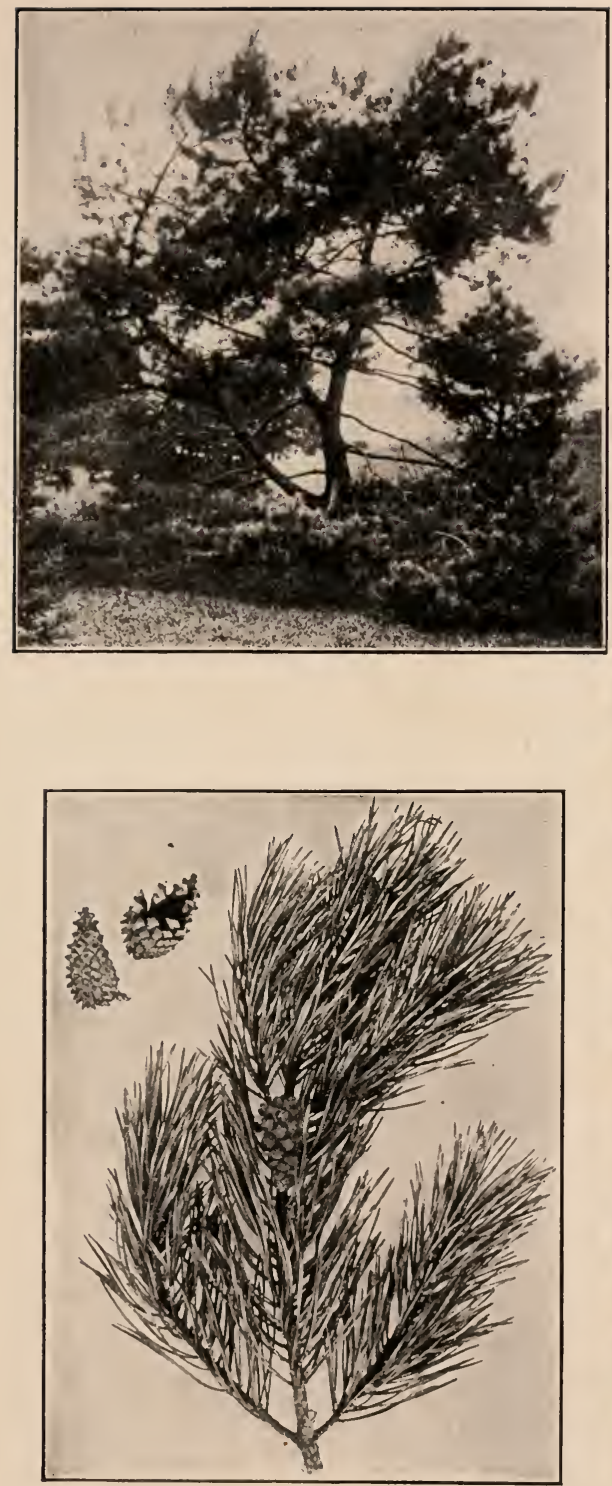

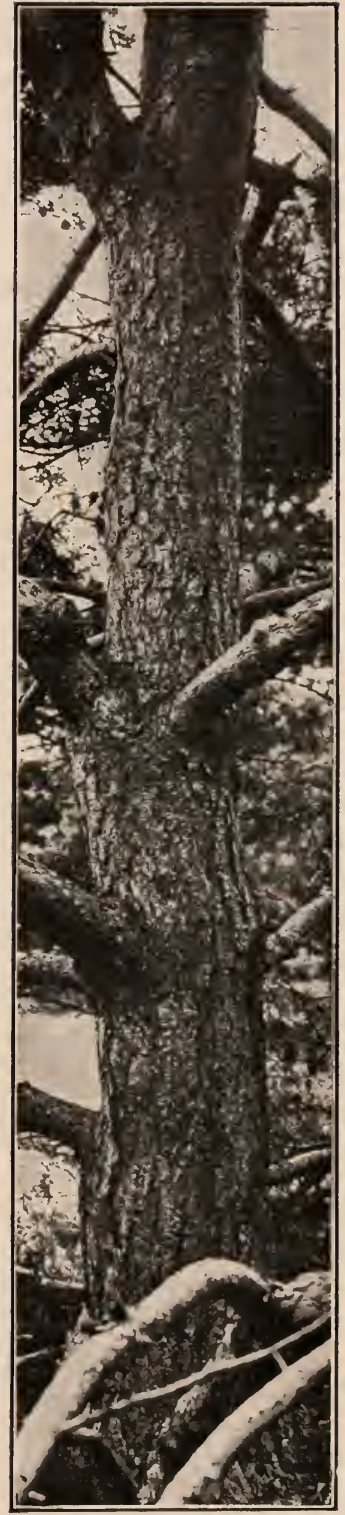

Scoten Pine 


\section{AMERICAN LARCH \\ Tamarack, Hackmatack, Black Larch, "Juniper." Larix laricina (Du Roi) Koch.}

L. americana Michx.

HABIT-A tree 30-70 ft. in height, with a trunk diameter of 1-3 ft., at high altitudes reduced to 1-2 feet in height; trunk erect continuous into the crown, branches irregular or indistinctly whorled, in young age and when crowded and in swamps forming a narrow symmetrical pyramidal head, in old age becoming broader and of irregular form. The Larch is the only New England cone-bearing tree that sheds its leaves in the fall; specimens in winter consequently are frequently mistaken for dead trees.

BARK-On young trunks smooth, with age becoming roughened with thin, close, reddish-brown, roundish scales.

TWIGS-Slender, smooth, pale orange colored to reddish-brown with short lateral wart-like branches, with resinous taste.

LEAF-SCARS-Scattered on rapidly grown shoots, very numerous and strongly decurrent, minute, triangular, with a single bundle-scar: also on short wart-like branches, smaller and densely clustered.

BUDS-Scattered along last season's twigs, on older growth at the ends of the short lateral branches, small, about $1 \mathrm{~mm}$. long, spherical, reddish, shining.

FRUIT-Ovate, oblong cones, about $1 / 2-3 / 4$ inch long on short, stout incurved stalks, persistent on trees throughout winter. SCALES-thin, about a dozen or fewer in number.

COMPARISONS-The American Larch or Tamarack as it is more commonly called by woodsmen is hardly to be confused with any other tree except the European Larch [Larix decidua Mill.; L. europaea DC.]. The European Larch is a species adapted to dryer situations than the American form. It is readily distinguished by its stouter, yellower twigs, larger cones, about 1 inch long, with numerous cone scales (see lower twig in plate).

DIS'TRIBUTION-Low lands, shaded hillsides, borders of ponds; in New England, preferring cold swamps; sometimes far up mountain slopes. Labrador, Newfoundland and Nova Scotia, west to the Rocky mountains; from the Rockies through British Columbia, northward along the Yukon and Mackenzie systems, to the limit of tree growth beyond the Arctic circle; south along the mountains to New Jersey and Pennsylvania; west to Minnesota.

IN NEW ENGLAND-Maine, New Hampshire and Vermont-abundant, filling swamps acres in extent, alone or associated with other trees, mostly Black Spruce; growing depressed and scattered on Katahdin at an altitude of 4,000 ft.; Massachusetts-rather common at least northward; Connecticut-absent near the coast; rare in the eastern part of the state: Union, Tolland; becoming occasional westward and frequent in Litchfield county; Rhode Island-not reported.

WoOD-Very heavy, hard and strong, rather coarse-grained, very durable in contact with soil, bright light red, with thin nearly white sapwood; largely used for the upper knees of small vessels, fence posts, telegraph poles, railroad ties, in cabinet making and for interior finish of buildings. 


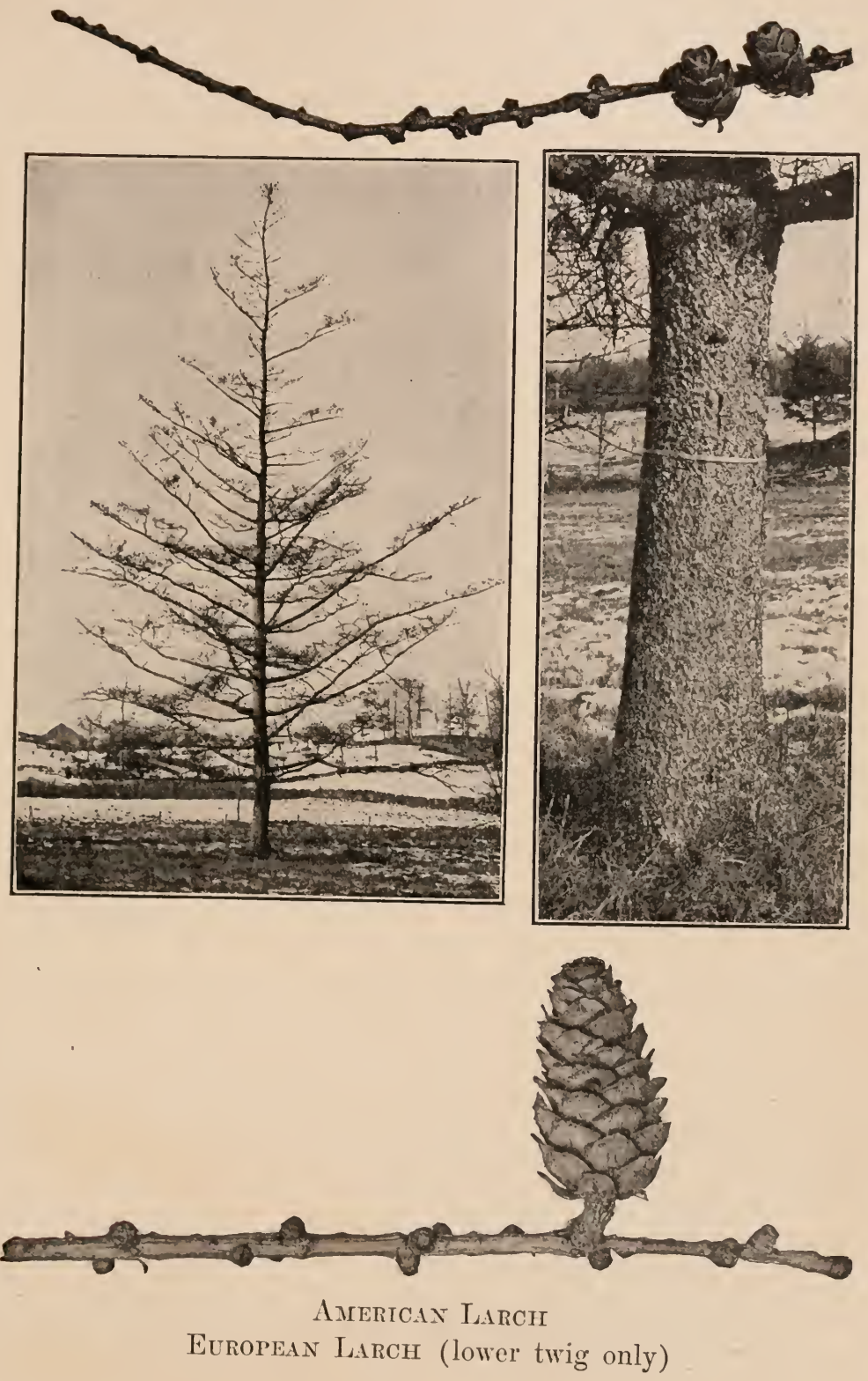




\section{WHITE SPRUCE \\ Cat, Skunk or Labrador Spruce.}

Picea canadensis (Mill.) BSP.

$P$. alba Link.

НАВІT-A tree 40-75 feet in height with a trunk diameter of 1-2 ft.; trunk straight, slowly tapering, branches numerous, slightly ascending or nearly horizontal, with numerous lateral, generally somewhat pendant branchlets, spread in more or less well marked dense planes, forming a broad-based pyramidal head; foliage bluish-green.

BARI--Grayish to pale reddish-brown; on young trunks and branches smoothish or slightly roughened becoming in a relatively late stage flaky with small closely appressed scales.

TWIGS-Light, yellc vish-brown, smooth.

LEAF-SCARS-Alternate, more than 2-ranked, on strongly projecting, decurrent ridges of the bark. BUNDLE-SCARS-single.

LEAVES-Bluish-green, 4-angled, 10-25 mm. long, blunt or sharppointed, straight or incurved, without proper leaf-stalks with a strong rank odor when bruised which is responsible for some of the common names.

BUDS-Ovate, blunt-pointed, light brown.

FRUIT-Oblong-cylindrical cones, $1 \frac{1 / 2-21 / 2}{2}$ inches long, generally falling the first winter. SCALES- thin, flexible and elastic; margin rounded or straight-topped, generally entire.

COMPARISONS-The White Spruce differs from our other native Spruces, the Red and the Black, by its smooth twigs, less scaly bark, rather longer and more nearly cylindrical cones and usually by the rank odor of its leaves; from the Red spruce further by its bluishgreen foliage. From the smooth-twigged Blue Spruce it is distinguished by its smaller cones and less distinctly layered arrangement of branches.

DISTRIBUTION-Low, damp, but not wet woods; dry, sandy soils, high, rocky slopes and exposed hilltops, often in scanty soil. Newfoundland and Nova Scotia, through the provinces of Quebec and Ontario to Manitoba and British Columbia, northward beyond all other trees, within 20 miles of the Arctic sea; west through the northern sections of the northern tier of states to the Rocky mountains. Sometimes cultivated as an ornamental tree.

IN NEW ENGLAND-Maine-frequent in sandy soils, often more common than the Red Spruce, as far south as the shores of Casco Bay; New Hampshire-abundant around the shores of the Connecticut river, disappearing southward at Fifteen-Mile falls; Vermont-restricted mainly to the northern sections, more common in the northeast; Massachusetts -occasional in the mountainous regions of Berkshire county; a few trees in Hancock; as far south as Amherst, and Northampton, probably about the southern limit of the species; Connecticut-rare, Waterford, a few trees in a pasture as an escape from cultivation; Rhode Islandnot reported.

WOOD-Light, soft, not strong, straight grained, light yellow, with hardly distinguishable sapwood; manufactured into lumber in the eastern provinces of Canada, and used in construction for the interior finish of buildings and for paper pulp. 

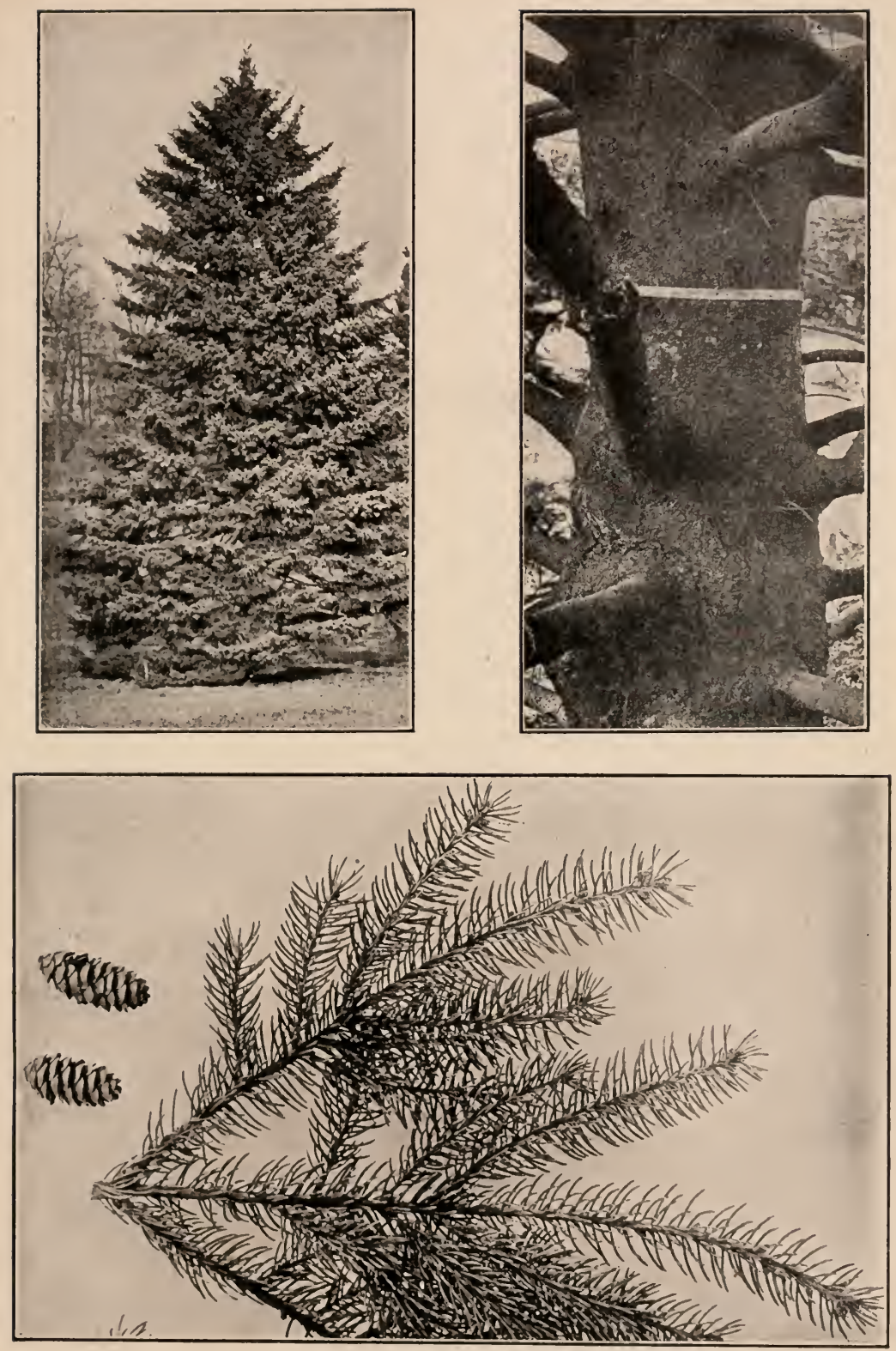

White Sprece 


\section{RED SPRUCE}

\section{Picea rubra (Du Roi) Dietr.}

P. nigra, var. rubra Engelm. ; P. rubens Sarg.

H.IBIT-A tree 40-75 ft, in height with a trunk diameter of $1-2 \frac{1}{2}$ ft.; trunk straight, slowly tapering; branches toward the middle of the tree horizontal with upcurved tips; more or less strongly declined toward the base forming a narrow conical head somewhat broader than that of the Black Spruce; foliage dark yellowish-green.

BARK-Reddish-brown, flaky with thin scales.

TWIGS-Brown, more or less densely covered with short rusty to black hairs.

LEAF-SCARS-Alternate, more than 2-ranked, on strongly projecting decurrent ridges of the bark. BUNDLE-SCARS-single.

LEAVES-Dark yellowish-green, 4-angled, 10-20 mm. long, bluntpointed, straight or curved, without proper leaf-stalks.

BUDS-Ovate, pointed, reddish-brown.

FRUIT-Ovate-oblong cones, 11/4-2 inches long, with short stalks not at all or but slightly recurved, falling the first autumn or sometimes remaining on the tree a year longer. SCALES-stiff, thin; margin rounded, entire or slightly toothed.

COMPARISONS-The Red Spruce from its close resemblance to the Black Spruce is considered by some authors as merely a variety of this latter species (see Black Spruce under Comparisons). It differs from the White and the Blue spruce by its hairy twigs and yellowish-green foliage and from the Norway Spruce by its shorter cones.

DISTRIBUTION-Cool, rich woods, well-drained valleys, slopes of mountains not infrequently extending down to the borders of swamps. Prince Edward Island and Nova Scotia along the valley of the St. Lawrence; south along the Alleghanies to Georgia, ascending to an altitude of 4,500 feet in the Adirondacks, and 4,000-5,000 feet in West Virginia; west through the northern tier of states to Minnesota.

IN NEW ENGLAND-Maine-throughout; most common towards the coast and in the extreme north, thus forming a belt around the central area, where it is often quite wanting except on cool or elevated slopes; New Hampshire-throughout; the most abundant conifer of upper Coos, the White Mountain region where it climbs to the alpine area, and the higher parts of the Connecticut-Merrimac watershed; Vermont -throughout; the common Spruce of the Green Mountains, often in dense groves on rocky slopes with thin soil; Massachusetts-common in the mountainous regions of Berkshire county and on uplands in the northern sections, occasional southward; Connecticut-rare, Litchfield, Canaan, Salisbury; Rhode Island-not reported.

WOOD-Light, soft, close-grained, not strong, pale, slightly tinged with red, with paler sapwood generally about 2 inches thick; largely manufactured into lumber in the northeastern states and used for the flooring and construction of houses, for the sounding-boards of musical instruments and in the manufacture of paper pulp. 

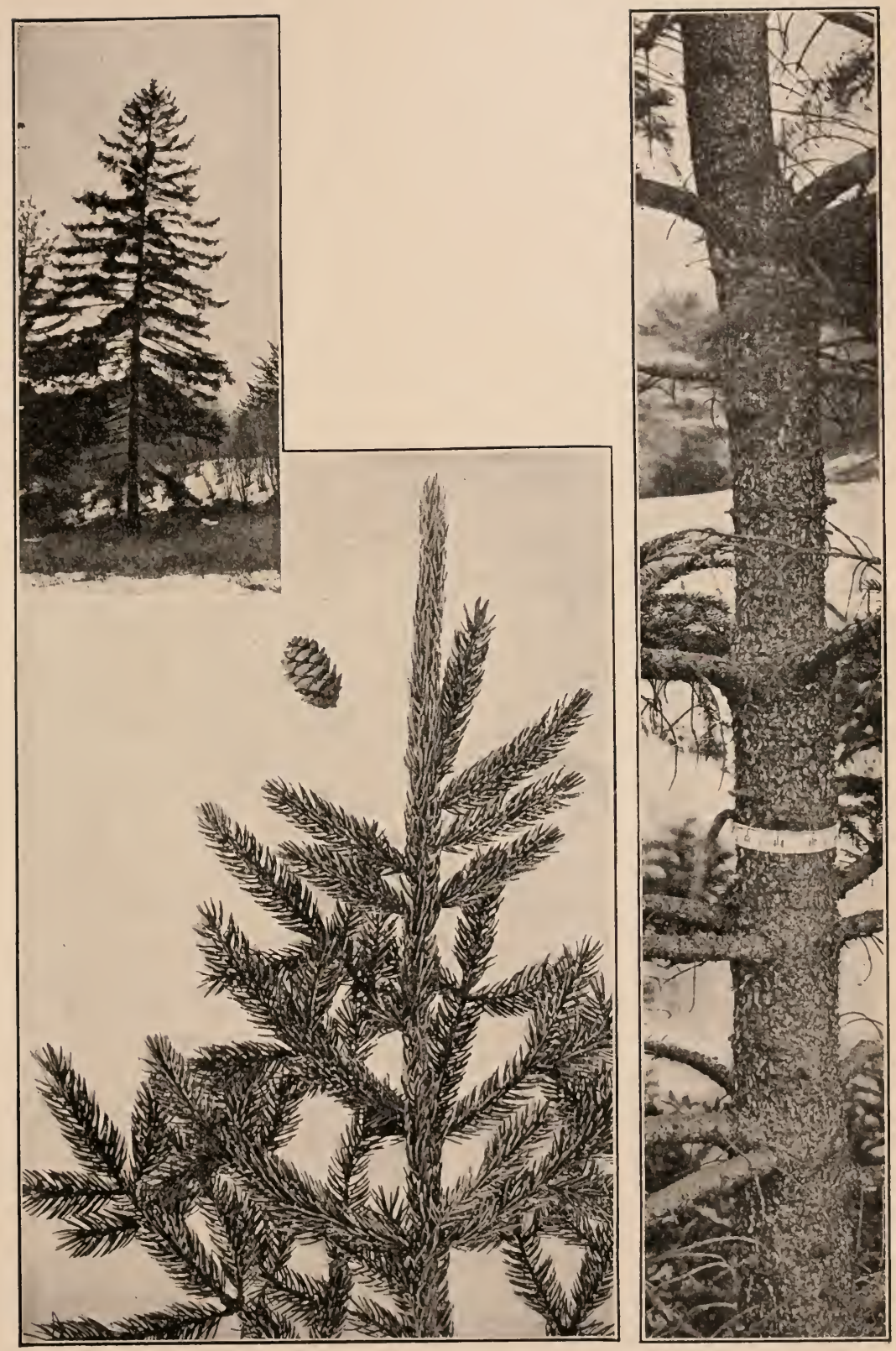

Red Spruce 


\title{
BLACK SPRUCE \\ Swamp, Bog, Water or Double Spruce. \\ Picea mariana (Mill.) BSP.
}

P. nigra Link; P. brevifolia Peck.

\begin{abstract}
HABIT-In New England usually a small slender tree 10-30 ft. in height with a trunk diameter of 5-8 inches, much larger northward and westward, reduced to a shrub 2-5 ft. in height at high altitudes; with relatively short, generally scattered branches, horizontal or usually declined and curving upward at the ends; in open-grown trees, basal branches frequently resting on the ground, taking root and sending up shoots; crown an irregular open narrow-based cone; foliage bluishgreen.
\end{abstract}

BARK-Grayish-brown, flaky, with thin scales.

TWIGS-Brown or yellowish-brown, more or less densely covered with short rusty to black hairs.

LEAF-SCARS-Alternate, more than 2-ranked, on strongly projecting decurrent ridges of the bark. BUNDLE-SCARS-single.

LEAVES-Bluish-green, 4-angled, 5-15 mm. long, blunt-pointed, straight or slightly incurved, without proper leaf-stalks.

BUDS-Ovate, pointed, reddish-brown.

FRU IT-Ovate cones, $1 / 2$ to $1 \frac{1}{2}$ inches long, becoming nearly spherical when open, on short strongly recurved stalks generally remaining on the tree for many years. SCALES-stiff, thin; margin rounded, uneven, ragged, toothed or rarely entire.

COMPARISONS-The Black Spruce closely resembles the Red Spruce from which it may be distinguished by its shorter, more nearly spherical cones which generally remain for many years on the tree, by the more ragged edging of the cone-scales, by the bluish-green color of its foliage and by its habitat in swampy land. Extreme forms of the two species are sufficiently distinct but they are often difficult to distinguish even in the fruiting condition.

DISTRIBUTION-Swamps, sphagnum bogs, shores of rivers and ponds, wet, rocky hillsides; not uncommon, especially northward, on dry uplands and mountain slopes. Labrador, Newfoundland, and Nova Scotia, westward beyond the Rocky mountains, extending northward along the tributaries of the Yukon in Alaska.

IN NEW ENGLAND-Maine-common throughout, covering extensive areas almost to the exclusion of other trees in the central and northern sections, occasional on the top of Katahdin $(5,215 \mathrm{ft}$.) ; New Hampshire and Vermont-common in sphagnum swamps of low and high altitudes; the dwarf form, var. semiprostrata, occurs on the summit of Mt. Mansfield; Massachusetts-frequent; Connecticut-swamps and sphagnum bogs; rare or local over most of the state but absent near the coast; usually a small stunted tree 5 to $15 \mathrm{ft}$. high but growing much larger in the cool swamps of Litchfield county; in open bogs the trees often produce cones when not more than $5 \mathrm{ft}$. high, and the cones persist on the tree for many years; Rhode Island-North Scituate.

wOOD-Light, soft, not strong, pale yellowish-white, with thin sapwood, probably rarely used outside of Manitoba and Saskatchewan except in the manufacture of paper pulp. Spruce gum is gathered from this and the other New England Spruces. Spruce beer is made by boiling the branches of the Black and Red spruces. 

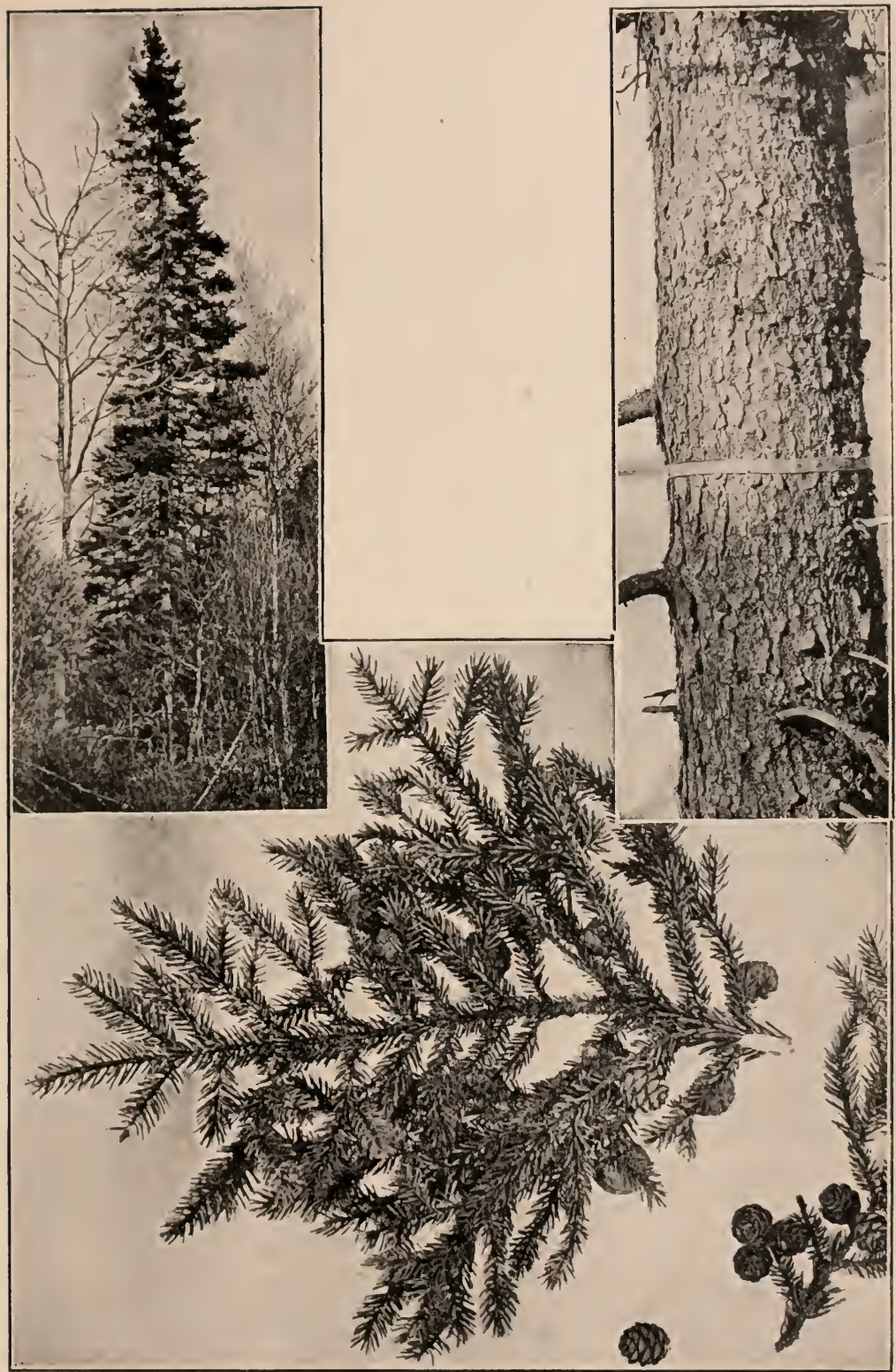

BLACK S'PRUCE 


\section{BLUE SPRUCE \\ Colorado Blue Spruce, Silver Spruce.}

Picea Menziesii Engelm.

P. Parryana (Andre) Sarg. ; P. pungens Engelm.

HABIT-A tree reaching in Colorado a height of $100 \mathrm{ft}$. and a trunk diameter of 2-3 ft., much-smaller in cultivation; branches rigid, horizontal with short, stout, stiff, lateral branchlets arranged in horizontal planes giving a layered effect to the tree, especially in the young stages; older trees becoming less regular with a thin, ragged, pyramidal crown; foliage bluish-green to silvery-white or rarely dull green.

BARK-Grayish-brown, scaly, becoming deeply ridged toward the base.

TWIGS-Bright yellowish to reddish-brown, smooth.

LEAF-SCARS-Alternate, more than 2-ranked, on strongly projecting decurrent ridges of the bark. BUNDLE-SCARS-single.

LEAVES-Bluish-green to silvery-white or rarely dull green, 4-angled, 25-30 mm. long on sterile branches, often not over half as long on fruiting branches, stout, stiff, sharp-pointed, incurved, without proper leaf-stalks, with a pungent somewhat disagreeable odor when bruised.

BUDS-Ovate, blunt-pointed, light brown.

FRUIT-Oblong-cylindrical cones $2 \frac{1}{2}$ to 4 inches long, generally not remaining on the tree after the second winter. SCALES-thin, distinctly longer than broad with narrowed, flexible, ragged, blunt tips.

COMPARISONS-The Blue Spruce as cultivated as an ornamental tree is strikingly distinct from other Spruces in its bluish-green or silvery foliage and the horizontally layered arrangement of its branchlets. The long stiff sharp-pointed needles and the narrowed elongated scales of the large cones are further characteristic.

DISTRIBUTION-Along or near streams. Colorado and eastern Utah, corthward to the Wind river mountains of Wyoming. Often planted as an ornamental tree in the eastern and northern states and also in Europe, especially individuals with blue foliage.

WOOD-Light, soft, close-grained, weak, pale brown, or often nearly white with hardly distinguishable sapwood. 

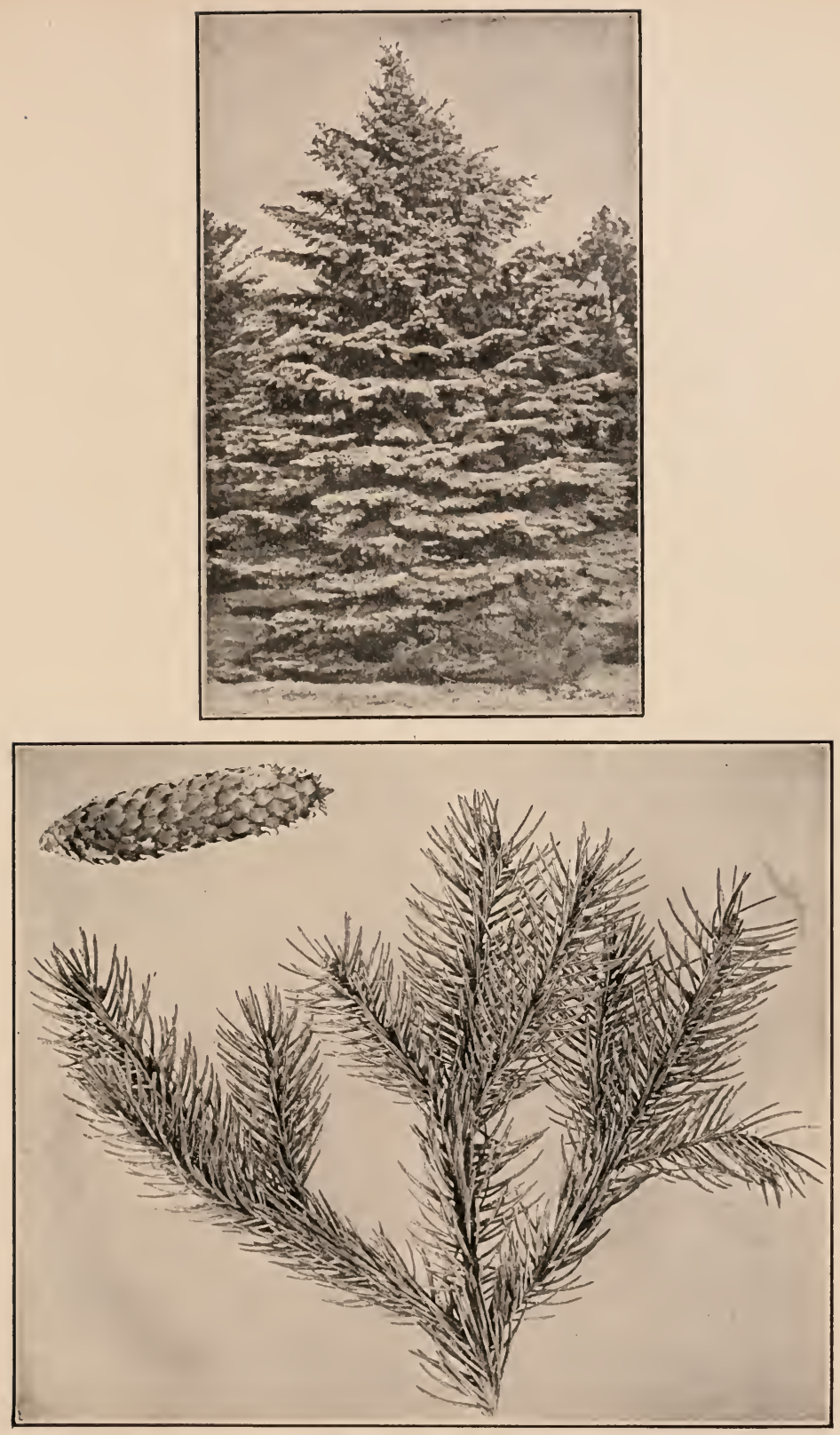

Blue Spruce 


\title{
NORWAY SPRUCE
}

\section{Picea Abies (L.) Karst.}

P. excelsa Link.

\begin{abstract}
HABIT-A large rapidly growing tree, 50-100 ft. or more in height with a trunk diameter up to $2 \mathrm{ft}$; with spreading horizontal or ascending branches and in mature trees generally with strongly drooping lateral branchlets, forming a rather broad pyramidal head; foliage dark green. The tree usually has a single erect trunk continuous into the crown but although the tree photographed shows a double stem it is typical in general outline.
\end{abstract}

BARI-Reddish-brown, on young trunks and branches smoothish with very fine flaky scales becoming with age roughened with larger thicker flaky scales.

TWIGS-Brown, smooth or hairy.

LEAF-SCARS-Alternate, more than 2-ranked, on strongly projecting decurrent ridges of the bark.

LEAVES-Dark green and usually shining, 4-angled, 15-25 mm. long, sharp-pointed, without proper leaf-stalks.

BUDS-Ovate, pointed, light brown.

FRUIT-Cylindrical-oblong, pendant cones, 4-7 inches long, light reddish-brown, falling after the first winter. SCALES-thin, stiff, generally broader than long, margin more or less irregular and finely toothed.

COMPIRISONS-The large cones form the most distintive character of the Norway Spruce, and when present easily separate this species from all others with which it might be confused. The pendant lateral branches generally strikingly noticeable on the older trees together with the vigor of growth furnish good habit characters of distinction.

DISTRIBUTION-A large tree of Europe especially abundant in Norway; largely cultivated in this country as ornamental individual trees, in hedges and for windbreaks.

WOOD-Light, soft, close-grained, reddish to yellowish white; used for spars, oars and masts to small vessels. 

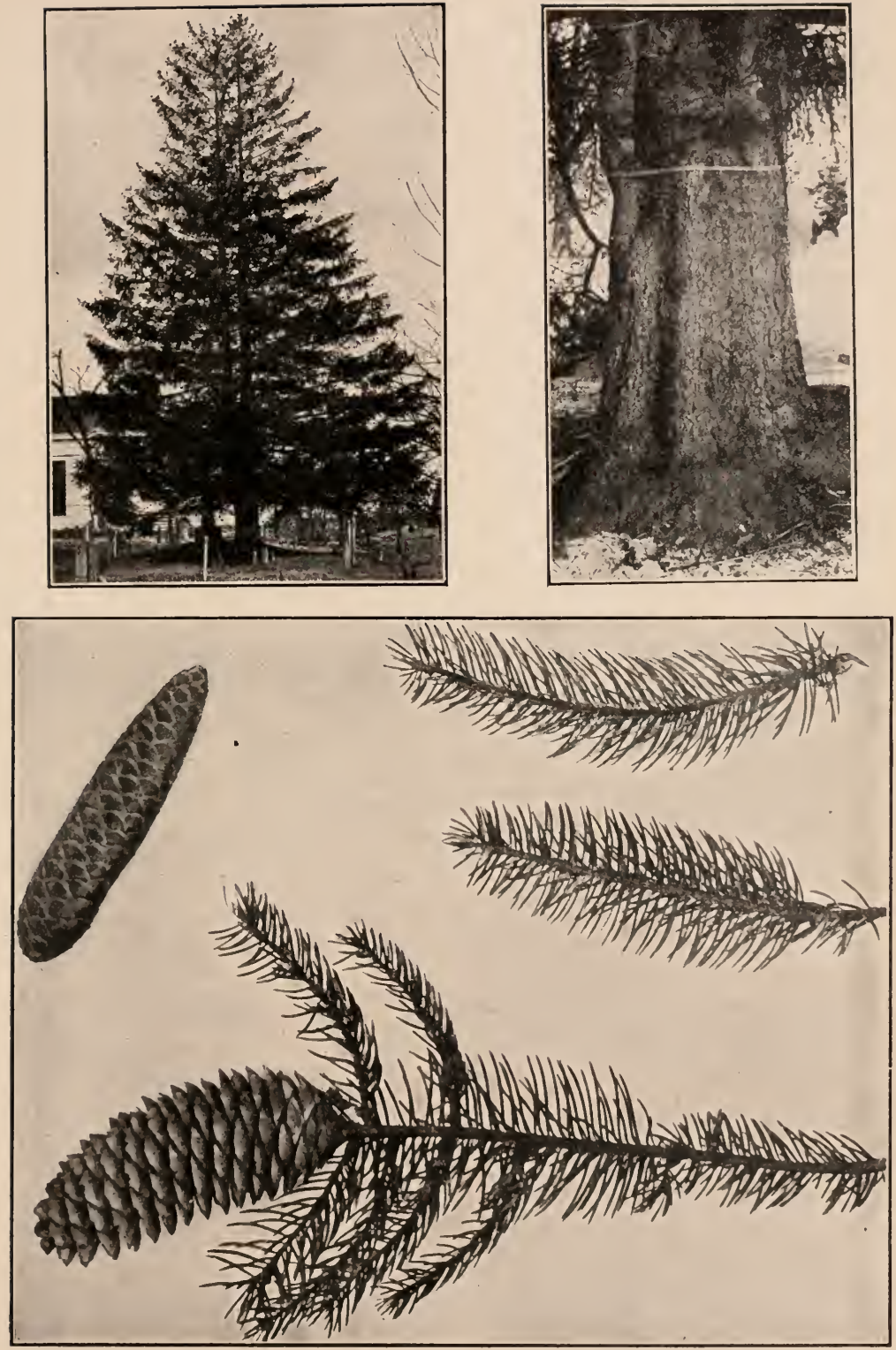

Norway Spruce 


\section{DOUGLAS FIR \\ Red Fir, Douglas Spruce. \\ Pseudotsuga taxifolia (Lam.) Britton. \\ P. mucronata (Raf.) Sudw.; P. Douglasii (Lindl.) Carr.}

HABIT-A tree under favorable conditions in the west reaching a height of $200 \mathrm{ft}$. or over and a trunk diameter up to 10 or $12 \mathrm{ft}$.; branches horizontal with more or less pendulus branchlets forming a pyramidal head. A number of varieties are in cultivation varying somewhat in habit and color of foliage.

BARI- On young trunks dark gray, smooth, with few resin blisters, soon becoming roughened, with reddish-brown scales and eventually deeply ridged.

TWIGS-Reddish to yellowish-brown, more or less downy, becoming with age smooth and dark grayish-brown. Photograph of $t w i g$ is about $1 / 3$ natural size.

LEIVES-Scattered, sometimes appearing somewhat 2-ranked but less distinctly so than leaves of the Balsam Fir, dark green above, pale below with grayish lines of minute dots, flattened, generally blunt, $3 / 4$ inch or more long, slightly narrowed at base but not distinctly stalked, arising at about a right angle to the twig and leaving in falling a round scar slightly raised at the base, slightly fragrant and aromatic when crushed. MICROSCOPIC SECTION-showing a sirgle fibrovascular bundle, 2 resin-ducts next to the epidermis, strengthening cells beneath the epidermis and generally around the resin-ducts, giant thick-walled irregularly lobed cells frequently appearing in crosssections of the leaf on either side of the bundle, stomata on the under side.

BUDS-Comparatively large, narrowly ovate to conical, sharp-pointed, reddish-brown, $7-12 \mathrm{~mm}$. long, loosely clustered at tips of twigs; budscales not resinous-coated, often with reflexed tips.

FKUIT-A cone maturing in one season, pendant, stalked, 2-41/3 inches long. SCALES-persistent, rounded on edges with conspicuous protruding bracts which are long-pointed and laterally winged like the feathering on an arrow.

COMPARISONS-The Douglas Fir resembles the Balsam Fir but may be readily distinguished by its large dark brown buds, free from resin, by the slightly projecting leaf-scars and especially by the cones with persistent scales and lobed bracts. Further, a thin knife section held toward the light and looked at with a hand-lens shows the two resin-ducts on the edge of the leaf while those of the Balsam Fir are located between the edge and the bundle.

DISTRIBUTION-Throughout the Rocky mountain system south of latitudes 55 degrees north to the Pacific coast, forming extensive forests. Planted for ornament in the eastern states where, however, only plants grown from seed obtained from the interior of the continent are successful.

woOD-Light red or yellow, with nearly white sapwood, very variable in density, quality and in the thickness of the sapwood; largely manufactured into lumber in British Columbia, western Washington and Oregon and used for all kinds of construction, fuel, railroad ties and piles. The bark is sometimes used in tanning leather. 

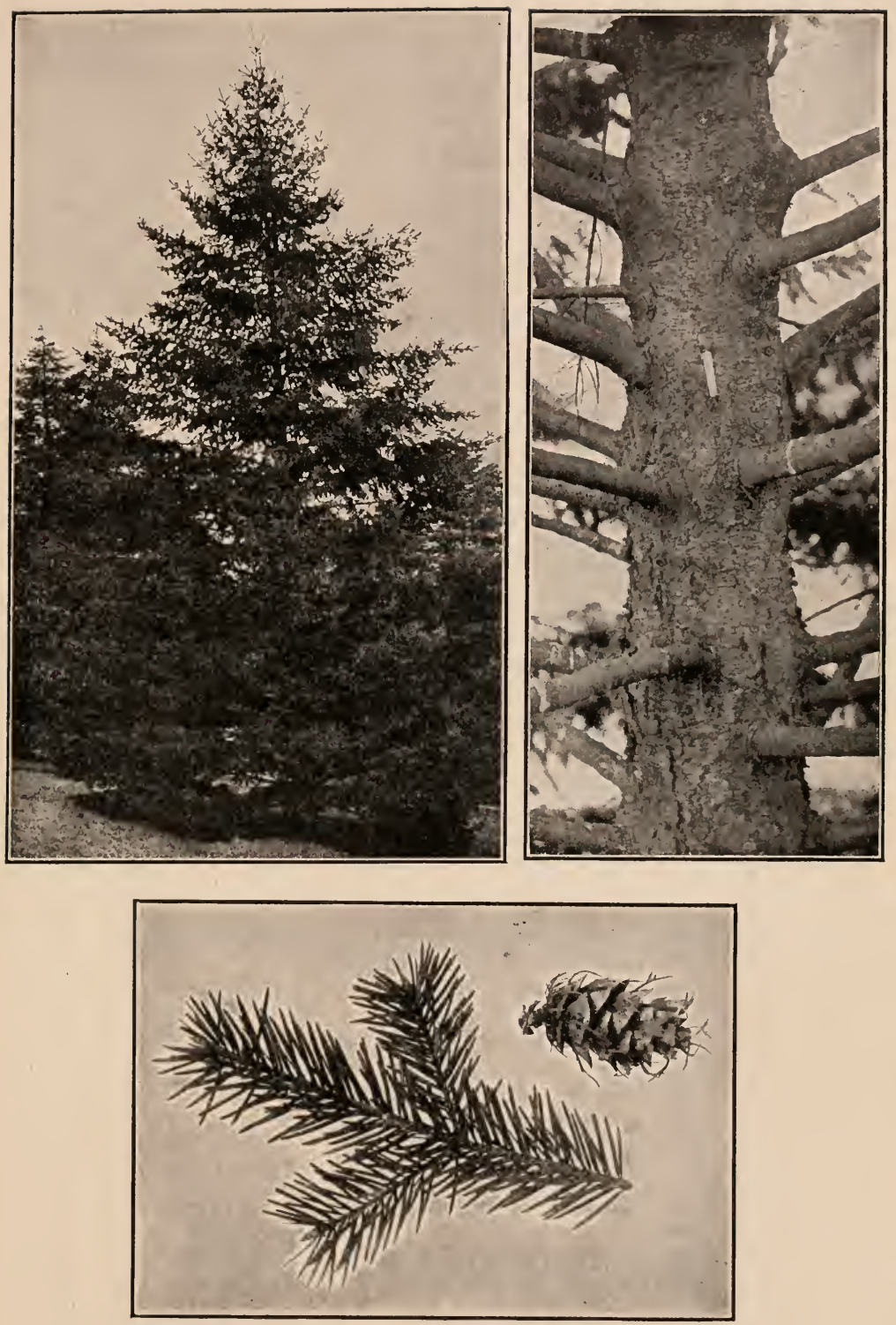

Douglas Fir 


\title{
BALSAM FIR \\ Balsam, Fir, Balm of Gilead Fir.
}

\author{
Abies balsamea (L.) Mill.
}

HABIT-A medium sized tree, 25-60 ft. in height with a trunk diameter of 1-2 ft., becoming a shrub toward the tops of high mountains: branches usually arising in distinct whorls and throughout horizontal, ascending or declining, or declining toward the base horizontal in the middle and ascending toward the top of the tree, forming a symmetrical broad-based conical head. A rapidly growing comparatively short-lived tree losing its lower branches at an early period.

BARK-Grayish-brown, smooth with raised blisters containing a fragrant oily resin; in old trees becoming somewhat roughened with small scales at base of trunk.

TWIGS-Grayish and more or less downy, becoming with age grayishbrown and smooth, branchlets mostly opposite arising at a wide angle. Photograph of twig is about $1 / 3$ natural size.

LEAVES-Scattered, on young trees and sterile twigs generally twisting so as to appear 2-ranked as in the Hemlock, on upper fruiting branches and leading shoots generally covering the upper side of the twigs; dark green and shining on upper side, pale below with grayish lines of minute dots, flattened, generally blunt, about $3 / 4$ inch or more long, slightly narrowed at base but not stalked, arising at about a right angle to the twig, leaving after falling a flat, round scar, fragrant, aromatic when crushed. MICROSCOPIC SECTION-showing 2 fibro-vascular bundles closely adjacent and appearing as one in a knife section, 2 resin-ducts between the bundles and the epidermis with stomata chiefly on the under side.

BUDS-Small, broadly ovate to spherical, generally less than $5 \mathrm{~mm}$. long, closely grouped at tips of main twigs; bud-scales varnished and glued together by resinous coating.

FRUIT-Erect cones ripening in the autumn of the first season. SCALES-falling and leaving persistent through winter only the erect central axes to which they were attached.

COMPARISONS-The Balsam Fir is distinguished from our native New England evergreens by its smooth blistery bark and by its leaves which are attached directly to the twig and leave a round, flat scar on falling. From the Hemlock it is further distinguished by the absence of leaf stalks and from the Spruce by the flattened apparently 2-ranked leaves. See under Douglas Fir for Comparisons with this species.

DISTRIBUTION-Rich, damp, cool woods, deep swamps, mountain slopes. Occasionally cultivated as an ornamental tree. Labrador, Newfoundland, and Nova Scotia, northwest to the Great Bear Lake region; south to Pennsylvania and along high mountains to Virginia; west to Minnesota.

IN NEW ENGLAND-Maine-very generally distributed, ordinarily associated with White Pine, Black Spruce, Red Spruce, and a few deciduous trees, growing at an altitude of 4,500 feet upon Katahdin; New Hampshire-common in upper coos county and in the White Mountains, where it climbs up to the alpine area; in the southern part of the state, in the extensive swamps around the sources of the Contoocook and Miller's rivers it is the prevailing timber; Vermontcommon; not rare on mountain slopes and even summits; Massachusetts - not uncommon on mountain slopes in the northwestern and central portions of the state, ranging above the Red Spruces upon Graylock; a few trees here and there in damp woods or cold swamps in the southern and eastern sections, where it has probably been accidentally introduced; Connecticut_-rare cold swamps and woods; Middlebury, Goshen, Cornwall, Salisbury; also occurs as an escape from cultivation at Woodstock, Andover and Farmington; Rhode Island-not reported.

WOOD-Light, soft, not strong, coarse-grained, perishable, pale brown, streaked with yellow, with thick lighter colored sapwood, occasionally made into lumber, principally used for packing cases, used largely in manufacture of wood pulp. From the blisters in the bark Canada balsam is obtained which is used in medicine and as a medium for mounting microscopic preparations. The fragrant leaves and small twigs are used to stuff balsam or so-called "pine" pillows. 

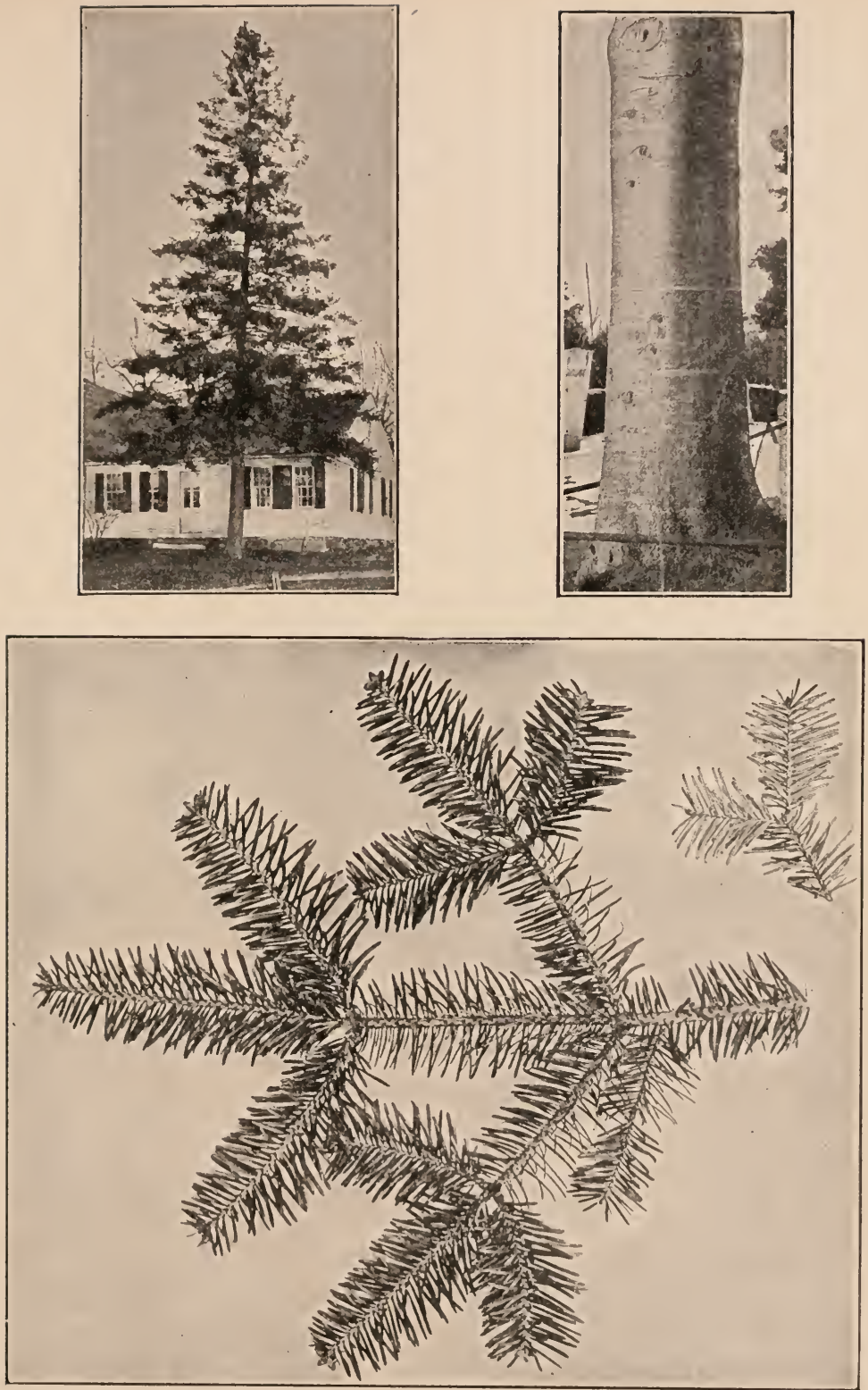

Balsall Fir 


\section{HEMLOCK \\ Hemlock Spruce.}

Tsuga canadensis (L.) Carr.

HA BIT-A large tree $50-80 \mathrm{ft}$. in height, with a trunk diameter of 2-4 ft.; branches long, slender, horizontal or drooping at base, ascending above, forming a broad-based pyramidal head with fine feathery spray giving a delicate airy appearance to the tree. The apex is plumelike and generally bent to one side indicating, so woodsmen claim, the direction of prevailing winds.

BARK-Reddish to grayish-brown, with shallow broad connecting ridges somewhat scaly on the surface.

TWIGS-Slender, yellowish-brown, more or less downy, branchlets generally not opposite and arising at less than a right angle. Photograph of twig is about $1 / 3$ natural size.

LEAVES-Scattered but generally twisting so as to appear z-ranked, dark, slightly yellowish-green above, pale green below with grayish lines of minute dots on either side of midrib, flattened generally blunt at the apex, about $1 / 2$ inch long with a distinct short stalk, borne upon a reddish-brown decurrent projection of the bark which is left as a raised scar at the fall of the leaf. MICROSCOPIC SECTION-showing a single fibro-vascular bundle and a large resin-duct filling the space between the bundle and the epidermis.

BUDS-Small, about $2 \mathrm{~mm}$. long, ovate, reddish-brown, not resinouscoated.

FRUIT-Small, stalked pendant cones, ripening the first season, and generally persistent through winter, about $3 / 4$ inch long.

COMPARISONS-In its flattened, apparently 2-ranked leaves the Hemlock resembles the Balsam Fir, but aside from the difference in habit and bark, the leaves of the Hemlock are shorter, distinctly stalked and leave projecting scars when they fall off. From the Spruces it is distinguished by its distinctly flattened and stalked leaves and flattened spray.

DISTRIBUTION-Cold soils, borders of swamps, deep woods, ravines, mountain slopes, and also cultivated as an ornamental tree. Nova Scotia, New Brunswick, through Quebec and Ontario; south to Delaware and along the mountains to Georgia and Alabama, ascending to an altitude of 2,000 feet in the Adirondacks; west to Michigan and Minnesota.

IN NEW ENGLAND-Maine-abundant, generally distributed in the southern and central portions, becoming rare northward, disappearing entirely in most of Aroostook county and the northern Penobscot region; New Hampshire-abundant, from the sea to a height of 2,000 feet in the White Mountains, disappearing in upper Coos county; Vermont-common especially in mountain forests; Connecticut-usually frequent but rather local in its distribution; Massachusetts and Rhode Island-common.

WOOD-Light, soft, not strong, brittle, coarse-grained, difficult to work, liable to wind-shake and splinter, not durable when exposed to the air, light brown tinged with red, with thin somewhat darker sapwood; largely manufactured into coarse lumber, employed for the outside finish of buildings. The astringent inner bark furnishes the largest part of the material used in the northeastern states and Canada in tanning leather. Oil of Hemlock is distilled from the young branches. 

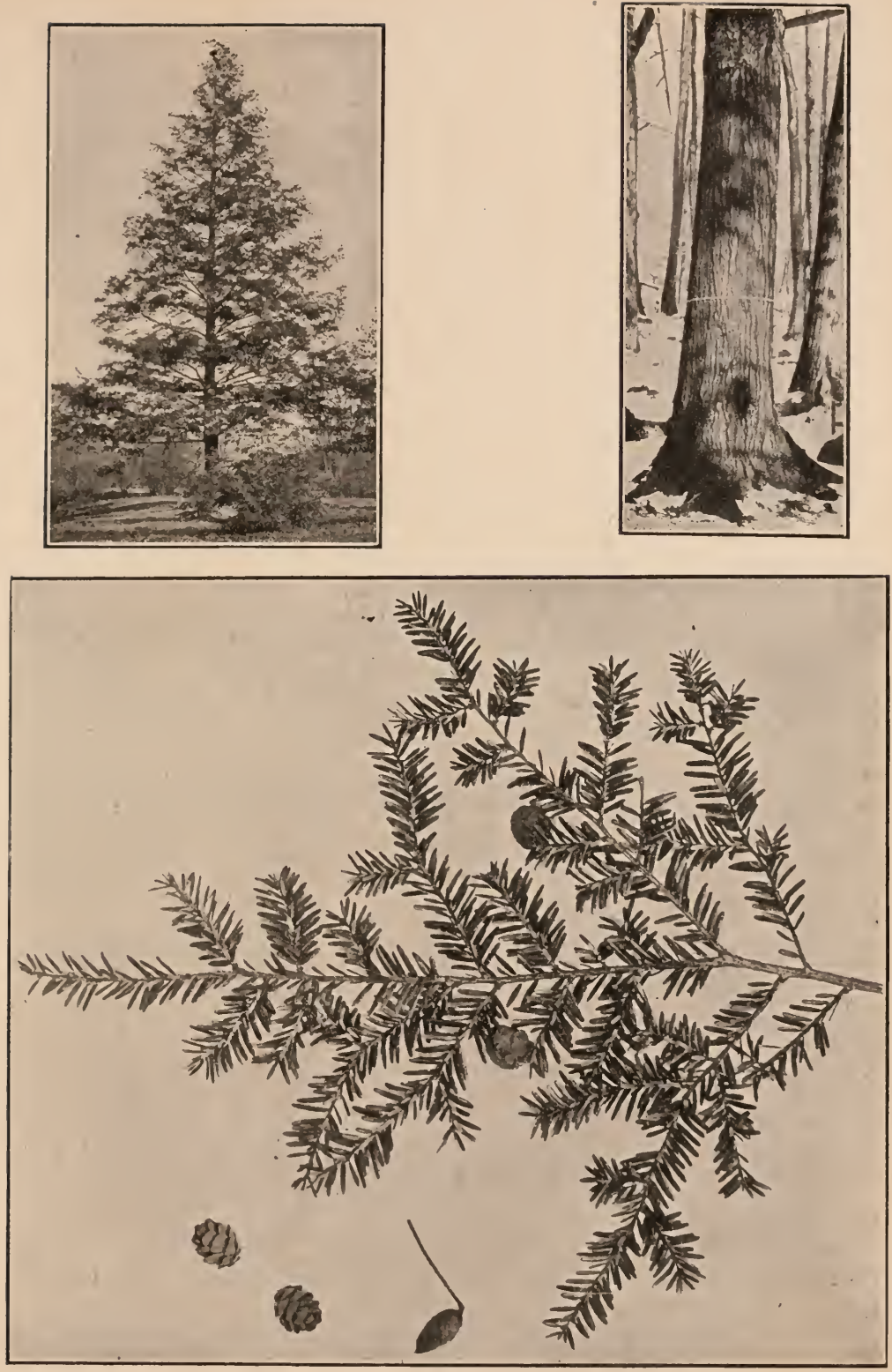

HemLOCK 


\title{
COAST WHITE CEDAR White Cedar, Cedar.
}

\author{
Chamaecyparis thyoides (L.) BSP.
}

\author{
C. sphaeroidea Spach; Cupressus thyoides L.
}

HABIT-A small tree, 20-50 ft. in height with a trunk diameter of 1-2 ft., further south reaching $90 \mathrm{ft}$. in height and a trunk diameter of 4 ft.; trunk tall, erect, tapering gradually, branches short, slender, more or less horizontal, with delicate feathery secondary branches and branchlets loosely enveloping the narrow conical head and surmounted by an airy, pliant, plume-like terminal shoot.

BIRK-Grayish-brown, separating off in narrow, shreddy strips, more or less spirally twisted; on younger and sometimes also on older trunks the bark separates off in broader reddish-brown strips, (see photograph of young trunk).

T:VIGS-Generally less than $1.5 \mathrm{~mm}$. thick, slightly but not prominently flattened, arranged in more or less fan-shaped clusters in planes at various angles, the last season's growth bluish-green from the complete covering of minute leaves, with death of leaves the second season becoming reddish-brown, older growth slowly losing its leaves and marked by scars of deciduous branchlets. Photograph of twig is about $4 / 5$ natural size.

LEAVES-Minute, scale-like, 1-2 mm. long, appressed and closely overlapping, opposite in 4 ranks, but not giving a conspicuously 4 -sided appearance to the twigs, more or less keeled and with a raised glandular dot at least on leaves of rapidly grown shoots, with spicy aromatic odor when crushed.

FRUTT-Small, spherical cones, 5-8 $\mathrm{mm}$. in diameter, inconspicuous in winter, opening toward the center never toward the base, maturing the first season and persistent through the winter. SCALES-thickened, woody, shield-shaped, with a slight projection in middle, each perched on a stalk connecting it with the center of the cone; seeds winged.

COMPIRISONS-The Coast White Cedar resembles the Arbor Vitae as indicated under this species but its twigs are only slightly flattened, the clusters of twigs are less distinctly fan-shaped, the twigs and leaves are smaller and the leaves are of a bluish rather than of a yellowishgreen. The cones are distinctive, being spherical and with thickened shield-shaped scales perched on stalks connecting them with the center. Aside from the fruit characters which separate them, the Coast White Cedar is distinguished from the Red Cedar by the more or less distinct fan-shaped arrangement of its twigs, the absence of two kinds of leaves, the more distinct glandular dot generally present on the leaf and by the fact that the twigs are round or slightly compressed in section and not distinctly 4 -sided as are those of the Red Cedar.

DISTRIBLTION-In deep swamps and marshes, which it often fills to the exclusion of other trees, mostly near the seacoast. Cape Breton island and near Halifax, Nova Scotia, perhaps introduced in both; southward, coast region to Florida and west to Mississippi.

IN NEW ENGLAND-Maine-reported from the southern part of York county; New Hampshire-Manchester; Rockingham county near the coast; Vermont-no station known; Massachusetts-occasional in central and eastern parts, very common in the southeast; Connecticut-rare in western and central districts-Danbury and New Fairfield. becoming occasional or frequent eastward; Rhode Island-common.

WOOD-Light, soft, not strong, close-grained, slightly fragrant, light brown, tinged with red, largely used in boat building, and cooperage and for woodenware, shingles, the interior finish of houses, fence posts and railroad ties. 

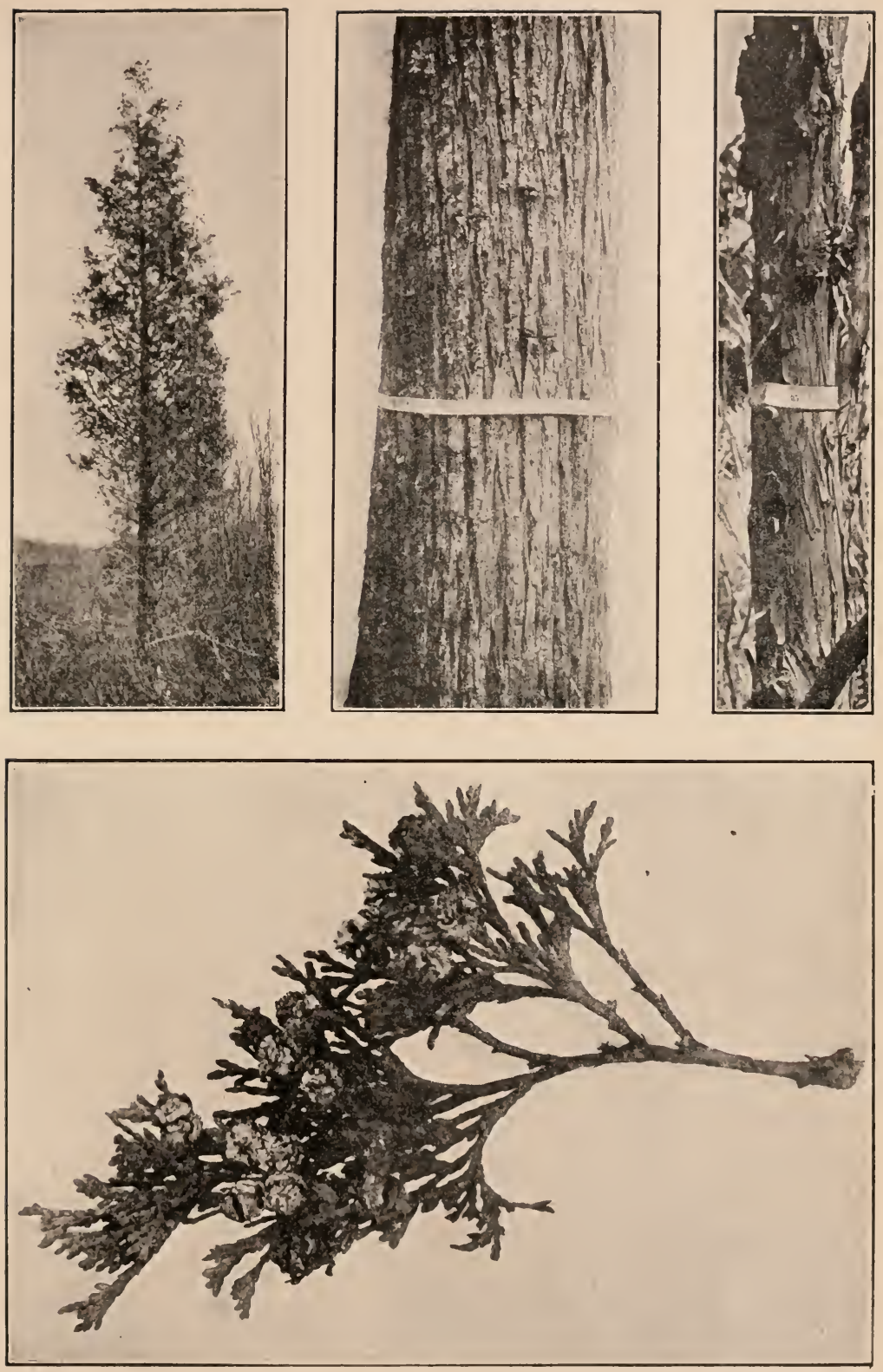

Co.lst Irhite CediR 


\section{ARBOR VITAE White Cedar, Cedar.}

Thuja occidentalis L.

HABIT-Commonly 25-50 ft. in height with trunk diameter of 1-s ft., in northern Maine occasionally reaching. a height of 70 ft. and a trunk diameter of 3-5 ft.; trunk more or less lobed and buttressed at base, often inclined and twisted, frequently dividing into two or more stout, erect stems; branches short, horizontal, lower branches often strongly declined, branchlets numerous, forming a dense, conical head clothed with foliage to near the base.

HIRK-Ashy gray to light reddish-brown, separating off in long, narrow, flat, shreddy strips, often more or less spirally twisted.

T5:IGS-Generally more than $2 \mathrm{~mm}$. wide, decidedly flattened, arranged in fan-shaped clusters, placed vertically or in planes at various angles, often mistaken for the true leaves which are minute and completely cover the last season's growth, dark yellowish-green, paler on the underside, with the death of the leaves in the second season becoming pale cinnamon brown and later shining reddish-brown, round in section, swollen at place of attachment to main branch, and marked by scars of deciduous branchlets. Photograph of twig is about $4 / 5$ natural size.

LEIVES-Minute, 3-6 mm. long, scale-like, appressed and closely overlapping, opposite in 4. ranks; or the flattened spray those in the side pairs keeled, those in the other pair flat, ovate, each with a single raised glandular spot especially conspicuous on leaves of leading shoots; with a characteristic camphor-like aromatic odor when crushed.

FRUI'T-Small, oblong cones, about 1/2 inch long, pale reddish-brown, opening to the base when mature, maturing the first season and persistent through the winter. SCALES-6-12, thin, oblong, dry with margins mostly entire.

COMPIRISONS-The Arbor Vitae is often called White Cedar and resembles the Coast White Cedar, which likewise is often known as White Cedar, in its bark, its habit of growth and its flattened fanshaped spray. The twigs of the Arbor Vitae are much more flattened and larger and the clusters of twigs more decidedly fan-shaped; the leaves are also larger and of a yellowish-green color. The cones of the two species are decidedly different, those of the Arbor Vitae being oblong with thin scales opening to the base of the cone, those of the Coast White Cedar being spherical with thickened shield-shaped scales, perched on stalks attatched to the center of the cone.

DIS'TRIBUTION-Low, swampy lands, rocky borders of rivers and ponds. Often cultivated as single ornamental trees and in hedges. Southern Labrador to Nora Scotia; west to Manitoba; south along the mountains to North Carolina and East Tennessee; west to Minnesota.

IN NEW ENGLAND-Maine-throughout the state; most abundant in the central and northern portions, forming extensive areas known as "Cedar Swamps"; sometimes bordering a growth of Black Spruce at a lower level; New Hampshire-mostly confined to the upper part of Coos county, disappearing at the White river narrows near Hanover; seen only in isolated localities south of the White Mountains; Vermont-common in swamps at levels below 1,000 ft.; MassachusettsBerkshire county; occasional in the northern sections of the Connecticut river valley; Connecticut-rare, Canaan, on a limestone ridge and in a nearby swamp, Salisbury, rocky hillsides and at another locality in a deep swamp; apparently native at these three localities; escaped from cultivation to fields and roadsides at Norwich, East Hartford, Killingly and Windsor; Rhode Island-not reported.

Wo(1)-Light, soft, brittle, very coarse-grained, durable, fragrant, pale yellowish-brown, largely used in Canada and the northern states, for fence posts, rails, railroad ties, spools and shingles. 

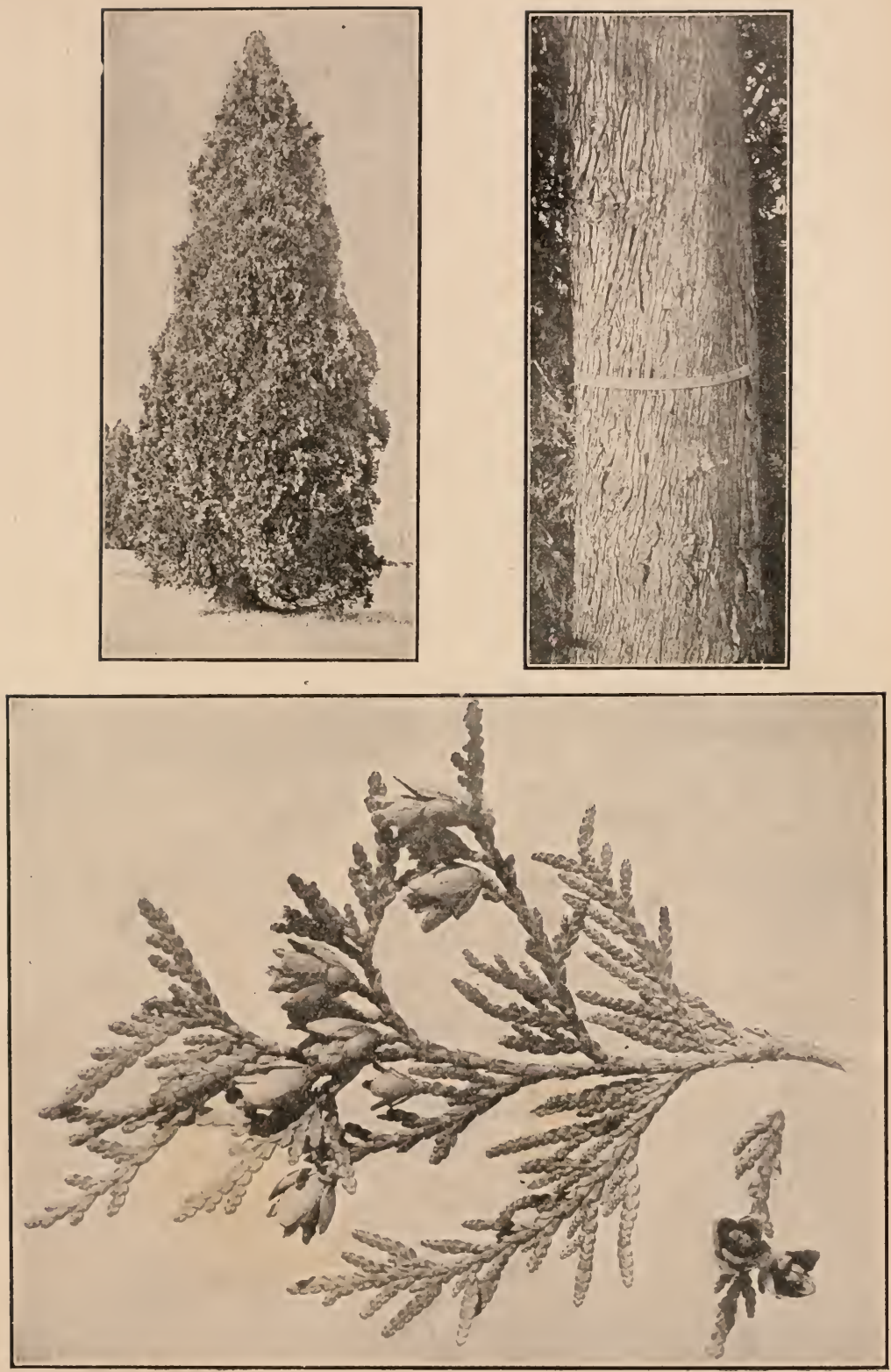

Arbor Vitae 


\title{
COMMON JUNIPER \\ Dwarf Juniper. \\ Juniperus communis L.
}

\begin{abstract}
HABIT-A shrub or small tree 5-15 ft. high; in the type form with generally several erect stems, bearing erect branches densely clothed with foliage, forming a narrow or rather broad compact plume-like erect growth (habit picture at the right); in the more common dwarf variety [Juniperus communis, var. depressa Pursh; J. nana of Britton's Manual in part; $J$. communis, var. conadensis Loud.; $J$. communis, var. alpina Gray's Manual ed. 6 in part], with low-lying branches, frequently rooting below, radiating from the center and curving upwards to form low, broad, round mats resembling gigantic birds' nests 1 to 3 ft. high and often 10 to $20 \mathrm{ft}$. in diameter (habit picture at the left).
\end{abstract}

BIIK-Grayish-brown, breaking on the surface into thin papery shreddy longitudinal layers, which lift at the ends and edges exposing the reddish bark below.

TWIGS-Smooth, light yellow, turning to red, prominently 3 -angled the first two years by decurrent ridges from below the leaves. Photograph of twig is about $4 / 5$ natural size.

LEIVES-All alike in whorls of 3 , separated by short internodes, spreading from the twigs at a broad angle, 7-20 $\mathrm{mm}$. long, awl-shaped, stiff and sharp-pointed, free from glandular dots, compressed, the upper side concave and conspicuously streaked with a broad white line, the dark green under side appearing uppermost by the bending over of the twigs and leaves; persistent for several seasons.

BUDS-Distinct, scaly.

FIRUIT-About the size of a pea, fleshy, berry-like, dark blue, covered with a bloom, sweetish with a resinous flavor, remaining on the plant during winter, but as the species is dioecious, to be found only on a part of the plants.

COMPIRISONS-The Common Juniper is distinguished from its near relative the Red Cedar, by its lower habit of growth, by the fact that its leaves are all alike and without glandular dots; in distinction from the typically appressed leaves of the Red Cedar, the leaves of the Common Juniper are spreading at a wide angle. They thus resemble the juvenile type of leaves found on young specimens of the Red Cedar and on rapid-growing twigs of older trees of the same species but may be distinguished by being almost always in 3's, wider and longer, more distinctly whitened above, with a greater separation between the nodes and by the presence of distinct scaly buds. A number of forms are described but not always recognized. The dwarf variety ( ar. depressa) is described as having leaves $8-13 \mathrm{~mm}$. long, and the type as having leaves 12-21 $\mathrm{mm}$. Iong but they are best distinguished by their different habits of growth as shown in the photographs.

DISTRIBITION-Tn poor, rocky soil, pastures and waste open places. Widely distributed through the colder regions and mountains of the northern part of the U. S., in a broad band extending westward from Newfoundland on the north and New Jersey and Pennsylvania on the south. The dwarf form (var. depressa) occurs throughout New England. The tvpe is reported as less common and as occurring in Massachusetts and southward; Connectirut-the type is listed as rare and is reported only irom Norwich. It is not uncommon, however, about Storrs. The variety depressa is frequent throughout the state.

WOOD-Hard, close-grained, very durable in contact with soil, light brown. with pale sapwood. In northern Europe the fruit is extensively used in giving its peculiar flavor to Holland gin. 

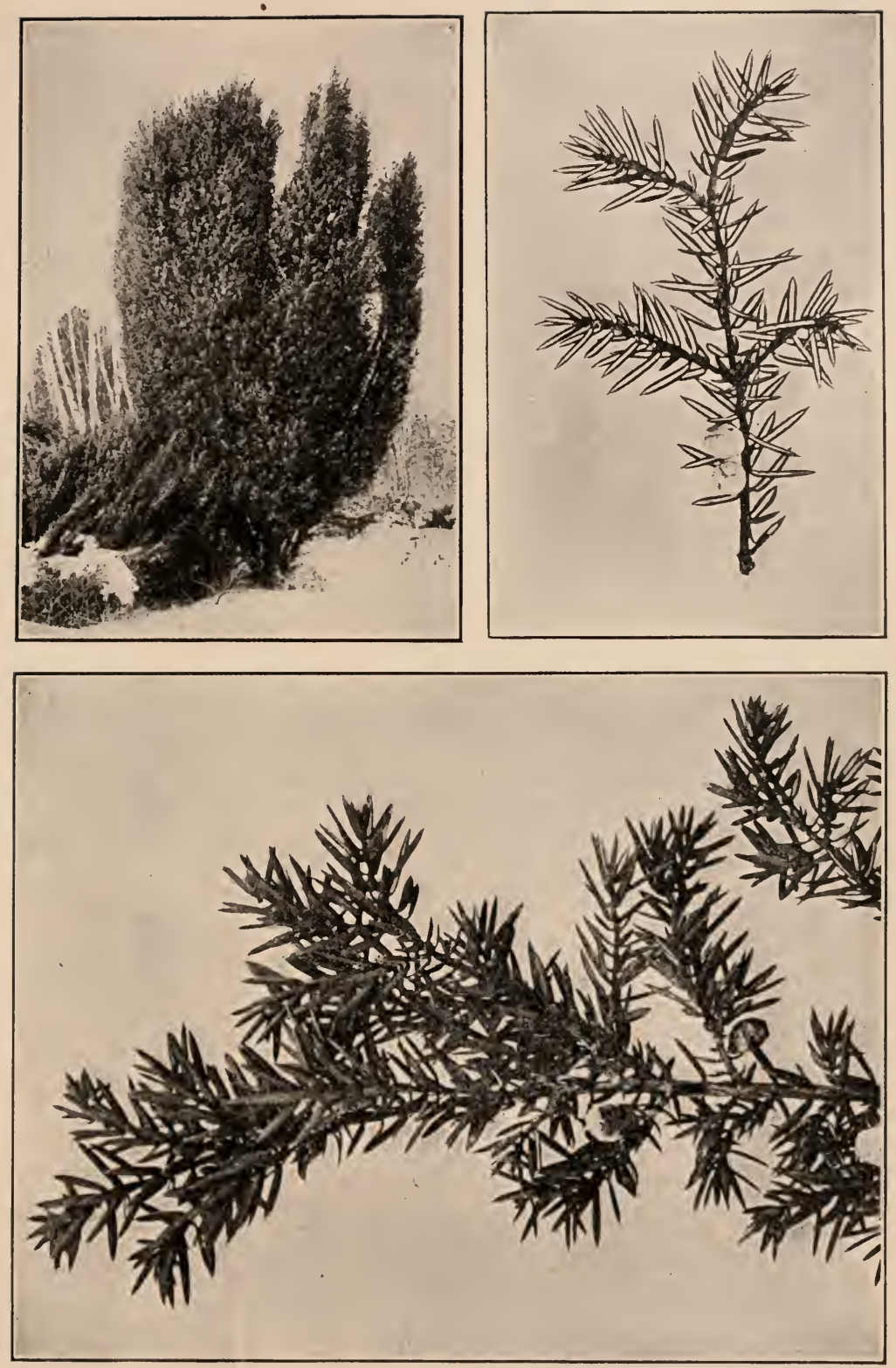

Common Juniper 


\section{RED CEDAR Savin, Cedar, Red Juniper. Juniperus virginiana L.}

HАВIT-A medium sized tree, 25-40 ft. in height with trunk diameter of $8-20$ inches, much larger in the southern states; trunk more or less ridged and buttressed at base, with slender branches horizontal below erect above, forming in young trees a narrow, conical head, becoming in old age wider, spreading, ovate, round-topped, or on bleak situations especially near the sea shore more or less irregularly distorted.

BARK-Light reddish-brown separating off in long narrow shreddy strips more or less fringed at the edges, frequently somewhat spirally twisted.

TWIGS-Generally 4-sided in mature trees, green from covering of minute leaves, not flattened nor arranged in fan-shaped clusters, becoming reddish-brown after the fall of the leaves. Photograph of twigs is about $4 / 5$ natural size.

LEIVES-Dark green or reddish-brown, with aromatic odor when crushed, persistent for several years, of two kinds:-

1. The form typical of the species; about $2 \mathrm{~mm}$. or less long. scalelike, opposite in pairs, forming 4 ranks, closely overlapping and appressed, rounded, with or without an inconspicuous glandular dot on the back, ovate, sharp or blunt-pointed. (See left hand twig.)

2. The juvenile form; occurring often exclusively on very young trees and also frequently together with the typical form on older trees; narrow, awl-shaped to needle-shaped, sharp-pointed without glands, spreading, scattered and not overlapping, opposite or in 3 's, 5-20 mm. long. (See right hand twig.)

BUDS-Inconspicuous.

FRUIT-About the size of a small pea, fleshy, berry-like, dark-blue, covered with a bloom, sweetish with a resinous flavor, containing generally 1-2 bony seeds. The fruit remains on the tree during winter but the species is dioecious and consequently not all the trees bear fruit.

COMPARISONS-The Red Cedar resembles the Coast White Cedar but it fails to show a flattened fan-shaped arrangement of its twigs, its twigs further are generally 4-sided when bearing iypical leaves and on young trees and generally on some twigs of older trees leaves of the juvenile type may be found. The berry-like fruit of the Red Cedar when present is the most distinctive character separating this species from the Coast White Cedar. The Common Juniper is not to be confused with Red Cedar trees that have typical leaves: It resembles somewhat the juvenile leaved form of the Red Cedar, however, but the growth of the former is generally less upright, the leaves always in 3 's and generally more whitened above and the buds are more conspicuous.

DISTRIBUTION - Dry, rocky hills but not at great altitudes, borders of lakes and streams, sterile plains, peaty swamps. Nova Scotia and New. Brunswick to Ontario; south to Florida; west to Dakota, Nebraska, Kansas and Oklahoma.

IN NEW ENGLAND--Maine-rare, though it extends northward to tne middle Kennebec valley; reduced almost to a shrub; New Hampshire -most frequent in the southeast part of the state; sparingly in the Connecticut valley, as far north as Haverhill; found also in Hart's location in the White Mountain region; Vermont-not abundant; occurs here and there on hills at levels less than 1,000 feet; frequent in the Champlain and lower Connecticut valleys; Massachusetts-west and center occasional, eastward common; Connecticut and Rhode Islandcommon.

WOOD-Light, close-grained, brittle, not strong, dull red with thin nearly white sapwood, very fragrant, easily worked; largely used for posts, the sills of buildings, the interior finish of houses, the lining of chests and closets as a protection of woolen garments against attacks of moths, for pails and other small articles of wooden-ware, and especially for lead pencils. A decoction of the fruit and leaves is used medicinally, and oil of Red Cedar is distilled from the leaves and wood as a perfume. 

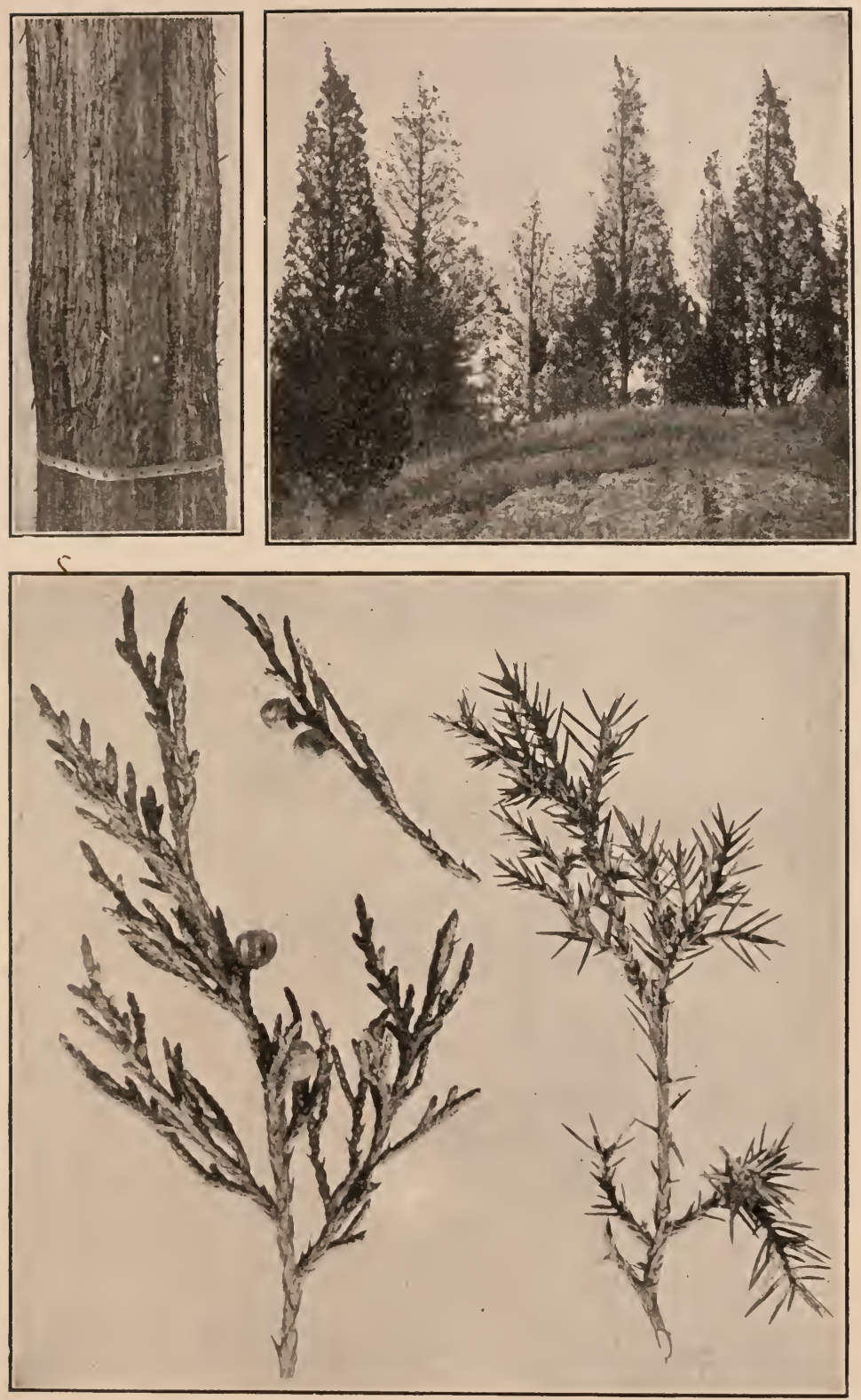

Red Cedar 


\section{GINKGO \\ Maidenhair Tree. \\ Ginkgo biloba L.}

Salisburia adiantifolia Smith.

HABIT-A tree reaching a height of 60-80 $\mathrm{ft}$., with generally a single erect trunk (a double trunk in tree photographed) continuous into the crown with straight, slender branches, making an angle of about 45 degrees with the trunk and regularly parallel except those below, which are more or less declined, forming in mature specimens a very regular symmetrical broadly ovate to pyramidal head. The secondary branches are slender and are but indistinctly shown in the photograph. There are several horticultural varieties including one weeping form.

BARK-Ashy gray, on younger trunks and branches smooth, becoming with age seamy and longitudinally roughened.

TWIGS-Rather stout, smooth, yellowish-brown, shining, a thin grayish skin separating off in narrow shreds on older twigs; rapidly grown twigs of one year's growth, comparatively rare, with scattered leaf-scars; stout lateral or terminal spurs with thickly crowded leafscars common. PITH-pale yellowish, with ragged outline.

LEAF-SCARS-Alternate, 2-ranked or more than 2-ranked, semi-oval, raised, upper margin generally fringed. STIPULE-SCARS-absent. BUNDLE-SCARS-2, often most distinct in recent leaf-scars on short spurs.

BUDS-Light chestnut brown, short, conical, generally under $4 \mathrm{~mm}$. long, isolated lateral buds on rapidly grown shoots, divergent, on short spurs generally only terminal buds developed. BUD-SCALES-about 5 visible, broader than long, thickened and dotted toward the middle with small reddish transparent lumps.

FRUIT-A stone-fruit with a sweet ill-smelling flesh. The tree is dioecious, there being separate male and female individual trees. On account of the disagreeable odor of the fruit the male trees are more frequently planted. The two sexes are said to differ in their growth forms, a male tree being more narrowly pyramidal while the femalo forms a broad head.

COMPARISONS-The Ginkgo belongs to the Gymnosperms, an order of plants which are mostly cone-bearing like the Pines and Spruces. It has a peculiarity with the Larch in that it is not evergreen as are most of its relatives but sheds its leaves in the fall. Like the Larch, too, it has numerous stubby spurs with crowded leaf-scars. It differs from the Larch in that its large leaf-scars are not strongly decurrent and are relatively far apart on the rapidly grown shoots and further have 2 bundle-scars.

DISTRIBLTION-A native of northern China, introduced into America early in the century and generally successful in the eastern states as far north as eastern Massachusetts and central Michigan and along the St. Lawrence River in parts of Canada. 

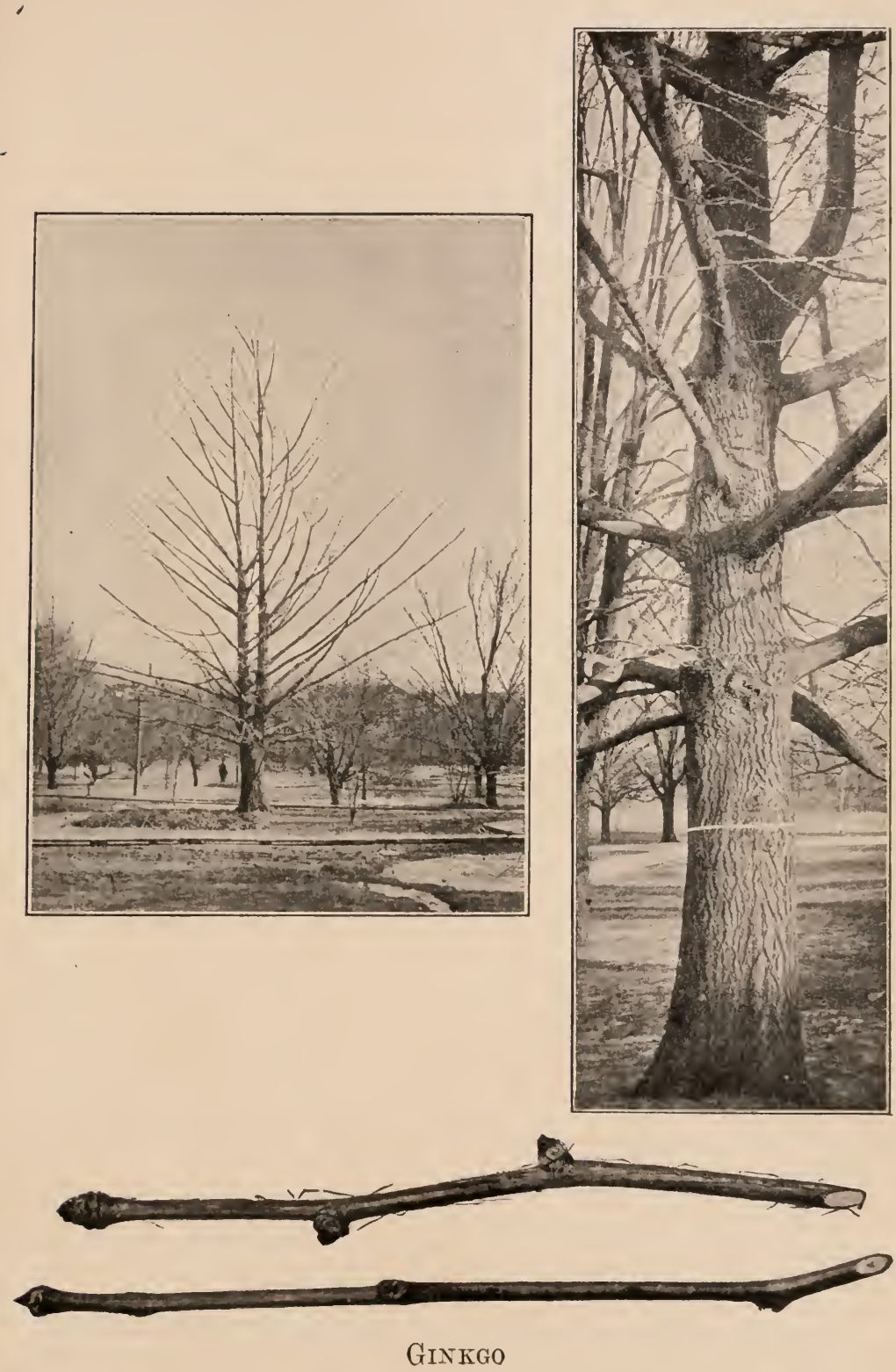


\title{
YELLOW WILLOW Golden Osier.
}

\author{
Salix alba, var. vitellina (L.) Koch.
}

\author{
S. vitellina Koch.
}

HABIT-A large tree reaching 50-80 ft. in height with a trung diameter of 3-5 ft.; trunk short, rarely erect, generally inclining to one side, dividing low down into a number of stout spreading limks, forming an irregular broad rounded head.

BARK-On young stems smooth, becoming with age dark gray arj deeply furrowed.

TwIGS-Rather slender, bright yellow, smooth and shining or dull with more or less dense covering of fine silky hairs, bitter to taste. LENTICELS-scattered, inconspicuous. PITH-more or less 5-pointed.

LEAF-SCARS-Alternate, more than 2-ranked, narrow, raised, broadly V-shaped, more or less swollen at the bundle-scars. STIPULE-SCARSoblique, close to leaf-scars and often appearing connected with them. BUNDLE-SCARS-3.

BUDS-Terminal bud absent, lateral buds about $5 \mathrm{~mm}$. long, oblong, rounded at apex, smooth or more or less silky-downy, flattened and appressed against twig. BUD-SCALES-a single bud-scale visible, rounded on back, flattened toward the twig, forming a cap to silkyhairy green leaves within.

FRUIT-A catkin of small capsules containing numerous hairy seeds ripening in spring. The Willows are dioecious and the male trees of the Yellow Willow are seldom planted in this country.

COMPARISONS-The species of Willows are closely related and have hybridized abundantly. Their classification is based largely upon differences in the pistils and stamens but since the Willows are dioecious and therefore bear the male and female flowers upon separate trees, their determination even when in flower is often a matter of considerable difficulty. The Yellow Willow here described, a yellowtwigged variety of the less common European White Willow [Salix alba L.], is one of the most common tree Willows - in New England. The European Weeping Willow [Salix babylonica L.] was formerly much planted for ornament especially in cemeteries and may be distinguished by the drooping habit of its branches. The Black Willow [Salix nigra Marsh.], a small-budded species, is the one sizable native Willow in New England. The Willows may be most readily separated from the other trees by the single cap-like scale to the bud in connection with the 3-bundle-scars in the narrow leaf-scar.

DISTRIBCTION-A European tree much planted in this country for ornament. It has become naturalized throughout the populated regions of New England, in moist places, near streams and ponds.

WOOD-Very light, soft, tough, light brown in color with thick nearly white sapwood, easily worked and taking a beautiful polish; used in this country for charcoal and for food. 


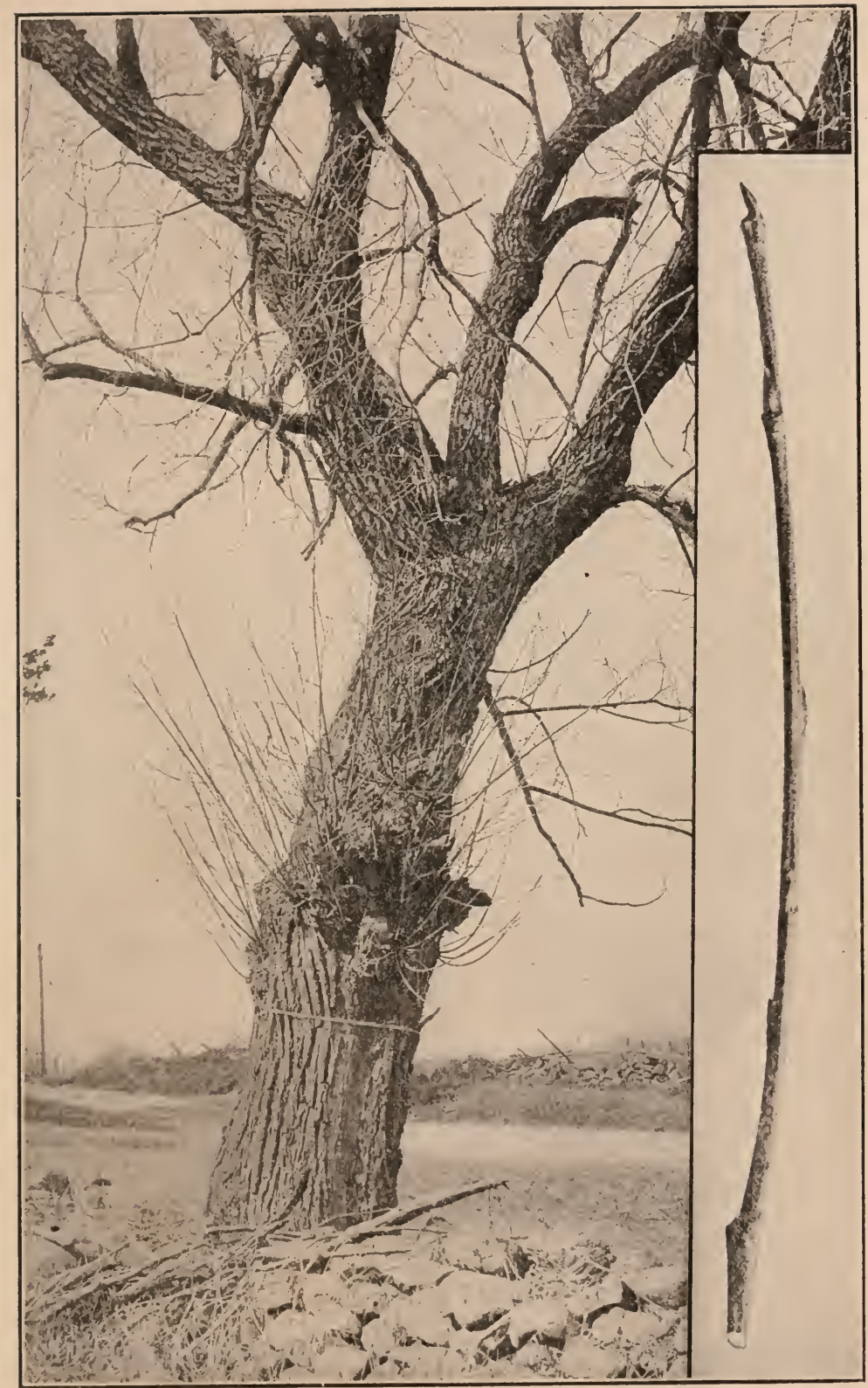

YRLLOW WILLOW 


\title{
SILVER POPLAR \\ White Poplar, Silver-leaf Poplar, Abele. \\ Populus alba L.
}

\begin{abstract}
HАBIT-A good sized tree 40-75 ft. high, with a trunk diameter of 2-4 ft.; limbs wide-spreading, developing a series of characteristic curves with their secondary branches which bend up, out and downward, forming a large, irregular, open, broad, round-topped head; spreading abundantly by means of root suckers.

BARIK-On young trunks and limbs smooth, characteristically light greenish-gray or whitish, often with dark blotches; base of older trunk at length deeply furrowed into firm dark ridges. The Silver Poplar retains its smooth light-colored bark longer than our other members of the genus.

TWIGS-Slender or sometimes stout, greenish-gray, densely covered with thick whitish-cottony wool which can be readily rubbed off and often remains throughout the winter only toward the apex; where wool is removed the surface is shiny; short spurs numerous with conspicuous raised leaf-scars and with terminal buds only. LENTICELS-pale, round, raised dots. PITH-5-pointed, star-shaped.
\end{abstract}

LEIF-SCARS-Alternate, more than 2-ranked, semi-circular to inversely triangular; on short spurs narrower. STIPULE-SCARS-distinct. BUNDLE-SCARS-3, simple or compound.

BUDS-Small, ovate to conical, light chestnut brown; neither sticky nor fragrant; shining or more or less covered especially toward base with cottony wool; lateral buds $5-7 \mathrm{~mm}$. long, terminal buds somewhat larger, thicker. BUD-SCALES-margined with very minute hairs; the first scale of lateral buds anterior. This first scale in front has a scale directly above it, the edges of the two being essentially parallel; likewise the first scale in back generally has a scale directly above it with similarly parallel edges. The first four scales therefore form two ranks facing respectively front and back. This condition seems constant for typical buds, but does not hold for abnormally small buds.

FRUI'T-A catkin of small capsules, with hairy seeds ripening in spring.

COMPARISONS-The Silver Poplar acquires a roughened trunk later than the other Poplars, retaining the smooth whitish-green appearance of its bark as a distinctive character. Its generally delicate twigs, greenish-gray when not covered with cottony wool which generally can he found at least at the apex. furnish further characters that distinguish this species from the other Poplars. The two rows of scales with parallel edges in the lateral buds are found to a less striking degree in the larger buds of the Small-toothed Aspen and the Large-toothed Aspen. Bolles' Poplar [P. alba, var. Bolleana] is a variety of the Silver Poplar occasionally planted. It is distinguished from the type form by its narrow outline and appressed branches, thus resembling the Lombardy Poplar in habit. The bark photograph is taken from a Bolles' Poplar.

DISTRIBUTION-Widely distributed in the Old World. Introduced from England by the early settlers and soon established in the colonial towns on the western shore of Massachusetts Bay. Planted or spontaneous over a wide area. New Brunswick and Nova Scotia, occasional; southward to Virginia. mon.

IN NEW ENGLAND-Occasional throughout, local, sometimes com-

WOOD-Light, soft, weak, reddish-yellow with nearly white sapwood; difficult to split and to ignite; used in Europe for rollers, packing cases and flooring. 

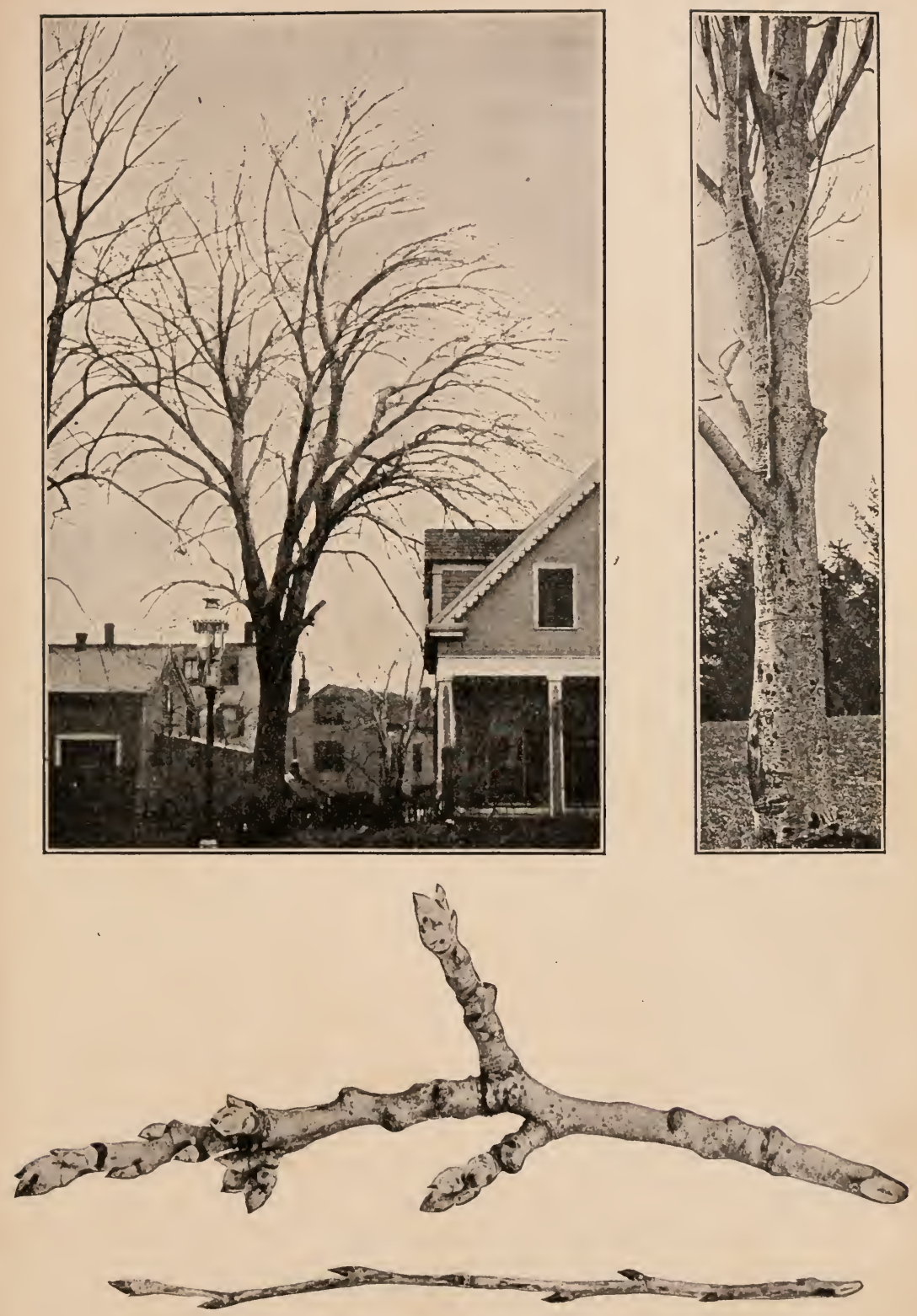

Silver Poplar 


\section{SMALL-TOOTHED ASPEN American or Quaking Aspen, Popple, Poplar, Aspen.} Populus tremuloides Michx.

HABIT-As generally found a small tree 35-40 ft. high, though not infrequently reaching $50-60 \mathrm{ft}$. in height with a trunk diameter of $11 / 2$ ft. or more; trunk tapering, continuous into top of tree; main branches slender, scattered, often drooping at the ends forming an open, narrow, round-topped head; spreading by means of root suckers.

BARK-On young trunks and branches thin, pale yellowish-brown, orange-green or nearly white with dark blotches below the branches, smooth with horizontal raised ridges (often encircling limbs); on older trunks especially toward the base, thick, furrowed and nearly black.

TWIGS-Slender, round, bright reddish-brown, smooth, shining. Older twigs grayish-brown, roughened by elevated leaf-scars and by swollen bases of detached branchlets. LENTICELS-light reddish-orange, scattered, oblong. PITH-5-pointed, star-shaped.

LEAF-SCARS-Alternate, more than 2-ranked, large, inversely triangular, covered with light colored corky layer, upper edge of scar more or less depressed. STIPULE-SCARS-blackish, more or less conspicuous. BUNDLE-SCARS-3, simple or each compounded.

BUDS-Narrowly conical, sharp-pointed, generally appressed especiially toward apex of twig or incurved, about 5-7 $\mathrm{mm}$. long, shining, slightly sticky but not fragrant; flower buds larger, ovate. BUDSCALES-6 or 7 in number, smooth, reddish-brown, shining, scarious along the margins; the first scale of lateral buds anterior, (i.e. facing outward), reaching about $1 / 3$ of the way to the apex, often splitting at the top.

FRUIT-A catkin of small capsules with hairy seeds ripening in spring.

COMPARISONS-In general habit and bark characters the Smalltoothed resembles the Large-toothed Aspen. It is readily distinguished from the latter by its shining reddish-brown, often slightly sticky, mostly appressed buds which are free from down. Those of the Largetoothed Aspen are thicker, dull, dusty-looking, more or less gray-downy, and for the most part divergent. The bark of the Small-toothed Aspen is generally somewhat lighter in color, often nearly white and generally earlier and more deeply roughened at the base; the larger branches of the Large-toothed Aspen have a tendency to grow out at a wider angle with the trunk than those of the Small-toothed Aspen. The buds resemble somewhat those of the Balsam Poplar but are much smaller, only slightly sticky and not fragrant. It is separated from the Carolina Poplar and Lombardy Poplar by its reddish twigs, those of the latter two species being yellow; from the Silver Poplar by absence of down on twigs.

DISTRIBUTION-In practically all soils and situations except in deep swamps though more often in dry ground; one of the first trees to take possession of clearings or burnt lands. Newfoundland, Labrador, and Nova Scotia to the Hudson Bay region and Alaska; south to New Jersey, along the mountains in Pennsylvania and Kentucky, ascending 3,000 feet in the Adirondacks: west to the slopes of the Rocky mountains, along which it extends to Mexico and lower California.

IN NEW ENGLAND-Common, reaching in the White Mountain region an altitude of $3,000 \mathrm{ft}$.

woOD-Light brown, with nearly white sapwood of 25-30 layers of annual growth, soft, weak, and soon decaying; used in great quantities for paper pulp and in the manufacture of excelsior. 

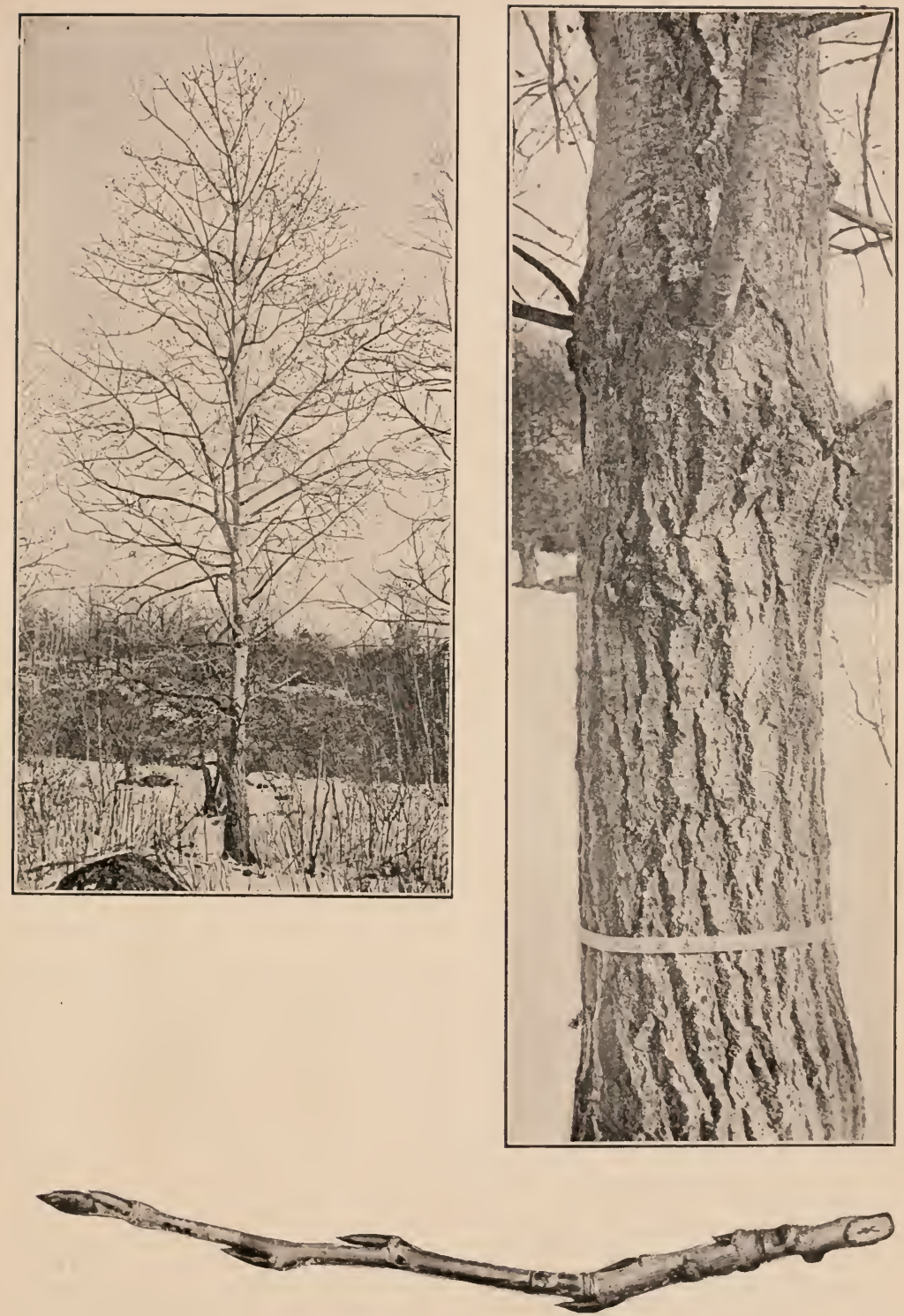

Simall-toothed Aspex 


\section{LARGE-TOOTHED ASPEN \\ Popple, Poplar.}

Populus grandidentata Michx.

HABIT-Generally' a small tree $30-45 \mathrm{ft}$, in height with trunk diameter of up to $1 \frac{1 / 2}{\mathrm{ft}}$, at times reaching much greater dimensions; resembling the Small-toothed Aspen; spreading by means of root suckers.

BARK Resembling that of Small-toothed Aspen though generally with more yellow or buff color to young trunks and limbs. The older trunks seem to be rather less deeply furrowed.

TWIGS-Stout, round, reddish-brown or somewhat yellowish-brown, in early winter often more or less pale-downy in protected portions, older twigs greenish-gray, otherwise resembling Small-toothed Aspen.

LEAF-SCARS-Resembling Small-toothed Aspen though the rather larger stipule-scars are often indistinct or absent.

BUDS-Averaging larger than those of Small-toothed Aspen, ovate to conical, pointed, generally divergent, dull, dusty-looking, due to 'fine, close, pale wool, especially at margins of scales; flower buds larger and thicker. BUD-SCALES-light chestnut brown with scarious margins: first scale of bud anterior.

FRUIT-A catkin of small capsules with hairy seeds ripening in spring.

COMPARISONS-The Large-toothed Aspen resembles the Smalltoothed Aspen with which it is frequently confused. For points of distinction see under the latter species. The Lombardy and Carolina Poplars are distinguished by their yellow twigs and smooth buds; the Balsam Poplar by its shining fragrant resinous buds; the Silver Poplar by its generally more delicate, greenish twigs which are cottonywoolly at least toward the apex.

DISTRIBUTION-In rich or poor soils; woods, hillsides, borders of ztreams. Nova Scotia, New Brunswick, southern Quebec, and Ontario; south to Pennsylvania and Delaware, along the mountains to Kentucky, North Carolina, and Tennessee; west to Minnesota.

IN NEW ENGLAND-Common, occasional at altitudes of 2,000 feet or more.

WOOD-Light brown, with thin nearly white sapwood of 20-30 layers ô annual growth, weak and soft, used in manufacture of paper, excelsior, and to a small extent for woodenware. 

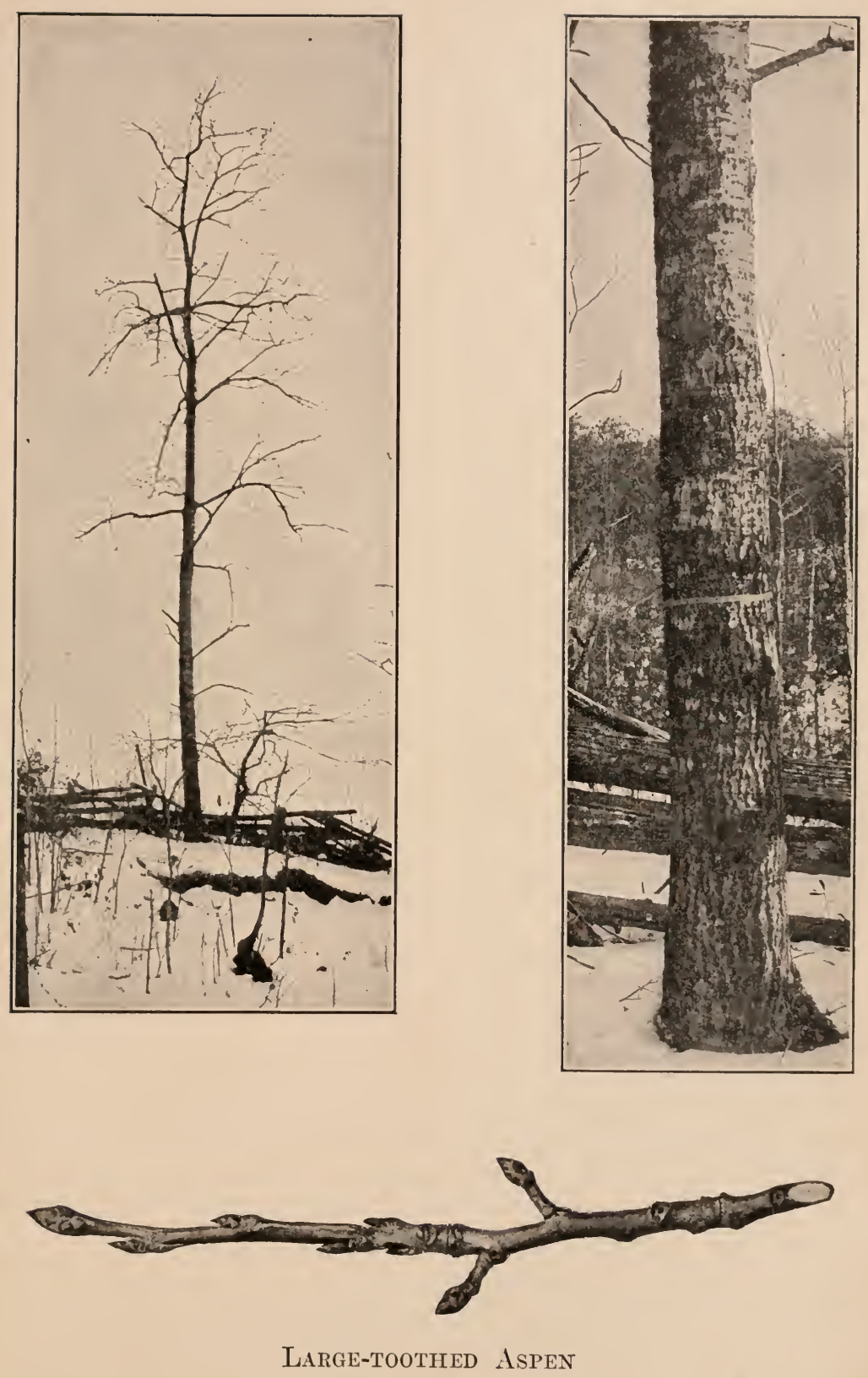


\section{BALSAM POPLAR \\ Balsam, Tacamahac, Balm of Gilead. \\ Populus balsamifera L.}

IABIT-A medium sized tree, 30-75 ft. in height with trunk diameter of 1-3 feet; head open, comparatively narrow, with spire-like tendency; spreading by means of root suckers.

BARK-On young trunks and branches smooth, light brown tinge with red, on older trunks dark gray tinged with red, broken into broad, firm, rounded ridges.

TWIGS-Stout to slender, round, bright reddish-brown, smooth, shining; older twigs dark orange colored becoming gray tinged with yellowish-green, roughened by thickened leaf-scars; short spurs numerous with terminal but without lateral buds. LENTICELS-oblong, light reddish-orange, scattered. PITH-5-pointed, star-shaped.

LEIF-SCIRS-Alternate, more than 2-ranked, large, 3-lobed, inversely triangular, rather narrow for the group. STIPULE-SCARS-distinct. BUNDLE-SCARS-3, simple or compound.

BUDS-Large, dark red, resinous, sticky, fragrant, especially if crushed, narrowly ovate to conical long-pointed, 15-25 $\mathrm{mm}$. long, terminal larger and relatively wider than lateral buds. BUD-SCALESthick, smooth, oblong, pointed, red or green, saturated with fragrant amber-colored resin which on the outside, where exposed to the air, forms a dark reddish, shining varnish to the bud; the first scale of lateral bud anterior.

FRUIT-A catkin of small capsules with hairy seeds ripening in spring.

COMPIRISONS-The Balsam Poplar with its varieties is distinguished from all other forms by the fragrance of its large resinous buds. Twigs and buds resemble those of the Small-toothed Aspen in color but are much larger and are distinctly fragrant especially if crushed. The Balm of Gilead [Populus candicans Ait.] is considered a distinct species by some and by others only a variety. It is extensively planted. It differs from the typical Balsam Poplar in its more spreading branches forming a broader and more open head but the twig characters are closely similar. The photographs were all taken from this latter variety, the descriptions from the type.

DISTRIBLTION-Alluvial soils; river banks, valleys, borders of swamps, woods. Newfoundland and Nova Scotia; west to Manitoba; northward to the coast of Alaska and along the Mackenzie River to the Arctic circle; west through northern New York, Michigan, Minnesota, Dakota (Black Hills), Montana, beyond the Rockies to the Pacific coast.

IN NEW ENGLAND-Maine-common; New Hampshire-Connecticut river valley, generally near the river, becoming more plentiful northward; Vermont-frequent; Connecticut-local; river banks, wet woods and roadsides, usually as an escape from cultivation; Southington, Milford, Wilton, Sherman, New Milford and Kent; apparently native at Norfolk; Massachusetts and Rhode Island-not reported.

woOD-Light, soft and weak; light brown, with thick nearly white sapwood; used for pails, boxes and paper pulp. 

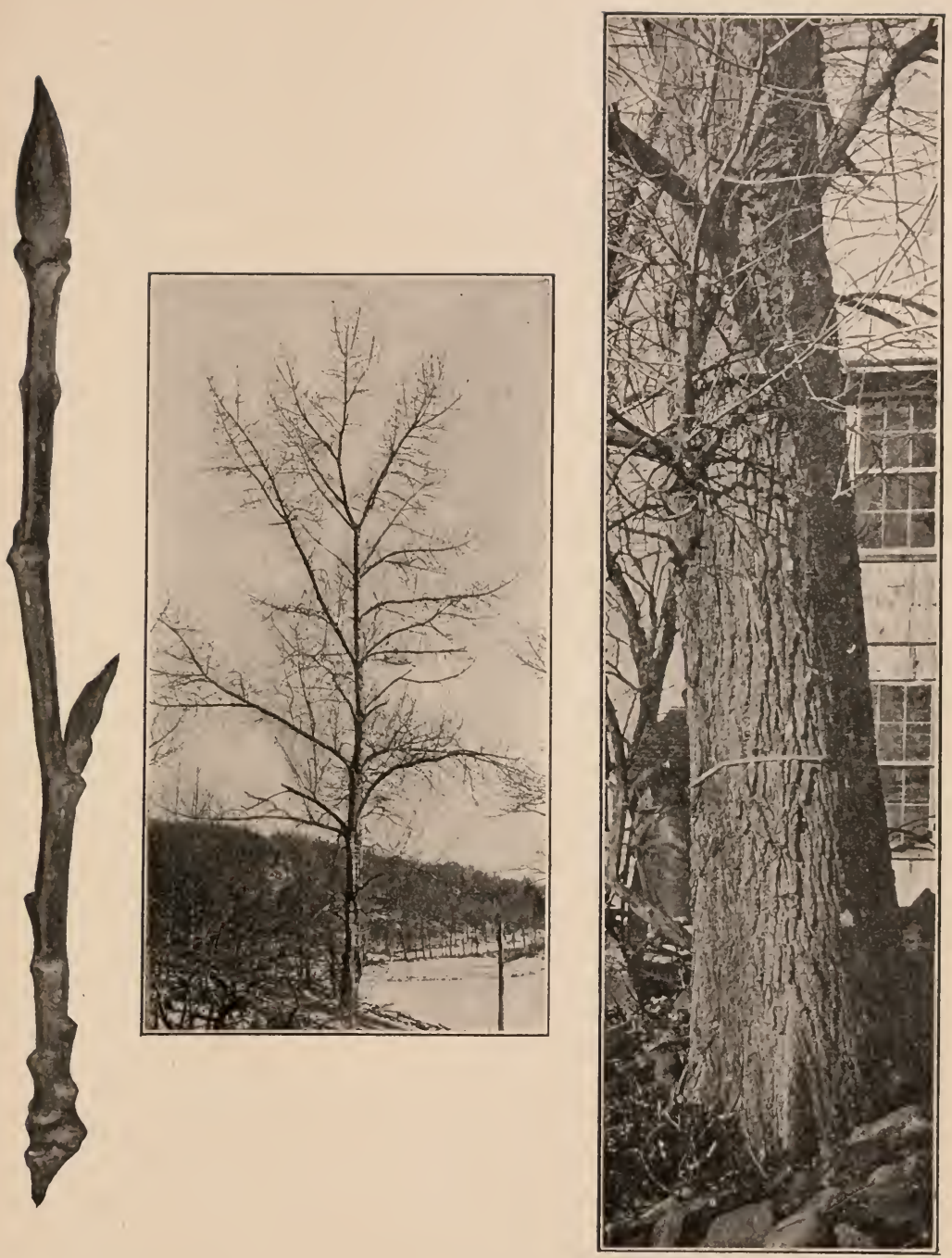

Balsame Poplar 


\section{CAROLINA POPLAR Cottonwood, Necklace Poplar. \\ Populus deltoides Marsh.}

P. monilifera Ait. ; P. canadensis Moench.

HABIT-A large tree, the largest of the Poplars, 75-100 ft. in height, with a trunk diameter of 3-5 ft.; lower branches massive nearly horizontal, those above arising at a sharper angle and forming altogether in old trees a broad-spreading, rather open head, often as broad as high; in younger individuals forming a more pyramidal head; of very rapid zrowth hence much planted for quick effects. The form cultivated under the name Carolina Poplar and considered by some distinct from the Cottonwood, is of pyramidal habit of growth with erect tapering trunk continuous to the top of the tree and producing branches in whorls at the upper limit of each year's growth. The habit photograph was taken from the more commonly cultivated form.

BARK-On young trunks and branches thin, smooth, light yellowishgreen. On older trunks thick, ashy-gray, deeply divided into long, broad, flattish or eventually rounded ridges of characteristic appearance in native-grown trees.

TWIGS-Stout, yellowish to greenish-yellow, sometimes with slight tinge of brown, smooth, round or marked especially on vigorous trees with more or less prominent wings running down from the two sides and bases of the leaf-scars. LENTICELS-large, pale, elongated longitudinally.

LEAF-SCARS-Alternate, more than 2-ranked, large, 3-lobed, inversely triangular. STIPULE-SCARS-generally conspicuous, blackish. BUNDLE-SCARS-3, simple or compound.

BUDS-Conical, large, the lateral buds reaching $15 \mathrm{~mm}$., and the terminal buds reaching $20 \mathrm{~mm}$. in length, frequently much smaller; lateral buds, especially the larger flower buds, generally divergent and often strongly recurved; terminal bud more or less distinctly 5 -sided. BUD-SCALES-smooth, light chestnut brown, shining, first scale of lateral bud anterior; outer scales slightly resinous-sticky, inner scales thickly coated with a light yellow sticky resin which is scarcely fragrant.

FRUIT-A catkin of small capsules with hairy seeds ripening in spring.

COMPARISONS-The Carolina Poplar is distinguished from our other Poplars except the Lombardy Poplar by its light yellow twigs. The Lombardy has somewhat similar twigs but they are more slender, the buds are generally much smaller and typically appressed. Appressed buds do occur on the Carolina Poplar and divergent buds on the Lombardy, but they are more typical on each tree as indicated. The distinct habit of the Lombardy Poplar is however a sufficient criterion of this latter species.

DISTRIBLTION-In moist soil, river banks and basins, shores of lakes not uncommon in drier locations, often cultivated. Throughout Quebec and Ontario to the base of the Rocky mountains; south to Florida, west to the Rocky mountains.

IN NEW ENGLAND-Maine-not reported; New Hampshire-restricted to the immediate vicinity of the Connecticut river, disappearing near the northern part of Westmoreland; Vermont-western sections, abundant along the shores of the Hoosac river in Pownal and along Lake Champlain; in the Connecticut valley as far north as Brattleboro; Massachusetts-along the Connecticut and its tributaries; Connecticutfrequent in the valleys of the Connecticut, Farmington and Housatonic rivers; rare or occasional elsewhere; Rhode Island-occasional.

WOOD-Dark brown, with thick nearly white sapwood, light and soft, warping badly in drying and difficult to season, used for paper pulp and in the manufacture of boxes. 

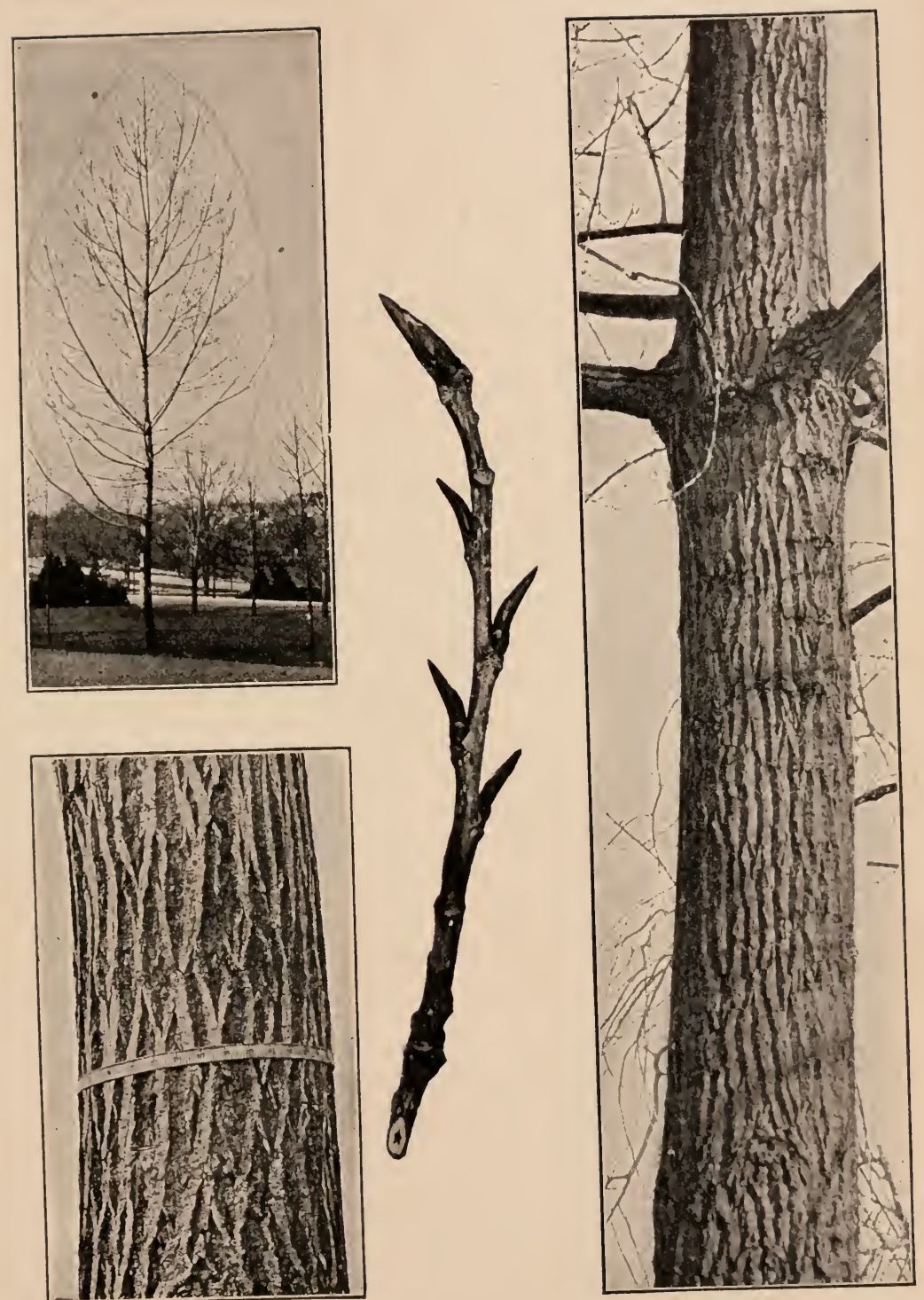

Chrolina Poplat 


\section{LOMBARDY POPLAR \\ Populus nigra, var. italica Du Roi. \\ P. dilatata Ait. ; P. pyramidalis Rozier; P. fastigiata Desf.}

HABIT-A tall tree reaching over $100 \mathrm{ft}$. in height with a buttressed tapering;, continuous trunk, sometimes as much as 6-8 ft. in diameter at base; branches numerous, arising low on the trunk, bending upward at a sharp angle with numerous branchlets also sharply ascending to form a very narrow spire-shaped tree of decidedly characteristic appearance; spreading by means of root suckers. It tends to retain its leaves on the lower part of the tree. (See bark picture.)

B.IRK-On old trees gray to brown, deeply furrowed.

Tw1GS-Resembling those of Carolina Poplar but slender, round and appressed.

LEAF-SCARS-Resembling those of Carolina Poplar, but smaller.

BUDS-Resembling those of Carolina Poplar but for the most part appressed, distinctly smaller, terminal buds seldom over $10 \mathrm{~mm}$. long and lateral buds generally under $8 \mathrm{~mm}$. in length.

FRUIT-Absent, only staminate trees being known of this variety.

COMPARIsoxs-The Lombardy Poplar is readily distinguished from all our other trees by its striking spire-shaped habit of growth. In twig characters it resembles the Carolina Poplar but the twigs are slender and the buds average smaller and are more characteristically appressed.

DISTRIBUTION-A European tree much planted in this country for ornament, escaping to a certain extent to roadsides and river banks.

wooD-Light, soft, weak, close-grained, reddish-brown with thick nearly white sapwood, used to a slight extent in the manufacture of boxes and wooden ware. 

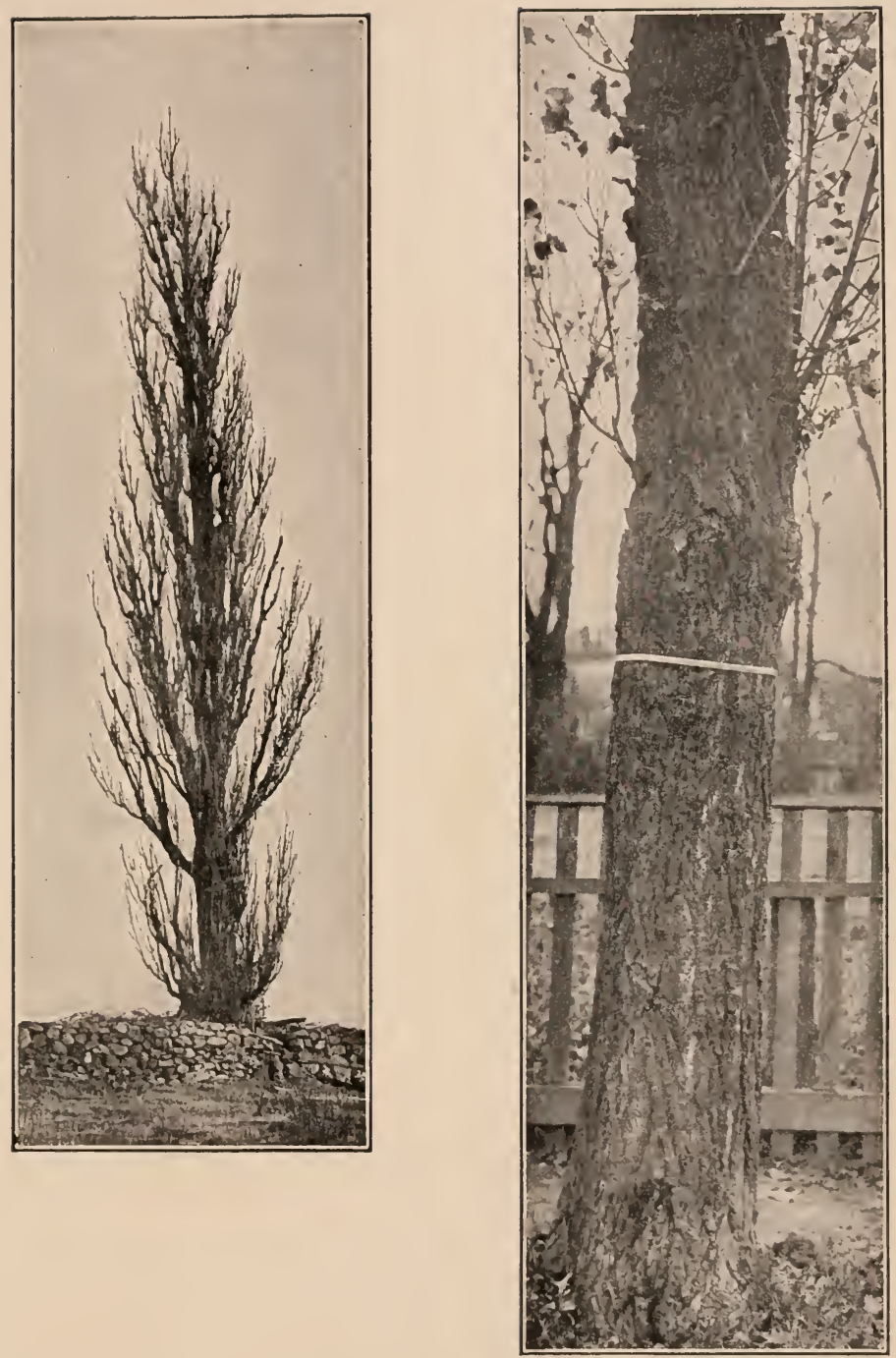

TAMB.IRIY POPLAR . 


\section{BUTTERNUT Oilnut, White Walnut. \\ Juglans cinerea L.}

HABIT-A small to medium-sized tree 20-45 ft. in height, with trunk diameter of 1-4 ft.; comparatively large for the height; soon dividing into a few stout spreading branches with lower branches somewhat drooping forming a symmetrical, broad, low, round-topped head of inversely pyramidal outline.

BARK-On young trunks and branches smooth, light gray, on older trunks deeply divided into long, rather broad, flat-topped, whitish ridges separated by smoothish, broader fissures, which are likewise gray or frequently become black in striking contrast to the whitish ridges; inner bark becoming yellow on exposure to air, bitter.

TWIGS-Stout, reddish-buff to greenish-gray, downy or nearly smooth, round or somewhat angled from lobes of leaf-scars, bitter to taste, and coloring saliva yellow when chewed. LENTICELS-small, pale, raised dots. PITH-somewhat 5-pointed, star-shaped, dark brown, chambered, the narrow chambers a little wider than the intervening diánhragms.

LE\F-SCARS-Large, conspicuous, 3-lobed, inversely triangular; margins elevated, upper margin generally convex, seldom slightly notched, surmounted by a raised, downy pad. BUNDLE-SCARS-dark, conspicuous in 3 U-shaped clusters.

BUDS-Densely pale-downy; terminal buds large, conical-oblong, 10$20 \mathrm{~mm}$. long, longer than broad, flattened oblong to conical, obliquely blunt-pointed; lateral buds smaller, ovate, rounded at apex, 1-3 superposed buds generally present above axillary bud, the uppermost, the largest, often far above the leaf-scar and more or less stalked or developing into a twig the first season, especially on rapidly grown shoots; staminate flower buds lateral, rather spherical, protruding the undeveloped catkins like miniature scaly cones from the envelope of short scales. BUD-SCALES-thick, outer scales of terminal bud lobed at apex.

FRIIT-Elongated, 4-10 cm. long, husk thickly covered with sticky hairs, not regularly splitting. NUT-light brown, elongated-ovate, 4ribbed, pointed, rough, deeply sculptured; within, 2-celled at base, 1celled above; seed sweet, edible, very oily, soon becoming rancid.

COMPAPISONS-In twig characters the Butternut most nearly resembles the Black Walnut but is easily distinguished from this species (see Comparisons under Black Walnut). Its points of dissimilarity to the Bitternut are given under this latter species.

DISTRIBITION-Roadsides, rich woods, river valleys, fertile, moist hillsides, high up on mountain slopes. New Brunswick, throughout Quebec and eastern ontario; south to Delaware, along the mountains to Georgia and Alabama; west to Minnesota, Kansas and Arkansas.

IN NEW ENGLAND-Maine-common, often abundant; New Hampshire-throughout the Connecticut valley, and along the Merrimac and its tributaries, to the base of the White Mountains; Vermont-frequent; Massachusetts-common in the eastern and central portions, frequent westward; Connecticut and Rhode Island-common.

woon-Light, soft, not strong, coarse-grained, light brown, turning darker with exposure, with thin, light-colored sapwood, composed of 5 or 6 layers of annual growth; largely employed in the interior finish of houses and for furniture. The inner bark possesses mild cathartic properties. Sugar is made from the sap and the green husks of the fruit are used to dye cloth yellow or orange color. 

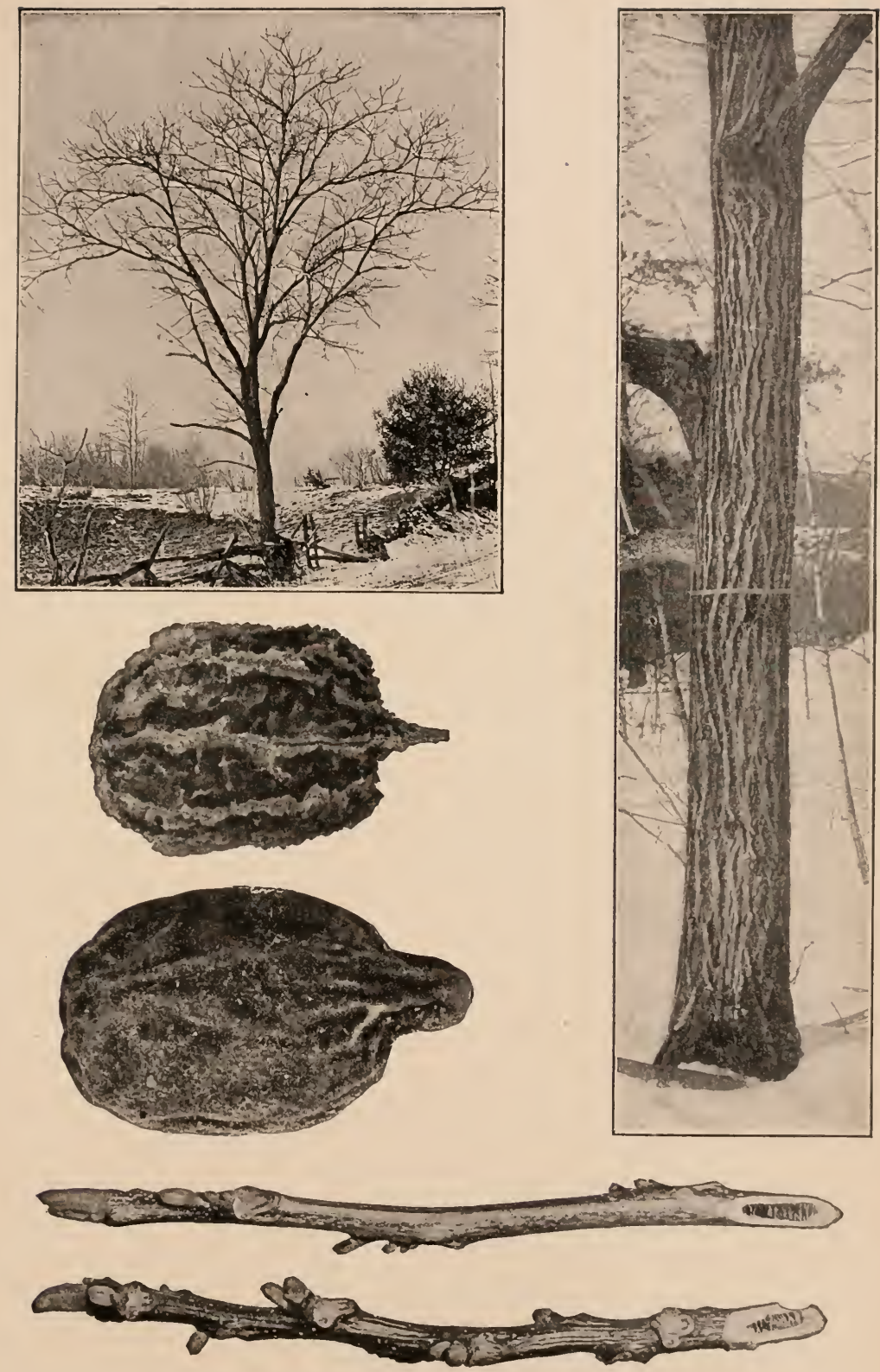

Butternut 


\section{BLACK WALNUT}

Juglans nigra L.

H. ВI'T-A large tree, 50-75 ft. high with a trank diameter of 2-5 ft. reaching a height of $150 \mathrm{ft}$. and a trunk diameter of $6-8 \mathrm{ft}$. in the ohio valley; trunk straight, tapering, giving off stout branches, those below often nearly horizontal or declined, those above arising at a sharper angle, spreading, forming an open, symmetrical, round-topped head.

BARK-Thick, dark, rough, deeply furrowed into rounded ridges; inner bark becoming yellow on exposure to air.

TWIGS-Stout, densely gray-downy to smooth and reddish-buff; bitter to taste and coloring saliva yellow when chewed. LENTICELS-small, pale, raised dots, rather inconspicuous. PITH-buff, paler than that of Bitternut, chambered, the open chambers several times wider than the intervening diaphragms.

LFAF-SCARS-Large, conspicuous, elevated, 3-lobed, inversely triangular to heart-shaped, upper margin distinctly notched, enclosing the axillary bud; no downy pad above leaf-scar. BUNDLE-SCARSdark, conspicuous in 3 U-shaped clusters.

BUDS-Pale, silky downy; terminal buds ovate, generally under 10 $\mathrm{mm}$. long and scarcely longer than broad, slightly flattened, obliquely blunt-pointed; lateral buds smaller, their outer scales opening at apex during winter, frequently a single superposed accessory bud above axillary bud. BUD-SCALES-thick, outer scales of terminal bud generally not evidently lobed.

FRUIT-Round-oval, 4-10 cm. in diameter, husk smooth not regularly splitting. NUT-dark brown, round-oval, slightly flattened, sculptured with interrupted, irregular, thick ridges; within 4-celled below the middle, 2-celled above; seed sweet, edible, oily, soon becoming rancid.

COMPIRISONS-The Black Walnut is most closely related to the Butternut which it resembles in its chambered pith and the general twig appearance. The Butternut, however, has terminal buds longer than broad, downy pads above leaf-scars, which are not notched as are leaf-scars of the Black Walnut, and it further has elongated rather than spherical nuts. The pith is dark brown while that of Black Walnut is pale buff and the chambers are not much wider than the diaphragms. In habit it is a lower, more spreading tree than the Black Walnut and the light gray color especially of the flat ridges of the bark is further characteristic. The points of dissimilarity to the Bitternut are mentioned under this latter species.

DISTRIBUTION-Rich woods, largely destroyed for its valuable timber and now scarce; occasionally cultivated as an ornamental tree in the eastern United States. Massachusetts, south to Florida; west to Minnesota, Kansas, Arkansas and Texas.

IN NEW ENGLAND-Maine, New Hampshire and Vermont-not reported native; Massachusetts-rare east of the Connecticut river, occasional along the western part of the Connecticut valley to the New York line; Connecticut-rare, roadsides and rocky hillsides in most localities derived from planted trees: Norwich, East Hartford, Newington, Southington. Seymour and Southbury, Trumbull and Easton; probably native at North Canaan; Rhode Island-doubtfully native, Apponaug, and elsewhere.

WOOD-Heavy, hard, strong, rather coarse-grained, very durable, rich dark brown, with thin, lighter colored sapwood of 10-20 layers of annual growth; largely used in cabinet-making, the interior finish of houses, gun-stocks, and in boat and ship building. 

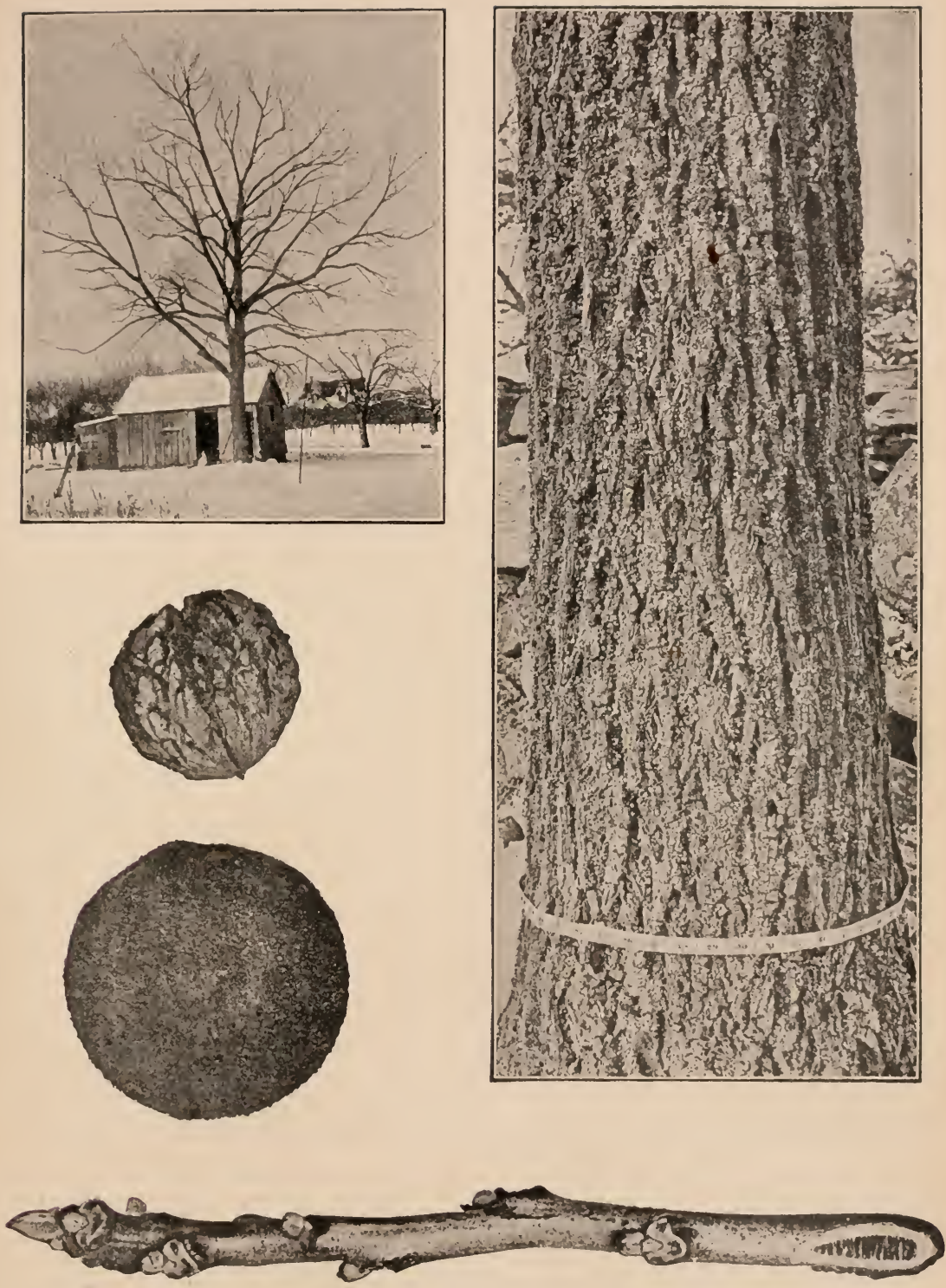

Black Walint 


\section{SHAG-BARK HICKORY Shell-Bark Hickory, Walnut. Carya ovata (Mill.) K. Koch. C. alba Nutt. ; Hickoria ovata Britton.}

HАBIT-A large tree, the tallest of the Hickories, 50-75 ft. high, with trunk diameter of less than $2 \mathrm{ft}$; in the forest producing a tall, straight trunk often free from branches for $50 \mathrm{ft}$. or more surmounted by a narrow head of few limbs; in the open generally forking low down or below the middle of the tree into stout ascending limbs forming an irregular open narrow oblong or inversely conical roundtopped head.

BARK-On young trunks and limbs smooth, light gray, becoming seamy; on old trunks shagging characteristically into long flat plates which are free at the base or both ends.

TWIGS-Stout, somewhat downy or smooth and shining, reddishbrown to light gray. LENTICELS-numerous, pale, conspicuous, longitudinally elongated. PITH-obscurely 5-pointed, star-shaped.

LEAF-SCARS-Alternate, more than 2-ranked, large, conspicuous, pale, slightly elevated 3-lobed heart-shaped to semi-circular. STIPULESCARS-absent. BUNDLE-SCARS-numerous, irregularly scattered or arranged in 3 more or less definite circular groups.

BUDS-Large, terminal bud 10-20 mm. long, broadly ovate, rather blunt-pointed. BUD-SCALES-the 3-4 outer scales dark brown, slightly downy or nearly smooth, fine-hairy on margins, broadly triangular, sharp-pointed, the outermost keeled and often with apex prolonged into a long, rigid point, persistent through winter but cracking and shagging off from the apex downward; inner scales yellowish-green, often tinged with red, densely downy on outer surface, shining within.

FRUIT-Nearly spherical, 3-5 cm. long, depressed at apex; husk 5-8 $\mathrm{mm}$. thick, with small pale lenticels, splitting to the base into four pieces. NUT-whitish, variable in size and shape, generally oblong, flattened, 4-ridged, rounded or pointed at base and apex; seed sweet.

COMPAIISONS-The Shag-bark Hickory is distinguished from other trees by the distinct shagging of its bark. The bark especially of one variety of the Pignut shags to a certain extent but not so extensively. From the Pignut, however, it is distinguished by its larger buds, and stouter twigs. From the Mockernut it is distinguished by its relatively longer buds, the darker, comparatively smooth, outer scales of which remain throughout the winter, though shagging away more or less completely from the tip toward the base.

DISTRIBUTION-In various soils and situations, fertile slopes, brooksides, rocky hills. Valley of the St. Lawrence; south to Delaware and along the mountains to Florida; west to Minnesota, Kansas, Oklahoma and Texas.

IN NEW ENGLAND-Maine, along or near the coast as far north as Harpswell; New Hampshire-common as far north as Lake Winnepesaukee; Vermont-occasional along the Connecticut to Windsor, rather common in the Champlain valley and along the western slopes of the Green mountains; Massachusetts, Connecticut and Rhode Island-common.

WOOD-Heary, very hard and strong, tough, close-grained, flexible, light brown with thin nearly white sapwood; largely used in the manufacture of agricultural implements, carriages, wagons, and for axehandles, baskets and fuel. The nut is the common hickory nut of commerce. 

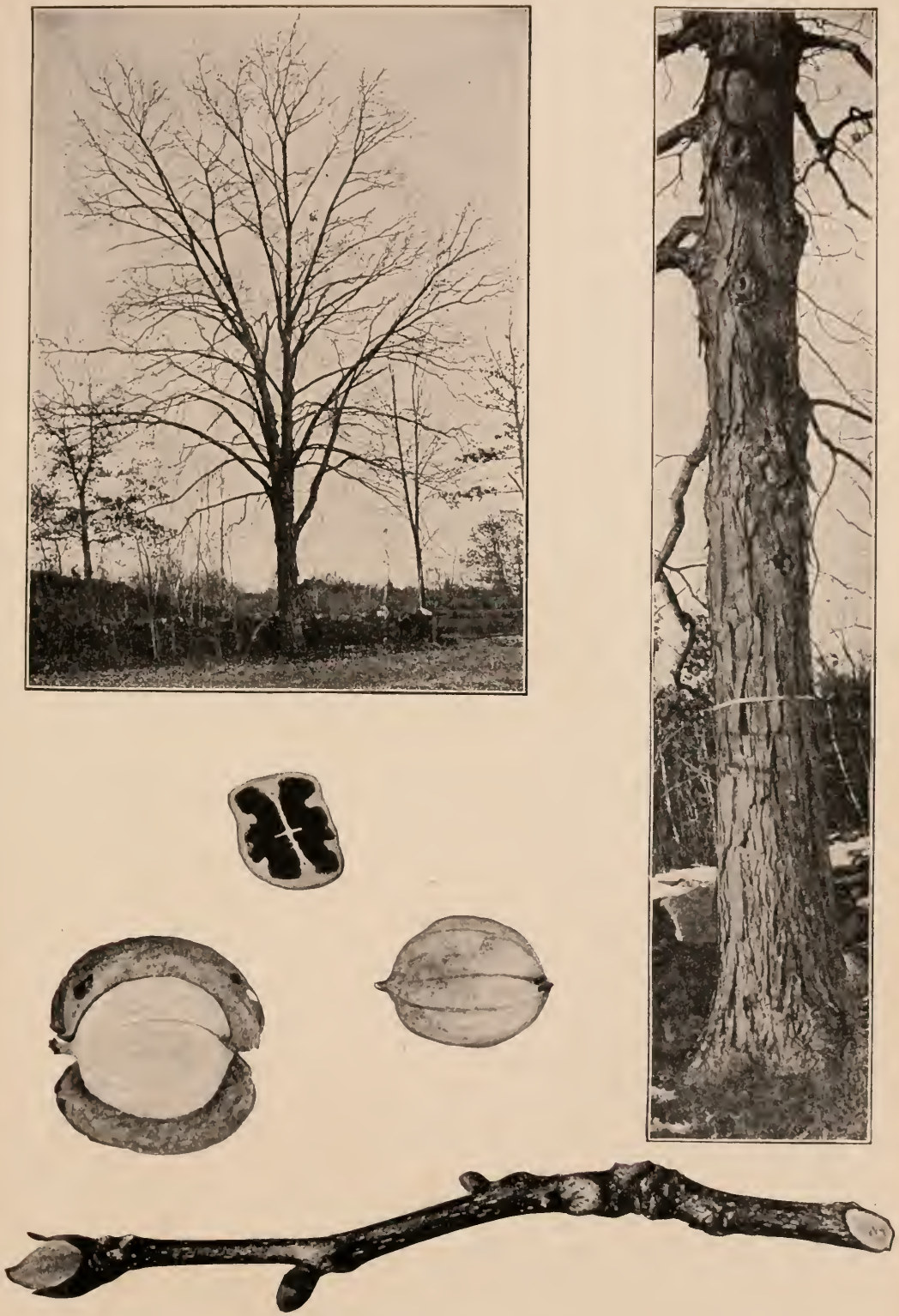

Shat-B.ARK Tickori 


\section{MOCKERNUT \\ Big Bud Hickory, White-heart Hickory. \\ Carya alba (L.) K. Koch. \\ C. tomentosa Nutt. ; Hickoria alba Britton.}

HABIT-A tall tree 50-70 ft. high with trunk diameter of 2-3 ft.; lower branches more or less drooping; those above ascending at a sharp angle, forming a narrow oblong or broad round-topped head, trunk somewhat swollen at base.

BARK-Light to dark gray, not shaggy, broken by irregular inter. rupted fissures into shallow rounded and smooth-topped ridges which are transversely cracked at intervals; the smoothness of the furrows and of the rounded ridges together with the grayness of the bark is quite characteristic, giving an appearance as if the roughness of the bark had been sandpapered down or as if a thin veil had been drawn over the trunk.

TWIGS-Very stout, generally more or less finely downy, reddishbrown to gray. LENTICELS-numerous, pale, conspicuous, longitudinally elongated. PITH-obscurely 5-pointed, star-shaped.

LEAF-SCARS-Alternate, more than 2-ranked, similar to those of Shag-bark Hickory but rather tending to be more distinctly 3 -lobed with basal lobe elongated.

BUDS-Terminal buds pale, densely hairy, broadly ovate, blunt or sharp-pointed, 10-20 $\mathrm{mm}$. long, outermost scales falling in early autumn, exposing the yellowish-gray, silky inner scales, some of which fall during the winter.

FRUIT-Spherical to obovate, 4-f cm. long, more or less narrowed at the ends; husk 3-4 mm. thick, splitting to middle or nearly to base. NUT-brown, variable in size and shape, spherical to oblong, more or less flattened and angled and generally pointed at both ends; shell very tnick; seed comparatively small, sweet.

COMPARISONS-The Mockernut, so named from the disappointingly small kernel obtained from the relatively large nut, is distinguished by its large, fat, pale, downy buds, which do not retain the outer dark scales as do the narrower buds of the Shag-bark Hickory. The peculiar smoothness of the ridges and furrows of the gray bark is also a distinctive characteristic.

DIS'TIRIBUTION-In various soils; woods, dry, rocky ridges, mountain slopes. Niagara peninsula and westward; south to Florida, ascending 3,500 feet in Virginia; west to Kansas, Nebraska, Missouri, Oklahoma, and Texas.

IN NEW ENGLAND-Maine and Vermont not reported; New Hampshire-sparingly along the coast; Massachusetts-rather common eastward; Connecticut-occasional or frequent; Rhode Island-common.

WOOD-Very heavy, hard, tough, strong, close-grained, flexible, rich dark brown, with thick nearly white sapwood; used for the same purpose as that of the Shag-bark Hickory. 

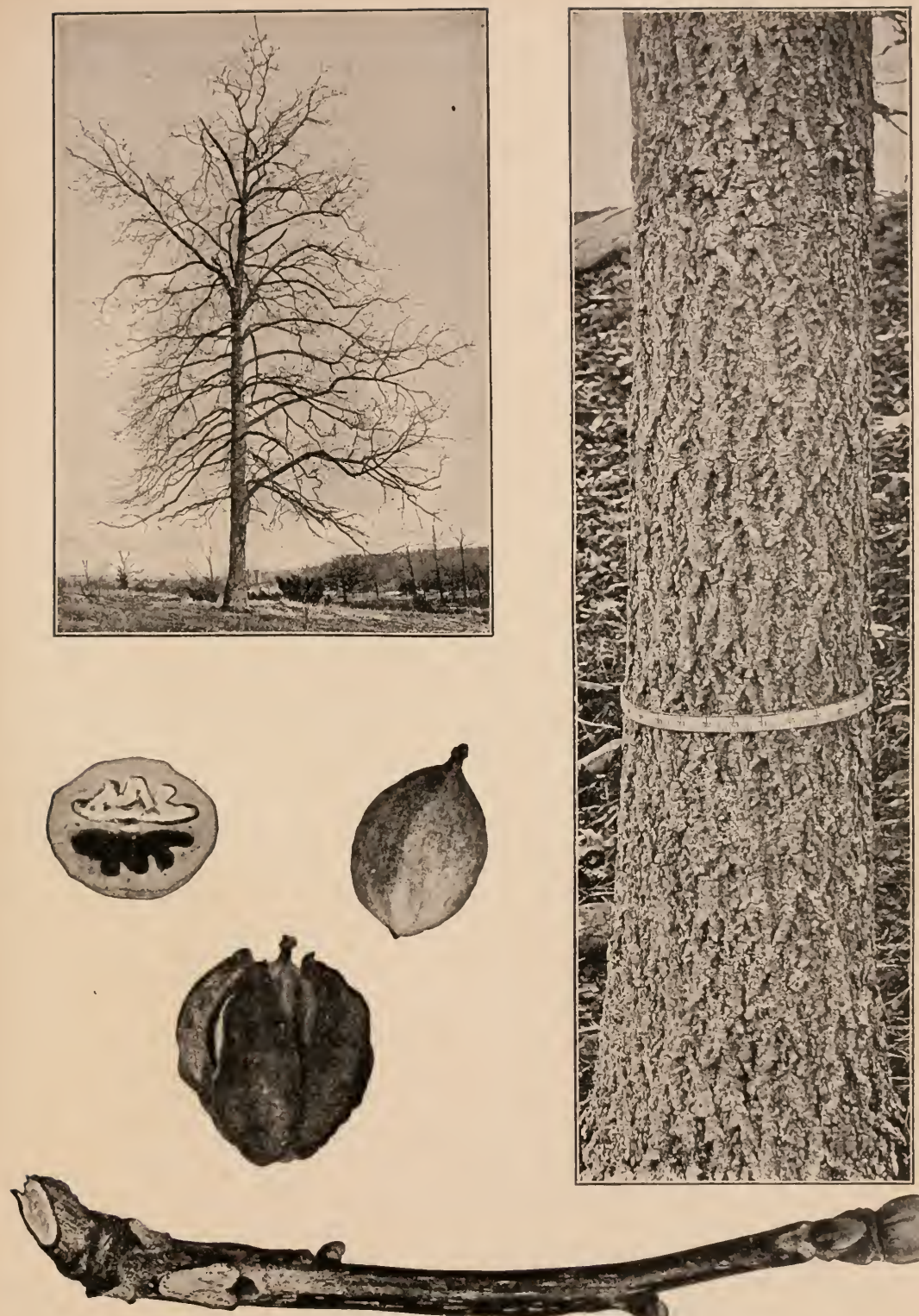


\section{PIGNUT}

\section{Pignut or Broom Hickory.}

Carya glabra (Mill.) Spach.

\section{C. porcina Nutt. ; Hickoria glabra Britton.}

HABIT-A good sized tree, 50-60 ft. in height with a trunk diameter of 2-5 feet.; branches slender, more or less contorted, the lower ones especially usually strongly pendulous, forming a narrow oblong head, well shown in the tree photographed, or broader in other specimens.

B IRI-Dark gray, fissured into irregular diamond-shaped areas somewhat suggesting bark of White Ash, but narrow ridges flattened, tough, tending to become detached at ends; sometimes somewhat shaggy especially in one of the varieties mentioned below, which has a bark approaching that of the Shag-bark Hickory.

TWIGS-Comparatively slender for the genus, smooth, reddish-brown to gray. LENTICELS-numerous, longitudinally elongated, more or less conspicuous. PITH-obscurely 5-pointed, star-shaped.

LEAF-SCARS-Alternate, more than 2-ranked, obscurely 3-lobed, heart-shaped to semi-circular or oblong. BUNDLE-SCARS-numerous, irregularly scattered or collected in 3 more or less definite groups.

BUDS-Reddish-brown to gray, small, terminal bud under $10 \mathrm{~mm}$. long, oval, blunt or sharp-pointed, becoming subglobose toward spring. BUD-SCALES-outer scales dark, smooth or finely downy, generally slightly yellow glandular-dotted, more or less keeled, and sometimes long-pointed, often falling before the end of winter and exposing the pale-silky inner scales.

FRUI'T-Pear-shaped to oblong to nearly spherical, 3-5 cm. long; very variable in size and shape; husk under $2 \mathrm{~mm}$. thick, in some forms splitting only at the apex and enclosing the nut after it has fallen to the ground, in other forms splitting to the middle or to the base. NUT-ihick or rather thin shelled, generally not ridged nor sharppointed; seed sweet or sometimes bitter.

COMPARISONS-The Pignut is a very variable species and there are several varieties described, some of which have been recognized as distinct species, as for instance Carya microcarpa Nutt., - the Smallfruited Hickory-which is perhaps the most conspicuous. It has a somewhat shaggy bark and a nearly spherical fruit with the husk splitting to the base. The most distinctive feature of the whole species is the small size of the buds, which before the outer dark scales drop off resemble buds of the Shag-bark Hickory except for size, and after these outer scales have been shed may be compared with miniature Mockernut buds. Its bark is not smoothed off like that of the Mockernut nor except in extreme cases shaggy like that of the Shagbark.

DIS'TRIBITION-Woods, dry hills and uplands. Niagara pensinsula and along Lake Erie; south to the Gulf of Mexico; west to Minnesota, Nebraska, Kansas, Oklahoma, and Texas.

IN NEW ENGLAND-Maine-frequent in the southern corner of York county; New Hampshire-common toward the coast and along the lower Merrimac valley; abundant on hills near the Connecticut river, but only occasional above Bellows Falls; Vermont-Marsh Hill, Ferrisburgh, W. Castlet on and Pownal; Massachusetts-common eastward; along the Connecticut river valley and some of the tributary valleys, more common than the Shag-bark; Connecticut-occasional or frequent; Rhode Island-common.

WOOD-Heavy, hard, very strong and tough, flexible, light or dark brown, with thick, lighter colored or often nearly white sapwood; used for the handles of tools and in the manufacture of wagons and agricultural implements, and largely for fuel. 

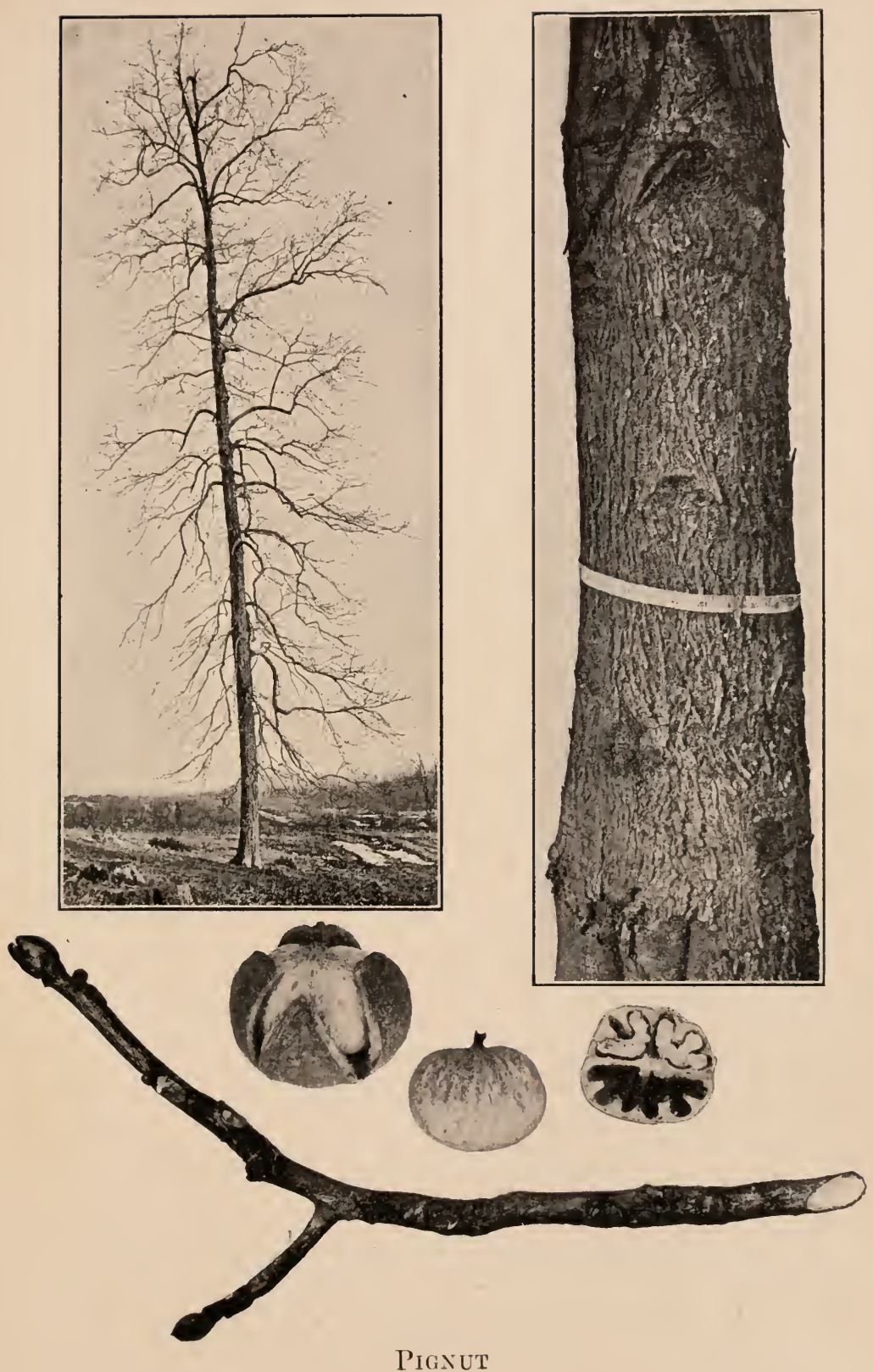

Pignut 


\title{
BITTERNUT \\ Swamp Hickory.
}

\author{
Carya cordiformis (Wang.) K. Koch.
}

C. amara Nutt.; Hickoria minima (Marsh.) Britton.

HABIT-A tall tree 50-75 ft. in height, with a trunk diameter of 1-21/2 ft.; trunk generally early developing several stout ascending and somewhat diverging branches to form a broad spreading head generally widest toward the top.

BAIRK-Thin, light gray, close, with shallow fissures and narrow ridges rarely flaking off in small, thin scales.

TWIGS-Slender, buff or gray or reddish, smooth or slightly downy toward apex, generally yellow-glandular above. LENTICELS-more or less distinct, pale, numerous, longitudinally elongated. PITH-infrequently star-shaped, brown.

LFAF-SCARS-Alternate, more than 2-ranked, obscurely 3-lobed, heart-shaped, inversely triangular to eliptical, pale, raised, large, prominent, the upper margin generally rounded, convex to sharppointed, often 2-toothed at apex. BUNDLE-SCARS-prominent, irreglarly scattered or collected into 3 more or less regular groups or sometimes apparently in single curved line.

IBUDS-Slender, strikingly yellow with crowded glandular dots, slightly hairy between the scales; terminal bud 5-15 mm. long, flattened, obliquely blunt-pointed; lateral buds more or less 4-angled, the axillary bud generally minute with one or more larger superposed buds above it, often considerably separated from each other, the uppermost of the series stalked or developing into a twig the first season. BUDSCALES-4, valvate in pairs.

FRUIT-Nearly spherical to pear-shaped, 2-3.5 cm. long, generally 4-winged from the apex to about the middle, husk about $1 \mathrm{~mm}$. thick, yellow glandular-dotted, tardily splitting to about the middle into 4 valves. NUT-usually thin-shelled, sometimes broader than long, smooth, short-pointed; seed deeply and irregularly roughened, sweetish at first, becoming intensely bitter.

COMPARISONS-The Bitternut will not be confused with any other tree if due notice is taken of the narrow bright yellow, glandulardotted often superposed buds. The Butternut has superposed buds but they are pale greenish-yellow and very downy, not bright yellow nor glandular dotted and the pith though similarly brown is distinctly chambered.

DISTRIBUTION-In varying soils and situations; wet woods, low, damp fields, river valleys, along roadsides, occasional upon uplands and hill slopes. From Montreal west to Georgian bay; south to Florida, ascending 3,500 feet in Virginia; west to Minnesota, Nebraska, Kansas, Oklahoma, and Texas.

IN NEW ENGLAND-Maine-southward, rare; New Hampshireeastern limit in the Connecticut valley, where it ranges farther north than any other of our Hickories, reaching Well's river; Vermontoccasional west of the Green mountains and in the southern Connecticut valley; Massachusetts-rather common, abundant in the vicinity of Boston; Connecticut-occasional; Rhode Island-common.

WoOD-Heavy, very hard, strong, tough, close-grained, dark brown, with thick light brown or often nearly white sapwood; largely used for hoops and ox-yokes and for fuel. 


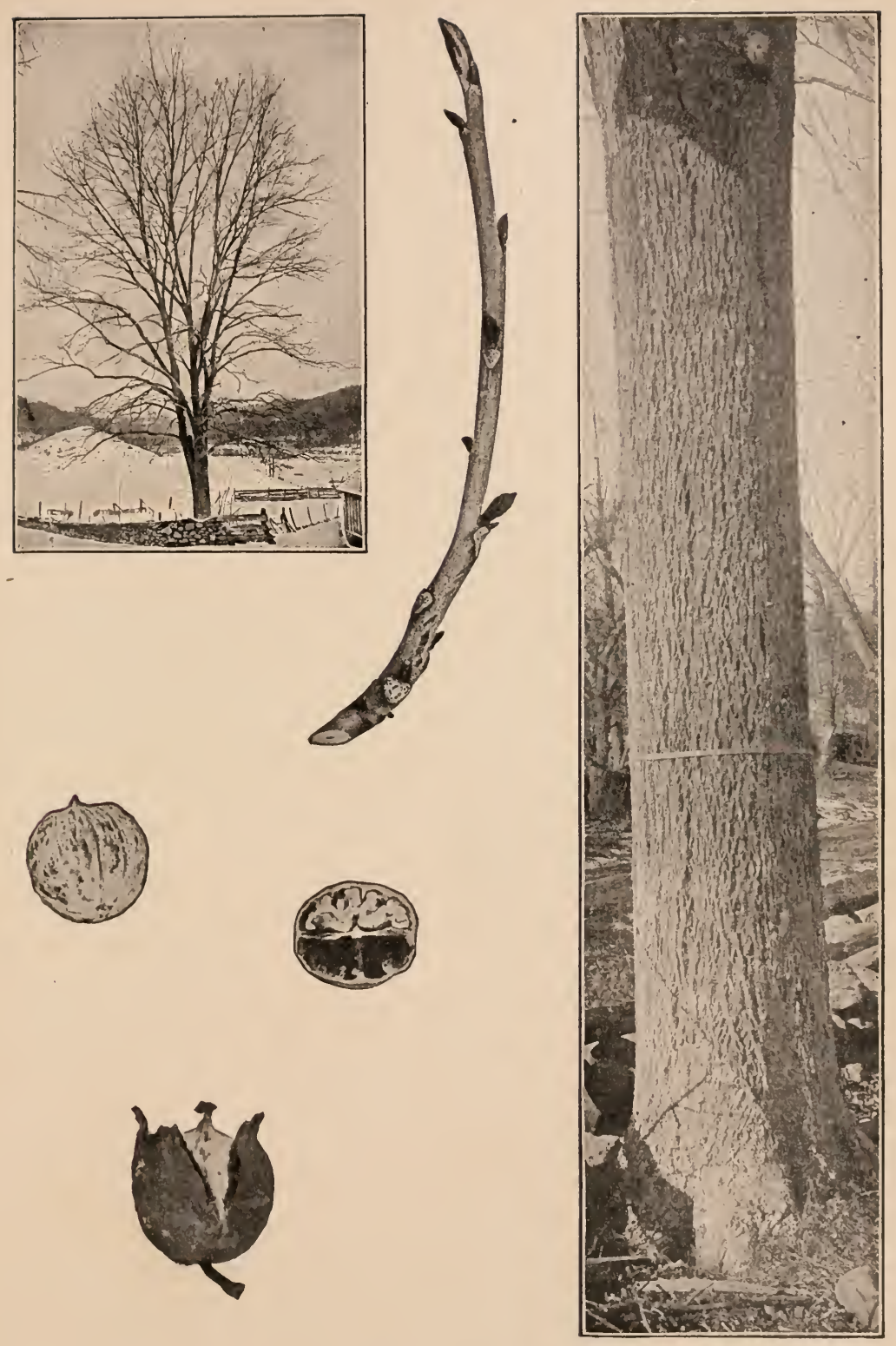

Bitternut 


\section{HOP HORNBEAM Ironwood, Leverwood, Deerwood.}

Ostrya virginiana (Mill.) K. Koch.

HABIT-A small tree $25-40 \mathrm{ft}$. in height with a trunk diameter of generally less than $1 \mathrm{ft}$; branches long, slender, those below widely spreading and often drooping but with branchlets tending upward forming an irregular oblong or broadly ovate head often as broad as all, with slender stiff spray.

BARK-Thin, flaky, light grayish-brown broken into narrow flattish pieces, loose at the ends.

TWIGS-Slender, 1-2 mm. in thickness, dark, reddish-brown, often zigzag, for the most part smooth and shining. LENTICELS-scattered, pale.

LEAF-SCARS-Alternate, 2-ranked, minute, $1.75 \mathrm{~mm}$. or less in diameter, flattened,. elliptical, projecting. STIPULE-SCARS-triangular, rather inconspicuous. BUNDLE-SCARS-generally 3, inconspicuous; if scar is surface-sectioned, 5 bundle-scars are evident.

BUDS-Small, 3-7 mm. long, narrowly ovate, pointed, light reddishbrown, smooth or somewhat finely downy, slightly gummy especially within, generally strongly divergent; terminal bud absent. BUD-SCALES -in 4 ranks, about 8 scales visible, increasing in size from below upwards, longitudinally striate if viewed toward light.

FRUIT-A small seed-like nutlet, enclosed in an inflated sac-like veiny bract, long-hairy at base; the fruits aggregated together in a hop-like cluster about $7 \mathrm{~cm}$. long, with stalks often hairy, generally falling before winter. Young staminate catkins abundantly present, cylindrical, usually in 3 's, their scales bristle-pointed.

COMPARISONS-The Hop Hornbeam from its general appearance and bark character is sometimes mistaken for a young Elm. The scales of the bark, however, are narrower and more flaky; the leaf-scars are smaller and the bundle-scars are not sunken, the bud-scales are in 4 ranks and the staminate flowers are borne in catkins which are generally present on the tree in winter. For differences between the Hop Hornbeam and the American Hornbeam, see under latter species.

DISTRIBITION-In rather open woods and along highlands. Novi Scotia to Lake Superior, scattered throughout the whole country east of the Mississippi, ranging through western Minnesota to Nebraska, Kansas, Oklahoma, and Texas.

IN NEW ENGLAND-common in all parts.

wooD-Strong, hard, tough, durable, light brown and tinged with red or often nearly white, with thick pale sapwood of 40-50 layers of annual growth, used for fence posts, levers, handles of tools, mallets and other small articles. 

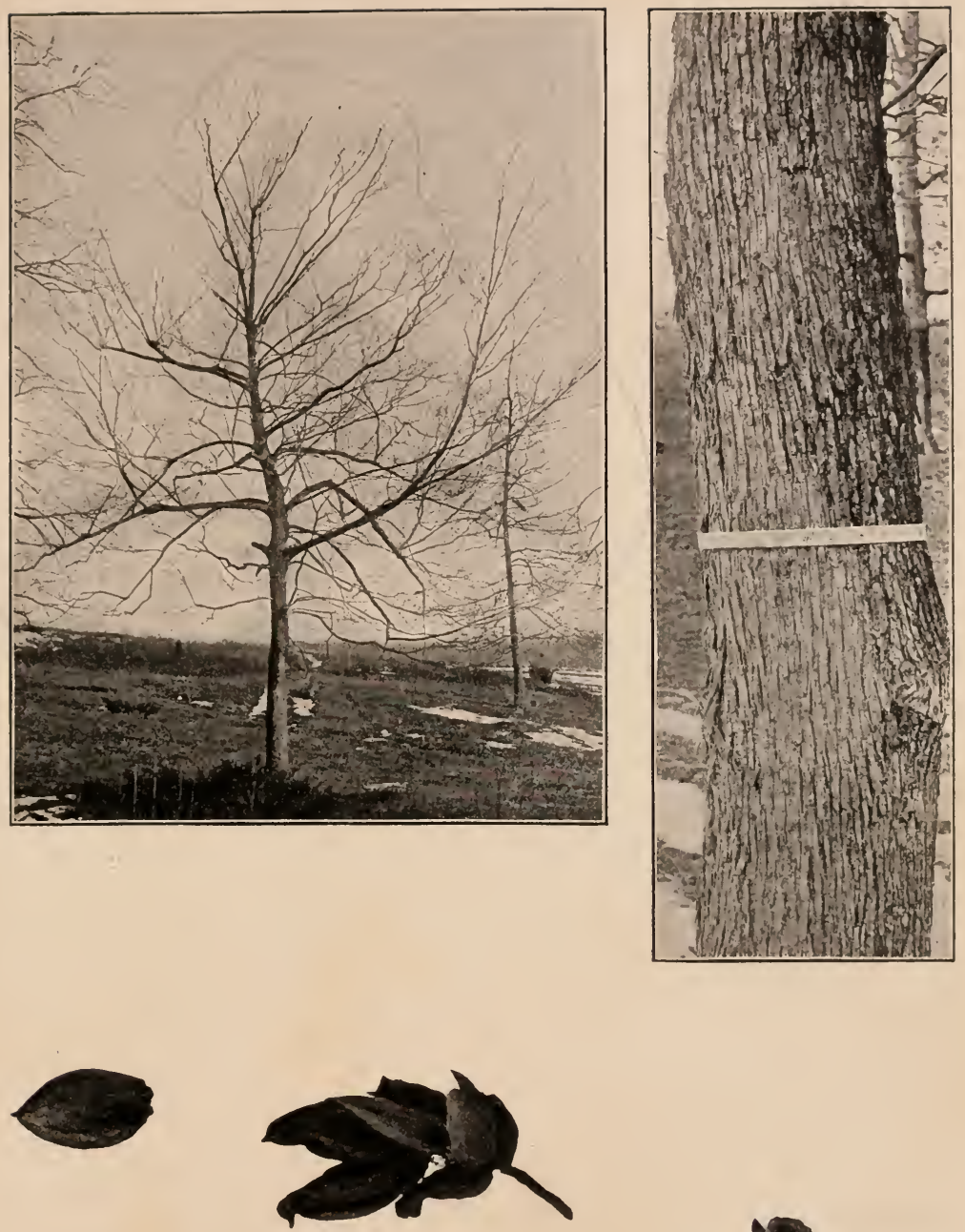

HoP HoRNBEATI 


\section{AMERICAN HORNBEAM Hornbeam, Blue Beech, Ironwood, Water Beech.} Carpinus caroliniana Walt.

HABIT-A low tree or shrub 10-30 ft. high with a trunk diameter generally under $1 \mathrm{ft}$; with long, slender, tough, more or less zigzag branches not easily broken, which are somewhat pendulous at ends forming a bushy wide spreading, flat or round-topped head; the trunk is frequently zigzag above giving appearance of being forked with broad, rounded crotches.

BARK-Smooth, thin, dark bluish-gray, close-fitting, sinewy-fluted with smooth, rounded, longitudinal ridges. The smooth ridges of the bark are very characteristic and may be compared to the appearance of the wrist which becomes similarly ridged by the protrusion of th $\ominus$ sinews when the hand is clenched.

TWIGS-Slender, about $1 \mathrm{~mm}$. thick or less toward apex, dark red, and shining, smooth, or often somewhat hairy. LENTICLES-scattered, pale, generally conspicuous.

LEAF-SCARS-Alternate, 2-ranked, minute, flattened, eliptical, projecting. STIPULE-SCARS-narrow, triangular, rather inconspicuous. BUNDLE-SCARS-generally 3, inconspicuous, up to 5 visible when surface-sectioned.

BUDS-Small, usually 2-4 $\mathrm{mm}$. long, narrowly ovate to oblong, pointed, reddish-brown, more or less hairly especially the buds containing staminate catkins which are larger and oval to obovate; leaf buds more or less appressed, or only slightly divergent, terminal bud absent. BUD-SCALES-in 4 ranks about $8-12$ scales visible, increasing in size from below upward, white-scarious and often downy on edges, frequently with a woolly patch of down on tip; longitudinally striate when viewed toward light.

FRUI'T-A small ribbed seed-like nutlet, enclosed by a veiny generally 3 -lobed bract about $2.5 \mathrm{~cm}$, long, which is saw-toothed on one side of larger lobe and often has one of lower lobes lacking, usually falling before winter. Staminate catkins entirely enclosed in the larger buds therefore not visible during winter.

COMPARISONS-The American Hornbeam is often confused with the Hop Hornbeam perhaps chiefly from their unfortunate similarity in common names. The smooth, close, bluish-gray bark together with the habitat in which it grows has given it the name of Water Beech. The sinewy-fluting to the bark is unique among our trees and readily distinguishes the American Hornbeam from the Hop Hornbeam, the bark of which is flaky in narrow scales. Further the American Hornbeam never shows any catkins in winter while they are generally abundant on the Hop Hornbeam; the buds of the American Hornbeam are smaller, and have whitish down on the edges; those of the Hop Hornbeam are for the most part smooth and slightly gummy. The Beech which the American Hornbeam resembles in its bark has much larger and relatively longer buds.

DISTRIBLTION-Low, wet woods and margins of swamps. Province of Quebec to Georgian bay; south to Florida; west to Minnesota, Nebraska, Kansas, Oklahoma, and Texas.

IN NEW ENGLAND-Rather common throughout, less frequent towards the coast.

woOD-Light brown with thick, nearly white sapwood, sometimes used for levers, the handles of tools and other small articles. 

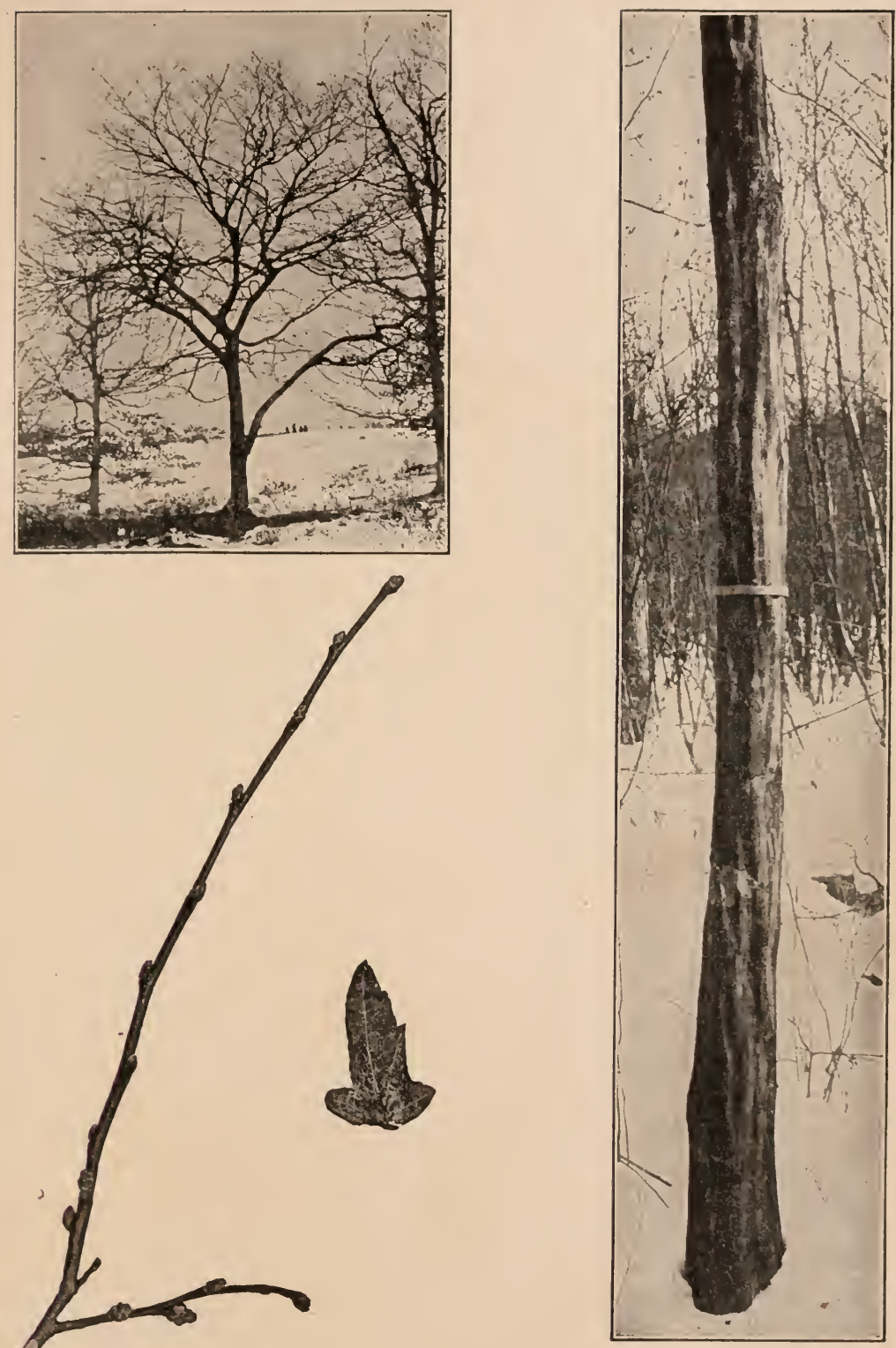

American Hornbeam 


\section{BLACK BIRCH \\ Cherry Birch; Sweet Birch.}

Betula lenta L.

НАВIT-A medium to large sized tree, 50-75 ft. high, with a trunk diameter of 1-4 ft.; branches long and slender, in young specimens upper branches ascending at sharp angle, lower branches horizontal or drooping with delicate spray forming a narrow head; in older trees becoming wide spreading, ovate in outline.

BARK-On young trunks and branches smooth, close, not peeling, dark reddish-brown, shining, with horizontally elongated pale lenticels resembling the bark of the cultivated Cherry whence the common name; in older trunks tardily broken into large thick irregular plates; inner bark with distinct wintergreen taste.

TWIGS-Slender, light reddish-brown, smooth, shining, with strong wintergreen flavor when chewed; short spur-like lateral shoots abundant, bearing two leaves each season, much roughened by leaf-scars of numerous past seasons. LENTICELS-pale, raised dots, becoming horizontally elongated with age. PITH-elliptical.

LEAF-SCARS-A loternate, 2-ranked, small, semi-oval to depressed inversely triangular to crescent-shaped, projecting. STIPULE-SCARSpresent, narrow, inconspicuous. BUNDLE-SCARS-generally 3 and inconspicuous.

BUDS-Medium, 5-10 $\mathrm{mm}$. long, conical, sharp-pointed, reddish-brown, divergent; terminal bud absent on long shoots; buds on short spurs terminal. BUD-SCALES-downy on margins, overlapping with more than 2 ranks; in buds of long shoots 3 scales visible, two lateral of equal size reaching half way up and a third with edges rolled around the bud; scales of terminal buds on short spurs more numerous, about 7 visible.

FRUI'T-An erect, stalkless, oval-oblong catkin, 2-4 cm. long, with smooth scales about 4-6 mm. long, equally 3-lobed above the middle and with seed-like winged nutlets about as broad as their wings.

COMPIIISONS-The Black Birch differs from other Birches in its close dark Cherry-like bark. It is most closely related to the Yellow Birch in the character of its fruit and the aromatic flavor of the young bark. Besides the bark differences, however, the twigs of the Black Birch have a more decided wintergreen flavor. It has in general a somewhat less spreading habit of growth, the buds are divergent and the catkins are not downy.

DISTRI I LTION-Moist grounds; rich woods, old pastures, fertile hill slopes, banks of rivers. Maine; south to Delaware, along the mountains to Florida; west to Minnesota and Kansas.

IN NEW ENGLAND-Maine-frequent; New Hampshire-in the highlands of the southern section, and along the Connecticut river valley to a short distance north of Windsor; Vermont-frequent in the western part of the state, and in the southern Connecticut valley; Connecticut - widely distributed, especially in the Connecticut river valley, frequent or common; Massachusetts and Rhode Island-frequent throughout, especially in the highlands, less often near the coast.

WOOD-Heavy, very strong and hard, close-grained, dark brown tinged with red, with thin light brown or yellow sapwood of 70-80 layers of annual growth; largely used in the manufacture of furniture and for fuel and occasionally in ship and boat building. Oil of wintergreen, used medicinally and as a flavor, is distilled from the wood, and beer is obtained by fermenting the sugary sap. 

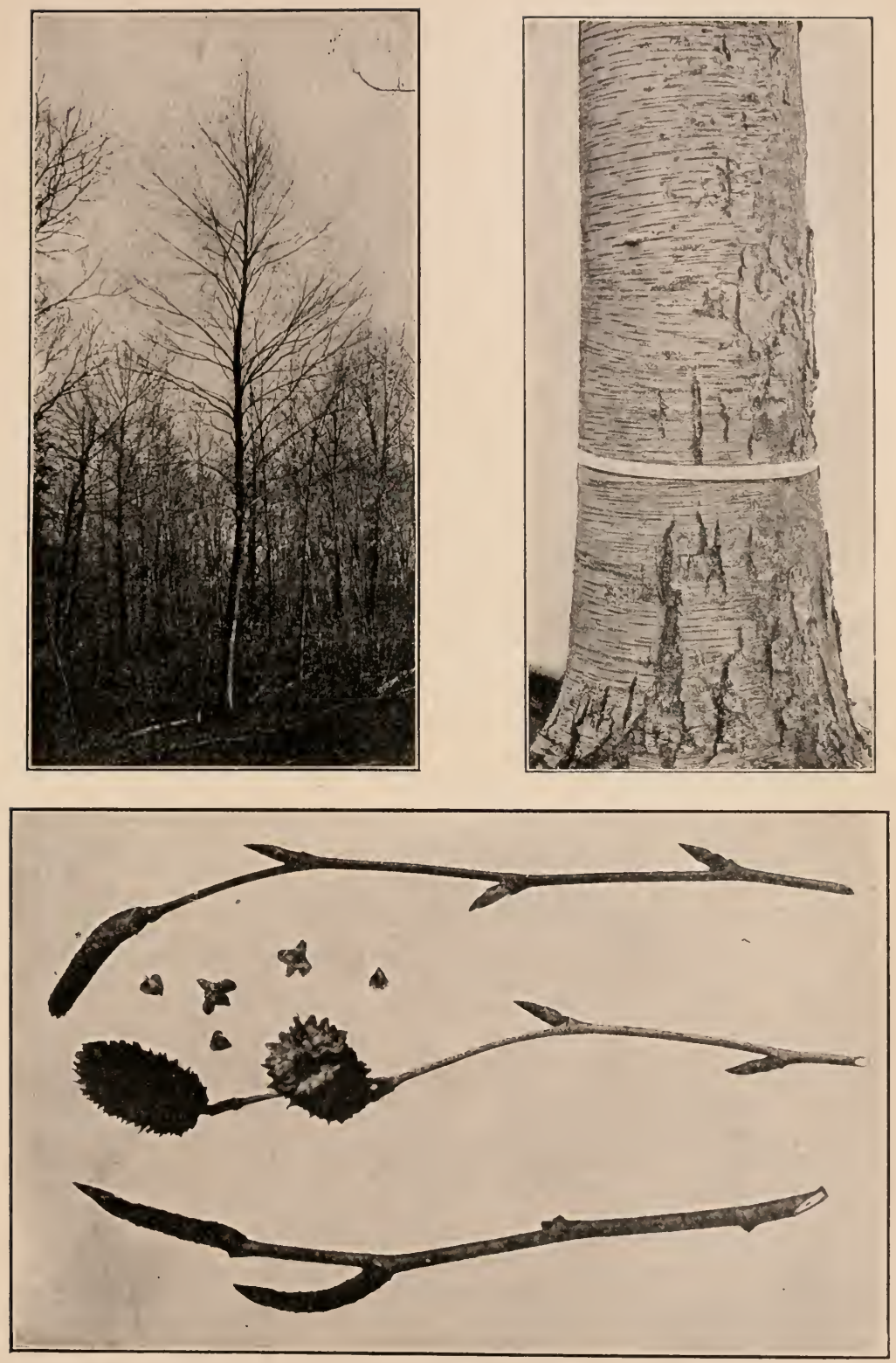

BLACK BIRCH 


\section{YELLOW BIRCH Silver or Gray Birch.}

Betula lutea Michx. f.

HABIT-A large tree 60-90 ft. in height, with trunk diameter of 2-4 ft., reaching its largest size in northern New England; in the open branching low down with long slender wide spreading somewhat pendulous branches forming a broadly ovate to hemispherical head. Older trees than the one photographed generally show a broader outline fwith the trunk less conspicuously continuous into the head.

BAIK-On young trunks and branches close, bright, silvery-yellowish gray, generally at length peeling into thin ribbon-like layers which roll back and extend up the trunk in long lines of ragged fringe. There is considerable variation in the amount of peeling of the outer bark. A well marked condition of peeling is shown in the bark photographed; the bark of the tree used for the habit showed scarcely any peeling. On older trunks especially toward the base the silvery bark is entirely shed and the bark below shows reddish-brown and becomes rough and fissured into irregular plate-like scales.

TWIGS-Slender, light yellowish-brown, becoming darker, smooth or somewhat hairy; with only slight wintergreen flavor when chewed; short spur-like lateral branches abundant, similar to those of Black Birch. LENTICELS-pale, raised dots, inconspicuous, becoming horizontally elongated with age.

LEAF-SCARS-Alternate, 2-ranked, similar to those of Black Birch.

BLDS-Similar to those of Black Birch, more. or less appressed. BUD-SCALES-more or less downy.

FRUIT-An erect, stalkless or short-stalked downy catkin, ovate to oblong, $2-4 \mathrm{~cm}$. long and about $2 \mathrm{~mm}$. wide and relatively wider than fruit of Black Birch; scales downy on the back and edges, 8-10 $\mathrm{mm}$. long, longer than broad, nearly equally 3 -lobed to the middle; with seed-like winged nutlets about as broad as their wings.

COMPARISONS-The Yellow Birch differs from the Black Birch as indicated in Comparisons under the latter species. In the peeling of the outer bark it resembles the Paper and the Red Birch. Its outer bark, however, is a dingy yellow and not a chalky white as is that of the exposed layers of the Paper Birch; moreover, in peeling, the thin layers tend to curl back to form longitudinal lines of ragged fringe. The fringes of bark are larger and more ragged than in the Red Birch but the color alone is sufficient to distinguish the two forms.

DISTRIBUTION-Low, rich woodlands, mountain slopes. Newfoundland and Nova Scotia to Rainy river; south to the middle states, and along the mountains to Tennessee and North Carolina; west to Minnesota.

IN NEW ENGLAND-Abundant northward; common throughout, from borders of lowland swamps to 1,000 feet above the sea level; more common at considerable altitudes, where it often occurs in extensive patches or belts.

wooD-Heavy, very strong, hard, close-grained, light brown tinged with red, with thin nearly white sapwood; largely used in the manufacture of furniture, button and tassel moulds, boxes, the hubs of wheels and for fuel. 

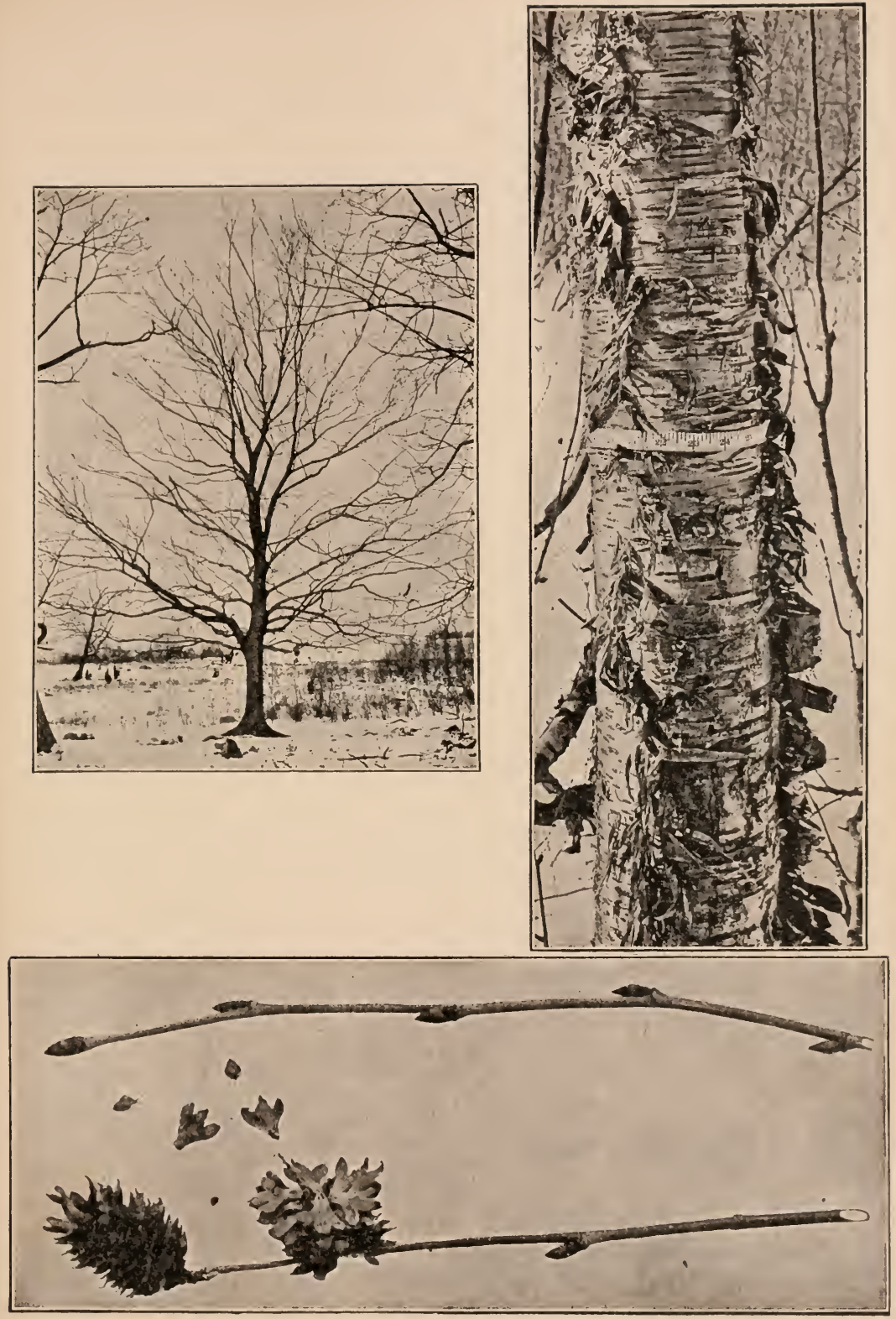

Yellow Birch 


\section{RED BIRCH River Birch.}

Betula nigra L.

HABIT-A medium sized tree, $30-50$ ft. in height with a trunk diameter of $1-1 \frac{1 / 2}{\mathrm{ft}}$, much larger southward; trunk often divided relatively low down as shown in photographs into a few slightly spreading limbs beset with numerous slender more or less pendulous branchlets, forming a rather narrow oblong head, becoming irregular and broader with age.

BIRK-On young trunks and branches, thin, shining, light reddishbrown, peeling freely into thin papery layers of various shades of red and brown which curl back and remain for several years as ragged fringes and show the light pinkish tints of the freshly exposed inner layers; at base of older trunks, dark reddish-brown, deeply furrowed and broken into thick irregular plate-like scales.

TWIGS-Slender, dark red, for the most part smooth. LENTICELSpale, becoming horizontally elongated.

LEAF-SCARS-Alternate, 2-ranked.

BUDS-Small, about $6 \mathrm{~mm}$. long, shining, light chestnut brown smooth or more or less hairy, ovate, pointed, more or less appressed.

FRUIT-Ripening in late spring or summer, a stalked, downy, eylindrical, erect catkin, $2-5 \mathrm{~cm}$. long; scales downy, with 3 narrow lobes, seed-like nutlet about as wide as the downy margined wings.

COMPARISONS-The Red Birch resembles the Yellow Birch in the more or less persistent ragged fringes of papery layers into which the outer bark peels. Its bark, however, is dark reddish to light cinnamon color, and is rather less ragged in peeling than that of the Yellow Birch which, moreover, is of a dirty yellowish color. The Black Birch with its dark bark and the white barked species cannot be confused with the tree under discussion. This tree is rare and local in New England and except as planted for ornament is found along river banks.

DISTRIBUTION-Along rivers, ponds and woodlands inundated a part of the year. Doubtfully and indefinitely reported from Canada; south, east of the Alleghany mountains, to Florida; west, locally through the northern tier of states to Minnesota and along the Gulf states to Texas; western limits, Nebraska, Kansas, Oklahoma, and Missouri.

IN NEW ENGLAND-Not reported in Maine, Vermont, Rhode Island or Connecticut; New Hampshire-found sparingly along streams in the southern part of the state; abundant along the banks of Beaver Brook, Pelham; Massachusetts-along the Merrimac river and its tributaries, bordering swamps in Methuen and ponds in North Andover.

WOOD-Light, rather hard, strong, close-grained, light brown with pale sapwood of 40-50 layers of annual growth; used in the manufacture of furniture, wooden ware, wooden shoes and in turnery. 


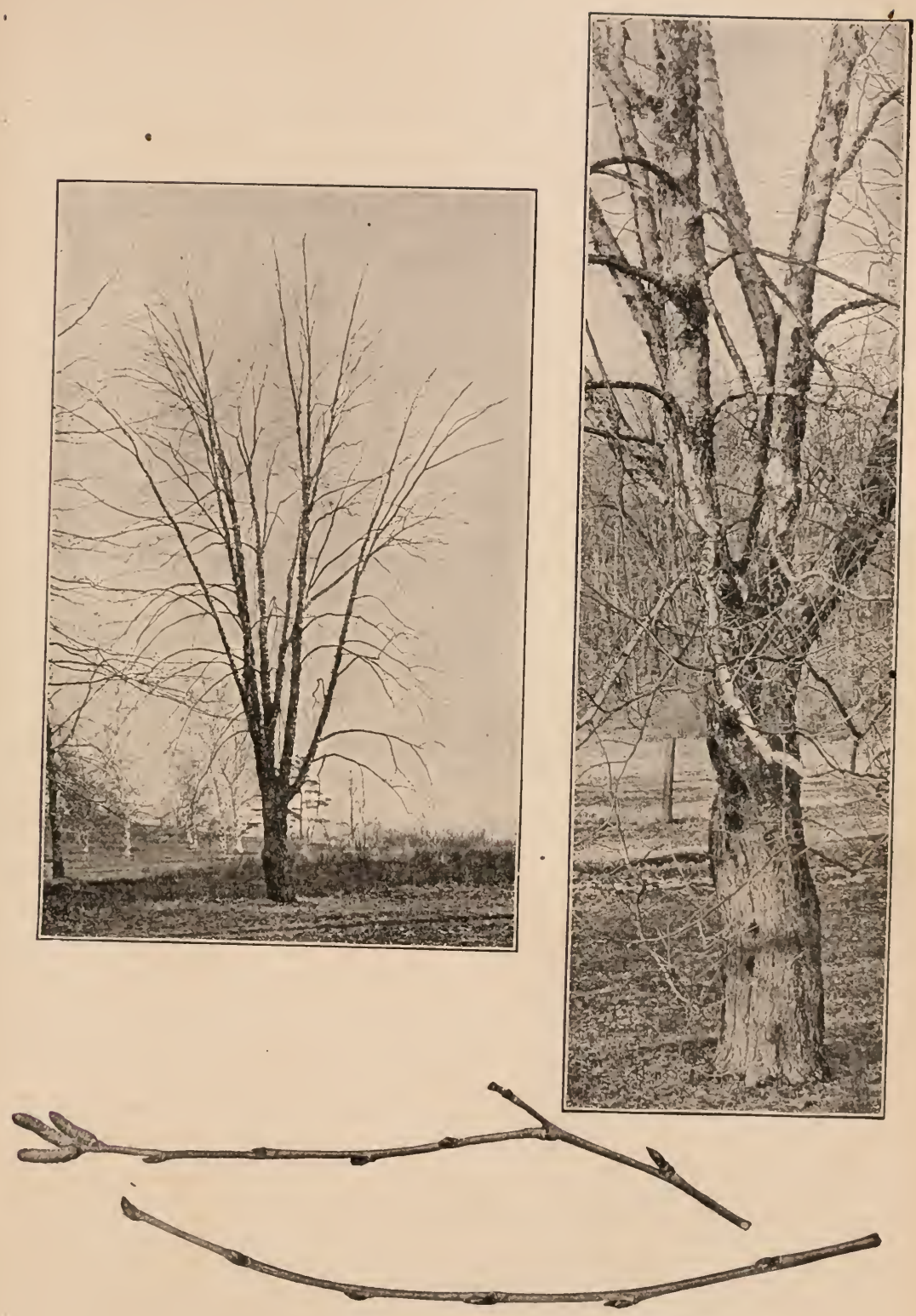

Red Bircit 


\section{GRAY BIRCH \\ Old-field, White, Poverty, Small White or Poplar Birch.}

Betula populifolia Marsh.

H. I I'T-A small short-lived tree, 20-35 ft. in height with a trunk diameter of generally less than 1 ft., commonly growing in clumps; trunk slender, generally inclined to one side, continuous into top of tree, with a fringe from top to bottom of short slender branches which grow upward for a short distance but soon bend downward, with delicate spray, forming a narrow, open, pyramidal, pointed head.

BIRK-Dull chalky-white, close, not peeling, with distinct dark triangular patches below insertion of branches; inner bark reddishorange yellow; base of older trees nearly black and roughened by irregular fissures; young trunks and branches bright reddish-brown.

TWIGS-Slender, bright reddish-brown or grayish, becoming with age dull chalky-white, much roughened by warty resinous exudations. LENTICELS - pale, raised dots becoming with age conspicuous and horizontally elongated.

LEAF-SCIRS-Alternate, 2-ranked, small, with characters of the genus.

BUDS-Small, about $5 \mathrm{~mm}$. or generally less in length, smooth, somewhat resinous especially within, ovate, pointed, divergent. BUDSCALES-finely downy on margins, 3-4 visible.

FIR UIT-An erect or pendant, slender-stalked, narrow-cylindrical cat$\mathrm{kin}, 1.5$ to $3.5 \mathrm{~cm}$. long; scales minute $2-4 \mathrm{~mm}$. long, finely downy with broad lateral recurved lobes, and narrow middle lobe suggesting the silhouette of a soaring bird; seed-like nutlet, minute, narrower than the wings. Staminate catkin usually solitary.

COMPARISONS-The Gray Birch resembles the Paper Birch in having a whitish outer bark. The bark, however, is a dingier gray and does not peel into thin papery layers as does that of the Paper Birch. A close inspection of its bark sometimes may show a certain breaking away of the outer part in minute inconspicuous scales, but this is not to be confused with a natural peeling. The bark, moreover, cannot be separated into thin papery layers.. The slender twigs are generally conspicuously roughened with resinous dots while those of the twigs of the Paper Birch are in general not so roughened except slightly in certain varieties. The Gray Birch is less inclined to produce large limbs and the numerous small branches are rather strongly pendant after leaving the trunk. The species is short lived, never forming a large tree, and is most frequently met with as a waste-land tree.

DISTRIBUTION-Dry, gravelly soils, occasional in swamps and frequent along their borders, often springing up on burnt lands and usually the first tree to take possession of abandoned or neglected fields; often difficult to eradicate as it sprouts readily from the cut stump. Nova Scotia to Lake Ontario; south, mostly in the coast region, to Delaware; west to Lake Ontario.

IN NEW ENGLAND-Maine-abundant; New Hampshire-abundant eastward, as far north as Conway and along the Connecticut to Westmoreland; Vermont-common in the western and frequent in the southern Sections; Massachusetts, Connecticut and Rhode Island-common.

wOOD-Light, soft, not strong, close-grained, not durable, light brown with thick nearly white sapwood; used in the manufacture of spools, shoe pegs and wood pulp, for the hoops of barrels and largely for fuel. 

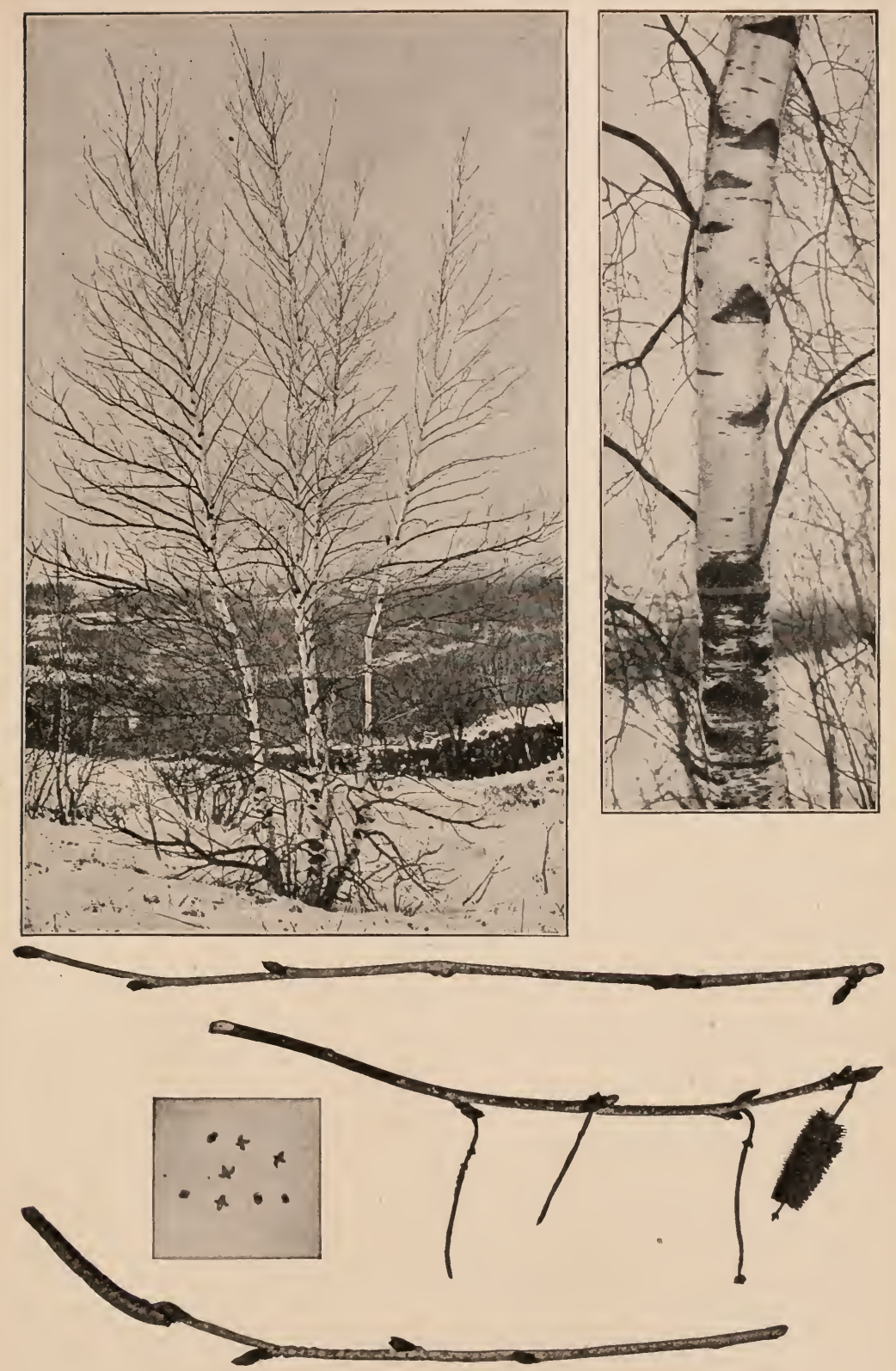

Gray Birch 


\title{
PAPER BIRCH \\ Canoe or White Birch.
}

Betula alba, var. papyrifera (Marsh.) Spach.

\author{
B. papyrifera Marsh.
}

HABIT-A large tree, 50-75 ft. or occasionally more in height with a trunk diameter of 1-3 ft.; developing when not crowded an open, irregular, rounded head, with numerous branches and erect branchlets.

BARK-Trunk and older branches chalky-white, peeling or easily separated into thin paper-like layers of a delicate pinkish to yellowish tinge where not exposed to the sun, with conspicuous horizontally elongated, raised lenticels; inner bark reddish-orange yellow. With age the outer bark rolls back in ragged sheets and the trunk becomes more or less black-streaked and blotched and the base rough and fissured into large irregular thick scales. The bark of the Paper Birch is much sought after by visitors in the woods for use as letter paper, small picture frames and other souvenir articles. In consequence trees of this species in the neighborhood of picnic grounds generally are despoiled of their bark and even its close-barked relative, the Gray Birch, is not immune from attacks of those who are ignorant of the difference in bark characters between the two species.

TWIGS-Stouter than those of the Gray Birch; smooth or somewhat hairy, reddish-brown. LENTICELS-pale, orange colored dots becoming horizontally elongated. LEAF-SCARS-2-ranked, resembling those of the Gray Birch.

BUDS-About 5-10 mm. long, ovate, pointed, divergent. BUD-SCALES - downy on margins.

FRUIT-A short-stalked, cylindrical, smooth catkin 2-5 cm. long; scales 4-6 mm. long, with thick lateral lobes, hairy-margined; seedlike nutlet, narrower than the wings; staminate catkins in 2's or usually in 3 's.

COMPARISONS-The Paper Birch, as known to woodsmen, is distinguished by its chalky-white bark peeling into thin papery layers. A number of botanically more or less distinct separate varieties and species have been recognized but Betula alba, var. papyrifera is the most common. The peeling of its bark distinguishes it from the Gray Birch. The exposed outer bark is more distinctly white and the dark triangular patches noticeable at the insertion of branches in the Gray Birch are often absent, especially on older trunks, or less distinct. The bark does not typically form the ragged fringe characteristic of the Yellow Birch and while it may not show the characteristic chalky-white where it has peeled, the color is not a dingy yellow but some delicate shade, generally of cinnamon.

DISTRIBUTION-Deep, rich woods, river banks, mountain slopes. Canada, Atlantic to Pacific, northward to Labrador and Alaska to the limit of deciduous trees; south to Pennsylvania and Illinois; west to the Rocky mountains and Washington on the Pacific coast.

IN NEW ENGLAND-Maine-abundant; New Hampshire-in all sections, most common on highlands up to the alpine area of the White Mountains, above the range of the Yellow Birch; Vermont-common; Massachusetts-common in the western and central sections, rare towards the coast; Connecticut-rare near the coast, Lyme, Huntington, becoming occasional northward and frequent in Litchfield county; Rhode Island-not reported.

wOOD-Light, strong, hard, tough, very close-grained, light brown, tinged with red, with thick nearly white sapwood; largely used for spools, shoe-lasts, pegs and in turnery, the manufacture of wood pulp and for fuel. The tough resinous durable bark impervious to water is used by all the northern Indians in their canoes, and for baskets, bags, drinking cups and other small articles, and often to cover their wigwams in winter. 

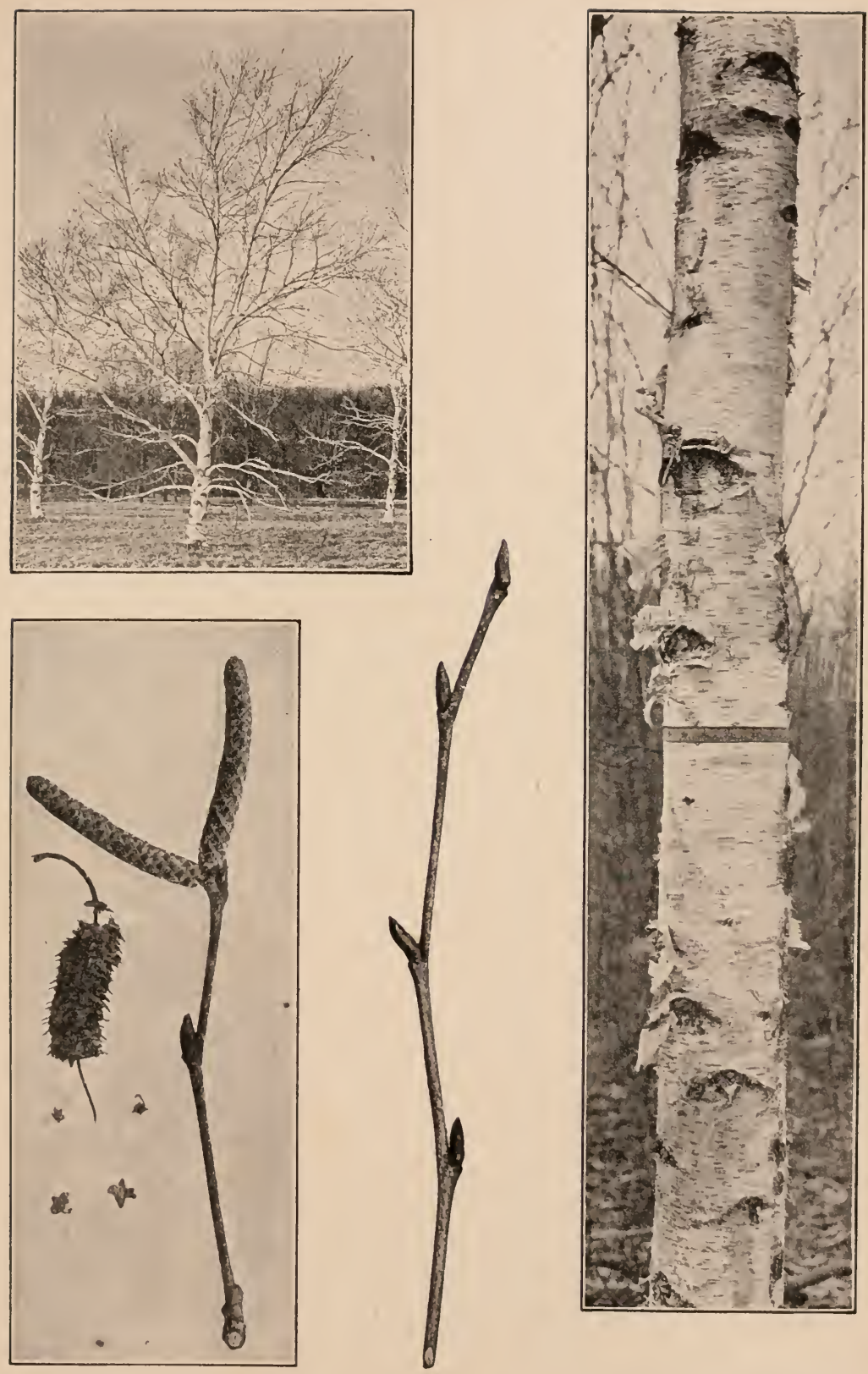

Paper Birch 


\title{
EUROPEAN WHITE BIRCH \\ European Paper Birch.
}

\author{
Betula alba L.
}

The European Birch of which our American Paper Birch is considered a variety is closely related to this latter species. There are many horticultural varieties. Aside from the weeping variety the forms most frequently seen in cultivation are erect with fine drooping spray. The bark is often slashed at the base of the trunk with deep "gusset"-like furrows exposing the inner bark in sharp contrast to the whiteness of the outer layers. The outer bark is separable into thin papery layers but does not seem inclined to peel spontaneously as our native Paper Birch. 

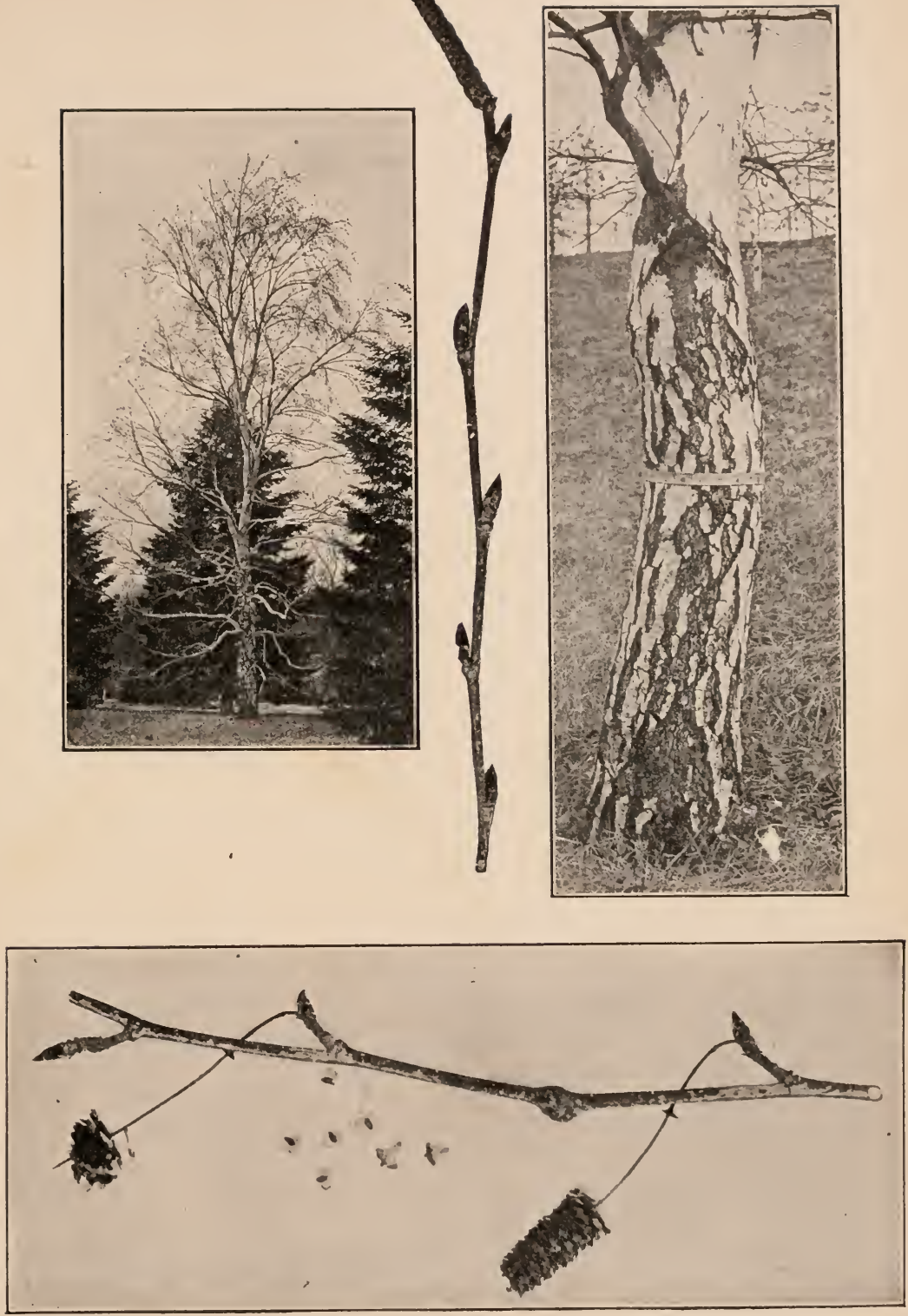

European White Birch 


\section{SPECKLED ALDER Hoary Alder, Alder. Alnus incana (L.) Moench.}

HABI'T-A small tree, or more frequently a shrub 8-25 ft. high with a trunk diameter generally under 5 inches; generally growing in clumps of several stems.

BARK-Grayish-brown, smooth, with prominent whitish lenticels somewhat elongated horizontally.

TWIGS-Rather slender, more or less zigzag, finely downy, grayishbrown, becoming hoary-white toward the tips especially of fruiting twigs. LENTICELS-scattered, whitish, conspicuous. PITH-dark green, 3-cornered.

LEAF-SCARS-Alternate, 2-ranked, or sometimes apparently more than 2-ranked, conspicuous, inversely triangular, raised, light yellowishbrown. STIPULE-SCARS-narrow, triangular. BUNDLE-SCARS-3, often compounded.

BUDS-Distinctly stalked, about $8 \mathrm{~mm}$. long, reddish, more or less whitened with fine down, slightly sticky within; terminal buds scarcely larger than laterals. BUD-SCALES-3 scales visible, closely stuck together.

FRUIT-A woody cone-like catkin, 6-12 $\mathrm{mm}$. long, remaining on the plant during winter, often distorted by strap-shaped projections caused by a fungus. Staminate catkins of the coming season pendant at the ends of reflexed branchlets with the young fertile catkins appearing lateral and pointing downward; seed-like nutlets, round, flattened.

COMPMrISONS-The Speckled Alder is distinguished from its most common relative, the Smooth Alder [Alnus rugosa (Du Roi) Spreng.], by position of the fertile catkins which in the Smooth Alder are erect and seem to be terminal and in the Speckled Alder point downward and seem to be lateral. These two common species occur throughout New England but intermediate forms are found, especially near their northern limits. The European Black Alder [Alnus vulgaris Hill.] is somewhat planted for ornament in this country and is reported in several localities as escaped from cultivation. In contrast to our native Alders it has an erect, distinctly tree-like habit of growth and reaches in Europe a height of $70 \mathrm{ft}$.

DISTRIBUTION-Swamps and borders of streams. Newfoundland to Saskatchewan, south to Pennsylvania and Nebraska.

IN NEW ENGLAND-Throughout, more or less common especially toward the north, local in sections toward the south; Connecticutlocal or occasional except in the southeastern part of the state where it is rare.

wOOD-Soft, used as a source of gunpowder charcoal and said to be further valuable because of its durability in water. 


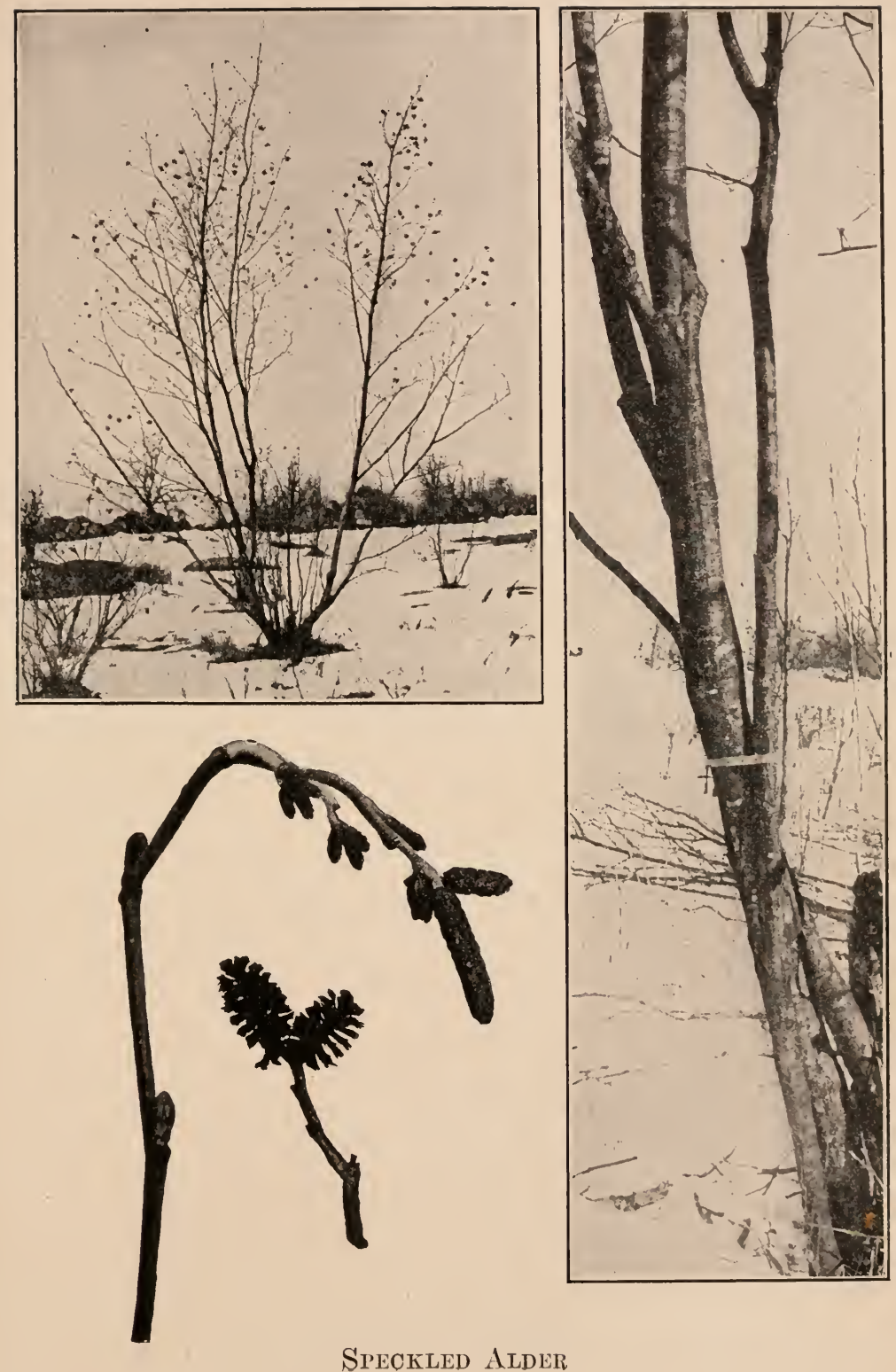




\title{
$\mathrm{BEECH}$ \\ American Beech.
}

\author{
Fagus grandifolia Ehrh.
}

$F$. ferruginia Ait. ; $F$. americana Sweet ; $F$. atropunicea Sudw.

HАBIT-A tall tree 50-75 ft. or more in height with a trunk diameter of 11/2-4 ft.; in the forest with a tall slender trunk free of branches for more than half its length; in the open low-branched with numerous long, slender, widely spreading or drooping branches, forming a symmetrical, broad, dense, rounded, oblong or obovate head; roots near the surface, widely spreading and sending up shoots which often surround the parent plant with a thicket of small trees.

BARK-Close, smooth, steel-gray; more or less dark mottled and covered with lichens in the country; in or about cities where lichen growth is prevented by injurious gases in the air, a clear, lighter bluishgray; from the ease with which it is carved, generally adorned with initials and conventionalized outlines of the human heart. Considering the uses to which the bark is often put the Beech might well be called the "Valentine Tree."

TWIGS-Slender, somewhat zigzag, smooth, shining, reddish-brown, becoming gray on older growth. Spray flattish from 2-ranked position of the buds; slow-growing branchlets numerous, leafy at tips, elongating each season only a small fraction of an inch, and growing but slightly in thickness; thus one of the twigs in photograph is 29 years old and had grown only $4 \frac{1}{2}$ inches in length and acquired a thickness of less than $3 \mathrm{~m}$ m. during this time. LENTICELS-numerous, conspicuous, orange to gray, elongated longitudinally. LEAVES-frequently remaining on tree in winter, pale yellow, oval, sharp-pointed, with prominent, straight veins, ending in teeth.

LEIF-SCIRS-Small, raised, elliptical to semi-circular. STIPULESCARS-narrow, distinct, nearly encircling twig. BUNDLE-SCARSinconspicuous, best seen by cutting surface section, 5 or more in double row or scattered.

BUDS-Conspicuously long and very slender, 10-20 mm. long, about 5 times as long as wide, gradually tapering to sharp-pointed apex; terminal bud present not conspicuously larger than laterals. BUD-SCALES -numerous, 10-20 in 4 ranks, increasing in length from base to apex, reddish-brown, their margins more or less finely hairy and often with a woolly patch of down at tip, leaving a rather long and distinct set of scale-scars marking each year's growth.

FRUIT-A stalked bur, densely downy and covered with soft spreading and more or less recurved prickles, 4-valved, splitting to near the base, remaining on the tree into winter, after the nut has fallen. NUTbrown, shining, 1.0-1.5 cm. long, 3-sided pyramidal; seed sweet, edible.

COMPIRISONS-The long narrow buds and the smooth, bluish-gray bark of the Beech make it an easy'tree to identify in the winter. The pale persistent dead leaves in connection with its habit may frequently be used to distinguish the tree from a distance, the Oaks being about the only other trees that have a similar retention of their withered leaves. The European Beech [Fagus sylvatica L.] with weeping and purpled-leaved varieties is frequently planted for ornament. It has a darker bark than the American tree but quite closely resembles it.

DISTIBITTION-Moist, rocky soil. Nora Scotia through Quebec and Ontario; south to Florida; west to Wisconsin, Missouri, and Texas.

IN NEW ENGLAND-Maine-abundant; New Hampshire-throughout the state; common on the Connecticut-Merrimac watershed, enters largely into the composition of the hardwood forests of Coos county; Vermont-abundant; Massachusetts-in western sections abundant, common eastward; Connecticut-occasional or frequent, rarely maturing perfect fruit; Rhode Island-common.

WOOD-Hard, strong, tough, very close-grained, not durable, difficult to season, dark or often light red, with thin nearly white sapwood of 20-30 layers of annual growth; largely used in the manufacture of chairs, shoe lasts, plane stocks, the handles of tools and for fuel. 

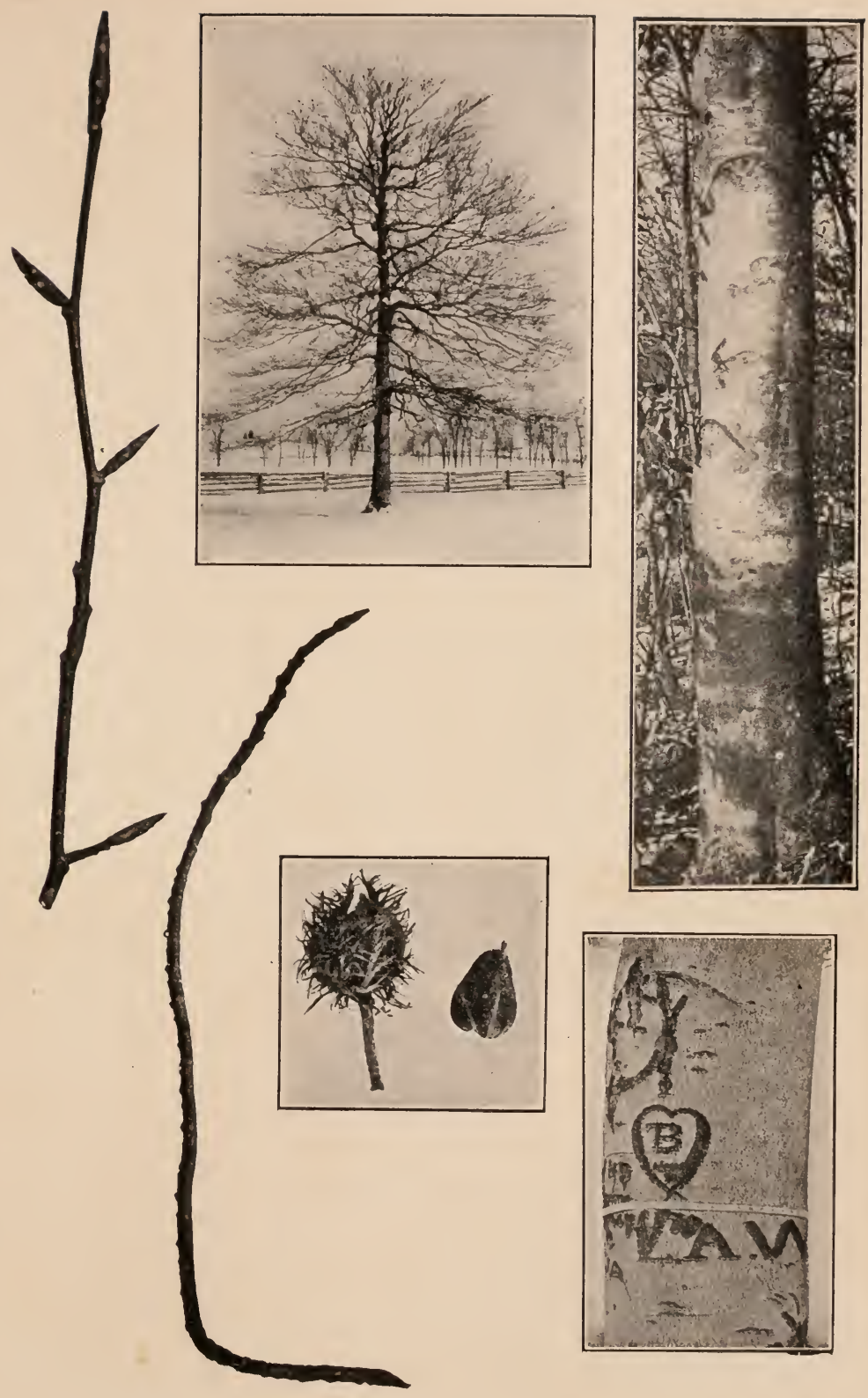

BeEch 


\title{
CHESTNUT
}

\author{
Castanea dentata (Marsh.) Borkh.
}

C. sativa, var. americana Sarg. ; C. vesca, var. americana Michx.

HABIT-A large tree, $60-80 \mathrm{ft}$. in height with trunk diameter of 5-6 ft. or larger; in the forest, trunk tall and slender, in the open, trunk short and thick generally tapering rapidly from point of branching into top of tree; lower branches horizontal or declining, often gnarled and twisted, upper branches arising at a sharper angle, forming a low, open, broad, spreading, rounded, ovate head often as broad as high. Young branches tend to bend up from all sides and give an even-edged outline to the tree as if the head had been trimmed like a roundtopped hedge. The Chestnut, when cut, sprouts readily from the stump and in consequence in wood-lots Chestnut trees are most commonly to be found in groups of $2-4$ or even more surrounding the old stump from which they originally sprouted. (See plate.)

B.IRK-On young trunks and branches smooth, reddish-bronze, often shining; with age broken by shallow fissures into long, broad, flat, more or less oblique ridges.

TWIGS-Stout, generally straight, greenish-yellow or reddish-brown, smooth, round or somewhat angled from base and outer edges of leafscars; somewhat swollen at nodes. LENTICELS-Numerous, conspicuous, forming minute, raised, white dots. PITH-5-pointed, star-shaped.

LEIF-SCIRS-Sometimes distinctly 2-ranked, generally more than 2-ranked, raised, semioval. STIPULE-SCARS-narrow, triangular, often inconspicuous. BUNDLE-SCARS-scattered, inconspicuous, if leaf-scar is surface-sectioned bundle-scars are found in two small lateral clusters and a large more or less circular basal cluster.

BUDS-Small, ovate, light to dark chestnut brown, 4-6 mm. long. often oblique to the leaf-scar; terminal bud generally absent, the end of the twig being marked by a small scar and the bud at end of twig. being in the axil of the uppermost leaf-scar. BUD-SCALES-2-3 only visible, thin-margined.

FRITT-A large, round bur, sharp-spiny without and hairy within, opening by 4 valves. Photograph of bur reduced to about $1 / 2$ natural size. NUTS-generally 3 (1-5), dark brown, white-downy at apex, ovate, flattened where in contact with other nuts; seed-sweet, edible.

COMPARISONS-From the appearance of gnarled old specimens grown in the open, the Chestnut might be taken for one of the Oaks. Its pith, further, is star-shaped but its buds are not clustered at ends of the twigs as in Oaks and have only 2-3 scales visible. At times the buds of the Chestnut have a 2-ranked arrangement and in this condition the twigs alone might be confused with those of the Linden (which see under Comparisons). Since the tree begins baaring early and the characteristic burs remain on the ground, the fruit is a valuable winter character. The bark in middle-aged trees resembles somewhat that of the Red Oak. If the bark is blazed the wood exposed does not show the short clear lines ronresenting medullary rays in tangential section seen in Oaks under similar treatment.

DISTRIBITION-In strong, well-drained soil; pastures, rocky woods, and hillsides. Ontario, common; south to Delaware, along the mountains to Alabama; west to Michigan, Indiana, and Tennessee.

IN NEW ENGLAND-Maine-southern sections, probably not indigenous north of latitude $44^{\circ} 20^{\prime}$; New Hampshire-Connecticut valley near the river as far north as Windsor, Vt.; most abundant in the Merrimac valley south of Concord, but occasional a short distance northward; Vermont-common in the southern sections, especially in the Connecticut valley; occasional as far north as Windsor, West Rutland, Burlington; Massachusetts-rather common throughout the state, but less frequent near the sea; Connecticut and Rhode Island-common.

WOOD-Light, soft, not very strong, liable to check and warp in drying, easily split, durable in contact with the soil, reddish-brown with thin lighter colored sapwood of 3 or 4 layers of annual growth; used largely in the manufacture of cheap furniture and in the interior finish of houses for railroad ties, piling, fence posts, and rails. The nuts, which are superior to those of the old World Chestnut in flavor and sweetness, are gathered in great quantities in the forest and sold in the cities. 

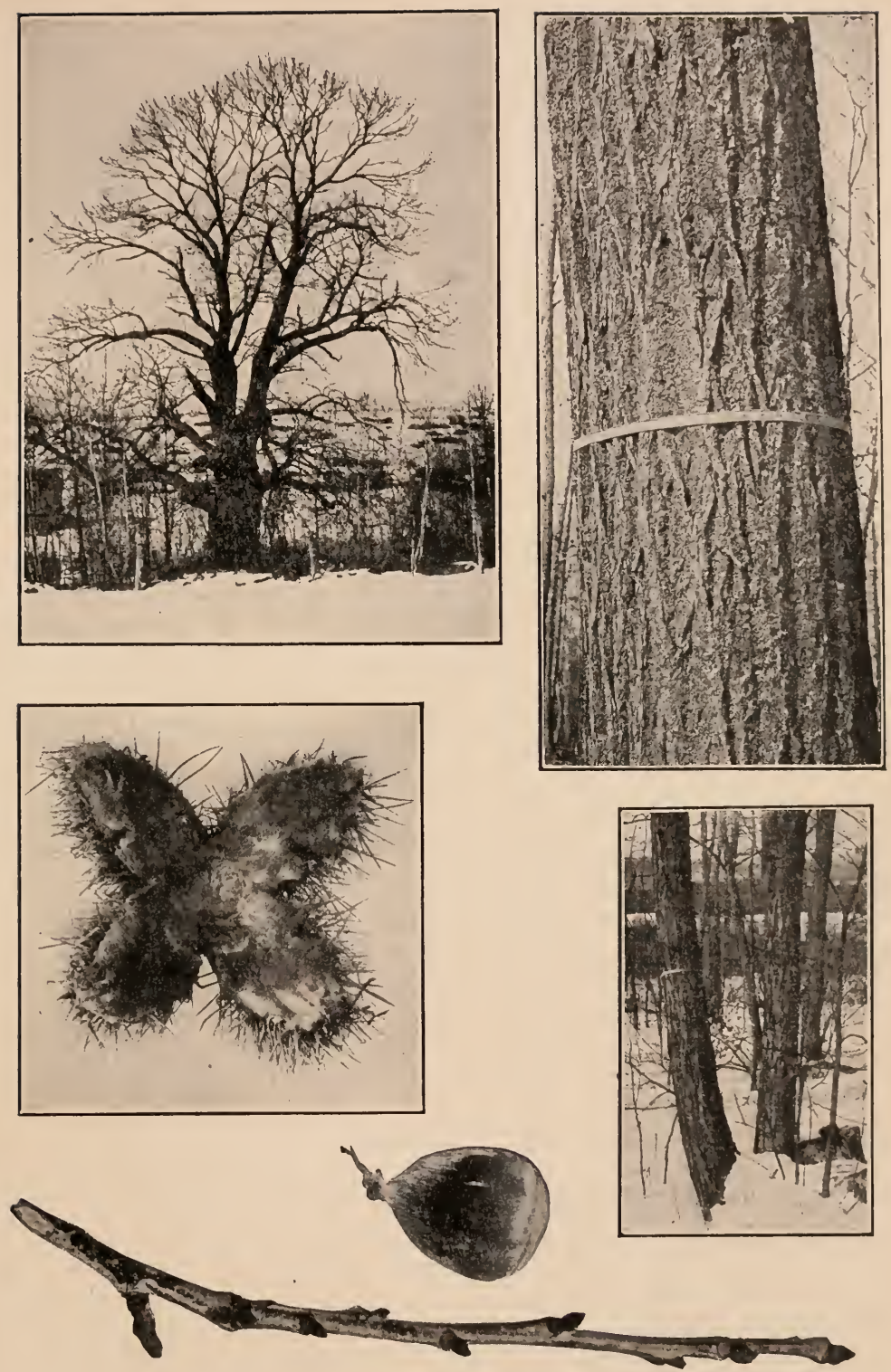

Chestnut 


\title{
WHITE OAK
}

\author{
Quercus alba $\mathrm{L}$.
}

HA IIT-A large tree with average height of 50-75 ft. and trunk diameter of $1-6 \mathrm{ft}$., somewhat various in habit, tending in the open to show a broad outline, sometimes 2-3 times as broad as high, with short trunk and lower limbs horizontal or declined, characteristically gnarled and twisted.

BNRI-Light gray or nearly white, whence its name; broken by shallow fissures into long, irregular, thin scales which readily flake off. On some trees ridges broken into short oblongs giving a rougher appearance to bark. Bark up to 2 inches thick in older trees; inner bark light. The bark is rich in tannin, is of medicinal value and is used in tanning.

TWIGS-Of medium thickness, greenish-reddish to gray, smooth, sometimes covered with a bloom. LENTICELS-forming conspicuous, light-colored, minute, rounded, raised, dots. LEAVES-frequently remaining on tree throughout winter, oblong to obovate with generally 7 large blunt lobes. PITH-5-pointed, star-shaped.

BUDS-Broadly ovate, blunt, about $3 \mathrm{~mm}$. long $(2-6 \mathrm{~mm}$.), reddishbrown, sometimes slightly hairy.

FRIIT-Maturing in autumn of first year singly or in pairs, sessile or sometimes on slender stalks. NUT-ovoid to oblong, rounded at apex, shiny, light chestnut brown, $1.5-2.5 \mathrm{~cm}$. long, enclosed $1 / 3-1 / 4$. of its length by deep saucer-shaped to hemispherical cup. Scales of cup white-woolly, thick-knobby at base, with short, blunt tips becoming thinner and flatter at rim of cup. Meat, sweet, edible, sometimes roasted and used as substitute for coffee, or when boiled said to be a good substitute for chestnuts.

COMPARISONS-The White Oak is the most common of the White Oak group. Its light flaky bark resembles that of several other Oaks. It is readily distinguished from the Swamp White Oak by absence of peeling of bark on young branches and by its larger and more pointed buds; from the Post Oak by absence of greenish down on twigs and by generally larger, narrower buds; from the Chinquapin oak by its blunt buds; from the Dwarf Cninquapin Oak by its larger stature, larger twigs and buds.

DISTRIBUTION-On moist or dry ground and in various soils, sometimes forming nearly pure forests. Quebec and Ontario; south to the Gulf of Mexico; west to Minnesota, Nebraska, Kansas, Arkansas and Texas.

IN NEW ENGLAND-Maine-southern sections; New Hampshire-most abundant eastward; in the Connecticut valley confined to the hills in the immediate vicinity of the river, extending up the tributary streams a short distance and disappearing entirely before reaching the mouth of the Passumpsic; Vermont-common west of the Green mountains, less so in the southern Connecticut valley; Massachusetts, Connecticut and Rhode Island-common.

WOOD-Strong, very heavy, hard, tough, close-grained, durable, light brown, with thin lighter colored sapwood; the most valuable of the Oaks for timber, used in shipbuilding, for construction and in cooperage, the manufacture of carriages, agricultural implements, baskets, the interior finish of houses, cabinet making, for railroad ties and fences, and largely as fuel. 

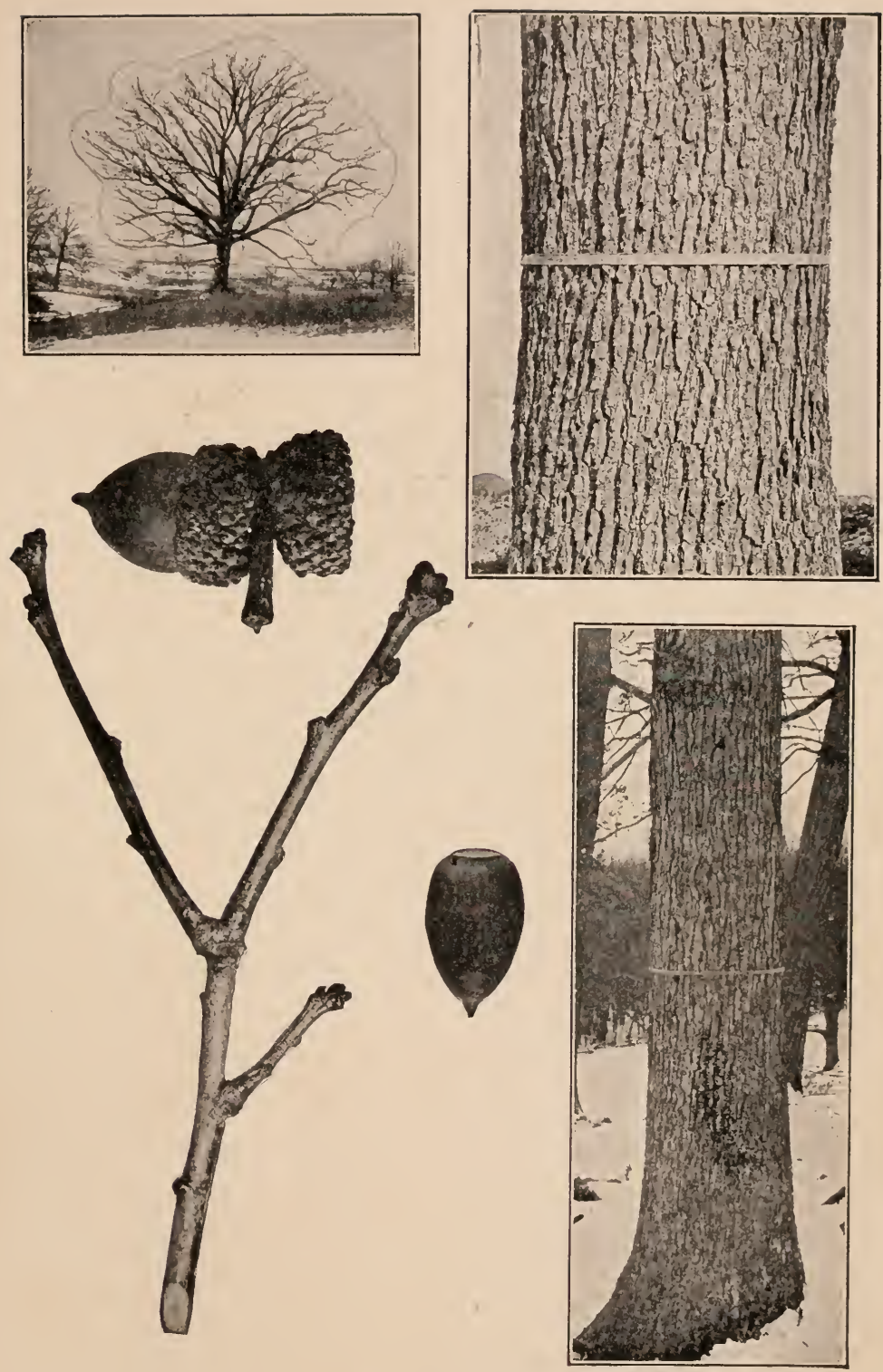

WHIT: O.IK 


\section{POST OAK \\ Box White Oak, Iron Oak.}

Quercus stellata Wang.

Q. minor Sarg. ; Q. obtusiloba Michx.

HABIT-In New England a small tree with height in southern section up to $60 \mathrm{ft}$, with trunk diameter of $3 \mathrm{ft}$.; at northern limit a shrub of 10-35 ft. high with trunk diameter of $1 / 2-1 \mathrm{ft}$; ; in the open forming a broad dense, round-topped head with stout spreading branches.

BARI-Flaky; similar to that of White Oak but rather darker, rougher, corresponding more to type of White Oak bark with short oblong ridges; $1 / 2-1$ inch in thickness. Twigs when $1 / 2$ inch to 1 inch in diameter begin to acquire a flaky bark with loose, dark gray scales lifting at sides and ends.

'TWIGS-Stout, light orange to reddish-brown; the younger growth by its light color, in striking contrast with darker, older growth which is often almost black; young twigs covered, at least in part, with short, dense orange-brown down, rough to the touch, often not easily noticed without a hand-lens. Late in season down may become almost black and disappear from the more exposed parts of twig. Bases of leafscars projecting with a sudden curve from the twig. LENTICELSpale, minute. LEAVES-often persistent, oblong, obovate, thick with generally 5 rounded lobes, the middle pair much the largest. PITH5 -pointed, star-shaped.

BUDS-Broadly ovate, often as broad as long and hemispherical, blunt, rarely acute, generally under $3 \mathrm{~mm}$. long, sometimes up to $6 \mathrm{~mm}$. in length. BUD-SCALES-bright, reddish-brown, sparingly downy.

FRUIT-Maturing in autumn of first year, single or in pairs or clustered; sessile or short-stalked. NUT-ovate to oblong, $1.5-2 \mathrm{~cm}$. long, generally covered with pale down at apex. CUP_-covering $1 / 3-1 / 2$ the nut, top-shaped or cup-shaped, scales rather thin and flat, only slightly knobby, pale, woolly. Meat sweet.

COMPIIISONS-Readily distinguished from White Oak, which it most nearly resembles, by rough, dirty orange-brown down which is to be found more or less completely covering twigs. Buds are blunter, shorter, generally more nearly hemispherical and of a brighter reddish tinge.

DISTRIBUTION-Doubtfully from southern Ontario; south to Florida; west to Kansas, Oklahoma and Texas.

IN NEW ENGLAND-Mostly in sterile soil near the sea-coast; Massachusetts-southern Cape Cod from Falmouth to Brewster, the most northern station reported, occasional; the islands of Naushon. Martha's Vineyard, where it is rather common, and Nantucket, where it is rare; Connecticut-local; usually in rocky ground on and near the coast: East Lyme and Old Lyme, Branford, New Haven, Orange and Milford, and westward; extending inland as far as Hamden; on Mt. Carmel and Huntington at $350 \mathrm{ft}$. elevation; Rhode Island-along the shore of the northern arm of Wickford harbor.

woOD-Very heavy, hard, close-grained, durable in contact with soil, difficult to season, light or dark brown, with thick lighter colored sapwood; used for fuel, fencing, railroad ties and sometimes in the manufacture of carriages, for cooperage and in construction. 

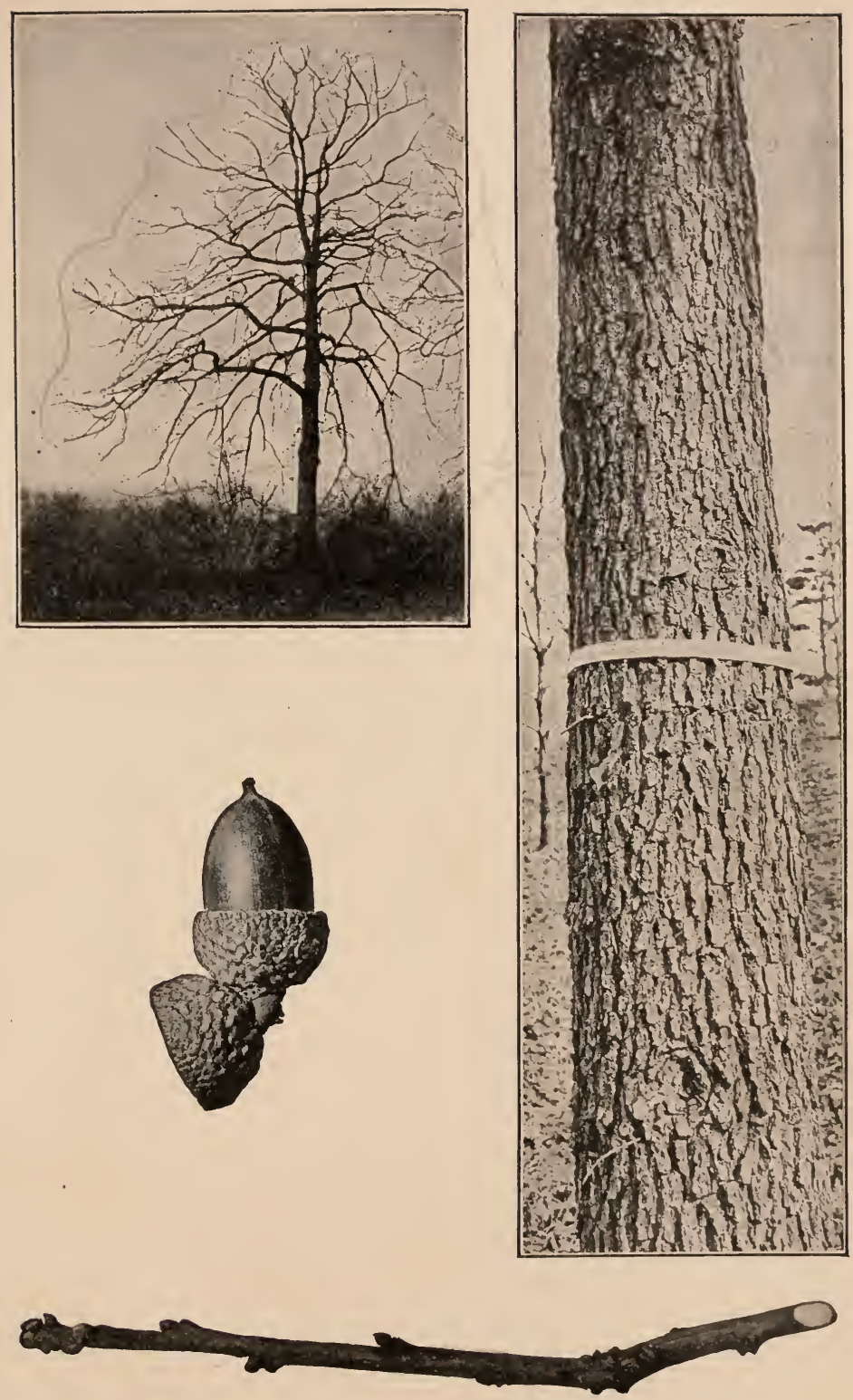

Post OAK

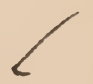




\section{BUR OAK \\ Mossy-cup or Over-cup Oak.}

Quercus macrocarpa Michx.

HABIT-Although one of our largest Oaks in the central states, in New England of medium size only 40-60 ft. in height with a trunk diameter of 1-3 ft.; in the open forming a broad, round top with thick spreading limbs and numerous often drooping branchlets.

BARI-Flaky, resembling that of White Oak but rather darker and with ridges rather firmer.

TWIGS-Stout, yellowish-brown, smooth or downy, twigs on some trees after the first year developing corky ridges. LENTICELS-minute, pale, raised dots, inconspicuous. LEAVES-which sometimes persist, obovate-oblong, divided by deep indentations into 5-7 rounded lobes, the terminal lobe the largest. PITH-5-pointed, star-shaped.

BLDS-Conical to broadly ovate, sharp-pointed or blunt, $3-5 \mathrm{~mm}$. long, reddish-brown, covered with pale wool; lateral buds more or less strongly appressed and flattened against the twig. Stipules often persisting at tips of twigs, long, downy thread-like. BUD-SCALESrelatively few to a bud.

FRLIT-Maturing in autumn of first year, very variable, sessile or stalked, generally single. NUT-ovate to oval, 2-5 cm. long, apex rounded or depressed, covered with pale down. CUP-thick, hemispherical to top-shaped enclosing from $1 / 3$ to the entire nut; scales of cup, pale, woolly, thickened at base with pointed tips, tips of upper scales prolonged into a more or less distinct fringe.

COMPARISONS-The Bur Oak is sharply distinguished from our other Oaks by a number of well-marked characters such as the presence of corky ridges on the young branchlets, the copious fringe to the large acorn, the appressed and downy buds. These characters, however, are not always present in a given specimen; thus the coiky ridges may fail to appear throughout an entire tree; the acorns may be reduced in size and in the distinctness of the fringe; and the lateral buds may be more or less divergent.

DISTRIBUTION-Low rich bottom lands. Nova Scotia to Manitoba; south to Pennsylvania and Tennessee; west to Montana, Nebraska, Kansas, Oklahoma and Texas.

IN NEW ENGLAND-Maine-known only in the valleys of the middle Penobscot and the Kennebec; Vermont-lowlands, about Lake Champlain, especially in Addison county, not common; Massachusetts-valley of the Ware river, Stockbridge and towns south along the Housatonic river; Connecticut-rich bottom lands or swampy places, rare or local and confined to the northwestern part of the state; reported from Canaan and Salisbury; Rhode Island-no station reported.

WOOD-Similar to that of White Oak from which it is not generally distinguished commercially, although superior in strength. 

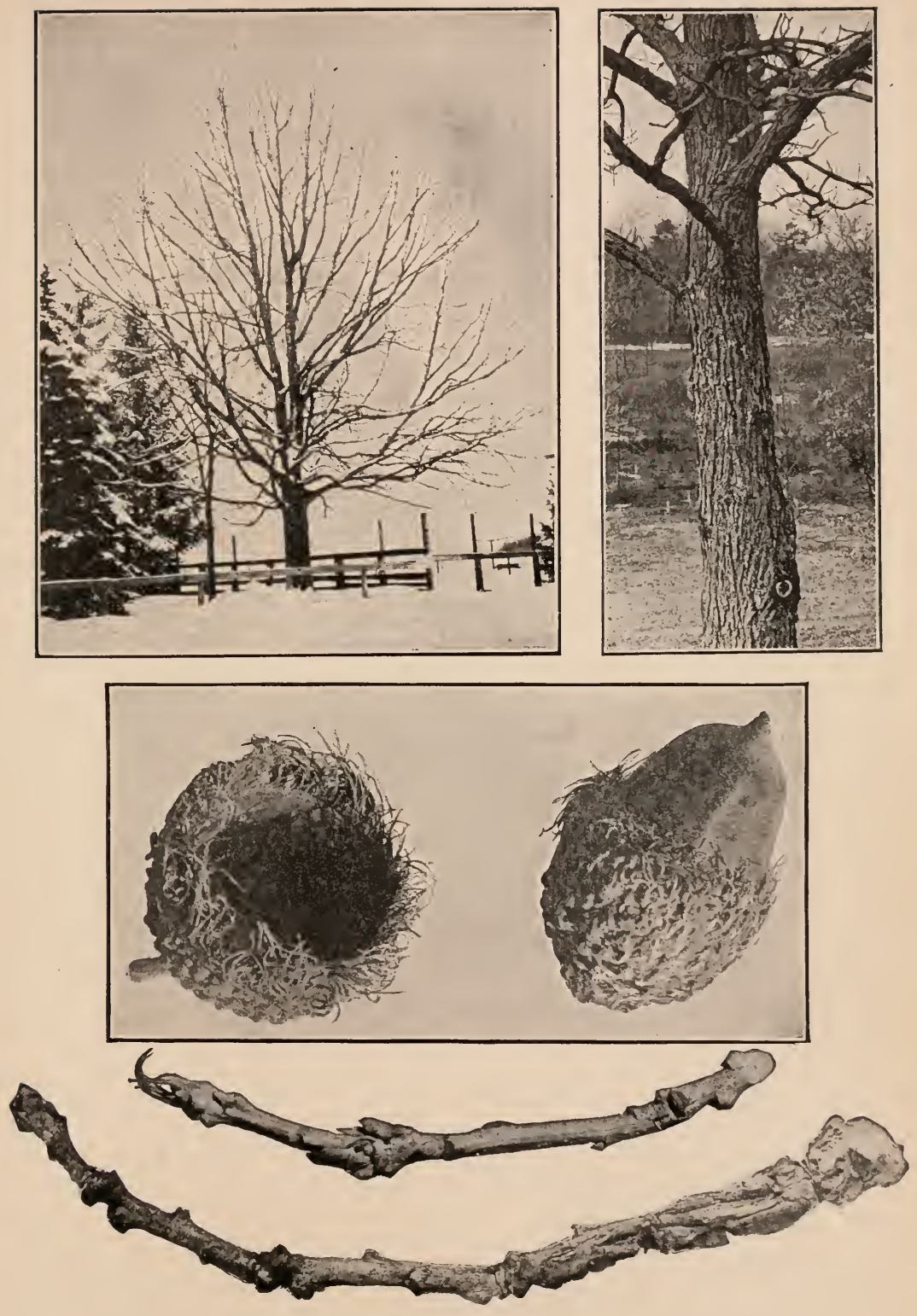

BUR OAK 


\section{SWAMP WHITE OAK}

Quercus bicolor Willd.

Q. platanoides Sudw.

HABIT-A medium sized tree, 40-60 ft. high, with trunk diameter of 2-3 ft.; in the open with round-topped open head, sometimes broader than high, upper limbs ascending, lower limbs rather small, horizontal or declined even to the ground, with numerous tufted, small, scraggly, lateral, pendant branchlets. The scraggly branchlets in connection with the peeling of the bark give a very rough unkempt appearance to the tree. Trunk erect, generally continuous,; sometimes forking above to give somewhat the aspect of an Elm in respect to main limbs. In the open this tree may generally be recognized at a distance by the lower branches which spread out below to form a fringe reminding one of an old-fashioned hoop-skirt.

BARK-Flaky, grayish-brown, divided by deep longitudinal fissures into rather long, fiat ridges. Bark on small branchlets, dark reddishbrown to black, peeling into long, persistent stiff-papery layers, which curl back and expose the lighter bark beneath.

TWIGS-Mediumly stout to slender, yellowish-green to reddishbrown, smooth (seldom slightly downy). Medullary rays generally absent in branchlets even of 6 to 8 years growth. LENTICELS-pale, raised. LEAVES-which may persist obovate-oblong, wedge-shaped at base, wavy-margined to blunt-lobed, with $6-8$ pairs of primary veins. PITH5-pointed, star-shaped.

BUDS-Broadly ovate to oval to spherical; blunt-pointed; small, 2-4 $\mathrm{mm}$. long. BUD-SCALES-brown, at times slightly hairy above middle.

FRIIT-Maturing in one year, single or in pairs or groups of 3, generally with long stalks, 2.5 to $10 \mathrm{~cm}$. long. NUT-light chestnut ovate to oblong, 2-3 cm. long, apex covered with pale down, rounded or pointed. CUP-thick, cup-shaped, about $1 / 3$ enclosing nut; scales pale woolly, those at base more or less thickened, at rim of cup tips of scales elongated, narrow, awn-pointed, often forming short fringe. Meat sweet, edible.

COMPARISONS-The sycamore-like peeling of the bark from the young branchlets easily distinguishes this species from all other Oaks. The bark somewhat resembles that of White Oak but is somewhat darker and the ridges are longer.

DISTRIBUTION-Borders of swamps and streams. Quebec to Ontario, where it is known as the Blue Oak; south to Delaware along the mountains to northern Georgia; west to Minnesota, Iowa, East Kansas and Arkansas.

IN NEW ENGLAND-Maine-York county; New Hampshire-Merrimac valley as far as the mouth of the Souhegan, and probably throughout Rockingham county; Vermont-low grounds about Lake Champlain; Massachusetts-frequent in the western and central sections, comman eastward; Connecticut-frequent; Rhode Island-common.

WoOD-Similar to that of White Oak, and used for same general purposes; sapwood, thin, hardly distinguishable from heartwood. 

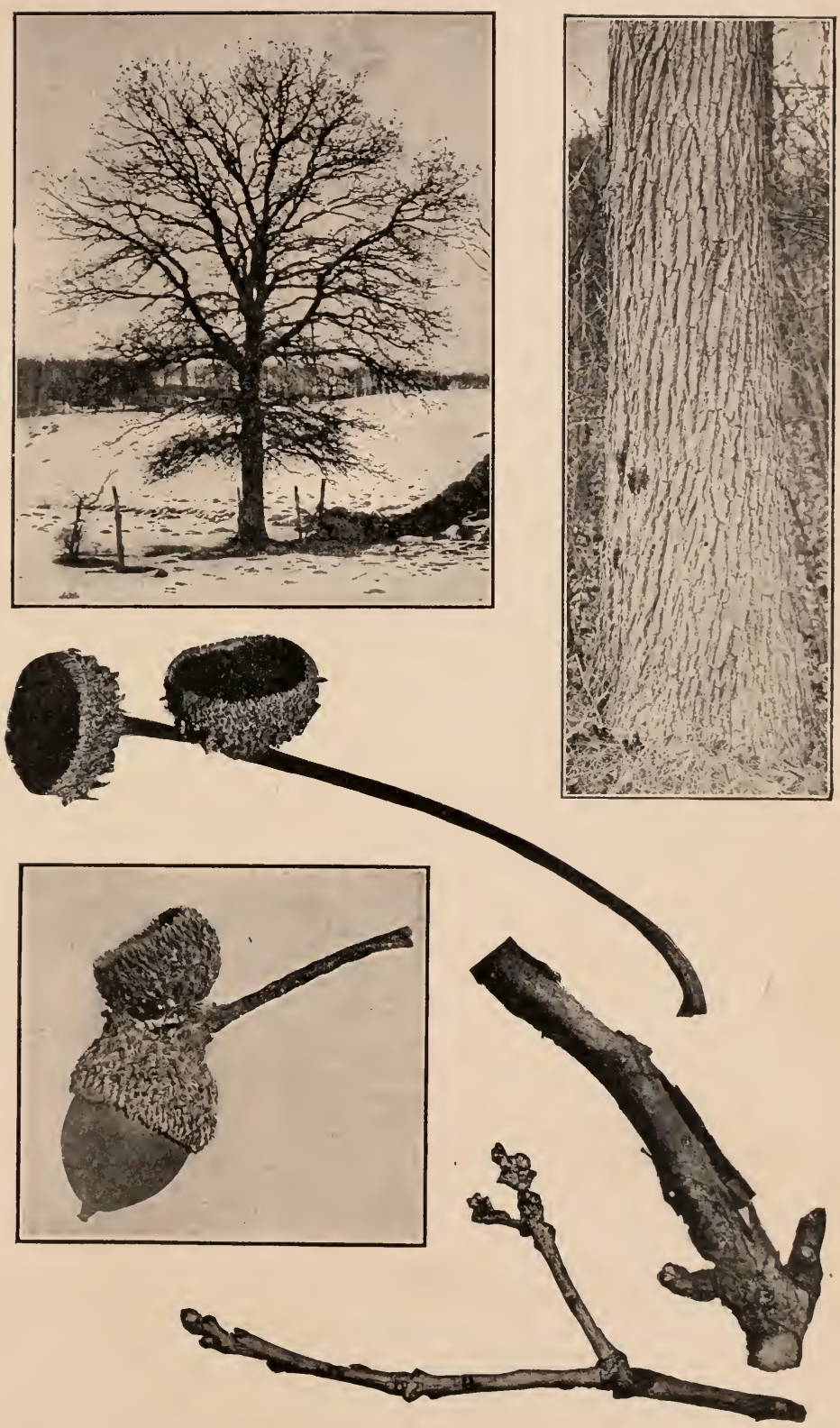

SwaMp White OAK 


\section{CHINQUAPIN OAK Chestnut Oak, Yellow Oak.} Quercus Muhlenbergii Engelm.

Q. acuminata Houba.

HАBIT-Small to medium sized tree $30-40 \mathrm{ft}$. high with a trunk diameter of 1-2 ft.; in basin of the Mississippi reaching an exceptional height of 160 feet; trunk buttressed at base in older specimens, branches comparatively small forming narrow, round-topped head.

BARK-Thin, flaky, broken into loose grayish or sometimes slightly brownish scales.

Twigs-Rather slender, light orange to reddish-brown, smooth. LENTICELS-pale, inconspicuous. LEAVES-resembling those of Chestnut with large, incurved, glandular-tipped teeth or rarely with wavy margin resembling the leaf of the Chestnut Oak. PITH5-pointed, star-shaped.

BUDS-Narrowly ovate to conical, sharp-pointed, 3-5 mm. long. BUDSCALES-light chestnut brown, slightly hairy on edges, appearing longitudinally striate if held toward light and viewed with a handlens. Buds similar to those of Chestnut Oak but smaller.

FRUIT-Maturing the first season, sessile or short-stalked, singly or in pairs. NUT-broadly ovate to oval, 15-20 $\mathrm{mm}$. long, narrowed and rounded at pale downy apex, light chestnut brown. CUP-thin, rather shallow cup-shaped enclosing about $1 / 2$ or less of the nut; scales pale brown, woolly, slightly knobby at base of cup, the brownish tips of the scales sometimes forming a slight fringe at rim of cup. Meat sweet, edible.

COMPARISONS-The Chinquapin Oak resembles the Chestnut Oak on the one hand and the Dwarf Chinquapin Oak on the other. It is distinguished from the former by its flaky, gray bark, and the smaller size of buds and acorns; from the latter by its sharp-pointed buds and larger size.

DISTRIBUTION-Rare and local in the Atlantic states, usually on limestone soil, on dry hillsides, rocky ridges and rich bottoms. Ontario; south to Delaware and District of Columbia, along the mountains to northern Alabama; west to Minnesota, Nebraska, Kansas, Oklahoma and Texas.

IN NEW ENGLAND-Vermont-Gardner's Island, Lake Champlain, Ferrisburg; Connecticut-rare; calcareous ridges in the northwestern pari of the state; Canaan, Salisbury, also along the Housatonic river in Kent, New Milford and bordering tide water in Milford.

WOOD-Heavy, very hard, strong, close-grained, durable, with thin, light-colored sapwood, largely used in cooperage, for wheels, fencing and railroad ties. 


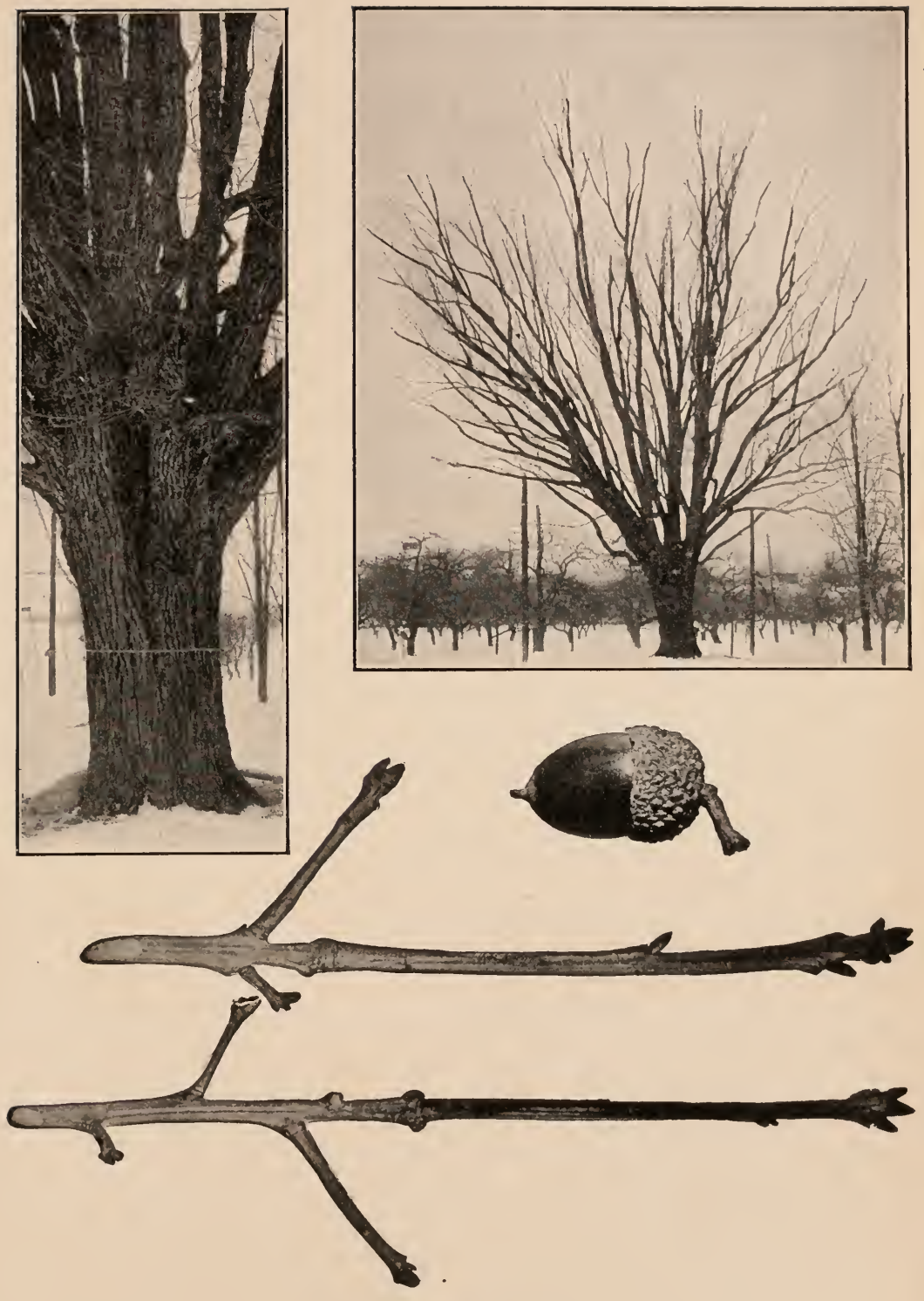

Chinquapin OaK 


\section{DWARF CHINQUAPIN OAK Scrub Chestnut Oak, Chinquapin Oak, Scrub Oak.}

Quercus prinoides Willd.

HABIT-A low shrub generally 2-4 ft. high or occasionally reaching $15 \mathrm{ft}$. in heigh, forming broad clumps by prolific stolons.

BARK-Light brown, scaly; scaliness evident when trunk reaches a diameter of $1 \frac{1}{2}$ inches.

TWIGS-Slender; generally not over $2 \mathrm{~mm}$. thick, orange to reddishbrown; generally smooth; a variety, rufescens Rehder, with yellowish aairs on twigs. LENTICELS-pale, rather conspicuous. LEAVESoblanceolate to obovate-oblong, coarsely wavy-toothed. PITH-5-pointed, star-shaped.

BUDS-Spherical to ovate, rounded or slightly narrowed at apex, about $3 \mathrm{~mm}$. long. SCALES-chestnut brown, thin, scarious and slightly hairy on edges; small collateral buds sometimes present on either side of axillary bud.

FRUIT-Maturing the first season, produced in great abundance, sessile or short-stalked, singly or in pairs. NUT-oval, light chestnut brown and shiny, apex blunt-pointed and covered with pale down, 15 to $25 \mathrm{~mm}$. long. CUP-thin, deep cup-shaped, covering $1 / 2$ or more of nut; scales pale woolly, more or less knobby, thickened at base of cup, thinner toward rim. Meat sweet.

COMPARISONS-In habit the Dwarf Chinquapin Oak most nearly resembles the Bear Oak but is smaller when of the same age; has flaky bark after reaching a trunk diameter of $1 \frac{1}{2}$ inches or more, while the bark of the Bear Oak is close, for the most part smooth, even on old specimens not flaky though developing small close scales. It further belongs to the White Oak group (see page 204) and since both these two Scrub Oaks produce fruit in great abundance acorns are generally accessible and easily distinguished. The Bear Oak generally has redder, sharp-pointed buds, while those of the Dwarf Chinquapin Oak are blunt with edges of scales ashy with fine wool or mealy scurfiness. Moreover, except in variety rufescens, twigs of the Dwarf Chinquapin Oak are smooth. The Chestnut Oak and the Chinquapin Oak are distinguished by their larger and sharp-pointed buds. The buds of the Swamp White Oak are somewhat similar to those of the Dwarf Chinquapin Oak but the larger size of the tree and peeling of the bark on branchlets of the Swamp White Oak are distinctive. Further west apparently the species inter-grades into the Chinquapin Oak.

DISTRIBUTION-Dry woods, rocky slopes and hillside pastures, some. times in open sandy soil. From Maine south to North Carolina, west to Kansas, Nebraska and Texas.

IN NEW ENGLAND-more or less common throughout.

WoOD-From small size of plant, of no economic value except as fuel. 

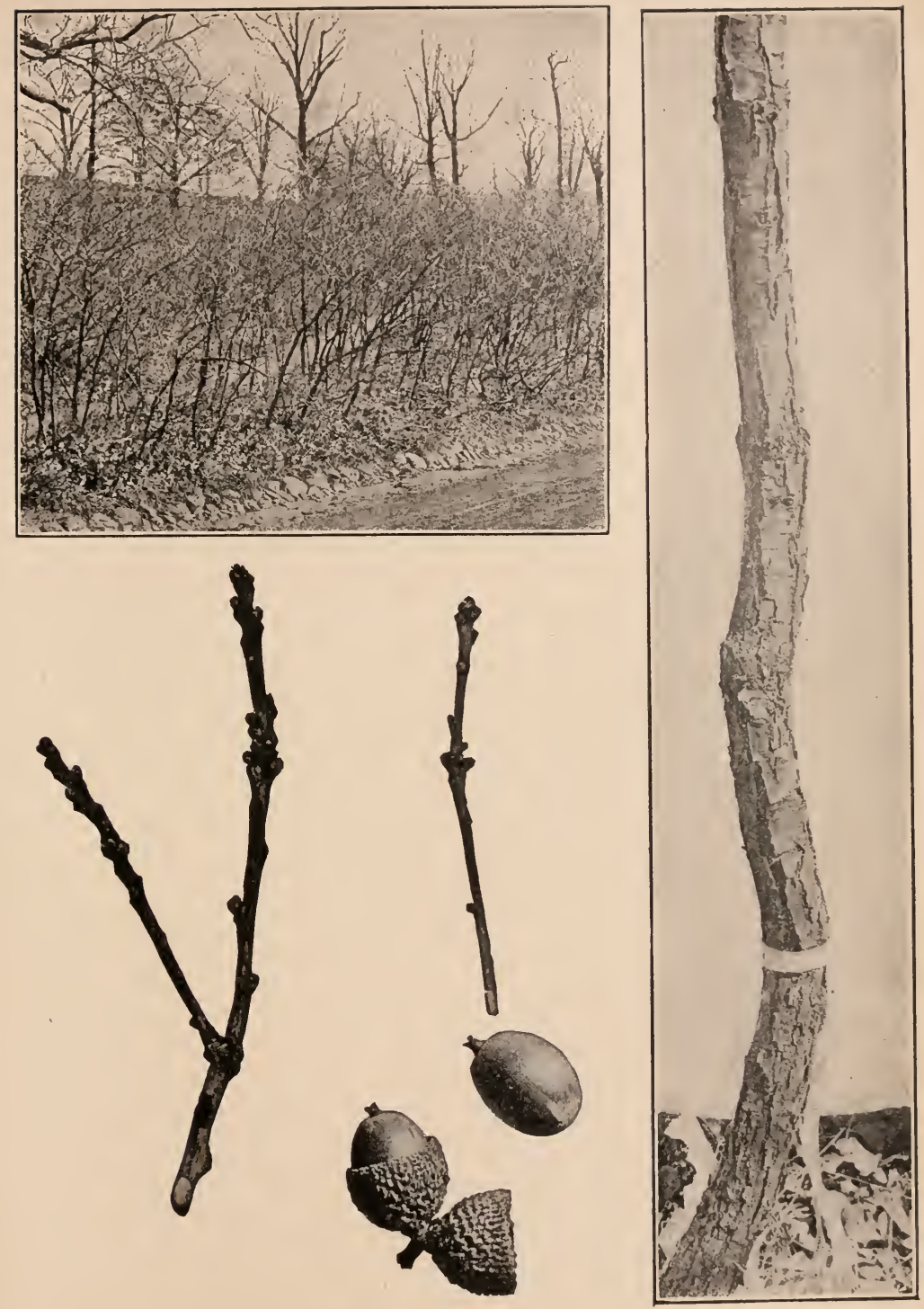

Dwarf Ciminquapix OaK 


\title{
CHESTNUT OAK \\ Rock Chestnut Oak, Rock Oak.
}

\author{
Quercus Prinus L.
}

HABIT-A medium sized or small tree, 25-50 ft. high with a trunk diameter of $1-21 / 2 \mathrm{ft}$; further south much larger, reaching $100 \mathrm{ft}$. in height; trunk tall, straight, continuous, or divided rather low down into large spreading limbs, forming broad open head, sometimes broader than high.

BIRK-Brown to black, deeply fissured into long, more or less continuous, thick, rough ridges which are somewhat flattened on surface or on older trees more characteristically rounded or sharp-edged, a section through one of the ridges forming thus an inverted letter "V" with its apex somewhat rounded or in younger specimens flattened; bark of young trees and of smaller branches smooth.

TWIGS-Stout, light orange to reddish-brown, smooth with somewhat bitter taste. LENTICELS-pale, generally inconspicuous. LEAVES -oblong, lanceolate to obovate, wavy-margined with 10-16 pairs of primary veins. PITH-5-pointed, star-shaped.

BUDS-Narrowly ovate-conical, sharp-pointed, 4-10 mm, long. BUISCALES-light chestnut brown, slightly hairy toward apex and on margins, appearing longitudinally striate if viewed toward light with a hand-lens. Margins of scales tend to lose their brown color and to become light or dark gray.

FRUIT-Maturing the first season, short-stalked, singly or in pairs. NUT-shiny, light chestnut brown, oval to ovate to nearly cylindrical, variable in size and relative thickness; $20-35 \mathrm{~mm}$ long; from three times to less than twice as long as broad. CUP-thin, deep, topshaped to hemispherical, covering $1 / 3$ or less of nut; scales reddishbrown, woolly, more or less knobby especially toward base of cup. Meat sweet.

COMPARISONS-The Chestnut Oak is readily distinguished from the other members of the White Oak group by the fact that its bark is not flaky. Its firm, round-ridged bark is definitely characteristic when typically developed. The buds resemble somewhat those of the Red Oak, but are somewhat lighter in color with edges of scales bleached, are much narrower and for the most part conical, with the widest part at or very near the base, whereas the buds of the Red Oak when typically developed, are much fatter, with the widest part about a third of the distance from the base. The bark of the Red Oak, moreover, has flat ridges.

DISTRIBLTION-Woods, rocky ridges and hillsides. Along the Canadian shore of Lake Erie; south to Delaware and along the mountains to Georgia, extending nearly to the summit of Mt. Pisgah in North Carolina; west to Kentucky, Tennessee, and Alabama.

IN NEW ENGLAND-Maine-Saco river and Mt. Agamenticus, near the southern coast; New Hampshire-belts or patches in the eastern part of the state and along the southern border, Hinsdale. Winchester, Brookline, Manchester, Hudson; Vermont; western part of the state throughout, not common; abundant at Smoke mountain at an altitude of 1,300 feet, and along the western flank of the Green mountains at least in Addison county; Massachusetts-eastern sections, Sterling. Lancaster Russell. Middleboro, rare in Medford and Sudbury, frequent on the Blue Hills; Connecticut-occasional near the coast; frequent or common elsewhere; Rhode Island-locally common.

WOOD-Heavy, hard, strong, rather tough, close grained, durable in contact with the soil, largely used for fencing, railroad ties, ranking next to the White Oak for this purpose, and for fuel. The bark is rich in tannin and is consumed in large quantities in tanning leather. 

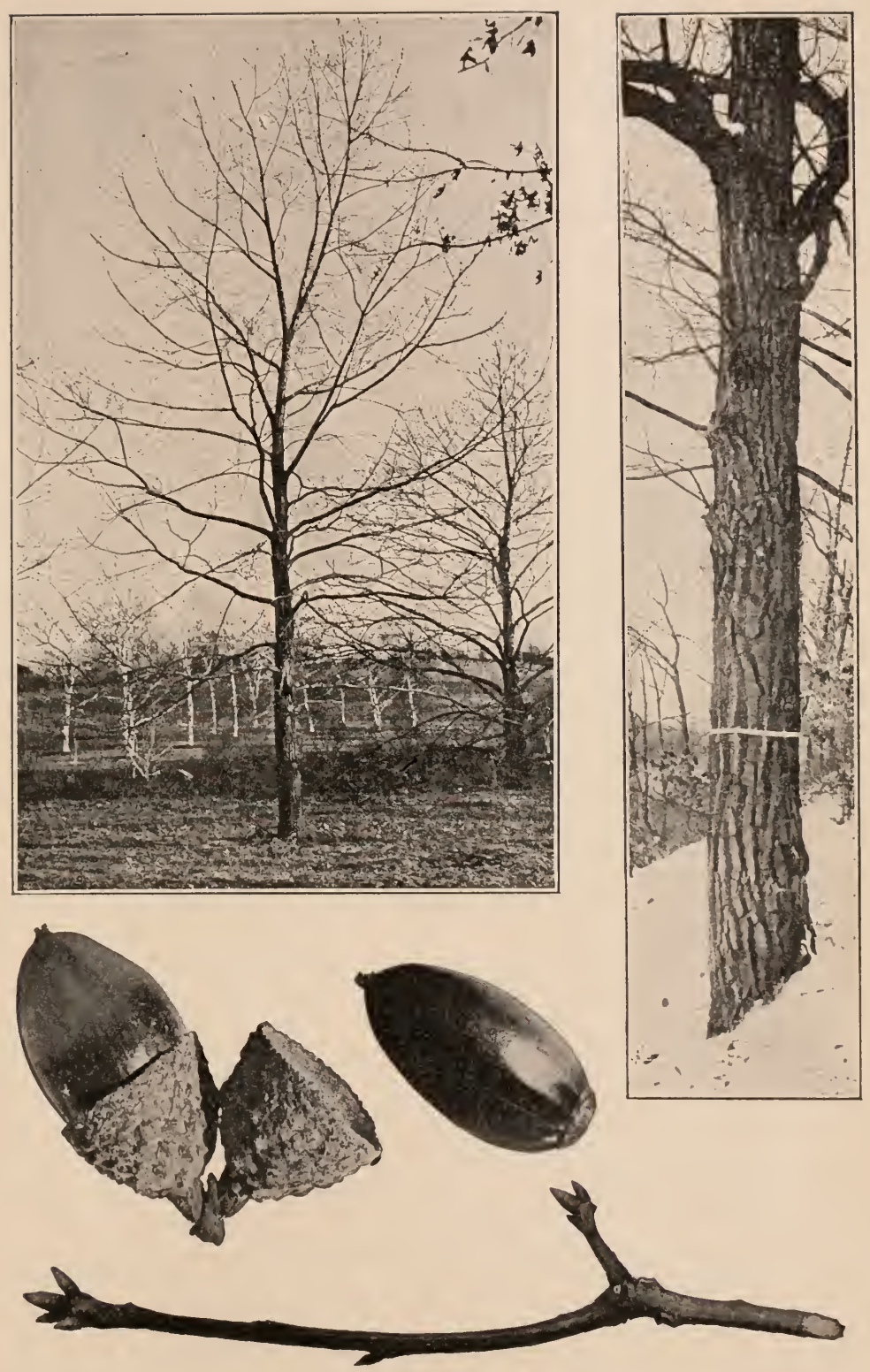

Chestnut OAK 


\section{RED OAK}

Quercus rubra L.

HABIT-The largest of our New England Oaks, 50-85 ft. high, reaching an exceptional height of $150 \mathrm{ft}$.; with trunk diameter of 2-6 ft.; trunk branching rather higher up than in the White Oak, often continuous into the top of the tree with ascending branches forming a rather narrow, round-topped head or spreading more widely as shown in the specimen photograpied becoming even broader than high. The limbs in the main are not so horizontal or declined nor so crooked as in the White Oak and the tree in consequence offers a less gnarled aspect.

BAIR-On young trees and upper parts of older trees smooth, graybrown; on trunks of mature trees and on their thicker limbs up to $4 \mathrm{~cm}$. thick, tardily broken by shallow furrows into dark brown, rather regular, elongated, firm, coarse, flat-topped ridges. The flat ridges which are characteristic of the species are often in older trees roughened up toward the base of the trunk so that the distinctive character of the bark must be sought higher up on the trunk or on the larger limbs. Inner bark, light reddish, not bitter.

TWIGS-Mediumly stout to slender, reddish to greenish-brown. LENTICELS-pale, often inconspicuous. LEAVES-obovate to oblong. with bristle-pointed lobes, often difficult to distinguish from those of Black Oak. PITH-5-pointed, star-shaped.

BUDS-Oval to ovate, 4-8 $\mathrm{mm}$. long, with widest part typically $1 / 4$ to $1 / 3$ above base suggesting appearance of a short stalk to the bud; sharp pointed with more or less distinct development of rusty hairs at the extreme apex, otherwise smooth or sometimes slightly pale-woolly on upper half. BUD-SCALES-n:amerous, light chestnut brown seen to be longitudinally striate with darker lines when viewed toward light with a hand-lens, margins slightly hairy.

FRUIT-Maturing in autumn of second season, singly or in pairs, sessile or on a short, thick stalk. NUT-ovate to cylindrical with broad base and narrowed, rounded apex; dark chestnut brown, large, $2-3 \mathrm{~cm}$. long. CUP-flat, shallow, thick, saucer-shaped (rarely somewhat top-shaped), rim somewhat constricted, enclosing about $1 / 5$ of the nut, $2-3.5 \mathrm{~cm}$. across. Scales thin, reddish-brown, shining, not at all or but slightly hairy, closely overlapping. Meat pale yellow, slightly bitter. Immature acorns generally divergent or but slightly appressed, with basal scales reaching about half way up, giving appearance of 3 rows of scales.

COMPARISONS-If the acorns are obtainable the Red Oak is not to be confused with any of our other species, the large flat cup being distinctive. The flat flutings of the bark and the fat, basally constricted, sharp-pointed buds are further characteristic. See Black Oak for comparison with Red and Black and Scarlet Oak, and Chestnut Oak for comparison with latter species.

DISTRIBLTION-Woods, widely adapted to various conditions of soil and situation except distinctly wet lands, ranges further north than our other Oaks and is most planted of the American Oaks in Europe. Nova Scotia and New Brunswick to divide west of Lake Superior; south to Tennessee, Virginia and along mountain ranges to Georgia; reported from Florida; west to Minnesota, Nebraska, Kansas and Texas.

IN NEW ENGLAND-Maine-common, at least south of the central portions; New Hampshire-extending into Coos County, far north of the White Mountains; Vermont, Massachusetts, Connecticut and Rhode Island-common; probably in most parts of New England the most common of the genus; found higher up the slopes of mountains than the White Oak.

WOOD-Heavy, hard, strong, coarse-grained, light reddish-brown, with thin lighter colored sapwood; used in construction, for the interior finish of houses, and in furniture. Timber of this species, as also of Black and Scarlet Oak, is relatively poor but is more used than formerly on account of scarcity of better. 

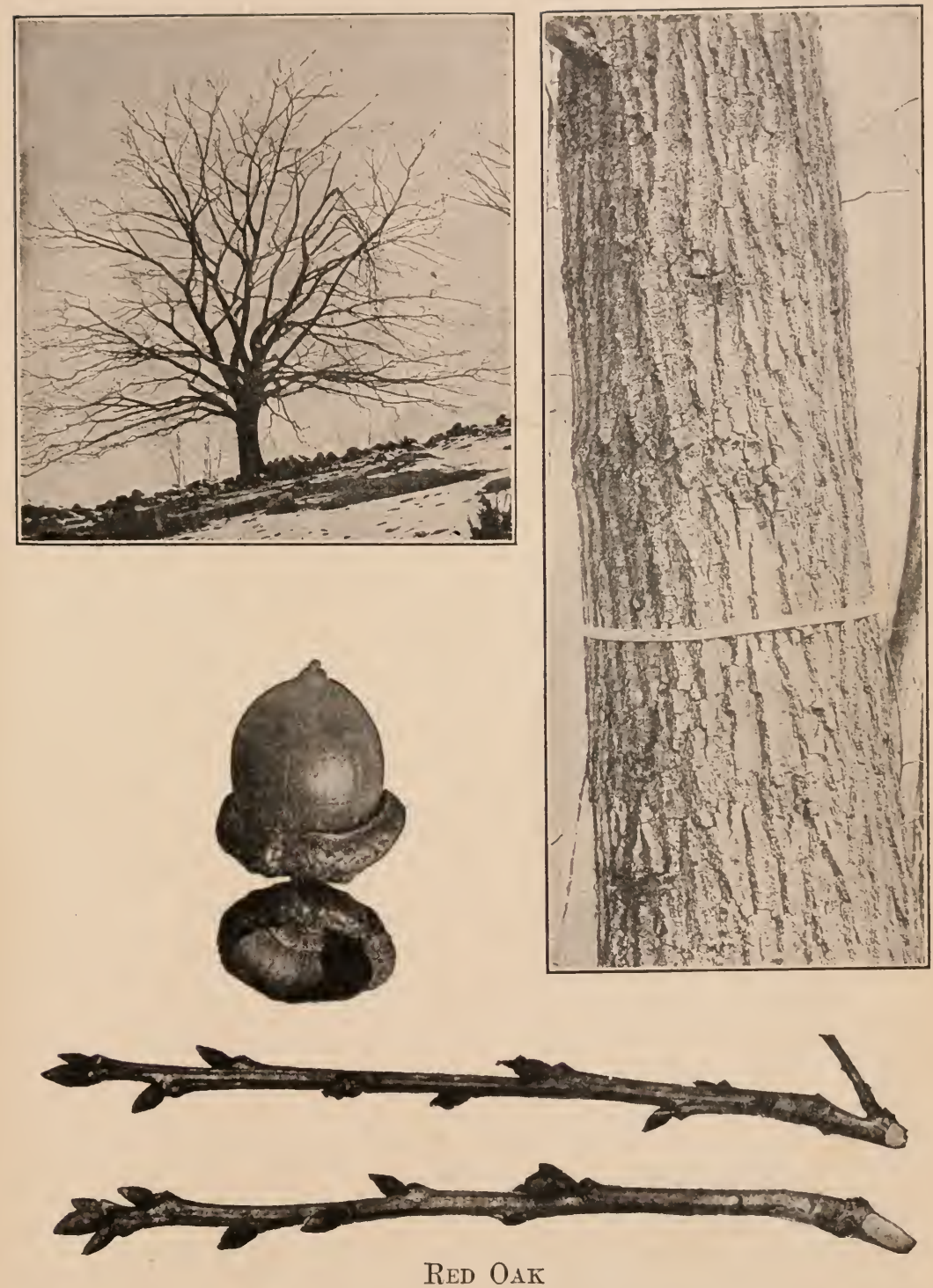


\section{PIN OAK \\ Swamp Oak, Water Oak. \\ Quercus palustris Muench.}

HАBIT-A medium sized tree 40-50 ft. high with trunk diameter of 1-2 ft., reaching a maximum height of over $100 \mathrm{ft}$. in the lower Ohio basin; trunk tall, straight, continuous up through the pyramidal head; limbs numerous, slender; lower limbs short, drooping, upper limbs longer horizontal or ascending, generally studded with short lateral shoots which give rise to the common name. The habit of this tree is very characteristic and is well shown in the two specimens in the illustration. In older trees the head is more open and irregular.

BARK-Of young trunks and limbs, smooth, shiny, light brown; on older trunks darker, furrowed with close, narrow, firm, low ridges.

TWIGS-Slender, reddish-brown to orange, shining. LENTICELS-pale, scattered, inconspicuous. LEAVES-small, obovate or oblong; lobes bristle-tipped, separated by deep, rounded indentations, resembling leaves of Scarlet Oak but smaller. PITH-5-pointed, star-shaped.

BUDS-Conical to ovate, generally sharp-pointed, small, 2-4 mm. long. BUD-SCALES-light chestnut brown, sometimes slightly hairy on the thin margins.

FRIIT-Maturing the second season, abundant, sessile or shortstalked, solitary or in pairs or clusters. NUT-light brown, often striate, nearly hemispherical, 10-15 $\mathrm{mm}$. long, wider than long, and generally wider than the cup. CUP-thin, saucer-shaped, 10-15 $\mathrm{mm}$. across, enclosing only the base of the nut; scales thin, slightly downy, closely overlapping. Meat pale yellow, slightly bitter.

COMPARISONS-When young the Pin Oak is one of the most easily recognized of any of our trees in winter from its general habit of growth. Its continuous trunk, fringed with slender branches, and its comparatively smooth bark roughened only slightly by narrow, low ridges are alone distinctive. Further characteristics are the small sharp-pointed buds and the small acorns with saucer-shaped cup.

DISTRIBLTION-Borders of swamps and river bottoms in deep moist rich soil. Ontario; south to the valley of the lower Potomac in Virginia; west to Minnesota, east Kansas, Missouri, Arkansas, and Oklahoma.

IN NEW ENGLAND-Massachusetts-Amherst; springfield, south to Connecticut, rare; Connecticut-common in the Connecticut river valley and near the coast in southwestern Connecticut; occasional or local elsewhere; Rhode Island-southern portions, bordering the great Kingston swamp and on the margin of the Pawcatuck River.

WOOD-Heavy, hard, coarse-grained, but liable to warp and check in drying; light brown, with thin rather darker colored sapwood; sometimes used in construction and for shingles and clapboards. 

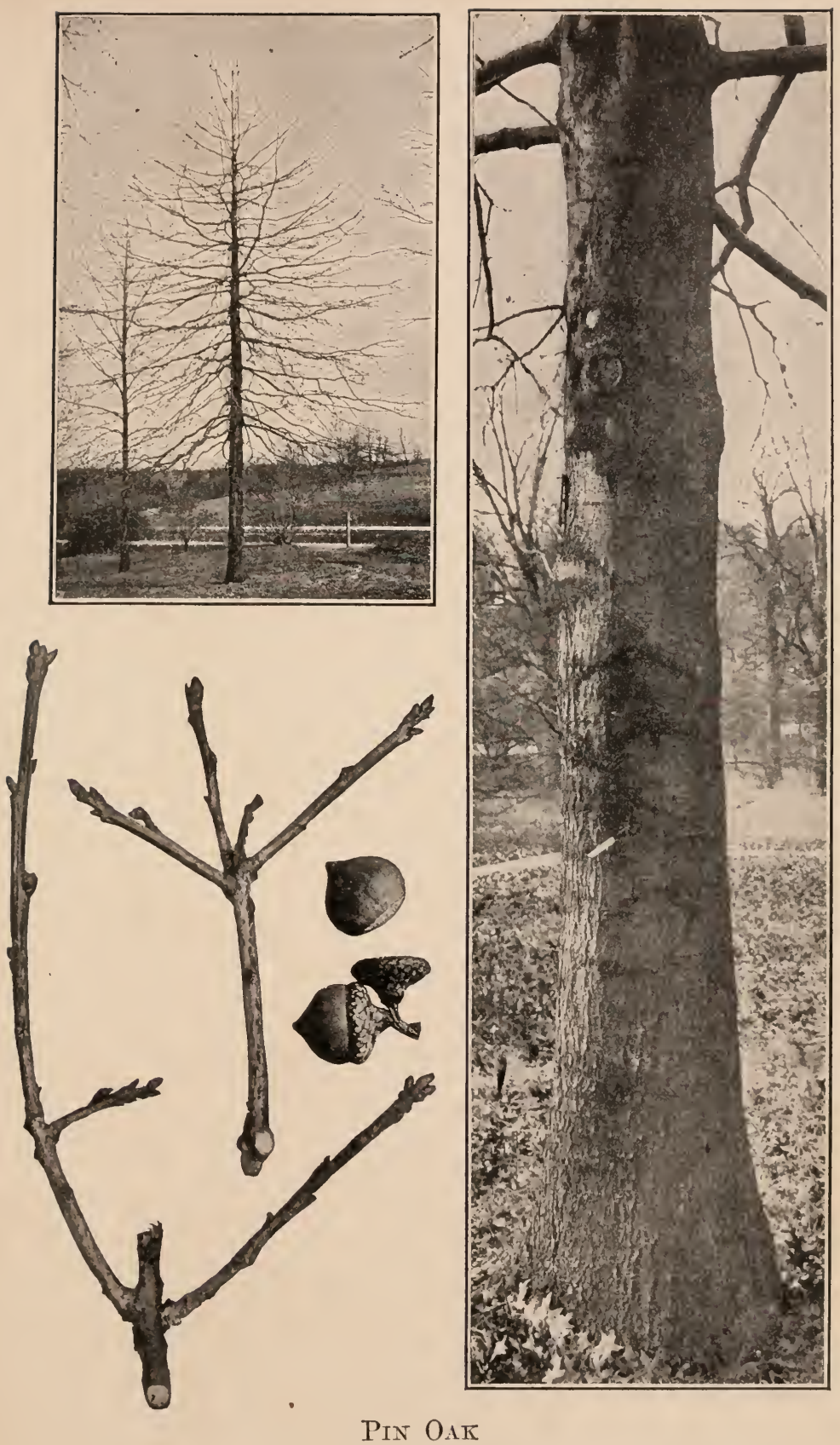


\title{
SCARLE'T OAK
}

\author{
Quercus coccinea Muench.
}

HABIT-A tree of medium size, $30-50 \mathrm{ft}$. high with trunk diameter of 1-3 ft., larger further south; trunk tends to be continuous into the crown, narrowed and giving off ascending branches above and horizontal, often terminally declined branches below; limbs long and comparatively slender for an Oak, forming a rather narrow, open head.

BARIK-Of young trunks and limbs smooth, light brown, on older trunks and limbs up to $2.5 \mathrm{~cm}$. thick, divided by shallow furrows into irregular ridges which in general are neither so regularly flat-topped as the ridges of the Red Oak nor so roughly broken up as those of the Black Oak. The bark therefore may be considered as intermediate in character between these two species. Inner bark, reddish not bitter.

TWIGS-Mediumly stout to slender, light red to orange red. LENTICELS-numerous, minute, pale, inconspicuous. LEAVES- broadly oval or obovate, with bristle-tipped lobes separated by deep rounded indentations. PITH-5-pointed, star-shaped.

BUDS-Broadly oval to ovate, narrowed above to a typically rather blunt apex, widest at or slightly below middle, dark reddish-brown, 4-8 $\mathrm{mm}$. long, pale woolly above middle, lower half mostly free from wool. BUD-SCALES-numerous, free from distinct longitudinal striations.

FRUIT-Maturing in autumn of second season, sessile or short-stalk @d, singly or in pairs. NUT-oval to oblong, variable in shape, 1 to 2.5 $\mathrm{cm}$. long, light reddish brown, occasionally striate. CUP-thin, topshaped or cup-shaped, constricted at base, enclosing $1 / 3$ to $1 / 2$ of nut. Scales, light reddish-brown, thin, closely overlapping, slightly downy, tips of scales at rim typically appressed against the nut-not spreading. Meat pale yellow, slightly bitter. Immature acorns appressed, rather smooth and shiny, light brown, main basal scales generally reaching less than halfway up giving appearance of 2 rows of scales.

COMPARISONS-The size and shape of the acorn cup as well as the greater woolliness of the upper part of the buds distinguish this species from the Red Oak. From the Black Oak it is distinguished by the appressed scales of acorn cup, by the fatter buds which are less wolly, and that only above the middle and by the pale inner bark. See also under Black Oak.

DISTRIBLTION-Most common on dry, sandy soil. Ontario; south to the middle states and along the mountains to North Carolina and Tennessee; reported from Florida; west to Minnesota, Nebraska and Missouri.

IN NEW ENGLAND-Maine-valley of the Androscoggin, southward; New Hampshire-common about Manchester; Vermont-not authoritatively reported by recent observers; Massachusetts-more common in the eastern than western sections, sometimes covering considerable areas; Connecticut and Rhode Island-common.

WoOD-Heavy, hard, strong, coarse-grained, light or reddish-brown, with thick darker colored sapwood, less valuable than wood of Red Oak but used for the same purposes. 

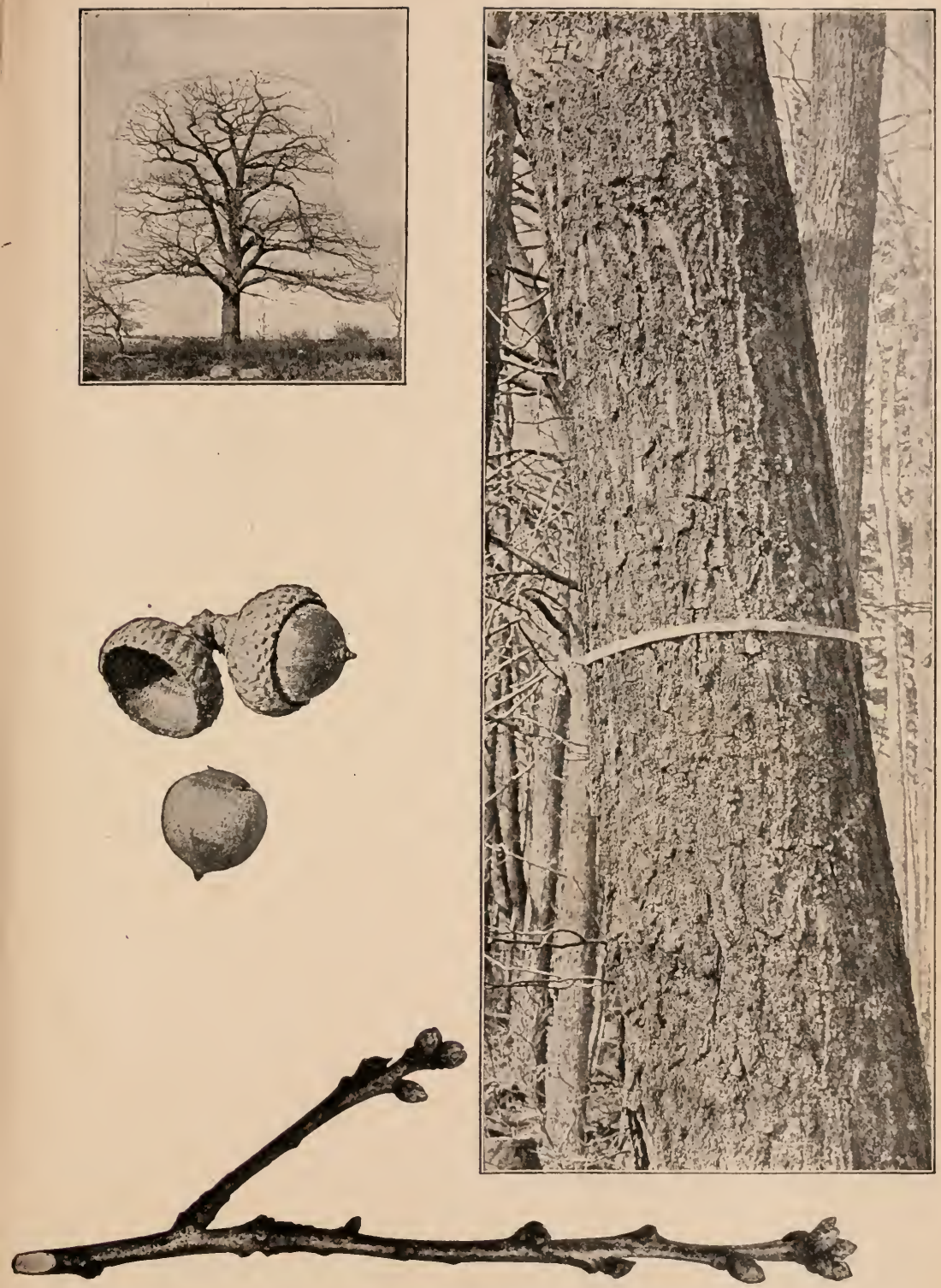

Scarlet OAK 


\section{BLACK OAK \\ Yellow-barked Oak, Quercitron, Yellow Oak.}

Quercus velutina Lam.

Q. coccinea, var. tinctoria A.DC. ; Q. tinctoria Bartr.

HABIT-One of our largest oaks 50-75 ft. high with a trunk diameter of 2-4 ft., reaching its greatest development in Ohio basin with a maximum height of $150 \mathrm{ft}$.; somewhat similar in general habit to the Scarlet Oak; limbs generally somewhat stouter; head may be wide spreading or narrowed oblong.

IIRK-Dark gray to blackish, often lighter near the seashore, up to $4 \mathrm{~cm}$. thick, very rough, broken by deep furrows into thick ridges which are further divided by cross fissures giving an appearance of irregular block-like strips. The bark is roughened especially at the base of trunk even in quite young trees. The young bark in beginning to fissure for a time may have flattened ridges resembling those of Red Oak, but they are soon transversely roughened. Inner bark orangeyellow, intensely bitter; this with the buds forms the most distinctive character.

TWIGS-Stout, reddish-brown or reddish, mottled with gray; tasting bitter if chewed and coloring saliva yellowish. LENTICELS-scattered, generally large, conspicuous. LEAVES-obovate to oblong with broad bristle-pointed lobes sometimes indistinguishable from those of Scarlet Oak. Large, thin-walled, spherical insect galls formed on leaves seem to be most common on the Black Oak. (See plate.) PITH-5-pointed, star-shaped.

HUDS-Ovate to conical, large 6-12 $\mathrm{mm}$. long, narrowed above to a rather sharp point, generally 5-sided, strongly angled, covered except basal row of scales with dense, pale yellowish-gray to dirty-white wool. BUD-SCALES-numerous, not distinctly longitudinally striate.

FR I'T-Maturing in autumn of second year, singly or in pairs, sessile or short-stalked, deep cup-shaped to top-shaped. NUT-ovate-oblong, variable in shape, $1-2 \mathrm{~cm}$. long, light reddish-brown, frequently coated with soft down, often striate. CUP-thin, deeply cup to topshaped, more or less constricted at base; scales of cup thin, light reddish-brown, finely woolly, closely overlapping at base, loosely overlapping above with free tips horizontally wrinkled and forming a loose more or less spreading fringe-like border to cup. Meat yellower and more bitter than that of the Scarlet Oak. Immature acorns appressed or recurved toward twig, slightly woolly; main scales extending nearly to the top giving the appearance of a single row of scales.

COMPIRISONS-The three most common trees of the Black Oak group (the Red, the Black and the Scarlet) are readily distinguished by their bud characters. Those of the Black Oak are densely pale woolly over whole surface, those of Scarlet Oak are less densely pale woolly, and the woolliness is confined to upper half. They are more nearly oval than those of the Black Oak, the widest part being toward the middle. The Red Oak Buds are generally free from pale woolliness though having often rusty hairs at extreme apex; in distinction from the Scarlet Oak the widest part is nearer the base. The yellow bitter inner bark and the yellow discoloration of the saliva when the twigs are chewed distinguish the Black Oak from the other two. The Red Oak has flat-topped ridges, these in the Black Oak are broken into rough blocks, while the bark of the Scarlet Oak is intermediate between the two types. The acorns of the Red Oak are large with large shallow saucer-shaped cups, those of the Scarlet and Black are smaller, and have deeper cups. The cup scales of the Black Oak form a loose fringe at the rim and are wrinkled, those of the Scarlet are closely over-lapping and form no fringe. The acorn characters are distinctive for the Red Oak but are not so good quite in separating the Black and Scarlet Oaks from each other, although when typically developed the acorns of the two trees can be readily distinguished. The bark characters can be used when typically developed in separating the Red from the Black Oak but are not as decisive as bud or inner bark characters.

DISTRIBITION-In poor soils; on dry gravelly plains and ridges. Southern and western Ontario; south to the Gulf states; west to Minnesota, Kansas, Oklahoma and Texas.

IN NEW ENGLAND-Maine-York county; New Hampshire-valley of the lower Merrimac and eastward, absent on the highlands, reappearing within three or four miles of the Connecticut, ceasing at North Charlestown; Vermont-western and southwester sections; Massachusetts-abundant eastward; Connecticut and Rhode Island-frequent.

WoOD-Heavy, hard, strong though not tough, coarse-grained and liable to check in drying, bright brown tinged with red, with thin lichter colored sapwood; of little value except as fuel. The bark abounds in tannic acid and is largely used in tanning, as a yellow dye and an astringent in medicine. 

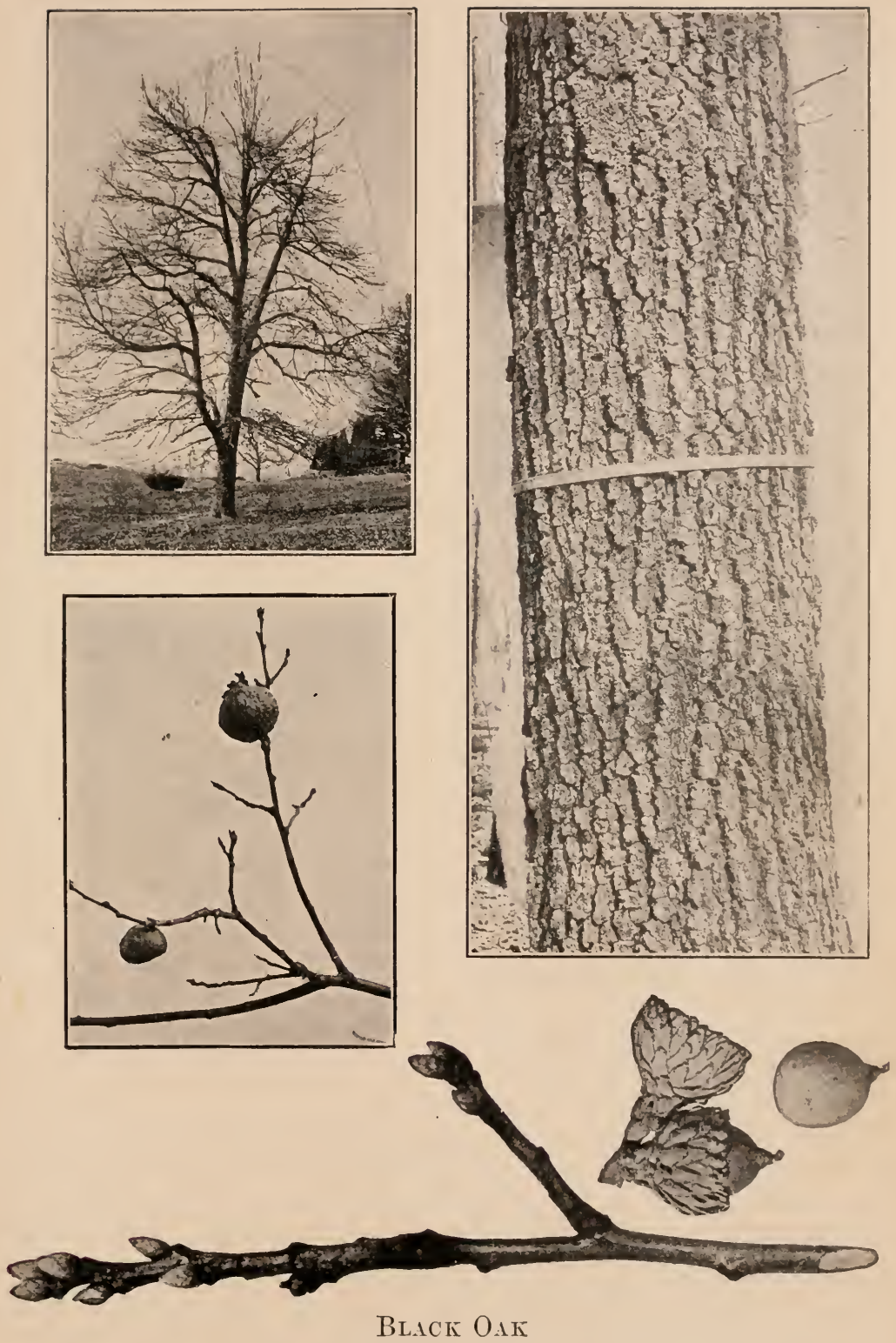


\section{BEAR OAK \\ Black Scrub Oak.}

Quercus ilicifolia Wang.

Q. nana Sarg. ; Q. pumila Sudw.

HABrT-Usually a shrub 3-10 ft. high, though frequently becoming tree-like and reaching a maximum height of $25 \mathrm{ft}$. with a trunk diameter of $1 / 2$ to $1 \mathrm{ft}$; trunk short, branches stiff, contorted, slender, spreading and forming a wide flat or round-topped head.

BMIK-Thin, dark brown, smooth, except for small, close, thin scales on older trunks, never however breaking into large, flaky scales.

TwIGS-Slender, yellowish-green to reddish-brown, covered with greenish-yellowish to reddish down which often disappears from exposed parts of the twig during the winter but which can generally be found in protected parts at the tips, bases or between the ridges of the season's shoots. LENTICELS-minute, pale, inconspicuous on shoots of season. Leaves often breaking off above place of attachment leaving base of leafstalk projecting throughout winter (see illustration). LEAVES-small, obovate, nearly entire or with 3-7 bristle-tipped lobes, downy beneath. PITH-5-pointed, star-shaped.

IBUDS-Ovate to conical, sharp or blunt pointed, small, generally not over $3 \mathrm{~mm}$. long. BUD-SCALES-dark chestnut brown, generally minutely hairy on the margins.

FRIIT-Maturing in second season, produced in great abundance, clustered along the stem, generally in pairs or rarely singly, sessile or generally short-stalked. NUT-varying in shape, ovate to spherical, 10-15 mm. long, light brown, shining, generally more or less longitudinally striate. Cup-top-shaped to rather deeply saucershaped, more or less constricted at base, thick, enclosing about $1 / 2$ the nut; scales of cup reddish-brown, slightly downy, thin, closely overlapping with free tips of upper scales forming a fringe-like border to cup.

CompIrisons-The Dwarf Chinquapin Oak is the only one likely to be confused with the Bear Oak. The points of difference between the two species may be found in Comparisons under Dwarf Chinquapin Oak.

DISTRIBßUTION-Dry sandy or rocky sterile ground. Maine; south to Ohio and the mountain regions of North Carolina and Kentucky; west to the Alleghany mountains.

IN NEW ENGLAND-Maine-frequent in eastern and southern sections and upon Mount Desert Island; New Hampshire-as far north as Conway, more common near the lower Connecticut; Vermont-in the eastern and southern sections as far north as Bellows Falls; Connecticut-rare in northwestern part of the state, local, frequent or common elsewhere; Massachusetts and Rhode Island-abundant, forming, in favorable situations, dense thickets, sometimes covering several acres.

WOOD-Too scant to be of an economic value. 

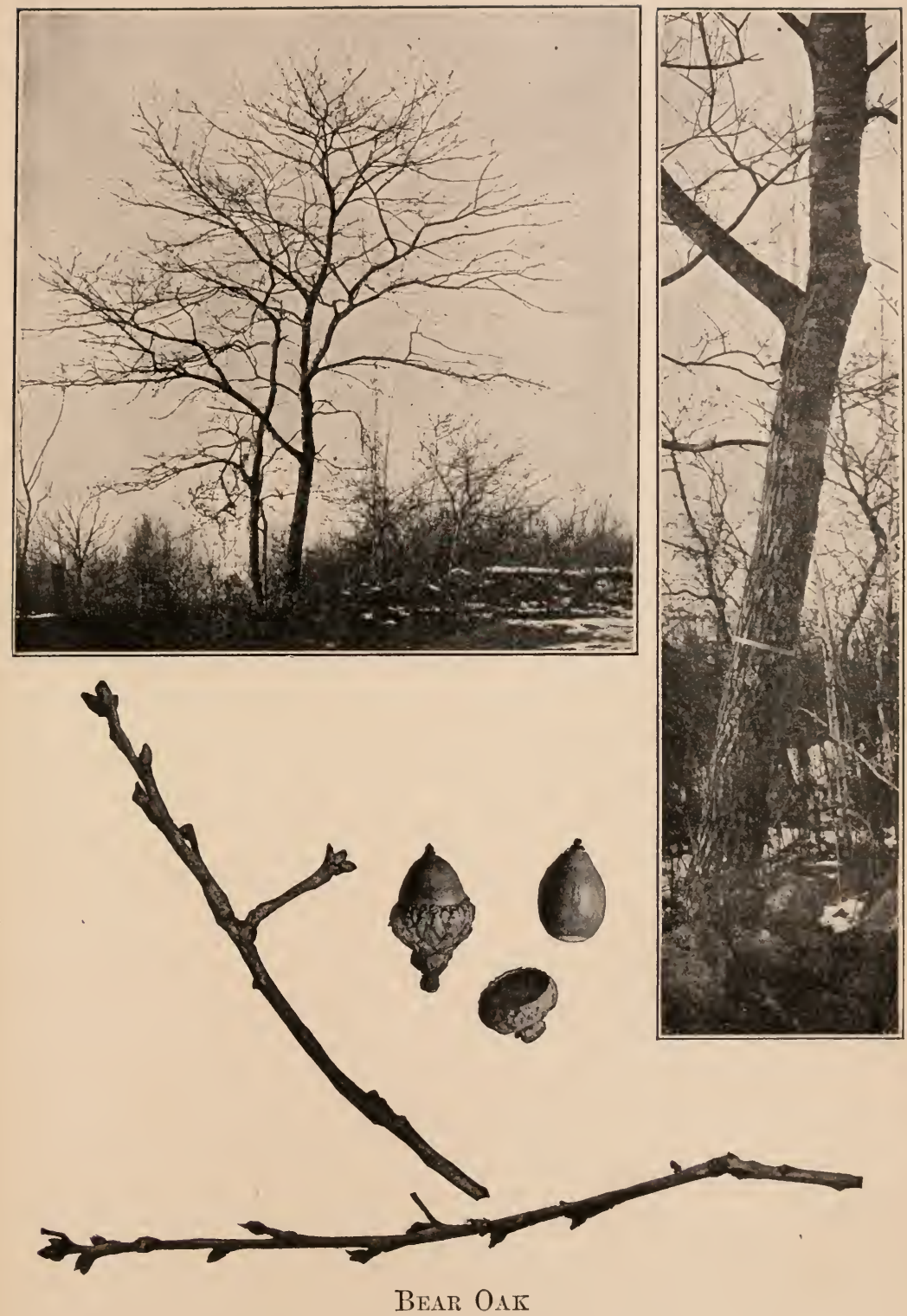


\section{SLIPPERY ELM Red Elm, Moose Elm.}

Ulmus fulva Michx.

U. pubescens Walt.

HABIT-A small to medium-sized tree, 40-60 ft. in height with a trunk diameter of $1-21 / 2 \mathrm{ft}$; forming a broad open rather flat-topped head, resembling the White Elm but with less drooping branches.

ВМRK-Grayish-brown, more or less deeply furrowed, the ridges tending rather more than in the White Elm to lift along one edge, internally reddish-brown without conspicuously whitish layers (see bark secion in plate); inner bark next the wood, whitish, strongly mucilagisous, giving the name Slippery Elm.

TWIGS-Light, grayish, hairy, roughened by numerous raised lenticels, strongly and characteristically mucilaginous if chewed.

LEAF-SCARS-Alternate, 2-ranked, with generally 3 sunken bundlescars, resembling those of the White Elm.

BUDS-Terminal bud absent; lateral buds about $6 \mathrm{~mm}$. long, dark brown, covered especially at their tips with long rusty hairs; flower buds more or less spherical. BUD-SCALES-in 2 ranks of a nearly uniform color.

FRUIT-A flat round entire-winged fruit without hairy fringe, ripening in spring.

COMPIRISONS-The Slippery Elm is easily distinguished from the common White Elm and the rarer Cork Elm by its rough gray twigs, its dark buds covered with long rusty hairs and by the strongly mucilaginous character of the inner bark of the trunk and even, though to a somewhat less extent, of the twigs, and further from the White Elm by the absence of distinct white layers in the outer bark.

DISTRIBLTION-Rich, low grounds; low, rocky woods and hillsides. Valley of the St. Lawrence, apparently not abundant; south to Florida; west to North Dakota and Texas.

IN NEW ENGLAND-Maine-District of Maine, rare; Waterborough, (York county); New Hampshire-valley of the Connecticut, usually disappearing within ten miles of the river; ranges as far north as the mouth of the Passumpsic; Vermont-frequent; Massachusetts-rare in the eastern sections, frequent westward; Connecticut-rare to frequent; Rhode Island-infrequent.

WoOD-Heavy, hard, strong, very coarse-grained, durable, easy to split, dark brown or red, with thin lighter colored sapwood; largely used for fence posts, railroad ties, the sills of buildings, the hubs of wheels and in agricultural implements. The thick fragrant mucilaginous inner bark is used in medicine as a demulcent and is somewhat nutritious. 

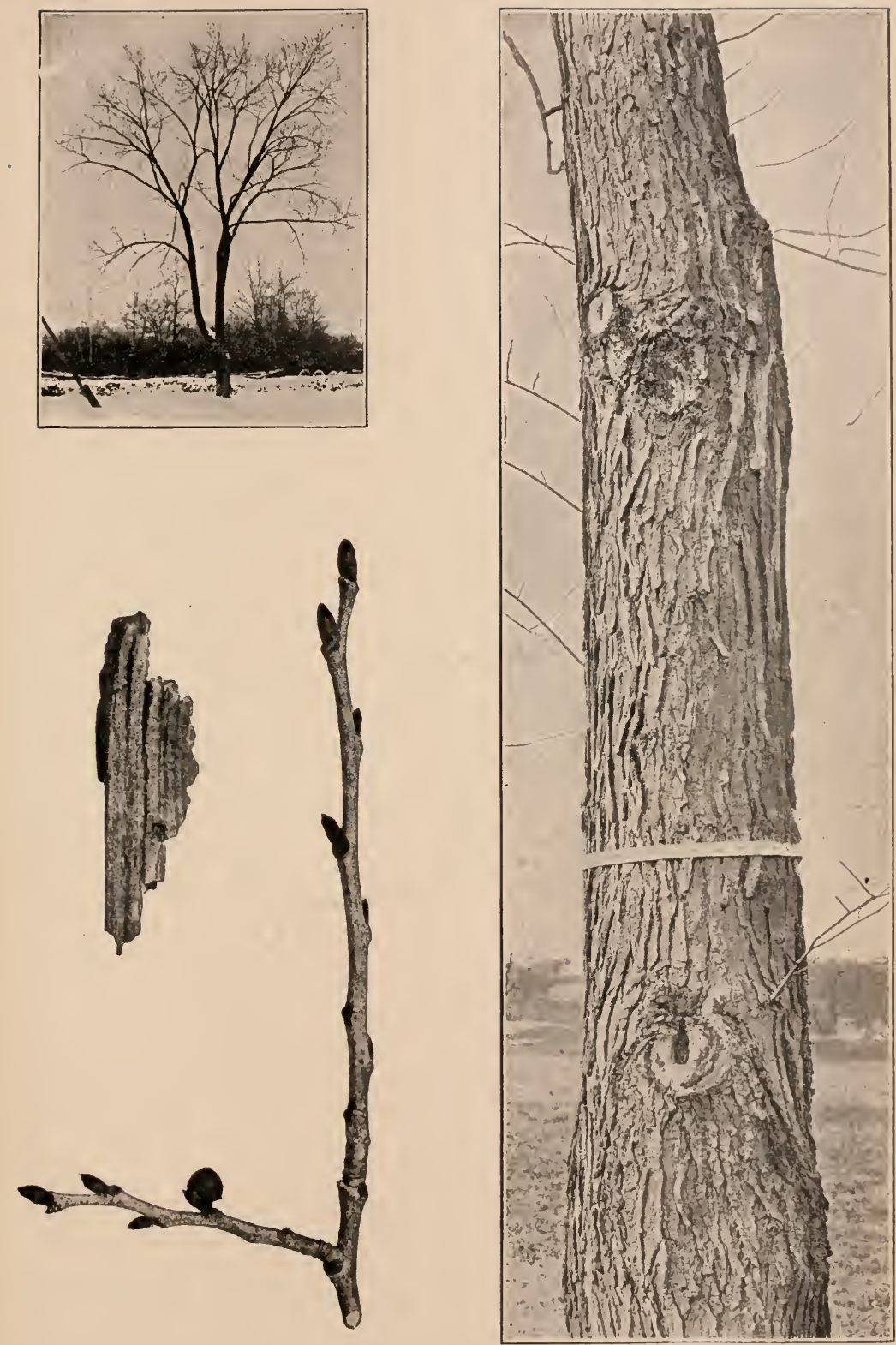

Shippery EliI 


\title{
ENGLISH ELM
}

Ulmus campestris L.

\author{
U. glabra Mill.
}

HАBIT-A large tree reaching $100 \mathrm{ft}$. in height; trunk erect, generally continuous well into the crown, with branches given off at a broad angle and continued horizontally or inclined upward, not drooping at the ends in the graceful curves characteristic of the American White Elm, producing rather an Oak-like appearance with an oblong roundiopped head.

ВМRК-Dark, with ridges broken transversely into firm oblong blocks.

Twigs-Similar to the White Elm but generally a darker reddishbrown, usually smooth or somewhat downy.

LEAR-SC.RS-Similar to the White Elm, bundle-scars frequently more than 3.

BUDS-Similar to the White Elm but of a dark smoky brown color or almost black, smooth or more or less hairy. BUD-SCALES-nearly uniform in color.

FHIIT-A flat, ovate, smooth, entire-winged fruit, ripening in spring.

COMPARISONS-The erect Oak-like habit, the firm blocked ridges of the bark, and the smoky smoothish buds will serve to distinguish the English Elm from its American cousins. There are a number of varieties of the English Elm differing in habit of growth, one form having corky ridges. We have described the most familiar type.

DISTRIBLTION-The English Elm is not confined to England but like the English sparrow occurs through Europe. It is $\mathrm{n}$ t native to America but was considerably planted formerly in the eastern sections especially in Boston and vicinity, where some fine old specimens are to be found. The trees in the plate were taken from Boston Common, the two at the right being English Elms, while the smaller one, indistinctly outlined at the left, is an American White Elm. They have all been rather severely pruned on account of insect depredations.

Woon-Heavy, hard, fine-grained, durable in water, not liable to crack when exposed to sun or weather; used in Europe for ships' blocks and other wooden parts of rigging, for the keels of ships, for pumps and water pipes, piles and other construction under water and for the hubs of wheels. 

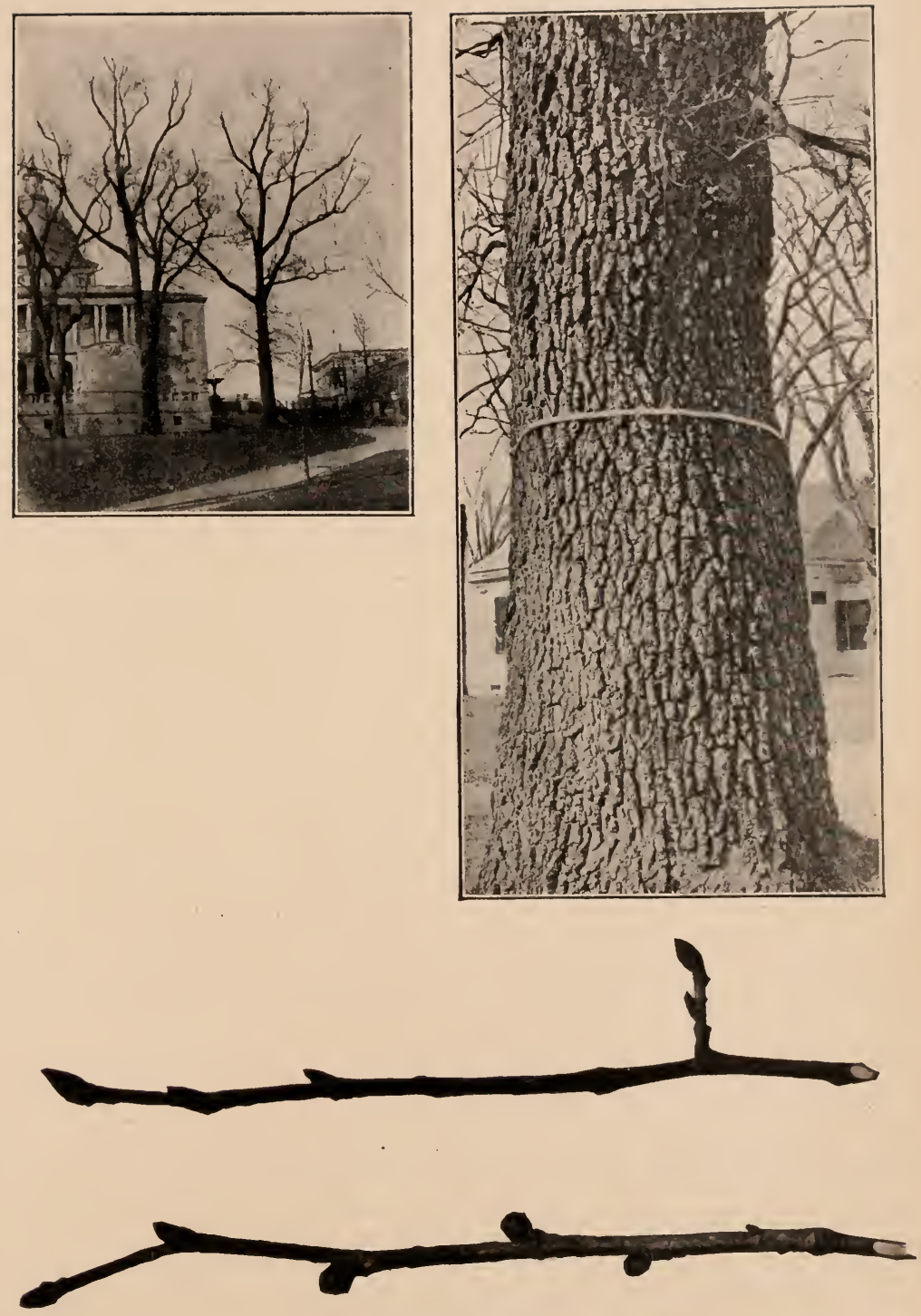

Exglish Elit 


\title{
WHITE ELM American or Water Elm.
}

\author{
Ulmus americana $\mathrm{L}$.
}

HABIT-A large tree 50-110 ft. in height with a trunk diameter of 1- 8 ft.; trunk more or less widely buttressed, dividing high up into a number of large limbs which grow upward, and bend gradually and gracefully outward, dividing repeatedly to form a broad, round or flat-topped inversely conical head with drooping branchlets. In respect to its general outline various types of the Elm have been distinguished as the "Vase Form" shown in the photograph; the "Umbrella Form" with trunk undivided to near the top with abruptly spreading branches forming a broad shallow arch; the "Plume Form" with a one-sided development of drooping branches from a tall trunk; the "Oak Form" with more tortuous and less arching limbs forming a wide rounded head; the "Feathered Form," a modification of any of the other types with the trunk fringed with short branches.

BARK-Dark gray, divided by irregular longitudinal fissures into broad flat-topped ridges, rather firm though sometimes in very old trees coming off in flakes; the bark is internally stratified by thick conspicuously whitish layers alternating with layers of a dark brown (see plate for section of a ridge of bark).

TWIGS-Slender, smooth or slightly or sometimes densely downy, light reddish-brown, often tinged with yellow, very slightly mucilaginous if chewed. LENTICELS-pale, scattered, more or less inconspicuous.

LEAF-SCIRS-Alternate, 2-ranked, semi-circular, raised, small but conspicuous because of contrast in color between the light corky surface of the scar and the darker brown of the twig. STIPULE-SCARSnarrow, minute, sometimes indistinct. BUNDLE-SCARS-relatively large, conspicuous, typically 3 in number though often more by compounding of single scars, generally sunken in depressions of the leaf-scar.

BLDS-Terminal bud absent; lateral buds small, often placed at one side of leaf-scar, ovate-conical, pointed, about $4 \mathrm{~mm}$. long, slightly flattened and more or less appressed against the twig, light reddishbrown, smooth and shining or slightly pale-downy; flower buds stouter, oborate, appearing as if stalked. BUD-SCALES-about 6-9 to a leafbud in 2 ranks, increasing in size from without inward, generally with darker and more or less hairy-edged margins.

FRUIT-A flat, oval, terminally deeply notched, winged fruit, hairyfringed on edges, ripening in spring and scarcely to be found in winter.

COMPIRISONS-The White Elm differs from the Slippery Elm in the whitish layers of the bark, the absence of rusty hairs on the buds and the brownish color of its relatively smooth twigs. From the Cork Elm it may be separated by its habit of growth and by the absence of corky ridges on the twigs. The graceful drooping habit of growth of its branches and the light reddish brown of its buds are sufficient to distinguish the American from the Fnglish Elm.

DISTRIBUTION-Lnw, moist ground, thrives especially on rich intervales. Frequently planted as a street and shade tree. From Cape Breton to Saskatchewan, as far north as $54^{\circ} 30^{\prime}$; south to Florida; west to Dakota, Nebraska, Kansas and Texas.

IN NETT ENGLAND-Maine-common, most abundant in central and southern portions; New Hampshire-common from the southern base of the Thite Mountains to the sea; in the remaining New England statesvery common. attaining its highest development in the rich alluvium of the Connecticut river valley.

woon-Heary, hard, strong, tough, difficult to split, coarse-grained, light brown. with thick somewhat lighter colored sapwood, largely used for the hubs of wheels, saddle-trees, in flooring and cooperage, and in boat and ship building. 

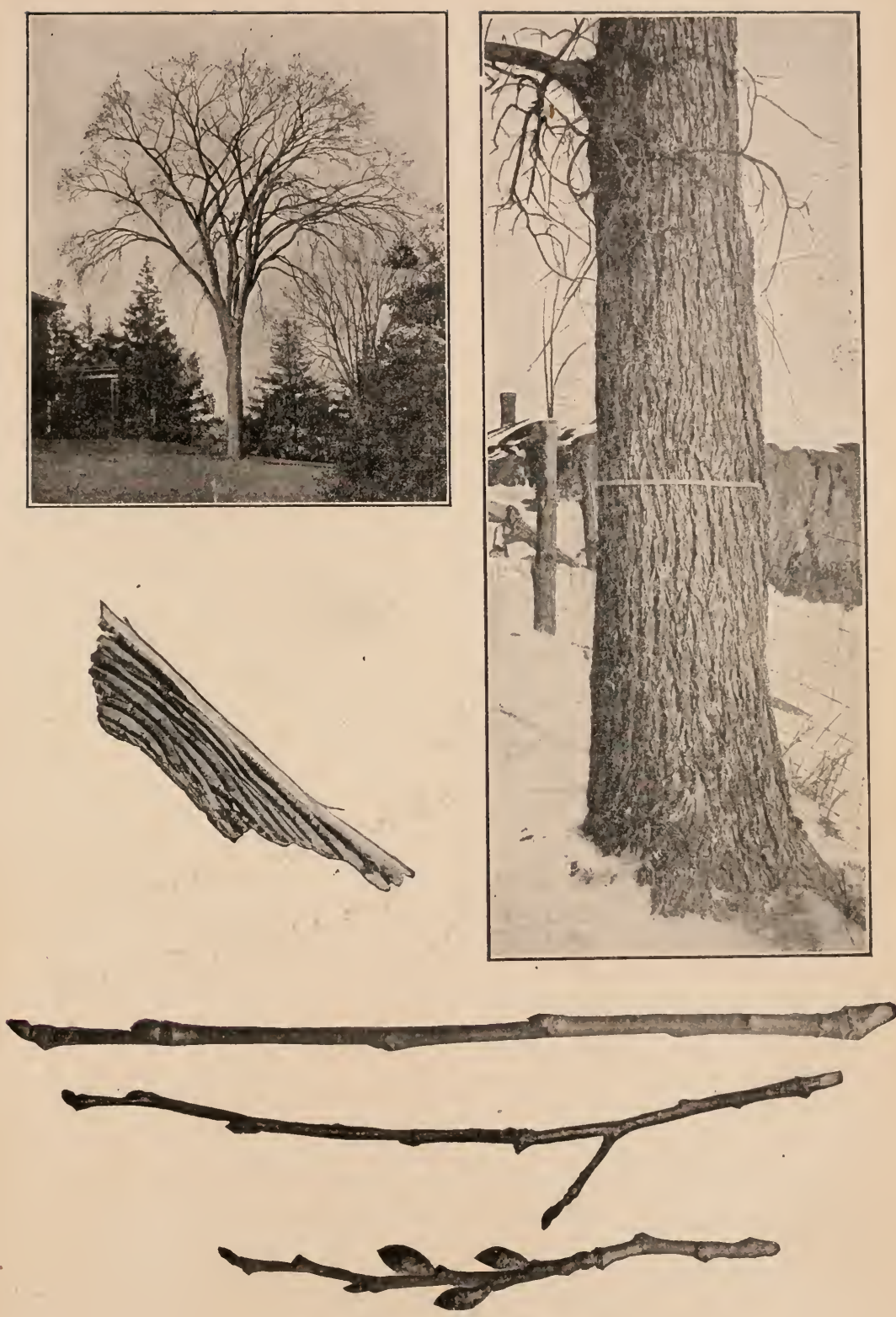

White Ela 


\title{
CORK ELM \\ Rock Elm, Hickory Elm, Northern Cork Elm. Ulmus racemosa Thomas.
}

\section{U. Thomasi Sarg.}

\begin{abstract}
HABIT-A large tree 50-75 ft. in height, with a trunk diameter of $2-3 \mathrm{ft} .$, in southern Michigan reaching $100 \mathrm{ft}$. in height with a trunk diameter of $5 \mathrm{ft}$; trunk slender, erect, generally continuous into the crown, developing numerous slender rigid branches arising at a wide angle, those below generally strongly drooping near the point of origin, forming a narrow, oblong, round-topped head having somewhat the aspect of a Hickory with short twiggy, generally corky-ridged branches in the interior of the tree. A young tree showing corky-ridged branchlets and an old tree showing a more characteristic habit, though with rather long trunk for the open, are shown in the plate.
\end{abstract}

BIRK-On young trunks more deeply furrowed than in the White Elm, becoming with age flat-ridged, resembling the latter species.

TWIGS-More or less downy, resembling twigs of White Elm but generally developing several irregular thick corky ridges not interrupted at the nodes.

LEAF-SCIRS-Alternate, 2-ranked, resembling those of White Elm. but with bundle-scars generally more than $3(4-6)$.

BLDS-Terminal bud absent; lateral buds similar to those of White Elm but longer (about $5 \mathrm{~mm}$. long) narrower, sharp-pointed, scarcely flattened, generally downy. BUD-SCALES-with darker and hairy-edged margins.

FRU1T-A flat, oval, downy, shallow-notched, winged fruit, with hairy-fringed margins ripening in spring.

COMPARISONS-In Hickory-like habit the Cork Elm differs from all our other Elms. The corky ridges on the twigs, moreover, occur on no other native New England Elm. The Winged Elm [Ulmus alata Michx.], a native of the south, is rarely cultivated in southern New England but is not hardy north. It $h$ s two opposite thin corky ridges which are abruptly interrupted at the nodes. A variety of the English Elm has several corky ridges to the twig which are interrupted at the nodes. The Cork Elm differs further from the White and especially from the slippery Elm in its narrower buds.

DISTRIBITION-Dry, gravelly soils, rich soils, river banks. Quebec through Ontario; south to Tennessee; west to Minnesota, Iowa, Nebraska, and Missouri. Occasionally planted as an ornamental shade tree.

IN NEW ENGLAND-Maine-not reported; New Hampshire-rare and extremely local; Meriden and one or two other places; Vermont-rare, Bennington, Pownal, Knowlton, Highgate, comparatively abundant in Champlain valley and westward; Massachusetts-rare; Connecticut and Rhode Island-not reported native.

wOOD-Heavy, hard, very strong and tough, close-grained and difficult to split, light clear brown, often tinged with red with thick, lighter colored sapwood; largely used in the manufacture of many agricultural implements, for the framework of chairs, hubs of wheels, railroad ties, the sills of buildings and other purposes demanding toughness, solidity and flexibility. 


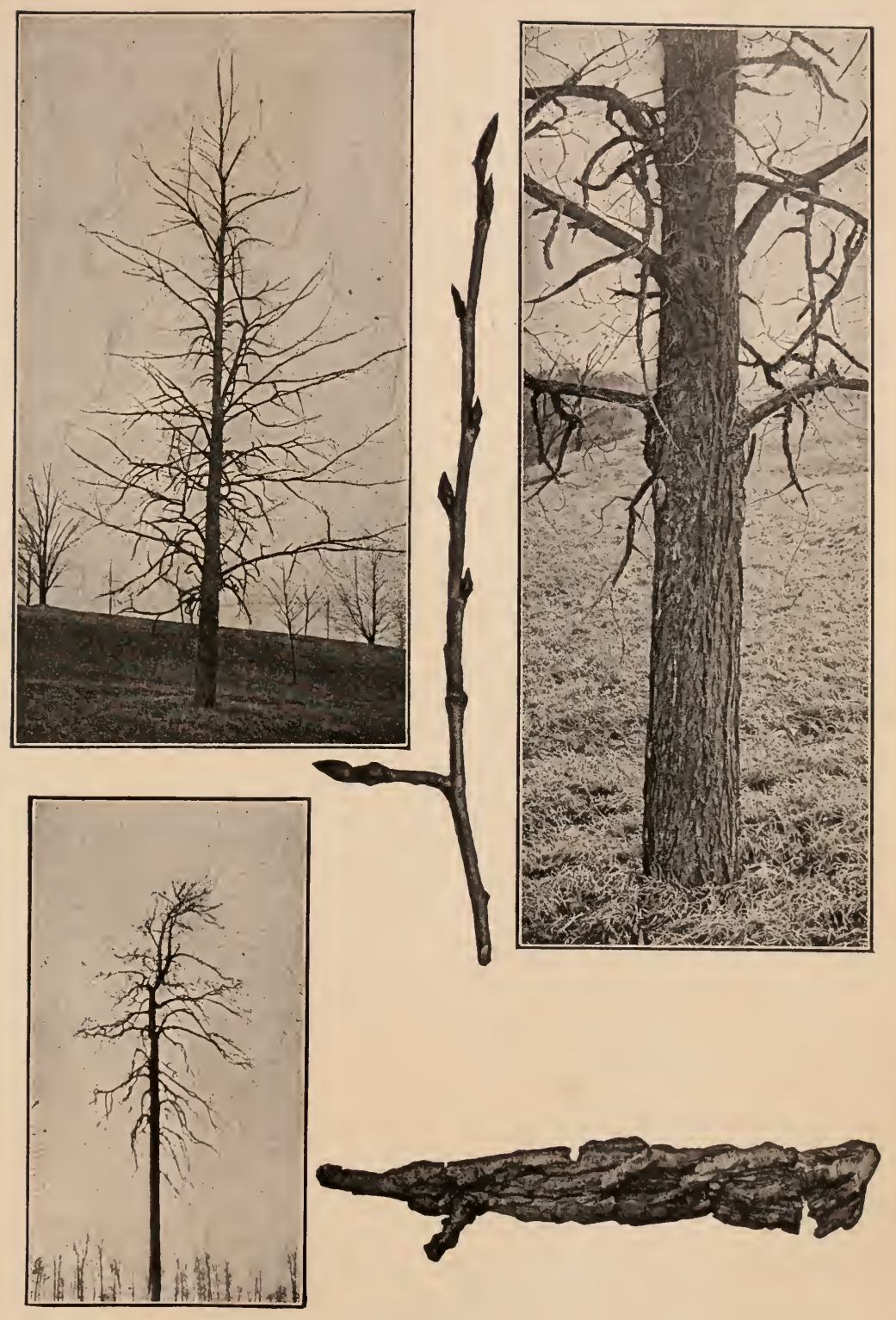

CORK ElM 


\section{HACKBERRY \\ Sugar Berry, Nettle Tree, False Elm, Hoop Ash.}

Celtis occidentalis L.

H. ВIT-A small to medium sized tree 20-45 ft. in height with a trunk diameter up to $2 \mathrm{ft}$, reaching over $100 \mathrm{ft}$. in height further south; rather variable in habit, generally forming a flattish to round-topped wide-spreading, oblong head with somewhat the aspect of an Elm; branches numerous, horizontal or slightly drooping, more or less zigzag; spray slender; berry-like fruit generally persistent throughout the winter.

B.IRK-Grayish-brown, on trunk and older limbs roughened with narrow projecting ridges which are sometimes reduced to warts or are almost entirely lacking.

TWIGS-Slender, somewhat zigzag, brownish, more or less shining, more or less downy; wood of twigs light greenish yellow when moistened. LENTICELS-scattered, raised and more or less elongated longitudinally. PITH-white, finely chambered.

LEAF-SCIRS-Alternate, 2-ranked, small, semi-oval, placed at right angles to the twig on a projecting cushion. STIPULE-SCARS-present, elongated, inconspicuous. BUNDLE-SCARS-appearing as a single confluent scar, evidently 3 in surface section.

BCDS-Small, $6 \mathrm{~mm}$. or generally under in length, downy, chestnut brown, ovate, sharp-pointed, flattened, appressed; terminal bud absent. Buds frequently transformed into insect galls (swellings on left hand twig). BUD-SCALES-3-4 visible, closely overlapping in two ranks increasing in size from without inward, longitudinally striate if viewed toward light, generally dark margined.

FRUTT-A small purplish, more or less spherical stone-fruit on long, slender stems, $7-10 \mathrm{~mm}$. in diameter, often remaining on tree throughout winter. Flesh edible, sweet as is also the seed inside the stone.

COMPIRIGONS-The Hackberry is often taken for an Elm. The warts or narrow ridges on its bark, however, and its chambered pith readily distinguish it from the Elm if the berry-like fruit which is generally present fails to be found. The twigs are so frequently disfigured by insect galls that their presence might almost be given as a distinguishing character.

DISTRIBITION-In divers situations and soils; woods, river banks, near salt marshes. Province of Quebec to Lake of the Woods, occasional; south to the Gulf states; west to Minnesota and Missouri.

IN NEW ENGLAND-Maine-not reported; New Hampshire-sparingly along the Connecticut valley, as far as Wells river; Vermont-along Lake Champlain, not common; Norwich and Windsor on the Connecticut; Massachusetts-occasional throughout the state; Connecticut-Occasional to frequent, especially in river valleys and along the coast; Rhode Island-common.

WoOD-Heavy, rather soft, not strong, coarse-grained, clear light yellow, with thick lighter colored sapwood; largely used for fencing and the manufacture of cheap furniture. 

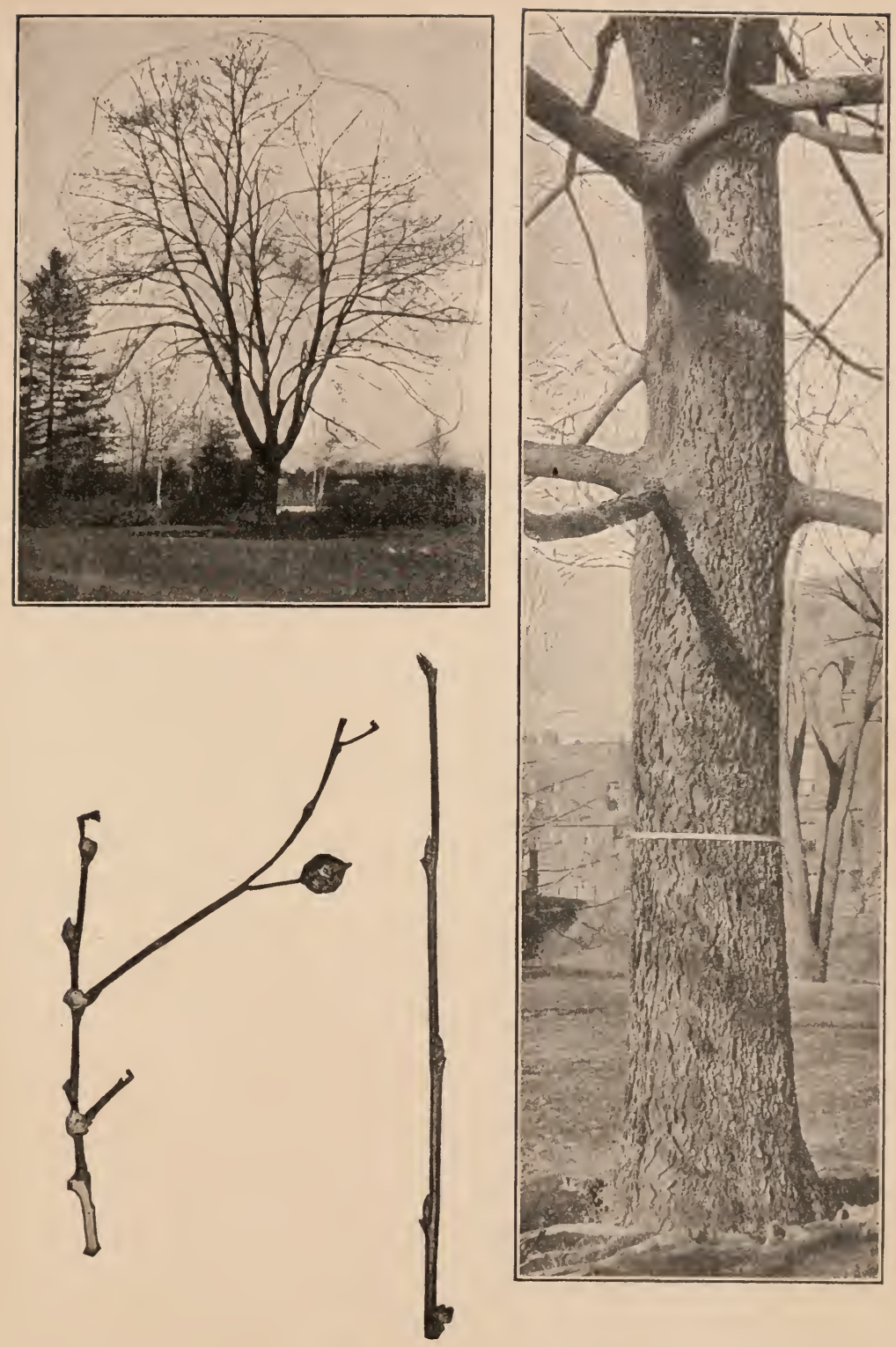

HACKBERRY 


\title{
RED MULBERRY
}

\author{
Morus rubra L.
}

HABIT-A small tree 15-25 $\mathrm{ft}$. in height with trunk diameter of 8-15 inches, of larger size in the Ohio and Mississippi basins; trunk short, dividing into a number of stout spreading limbs developing a compact, broad, rounded head with numerous small branches, in aspect resembling an Apple tree.

BARK-Dark brown, divided into irregular longitudinal plates which tend to lift at the ends and flake off, sometimes, however, not conspicuously flaky.

TWIGS-Slender though rather stouter than those of the White Mulberry; somewhat zigzag, reddish to greenish-brown, with rather sweetish taste, cut twig showing milky juice. LENTICELS-small, scatterea, inconspicuous.

LEAF-SCARS-Alternate, 2-ranked, raised, nearly circular, slightly hollowed in the center. STIPULE-SCARS-narrow. BUNDLE-SCARSraised but generally less distinctly so than in the White Mulberry, forming a closed ring or irregularly scattered in the center.

BLDS-Terminal bud absent, lateral buds ovate, pointed, about $6 \mathrm{~mm}$. long, stout but longer than broad, not at all or but slightly flattened, divergent, shining, greenish to chestnut brown. BUD-SCALES-2ranked, with thin, distinctly darker margins, 4-8 scales visible.

FRUIT-Red, not to be found in winter.

COMPARISONS-The Red is most readily separated from the White Mulberry by its darker twigs, its larger shining, greenish to chestnut brown buds with dark-margined bud-scales.

DISTRIBUTION-Banks of rivers, rich woods. Canadian shore of Lake Erie; south to Florida; west to Michigan, South Dakota, and Texas.

IN NEW ENGLAND-A rare tree; Maine-doubtfully reported; New Hampshire-Pemigewasset valley, White Mountains; Vermont-northern extremity of Lake Champlain, banks of the Connecticut, Pownal, North Pownal; Massachusetts-rare; Connecticut-rare or occasional; Bristol, Plainville, North Guilford, East Rock and Norwich; Rhode Island-no station reported.

WOOD-Light, soft, not strong, rather tough, coarse-grained, very durable, light orange color with thick lighter colored sapwood, used largely for fencing, in cooperage and in ship and boat building. 

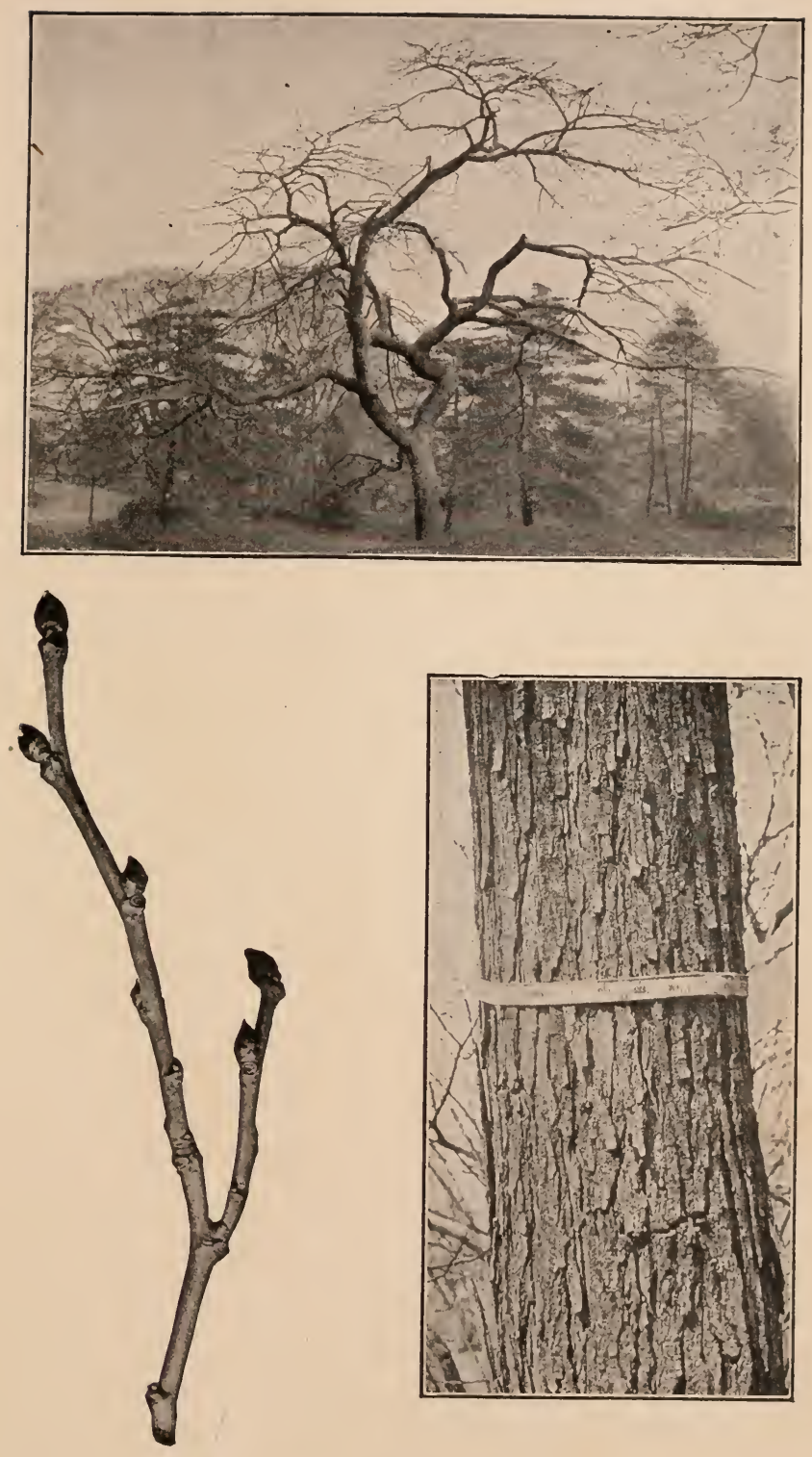

Red Mulberr 


\title{
WHITE MULBERRY Silkworm Mulberry.
}

\author{
Morus alba $\mathrm{L}$.
}

HIBIT-A small tree with a maximum height of 30-40 ft., and with a trunk diameter of less than $3 \mathrm{ft}$; branching low with wide-spreading limbs forming a low rounded head resembling an Apple tree somewhat in habit, but with a characteristic scraggly twigginess to the more slender branchlets.

HIRK-Deeply furrowed into long more or less wavy light yellowish brown ridges.

TWIGS-Slender, yellowish-green to brownish-gray, for the most part smooth, round, more or less shining, generally zigzag, swollen at the nodes, short branches numerous, often àrising at right angles to ranks of previous years and producing a characteristic scraggly complex of branchlets. Twigs slightly sweetish if chewed; bark exuding a white milk if cut on warm days or after being brought into a warm room. LENTICELS-scattered, similar in color to the twigs and hence inconspicuous. PITH-light, rounded in cross-section.

LEIF-SCARS-Alternate, in 2 ranks, small, projecting, oval to depressed circular. STIPULE-SCARS-narrow, inconspicuous. BUNDLE SCARS-conspicuous, 3-10 projecting above leaf-scar, irregularly scattered. If leaf-scar is surface-sectioned leaf-traces are reduced to 3 in number.

HUDS-Terminal bud absent; lateral buds small, about $3 \mathrm{~mm}$. long, bright reddish-brown, roundish, generally about as broad as long, sharp or blunt pointed, somewhat flattended against twigs, often set oblique to the leaf-scar, 1 to 2 small collateral accessory buds sometimes present. BUD-SCALES-in 2 ranks, about 5 scales visible, increasing in size from below upward, margins somewhat finely hairy.

FIRIIT-A white, juicy, multiple fruit not to be found in winter.

COMPAIISONS-The projecting bundle-scars are characteristic of the Mulberries; for points of distinction from the Red Mulberry see under this species.

DISTRIBUTION-Probably a native of China where its leaves have from time immemorial furnished food for silkworms, introduced into to the United States and Canada from Ontario to Florida and naturalized more or less throughout New England appearing by roadsides or along fences and in waste places, being spread by birds which are very fond of its fruit. Connecticut-occasional; early in last century extensively planted to furnish food for silkworms and many large trees remain about farm houses.

WOOD-Moderately hard, close-grained, light yel owish-brown. 

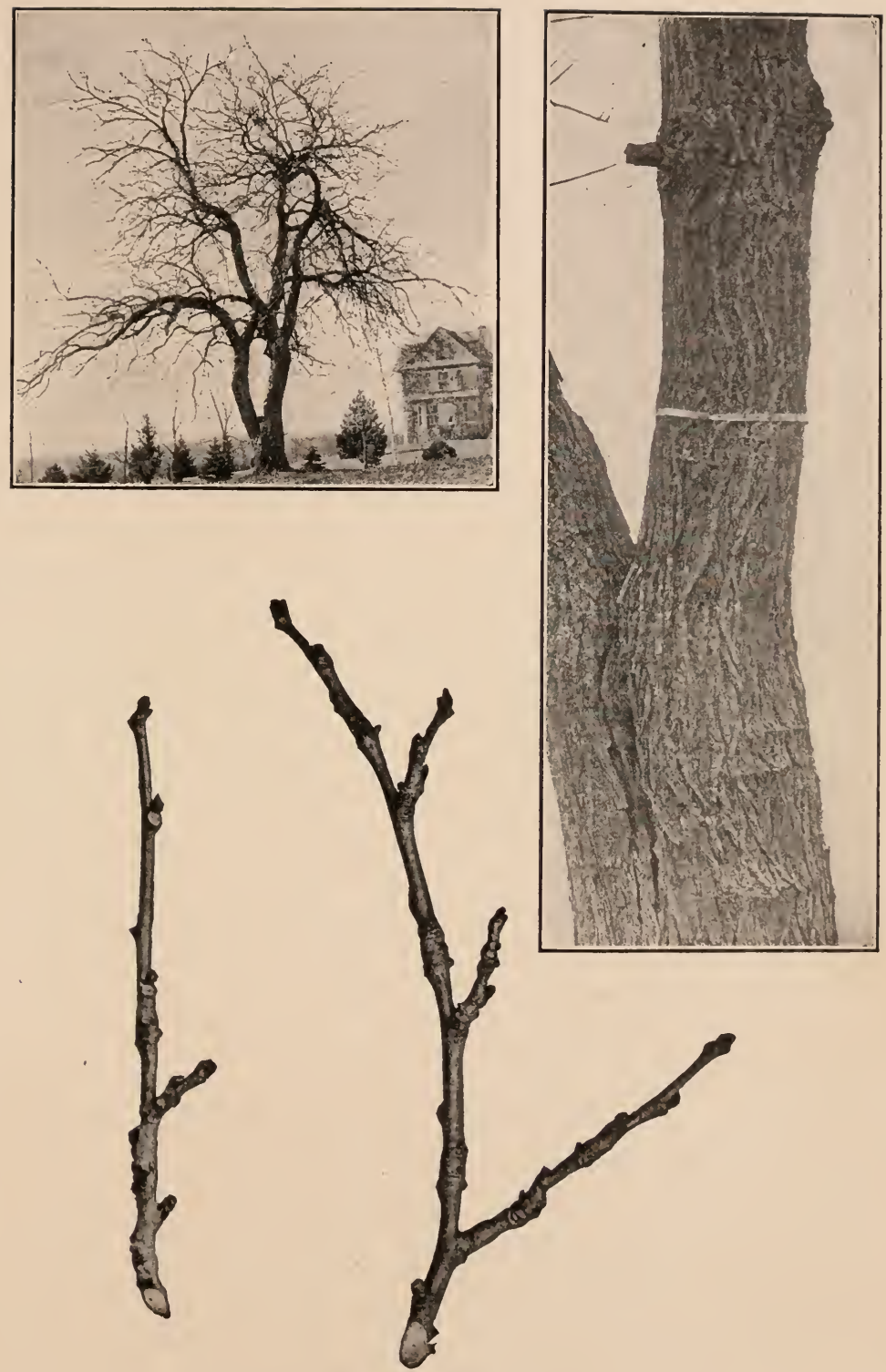

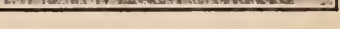

White MulberRy 


\section{CUCUMBER TREE \\ Mountain Magnolia. \\ Magnolia acuminata L.}

HABIT-When fully developed a tall tree up to $90 \mathrm{ft}$. in height with a trunk diameter of 3-4 ft. with comparatively slender branches widely spreading at the base, ascending above, forming a broadly conical head; when young having somewhat the aspect of a Pear Tree.

BARK-Grayish-brown ridged and flaky.

TwiGs-Slender, brown, shining, smooth or at times slightly downy, aromatic. LENTICELS-scattered, inconspicuous, orange colored. PITH -white.

LEAF-SCARS-Alternate, more than 2-ranked, crescent to. U-shaped, elevated. STIPULE-SCARS-distinct, arising from upper margins of leaf-scar and encircling twig. BUNDLE-SCARS-large, few to numerous, scattered in an imperfectly double row, more or less raised.

BUDS-Thickly covered with pale silky hairs; lateral buds blunt, nearly surrounded by leaf-scars, about $1 / 3$ the size of terminal bud; terminal bud oblong, blunt, 10-20 $\mathrm{mm}$. long. BUD-SCALES-valvate and adhering in pairs, with rudimentary leaf-scar and decurrent ridge at side of bud.

FR UIT-An ovate to oblong cone, often curved, generally under $6 \mathrm{~cm}$. long; in the young condition supposedly resembling a cucumber; seed flattish about $1 \mathrm{~cm}$. in diameter.

COMPARISONS-The Cucumber Tree belongs to the same genus as the Umbrella Tree, but differs from it in its smaller, blunt, downy buds, its narrow leaf-scars and its scaly ridged bark; from the Large-leaved Magnolia by the smaller size of its buds, its narrow leaf-scars and its scaly ridged bark; from the Sweet Bay by its larger size, the color of its twigs and the character of its bark. For character of the Sweet Bay see p. 206. The Chinese Magnolia [Magnolia conspicua Salisb.] is often culitivated and has downy buds resembling those of the Cucumber Tree. The buds, however, are stouter, the bark is smooth and the species is more shrubby than tree-like.

DISTRIBUTION-Not native to New England; the hardiest of the Magnolias and extensively planted as an ornamental shade tree. It grows wild from western New York to southern Illinois and southward along the Appalachian mountains to southern Alabama.

wOOD-Light, soft, not strong, close-grained and durable, light yellow brown, with thin lighter colored often nearly white sapwood of usualiy 25-30 layers of annual growth; occasionally manufactured into lumber used for flooring and cabinet making. 

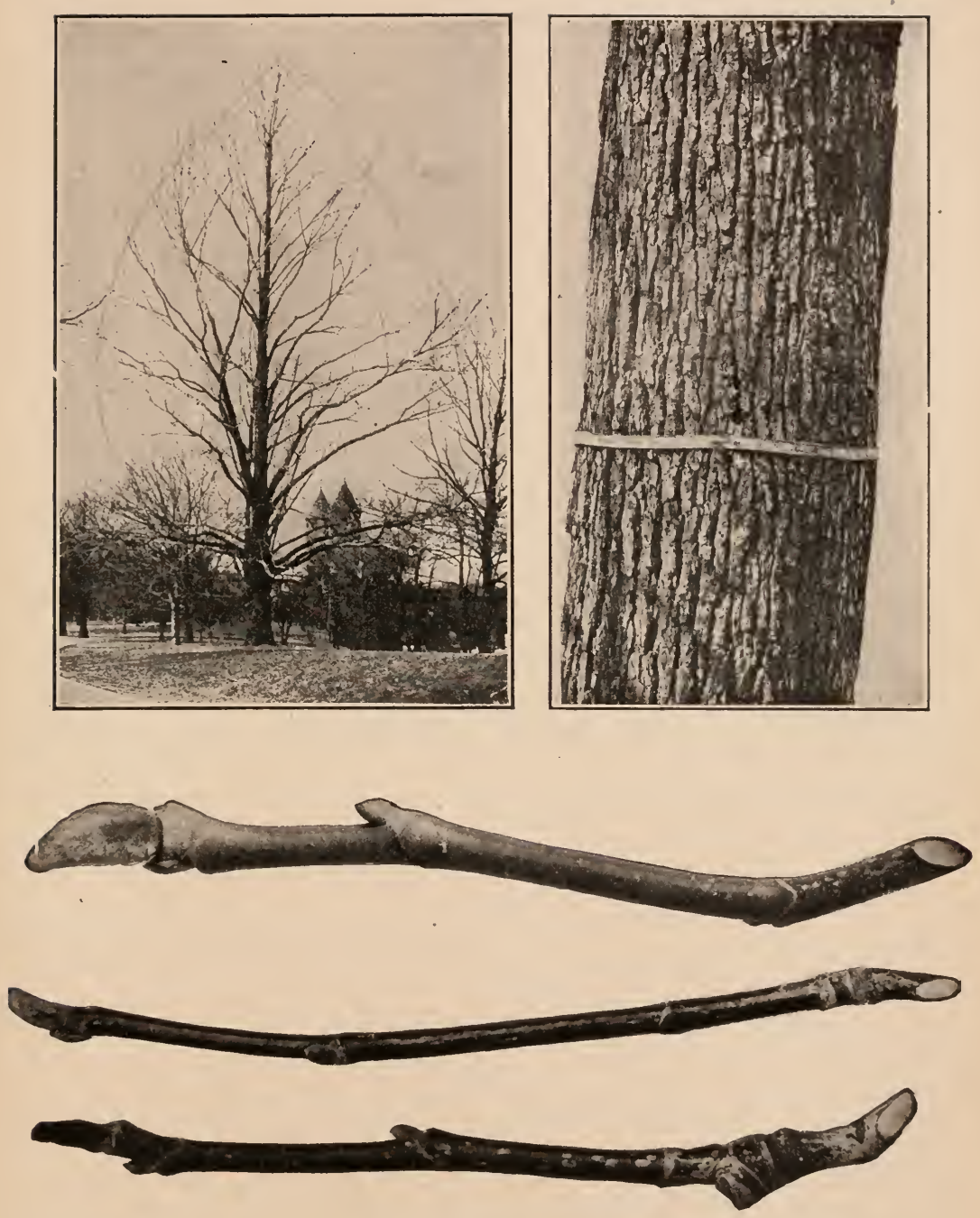

Cucumber Tree 


\section{UMBRELLA TREE Elkwood.}

Magnolia tripetala L.

M. Umbrella Lam.

HАBIT-A small tree with a maximum height of about $40 \mathrm{ft}$. and a trunk diameter of $1 \frac{1 / 2}{2}$ feet, in New England generally much smaller; trunk erect or inclined with wide-spreading branches which generally bend up at their tips forming a wide-spreading irregular open head; at times with several stems springing from near the base of the trunk, forming a bushy growth around the main stem.

BARK-Light gray, smooth, marked with small excrescences, frequently wrinkled and lumpy at the scars of branches.

TWIGS-Stout, reddish to greenish-brown, shining, swollen at the base of each year's growth, aromatic. LENTICELS-conspicuous, scattered pale dots. PITH-white, with minute pink dots.

LEAF-SCARS-Alternate, more than 2-ranked, large, conspicuous, oval, slightly raised, mainly clustered at swellings along the twig. STIPULE-SCARS-distinct, arising from the side of leaf-scar and encircling twig. BUNDLE-SCARS-numerous, irregularly scattered, often slightly raised.

BLDS-Lateral buds at best small, conical, divergent, frequently undeveloped or showing as mere bulges of the bark; terminal buds large up to $5 \mathrm{~cm}$. long, conical, with curved pointed apex, purple, with a bloom, with minute pale dots, smooth with patch of rusty hairs at base of leaf ridge. BUD-SCALES-valvate and adhering in pairs corresponding to stipules, each pair enclosing in succession an erect folded downy leaf, the stalk of which is united with the next inner pair of scales; the leaf connected with the outer pair of scales falls off before maturing, leaving a rudimentary scar on the bud with a decurrent ridge corresponding to its leaf-stalk.

FRLIT-Ovate to oblong cone, $6-10 \mathrm{~cm}$. long, made up of numerous follicles which split open in the fall and let out the red flattish seeds, which are about $1 \mathrm{~cm}$. in diameter.

COMPIRISONS-For comparisons with the Tulip Tree see this species. The Umbrella Tree differs from the Cucumber Tree, the Large-leaved Magnolia and the Chinese Magnolia by its smooth buds and from the Sweet Bay by the size and color of its twigs and buds.

DISTRIBLTION-Not native to New England but extensively cultivated as an ornamental tree. It grows wild in the Appalachian mountain region from the valley of the Susquehanna river, Pennsylvania to southern Alabama.

wOOD-Light, soft, close-grained, not strong, light brown, with creamy white sapwood of 35-40 layers of annual growth. 

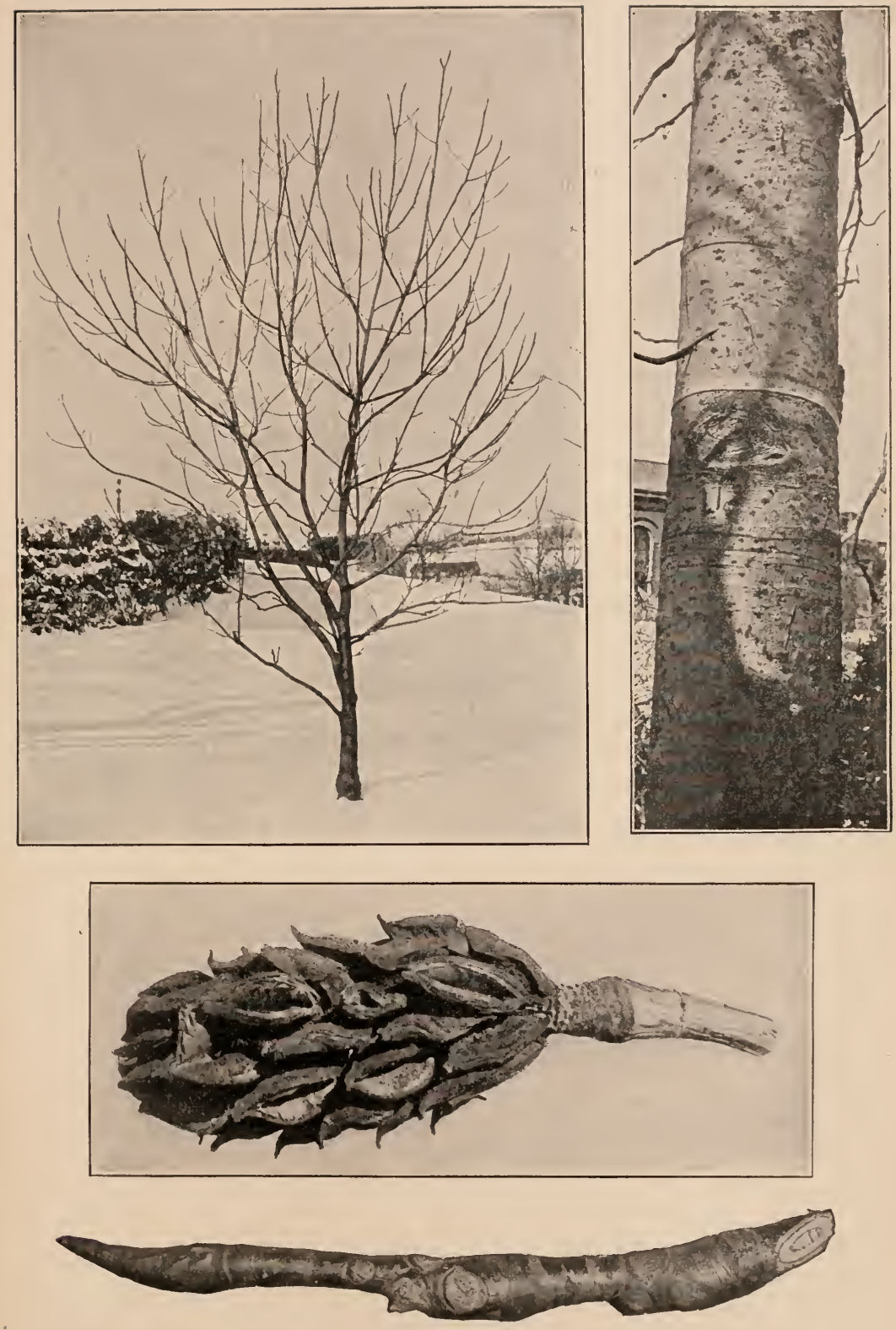

Umbrella Tree 


\section{TULIP TREE Whitewood, Yellow Poplar. Liriodendron Tulipifera L.}

HABIT-A good sized tree 50-70 ft. in height with a trunk diameter of 2-3 ft., in the Ohio basin reaching an exceptional height of nearly $200 \mathrm{ft}$; trunk tall, straight, continuous into the crown and giving off comparatively short, horizontal, declined or slightly ascending branches with upcurved tips, forming in young trees a pyramidal and in older trees an oblong head. Light yellow fruiting cones or at least their axes conspicuous at ends of twigs.

HIRK-Somewhat resembling bark of White Ash but generally lighter, with ridges longer and furrows shallower and more rounded and less inclined to form diamond-shaped patches; inner bark bitter; young bark ashy-gray and smooth, becoming dark with light colored seams.

TWIGS-Slender to somewhat stout, reddish-brown, smooth and shining with more or less evident bloom, with an agreeable aromatic smell when broken but with an intensely bitter taste, not mucilaginous; on vigorous shoots often branching the first season. LENTICELS-conspicuous pale dots. PITH-white with rather inconspicuous transverse woody partitions through the ground-mass.

LEAF-SCIRS-Alternate, more than 2-ranked, large, conspicuous, elevated, circular or slightly flattened at the top. STIPULE-SCARSconspicuous, arising from top of leaf-scar, encircling twig. BUNDLESCARS-small, numerous, scattered like perforations in a sieve.

BLDS-Dark reddish-brown, covered with a bloom, white-dotted, blunt, flattish; lateral buds small, on vigorous twigs superposed accessory buds sometimes present which may be stalked or develop into branches the first season; terminal buds large 5-20 mm. long, oblong, blunt. BUD-SCALES-spoon-shaped, smooth, valvate in pairs corresponding to stipules, each pair enclosing in succession a long-stalked, smooth, reflexed and folded leaf with its 2 scale-like stipules; leafstalk attached only at its base, hence scar of rudimentary leaf when present located at base of bud.

FRIIT-A light brown cone made up of winged seed-like portions, 20-40 $\mathrm{mm}$. long which remain aggregated together into the winter but which are gradually dropped leaving the persistent terminal axis.

COMPARISONS-The Magnolias to which the Tulip Tree is botanically related have likewise aromatic twigs with circular stipule-scars. Their leaf-scars, however, are not circular; their buds are pointed or hairy and the scar of the rudimentary leaf is considerably above base of bud. The light brown fruiting cones from which the winged seedlike bodies have partially fallen are generally to be found on the Tulip Tree and are distinctive for this species.

DISTRIBUTION-Prefers a rich, loamy, moist soil. Is sometimes planted as an ornamental tree. From New England south to the Gulf states; west to Wisconsin; occasional in the eastern sections of Missouri and Arkansas.

IN NEW ENGLAND-Vermont-valley of the Hoosac River in the southwestern corner of the state; Massachusetts-frequent in the Connecticut river valley and westward; reported as far east as Douglas, southeastern corner of Worcester county; Connecticut-occasional, local or frequent; Rhode Island-frequent.

WOOD-Light, soft, brittle not strong, easily worked, light yellow or brown, with thin creamy white sapwood; largely manufactured into lumber generally under the name of "Whitewood"; used in construction, the interior finish of houses, boat building and for shingles, brooms and woodenware. The intensely acrid bitter inner bark, especially of the root, is used domestically as a tonic and stimulant and hydrochlorate of tulipiferine, an alkaloid, separated from the bark, possesses the property of stimulating the heart. 

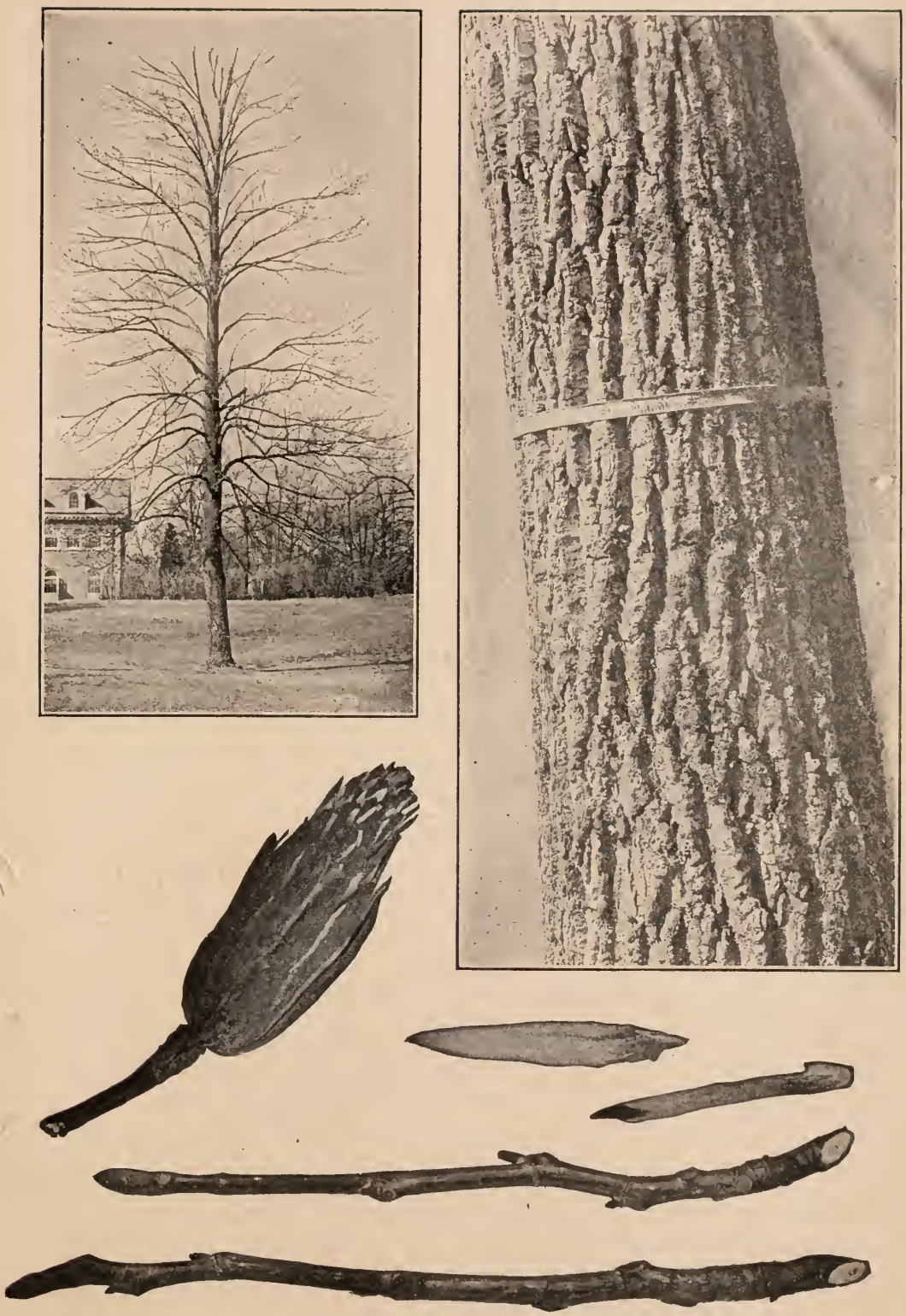

Tulip Tree 


\title{
SASSAFRAS
}

\author{
Sassafras variifolium (Salisb.) Kuntze.
}

s. officinale Nees \& Eberm.; S. Sassafras Karst.

HIIIT-A small tree at times reaching $40-50 \mathrm{ft}$ in height, with a trunk diameter of $2-4 \mathrm{ft}$; at the north smaller and often shrubby; in the southern states reaching a height of $100 \mathrm{ft}$.; branches numerous, stout, more or less contorted, often distinctly in yearly whorls, horizontal or forming a broad angle with the trunk, subdividing to produce a dense bushy spray and forming a flat-topped or slightly rounded oblong head (upper photograph). Limbs brittle and frequently lost through ice storms or other injuries, giving the tree a battered appearance as shown in lower photograph. The tree sprouts abundantly from the roots, often surrounding itself with a thicket of saplings (see those at right in lower picture).

BARI-Redaish brown, deeply furrowed even in comparatively young trees into broad flat ridges with narrow horizontal cracks running part way around the trunk and dividing the ridges into short blocks, which are oblong or in the form of erect or inverted Y's and V's.

TWIGS-Slender to stout, bright yellowish-green, often reddish where exposed to light, smooth and shining or somewhat downy; internodes very unequal; rapidly grown shoots freely branching the first season, the branches exceeding the main axis; twigs spicy-aromatic to both smell and taste, mucilaginous if chewed. LENTICELS-scattered, very inconspicuous.

LEIF-SCIRS-Alternate, more than 2-ranked, small, raised, semielliptical, with elevated margins. STIPULE-SCARS-absent. BUNDLESCAPS-single, forming horizontal line.

BLDS-Green, more or less tinged with red toward tip; lateral buds small, divergent; terminal buds large, 5-10 $\mathrm{mm}$. long, ovate, pointed; flower buds terminal. BUD-SCALES-with thickened veins; generally 3 narrower, thicker, shorter scales surrounding terminal bud.

FRII'T-Generally scanty, a blue drupe falling early. The Sassafras is generally dioecious.

COMPIRISONS-Its bright green aromatic mucilaginous twigs which form branches the first season surpassing the main axis, its single bundle-scar and the transverse cracking of the ridges of the bark render the Sassafras one of the most interesting of our native trees in winter. It is scarcely to be confused with any other form.

DIS'TRIBITION-In various soils and situations; sandy or rich woods, along the borders of peaty swamps, thickets and fence rows. Provinces of Quebec and Ontario; south to Florida; west to Michigan, Iowa, Kansas, and Texas.

IN NEW ENGLAND-Maine-this tree grows not beyond Black Point (Scarboro, Cumberland county) eastward; (Josselyn's New England Rarities, 1672); not reported again by botanists for more than two hundred years; rediscovered at Wells in 1895 and North Berwick in 1896; New Hampshire-lower Merrimac valley, eastward to the coast and along the Connecticut valley to Bellows Falls; Vermont-occasional south of the center; Pownal; Hartland and Brattleboro; Vernon; Massachusetts-common especially in the eastern sections; Connecticut and Rhode Island-common.

WOOD-Soft, weak, brittle, coarse-grained, very durable in the soil, aromatic, dull orange-brown, with thin light yellow sapwood of 7-8 layers of annual growth; largely used for fence-posts and rails and in the construction of light boats, ox-yokes, and in cooperage. The roots and especially their bark are a mild aromatic stimulant, and oil of sassafras used to perfume soaps, flavor candy, etc., and as an ingredient in liniment is distilled from them. 

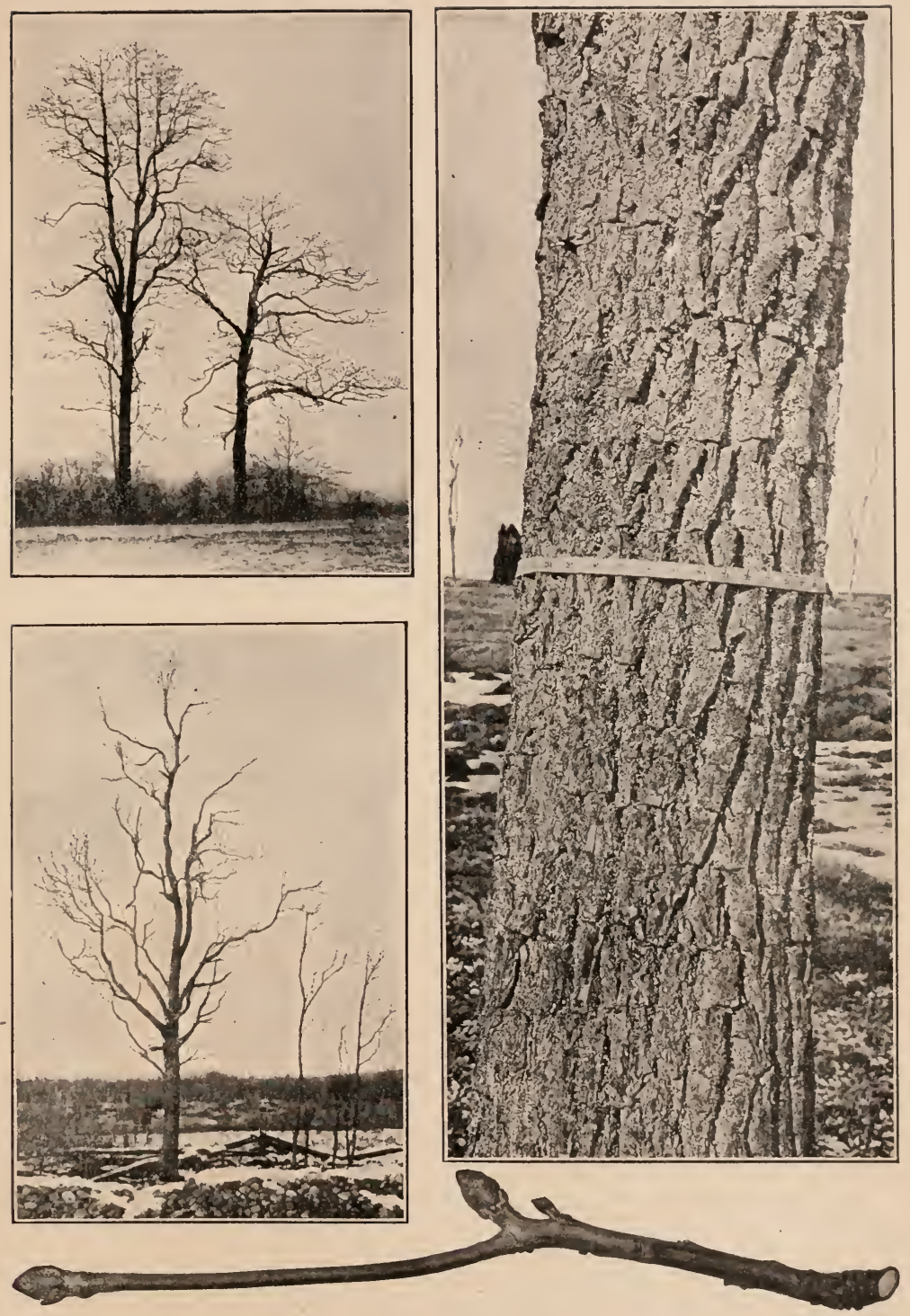

SASSAFRAS 


\title{
WITCH HAZEL
}

\author{
Hamamelis virginiana $\mathrm{L}$.
}

HIBIT-A large shrub or small tree occasionally 25-30 ft. in height with a trunk diameter of 10-14 inches, with short trunk, spreading crooked branches with conspicuous persistent fruiting capsules, forming a broad open head.

BIRK-Light brown, more or less mottled, generally smooth or minutely scaly.

TwIGS-Rather slender, light orange brown, smooth and shining, or downy especially toward apex, more or less zigzag. LENTICELS-few, scattered, whitish dots.

LEAN-SC.IRS-Alternate, 2-ranked, small, inversely triangular. STIPULE-SCARS-distinct, narrow, oblong, somewhat separate from leafscar. BUNDLE-SCARS-Whitish in conspicuous contrast to dark brown surface of leaf-scar, generally 3 and separate or these may be compounded or more or less confluent.

BUDS-Stalked, flattish, slightly curved, densely downy with short, fine light to dark olive brown hairs; terminal bud larger than laterals, 5-12 mm. long. BUD-SCALES-an outer pair of relatively thin scales corresponding to stipules and often represented by only a scar accompanying the outermost thick downy laterally folded undeveloped leaf, which with smaller leaves within serves the function of bud scales. The bud is therefore essentially naked.

FRUI'T-Produced in abundance, a downy 2-chambered capsule about $15 \mathrm{~mm}$. long, surrounded by the persistent calyx, discharging in autumn 4 shining, brown, oblong seeds and remaining widely gaping on the tree throughout winter (see lower part of twig picture). The plant produces flowers in the autumn at the same time with the ripening of the fruit, and the remains of the flowers, showing the 4 downy sepals with their enclosing bracts, are to be found in clusters on the recent twigs (upper part of twig picture).

COMPARISONS-In habitat and in its stalked buds the Witch Hazel resembles the Alders. The buds of the latter, however, are essentially smooth or at most fine-downy, not hairy and their fruit is a woody cone not a capsule.

DISTRIBLTION-In moist or wet often rocky places. Nova Scotia to Ontario and Minnesota; south to Florida and Texas; west to eastern Nebraska.

\section{IN NEW ENGLAND-Common throughout.}

WOOD-Heavy, hard, very close-grained, light brown tinged with red, with thick nearly white sapwood of 30-40 layers of annual growth. The bark is slightly astringent and though not known to have essential properties is largely used in the form of fluid extracts and decoctions as a popular application for sprains and bruises, Pond's Extract being made by distilling the bark in dilute alcohol. Probably equally efficacious is the use of the twigs as divining rods to locate water and minerals. 

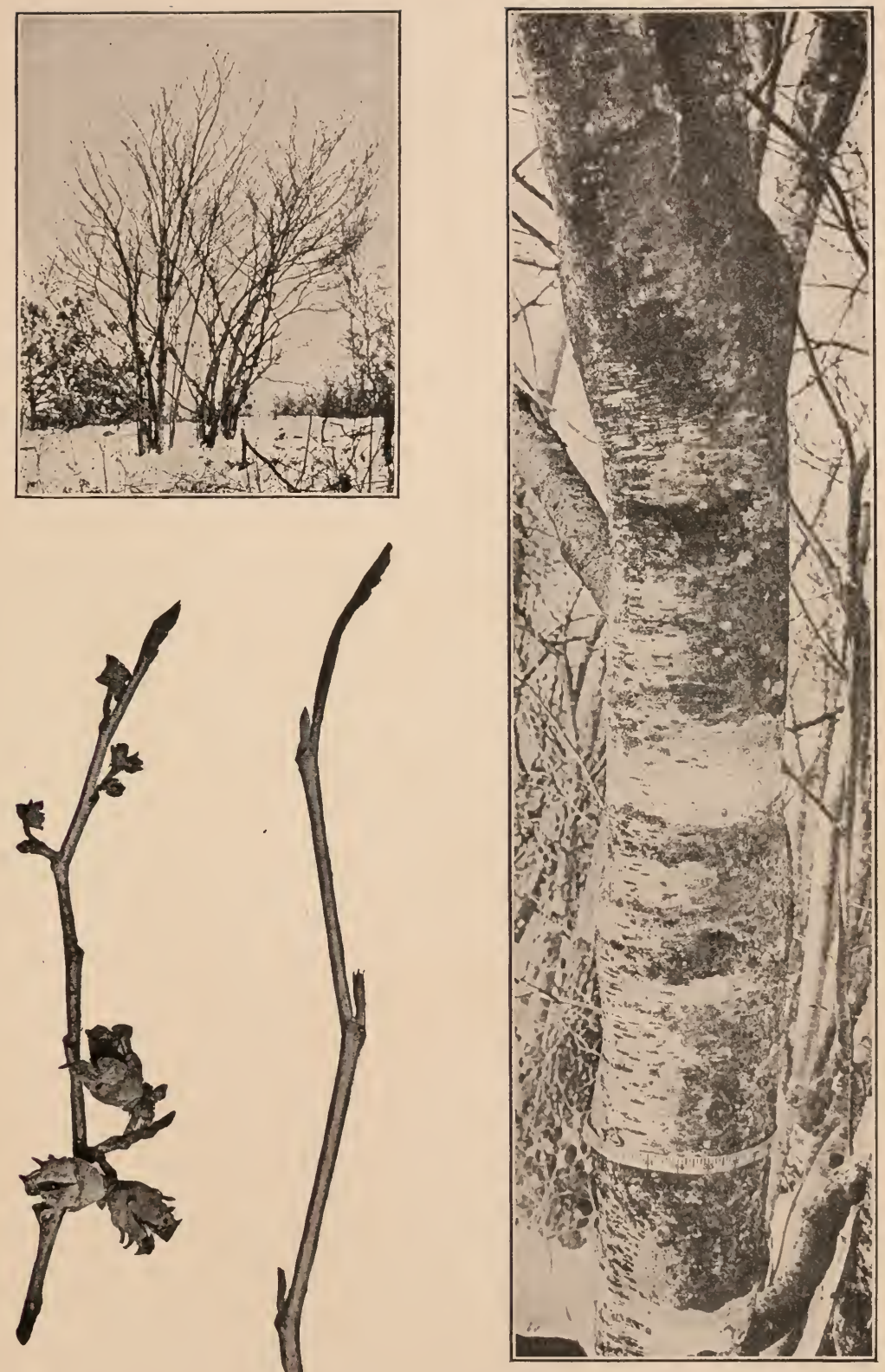

Witch HAzEL 


\title{
SWEET GUM
}

\section{Bilsted, Red Gum, Alligator-wood, Liquidambar.}

\author{
Liquidambar Styraciflua L.
}

HABIT-A tree 40-60 ft. in height with a trunk diameter up to $2 \mathrm{ft}$., reaching $150 \mathrm{ft}$. in height and a trunk diameter of $3-5 \mathrm{ft}$. in the Mississippi and Ohio valleys; branches slender, regular and spreading, forming a very symmetrical tree, when young (right hand tree in plate) narrowly oblong-conical, with age (left hand tree in plate) becoming broader and rounded ovate, generally showing persistent stalked spherical fruits.

B.IRK-Grayish brown, deeply furrowed into broad more or less flaky ridges.

TWIGS-Mediumly stout to slender, light to dark reddish to yellowishbrown, rounded or often somewhat angled, smooth and shiny or seldom slightly hairy; generally developing the second season 3-4 parallel corky ridges on the upper side of horizontal branchlets and on all sides of vertical branchlets (lower twig figure). LENTICELS-scattered, dark. PITH-wide, more or less 5-pointed, star-shaped.

LEAF-SCARS-Alt ernate, more than 2-ranked, broadly crescent-shaped to inversely triangthar, raised. STIPULE-SCARS-absent. BUNDLESCARS-3, each a circular white ring with dark center conspicuous against the dark surface of leaf-scar.

HUDS-Ovate to conical, pointed, shiny, reddish-brown, more or less fragrant when crushed, lateral buds divergent, on rapidly grown shoots sometimes stalked or developing into branches the first season and then frequently with a pair of collateral accessory buds at a node; terminal buds exceeding the laterals, 5-10 $\mathrm{mm}$. long. BUD-SCALESovate, fine-downy on the margins, rounded on the back, generally with a short abrupt point at the apex.

FRUI'T-A long-stalked spherical spiny aggregate of ovaries, $2-4 \mathrm{~cm}$. in diameter hanging on the tree through the winter; the mature seeds falling in autumn leaving many minute abortive seeds in the ovaries.

COMPIRISONS-The corky ridges on the twigs of the Sweet Gum are striking distinctive characters which are found also in the Cork Elm and the Bur Oak. The Elm, however, has 2-ranked leaf-scars and the buds of the Oak are bunched at the twig ends; neither are shiny reddish-brown between the ridges. The corky ridges may be but sparingly developed upon some trees and may even fail entirely. The spiny fruits which persist through winter form the best single distinctive character.

DISTRIBUTION-Low, wet soils, swamps, moist woods, somewhat cultivated as an ornamental tree. Connecticut; south to Florida; west to Missouri and Texas.

IN NEW ENGLAND-Growing native only in Connecticut, south Norwalk and occasional or frequent westward near the shores of the Sound.

WOOD-Heavy, hard, straight, close-grained, not strong. bright brown tinged with red, with thin almost white sapwood of 60-70 layers of annual growth, inclined to warp and shrink badly; used for the outside finish of houses, in cabinet making. for street pavement, wooden dishes and fruit boxes. The resinous exudation from the stems (liquidambar), which is more marked in trees grown in the south, is used in the preparation of chewing gum. 

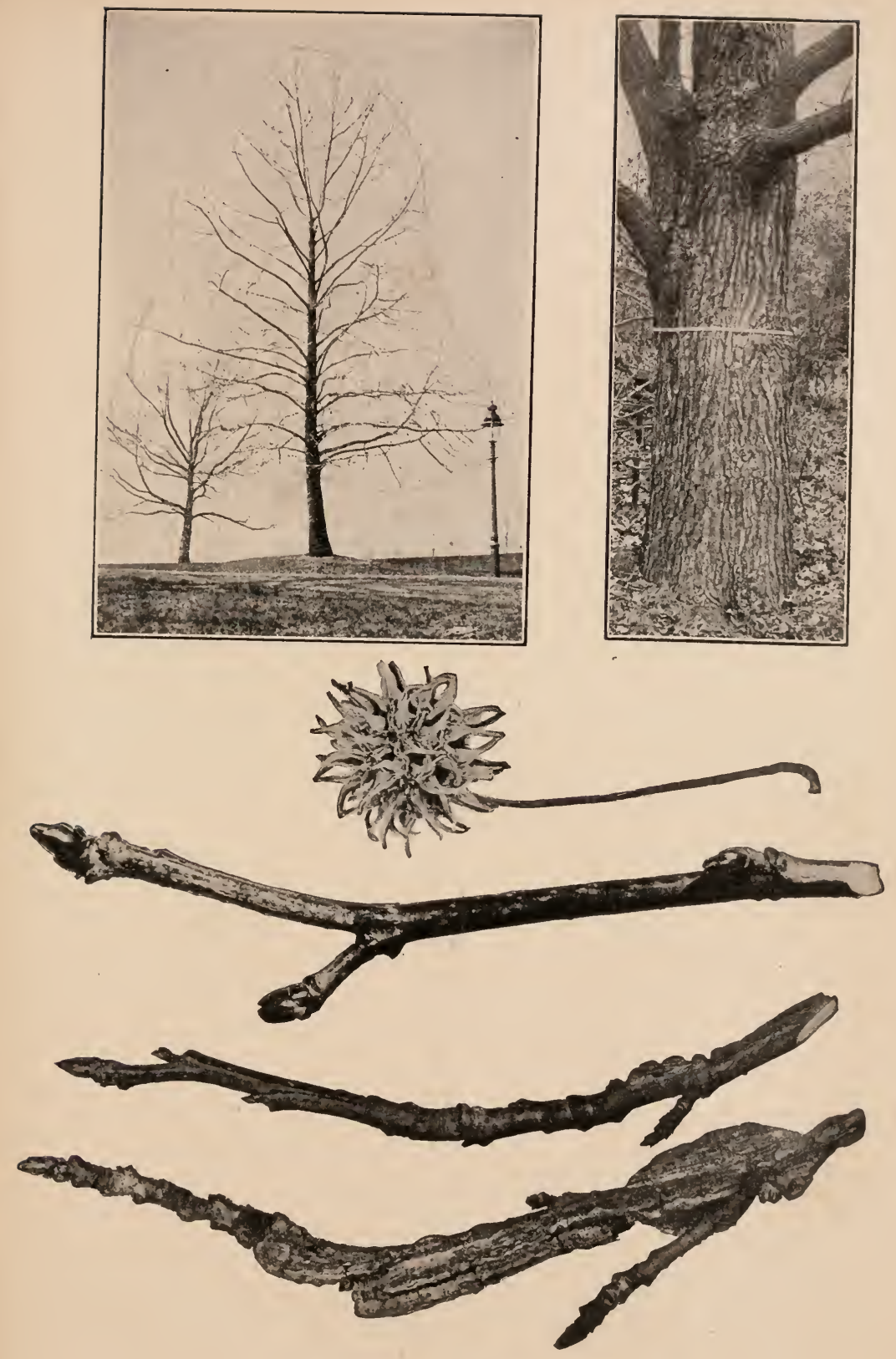

Sweet Gun 


\section{SYCAMORE \\ Buttonwood, Buttonball, Plane Tree. Platanus occidentalis $\mathrm{L}$.}

HA BIT-A large tree 50-100 ft. In height with a trunk diameter of 3-8 ft., in the bottom lands of the lower Ohio and Mississippi valleys reaching occasionally a height of $170 \mathrm{ft}$. with a trunk diameter of 10-11 ft., the largest tree of the New England forest; with an erect or often declined trunk very gradually tapering and continuous into the top (see habit picture) or branched near the base into two or three secondary trunks (see bark picture) forming an open, irregular or rounded wide-spreading head; branchlets scraggly, often in tufts with dead twigs not infrequent. (See low cross-branch in bark picture).

BARI-Dark brown, at the base of older trunks shallowly furrowed into broad ridges which are broken into small oblong thick plate-like scales; higher up on the trunk peeling off in large thin plates, exposing: conspicuous areas of the whitish, yellowish or greenish inner bark.

TWIGS-Slender, rather shiny, smooth, yellowish-brown, generally zigzag. swollen at the nodes, rounded or with decurrent ridges from the bundle-scars; medullary rays conspicuous in sectioned twig. LENTICELS-pale, minute. PITH-thick.

LEAF-SCARS-Alternate, generally 2-ránked, sometimes appearing more ranked; narrow, projecting, nearly surrounding the bud, more or less swollen at the bundle-scars. STIPULE-SCARS-encircling twig. BUNDLE-SCARS-conspicuous, dark, generally raised, 5-10 or more in single curved line.

BUDS-Terminal bud absent; lateral buds generally large, conical, 5-10 mm. long, occasionally shorter, blunt-pointed, smooth, dark reddishbrown, divergent. BUD-SCALES-a single scale visible, forming a cap to the bud, second scale green, gummy, innermost scale covered with long rusty hairs.

FRITT-Spherical heads $2.5-4 \mathrm{~cm}$. in diameter, on long stalks mostly solitary or seldom in 2's, composed of small hairy 1-seeded nutlets. The heads hang on the tree till spring.

COMPARISONS-The native Sycamore [Platanus occidentalis] is closely related to the Oriental Sycamore [Platanus orientalis L.] which is extensively planted as an ornamental tree. It bears its fruiting heads singly or rarely in 2's, while the Oriental Sycamore has its fruiting heads in clusters of 2-4. The whitewashed appearance of the upper limbs, the single cap-like scale of its bud, which is nearly surrounded by the leaf-scar, present characters which prevent the sycamores from being confused with any other trees.

DISTRIRYTION-Near streams, river bottoms, and low, damp woods; sometimes in dryer places. Ontario; south to Florida; west to Minnesota, Nebraska, Kansas and Texas.

IN NEW ENGLAND-Maine-apparéntly restricted to York county; New Hampshire-Merrimac valley towards the coast; along the Connecticut as far as Walpole; Vermont-scattering along the river shores, quite abundant along the Hoosac in Pownal; Massachusetts-occasional; Connecticut and Rhode Island-rather common.

WOOD-Reddish-brown with light somewhat yellowish sapwood, heavy, tough, hard, not very strong. coarse-grained, diffeult to split and work; is used in manufacture of tobacco boxes, crates, butchers' blocks. ox-yokes and when cut quartering is used for inside finishing of buildings and for furnture. 

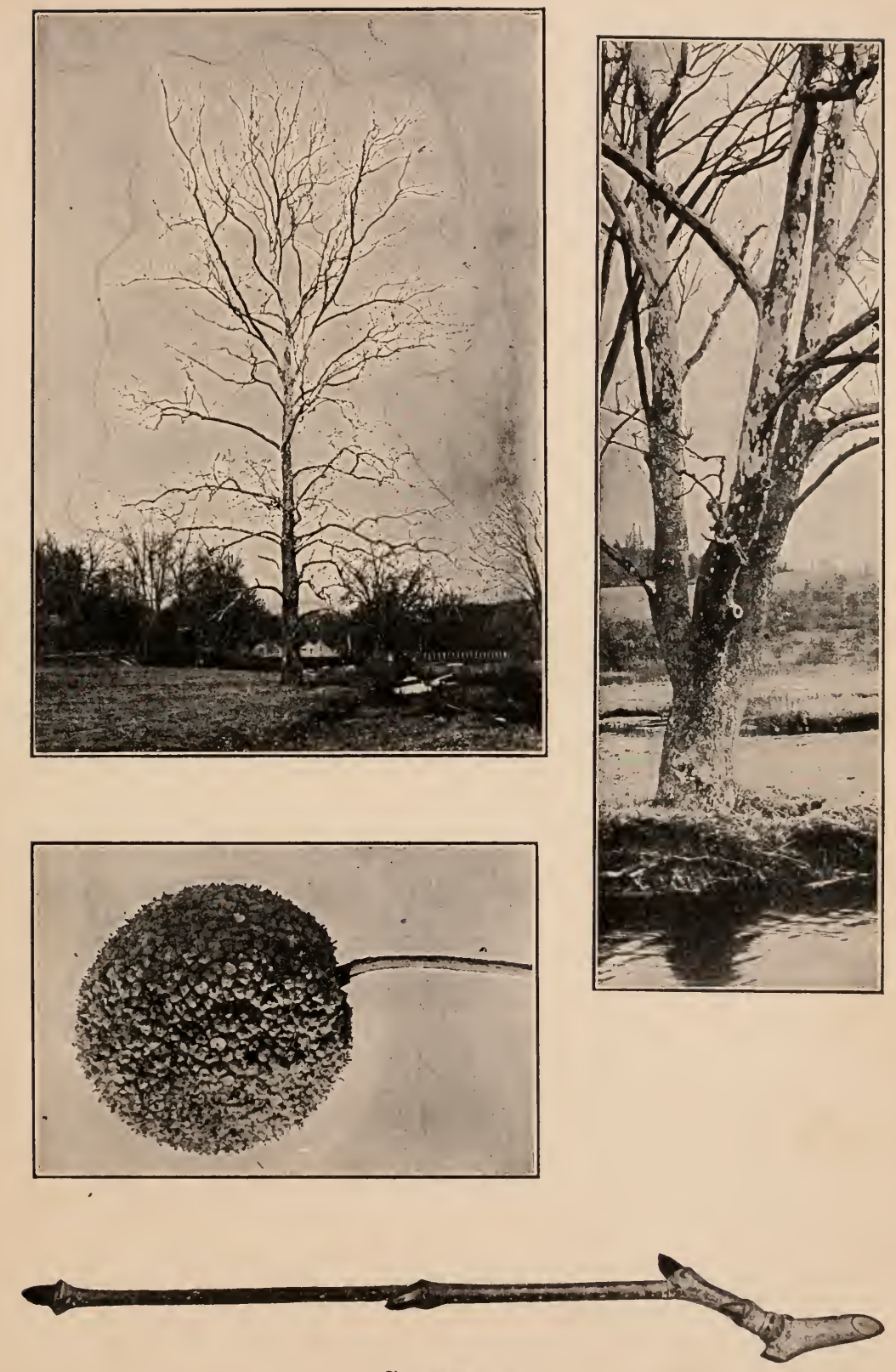

Sycamore 


\section{PEAR}

Pyrus communis L.

HABIT-A tree sometimes $75 \mathrm{ft}$. in height with a trunk diameter of $2 \mathrm{ft}$. or more, dimensions generally smaller; trunk erect, more or less continuous into the head, with ascending branches and numerous stubby branchlets forming an upright pyramidal head.

BARK-Grayish-brown, on young trunks and branches smooth, becoming with age longitudinally fissured into flat-topped ridges which are further broken by transverse fissures into oblong scales.

TWIGS-Stout, smooth or but slightly downy, yellowish-green or sometimes with tinge of brown, without characteristic taste; short sharp-pointed branches not infrequently present; stubby, branched slow-growing fruit spurs abundant, with prominent fruit-scars. LENTICELS-scattered, pale, more or less conspicuous.

LEAF-SCARS-Alternate, more than 2-ranked, crescent-shaped, raised, narrow, generally several times as broad as high. STIPULESCARS-absent. BUNDLE-SCARS-3, often indistinct.

BUDS-Conical, sharp-pointed, smooth or but slightly hairy; terminal bud about $8 \mathrm{~mm}$. or less in length, lateral buds smaller, generally divergent and not flattened or at times on vigorous shoots both flattened and appressed. BUD-SCALES-ovate, generally with conspicuous grayish skin on surface, generally 4 or more visible scales to lateral buds, more to terminal bud.

FRUTT-A large fleshy pome.

Comparisons-The Pear Tree may be distinguished from the Apple by its erect habit of growth. The twig characters vary somewhat among the different varieties but in general the twigs of the Pear differ from those of the Apple in being smooth, generally of a yellowish-green color, devoid of a licorice-like taste and in having pointed, mostly divergent buds, the scales of which are more or less covered with a grayish skin.

DISTRIBUTION-A native of the old World cultivated in this country for its fruit and escaped from cultivation in waste piaces.

woOD-Hard, close-grained, reddish-brown; used for drawing instruments, for tools, in imitation of ebony and by the wood engraver: 


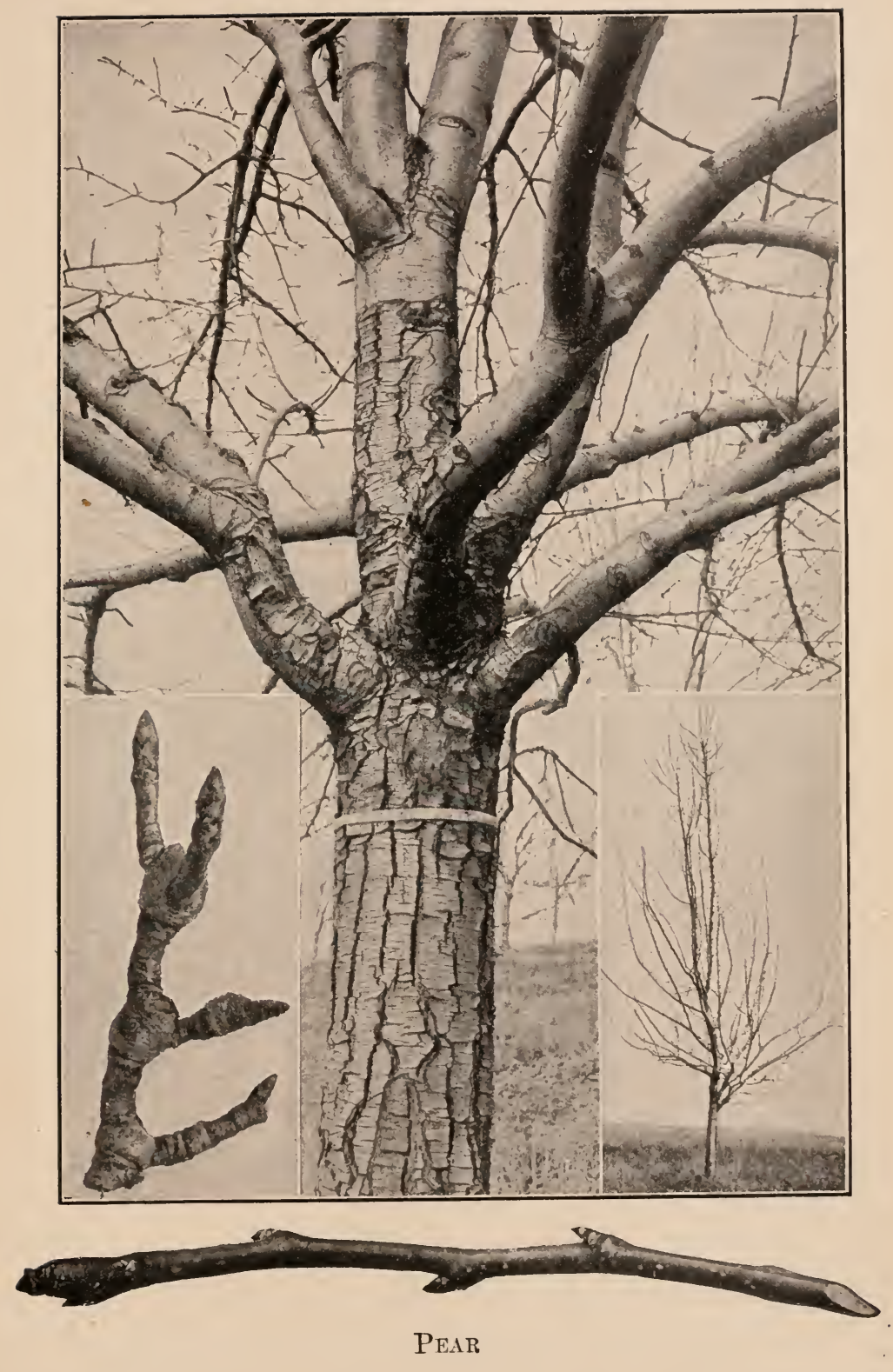




\section{APPLE \\ Pyrus Malus L. Malus Malus (L.) Britton.}

HABIT-A tree reaching 30-50 ft. in height and a trunk diameter of 2-3 ft.; trunk short with wide-spreading limbs forming a broad roundtopped head of familiar and very characteristic habit.

BARI-Grayish-brown, scaling off in thin, brittle, flaky plates.

TWIGS-Stout, pale-woolly, at least toward the apex, mostly, reddishbrown, rarely yellowish, shining where free from wool, with characteristically slightly bitter and licorice-like taste when chewed; short, stubby, contorted fruit-spurs abundantly present. LENTICELS-scattered, pale, more or less conspicuous. PITH-whitish.

LEAF-SCARS-Alternate, more than 2-ranked, narrow, crescentshaped, raised. STIPULE-SCARS-absent. BUNDLE-SCARS-3, often indistinct.

BUDS-Ovate, blunt, bright, reddish-brown, more or less densely covered with pale wool; terminal bud $8 \mathrm{~mm}$. or less long, lateral buds smaller, often triangular, flattened and appressed against twig. BUDSCALES-ovate, about 3 scales visible to lateral bud, more to terminal bud.

FRUIT-A large fleshy pome.

COMPARISONS-The Apple Tree resembles the Pear but is readily distinguished from this species by its low spreading habit of growth. The numerous varieties differ somewhat in the twig characters, some with twigs and buds nearly smooth, others with yellowish rather than reddish-brown twigs. The licorice-like taste of the twigs seems to be a constant character for the Apple. Among its distinguishing characters which in the main hold good, may be mentioned the pale wool on the twigs and buds, the flat appressed lateral buds and the reddish-brown color of the twigs.

DISTRIBUTION-A native of the Old World, cultivated in this country for its fruit and frequently escaped from cultivation in waste places when it assumes a bushier habit of growth, with smaller twigs frequently beset with short sharp-pointed thorn-like branches.

WOOD-Hard, tough, close-grained, reddish-brown, used for tool handles, shoemakers' lasts, by the cabinet maker and esteemed as a fuel in open grate fires. 

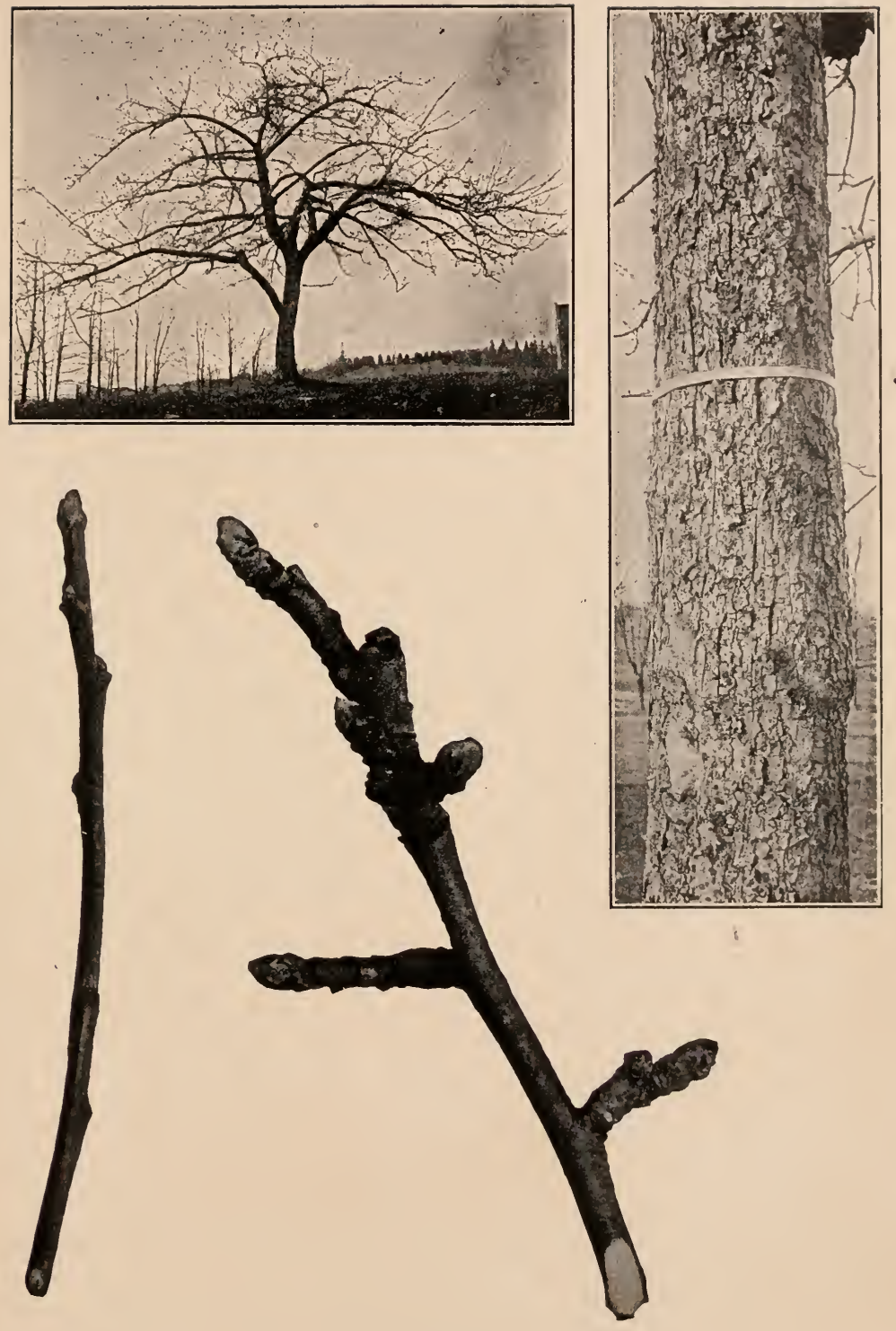

Apple 


\title{
AMERICAN MOUNTAIN ASH Rowan or Service Tree.
}

\author{
Pyrus americana (Marsh.) DC.
}

Sorbus americana Marsh.

HА ВI'T-A shrub or small tree 15-20 ft. high or in northern New England reaching a height of $25-30 \mathrm{ft}$ with a trunk diameter of 12-15 inches, with slender spreading branches forming a rather narrow round-topped head.

BIRK-Grayish-brown, smooth or on older trees somewhat roughish.

TWIGS-Stout, smooth, reddish to grayish-brown. LENTICELS-conspicuous, large, pale, oblong, remotely scattered. PITH-broad, slightly reddish-brown.

LEAF-SCARS-Alternate, more than 2-ranked, large, crescent to broadly $U$ or $\mathrm{V}$-shaped, raised on a projection darker than the twig. STIPULE-SCARS-absent. BUNDLE-SCARS-regularly 5, often raised, arranged in a single curved line.

BUDS-Terminal buds large, about $13 \mathrm{~mm}$. long, ovate to broadly conical, with a curved pointed apex, dark purplish-red, gummy and smooth or with few hairs on the surface, densely woolly within; lateral buds smaller, flattened and appressed. BUD-SCALES-2-3 visible to terminal bud, 1-2 to lateral bud.

FRUIT-Berry-like, bright red, strongly acid, round, about the size of a pea, in flat-topped clusters persistent through the winter.

COMPARISONS-A larger fruited form, the Western Mcuntain Ash [Pyrus sitchensis (Roem.) Piper], is considered by some a distinct species but by others only a variety of the type described. It is more northerly and westerly in its distribution. The European Mountain Ash [Pyrus Aucuparia (L.) Ehrh.] with many horticultural forms is more frequently cultivated than the American species and has escaped from cultivation in some places. It may be distinguished by the white hairy down present especially on the upper half of the terminal bud and by the larger fruits (about $10 \mathrm{~mm}$. broad) arranged in a rather round-topped cluster. The habit, bark, fruit and lower twig photographs are of the European species.

DIS'TRIBUTION-River banks, cool woods, swamps and mountains, Newfoundland to Manitoba; south, in cold swamps and along the mountains to North Carolina; west to Michigan and Minnesota.

IN NEW ENGLAND-Maine-common; New Hampshire-common along the watersheds of the Connecticut and Merrimac rivers and on the slopes of the White Mountains; Vermont-abundant far up the slopes of the Green mountains; Massachusetts-Graylock, Wachusett, Watatic, and other mountainous regions; rare eastward; Connecticutrare or local; swamps and about ponds or sometimes on dry ledges or in rocky woods; Stafford, Durham and Meriden, Granby, Winchester, Norfolk, Canaan, Salisbury, Kent; Rhode Island-occasional in the northern sections.

The variety (Pyrus sitchensis) the Western Mountain Ash, has the following distribution-Mountain slopes, cool woods, along the shores of rivers and ponds, often associated with Pyrus americana, but climbing higher up the mountains. From Labrador and Nova Scotia west to the Rocky mountains, then northward along the mountain ranges to Alaska. In New England, confined to Maine, New Hampshire and Vermont.

WOOD-Close-grained, light, soft and weak, pale brown with lighter colored sapwood of $15-20$ layers of annual growth; of little economic value. The very astringent bark and berries are employed medicinally. 

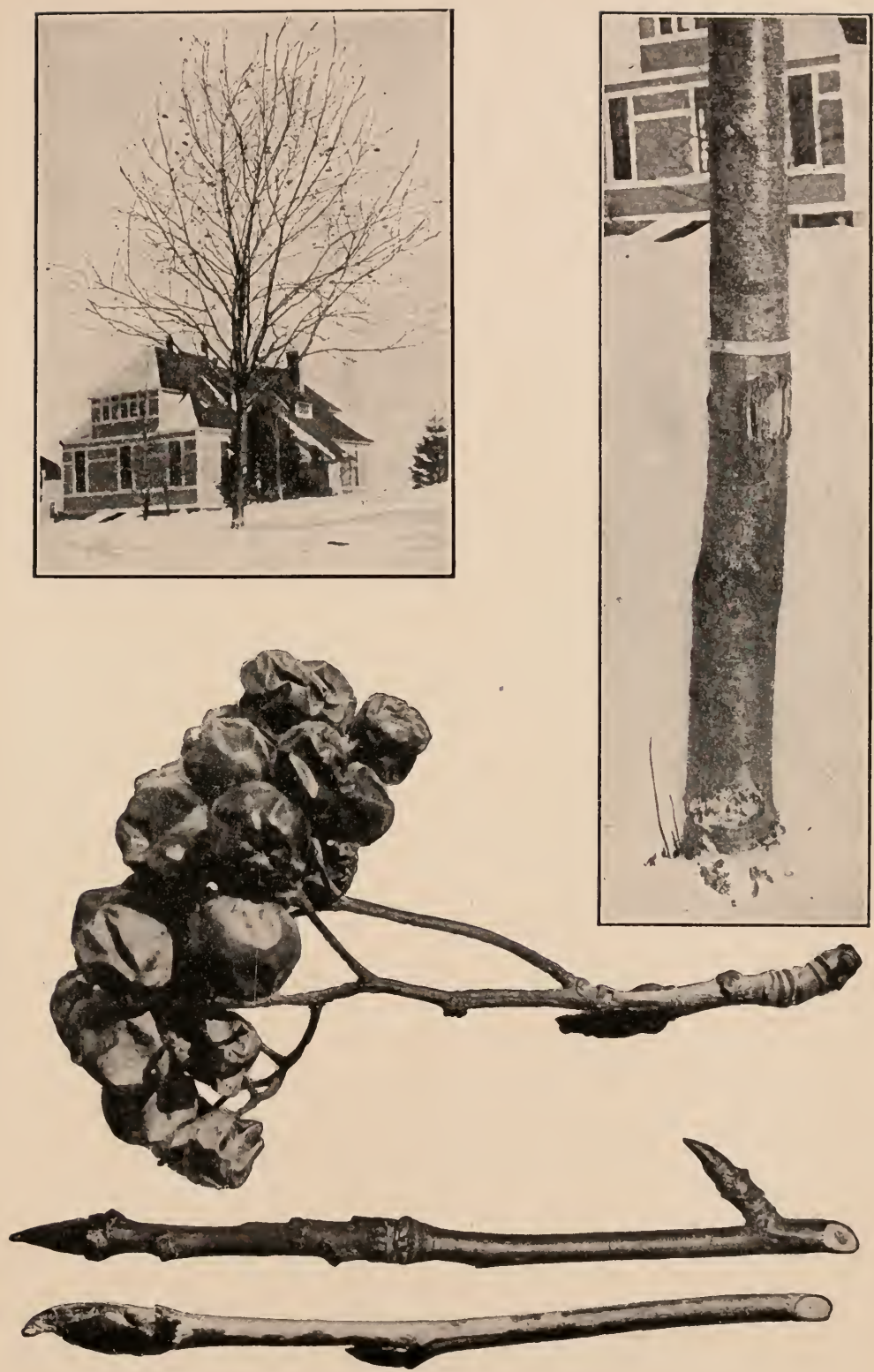

Mountain Ash 


\section{QUINCE}

\section{Cydonia vulgaris Pers.}

Pyrus Cydonia L.

HABIT-A low bushy straggling rounded shrub or small tree rarely exceeding $15 \mathrm{ft}$. in height with crooked distorted branches.

BARK-Dark gray, finely streaked, becoming with age more or less zoughened with large flaky scales.

TWIGS-Slender, dark reddish-brown, often with tinge of green; in protected places and especially toward the tip of the twig generally more or less densely covered with pale wool, bright-shining where imooth; mostly tasteless. LENTICELS-small, numerous, becoming conspicuous brownish dots on older growth. PITH-narrow, greenish.

LEAF-SCAPS-Alternate, more than 2-ranked, small, crescent-shaped to inversely triangular, raised ${ }^{\circ}$ on a somewhat shrivelled projection slightly darker than the twig and containing at its outer edges the roundish, rather inconspicuous stipule-scars at either side of the leafscar. BUNDLE-SCARS-3.

BUDS-Terminal bud absent; lateral buds minute, about $3 \mathrm{~mm}$. or often less in length, ovate, blunt, flattened and appressed against twig; smoothish or somewhat hairy at base, with dense pale-rusty hairs within showing through at apex. BUD-SCALES-not easily distinguished. about 2 visible, reddish-brown to light reddish, breaking away at the tip.

FRUIT-A large, firm, fleshy, downy pome.

COMPIRISONS-The twigs and buds of the Quince resemble somewhat those of the Apple but the twigs are much more slender and the buds show a distinctive tuft of rusty hairs. The bushy habit of growth further will distinguish the Quince from the other cultivated fruit trees.

DISTRIBUTION-A tree native of Europe, cultivated for the fruit and escaped to a slight extent in some localities.

wooD-The wood is of no commercial importance. The fruit is valued for preserving. The raw fruit and mucilaginous seed are used in domestic medicinal practice. 

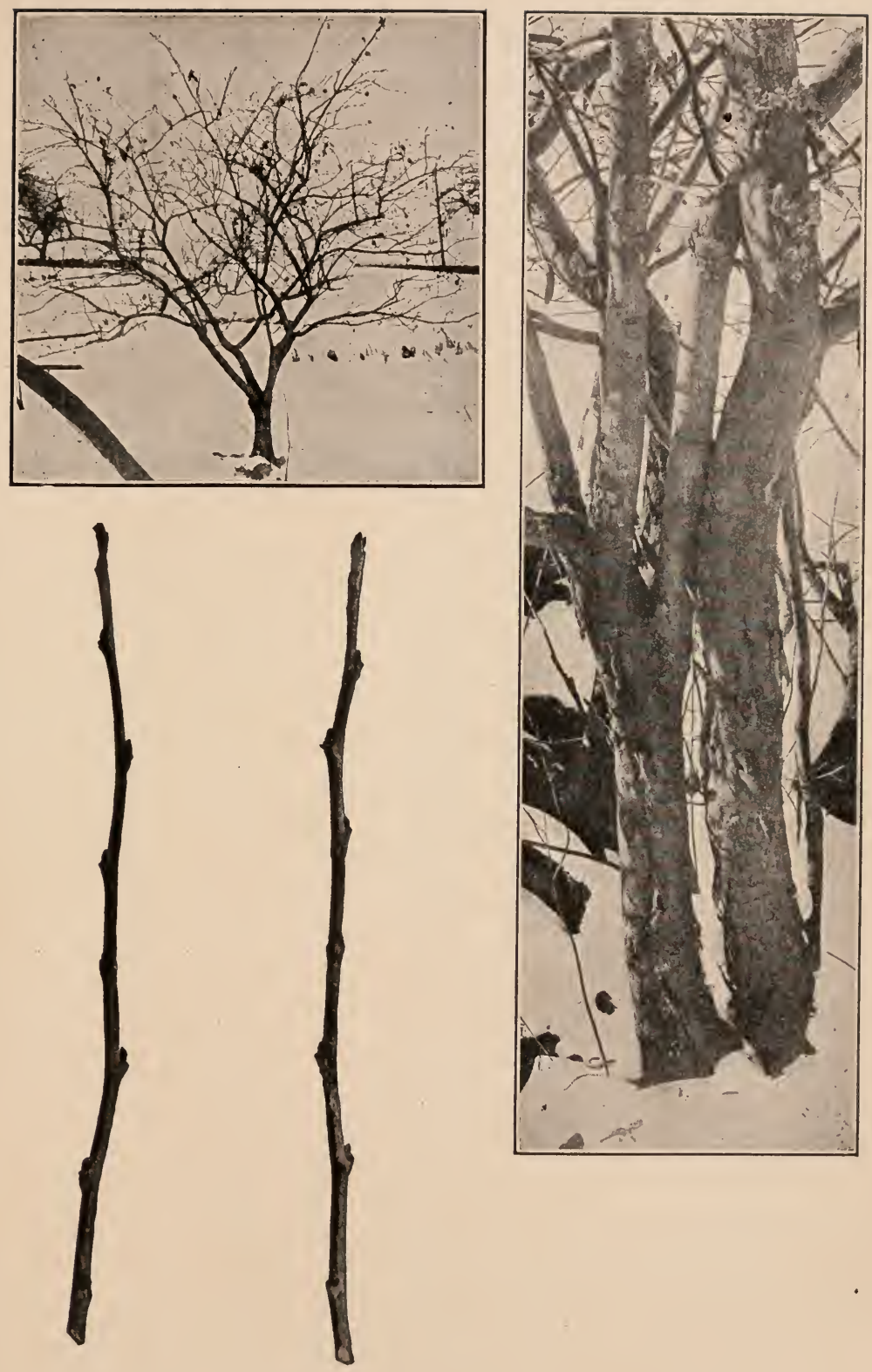

Quince 


\section{SHAD BUSH \\ Service Berry, Shadblow, Juneberry.}

Amelanchier canadensis (L.) Medic.

HABIT-A shrub or small tree 10-25 ft. in height with a trunk diameter of 6-10 inches, sometimes reaching a height of $40 \mathrm{ft}$. with a trunk diameter of $1 \frac{1}{2} \mathrm{ft}$.; of variable habit, at times a shrub with many stems in a clump (see plate, picture at right) or again a symmetrical tree with a single trunk with many small limbs and fine branchlets forming an oblong or rather wide-spreading round-topped head (see plate).

BARK-Essentially smooth, grayish-brown, older trunks with narrow longitudinal fissures separating off shallow flat ridges which are somewhat scaly at base of trunk; younger trunks and branches smooth, often characteristically streaked with darker longitudinal lines (see plate).

TWIGS-Slender, grayish, olive-green to reddish-brown often covered with a gray skin, generally smooth, with slight taste of bitter almonds. LENTICELS - scattered or numerous, pale, minute dots. PITHgreenish with irregular edges.

LEAF-SCARS-Alternate, 2-ranked or at times appearing more than 2-ranked, a raised very narrow flattened V-shaped line swollen at the bundle-scars, often with short somewhat decurrent ridges at outer edges. STIPULE-SCARS-absent. BUNDLE-SCARS-3, rather large.

BUDS-Terminal buds present, long, narrow, 7-12 mm. long and 3-4 times as long as broad, narrowly ovate to conical, sharp-pointed, greenish-yellowish more or less tinged with reddish-purple, smooth or with white silky hairs at apex and edges of scales, mostly appressed; lateral buds on rapidly grown shoots normal, on slowly grown spurs, undeveloped or rudimentary; generally a small lateral bud just below terminal bud. BUD-SCALES-increasing from below upward, the two lowest about $1 / 3$ length of the bud, more or less keeled and 3-nerved, darkmargined and with a single short dark spiny tip, lower scales often 3tipped, edges from slightly downy on outermost scales to densely silkyhairy on inner scales; on terminal buds about 5 scales visible, more or less imperfectly 2-ranked; lateral buds on vigorous shoots often with pair of extra lateral scales basally united giving short-stalked appearance to bud.

FRUI'T-Berry-like, sometimes if infected by a rust fungus remaining dried on the tree through the winter.

COMPARISONS-The long narrow buds of the Shad Bush bear a superficial resemblance to those of the Beech. The Beech buds, however, are divergent, narrower, with $10-20$ scales regularly arranged in four rows and have stipule-scars nearly encircling the twig. The Shad Bush is subject to the attacks of a fungus [Dimerosporium Collinsii] which blackens the leaves and causes a profuse branching at the point of infection. The "witches' brooms" thus formed with the persistentent blackened leaves often enables the tree to be recognized at a distance. It is probable that the Shad Bush, as here described includes a number of forms or distinct species.

DISTRIBUTION-Dry, open woods, hillsides. Newfoundland and Nova Scotia to Lake Superior; south to the Gulf of Mexico; west to Minnesota, Kansas, and Louisiana.

IN NEW ENGLAND-Throughout.

WOOD-Heavy, exceedingly hard, strong, close-grained, dark brown often tinged with red, with thick lighter colored sapwood of 40-50 layers of annual growth; occasionally used for the handles of tools and other small implements; under the name of "Lancewood" it is used in the manufacture of fish rods. 

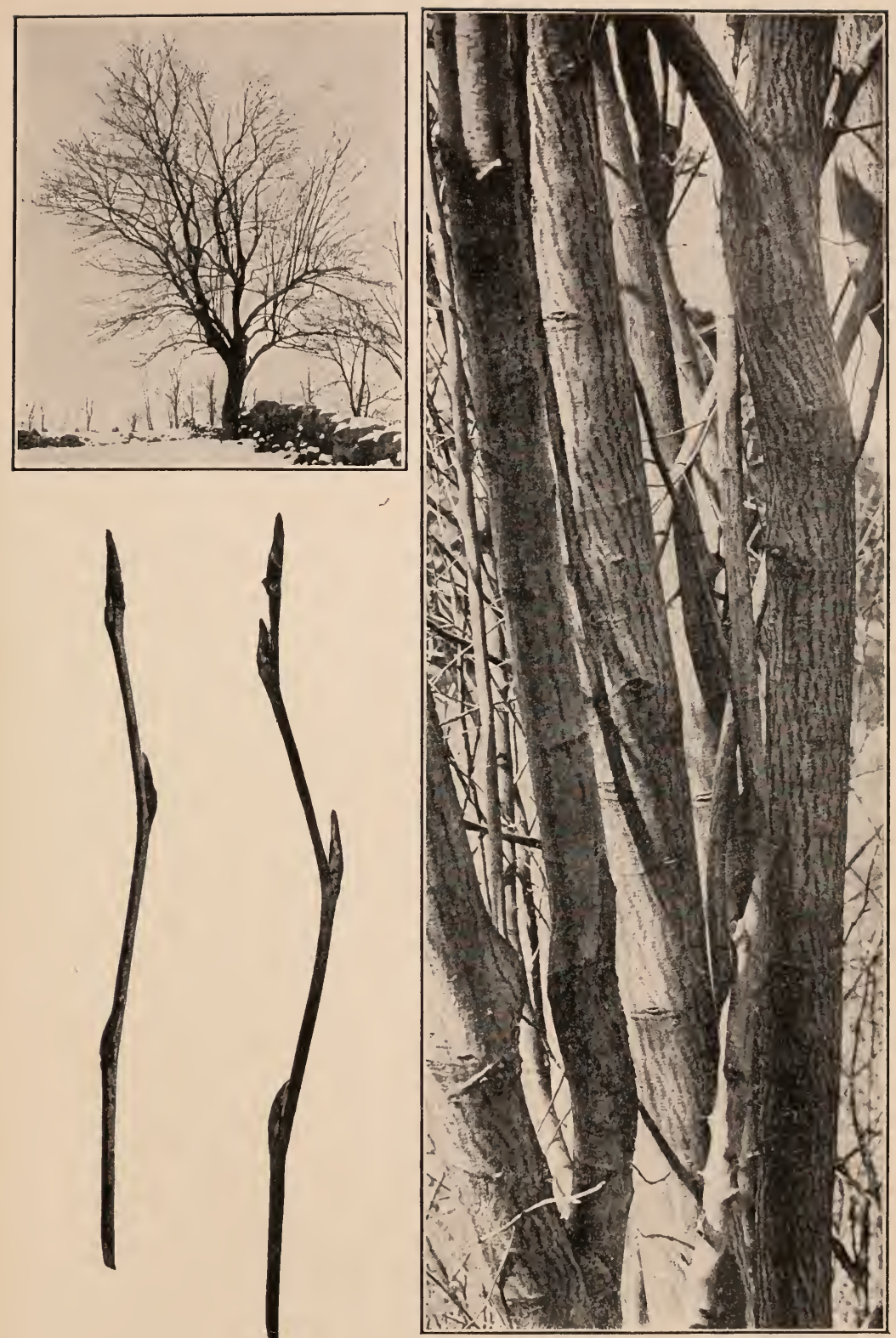

Shad Bush 


\title{
THE HAWTHORNS \\ Thorns, Haws, Thorn Apples, White Thorns.
}

\author{
Crataegus L.
}

NoTE-The Hawthorns form one of the most perplexing genera among flowering plants. Some 600 species have been described and Sargent in his Manual gives descriptions of 132 tree-like forms for North America. The distinctions used are based largely upon flower and fruit characters. They are at best often difficult of application and entirely unavailable in the winter. It seems, therefore, most advisable to give a description which will hold good for the whole group rather than a detailed account of any single species. The twig photographed was taken from the Cockspur Thorn [Crataegus Crus-galli L.]; the habit photograph from an undetermined specimen belonging to the Pruinosa group growing in a deserted pasture.

HABIT-Generally low wide spreading trees or shrubs.

BARK-Generally dark, scaly.

TWIGS-Rigid, round in section, more or less zigzag, rarely unarmed, generally armed with axillary thorns which are almost always unbranched-not infrequently branched when arising from the trunk and larger branches-generally similar in color to branches from which they grow; thorns generally absent from many of the nodes. LENTICELSoblong, generally pale.

LEAF-SCARS-Alternate, more than 2-ranked, small, narrow, crescent-shaped, slightly raised. STIPULE-SCARS-absent. BUNDLESCARS-3.

BUDS-Small, spherical or nearly so; terminal bud generally present, scarcely larger than lateral buds; a lateral accessory bud on each side of the axillary thorn, frequently only one of the two developed. BUDSCALES-numerous, overlapping, thick, rounded, blunt, bright chestnut brown, shining.

FRUIT-Berry-like, botanically a small drupe-like pome with 1-5 nutlets.

COMPIRISONS-The Hawthorns may be distinguished from other genera by the unbranched axillary thorns usually present on their twigs, and by the bright, shining, chestnut brown, generally spherical buds. The thorns of the Honey Locust are branched and situated some distance above the axillary buds. The Osage Orange [Maclura pomifera (Raf.) Schneider], sometimes grown in hedges, has unbranched thorns generally present at all the nodes, decreasing regularly. toward the tip of the greenish-gray twigs, without terminal buds but with buds lateral to the thorns and in the broad leaf-scar a single more or less ring-shaped bundle-scar or a number of nearly confluent bundlescars.

DISTRIBUTION-The Hawthorns are most abundant in eastern North America occurring here from Newfoundland to the mountains of northern Mexico. A few species occur in the Rocky mountains and Pacfic coast regions and in China, Japan, Siberia, central and southern Asia and in Europe.

woon-Heavy, hard, tough, close-grained, reddish-brown. with thick lighter colored usually pale sapwood; useful for the handies of tools, mallets and other small articles. 

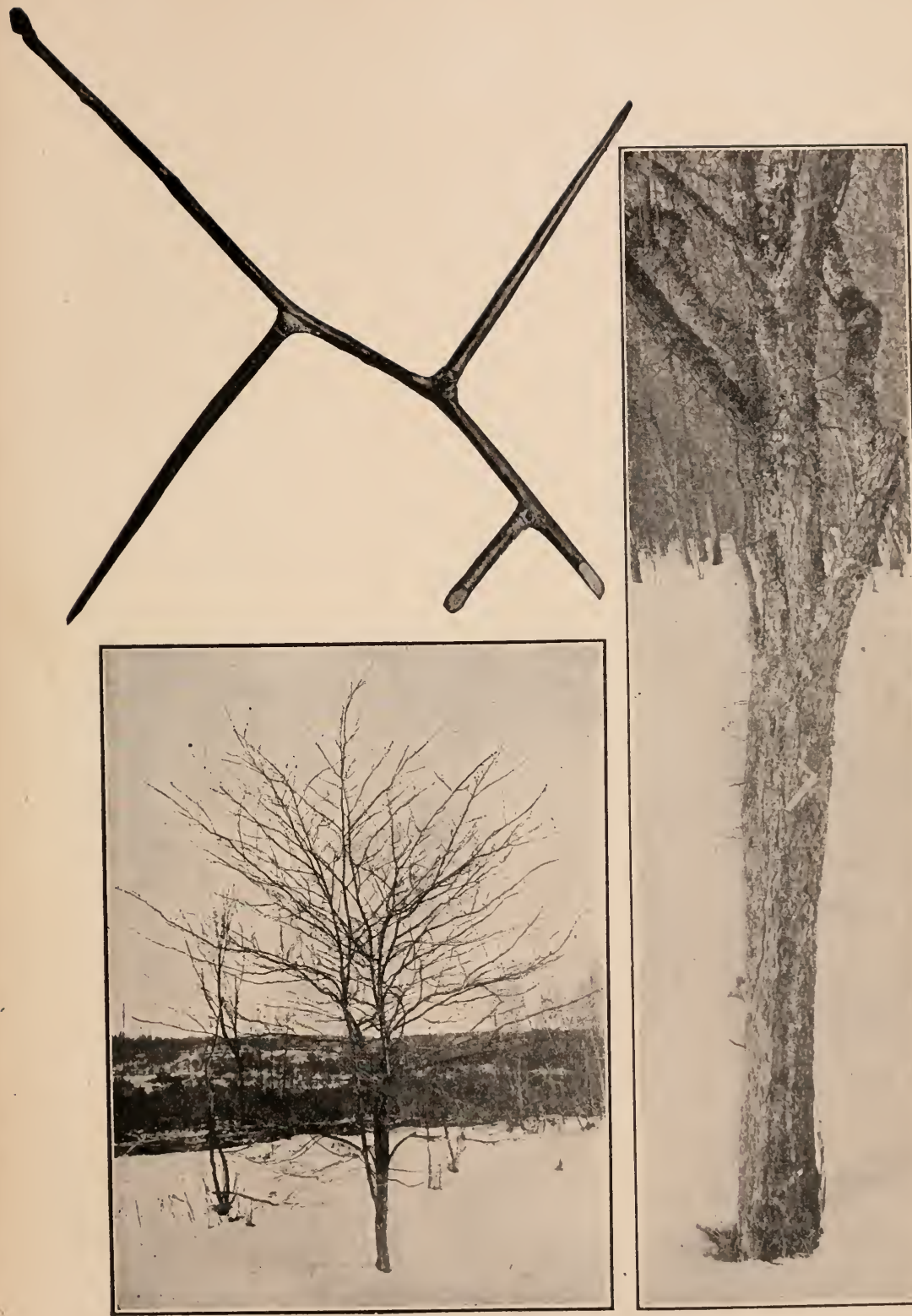
I

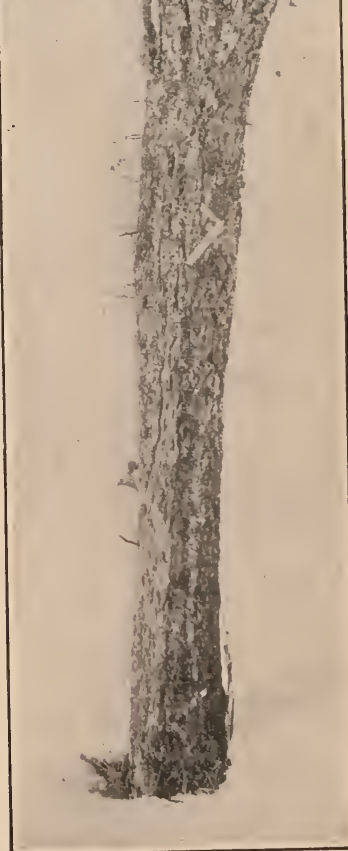

HAWTHORN 


\section{WILD BLACK CHERRY Rum, Cabinet or Black Cherry.}

Prunus serotina Ehrh.

Padus serotina (Ehrh.) Agardh.

HABIT-A medium sized tree 30-50 ft. in height with a trunk diameter from 8 or 10 inches to 2 feet, becoming much larger in the middle and southern states; branches spreading often more or less zigzag forming an irregular oblong head.

BARK-On young trunks and branches smooth reddish-brown with conspicuous oblong whitish horizontal lenticels, easly peeled off in thin dark papery layers exposing the bright green bark below, becoming with age very much roughened by irregular, close, dark, scaly plates with upturned edges.

TWIGS-Rather slender, smooth, reddish-brown, more or less covered with a grayish skin easily rubbed off; crushed twigs with odor and taste of bitter almonds. LENTICELS-numerous, pale, minute, rounded dots, becoming horizontally elongated and more conspicuous on later growth. PITH-whitish or brownish.

LEAF-SCIRS-Alternate, more than 2-ranked, small, semi-oval to inversely triangular, raised. STIPULE-SCARS-inconspicuous or apparently absent. BUNDLE-SCARS-3, often inconspicuous.

BUDS-Medium sized, ovate, blunt to sharp-pointed, about $4 \mathrm{~mm}$. long, smooth, bright reddish-brown, divergent or sometimes somewhat flattened and appressed; terminal bud slightly larger than lateral buds. BUD-SCALES-about 4 visible, broadly ovate, more or less rounded and keeled on the back, of nearly uniform color or with darker edges, sometimes partially covered with a grayish skin, similar to that usual on the twigs.

FRUIT-A drupe about the size of a pea, ripening in summer in drooping elongated clusters.

CoMpurisons-The wild Black Cherry in its young growth resembles the Choke Cherry but grows to be a good sized tree and develops a very rough scaly bark. Further the lenticels tend to be whitish and elongate horizontally with age, the buds are smaller and redder and their scales are not white-margined. From the cultivated Sweet and Sour Cherries the Black Cherry is distinguished by absence of fruiting spurs, by smaller buds and by the character of its bark.

DISTRIBUTION-In all sorts of soils and exposures; open places and rich woods. Nova Scotia to Lake Superior; south to Florida; west to North Dakota, Kansas, and Texas, extending through Mexico, along the Pacific coast of Central America to Peru.

IN NEW ENGLAND-Maine-not reported north of Oldtown (Penobscot county), frequent throughout the other New England states.

woOD-Light, strong, rather hard, close straight-grained, with a satiny surface, light brown or red, with thin yellow sapwood of 10-12 layers of annual growth; largely used in cabinet-making and the interior finish of houses. The bark, especially that of the branches and roots, yields hydrocyanic acid used in medicine as a tonic and sedative. The ripe fruit is used to flavor alcoholic liquors whence one of the common names. 


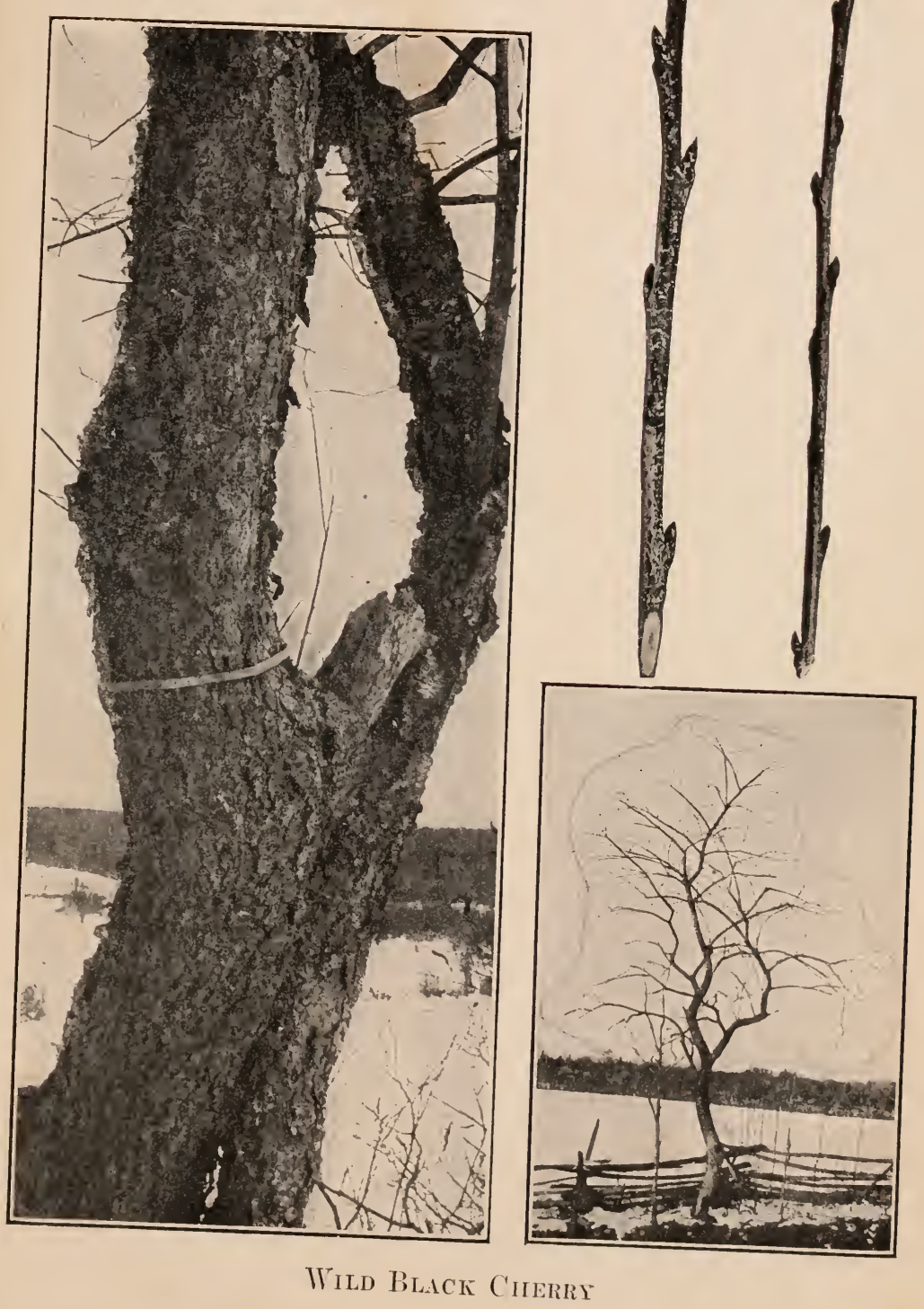




\section{CHOKE CHERRY}

\section{Prunus virginiana $\mathrm{L}$.}

Padus virginiana (L.) Roemer.

HABIT-Generally a tall shrub or a small tree rarely reaching 20-30 ft. in height with a trunk diameter of 6-8 inches.

BIRK-Dull grayish-brown, smoothish but slightly roughened with raised buff-orange rounded dots formed by the enlarged lenticels, not becoming rough-scaly with age; on young trunks and branches easily peeled off in thin, dark papery layers exposing the bright green bark below.

TWIGS-Slender to rather stout, averaging stouter than those of the Wild Black Cherry, smooth, reddish to grayish-brown, without grayish skin easily rubbed off, crushed twigs with a rank odor and taste in addition to that of bitter almonds. LENTICELS-numerous, rather conspicuous, buff-orange dots, slightly elongated longitudinally the first year and not becoming distinctly elongated horizontally on later growth. PITH-of recent growth white.

LEAF-SCARS-Alternate, more than 2-ranked, elliptical, raised. STIPULE-SCARS-inconspicuous or absent. BUNDLE-SCARS-3, frequently sunken.

BUDS-Rather large, narrow, ovate to conical, about $6 \mathrm{~mm}$. or more long, smooth, pale brown, sharp-pointed, generally divergent with more or less strongly curved apex; terminal bud frequently slightly smaller than lateral buds. BUD-SCALES-a half dozen or more scales visible, broadly ovate, more or less rounded and keeled on the back with thin grayish-margins.

FRUIT-A drupe about the size of a pea, ripening in summer in drooping elongated clusters.

COMHMIsons-The Choke Cherry may be distinguished from the Wild Black Cherry with which it is frequently confused by its smaller size, smoothish bark even in old age, its buff colored lenticels which do not elongate horizontally, the rank odor of its twigs and by its larger and paler buds with whitsh-margined bud-scales. From the cultivated Sweet and Sour Cherries the Choke Cherry is distinguished by the absence of short fruit spurs and by its gray-margined bud-scales. The lower twig in the plate is infected by a fungus disease-Black Knot (Plowrightia morbosa)-which occurs less abundantly upon the Wild Black and Wild Red Cherries and also upon our cultivated Cherries as well as upon the Plums.

DISTRIBUTION-In varying soils; along river banks, on dry plains, in woods, common along walls and often in thickets. From Newfoundland across the continent, as far north on the Mackenzie river as 62 degrees; south to Georgia; west to Minnesota and Texas.

IN NEW ENGLAND-Common throughout; at an altitude of 4,500 feet upon Mt. Katahdin. In Connecticut, rare near the coast in the southeastern part of the state but frequent or common elsewhere.

WOOD-Hard, close-grained, weak, light brown; of insufficient size to be of value commercially. 

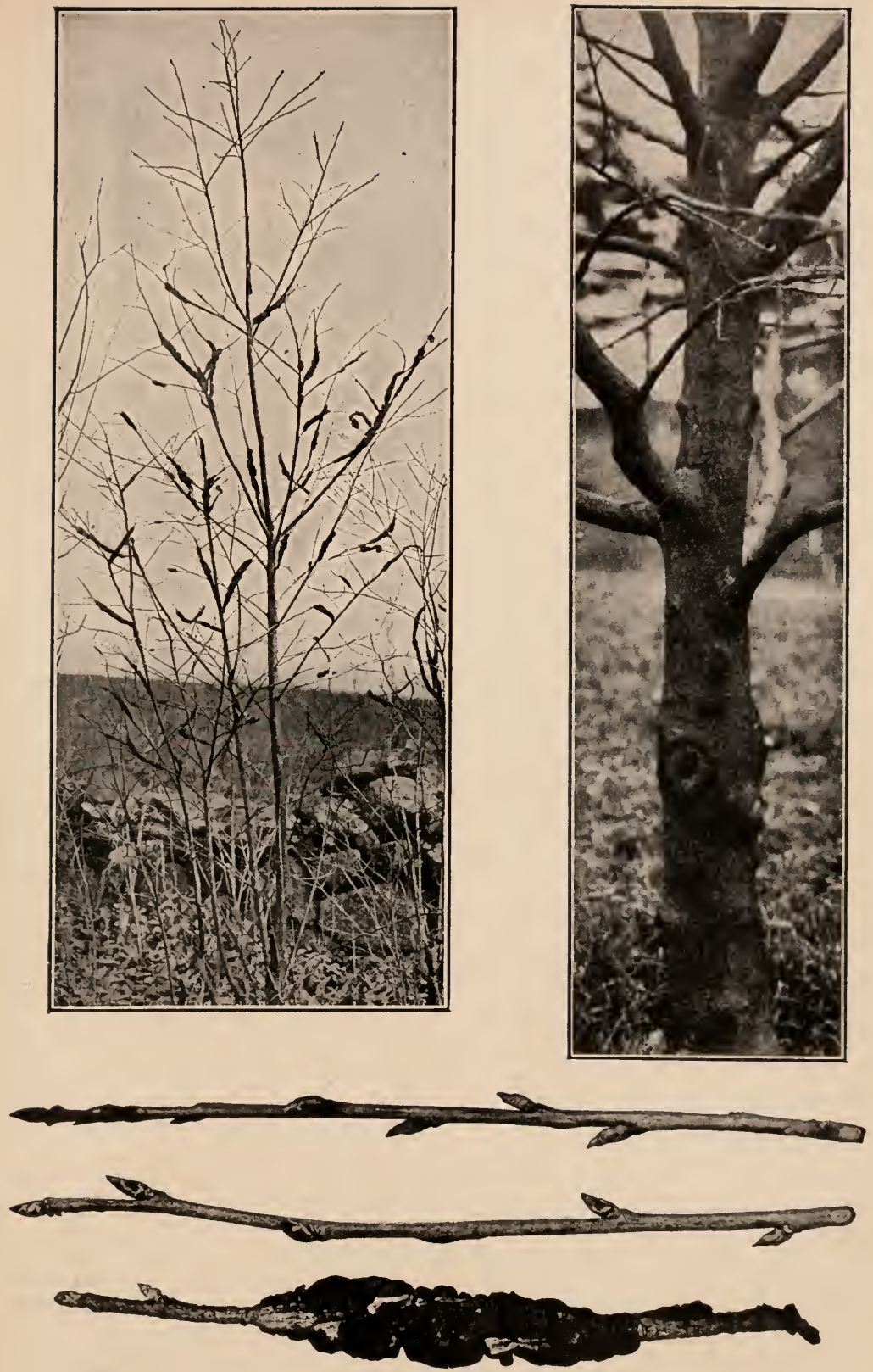

Choke Cherry 


\section{WILD RED CHERRY Bird, Fire, Pin or Pigeon Cherry}

Prunus pennsylvanica L. f.

HABIT-A shrub or small tree generally under $30 \mathrm{ft}$. in height with trunk diameter of $8-10$ inches; trunk erect generally continuous into crown with slender branches arising at a rather sharp angle, forming a rather narrow oblong open head. The trees growing in the open about 3torrs have in general a narrower outline than the tree photographed.

BARK-Bright reddish-brown, for the most part smooth, often slightly peeling in transverse strips especially toward the base of the trunk and in old trees somewhat roughened; inner bark on young branches bright green. LENTICELS-conspicuous, horizontally elongated, lensshaped, orange colored and powdery on the surface.

TWIGS-Slender, generally less than $2 \mathrm{~mm}$. thick, often less than $1.5 \mathrm{~mm}$. thick, smooth, bright red and shining, more or less covered with a gray skin easily rubbed off; bitter aromatic. LENTICELS-scattered, pale to bright orange colored, becoming slightly elongated horizontally and more conspicuous on older growth. PITH-brown, narrow.

LEAF-SCARS-Alternate, more than 2-ranked, semi-oval, raised. STIPULE-SCARS-back of leaf-scars, generally indistinct or absent. BUNDLE-SCARS-3, the central larger one often alone distinct.

BUDS-Minute, generally under $3 \mathrm{~mm}$. long, blunt-pointed, ovate, reddish-brown, smooth, often partially covered with a grayish skin, divergent, on rapidly grown shoots characteristically clustered at the tips as well as scattered, with the terminal bud present but generally smaller than those in the cluster around it; also clustered buds at ends of short fruiting spurs; collateral accessory buds sometimes present. BUD-SCALES-ovate, often notched and short-pointed, not readily distinguished as separate scales with the naked eye.

FRU1T-A drupe about the size of a pea, ripening in summer in short clusters or with stalks arising from a common point on the stem.

COMPARISONS-The appearance of the bark and the taste of the twigs show the Wild Red Cherry to belong to the Cherry group. It differs from the other cherries in its very slender twigs and small buds which are constantly clustered at the tips even of rapidly grown shoots. The Wild Black Cherry when tree-like is further distinguished by its scaly bark. The powdery bright reddish-orange lenticels on young and even old trunks form a striking character but a similar color may occur in the lenticels of the other Cherries especially if the outer surface is rubbed off.

DIS'TRIBLTION-Roadsides, clearings, burnt lands, hill slopes, occasional in rather low grounds. From Labrador to the Rocky mountains, through British Columbia to the Coast Range; south to North Carolina; west to Minnesota and Missouri.

IN NEW ENGLAND-Throughout; very common in the northern portions, as high up as $4,500 \mathrm{ft}$. upon Katahdin, less common southward and near the seacoast.

WOOD-Light, soft, close-grained, light brown, with thin yellow sapwood of little commercial importance. 

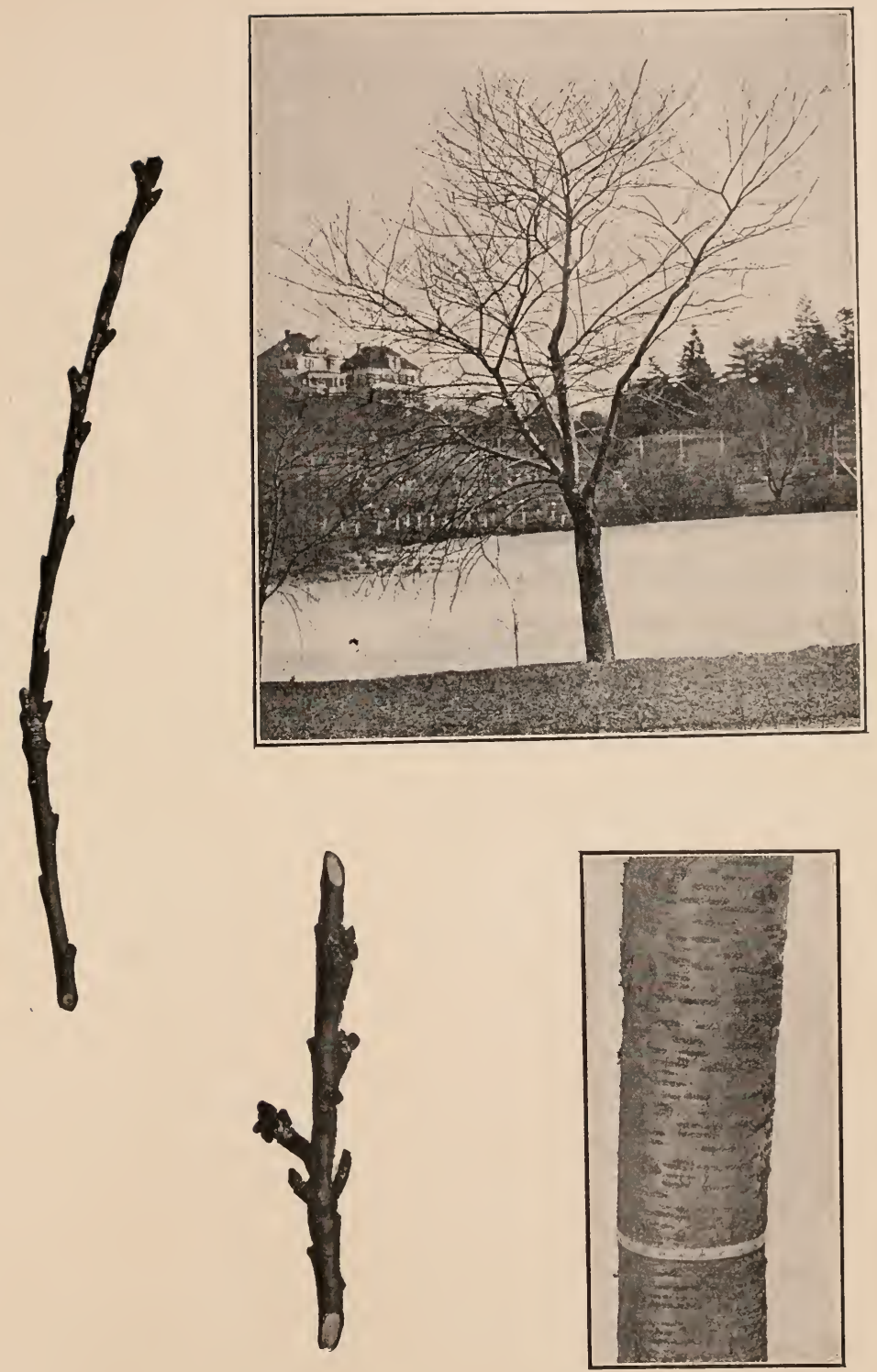

Wild Red Cherry 


\section{SWEET CHERRY \\ Mazzard Cherry, European Bird Cherry.}

Prunus avium L.

HABIT-A good sized tree reaching 50-75 ft. in height with a trunk diameter of 2-3 ft.; trunk erect continuous into the crown with slender ascending branches forming a narrow pyramidal head; with age becomng broad-spreading.

BARK-Characteristically reddish-brown with horizontally elongated buff colored lenticels, tardily peeling off in transverse strips which curl back and expose the lighter bark below which on very old trunks may be roughened by scaly ridges; on young branches bark easily peeled off in a thin dark papery layer exposing the bright green bark below.

TWIGS-Stout, bright reddish-brown, smooth and shining, more or less covered with a grayish skin easily rubbed off; crushed twigs with bitter taste. In addition to long rapidly grown shoots, stubby slowly grown fruit spurs with terminally clustered buds are abundant. LENTICELS-rather numerous, pale, becoming horizontally elongated. PITH-brown.

LEAF-SCARS-Alternate, more than 2-ranked, rather broad, semioval to inversely triangular, raised. STIPULE-SCARS-slightly behind leaf-scars, oblique, often indistinct or absent. BUNDLE-SCARS-3.

BUDS-Clustered at ends of fruiting spurs or scattered on rapidly grown shoots; terminal bud scarcely larger than lateral buds; lateral buds divergent, stout, ovate, pointed, constricted at base, about $7 \mathrm{~mm}$. long, reddish-brown, smooth, often partially covered with a grayish skin. BUD-SCALES-broadly ovate, with edges often lighter colored and more or less frayed and ragged.

FRLIT-A drupe with edible flesh, generally sweet though in some varieties tart, with hard stone or pit enclosing the seed, ripening in summer, with stalks generally several in a cluster arising from a common point on the stem.

COMPARISONS-The two types of cultivated cherries, the Sweet and the Sour, are to be distinguished chiefly by habit of growth and relative size of twigs and buds, the Sweet Cherry having a pyramidal outline generally with a central leader and with relatively stout twigs and larger buds. These differences are well shown in the plates. (See Comparisons under Sour Cherry.)

DISTRIBUTION-A native of Europe, in this country cultivated for its fruit in several improved varieties such as the Black Tartarian, May Duke, Windsor, Napoleon, etc., and in some places escaped from cultivation.

WOOD-Strong, rather soft, close-grained, yellowish-red, taking a fine polish; largely used in Europe for fine furniture, inside finishing and for musical and other instruments. 

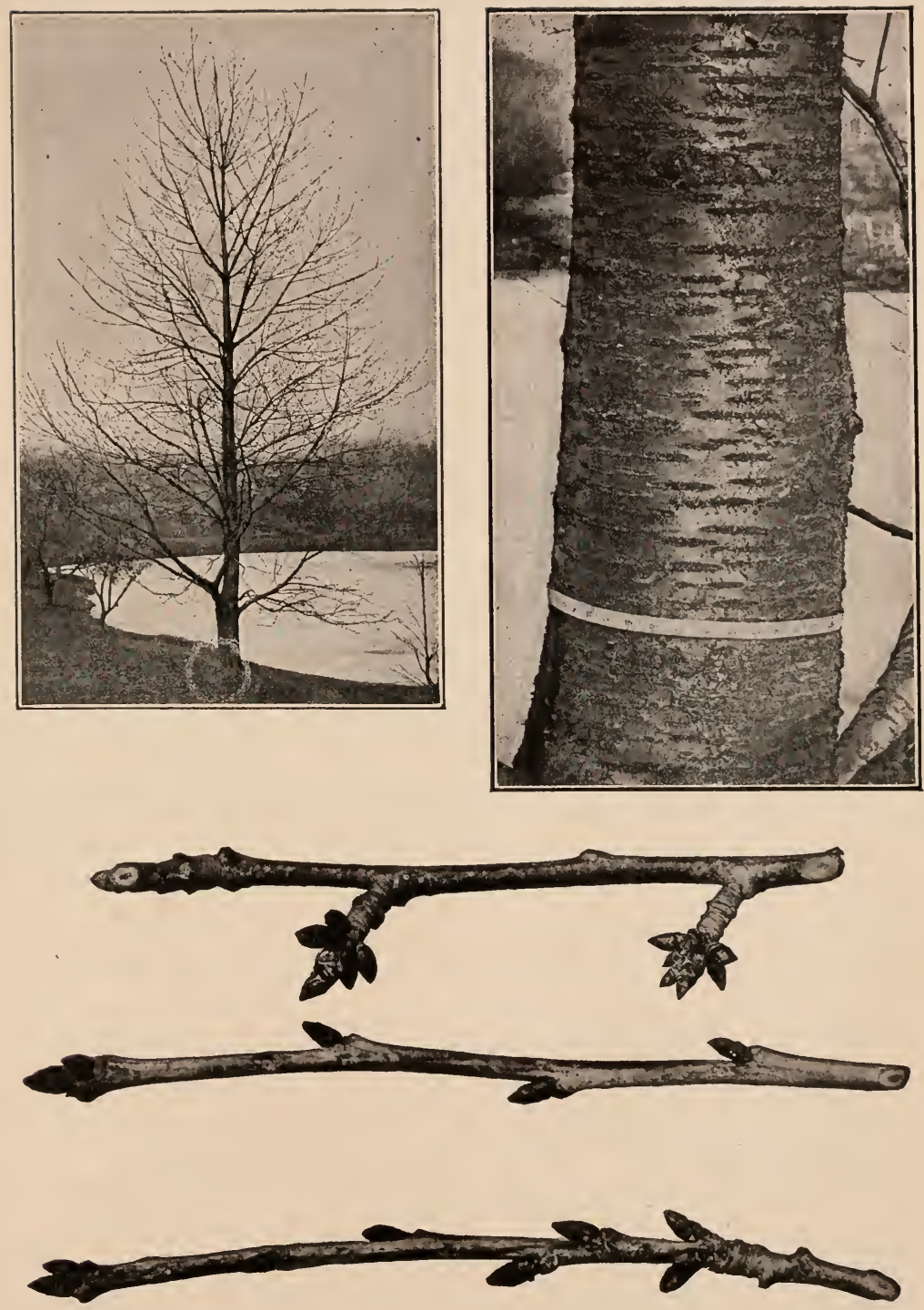

Siveet Cherry 


\section{SOUR CHERRY Pie or Morello Cherry.} Prunus Cerasus L.

H.BIT-A small tree 20-30 ft. or less in height with a trunk diameter of 10 or 12 inches; with stout spreading branches and more or less drooping branchlets forming a broad, low, rounded head.

BIRK-Similar to that of the Sweet Cherry, but the outer smooth bark sooner peeling back and exposing the roughened inner bark.

TWIGS-Slender, otherwise resembling twigs of Sweet Cherry.

LEAF-SCARS-Similar to those of the Sweet Cherry.

BCDS-Similar to those of the Sweet Cherry but smaller and apparently more frequently clustered toward the ends of long shoots. Compare the twig photographs of the two species.

FRIIT-Similar to that of Sweet Cherry but flesh tart.

Compurisons-The Sour Cherry differs from the Sweet Cherry in its spreading habit of growth, its more slender twigs and smaller buds. Compare plates of the two species. From the native Wild Black and Choke Cherries the cultivated Sweet and Sour Cherries are distinguished by the short fruit spurs; from the Wild Red Cherry by their stouter twigs and buds and absence of a bud cluster at the tip of long shoots.

DISTRIBUTION-A native of Europe, in this country cultivated for its fruit in several improved varieties such as the Amarelles, Early Richmond, Montmorency, etc., and the Morellos, Louis Philippe, etc., and in some places escaped from cultivation.

WOOD-Similar in appearance and uses to that of the Sweet Cherry from which it is not distinguished by wood workers. 

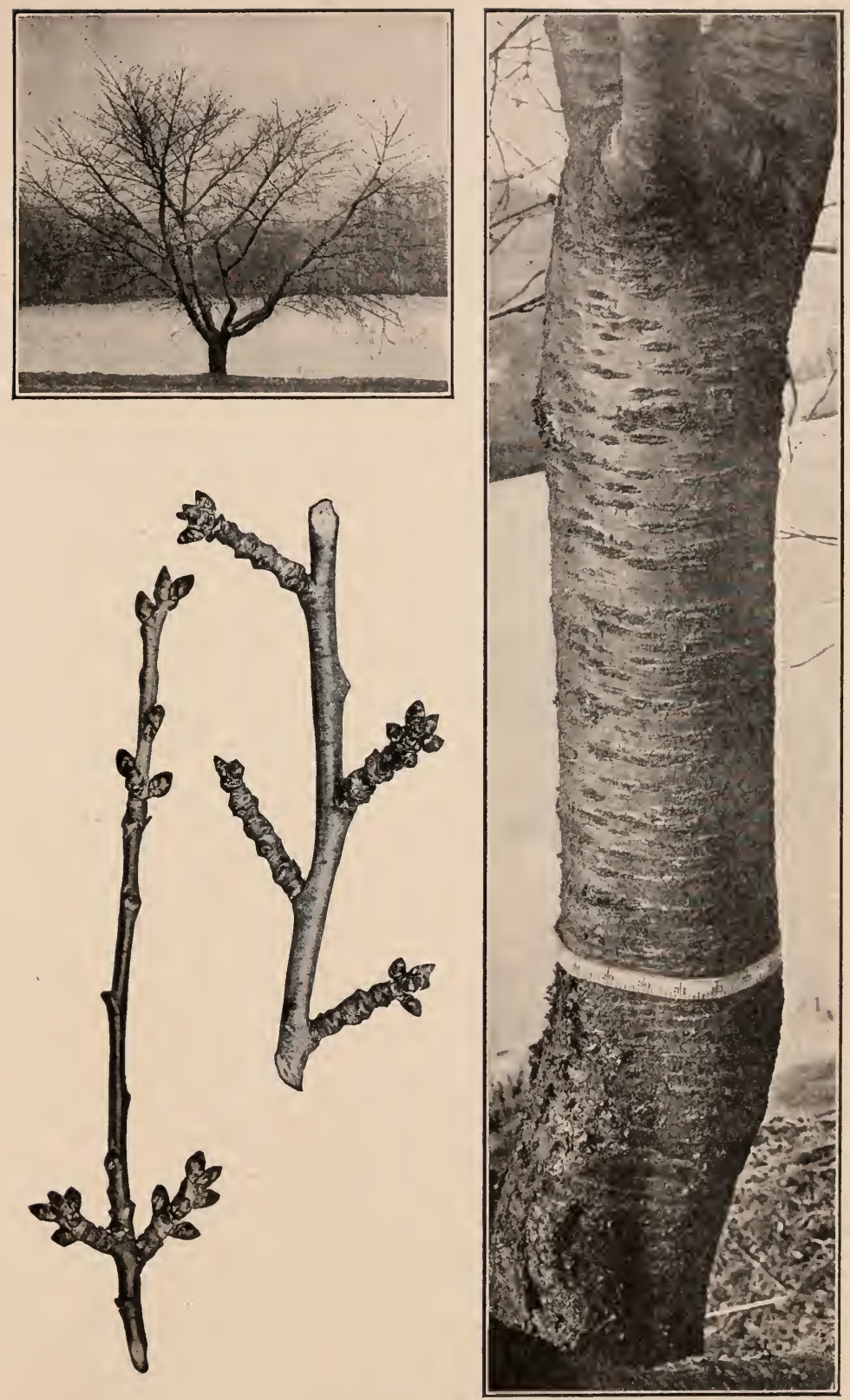

Sour Cherry 


\section{CANADA PLUM Red, Horse or Wild Plum.}

Prunus nigra Ait.

$P$. americana, var. nigra Waugh

HABIT-A shrub or small tree $20-25 \mathrm{ft}$. in height with a trunk diameter of 5-8 inches; with contorted branches and more or less zigzag branchlets forming a low spreading head. It tends to sucker freely forming low thickets.

BARK-On young trunks and branches dark brown with prominent raised lenticels which are horizontally slightly elongated; at first smooth but soon splitting and curling back in thick grayish-brown layered plates exposing the rough scaly bark below.

TWIGS-Slender, smooth, reddish-brown, often more or less covered with a grayish skin, bitter aromatic, lateral spiny spurs generally present. LENTICELS-scattered, large and rather conspicuous pale dots.

LEAF-SCARS-Alternate, more than 2-ranked, broadly crescentshaped. STIPULE-SCARS-indistinct or absent. BUNDLE-SCARS3 , often inconspicuous.

BUDS-Terminal bud absent, lateral buds about $4-8 \mathrm{~mm}$. long, conical, narrow-pointed, grayish-brown; collateral buds sometimes present. BUD-SCALES-triangular, pale and thin on the margins, generally hairy at the apex.

FRUIT-A smooth-skinned drupe with smooth stone.

COMPARISONS-The Plums are distinguished from the other members of the genus Prunus by the absence of a terminal bud. The Canada Plum so far as one can judge from the material investigated is distinguishable by its larger buds from the American Plum, of which it is considered by some only as a variety.

DISTRIBUTION-Native along streams and in thickets, often spontaneous around dwellings and along fences. From Newfoundland through the valley of the St. Lawrence to Lake Manitoba; rare south of New England; west to Wisconsin. Has given rise to some valuable iruit-bearing varieties in cultivation.

IN NEW ENGLAND-Maine-abundant in the northern sections and common throughout; New Hampshire and Vermont-frequent, especially in the northern sections; Massachusetts-occasional; Connecticut-rare, Norfolk, a few trees about an abandoned garden; Oxford; Rhode Islandnot reported.

wooD-Heavy, hard, strong, close-grained, rich, bright reddishbrown with thin lighter colored sapwood. 


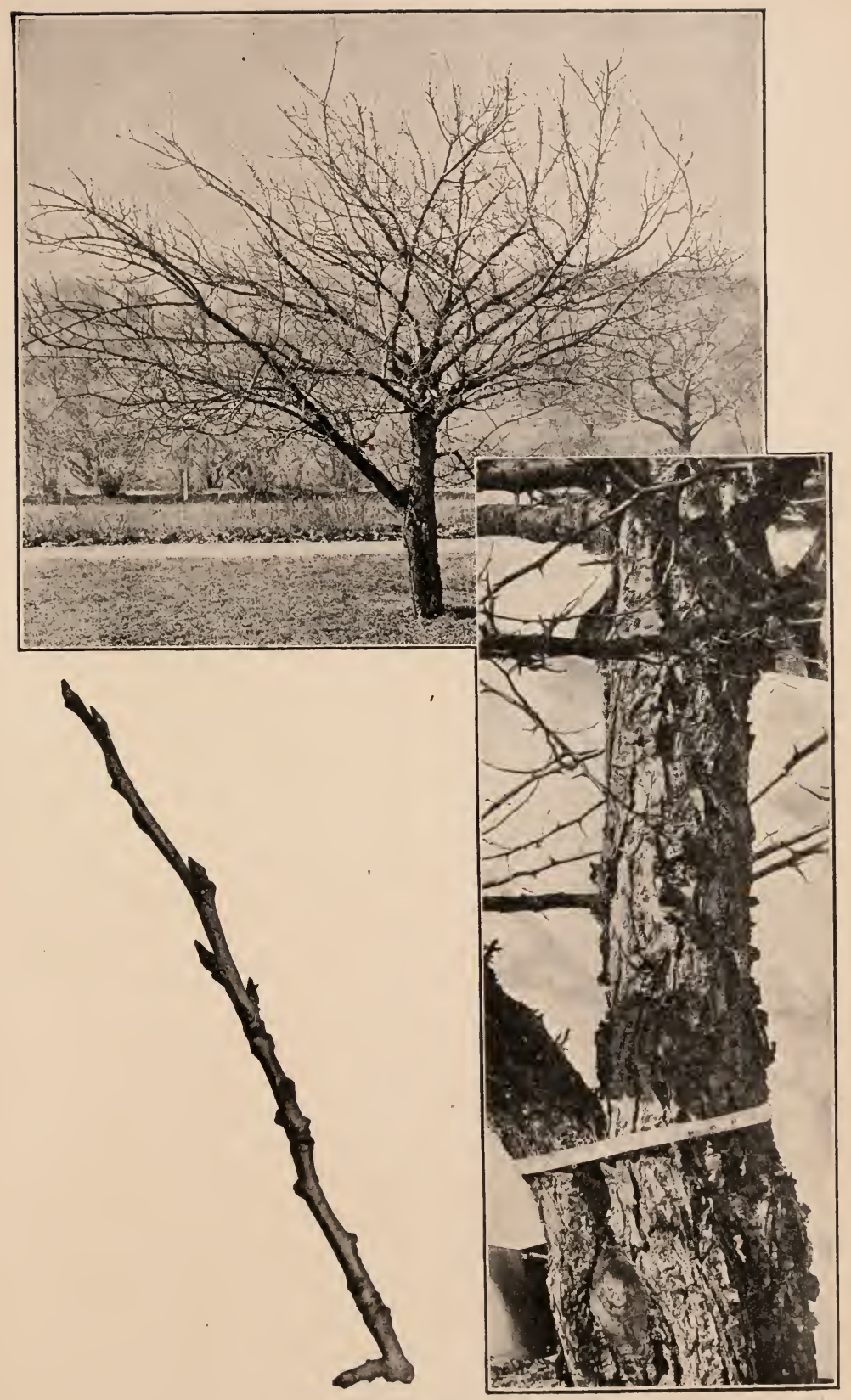

Canada Plum 


\section{CULTIVATED PLUMS}

NOTE-The Cultivated Plums are either improved forms of originally wild species or have been derived by hybridization from a number of such forms. The types most cultivated in the United States are the American (derived from Prunus americana), the European (derived from Prunus domestica) and the Japanese (derived from Prunus triflora). Although the varieties of a given type differ considerably so that without further study it does not seem desirable to try to offer a detailed winter classification of the cultivated plums, still the general characteristics of the unmixed types are recognizable in winter. Certain varieties, the Gold, the Lombard and the Red June have been chosen for the photographs to illustrate respectively the American, the European and the Japanese types.

\section{THE AMERICAN PLUM. VARIETY-GOLD}

\section{Prunus americana Marsh.}

Illustrations on page 375 .

The American cultivated type of Plum has very slender grayishbrown twigs and branches which have a decidedly drooping habit of growth. The bark is brown; on young trunks and branches smooth, shining, with prominent, light-colored, horizontally elongated lenticels (see upper part of bark picture). The habit photograph was taken from a specimen of the native form, grown in the Arnold Aboretum. The American Plum, as growing wild, closely resembles the Canada Plum and by some this latter species is considered merely a variety of the former. The material examined shows smaller twigs than the Canada Plum with buds generally under $4 \mathrm{~mm}$. long. The most northern station has been reported to be along the slopes of Graylock, Mass. In Connecticut it is reported as rare in the southern district, becoming occasional northward.

\section{THE EUROPEAN PLUM. VARIETY-LOMBARD}

Prunus domestica L.

Illustrations on page 376 .

The European Plum has a lighter bark than the other two types without conspicuous horizontal lenticels, with stout, upright, long shoots and an upright habit of growth.

\section{THE JAPANESE PLUM. VARIETY-RED JUNE}

Prunus triflora Roxbg.

Illustrations on page 377 .

The Japanese Plum has a very dark deeply ridged bark without conspicuous lenticels. The long shoots are rather slender and bright colored and stout fruit spurs are numerous. 

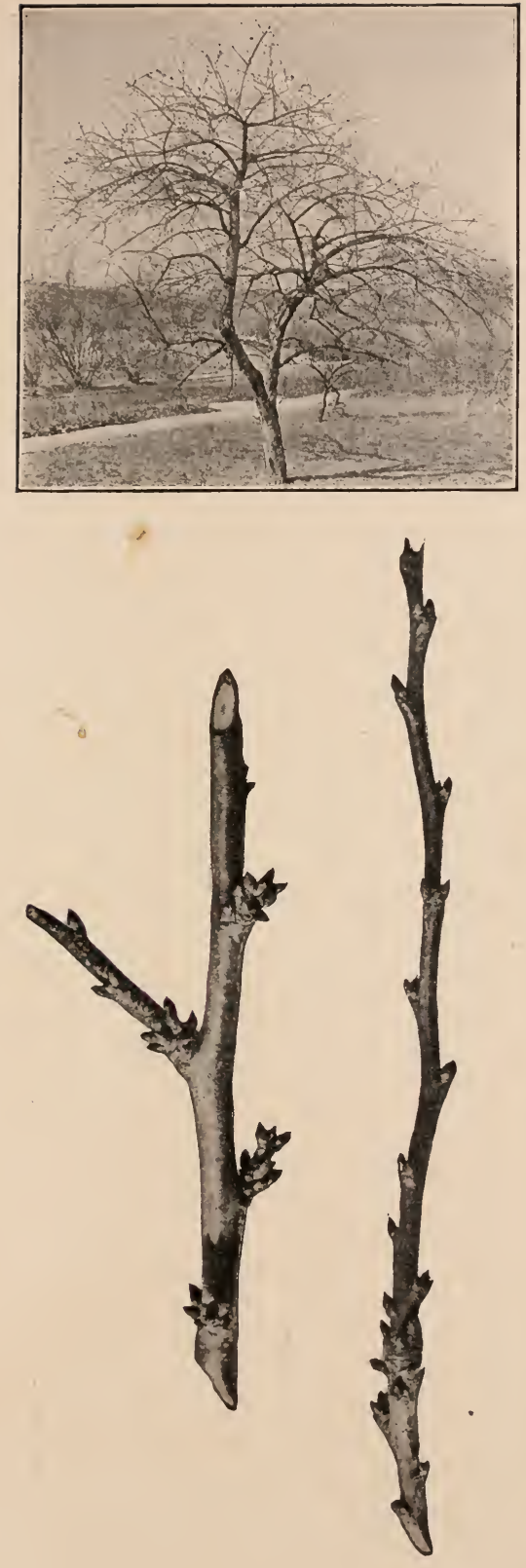

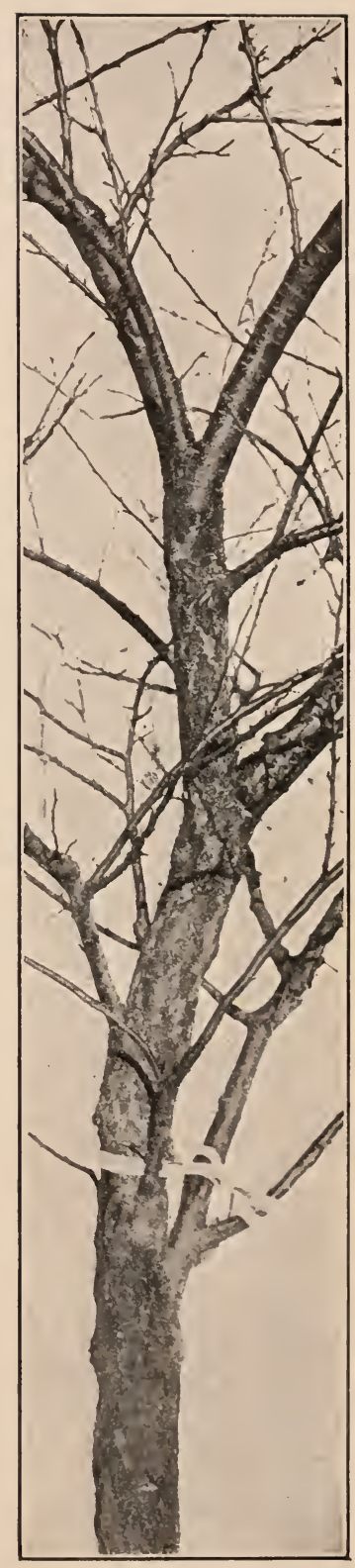

American Plum 

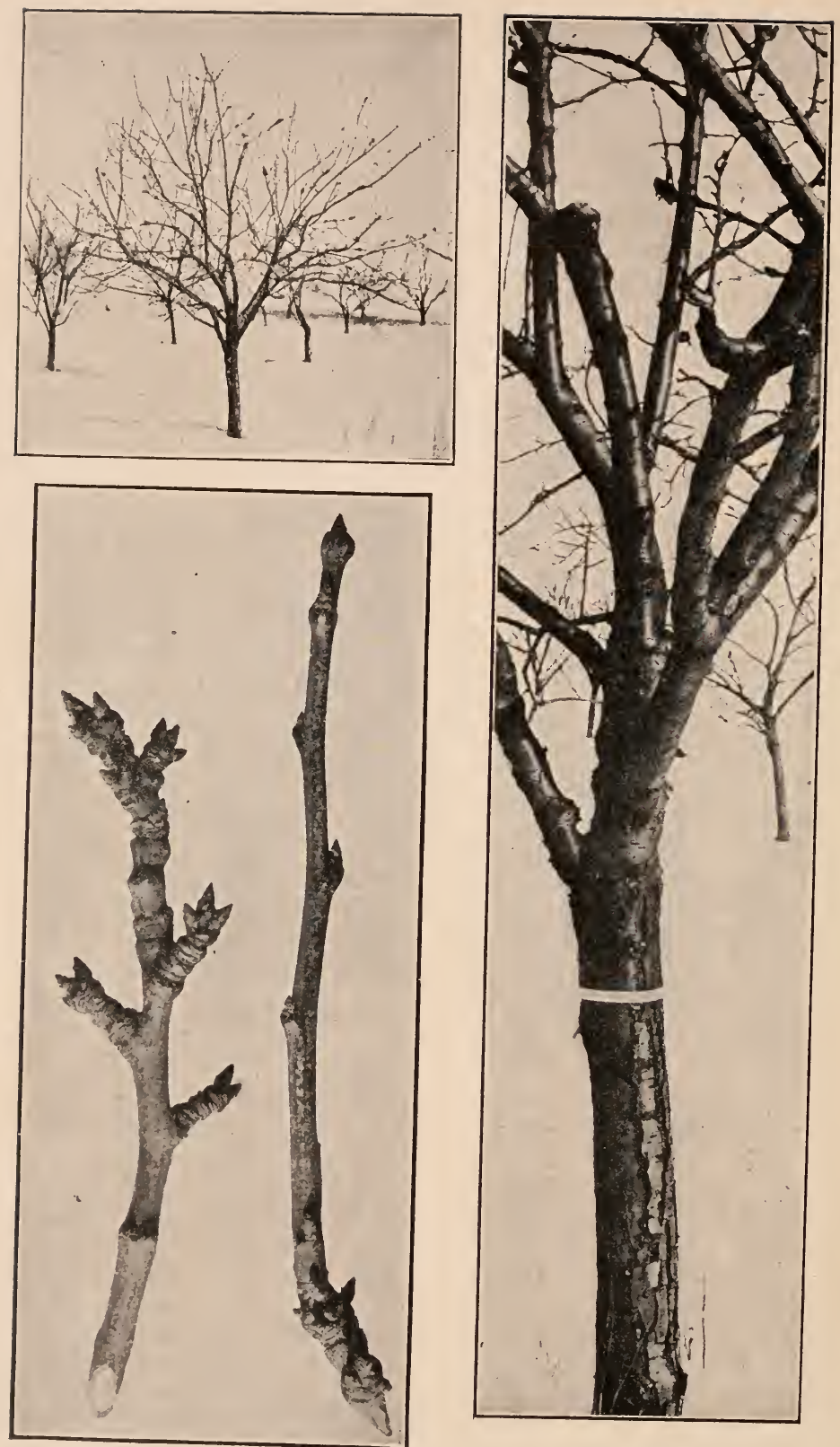

European Plum 

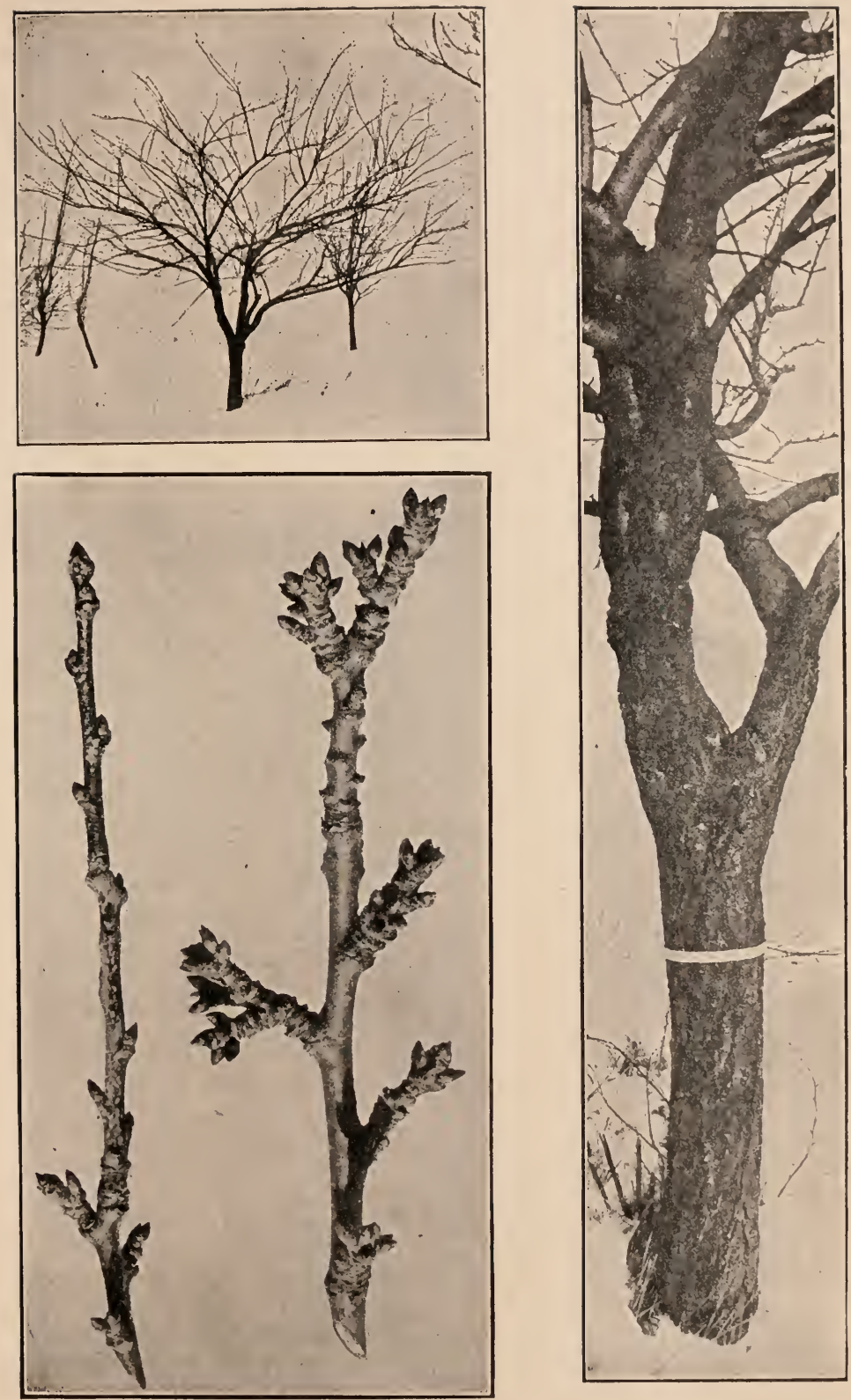

Japanese Plun 


\section{PEACH \\ Prunus Persica (L.) Stokes.}

Amygdalus Persica L.

HABIT-A small tree generally under $20 \mathrm{ft}$. in height with a trunk diameter of about 6 inches; trunk low with spreading limbs and ascending branchlets forming a low broad rounded head.

BARK-Dark reddish-brown, smooth, with prominent horizontally elongated lenticels, becoming roughened and scaly at base.

TWIGS-Of medium thickness, smooth and very shiny, greenish to bright reddish-purple, often green below and red above toward the light, becoming redder as spring approaches; on rapidly grown shoots branches sometimes produced the same season; crushed twigs with odor and taste of bitter almonds. LENTICELS-very numerous and very minute pale dots, in reality stomata, best seen with hand-lens and on reddish portions of twigs, only part of them elongating with age. PITH-rather wide, often somewhat 5-pointed, whitish or tinged with brown.

LEAF-SCARS-Alternate, more than 2-ranked, elliptical to semioval, strongly raised, often more or less decurrent. STIPULE-SCARSbehind and above leaf-scars or raised on persistent bases of stipules, often indistinct and readily confused with broken bud-scales; often a small raised leaf-scar above and on either side of the main leaf-scar in connection with the collateral buds when these are present. BUNDLESCARS-3, often inconspicuous.

BUDS-Ovate, rounded at apex or blunt-pointed, generally under 5 $\mathrm{mm}$. long, densely pale-woolly at least toward apez and within, more or less appressed, 1 or 2 collateral buds often present at a nodethese generally stout flower buds in sharp contrast to the narrower leaf bud between (in the group of three buds on twig in plate all are flower buds); terminal bud present often with one or more lateral buds adjacent. BUD-SCALES-reddish-brown, often with ragged edges and generally indistinct and covered with grayish wool.

FRUIT-A large downy drupe with an irregularly pitted stone.

COMPARISONS-The dense woolliness of its stout buds and the very numerous and extremely minute pale dots on its highly colored and polished twigs readily distinguish the Peach from its near relatives.

DISTRIBUTION-A native of Asia, cultivated in this country for its fruit, naturalized throughout the greater portion of the northern states and spontaneous in waste places and on road-sides in the northern states.

wooD-Rather soft, close-grained and light brown. The seeds develop considerable hydrocyanic acid and are used in the manufacture of a substitute for oil of bitter almonds. 


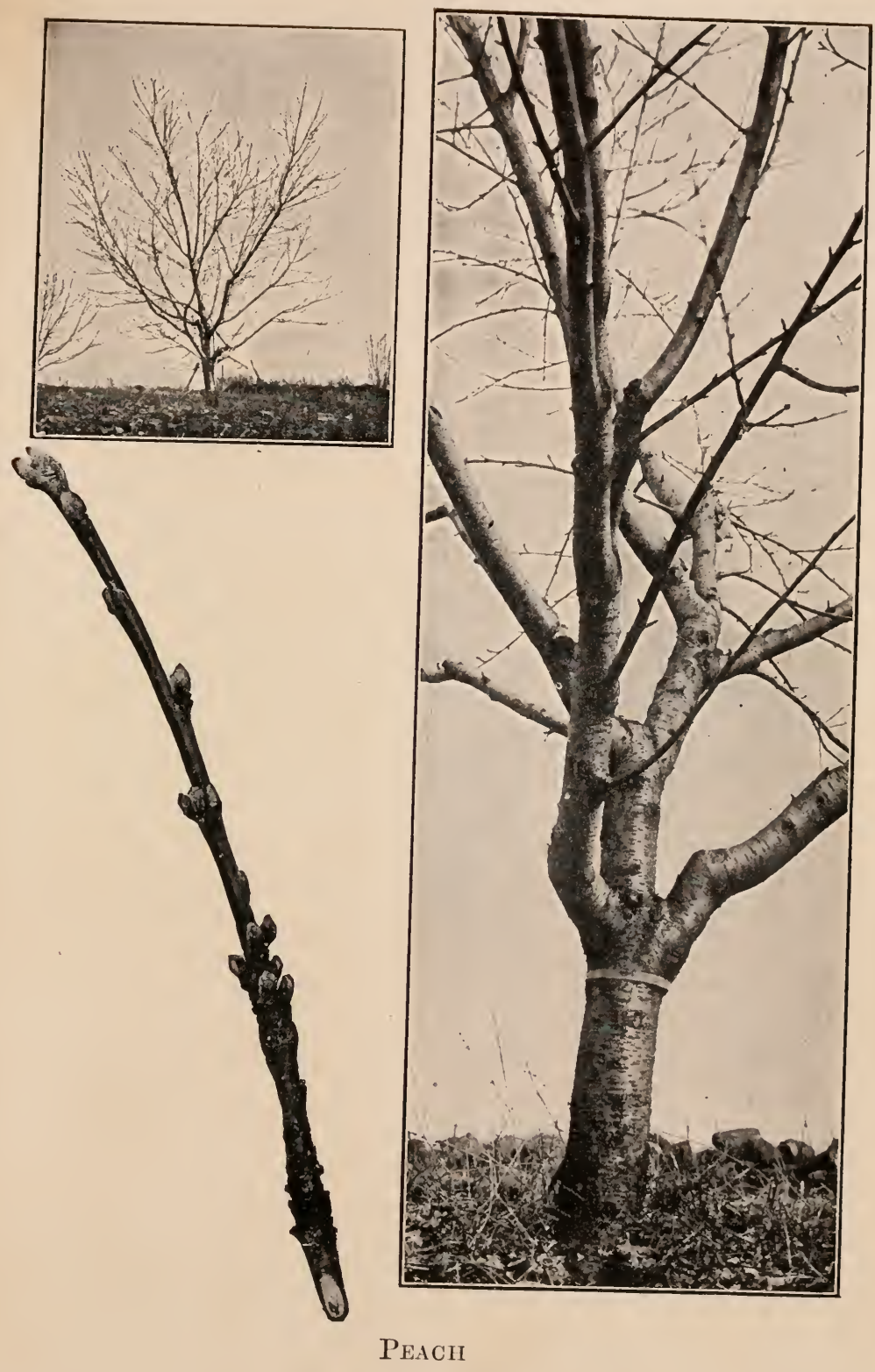




\section{KENTUCKY COFFEE TREE Coffee Nut, Coffee Bean, Nicker Tree, Mahogany. Gymnocladus dioica (L.) Koch.}

G. canadensis Lam.

HABIT-A medium sized tree 30-60 ft. in height, trunk generally soon dividing into 3 or 4 slightly spreading limbs or less frequently with a continuous trunk, forming a narrow obovate head with thick branchlets devoid of spray; the large stout pods often remaining on tree throughout the winter.

BARK-Dark brown, characteristically roughened with thin tortuous recurved scale-like ridges which are distinct even upon comparatively young branches.

TWIGS-Very stout, more or less contorted, blunt, brown or slightly greenish, generally white-crusted, smooth or often velvety-downy. LENTICELS-rather numerous, large, generally more conspicuous on second year's growth. PITH-wide, salmon-pink to brown.

LEAF-SCARS-Alternate, more than 2-ranked, large, pale, raised, broadly heart-shaped. STIPULE-SCARS-absent. BUNDLE-SCARSlarge, raised, generally $3-5$.

BUDS-Terminal bud absent, lateral buds small, bronze, silky, downy, partially sunken, scarcely projecting beyond the surface of the twig, surrounded by an incurved downy rim of the bark; axillary bud in the depression at top of leaf-scar, one or sometimes 2 superposed buds present. BUD-SCALES-sometimes 2 lateral scales visible.

FRLIT-A reddish-brown, large, broad, flat, oblong, abruptly poirted

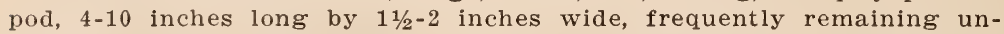
opened on tree during winter, generally somewhat larger than shown in the photograph. Seed, dark brown, flattish.

Compinisons-A superficial glance at the habit of the Kentucky Coffee Tree might lead one to mistake its stout branchlets for those of the Ailanthus. Its curious narrow ridged bark, however, should at once prevent any confusion between the two trees. The silky bronze superposed buds partially sunken in downy dimples of the bark in connection with the stout twigs and salmon-colored pith are sufficient characters to distinguish this tree from all other forms.

DISTRIBUTION-Not native in New England but frequently cultivated as an ornamental tree; grows wild in rich deep soil from central New York and southern Minnesota southward to Tennessee and Oklahoma.

WoOD-Heary, though not hard, strong, coarse-grained, very durable in contact with soil, rich light brown tinged with red, with thin lighter colored sapwood of 5-6 layers of annual growth; it takes a fine polish and is occasionally used in cabinet-making and for fence-posts, rails and in construction. Its seeds were formerly used as a substitute for coffee. 

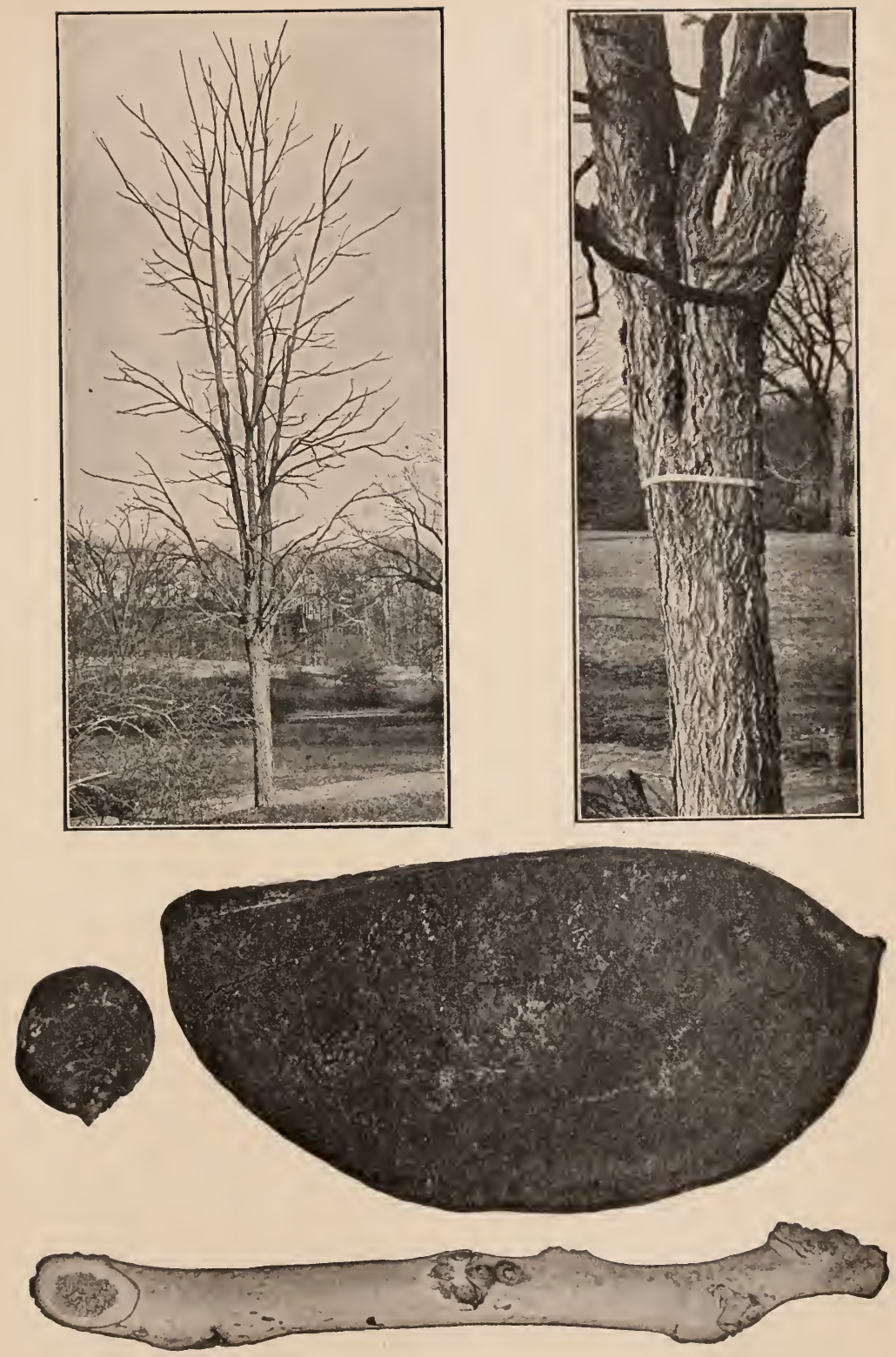

Kentucky Coffee Tree 


\title{
HONEY LOCUST
}

\section{Three-thorned Acacia, Honey Shucks, Sweet Locust, Thorn}

Tree.

\author{
Gleditsia triacanthus L. (Sometimes called Gleditschia.)
}

\begin{abstract}
HABIT-A medium sized tree 40-60 ft. in.height. with a trunk diameter of $1-3$ ft.; trunk commonly short dividing into a number of slightly spreading limbs, with somewhat drooping lateral branches, forming a broad rounded obovate or flat-topped head. Seen against the sky the smaller branches appear zigzag with characteristic swellings at the nodes often surmounted with thorns and rudimentary branchlets developed from the extra buds. (See branches at side of trunk in bark picture.)
\end{abstract}

BARI-Grayish-brown darkening with age, on young trunks and branches smooth, with raised oblong lenticels, on older trunks more or less roughened into broad ridges with firm, persistent recurved edges. Some trunks have bark practically smooth except for a few deep fissures: some trunks are thickly fringed with dense masses of long branched spines, while others are free from them.

TWIGS-Slender, shining, smooth, reddish to greenish-brown, often light mottled or streaked, zigzag with enlarged nodes; a large branched thorn with pale reddish-brown pith, discontinuous with that of the stem, generally present above node. LENTICELS-minute, scattered, becoming conspicuous brown raised dots on older growth. PITHthick, whitish.

LEAF-SCARS-Alternate, generally more than 2-ranked, V-shaped with upper margins and apex generally swollen. STIPULE-SCARS -absent or inconspicuous. BUNDLE-SCARS-3, rather inconspicuous.

BUDS-Terminal bud absent, the lateral buds small, generally about 5 more or less distinct at a node, separated one above the other, decreasing in size from above downward, the uppermost a superposed smooth scaly bud breaking through the bark, the next also scaly covered by or breaking through the leaf-scar, the lower buds without scales, covered by bark and seen as minute green dots in a longitudinal section of twig; buds often continue to be produced at the nodes for several years especially when the twigs are trimmed as in hedges and give rise to a bunch of more or less rudimentary branches.

FRUTT-A long, flat, reddish-brown, more or less twisted, indehiscent pod 10 to 18 inches long, containing numerous flat oval seeds about $10 \mathrm{~mm}$. long. The photograph of the fruit is reduced to about $1 / 3$ natural size.

COMIMAISONS-The Honey Locust is at once distinguished from the various other thorny species such as the Hawthorn and Common Locust by its large branched thorns situated above the leaf-scar. When the thorns are absent, as is sometimes the case, the vertical row of separated smooth buds, the upper scaly and superposed, the lower hidden by the bark, are sufficient points of distinction.

DISTRIBUTION-In its native habitat growing in a variety of soils; rich woods, mountain sides, sterile plains. Southern Ontario; spreading by seed southward; indigenous along the western slopes of the Alleghanies in Pennsylvania; south to Georgia and Alabama; west from western New York through southern Ontario and Michigan to Nebraska, Kansas, Oklahoma and Texas.

IN NEW ENGLAND-Not native, but frequently planted as an ornamental tree or for hedges and escaped from cultivation; Maine-young trees in the southern sections said to have been produced from selfsown seed; New Hampshire and Vermont-introduced; Massachusettsoccasional; Connecticut-rare, occasional or local; Rhode Island-introduced and fully at home. Probably sparingly naturalized in many other places in New England.

WOOD-Hard, strong, coarse-grained, very durable in contact with soils, red or bright red-brown, with thin, pale sapwood of 10-12 layers of annual growth; largely used for fence posts and rails, for the hubs of wheels and in construction. 

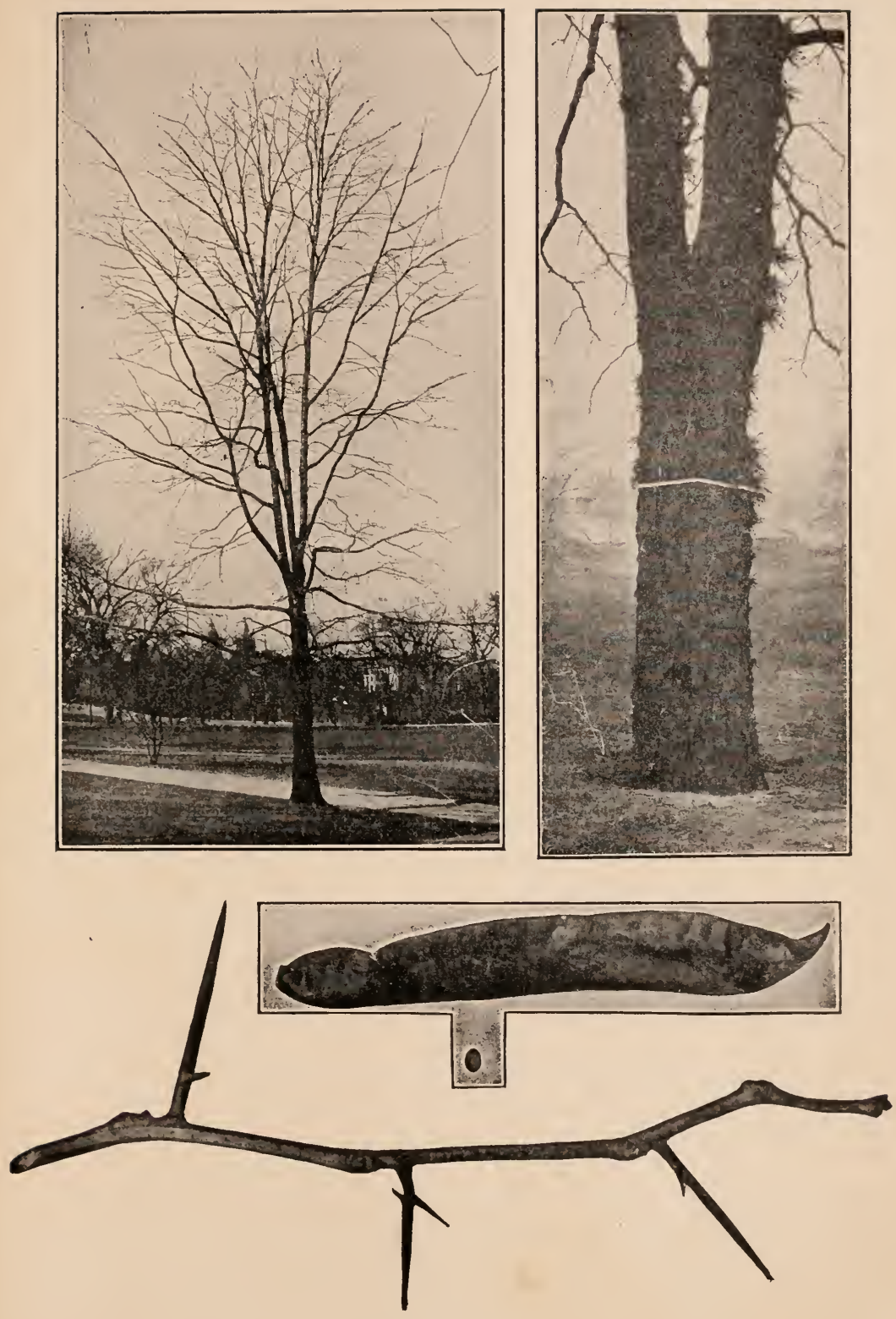

HoNey Locust 


\section{REDBUD \\ Judas Tree.}

Cercis canadensis $\mathrm{L}$.

НАВIT-A small tree up to $40 \mathrm{ft}$. in height though generally smaller, developing an upright or a low, broad, irregular head.

BARK-Reddish-brown to almost black, somewhat ridged and scaly.

TWIGS-Slender, dark reddish-brown, smooth, more or less zigzig. LENTICELS-very numerous, minute. PITH-especially of older growth, generally with reddish longitudinal streaks.

LEAF-SCARS-Alternate, 2-ranked, small, slightly raised, inversely triangular, with short, decurrent, spreading, more or less evident ridge from outer edges. STIPULE-SCARS-absent. BUNDLE-SCARS-3, large.

BUDS-Terminal bud absent, lateral buds small, $3 \mathrm{~mm}$. long, or generally much smaller, blunt, dark purplish red, somewhat flattened and appressed, one or more superposed buds often present the uppermost the largest; flower buds conspicuously present on older wood often at the base of a branch (see plate) or even on the trunk itself. BUD-SCALES-overlapping, somewhat hairy on the edges, about 2 visible to a leaf bud, several to a flower bud.

FRUI'T-A flat pod about 3 inches long, with small compressed seeds.

COMPARISONS-The stout purplish flower buds below the insertion of the branches on the old wood will serve to identify this small tree. The reddish streaks in the older pith seem to be a constant character so far as investigated and if so will be a useful mark of distinction.

DISTRIBLTION-Not native to New England but frequently planted as an ornamental tree. It grows native along the borders of streams and rich bottom land from Ontario to New Jersey south to Florida and west to Minnesota and Arkansas.

WOOD-Heavy, hard, not strong, close-grained, rich dark brown tinged with red, with thin lighter colored sapwood of 8-10 layers of annual growth; of littie commercial importance. 


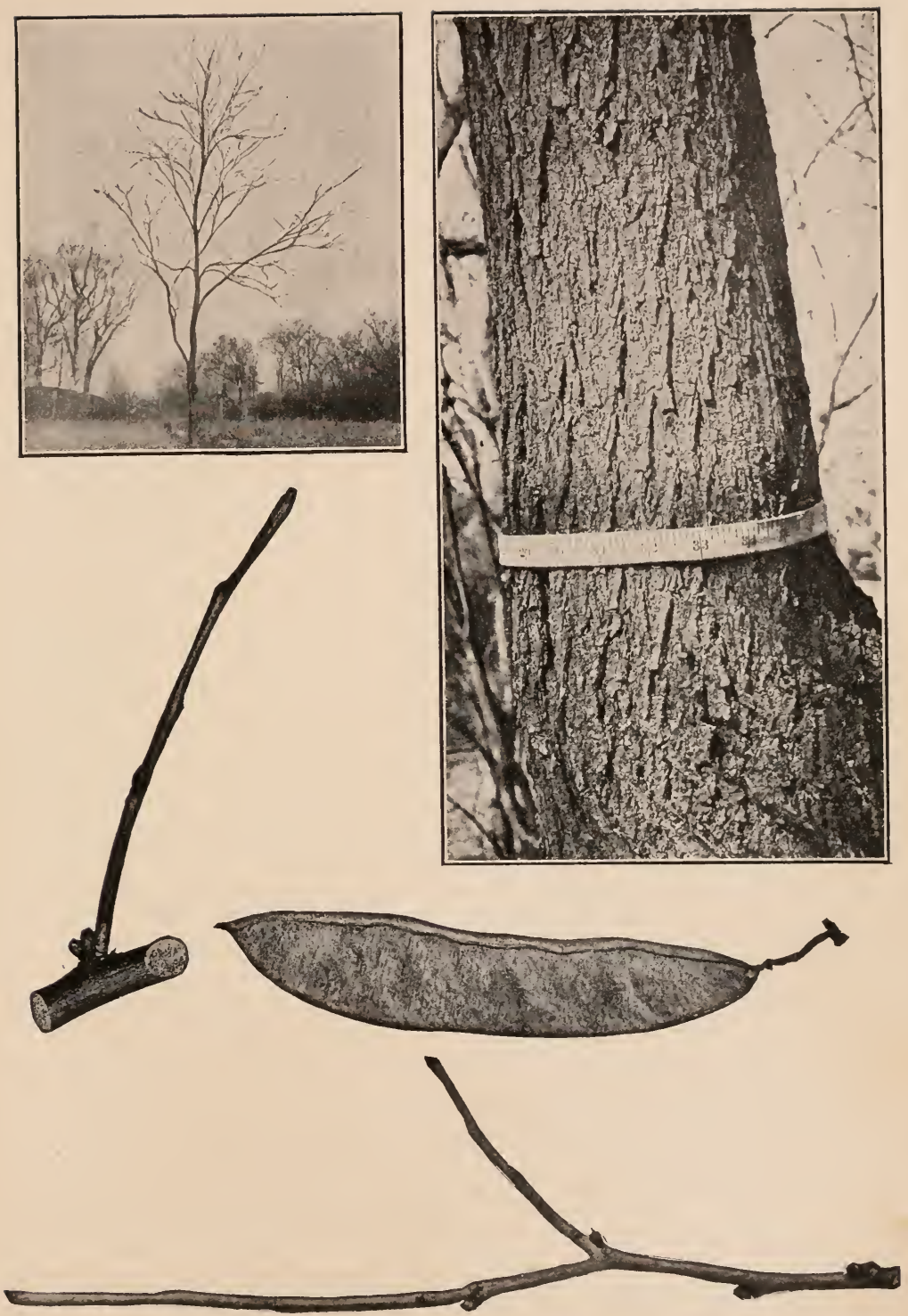

Redbud 


\section{YELLOW WOOD Virgilia, Gopher Wood.}

Cladrastis lutea (Mx. f.) Koch.

HABIT-A small tree under $50 \mathrm{ft}$. in height with trunk diameter of 1-2 ft.; trunk generally dividing low down into several slightly spreading limbs with numerous slender more or less zigzag branches, the lower often strongly declined, forming a broad rounded head.

BIRK-Thin, gray to light brown, in general smooth, resembling bark of the Beech with slight protuberances or ridges and horizontal wrinkles.

TWIGS-Rather slender, more or less zigzag, brittle, smooth bright reddish-brown, covered often by a grayish skin, odor and taste resembling that of a raw dried pea or bean. LENTICELS-pale, scattered, generally conspicuous. PITH-wide, white, round in section.

LEIF-SCARS-Alternate, 2-ranked, or more than 2-ranked, raised, pale yellow, forming a V-shaped collar of almost uniform diameter nearly encircling the bud. STIPULE-SCARS-absent. BUNDLE-SCARS -typically 5 (4-9) generally regularly spaced and raised or at times some of the five indistinct or lacking.

1.UDS-Terminal bud absent, lateral buds naked, superposed, 3-4, the uppermost the largest and generally alone developing, flattened, closely packed together to form a pointed bud-like hairy cone generally under $5 \mathrm{~mm}$. long, nearly surrounded by the leaf-scar. BUD-SCALESabsent, their place taken by the densely hairy immature leaves.

FRUIT-A smooth flat margined pod 5-10 $\mathrm{cm}$. long, containing a few small oblong compressed seeds.

Comp.IRIsons-The Yellow Wood is well characterized by its beech-like bark, its slender twigs, and its superposed hairy buds closely clustered into a bud-like cone and practically surrounded by the leafscar and is therefore scarcely to be confused with any other tree.

DISTRIBLTION-In rich soil, limestone ridges and often along mountain streams, rare and local. Western North Carolina, Kentucky, Tennessee, Alabama, Missouri; often cultivated in New England as an ornamental tree.

Woon-Heavy, very hard, strong and close-grained, with a smooth, satiny surface, bright, clear yellow changing to light brown on exposure, with thin nearly white sapwood; used for fuel, occasionally for gun stocks and yielding a clear yellow dye. 

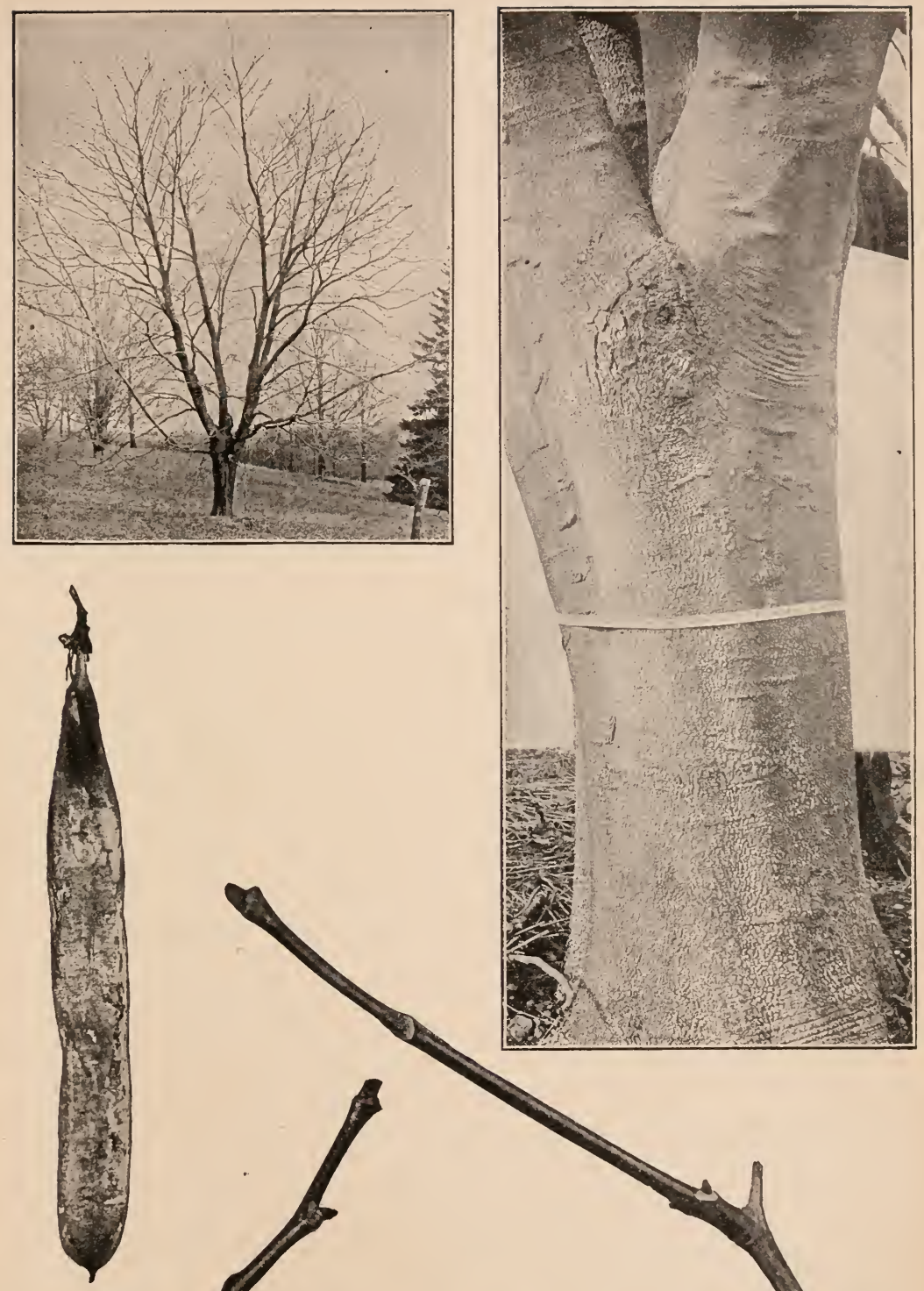


\section{COMMON LOCUST \\ Black, Yellow or White Locust, Locust, Acacia. Robinia Pseudo-Acacia L.}

HADIT-Generally a small tree 20-35 ft. or occasionally 50-75 $\mathrm{ft}$. in height with a trunk diameter of eight inches to $2 \frac{1}{2} \mathrm{ft}$.; trunk erect or inclined, frequently dividing into a number of ascending limbs with slender scraggly branches forming a narrow oblong open head; often spreading by underground stems and forming thickets of small trees. A rapidly growing tree but short lived and subject to the attacks of borers.

B.IRK-Rough even on young trunks, dark reddish to yellowishbrown, becoming deeply furrowed into rounded ridges, not flaky.

TWIGS-Rather slender, brittle, often zigzag, light reddish to greenish-brown, smooth or nearly so, more or less angled with decurrent ridges from base and outer angles of leaf-scars, generally spiny with paired stipular prickles at nodes. LENTICELS-pale, scattered. PITH -wide, more or less angled.

LEAF-SCARS-Alternate, more than 2-ranked, generally large and conspicuous, inversely triangular to pentagonal, raised, covering the buds. STIPULES-in the form of prickles, sometimes poorly developed or entirely lacking. BUNDLE-SCARS-3.

BLDS-Terminal bud absent; lateral buds minute, rusty-downy, 3-4 superposed, generally close together, enclosed in a rusty-downy cavity below the leaf-scar, which cracks between the bundle-scars at the development of a branch usually from the uppermost bud exposing the long rusty hairs attached to under side of the three persistent lobes of the leaf-scar; on rapidly grown shoots, the uppermost bud often develops into a branch the first season, which may be rudimentary and deciduous, leaving a small scar above leaf-scar.

FRUIT-A dark brown flat pod, 5-10 $\mathrm{cm}$. long, containing 4-8 small brown mottled flattish seeds, persistent on the tree throughout the winter.

CONPIRISONS-The paired prickles at the nodes form the most striking character of the Common Locust but since they are absent on some twigs and entirely lacking on certain varieties, the hidden, closelypacked downy buds must be taken as the chief distinguishing features. They separate the Common Locust from the Honey Locust when the characteristic branched thorns are not present on the latter species. The Clammy Locust [Robinia viscosa Vent.] is a small southern tree frequently cultivated and established at many points throughout New England. It has the general characters of the Common Locust but the stipular prickles are less well developed and its twigs are covered with a sticky glandular coating. The Bristly Locust [Robinia hispida L.] is a mere shrub with twigs beset with bristly hairs but generally without stipular prickles. The Prickly Ash or Toothache Tree [Zanthoxylon americanum L.], a shrub occurring throughout New England, resembles the Locust in its stipular prickles (lower twig in plate). It is readily distinguished from the Locusts, however, by the red downy exposed clustered buds, the presence of a terminal bud and the pungent flavor of its twigs.

DISTRIIITION-In its native habitat growing upon mountain slopes, along the borders of forests, in rich soils. Naturalized from Nova Scotia to Ontario. Native from southern Pennsylvania along the mountains to Georgia; west to Iowa and southward. Formerly much planted as an ormamental and timber tree; more cultivated in Europe than any other American tree.

IN NEW ENGLAND-Maine-thoroughly at home, forming wooded banks along streams; New Hampshire-abundant enough to be recl ined among the valuable timber trees; Vermont-escaped from cultivation in many places; Massachusetts, Connecticut and Rhode Island-common in patches and thickets and along the roadsides and fences.

WOOD-Heavy, exceedingly hard and strong, close-grained, very durable in contact with the soil, brown or rarely light green, with pale yellow sapwood of two or three layers of annual growth; extensively used in shipbuilding for all sorts of posts, in construction and turnery; preferred for tree nails and valued as fuel. 

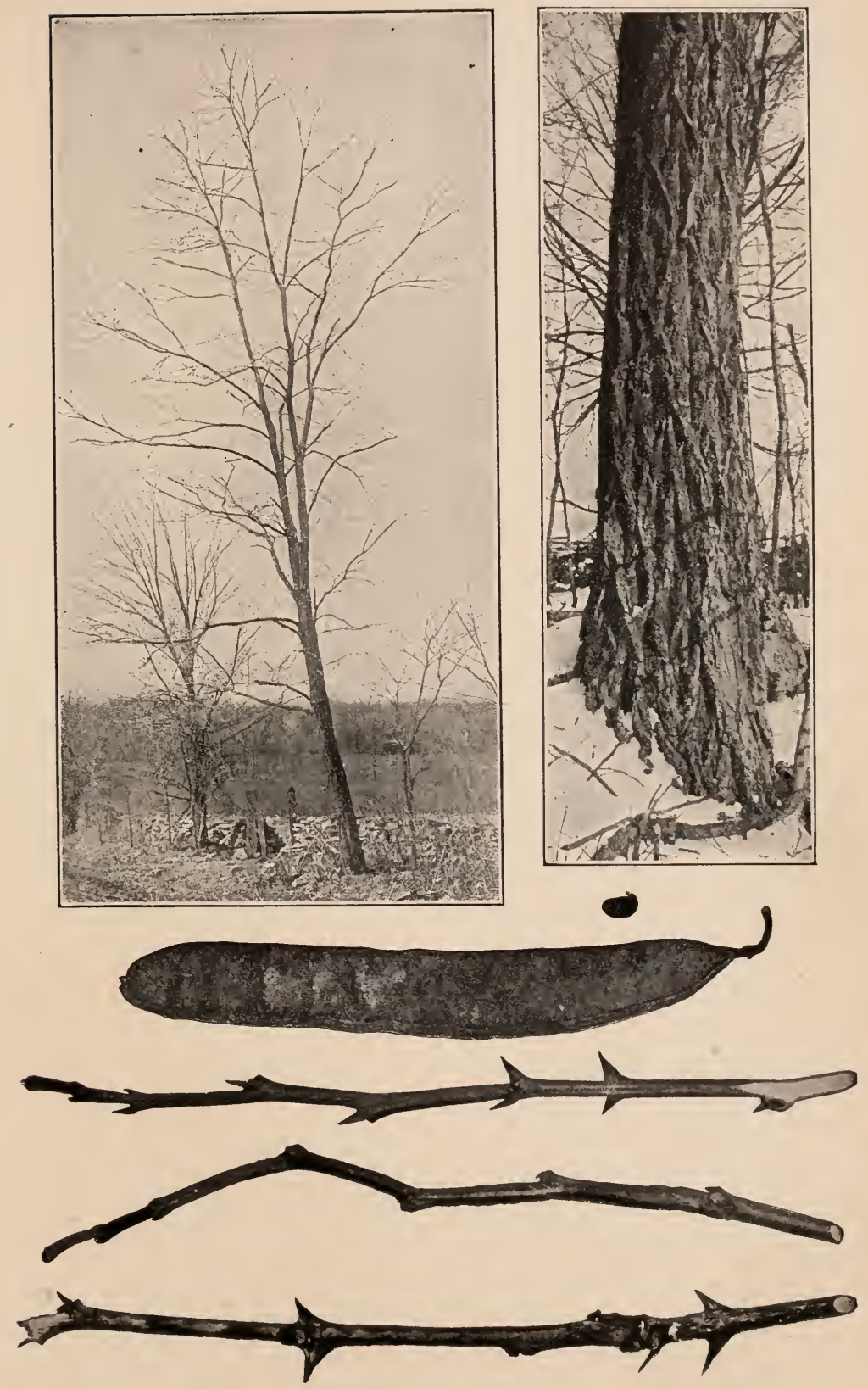

Common Locust

Prickly AsH (lower twig only) 


\section{AILANTHUS \\ Tree of Heaven, Chinese Sumach.}

Ailanthus glandulosa Desf.

HABIT-A small to good sized tree 50-75 $\mathrm{ft}$. in height with a trunk diameter of 2-3 ft.; forming a wide flat-topped head with stout branchlets devoid of spray; freely sprouting from the roots; the female trees which are more frequently planted than the male often retaining the clusters of winged fruit throughout the winter.

BARK-Grayish, slightly roughened with fine light colored longitudinal streaks in striking contrast to the darker background.

TWIGS-Stout, yellowish to reddish-brown covered with very short fine velvety down, or smooth, rather rank-smelling when crushed, older twigs often shedding the down in the form of a thin skin and exposing very fine light longitudinal striations below. LENTICELS-scattered, pale, somewhat longitudinally elongated becoming on older growth conspicuous more or less diamond-shaped cracks. PITH-wide, chocolate brown.

LEAF-SCARS-Alternate, more than 2-ranked, large, conspicuous heart-shaped. STIPULE-SCARS-absent. BUNDLE-SCARS-conspicuous, often compound or curved, generally under a dozen in number, forming a curved line.

BUDS-Terminal bud absent, lateral buds relatively small, generally under $4 \mathrm{~mm}$. long, half-spherical, reddish-brown, downy. BUD-SCALES -thick, the 2 opposite lateral scales generally alone showing.

FRUIT-About $4 \mathrm{~cm}$. long, winged, spirally twisted, the seed in the center borne in conspicuous clusters which frequently remain on tree during winter. The species is dioecious, there being male trees bearing only staminate flowers and hence producing no fruit and female trees bearing only pistillate flowers and producing fruit. Owing to the vile smelling character of the staminate flowers, the male trees are now seldom planted.

COMPARISONS-The Ailanthus in its stout twigs resembles somewhat the Kentucky Coffee Tree but its buds are solitary and not sunken, its pith is brown rather than salmon-colored and its bark is not ridged as is the bark of the Kentucky Coffee Tree. From the stout-twigged Black Walnut and Butternut it is distinguished by its solitary buds and continuous pith; from the Staghorn and Smooth Sumachs by its broad leaf-scars.

DISTRIBUTION-A native of China sparsely and locally naturalized in southern Ontario, New England and southward; a very rapid grower, thriving under the most unfavorable conditions of city existence.

wOOD-Light, brownish-yellow, with lighter sapwood, soft, weak, rather open-grained; in Europe used in the manufacture of woodesware and charcoal, little used in this country. 

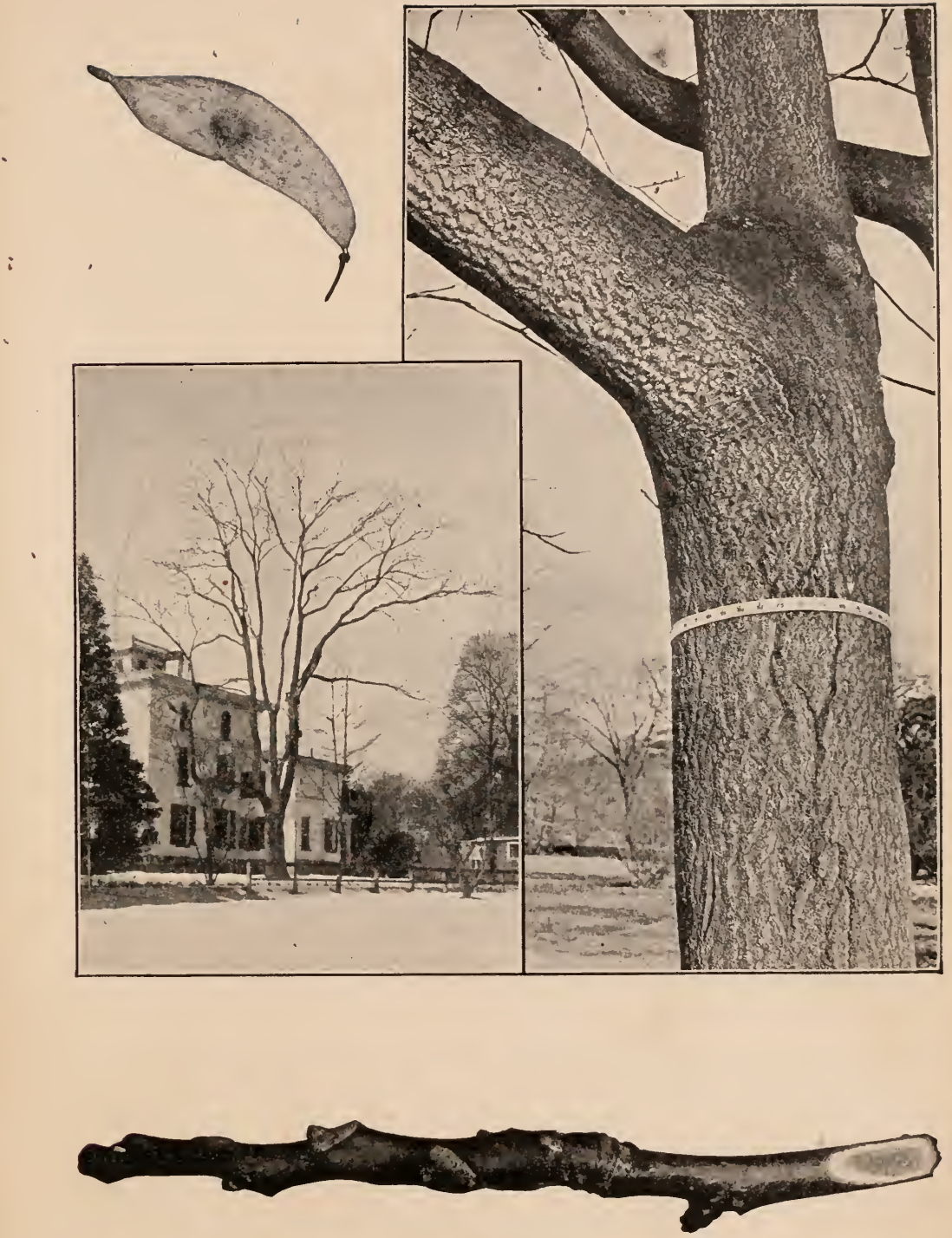

Ailanthits 


\title{
STAGHORN SUMACH
}

\author{
Rhus typhina L. \\ R. hirta (L.) Sudw.
}

(Left hand twig and lower habit picture in plate)

HABIT-A shrub or small tree rarely over $25 \mathrm{ft}$ in height with a trunk diameter less than a foot; making a straggling growth with forked branching forming a flat head with conspicuous red fruit clusters generally present and stout velvety branchlets; sprouting abundantly rom the roots and thus forming broad thickets.

BIRK-Thin, dark brown, smooth or in older trees more or less rough-scaly.

TWIGS-Stout, conspicuously covered with long velvety olive brown io almost black hairs, whence the common name from resemblance to a stag"s antlers in the "velvet"; the tips often killed back several inches by the frost; cut twig exuding a copious white milky.juice LENTICELS-conspicuous except as covered by the hairs, orange colored, becoming laterally enlarged rough dots on older growth. PITH -wide, yellowish brown.

LEAF-SCARS-Alternate, more than 2-ranked, deeply V-shaped, almost encircling the bud. STIPULE-SCARS-absent. BUNDLE-SCARS -scattered or frequently arranged in 3 groups, generally not con-
spicuous.

BUDS-Terminal buds absent, lateral buds conical, densely coated with long rusty hairs.

FRIIT-In rather compact, erect, cone-like clusters; individual fruits, drupes about $4 \mathrm{~mm}$. in diameter, coated with acid-tasting red hairs and enclosing a small bony-covered seed. It is said that a good lemonade or "sumachade" may be made by extracting the acid from the drupes with water and sweetening to taste. The conspicuous red fruiting clusters are persistent throughout the winter but, since the species tends to be dioecious, are not borne by all trees.

COMPIISISONS-A somewhat smaller form, the Smooth Sumach [Rhus glabra L.], closely resembles the Staghorn Sumach in habit, twig and fruit characters, but the twigs are smooth (except the fruit stalks which may be downy) and generally are covered with a bloom. (See twig on right and upper habit picture in plate.) The Dwarf Sumach [Rhus copallina L.] is generally smaller in New England than the other Sumachs. It has red fruit clusters like the Smooth and the Staghorn Sumachs but is distinguished from these two forms by the watery instead of white milky juice, by the leaf-scars which do not surround the bud and by the turpentine flavor to the young twigs. For comparison with the Poison Sumach see latter species.

DISTRIBITION-In widely varying soils and localities, river banks, rocky slopes to an altitude of $2,000 \mathrm{ft}$, cellar holes and waste places generally, often forming copses. From Nora Scotia to Lake Huron; south to Georgia; west to Minnesota and Missouri.

IN NEW ENGLAND-Common throughout.

WOOD-Light, brittle, soft, coarse-grained, orange-colored, streaker with green, with thick nearly white sapwood. Pipes for drawing the sap of the Sugar Maple are made from the young shoots. The bark especially of the roots is rich in tannin. 

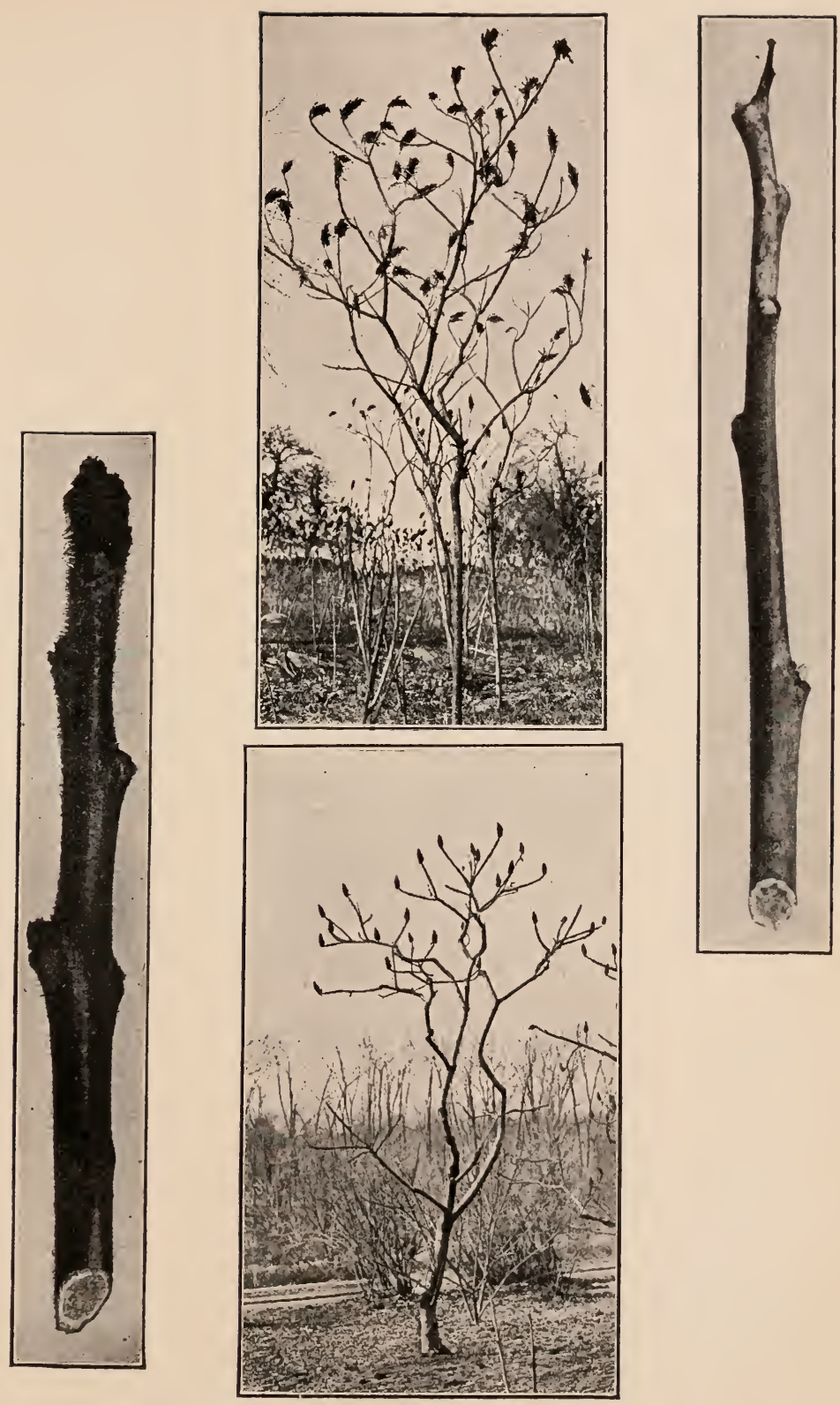

Staghorn and Smooth Sumach 


\section{POISON SUMACH \\ Poison Dogwood, Poison Elder, Swamp Sumach. \\ Rhus Vernix L.}

R. venenata DC.

HABIT-A shrub or small tree 5-20 ft. in height with a trunk diameter reaching $8-10$ inches; trunk generally forking near the ground producing an open, rounded, bushy head.

BARK-Thin, light gray, smooth or slightly roughened with more or less conspicuous horizontally elongated lenticels.

TWIGS-Stout, brown to orange brown, older growth light gray, smooth with watery resinous juice turning black on exposure. LENTICELS-numerous, minute, raised dots. PITH-yellowish-brown.

LEAF-SCARS-Alternate, more than 2-ranked, comparatively large. conspicuous, inversely triangular, raised, upper margin straight, slightly depressed or elevated, pointed and projecting. STIPULE-SCARS -absent. BUNDLE-SCARS-conspicuous, irregularly scattered in a closed ring or a single curved line.

BUDS-Terminal buds present, small but larger than laterals; shortconical, 3-20 mm. long, purplish. BUD-SCALES-finely downv on the back and margins.

FRIIT-A globular, slightly compressed, striate drupe about $5 \mathrm{~mm}$. in diameter, very shiny, ivory white or yellowish-white, generally persistent through the winter in long pendant clusters. The species is dioecious, however, and therefore some trees do not fruit.

COMPARISONS-From the other Sumachs the Poison Sumach is distinguished by the presence of a terminal bud, its broad leaf-scars not encircling the bud, with conspicuous generally scattered bundle-scars. The loose elusters of white fruit are distinctive when sresent. The Poison Sumach is almost entirely confined to swamps or wet places while the other Sumachs grow for the most part in dryer situations. The Poison Sumach resembles its climbing relative the Poison Ivy [Rhus Toxicodendron L.] in that all parts of the plant at all times of the year contain an oil poisonous to the touch, only more actizely so. Some individuals are more and others less susceptible. A preventive against the poison is thoroughly to wash as soon as possible in strong alcohol or strong soap suds the parts of the body that have come in contact with the plant.

DISTRIBUTION-Low grounds and swamps; occasional on the moist slopes of hills. Infrequent in Ontario; south to northern Florida; west to Minnesota and Louisiana.

IN NEW ENGLAND-Maine-local and apparently restricted to the southwestern sections; as far north as Chesterville, Franklin county; Vermont-infrequent; common throughout the other New England states, especially near the seacoast.

WOOD-Light, soft, coarse-grained, light yellow, streaked with brown, with lighter colored sapwood. The juice can be used as a black lustrous durable varnish. 

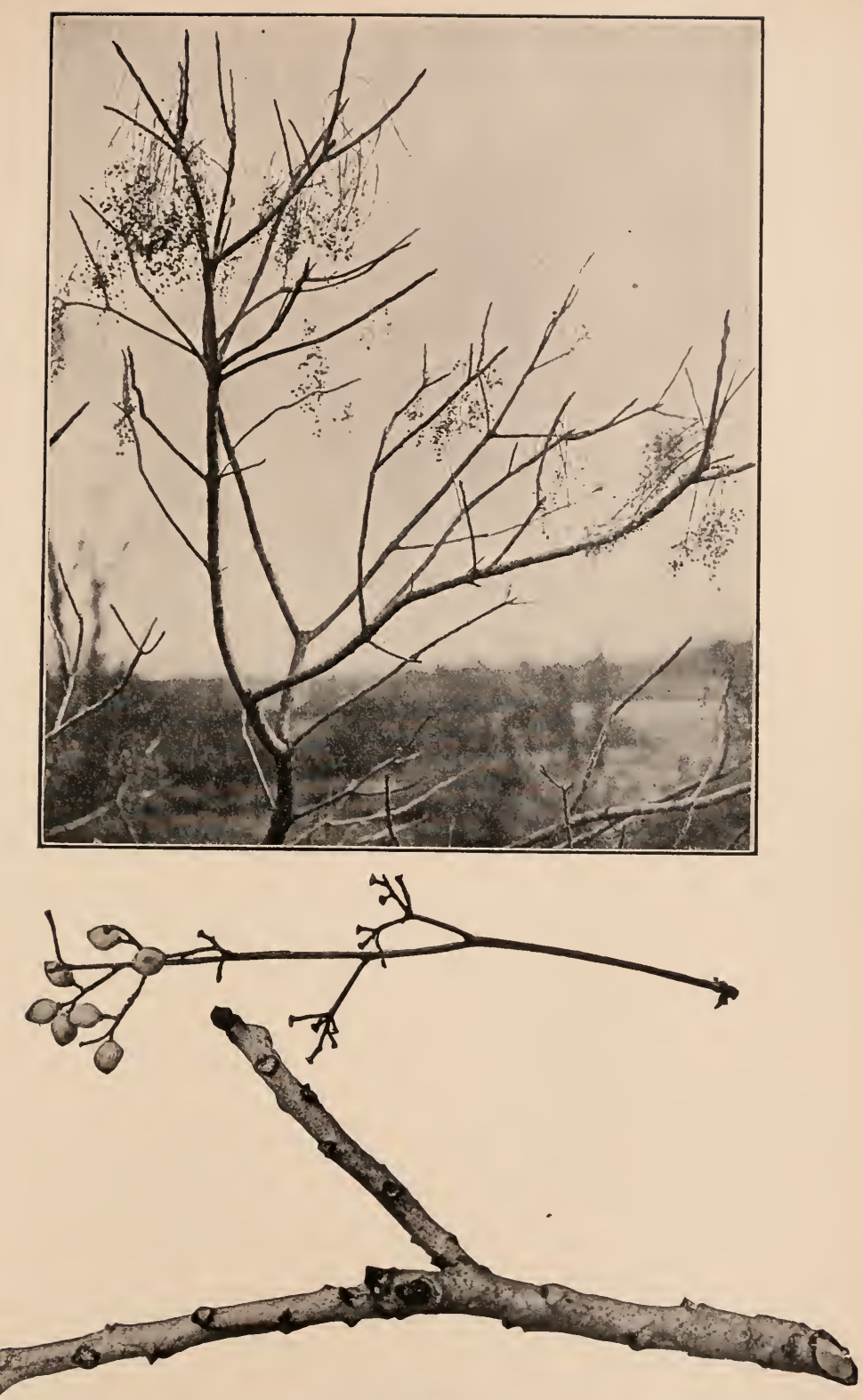

Poison Sumacit 


\section{HOLLY \\ American Holly, White Holly.} Ilex opaca Ait.

HABIT-A shrub or small tree, rarely reaching $30 \mathrm{ft}$. in height, with a trunk diameter of 15-18 inches; larger south and west; with slender horizontal drooping or slightly ascending branches forming a compact conical head with spiny evergreen leaves.

BIRK-Light gray, smooth becoming somewhat roughened with age.

TWIGS-Rather slender, grayish to yellowish brown, smooth or more or less downy. LENTICELS-inconspicuous.

LEAF-SCARS-Alternate, more than 2-ranked, semi-oval. BUNDLESCARS-solitary.

LEAVES-Thick, evergreen, elliptical to obovate, spiny-tipped and with few spiny teeth or rarely entire, dull yellowish-green above, pale and yellower beneath; midrib prominent beneath, with short, stout slightly fine-downy leaf-stalks, groove above. STIPULES-minute, awl-shaped, persistent.

BUDS-Short, blunt, roundish, more or less downy, terminal bud pointed.

FRUIT-Persistent through the winter, about the size of a pea, dull red or rarely yellow, berry-like, with four ribbed nutlets. Some trees bear only sterile flowers and therefore never produce fruit.

COMPARISONS-The American Holly closely resembles the cultivated European Holly [Ilex Aquifoilum L.] but the leaves of this latter species are described as glossier, of a deeper green color, more wavymargined with whitish translucent edges, and the berries as of a deeper red color.

DISTRIBUTION-Generally found in somewhat sheltered situations in sandy loam or in low, moist soil in the vicinity of water. Massachusetts, southward to Florida; westward to Missouri and the bottom-lands of eastern Texas.

IN NEW ENGLAND-Maine-reported on the authority of Gray's Manual, sixth edition, in various botanical works but no station is known; New Hampshire and Vermont-no station reported; Massachusetts-occasional from Quincy southward upon the mainland and the Island of Naushon; rare in the peat swamps of Nantucket; Connecticut -rare; roadsides and thickets; escaped from cultivation or possibly native; Rhode Island-common in South Kingst on and Little Compton and sparingly found upon Prudence and Conanicut islands in Narragansett Bay.

WOOD-Light, tough, not strong, close-grained, nearly white when first cut, turning brown with age and exposure, with thick rather lighter colored sapwood, valued and much used in cabinet making, in the interior finish of houses and in turnery; the branches are much used in Christmas decorations. 

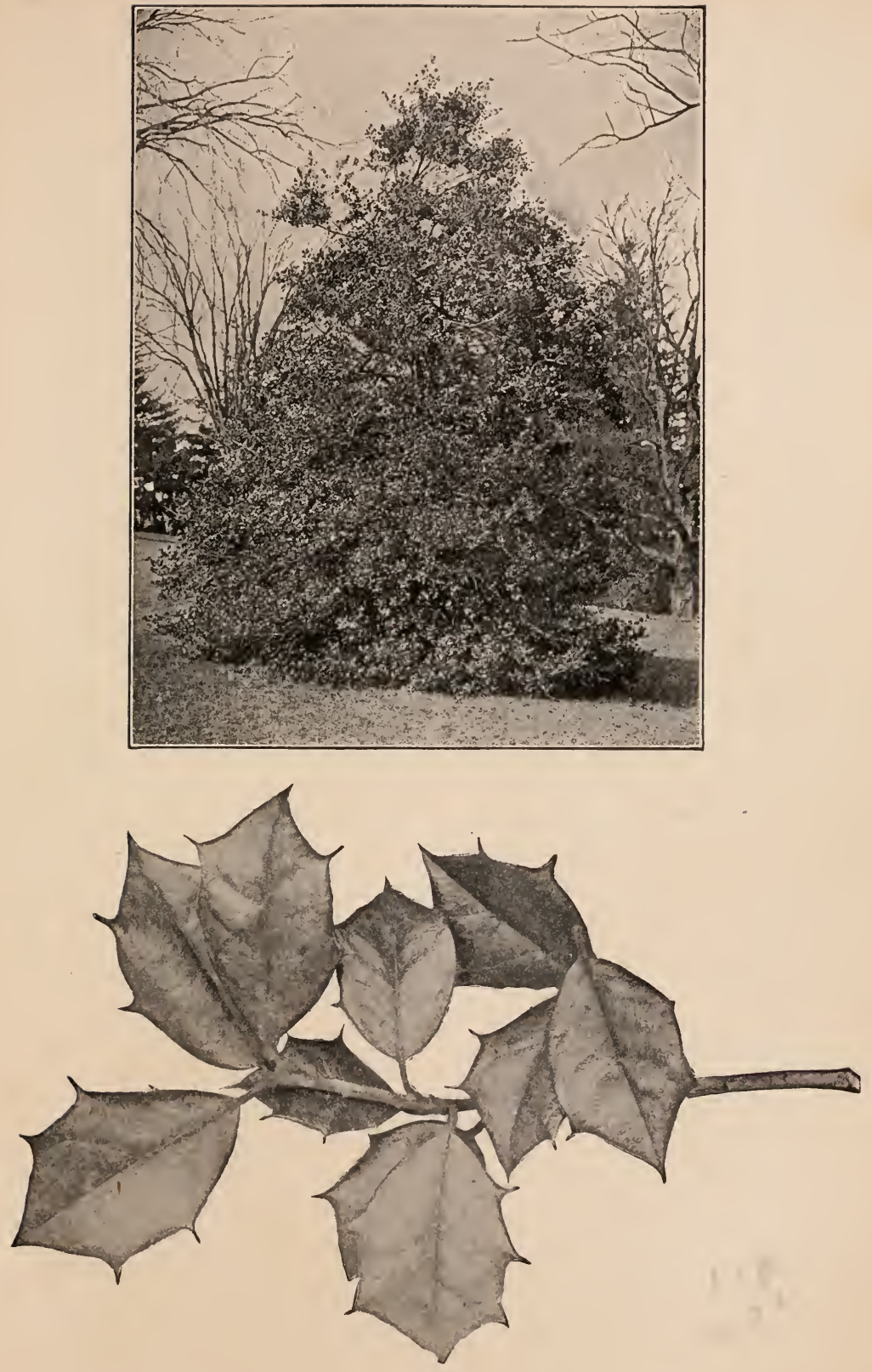

Holly 


\section{STRIPED MAPLE Moosewood, Whistlewood.}

Acer pennsylvanicum $\mathrm{L}$.

HABIT-A shrub or small tree 15-30 ft. high with a short trunk 5-10 inches in diameter and slender straight branches, forming in northern New England a large part of the underbrush and a favorite food of moose and deer whence the name of Moosewood.

BARK-Rather thin, smooth, reddish-brown or dark green, conspicuously streaked longitudinally with narrow white lines, at length dark gray, often transversely warty.

TWIGS-Stout, smooth, red or green; year's growth marked by two circles formed by scars of the two outer pairs of bud-scales. LENTICELS-inconspicuous. PITH-brownish.

LEA F-SCARS-Opposite; wide, broadly V-shaped; their adjacent edges nearly meeting and forming a pair of short stubby teeth separated by a more or less well developed decurrent ridge. BUNDLE-SCARS-3, generally more or less compounded forming often 5 to 7 separate bundle-scars.

BUDS-Distinctly stalked, 6-10 $\mathrm{mm}$. long exclusive of the rather long stalk, tapering to a blunt tip, red, shining, more or less 4 -sided; terminal bud larger than appressed lateral buds. BUD-SCALES-the thick, red, single, outer pair only visible, enclosing an inner pair of thick palehairy scales, within which are enclosed one or more pairs of thin green scales.

FRUIT-In long drooping terminal racemes with thin widely spreading wings; $2-2.5 \mathrm{~cm}$. long, seed-like portion rather long with a pit-like depression on one side; the elongated racemes from which the fruit has fallen often remaining on tree throughout winter.

COMPARISONS-Easily distinguishable at all times from all other Maples by the striking white streaks in the young bark which appear often as early as the second year (see photograph of twig), and persist even on comparatively old trunks. The large stalked buds are also characteristic. The brown pith of the twig and the one-sided pitting of the seed-like portion of the fruit are characters which distinguish the Bush Maples (i.e. the Mountain and the Striped) from our other species of the genus. Forms of the genus Viburnum, which are for the most part shrubs, resemble somewhat the Bush Maples, but, aside from having drupe-like fruits, may generally be easily distinguished by bud characters-some having naked, others scurfy buds, some with the first pair of scales shorter than the bud and some with the second pair of scales smooth.

DISTRIBUTION-Cool, rocky or sandy woods, usually in the shade of other trees. Nova Scotia to Lake Superior; south on shaded mountain slopes and in deep ravines to Georgia; west to Minnesota.

IN NEW ENGLAND-Maine-abundant, especially northward in the forests; New Hampshire and Vermont-common in highland woods; Massachusetts-common in the western and central sections, rare towards the coast; Connecticut-occasional in the northwestern part of the state, becoming rare eastward and southward, reaching Ashford, East Haddam, Huntington and Redding; Rhode Island-frequent northward.

WOOD-Light, soft, close-grained, light brown with thick lighter colored sapwood of 30-40 layers of annual growth. 

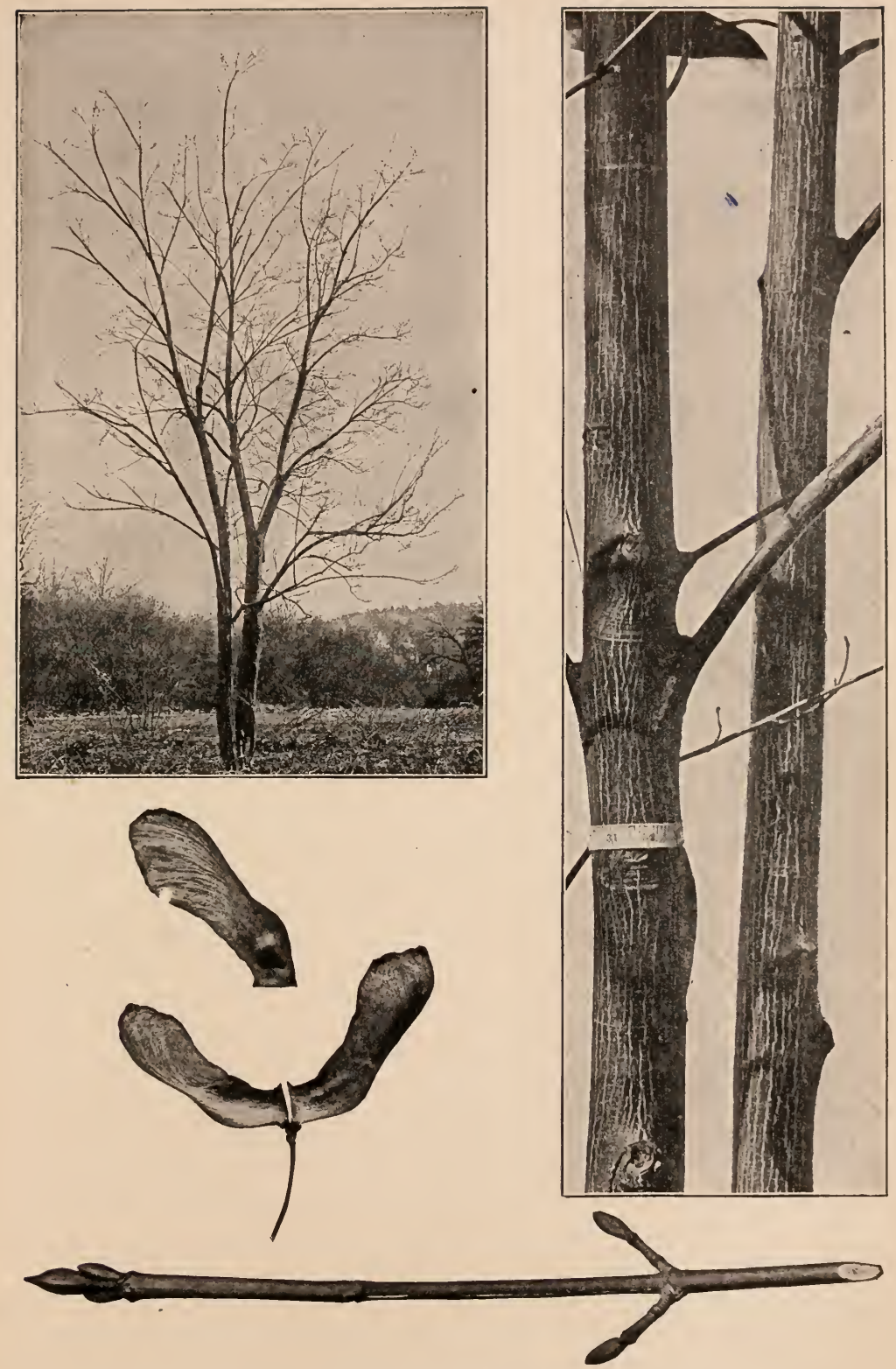

Striped Mífple 


\title{
MOUNTAIN MAPLE
}

\author{
Acer spicatum Lam.
}

HABIT-Shrub or small bushy tree up to $25 \mathrm{ft}$. in height with a trunk diameter of $6-8$ inches; trunk short, straight, with slender upright branches.

BARK-Very thin, reddish-brown to dingy-gray, smooth or slightly furrowed or warty.

TwIGS-Slender, bright red to purple on upper side where exposed to the light, yellowish to greenish on shaded under side, color persisting for several years; ccvered especially toward tip with short appressed grayish hairs, which may persist in scant amount for several years toward upper part of each year's growth. Year's growth marked by 2-3 circles formed by scars of bud-scales. LENTICELS-few, inconspicuous. PITH-brownish.

LEAF-SCARS-Opposite, narrow, V-shaped, margined by a lighter colored and more or less raised rim, nearly meeting. BUNDLE-SCARS3 , undivided.

BUD-Stalked, small, slender, pointed; generally under $6 \mathrm{~mm}$. in length including stalk, red or greenish, covered, especially the terminal buds, with short appressed grayish hairs; terminal bud larger than appressed lateral buds. BUD-SCALES-thick, 2-3 pairs, one or at most 2 pairs visible, the second pair hairy.

FRUIT-In drooping racemes with wide more or less spreading wings about $2 \mathrm{~cm}$. or less long, seed-like portion short, with pit-like depression on one side.

COMPARISONS-Resembles the Striped Maple (which see) in habit, distribution, color of twigs and few scales to the stalked buds. It differs from the Striped Maple in absence of white streaks on young bark and by pale down on twigs and especially on the smaller buds.

DISTRIBUTION-Moist rocky hillsides usually in the shade of other trees. From Nova Scotia and Newfoundland to Saskatchewan, along mountain ranges to Georgia.

IN NEW ENGLAND-Maine-common, especially northward in the forests; New Hampshire and Vermont-common; Massachusetts-rather common in western and central sections, occasional eastward; Connecticut-occasional in the northern part of the state, becoming rare southward, reaching East Haddam, Guilford at Bluff Head, Meriden and Redding; Rhode Island-occasional northward.

wooD-Light, soft, close-grained, light brown tinged with red, with thick lighter colored sapwood. 

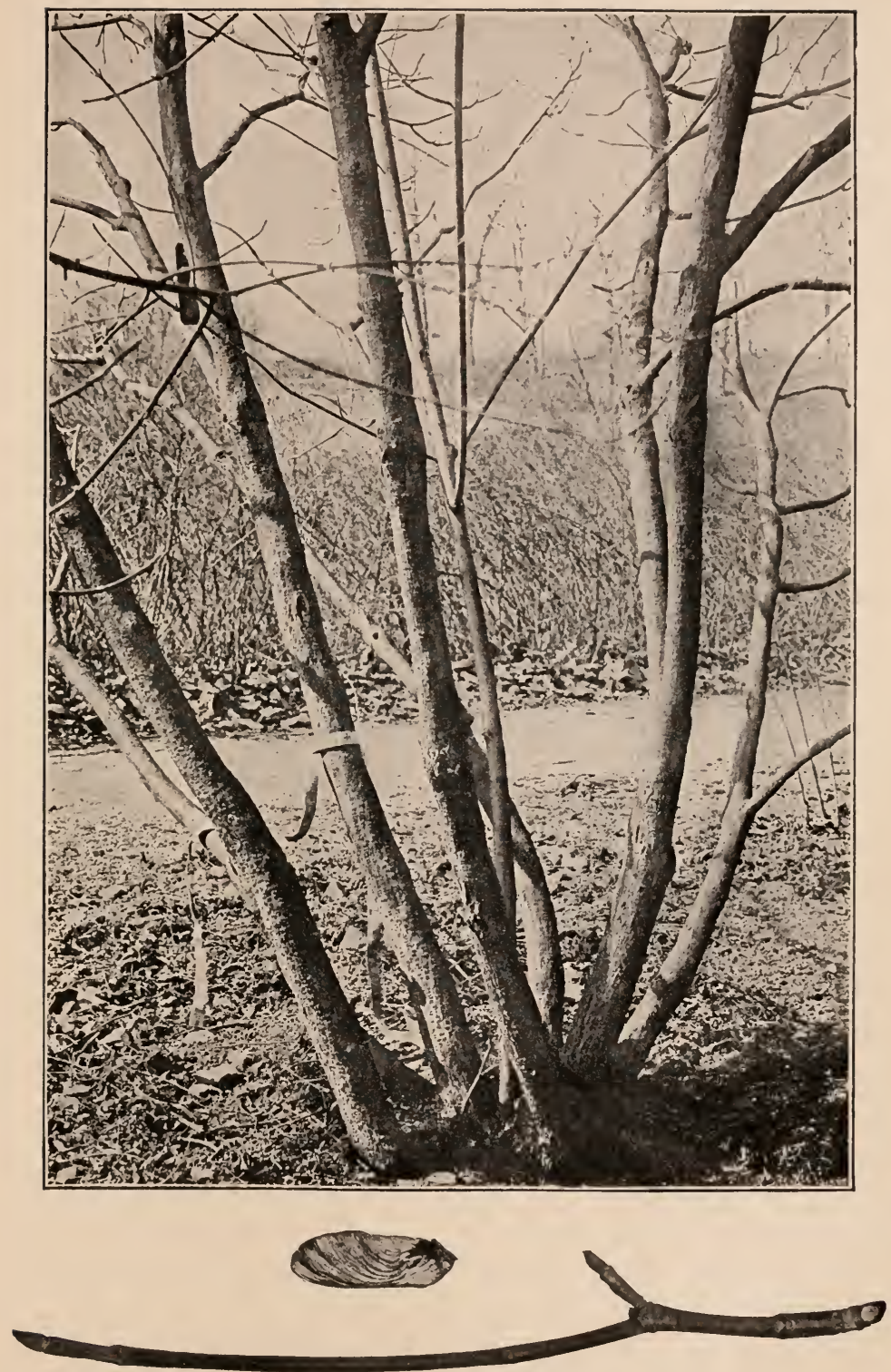

Mountain Maple 


\title{
SUGAR MAPLE Rock Maple, Hard Maple.
}

\author{
Acer saccharum Marsh.
}

\section{A. saccharinum Wang., not L. ; A. barbatum Michx.}

HABIT-A large tree 50-90 ft. in height, with trunk diameter of 2-5 ft.; trunk more or less continuous, in the open developing at $8-10 \mathrm{ft}$. from the ground stout, erect branches which form in young trees a broad or narrow egg-shaped head, becoming frequently a broad, roundtopped head when older. Leaves sometimes persistent into winter especially on lower branches of young trees.

BARK-On young trunks and limbs dark gray, with tinge of buff, close and firm, smooth or slightly fissured, becoming deeply furrowed into long, thick, irregular plates which often curve back along one edge, giving ploughed appearance to the trunk. Some trees are to be found with yellowish-gray, more or less flaky bark. (See upper bark picture.)

TWIGS-Slender, shining, reddish-brown to buff tinged with orange, smooth. LENTICELS-numerous, pale, conspicuous. PITH-whitish.

LFAF-SCARS-Opposite, narrow V-shaped; outer margins of a pair nearly meeting; often pale downiness within leaf-scar. BUNDLESCARS-3, sometimes compound.

BUDS-Conical to ovate, sharp-pointed, reddish-brown, rather downy especially toward tip; terminal bud 4-6 $\mathrm{mm}$. long; about twice as long as appressed lateral buds. BUD-SCALES-overlapping, 4-8 pairs visible, their margins finely hairy.

FRUIT-3-5 cm. long, in short terminal clusters, wings broad, parallel or slightly spreading.

COMPARISONS-The Sugar Maple is readily distinguished from other Maples by its narrow, conical, sharp-pointed, brown buds and by the large number of scales to the bud. The fruit clusters of the Sugar Maple are from terminal buds, those of the Red and the Silver Maple are from lateral buds. The fruiting of the Sugar Maple in consequence causes a noticeable forking of the twigs while it does not interrupt the growth in the Red and the Silver Maple. Further fruit stalks and sometimes even the fruits themselves are persistent into winter on the Sugar Maple and are not persistent on the Red and the Silver. The Black Maple [Acer saccharum, var. nigrum (Michx. f.) Britton] is found in the northern part of New England but is too closely related to the Sugar Maple to be considered a distinct species. It has darker buds and bark than the type form.

DISTRIBUTYON-Rich woods and rocky slopes, frequently planted by roadsides. Nova Scotia and Newfoundland; westward to Lake of the Woods; south to the Gulf States; west to Minnesota, Nebraska, Kansas and Texas.

IN NEW ENGLAND-Abundant, distributed throughout the woods, often forming in the northern portions extensive upland forests; attaining great size in the mountainous portions of New Hampshire and Vermont, and in the Connecticut river valley; less frequent toward the seacoast.

WOOD-Heavy, hard, strong, close-grained, tough, with a fine satiny surface, susceptible of receiving a good polish, light brown tinged with red, with thin sapwood of 30-40 layers of annual growth; largely used for the interior finish of buildings, especially for floors, in the manufacture of furniture and in turnery, in shipbuilding, shoe-lasts and pegs and largely as fuel. Accidental forms with the grain curled and contorted, known as Curly Maple and Bird's Eye Maple are common and highly prized in cabinet making. Maple sugar is principally made from the sap of this tree. 

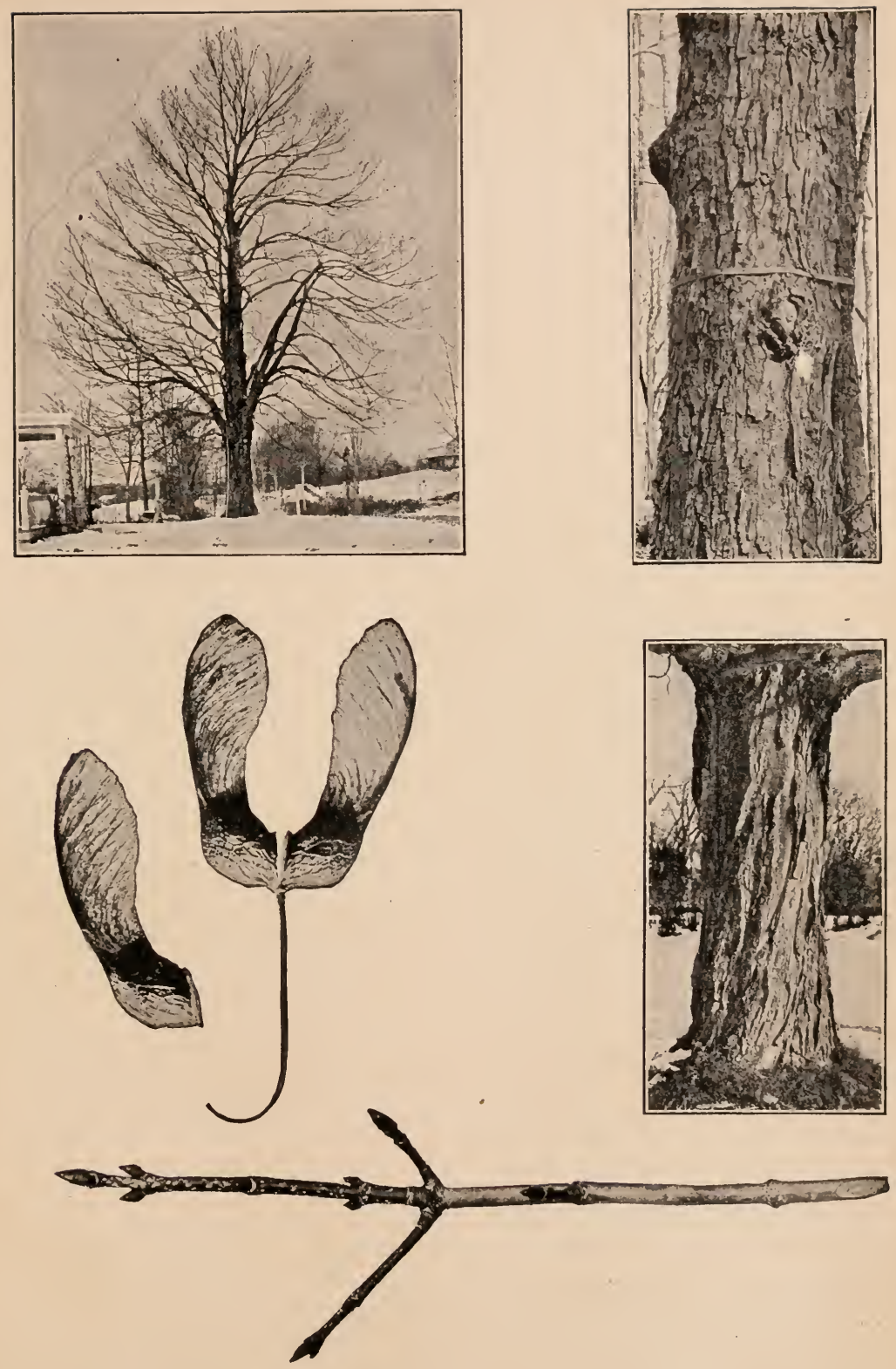

Sugar Maple 


\section{SILVER MAPLE \\ White, River, or Soft Maple.}

Acer saccharinum L.

A. dasycarpum Ehrh.

HABIT-A good sized tree 50-60 ft. high with trunk diameter of 2-5 ft.; dividing near the ground into several slightly spreading limbs which branch further up, forming a very wide, broad-topped head. Lateral branchlets strongly tend to grow downward and then curve sharply upward at their tips.

BARK-Smooth, gray, with reddish tinge on young trunks and branches; on older trunks reddish-brown more or less furrowed; the surface separating into long thin flakes which become free at the ends and flake off exposing the redder inner layers.

TWIGS-Similar to those of Red Maple but with a distinct rank odor when freshly cut or broken.

LEAF-SCARS-Similar to those of Red Maple.

BUDS-Similar to those of the Red Maple but generally somewhat larger, the flower buds more densely clustered with a larger number of buds in a cluster.

FRUIT-Large, 4-7 cm. long, wings spreading, in lateral clusters, ripening in early spring and therefore difficult to find in winter.

COMPARISONS-The Silver Maple closely resembles the Red Maple in twig characters but can be readily distinguished from the latter by the rank odor of the fresh twigs when broken. The flakiness of the bark of the Silver Maple is also distinctive. The bending down of the branchlets with a sharp upward curve at their tips while much more marked in the Silver Maple occurs to a certain extent in the Red and therefore cannot be depended upon alone as a distinctive character. If the flower buds be dissected out and examined with a hand-lens the immature flowers of the Silver Maple will be found to be surrounded by a cup-like calyx which in the Red Maple is made up of separate divisions. See under Red Maple for Comparisons with other species.

DISTRIBUTION-Along river banks and in moist, deep-soiled woods, not typically in swamps; often planted for ornament under the name of White Maple. Infrequent from New Brunswick to Ottawa, abundant from Ottawa throughout Ontario; south to the Gulf states; west to Dakota, Nebraska, Kansas and Oklahoma; attaining its maximum size in the basins of the Ohio and its tributaries; rare towards the seacoast throughout the whole range.

IN NEW ENGLAND-Occasional throughout; most common and best developed upon the banks of rivers and lakes at low altitudes.

woon-Hard, strong, close-grained, easily worked, rather brittle, pale brown with thick sapwood of 40-50 layers of annual growth; now sometimes used for flooring and in the manufacture of furniture. Sugar is occasionally made from the sap. 

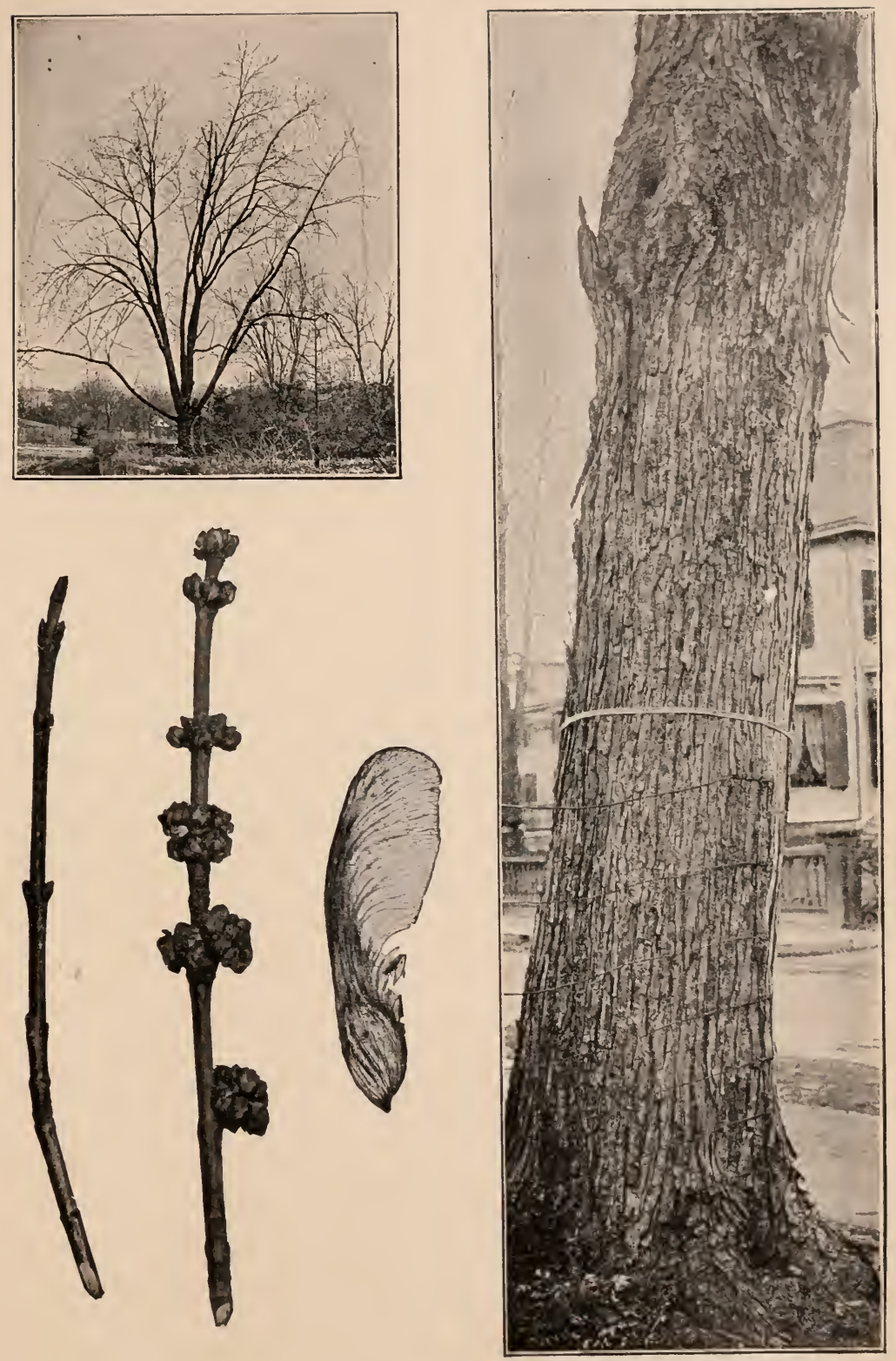

Silver Mifle 


\title{
RED MAPLE \\ Swamp, Soft or White Maple.
}

\author{
Acer rubrum L.
}

HABIT-A medium sized tree, 40-50 ft. high, occasionally in swamps reaching $75 \mathrm{ft}$. in height, with trunk diameter of $2-4 \mathrm{ft}$; branching low down and forming an oblong rather compact head, frequently largest at the top but sometimes broad at the base. Branches slender as well as branchlets, the latter showing slight tendency to turn up at their tips; horizontal or even declined limbs common at base; upper branches appearing decidedly gray and often resembling those of the Beech if viewed with the light.

BARI-Smooth, light gray on young trunks and branches; on older trunks very dark gray, roughened into long ridges, sometimes somewhat shaggy and separating in long plates (see right hand bark photograph); in some localities remaining smooth till a foot or more in diameter.

TWIGS-Rather slender, bright or dark red, shining; odorless wher cut. LENTICELS-numerous, conspicuous. PITH-pinkish toward upper part, at least of each year's growth beyond the second.

LEAF-SCARS-Broad, U to V-shaped, adjacent edges not meeting. BUNDLE-SCARS-3.

BUOS-Red, blunt-pointed, broadly oval-ovate to spherical in flower buds, generally under $5 \mathrm{~mm}$. long, short-stalked; flower buds numerous, stout, collateral (one on either side of smaller axillary bud). BUDSCALES-4 pairs or generally fewer visible with pale hairs on margins, outer pair of scales not over half covering the bud.

FRUIT-Small, generally under $3 \mathrm{~cm}$. long, wings spreading, in lateral clusters, ripening in spring and therefore difficult to find in winter.

COMPARISONS-The Red Maple closely resembles the Silver Maple in the winter condition. See Silver Maple under Comparisons for differences. The Red and the Silver Maple are distinguishable from our other Maples except the Box EIder by presence of collateral buds, and the numerous clusters of these flower buds give a characteristic beaded appearance to the twigs against the sky; from the Striped and Mountain Maples by the larger number of scales exposed in the bud; from the Striped and the Norway and Sycamore Maples by much smaller buds; from the Mountain Maple and the Box Elder by their smooth outer budscales; from the Sugar Maple by their red twigs and by their red, blunt buds with few scales. See under Sugar Maple.

DISTRIBUTION-Borders of streams, in low lands, wet woods and swamps or sometimes in dry ground, of rapid growth and a favorite for park planting but usually not adapted to city streets. Nova Scotia to the Lake of the Woods; south to southern Florida; west to Dakota, Nebraska and Texas.

IN NEW ENGLAND-Common throughout from the sea to an altitude of $3,000 \mathrm{ft}$. on Katahdin.

wooD-Very heavy, close-grained, not strong, light brown often slightly tinged with red, with thick, rather lighter colored sapwood; used in large quantities in the manufacture of chairs and other furniture, in turnery, for woodenware and gun-stocks, 

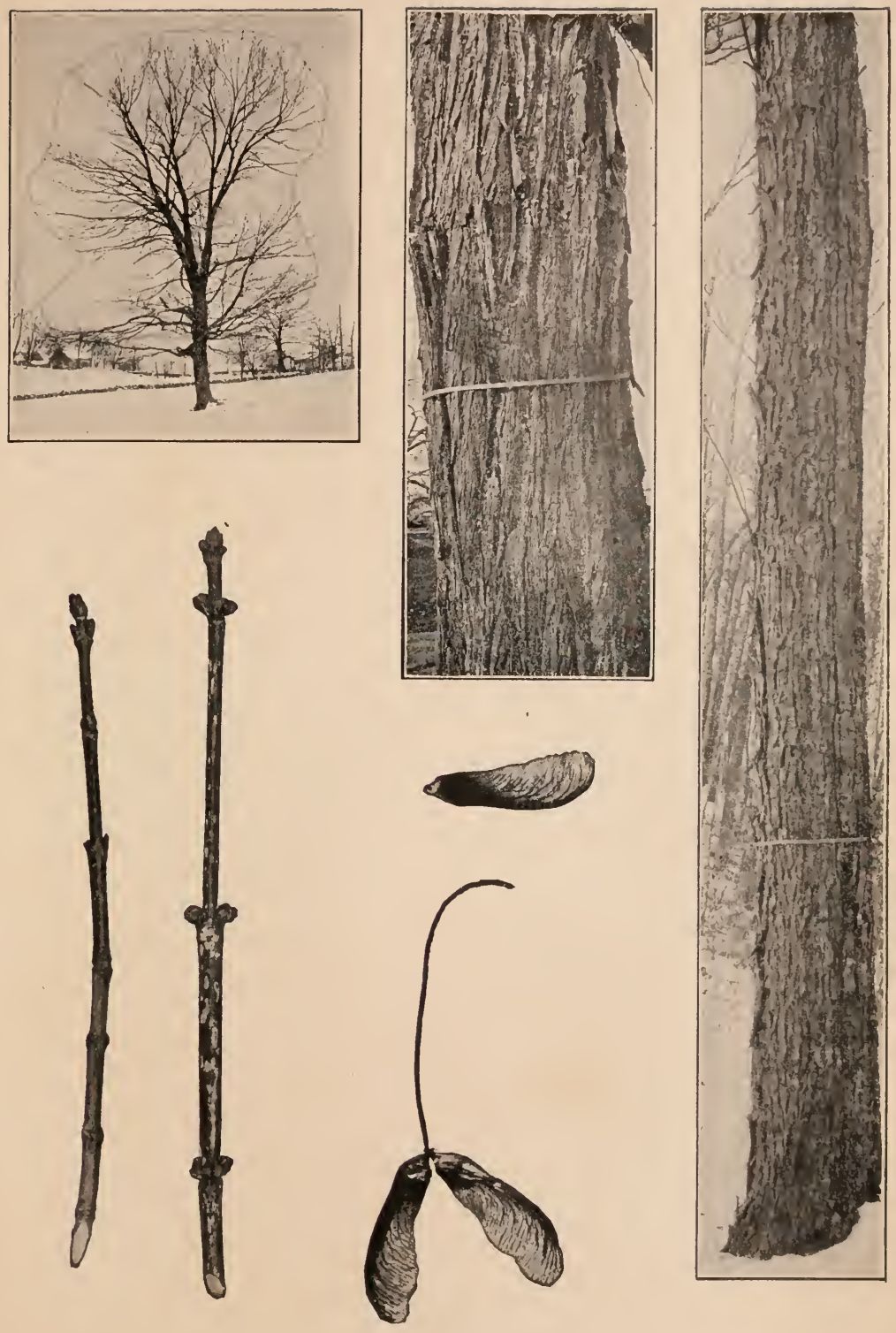

Ren Maple 


\title{
NORWAY MAPLE
}

\author{
Acer platanoides L.
}

HABIT-A mediumly large tree reaching in Europe $100 \mathrm{ft}$. in height, with round spreading head.

BARK-Dark, broken into firm, close, narrow ridges which run together and enclose small diamond-shaped spaces, somewhat resembling hark of White Ash but the ridges and diamond-shaped spaces are finer.

TWIGS-Stout, generally smooth and shining, brown to greenish or yellowish-brown, branchlets of two or more years growth and even vigorous season's shoots plainly streaked with fine, irregular, longitudinal cracks in bark.

LEAF-SCARS-Opposite, narrow V-shaped, half encircling the twig, the adjacent edges of opposite leaf-scars meeting and continued upward into a short tooth. BUNDLE-SCARS-3.

BUDS-Completely red or yellowish-green toward the base, sometimes whole bud strongly tinged with yellowish-green; terminal bud larger than lateral buds, $5-\delta \mathrm{mm}$. long, more than $1 / 2$ as broad as long, oval to ovate; generally with a pair of comparatively large lateral buds below terminal bud; lateral buds small, appressed. BUD-SCALESthick, more or less keeled, margin very finely hairy; scales to terminal bud generally 5 pairs-only 2, or at most 3 pairs showing, smooth but enclosing 2 pairs which are thickly covered with dark rusty-brown hairs; in small buds sometimes 4 pairs smooth and 1 pair hairy.

FRUIT-Generally over $5 \mathrm{~cm}$. long, seed-like portion flattish, with wings diverging in a straight line.

COMPARisons-The Norway Maple is easily distinguished from the Sycamore Maple by the redness of its buds, the brown hairiness of the inner scales, the ridging of the bark and the divergence of the wings of the fruit; from the native Maples by the large buds and the characteristically ridged bark.

DISTRIBLTION-A European form extensively cultivated as a shade tree being more tolerant of unfavorable city conditions than most other forms. Its low head, however, is a disadvantage for city street planting.

WOOD-Moderately heavy, hard, close-grained, white or yellowishwhite, fairly durable under cover but of short duration in the open; used in Europe by joiners, for finer wheelwrights' work, for carving, for mathematical instruments and for various other purposes. 

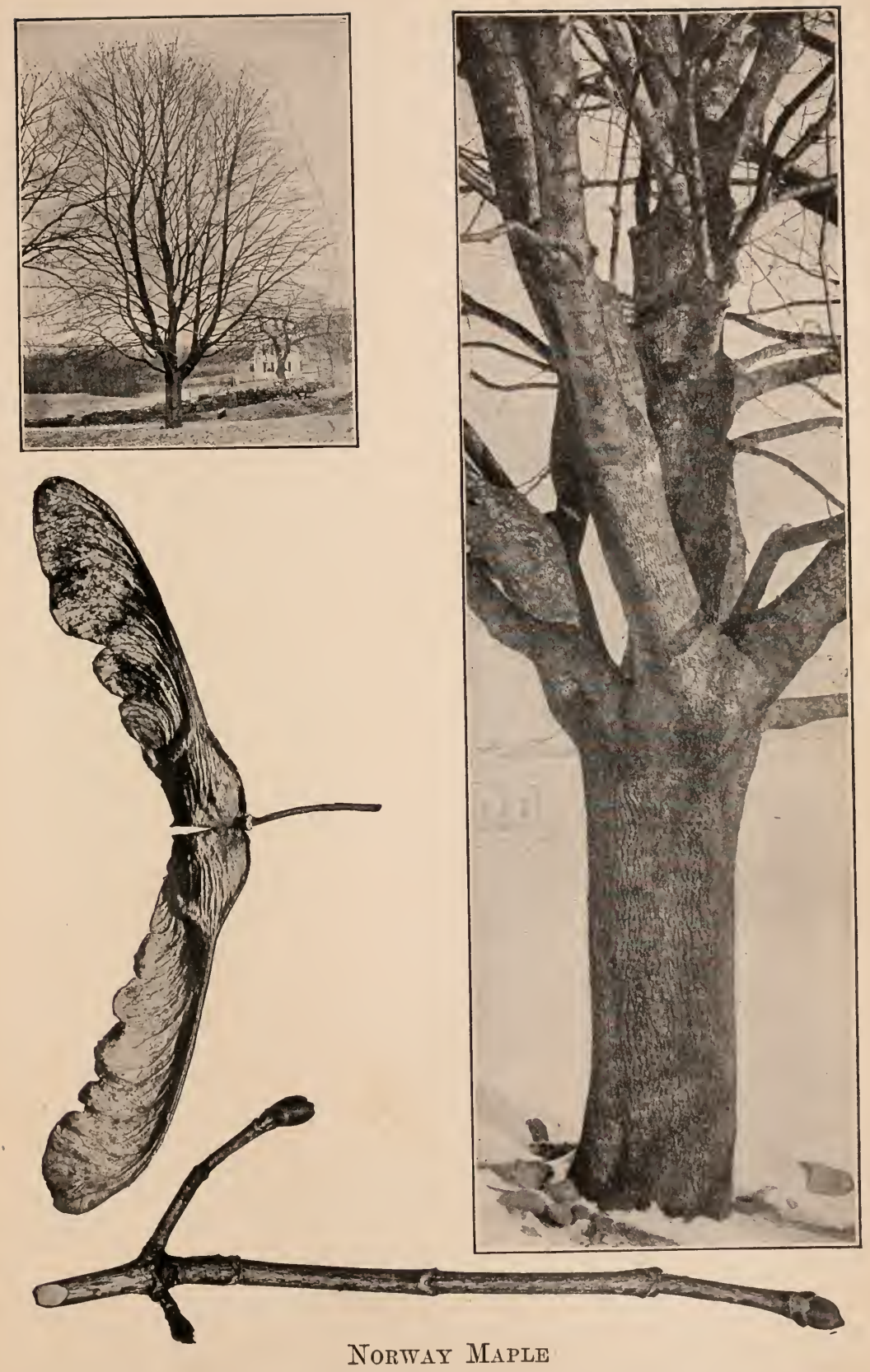


\title{
SYCAMORE MAPLE
}

\author{
Acer Pseudo-Platanus L.
}

HABIT-A rather large tree of vigorous growth, reaching in Europe $120 \mathrm{ft}$. in height, with large spreading head.

BMIK-Dark reddish-brown, flaking off in squarish or short oblong scales.

TWIGS-Stout, smooth, shining; yellowish-greenish to brown.

LEAF-SCARS-Opposite, shallow V-shaped; adjacent edges of opposite leaf-scars not meeting. BUNDLE-SCARS-3, elongated lengthwise with the leaf-scar or compound.

BIDS-Green, sometimes slightly reddish, terminal bud larger than lateral buds, 7-12 $\mathrm{mm}$. long, broadly oval to ovate to nearly spherical, much more than $1 / 2$ as wide as long; lateral buds divergent. BUDSCALES-more or less keeled, with dark brown edging, dark pointed apex and finely hairy margin; scales to terminal bud, 6-7 pairs, 3 pairs at least generally visible, the outer scales smooth, the 2 inner scales thickly covered with silvery white hairs.

FRUIT-Generally less than $5 \mathrm{~cm}$. long, seed-like portion nearly spherical, wings making about a right angle resembling fruit of the Sugar Maple.

COMPARISONS-Distinguished from the Norway Maple by the green buds, having outer scales with dark margins and white-hairy inner scales, and by the flaky bark; from the native Maples by the larger buds and the peculiar bark.

DISTRIBUTION-A European form, cultivated in the United States as a shade tree but less extensively than the Norway Maple.

WOOD-Similar in character to that of the Norway Maple and used for the same purposes. 

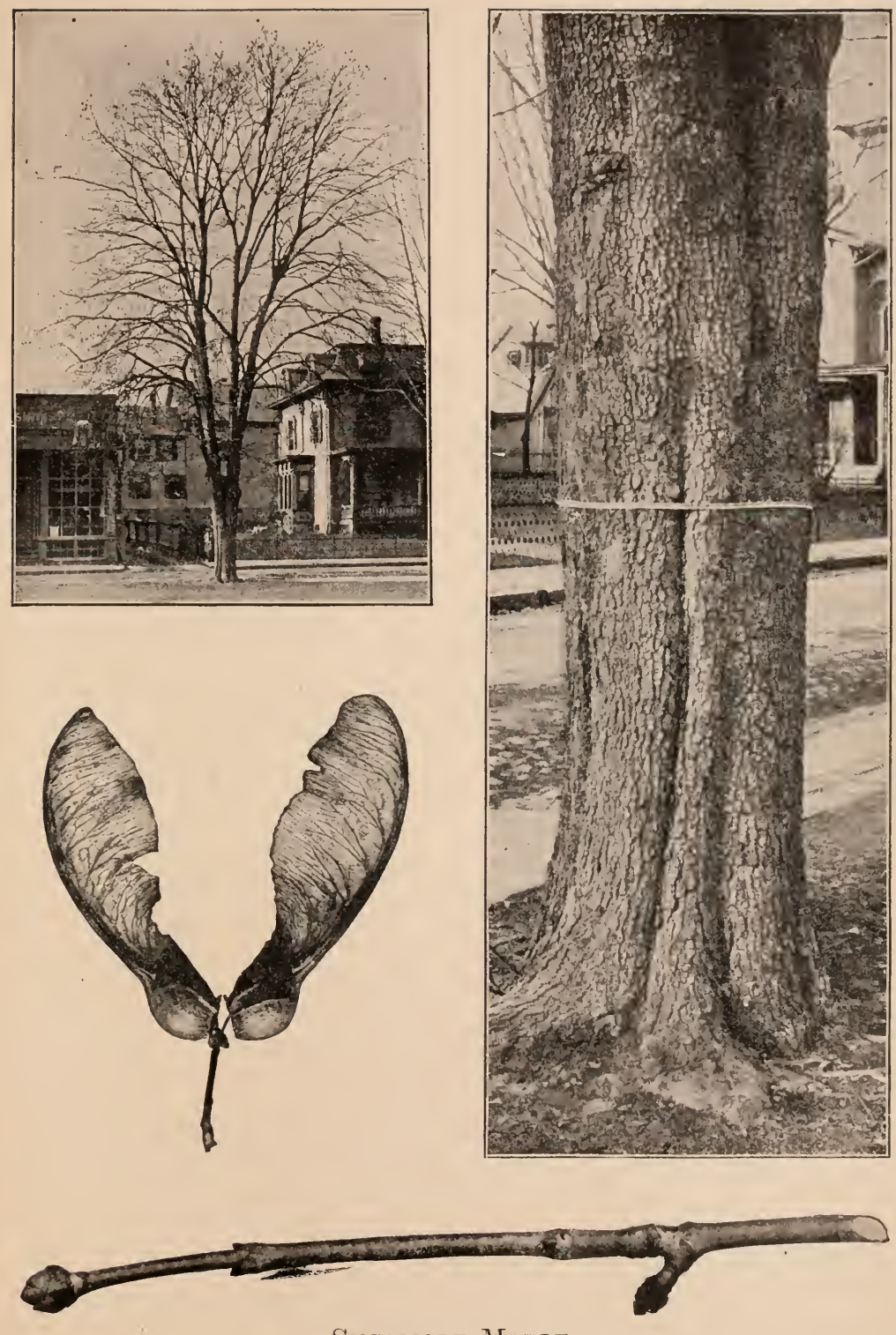

Sicamore Maple 


\section{BOX ELDER Ash-leaved Maple, Manitoba Maple. Acer Negundo L.}

Negundo aceroides Moench; Negundo Negundo Karst.

HABIT-A medium sized tree 40-50 ft. high with a trunk diameter of 1-2 ft.; dividing low down, sometimes only a few feet from the ground, into a number of stout spreading branches, forming a wide head.

BARK-Pale gray or light brown, broken by rather shallow furrows nto narrow, firm, close, irregular flat-topped ridges which are further cracked horizontally; bark of young trunks and branches smooth, with raised buff lenticels, which are horizontally more or less elongated.

TWIGS-Stout, reddish-purple or green, smooth, polished or often with a whitish bloom which readily rubs off. LENTICELS-conspicuous, forming somewhat longitudinally elongated, scattered, raised buff dots.

LFA F-SCARS-Opposite, narrow V-shaped, margined by a lighter colored outer rim, half encircling the twig, the adjacent edges of opposite leaf-scars meeting and prolonged upward into a conspicuous narrow tooth, the inner margin often hairy. BUNDLE-SCARS-large, 3 in number, generally undivided.

BLDS-Short-stalked, red, more or less white-woolly, the terminal buds $6 \mathrm{~mm}$. or less long, rather longer than the appressed lateral buds. BUD-SCALES-outer pair less densely woolly than inner pairs, grown together at base, entirely enclosing the bud or slightly gaping and exposing next inner pair; outer scales of lateral buds often distended by formation in their axils of stout collateral buds.

FRTIT-3.5-5 cm. long in drooping racemes, wings spreading at a sharp angle, seed-like portion long. flattish; fruit stalks remaining on tree throughout winter. The Box Elder is strictly dioecious, therefore fruit is not borne by all individuals.

COMPARISONS-The stout brightly colored red or green twigs and branchlets often covered with a bloom the first year and the downy buds with generally collateral buds present on some of the twigs, as well as the narrow tooth formed at the junction of adjacent deeply $T$-shaped leaf-scars render the Box Elder easily distinguishable in the winter condition.

DISTRIBITION-Banks of streams, lakes and borders of. swamps; a rapid grower and often planted as a shade tree, thrives best in moist soil but is tolerant of dry situations. Infrequent from eastern Ontario to Lake of the Woods; abundant from Manitoba westward to the Rocky mountains south of 55 degrees north latitude; south to Florida; west to the Rocky and Wahsatch mountains, reaching its greatest size in the river bottoms of the Ohio and its tributaries.

IN NEW ENGLAND-Maine-along the St. John and its tributaries, especially in the French villages, the commonest roadside tree, brought in from the wild state according to the people there; thoroughly established young trees, originating from planted specimens, in various parts of the state; New Hampshire-occasional along the Connecticut, abundant at Walpole; extending northward as far as South Charlestown; Vermont-shores of the Winooski river and of Lake Champlain; Connecticut-rare or local; apparently native along the Housatonic river from Oxford to Salisbury; escaped from cultivation at Putnam, Groton, Southington, Wethersfield and Norwalk.

WOOD-Light, soft, close-grained, not strong, creamy white with thick hardly distinguishable sapwood; occasionally manufactured into cheap furniture and sometimes used for the interior finish of houses. for woodenware, cooperage and paper pulp. Small quantities of maple sugar are occasionally made from this tree. 

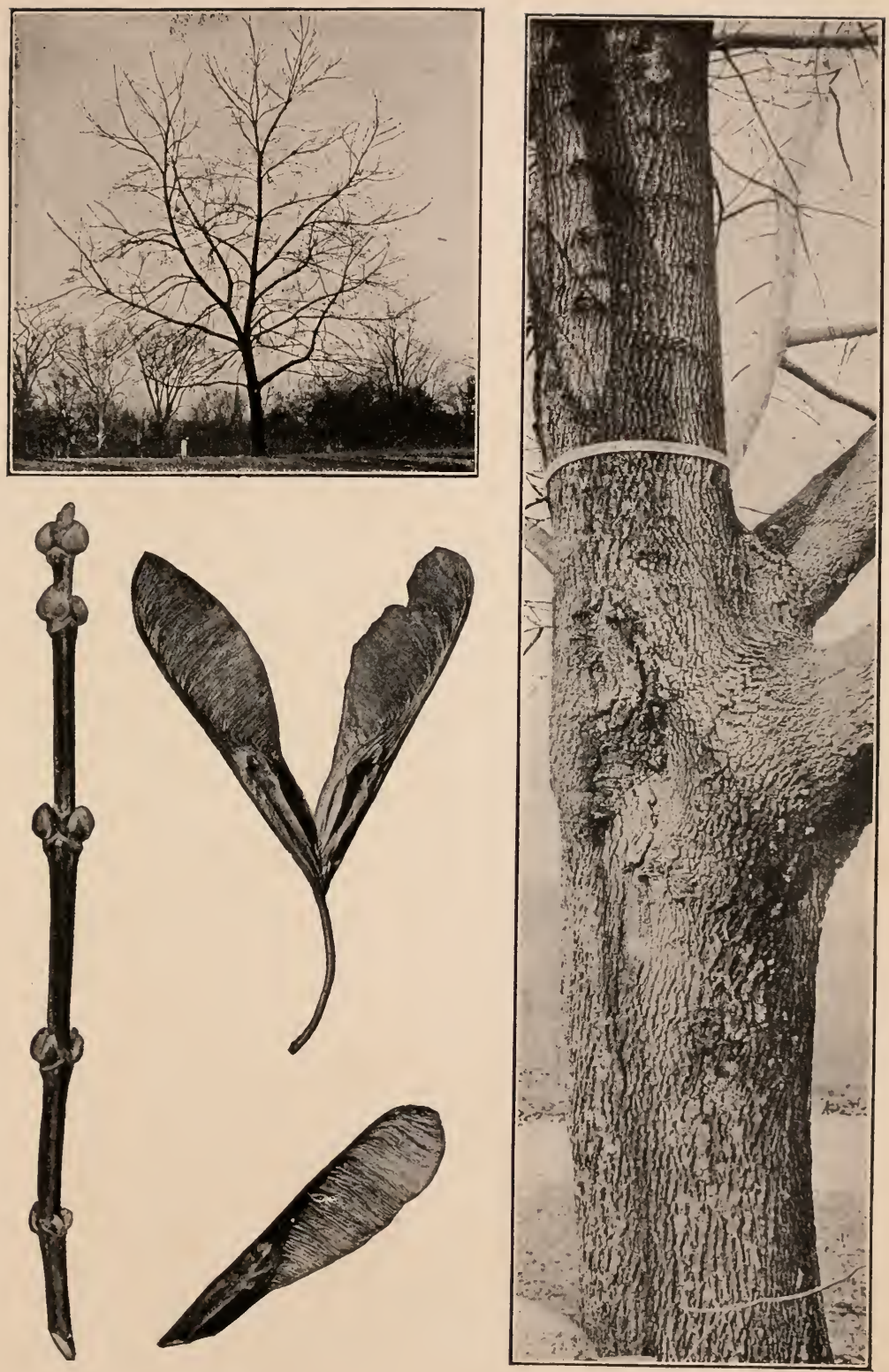

Box Elder 


\section{HORSE-CHESTNUT}

Aesculus Hippocastanum L.

HABIT-A good sized tree reaching $70 \mathrm{ft}$. in height with a trunk diameter of 2-3 ft.; sometimes with trunk continuous into top of tree but more frequently dividing soon into a number of large slightly spreading limbs forming an oblong or broadly conical head, in old age with drooping lower branches with upturned tips; spray stiff and coarse with conspicuous terminal buds.

BARK-Dull brown becoming shallowly fissured into irregular platelike scales somewhat resembling bark of Apple Tree.

TWIGS-Stout, reddish-yellowish to grayish-brown, smooth or slightly fine-downy. SCALE-SCARS-marking annual growth, distinct. LENTICELS-large, conspicuous, scattered. PITH-wide.

LEAF-SCARS-Opposite, large, inversely triangular. STIPULESCARS-absent. BUNDLE-SCARS-3-9, generally 7, large conspicuous, in a single curved line.

BUDS-Large, dark reddish-brown, varnished with sticky gum; terminal buds often flower buds, larger than laterals, 1.5 to $3 \mathrm{~cm}$. long; when a flower bud, a terminal scar is left and the twig forks from growth of bud pair below. BUD-SCALES-opposite in 4 rows, about 5 pairs visible in terminal bud, thick with thin margins, the lower pairs more or less keeled and often with abrupt sharp points.

FRUIT-A weak-spined bur, containing the large seeds marked with a large conspicuous scar; not remaining on the tree during winter.

COMPIRISONS-Two western trees with buds free from resinous coating, i.e. the Fetid or Ohio Buckeye [Aesculus glabra Willd.] and the Sweet Buckeye [Aesculus octandra Marsh.], are sometimes planted in New England. They belong with the Horse-chestnut to the genus Aesculus which is readily distinguished from other New England genera by the large size of the twigs, buds, opposite leaf-scars and bundlescars.

DISTRIBUTION-A native of southern Asia much planted as an ornamental shade tree in this country and in Europe and naturalized in many places.

wOOD-Light, soft, very close-grained, whitish, slightly tinged with yellow; in Europe used by carvers and turners. 

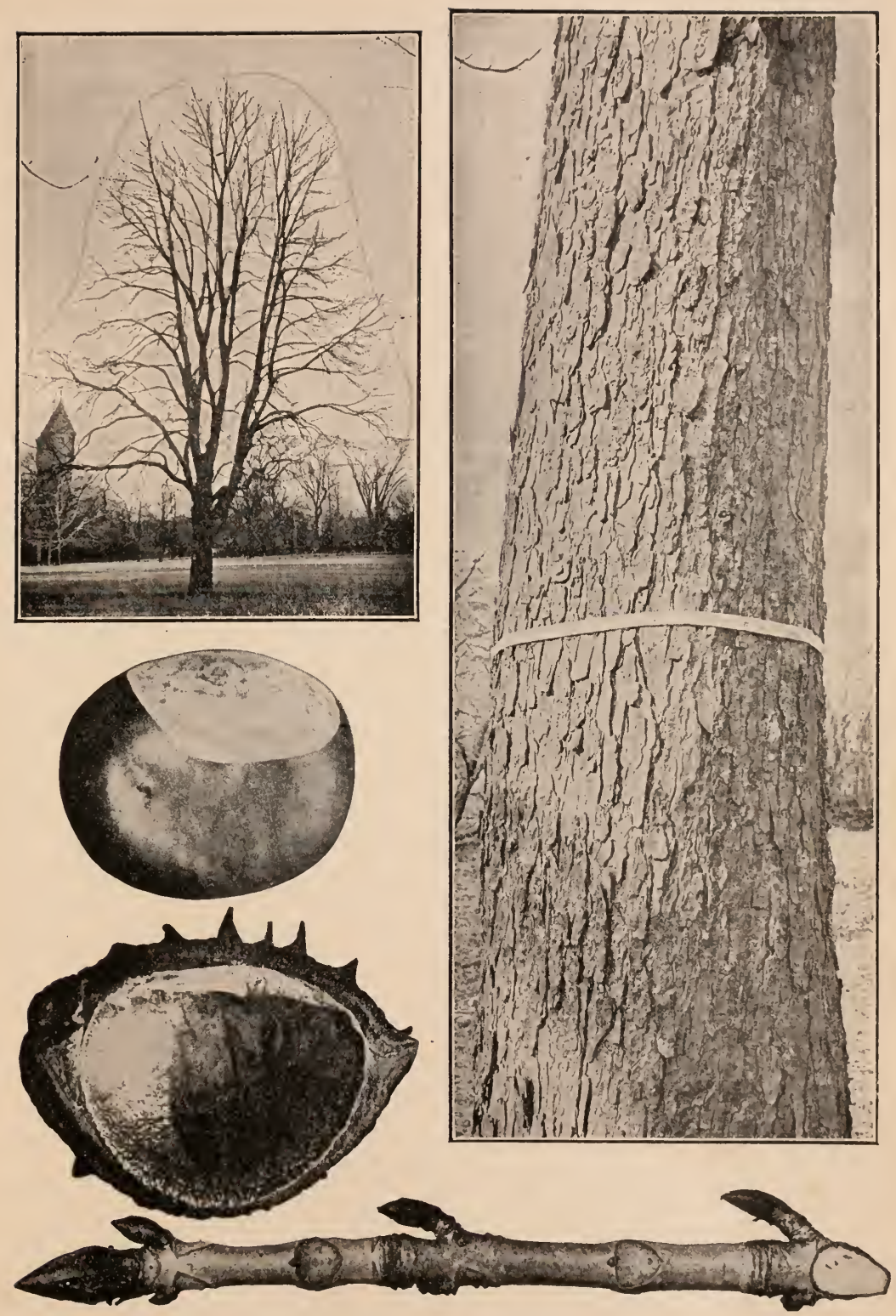

Horse-chesteut 


\section{LINDEN}

\section{Basswood, Lime, Whitewood, Beetree.}

Tilia americana $\mathrm{L}$.

HАBIT-A large tree 50-75 ft., to $100 \mathrm{ft}$. in height in the upper valley of the Connecticut river, with a trunk diameter of $2-4$ ft.; with a straight trunk generally continuous into the top, beset with numerous slender branches, those at the base often strongly drooping, forming a narrow pyramidal head as shown in habit picture or more commonly becoming broadly ovate or round-topped and oblong. [Habit picture is taken from the European Linden, which resembles the American species in habit.]

BARI-Dark gray, firm but easily cut, in young stems smooth (upper part of smaller trunk in photograph), becoming fissured into long rather narrow flat-topped ridges, divided by characteristically transverse cracks into short blocks (lower bark picture), becoming with age deeply furrowed with broader more rounded ridges (older trunk).

TWIGS-Rather slender, smooth, shining, bright red or greenish or covered with a gray skin; generally zigzag, somewhat mucilaginous when chewed: fibres in inner bark long, tough, appearing as blunt conical masses in cross section of older twig, and in surface sections of the bark as whitish wavy lines enclosing lens-shaped darker masses which show externally as wrinkled depressions of the bark. LENTICELS - scattered, dark, oblong.

LEAF-SCARS-Alternate, 2-ranked; large, elevated, semi-oval to elliptical. STIPULE-SCARS-generally narrow, often showing bundle-scars. BUNDLE-SCARS-few to many, scattered or in a ring or forming a single curved line, showing as 3 in deep surface section.

BUDS-Terminal bud absent; lateral buds large to medium, ovate, 3-10 mm. long, somewhat flattened, often lopsided, divergent, dark red or sometimes green, smooth or slightly downy at apex; mucilaginous when chewed. BUD-SCALES-rarely more than 2-3 visible, thick, rounded at the back, not 2 -ranked nor in pairs.

FIRUT-About the size of a pea, woody, spherical, singly or in clusters of several with a common stalk attached midway to a leafy bract, sometimes remaining on the tree into the winter.

COMPARISONS-The American Linden, more commonly known among lumbermen as Basswood, differs but slightly in winter or summer condition from the European species [Tilia vulgaris Hayne] which is much cultivated as a street tree. Another Basswood [Tilia Michauxii Nutt.] has been reported in New England only from Connecticut, but is rare in this state. The Lindens are sometimes confused with the Elms, but aside from the different habit of growth the Linden has larger, bright colored buds with 2-3 scales only showing. while the Elms have many scales visible and their bundle-scars are depressed. From the Chestnut, the Linden is best distinguished by its twigs and buds which are mucilaginous when chewed.

DISTRIBITION-In rich woods and loamy soils and often cultivated. Southern Canada from New Brunswick to Lake Winnipeg; south along the mountains to Georgia; west to Kansas, Nebraska and Texas.

IN NEW ENGLAND-Throughout, frequent from the sea coast to altitudes of $1,000 \mathrm{ft}$, rare from 1,000 to $2,000 \mathrm{ft}$.

WOOD-Soft, straight-grained, light brown faintly tinged with red, with thick hardly distinguishable sapwood of $55-65$ layers of annual growth, employed in the manufacture of paper-pulp; under the name of Whitewood largely used for woodenware, cheap furniture, the panels of carriages, and for inner soles of shoes. The tough inner bark furnishes fibres for mats, cordage, etc. 

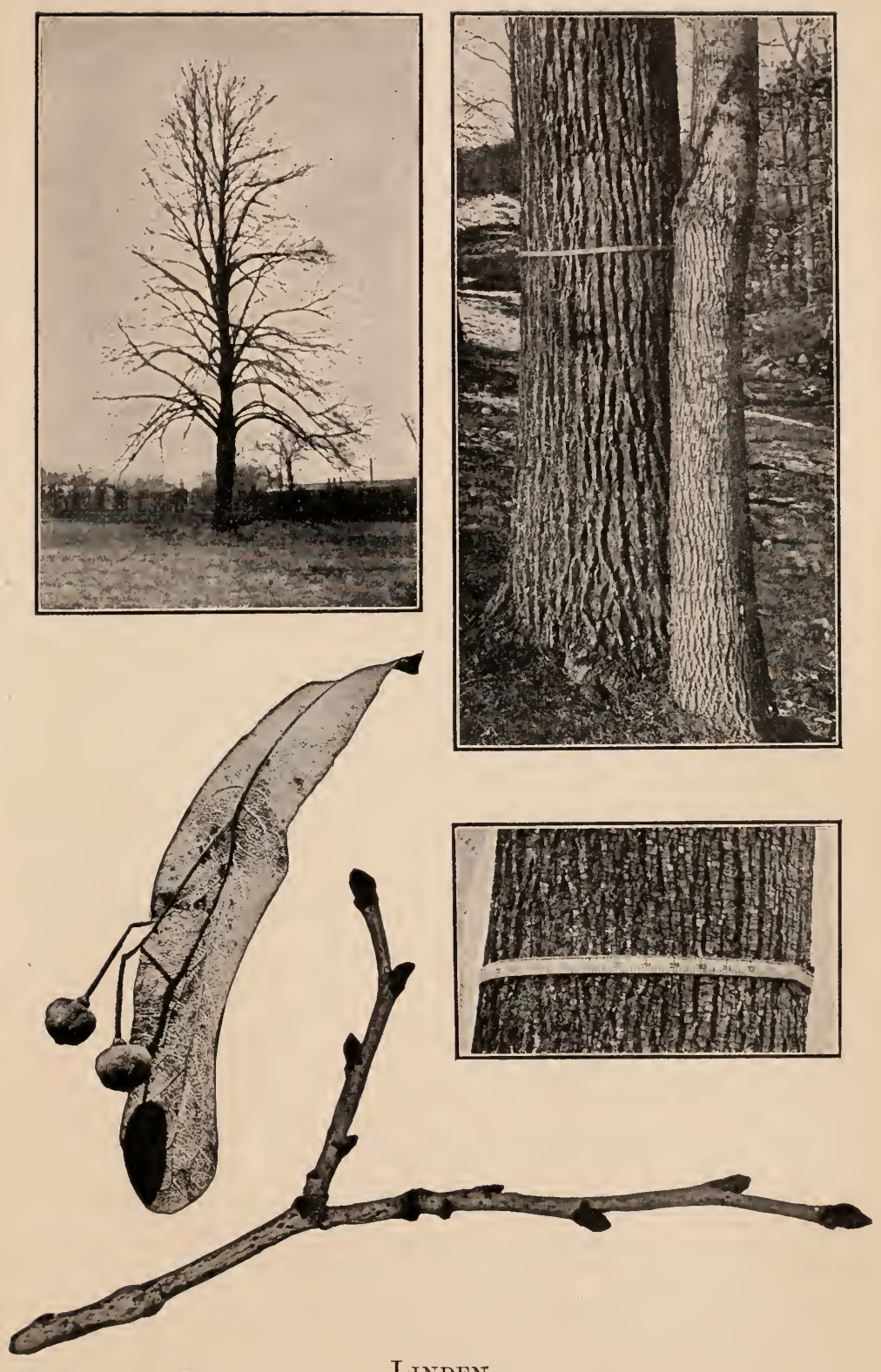

LINDEN 


\section{FLOWERING DOGWOOD Boxwood, Dogwood, Flowering Cornel.} Cornus florida L.

HА BIT-A small tree 15-30 ft, in height, with a trunk diameter of 6-10 inches; developing a low spreading bushy head with slender upright or spreading branches and divergent sinously curved branchlets turning upward near the end and bearing on their upper sides clusters of fruiting twigs terminated by large conspicuous erect flower buds.

B.IIK-Dark brown to blackish, ridged and broken into small 4-sided or rounded plate-like scales, resembling alligator leather in appearance.

TWIGS-Slender, bright red or yellowish-green, smooth or generally appearing more or less mealy from minute closely appressed gray hairs; with bitter taste. LENTICELS-inconspicuous. PITH-gritty, granular.

LEAF-SCARS-Opposite, on twigs of the season raised on bases of leaf-stalks with deep V-shaped notch between, on older growth practically encircling twig. STIPULE-SCARS-absent. BUNDLESCARS-3, in leaf-scars of the season often confluent and first seen in section through persistent base of leaf-stalk.

BUDS-Lateral buds minute, covered by persistent bases of leafstalks; terminal leaf-buds flattened-conical, red, generally downy at least at apex, covered by a single pair of opposite pointed scales rounded at back and joined below for $1 / 3$ their length; flowering buds very abundant, terminal, large, spherical to inverted flat turnipshaped, 4-8 mm. broad, covered by two opposite pairs of bud-scales, the first 2-3 pairs of leaves below the flower buds generally reduced to narrow-pointed persistent scales.

FRUIT-Scarlet, oblong, about $1.5 \mathrm{~cm}$. long, fleshy, with a grooved stone, clustered, ripening in October and generally not remaining on the tree during winter.

COMPIRIGONS-The Flowering Dogwood differs from its relative the Alternate-leaved Dogwood [Cornus alternifolia L.] by its opposite leafscars, from the Bush Maples, - the Striped and the Mountain-which it somewhat resembles in twig characters, by its alligator bark, the presence of but a single pair of scales to terminal leaf-bud, by the persistent bases of leaf-stalks covering the lateral buds and by the generally abundant large flower buds.

DISTRIBUTION-Woodlands, rocky hillsides, moist, gravelly ridges, frequently cultivated as an ornamental tree. Provinces of Quebec and Ontario; south to Florida; west to Minnesota and Texas.

IN NEW ENGLAND-Maine-Fayette Ridge, Kenebec county; New Hampshire-along the Atlantic coast and very near the Connecticut river, rarely farther north than its junction with the West river; Vermont - southern and southwestern sections, rare; Massachusettsoccasional throughout the state, common in the connecticut river valley, frequent eastward; Connecticut-occasional, local or frequent; Rhode Island-common.

WOOD-Heavy, hard, strong, close-grained, brown sometimes changing to shades of green and red, with lighter colored sapwood of 30-40 layers of annual growth; largely used in turnery, for the bearings of machinery, the hubs of small wheels, barrel hoops, the handles of tools and occasionally for engravers' blocks. 

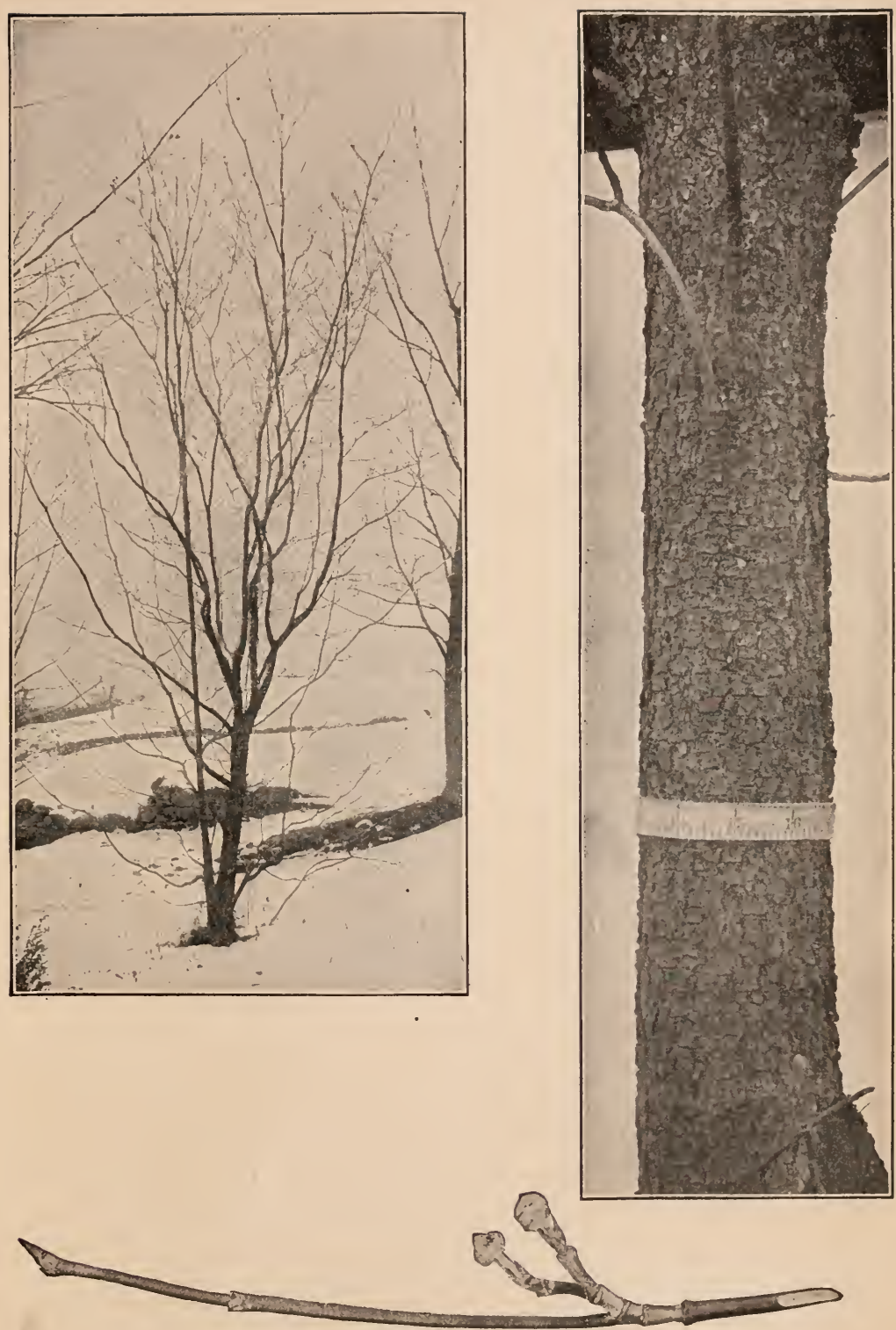

Floweriag Dogwood 


\title{
TUPELO
}

\section{Pepperidge, Sour or Black Gum.}

\author{
Nyssa sylvatica Marsh.
}

N. multiflora Wang.

HАВIT-A tree 20-50 ft. in height with trunk diameter of 1-2 ft. or in the forest $60-80 \mathrm{ft}$. high, reaching greater dimensions further south; generally easily recognized from the manner of branching alone, though extremely variable in outline. The trunk is erect, generally continuous well into the top, lower branches developed low down on trunk, horizontal or declined often to the ground, upper branches horizontal or slightly ascending, with numerous lateral branches and stubby branchlets forming horizontal layers. The branches are slender and exceedingly numerous, more so than in any other of our trees. The head may be short, cylindrical and flat-topped, or low and broader than tall (see plate lower habit picture), or more commonly as when crowded in the forest, narrow, pyramidal or conical (see plate upper habit picture) or inversely conical and broad and flat at top.

BARK-On young tree, grayish, flaky, on older trunks darker with deeper furrows and ridges broken into somewhat regular hexagonal blocks.

TWIGS-Slender, smooth or nearly so, grayish to light reddish-brown, producing numerous short slow-growing spurs crowded with leaf-scars on the sides of more rapidly grown shoots. LENTICELS-scattered, inconspicuous. PITH - with thin transverse woody partitions through the ground-mass, best seen with aid of a hand-lens.

LEAF-SCARS-Alternate, generally more than 2-ranked, distinct, broadly crescent-shaped. STIPULE-SCARS-absent. BUNDLE-SCARSconspicuous, 3 , simple or slightly compound but in 3 distinct groups, generally depressed, whitish in contrast to reddish-brown of leaf-scar.

BUOS-Ovate, dark reddish-brown, smooth or slightly downy at tip, the lateral buds generally blunt-pointed, divergent, on vigorous shoots slightly raised on a cushion of the bark, sometimes on vigorous shoots developing a superposed accessory bud larger than the axillary one; terminal bud slightly larger than laterals, about $5 \mathrm{~mm}$. long, generally sharper pointed, with slightly curved apex. BUD-SCALES-3-4 visible, broadly ovate, rounded, terminally somewhat keeled and pointed.

FRUIT-A small bluish drupe ripening in autumn.

COMPAIISONS-Although the outline of the crown differs widely, the numerous slender horizontally layered branches generally render the Tupelo distinguishable at a distance. Its stubby branchlets remind one somewhat of the Pear Tree. Its broad leaf-scars and 3 conspicuous bundle-scars in connection with the woody partitions in the pith will prevent its being confused with any other tree.

DISTRIBUTION-In rich, moist soil, in swamps and on the borders of rivers and ponds. Ontario; south to Florida; west to Michigan, Missouri, and Texas.

IN NEW ENGLAND-Maine-Waterville on the Kennebec, the most northern station yet reported; New Hampshire-most common in the Merrimac valley, seldom seen north of the White Mountains; Vermontoccasional; Massachusetts, Connecticut and Rhode Island-rather common.

WOOD-Heavy, soft, strong, fine-grained, very tough, difficult to split, not durable, light yellow or nearly white, with thick lighter colored sapwood of $80-100$ layers of annual growth; used for the hubs of wheels, rollers in glass factories, ox-yokes, wharf piles and sometimes for the soles of shoes. 

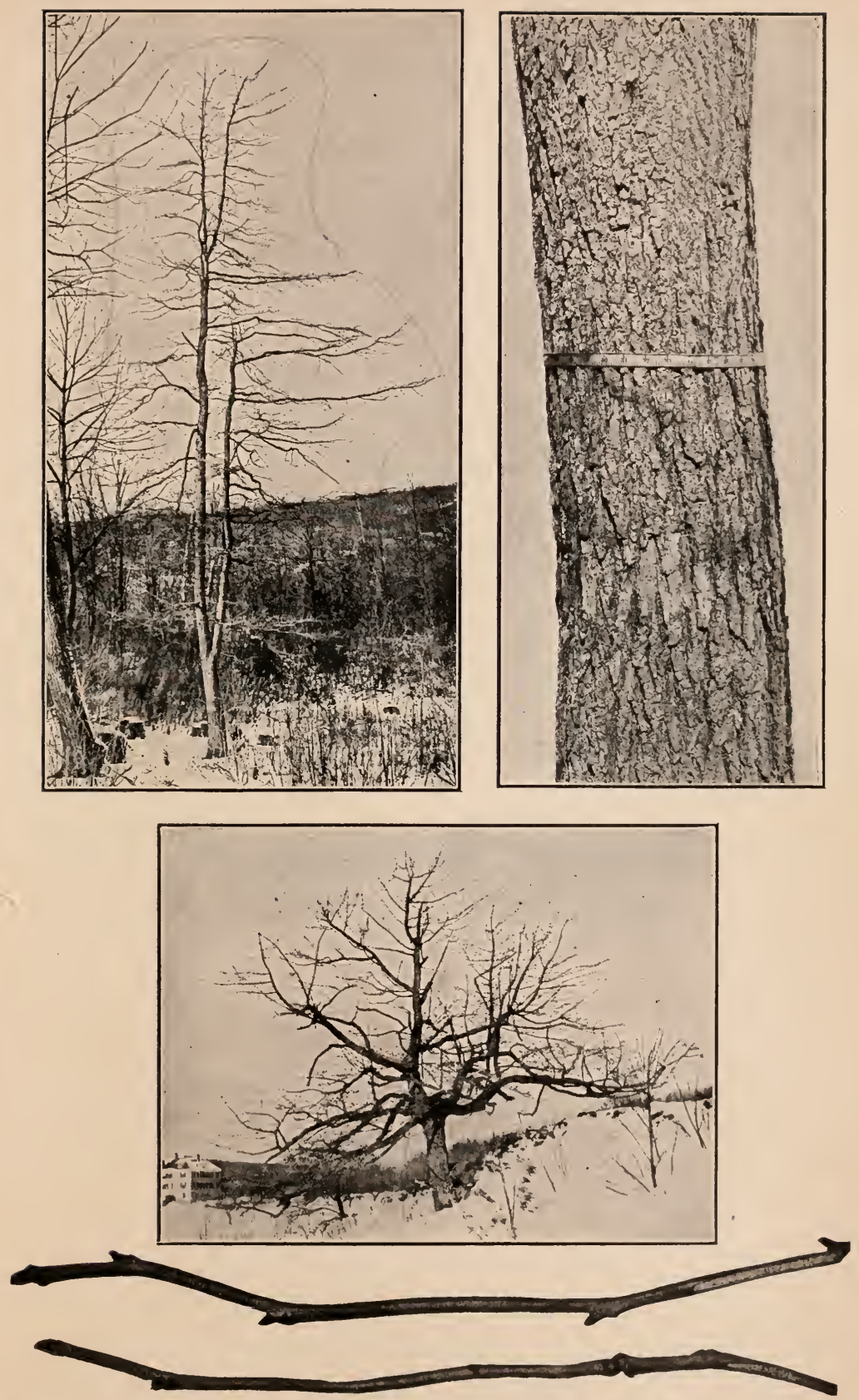

Tupelo 


\section{WHITE ASH}

Fraxinus americana $\mathrm{L}$.

HABIT-In the forests a large tree with straight, tall trunk, free from branches to near the narrow crown, $50-75 \mathrm{ft}$. in height with trunk diameter of $2-3 \mathrm{ft}$., reaching over $100 \mathrm{ft}$. in height in the Ohio basin; in the open a broader tree with ovate, round-topped or pyramidal to oblong outline, the trunk at times continuous into the crown but generally dividing comparatively low down into a number of slightly spreading limbs with slender spreading branches, the lower more or less drooping and recurved. The coarse twigs are formed at a broad angle approaching a right angle with the branch and this cross-shaped branching seen against the sky is an easy means of identification.

BARK-Grayish-brown, characteristically furrowed with narrow, flattopped, firm, irregular, longitudinal ridges which are transversely broken, more or less confluent and enclose diamond-shaped hollows; old trunks becoming smoother by scaling off of the ridges.

TWIGS-Stout, smooth and shining, grayish or greenish-brown often with a slight bloom, very brittle, flattened at nodes at right angles to leaf-scars. LENTICELS-large, pale, scattered dots.

LEAF-SCARS-Opposite, large, conspicuous, raised, crescent-shaped to nearly semi-circular but always notched at the top. STIPULE-SCARSabsent. BUNDLE-SCARS-numerous, minute, in a curved line, often indistinct, sometimes more or less confluent.

BUDS-Stout, semi-spherical to broadly ovate, scurfy, and more or less slightly downy, rusty to dark brown to sometimes almost black; on rapidly growing shoots, superposed buds often present; terminal bud larger than the laterals, about $5 \mathrm{~mm}$. or less long, blunt, generally decidedly broader than long. A pair of lateral buds generally present at end of twig nearly on level with terminal bud, their leaf-scars causing terminal swelling of twig. BUD-SCALES-generally broadly ovate, opposite in pairs, $2-3$ pairs visible, those of terminal bud with sharp, abrupt, sometimes deciduous points.

FRUIT-Winged, $2-5 \mathrm{~cm}$. long, the seed-bearing portion round in section, marginless below with much longer wing dilating from near the tip, hanging on the tree in clusters into the winter. The Ash is dioecious and consequently only the female trees ever bear fruit. Since further these do not bear every season, the fruit does not form a very usable winter character for any of the Ashes. The staminate flowers on the male trees are frequently infected by mites and persist through the winter in blackish distorted clusters.

COMPIRISONS-The White Ash is hardly to be confused with the few other genera of trees that have opposite leaf-scars. It is distinguished from the other Ashes figured here in that its leaf-scar is generally narrow and deeply concave, further from the Black Ash by its rough ridged bark and generally rusty and blunter bud-scales and from the Red Ash by its smooth, generally shiny twigs.

DISTRIBUTION-Rich or moist woods, fields and pastures near streams. Newfoundland and Nova Scotia to Ontario; south to Florida; west to Minnesota, Nebraska, Kansas and Texas.

IN NEỊ ENGLAND-Maine-very common, often forming large forest areas; in the other New England states, widely distributed. but seldom occurring in large masses.

woOD-Heavy, hard, strong, close-grained, tough and brown with thick lighter colored sapwood; usea in large quantity in the manufacture of agricultural implements for the handles of tools, in carriage building, for oars and furniture, and in the interior finish of buillings; the most valuable of the American species as a timber tree. 

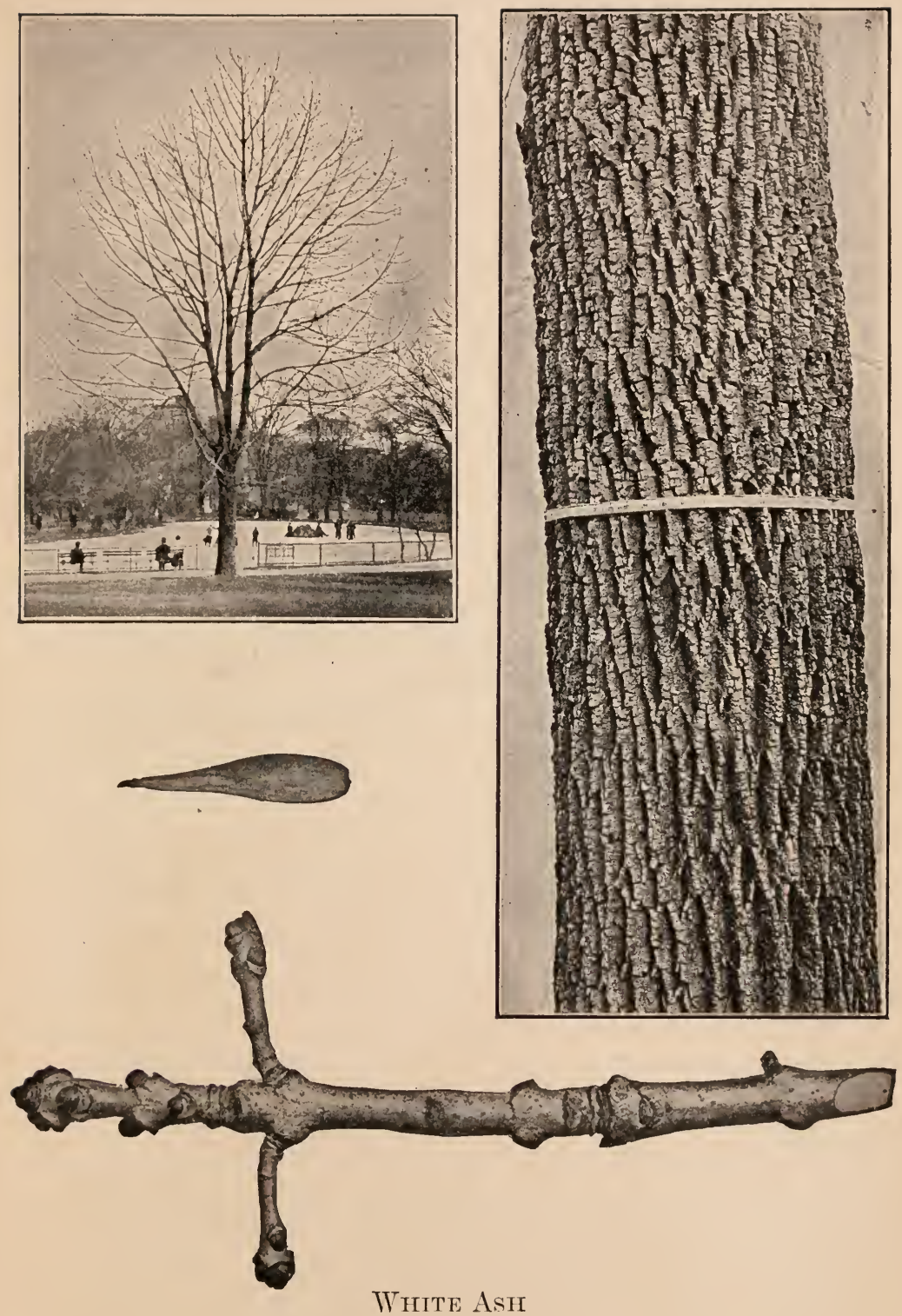


\section{RED ASH \\ Brown, or River Ash. \\ Fraxinus pennsylvanica Marsh. \\ $F$. pubescens Lam.; F. Darlingtonii Britton.}

HABIT-A medium to large-sized tree, 30-70 ft. in height with a trunk diameter of 1-3 ft.; in general appearance resembling the White Ash.

BARK-Similar to that of White Ash but with somewhat shallower furrows.

TWIGS-More slender than those of White Ash, densely velvetydowny in typical condition but often without down especially in the Green Ash [Fraxinus pennsylvanica, var. lanceolata (Bork.) Sarg.].

LEAF-SCARS-Semi-circular, upper margin rarely somewhat depressed.

BUDS-Dark rusty brown, smaller and narrower than those of the White Ash, about 2 pairs of scales visible to terminal bud.

FRUIT-Seed-bearing portion round in section, marginless below with wing extending down its sides.

COMPARISONS-The Red Ash is not distinguished by most people from the White Ash which it closely resembles. The downiness of its twigs which is considered its chief specific character is not constant. The shape of its leaf-scar, in general semi-circular with upper margin not concave, is perhaps its best distinguishing character. Further its terminal buds are narrower, showing fewer scales and the twigs are more slender. The smooth-twigged Green Ash [Fraxinus pennsylvanica, var. lanceolata (Bork.) Sarg.] is considered by the best authorities only a variety of the Red. The Black Ash is best separated by its characteristic scaly bark and generally black buds.

The European Ash [Fraxinus excelsior L.] is frequently cultivated. It has a bark resembling that of the White Ash and has a pair of lateral buds nearly on level with terminal buds; but its leaf-scars are semicircular and its buds jet black.

DISTRIBUTION-River banks, swampy lowlands, margins of 'streams and ponds. New Brunswick to Manitoba; south to Florida and Alabama; west to Dakota, Nebraska, Kansas, and Missouri.

IN NEW ENGLAND-Maine-infrequent; New Hampshire-ocćasional, extending as far north as Boscawen in the Merrimac valley; Vermontcommon along Lake Champlain and its tributaries; occasional in other sections; Connecticut-frequent; Massachusetts and Rhode Islandsparingly scattered throughout.

WoOD-Heavy, hard, rather strong, brittle, coarse-grained, light brown with thick, lighter brown sapwood streaked with yellow; sometimes confounded commercially with the more valuable wood of the White Ash. 

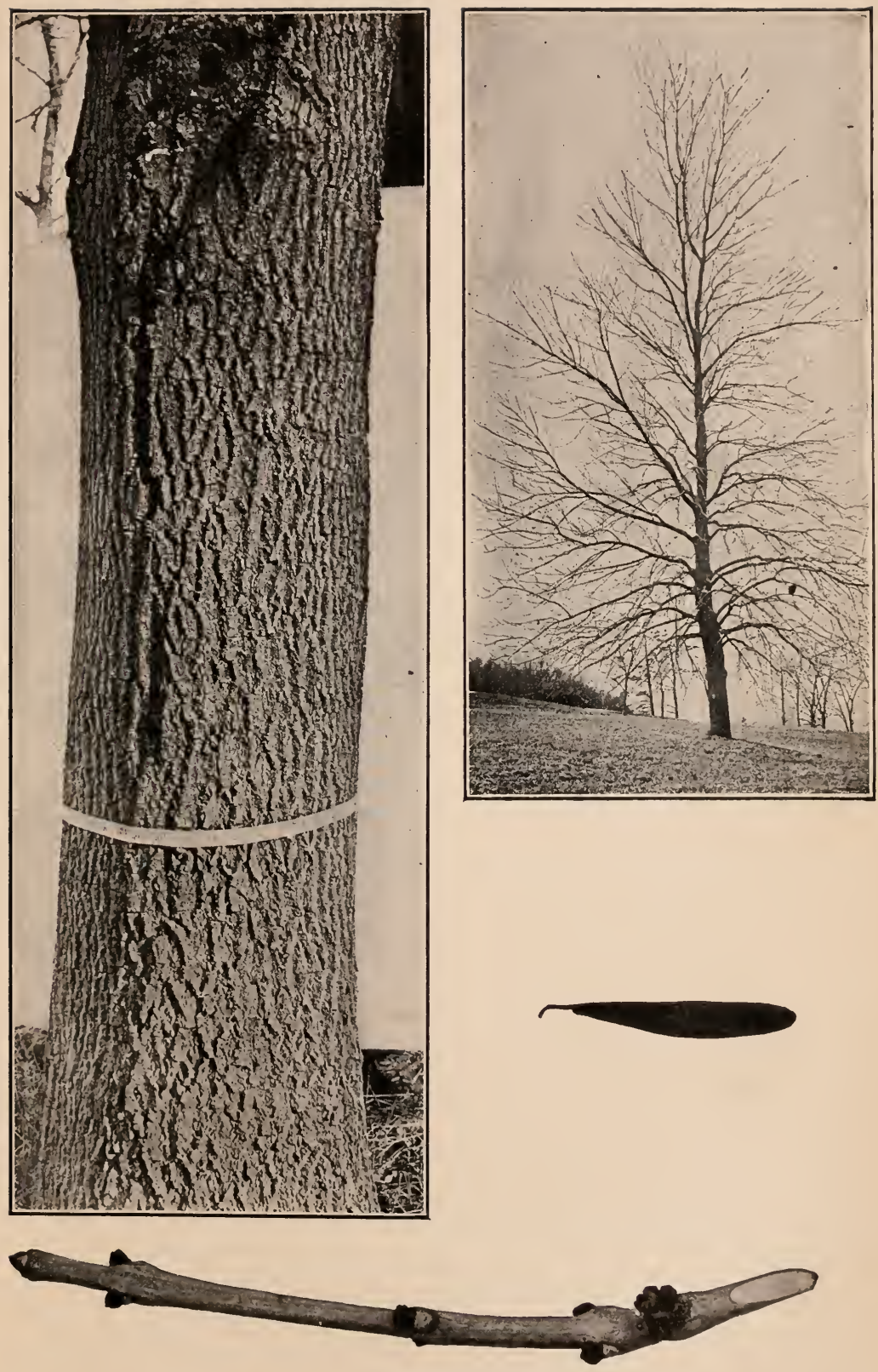

Red Ash 


\section{BLACK ASH \\ Hoop, Swamp, Basket or Brown Ash.}

Fraxinus nigra Marsh.

F. sambucifolia Lam.

HABIT-A tall tree 60-80 ft. in height with trunk diameter of 1-2 ft., larger further south; in swamps in company with other trees with tall slender trunk of nearly uniform diameter to point of branching supporting a narrow head; in the open, where it is seldom found, said to have a habit similar to that of the White Ash.

BARK-Ash-gray, slightly tinged with buff, somewhat furrowed but generally without deep ridges, forming thin scales smoothish on the outside and edges, easily rubbed off and exposing a surface rather soft to the touch suggesting somewhat the feel of asbestos or talcum powder; trunk frequently with knobby excrescences.

TwIGS-Very stout, similar to those of White Ash but lighter gray and not shiny.

LEAF-SCARS-Opposite, large, conspicuous, circular to semi-circular; the upper margin not concave, often extending upward as a thin flap partially hiding the bud; otherwise resembling the White Ash.

BUDS-Resembling those of White Ash but generally decidedily black though occasionally rusty, terminal bud ovate, pointed, as long as or lenger than broad, more or less flattened at right angles to outer pair of scales, last pair of lateral buds generally at some distance from the end giving terminal bud a stalked appearance. BUD-SCALES-of terminal bud broadly keeled and narrower than in White Ash, generally only 1-2 pairs visible.

FRUIT-With broad wing, distinctly notched at apex, surrounding the flattened seed-bearing portion.

COMPARISONS-The Black Ash is easily distinguished from the White by its soft, scaly bark, the even or raised upper margin of its leaf-scars, its narrower and generally black buds, and the stalked appearance of its terminal bud. When growing in the swamps beside the White Ash its twigs can be seen to be much stouter and fewer than those of the latter species.

DISTRIBUTION-Wet woods, river bottoms, and swamps. Anticosti through Ontario; south to Delaware and Virginia; west to Arkansas and Missouri.

IN NEW ENGLAND-Maine--common; New Hampshire-south of the White Mountains; Vermont-common; Massachusetts-more common in central and western sections; Connecticut-occasional; Rhode Islandinfrequent.

WOOD-Heavy, rather soft, not strong, tough, coarse-grained, durable, easily separable into thin layers, dark brown with thin light brown often nearly white sapwood; largely used for the interior finish of houses and cabinet-making, and for fences, barrel hoops and in the manufacture of baskets. 

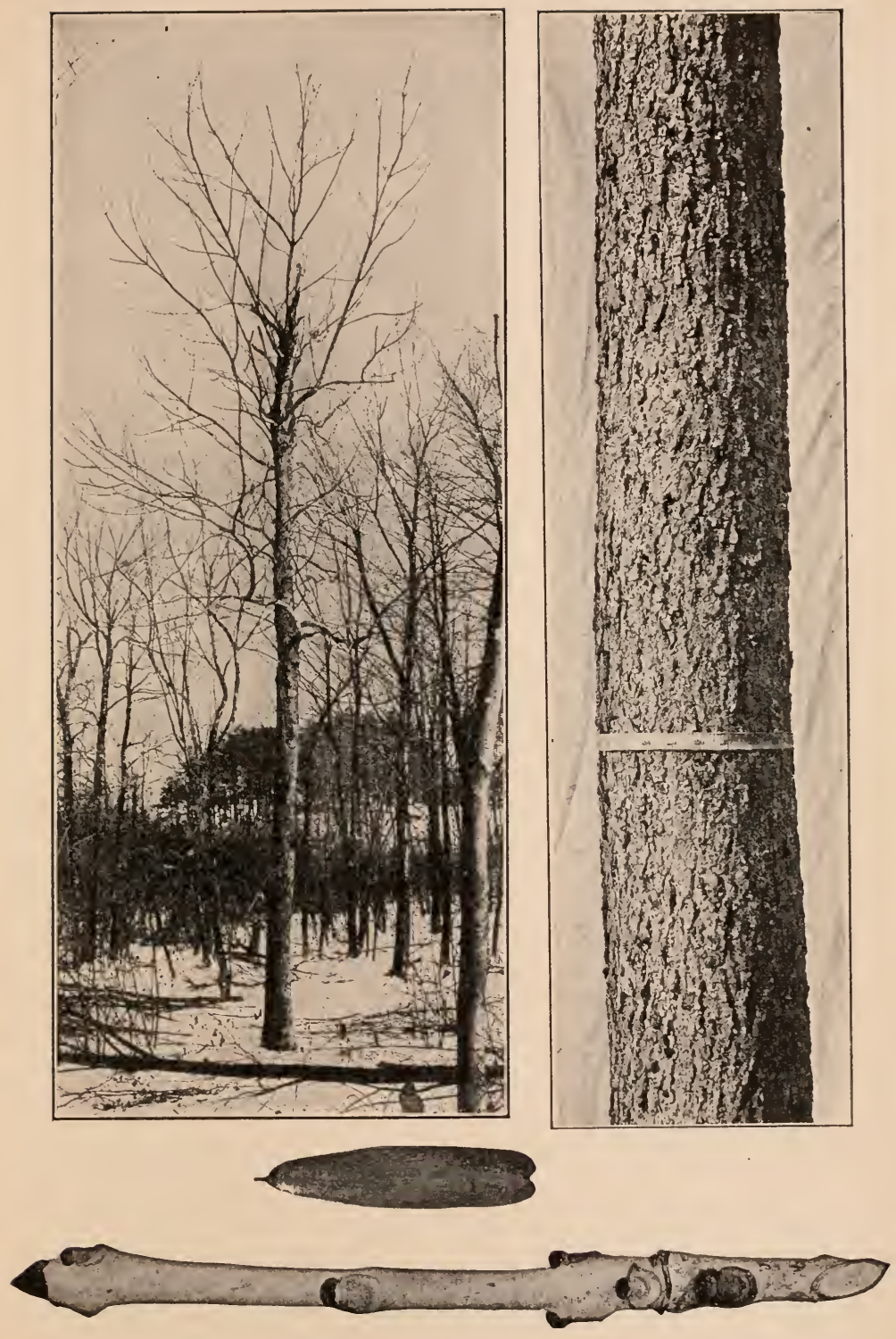

Black AsIt 


\title{
HARDY CATALPA \\ Cigar Tree, Indian Bean, Western Catalpa. \\ Catalpa speciosa Warder.
}

\begin{abstract}
HABIT-A tall tree reaching $100^{\circ} \mathrm{ft}$. in height and $4 \mathrm{ft}$. in trunk diameter in the Ohio basin, of smaller dimensions in New England, with slender branches, forming a comparatively narrow round-topped head.
\end{abstract}

BARK-Reddish to grayish brown, with longitudinal scaly ridges.

TWIGS-Stout, smooth or slightly short-downy, reddish to yellowishbrown, the tips of twigs generally winter-killed. LENTICELS-conspicuous, rather large and numerous. PITH-white, wide, occasionally chambered at the nodes.

LEAF-SCARS-Opposite or more frequently 3 at a node, large and conspicuous, round to elliptical, with depressed center. STIPULE-SCARS -absent. BUNDLE-SCARS-conspicuous, often raised, forming a closed ring.

BUDS-Terminal bud absent, lateral buds small, semi-spherical, generally under $2 \mathrm{~mm}$. high. BUD-SCALES-brown, loosely overlapping, about 5 or 6 visible.

FRUIT-A long cylindrical capsule, 8-20 inches in length, with numerous flattened, winged, white-hairy, fringed seeds, persistent on the tree through winter. The photograph of the capsule is reduced to about $2 / 5$ natural size.

COMPARISONS-The 3 large circular leaf-scars at a node with complete ring of bundle-scars render the Catalpa twig easily recognizable. The long cigar-like fruits that hang on the tree supply a distinctive habit character. A very closely related southern and less hardy species, the Common Catalpa [Catalpa bignonioides Walt.], was formerly more planted than the Hardy Catalpa. It is a smaller tree with a rather more spreading habit but is most readily distinguished from the western species at the time of flowering.

DISTRIBUTION-Not native in New England but planted as an ornamental shade tree and for timber. It grows native along borders of streams and ponds and rich often inundated bottom-land; southern Indiana, Illinois, and Missouri south into Kentucky, Tennessee and Arkansas.

WOOD-Light, soft, not strong, coarse-grained, very durable in contact with the soil, light brown with thin nearly white sapwood of 1 or 2 layers of annual growth; largely used for railroad ties, fence posts and rails and occasionally for furniture and the interior finish of houses. 


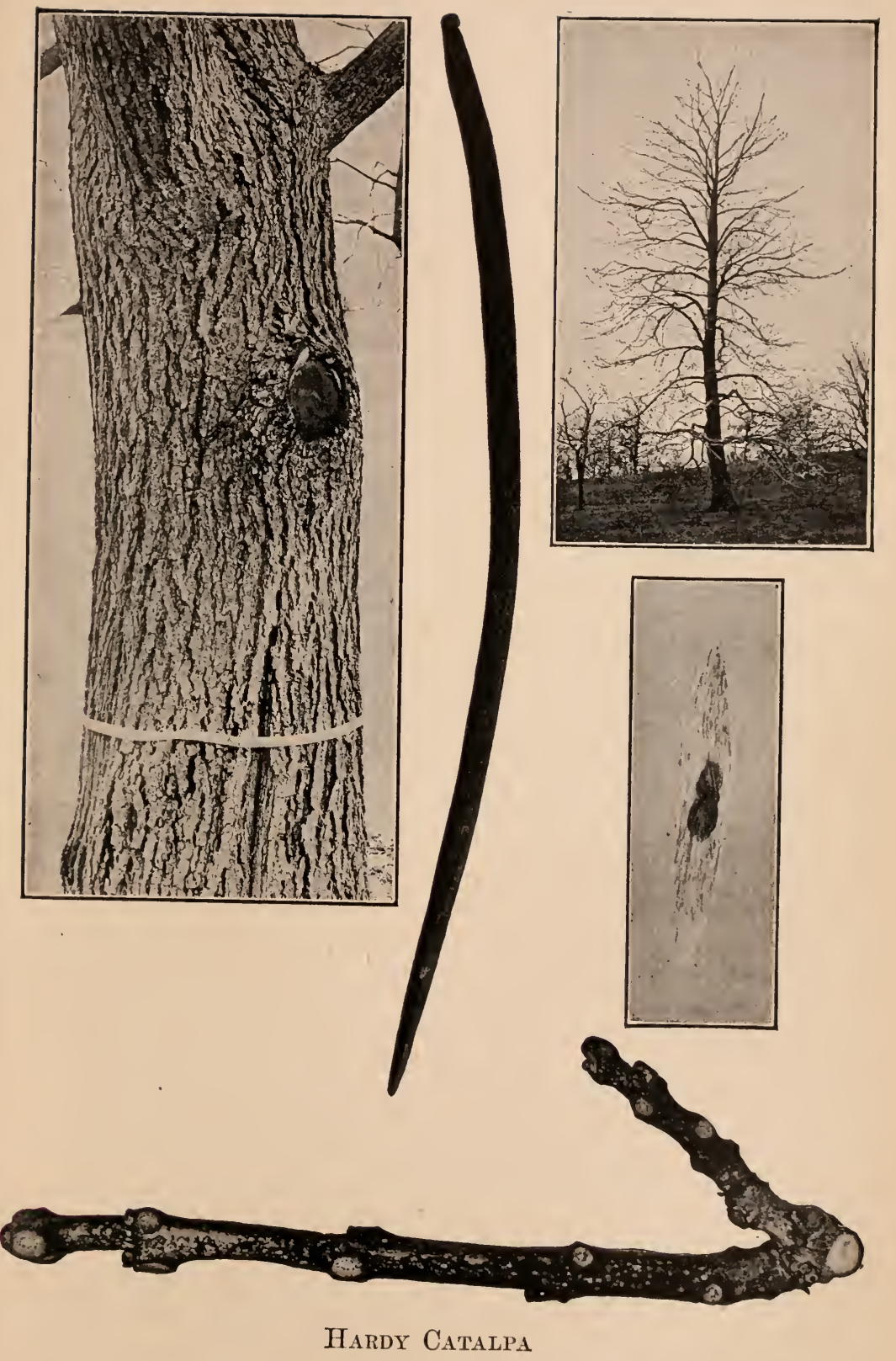




\section{GLOSSARY}

Accessory buds. Buds at or near the nodes but not in the axil. Of two kinds, collateral and superposed.

Acorn. The complete fruit of an Oak consisting of a nut partially enclosed by an involucrate cup.

Adjacent. Situated in close proximity.

Alternate. Scattered along the stem; said of leaves and scales in distinction from opposite.

Apex. The top, as the tip of the bud.

Appressed. Lying close against the twig, as the buds of the Shad Bush (p. 359 ).

Awn. A long hair-like point.

Awl-shaped. Small and sapering to a slender point.

Axil. The angle formed at the upper side of the attachment of the leaf to the stem.

Axillary. In an axil. An axillary bud is the first bud above the leaf or leaf-scar.

Bark. The outer covering of the trunk or branch. Unless otherwise specified, the heading "Bark" in the descriptions refers to the bark of the trunk.

Berry. A fruit fleshy throughout.

Bloom. The powdery waxy substance easily rubbed off, as the bloom on the twigs of the Dox Elder and cabbage.

Bract. A more or less modified leaf.

Branch. A secondary division of a trunk.

Branchlet. A small branch.

Bud. An undeveloped branch or fruit cluster with or without a protective covering of scales.

Bud-scales. Reduced leaves covering a bud.

Bundle-scars. Scars of the fibro-vascular bundles which ran up through the leaf-stalk and connected with the veins of the leaf, seen as dots in the leaf-scar (fig. 20 ).

Bur. A spiny fruit, as the bur of the Chestnut (p. 297).

Buttressed. Said of the trunk when enlarged at the base as frequently is the case in the White EIm (p. 327).

Calyx. The outer portion of a flower consisting of a circle of modified leaves usually green in color.

Capsule. A dry fruit which splits at maturity to let out the seeds.

Catkin. A unisexual, elongated, compact cluster of flowers with scaly bracts usually falling away in one piece, as in the Alders (p. 293), Birches (p. 281-291), etc.

Cell. One of the chambers of the ovary. One of the microscopic structural elements out of which plant tissues are built up.

Chambered. Said of the pith when interrupted by hollow spaces, as in the Butternut (fig. 101).

Clustered. Said of buds when several are produced near together as in the Oaks (p. 317). 
Collateral buds. Accessory buds at the side of the axillary bud as in the Red Maple (fig. 102).

Concave. Curved with the upper margin depressed.

Cone. A fruit such as of the Pines with woody closely overlapping scales.

Confluent. Said of bundle-scars, when the separate scars are so close together that they appear to form a single scar.

Conical. Cone-shaped, largest at the base and tapering to the apex.

Crown. The upper mass of branches.

Cup-shaped. Shaped like a cup; deeper than saucer-shaped.

Deciduous. Falling away; said of trees that drop their leaves before winter.

Decurrent. Said of ridges that run down from the leaf-scar.

Deliquescent. Said of a tree with broad spreading habit as the Apple (p. 353 ).

Dioecious. Said of plants such as the Willows and Poplars that have separate male and female individuals.

Divergent. Said of buds that point away from the twig as in the Carolina Poplar (fig. 100).

Downy. Covered with fine hairs.

Drupe. A stone-fruit as in the Cherries with the seed enclosed in a stone or pit which is surrounded by a fleshy portion.

Egg-shaped. Shaped like an egg with the broadest part below the middle.

Elliptical. Oblong with regularly rounded ends.

Entire. Margin without indentations.

Epidermis. The outermost layer of cells.

Escape. A plant originally cultivated but now growing like a wild plant.

Evergreen. With green leaves in winter, as the Pines and Holly.

Excurrent. Said of a tree of erect habit of growth, such as the Spruce (p. 225) or Poplar (p. 261).

Fan-shaped. Shaped like an expanded fan.

Fibro-vascular bundles. The strands containing the elements for the transportation of fluids through the plant. They ultimately connect with the veins of the leaves.

Flaky (bark). With loose scales easily rubbed off.

Flower bud. A bud containing an undeveloped flower or flower cluster.

Fluted. With rounded ridges.

Follicle. A pod which opens along one side only.

Fruit. The part of a plant containing the seeds.

Gland. A small protuberance, as on the leaves of the Arbor Vitae (p. 243).

Glandular. Provided with glands.

Habit. The general appearance of the tree as seen at a distance.

Habitat. The place where the tree naturally grows, such as swamps, sandy plains, etc.

Hairy. With long hairs.

Head. The upper portion of a tree. 
Heartwood. The dead central portion of the trunk.

Hoary. Grayish-white with a fine close down.

Hybrid. A cross between two species or varieties.

Internode. The portion of the stem between two nodes.

Inversely triangular. Inverted triangular with the apex below.

Involucre. The bracts surrounding the flower cluster.

Juvenile. Youthful, said of the leaves formed in the early stages of development.

Keeled. With a central ridge like the keel of a boat.

Key. A winged fruit.

Lanceolate. Lance-shaped; similar to ovate but narrower with outline tapering gradually to the apex.

Lateral bud. A bud produced on the side of a twig.

Leaf bud. A bud containin's undeveloped leaves but not flowers.

Leaf-scar. The scar left by the fall of the leaf (fig. 20).

Leaf-stalk. The stem of a leaf.

Lenticels. Corky spots on the surface which admit air to the interior of the twig.

Limbs. The larger branches.

Linear. Long and narrow, several times as long as broad with parallel edges, as the leaves of the Pines.

Lobed. With rounded indentations running $1 / 3$ to $\%$ the way from the margin inward.

Longitudinal. Lengthwise.

Medullary rays. Rays of tissue extending from the pith toward the bark, best seen in cross section.

Midrib. The central vein of a leaf.

Mucilaginous. Slimy when chewed.

Naked bud. A bud without bud-scales.

Needle. A narrow leaf as in the Pines.

Node. The place on the twig at which one or more leaves were produced (fig. 20).

Nut. A large hard fruit as in Hickory, Oak and Chestnut.

Nutlet. A small nut.

Oblanceolate. Inverted lanceolate.

oblong. Two or three times longer than broad with about uniform diameter.

Obovate. Inverted ovate.

Opposite (leaves and leaf-scars). With two leaves or leaf-scars opposed at a node.

Oval. Broadly elliptical.

Ovary. T'he part of the pistil producing the seeds.

Ovate. Egg-shaped, with the broadest part below the middle.

Persistent. Remaining on the tree. 
Peripheral. Situated near the margin.

Pistil. The seed-bearing portion of the flower.

Pith. The softer central portion of a twig.

Pod. A dry fruit which splits open at maturity.

Pome. A fruit like the Apple or Pear.

Pungent. Sharp to the taste.

Pyramidal. Shaped like a pyramid with broadest portion at the base.

Raceme. A simple cluster of stalked flowers arranged along an elongated axis.

Resin-duct. A tube for the conduction of resin seen in the leaves of the Pines.

Sapwood. The young living wood outside the heartwood.

Saucer-shaped. Shaped like a saucer, shallower than cup-shaped.

Scale. A small modified leaf seen in buds and cones. One of the flakes into which the outer bark often divides.

Scarious. Thin, dry and membranaceous, not green.

Scurfy. Covered with small bran-like scales.

Sepal. One of the divisions of the calyx.

Sessile. Without a stalk.

Shrub. A low woody growth, smaller than a tree and generally branching near the base.

Smooth. Not rough nor hairy.

Spray. The aggregate of smaller branches and branchlets.

Spine. A sharp rigid outgrowth from the stem.

Spur. A short, slowly-grown branchlet.

Stamens. The pollen-bearing portions of a flower.

Staminate. Having stamens; said of trees bearing only male flowers.

Sterile. Not producing seed.

Stipular. Similar in form or position to stipules.

Stipules. Two small leaf-like bodies located at the base of the leaf-stalk in some species.

Stipule-scar. The scar left by the fall of a stipule (fig. 100).

Stomata. Breathing pores in leaves.

Stone-fruit. A fruit like that of the Cherry. The same as drupe.

Strengthening cells. Thick walled cells present in the leaves of some of he Pines.

Striate. Longitudinally streaked.

Submerged. Covered, as by the bark.

Sucker. A shoot arising from below ground.

Superposed buds. Accessory buds above the axillary bud, as in the Butternut (fig. 101).

Surface-sectioned. Cut parallel to and near the surface. 
Teeth. Small projections along the margin.

Terminal bud. The bud formed at the tip of a twig.

Thorn. A stiff woody sharp-pointed projection.

Top-shaped. Shaped like a top with the broadest part above.

Tree. A woody plant, larger than a shrub, from which it cannot always be distinguished. Usually defined as a woody growth, unbranched near the base and reaching a height of at least fifteen feet.

Triangular. Shaped like a triangle with the base below.

Trunk. The main stem of a tree.

Twig. A young shoot. Unless otherwise specified, used in the descriptions to denote the growth of the past season only.

Type. A term used to designate the characteristic form of a species in distinction from its varieties.

Valvate. Said of buds in which the scales meet without overlapping.

Whorl. A cluster of three or more leaves or leaf-scars at a single node.

Wing. A thin flat appendage.

Woolly. Covered with tangled or matted hairs resembling wool.

\section{Library \\ N. C. State Colloge}




\section{INDEX}

Where the species receives its most extended description, the page number appears in boldface type. Where the species is otherwise mentioned, the page number is printed in ordinary type. Synonyms of both common and scientific names are printed in italics and their page numbers in ordinary type.

Abele .................252

Abies balsamea ..........236

Acacia .....................

Three-thorned ...........3s2

Acer ..................208

barbatum ...............402

dasycarpum ................404

Key to Species ..........208

Negundo ..............412

pennsylvanicum .........398

platanoides ............408

Pseudo-Platanus ........410

rubrum .............406

saccharinum .............402

saccharinum ..........404

saccharum ............402

var. nigrum .........402

spicatum .............400

Aesculus :

glabra ..............414

Hippocastanum ........414

octandra .............414

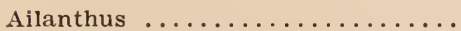

$46,53,79,80,81,96,153,380, \mathbf{3 9 0}$

glandulosa ........... 390

Alder ..............292, 344

European Black .........292

Hoary ................292

Smooth .............292

Speckled .............2!2

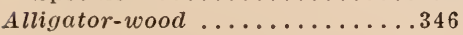

Alnus :

incana.$\ldots \ldots \ldots \ldots \ldots \ldots .292$

rugosa $\ldots \ldots \ldots \ldots \ldots \ldots .292$

vulgaris ............292

Alternate-leaved Dogwood ....418

Amelanchier canadensis ......358

American :

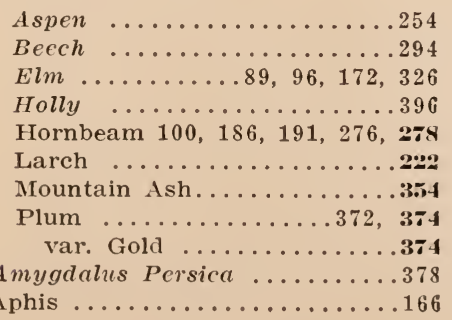

Apple $\ldots \ldots \ldots \ldots 20,53,55,58$, $93,135,136,157,163,170,184$, $187,332,334,350,352,356,414$ Apple, Thorn ................ 360 Arbor Vitae .........54, 242 Art :

Tree study in relation to .... 13 Ash .....13, 33, 43, 45, 47, 48, $49,51,132,190,192,193, \mathbf{2 0 9}, 422$ American Mountain .......354 Basket .............426 Black ......188, 422, 424, 426 Brown ...........424, 426 European ............ 43 24 European Mountain .......354 Green ............424 Hoop .............330, 426

Key to Species .........209 Mountain ....46, 53, 170, 354

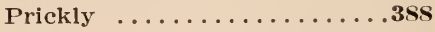
Red ..............424 River .............424

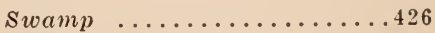

Western Mountain .........354 White $66,79,81,110,186,188,192$ $193,272,340,408,422,424,426$ Ash-leaved Maple ........412

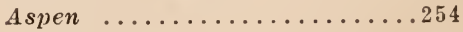
American .............254 Large-toothed $\ldots \ldots 252,254, \mathbf{2 5 6}$

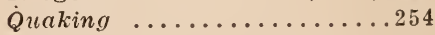
Small-toothed ............. $\ldots \ldots \ldots 190,252, \mathbf{2 5 4}, 256,258$ Austrian Pine ...........218 Back-yard planting ....... 93

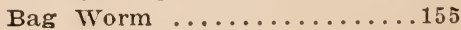
Bald Cypress ............133 Balm of Gilead ...........258

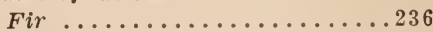
Balsam ...........2236, 258 Fir ......101, 234, 236, 238 Poplar ......100, 254, 256, 25s Banding .................. Bark ..................185 Bark-beetles ..............154 Basket Ash ...........426 Basswood .....47, 110, 153, 416 Bay :

Swamp ................207

Sweet ......207, 336, 338 
Bean, Indian ...........428

Bear Oak ...........308, 320

Beaver Tree .............207

Beech ............. 36, 41 $48,186,278, \mathbf{2 9 4}, 358,386,406$ American ..............294 Blue ...............278 European ...........294 Water .................278

Beetree ..............416

Betula ................203 alba $\quad \ldots \ldots \ldots \ldots \ldots \ldots \ldots .290$

var. papyrifera ........2ss

Key to Species ..........203 lenta ...............280 lutea ...............282 nigra ...............284 papyrifera .............288 populifolia ............286

Big Bud Hickory ..........270

Big Tree .................133

Bilsted ..................346

Birch .........33, 36, 46, 47 $48, \quad 50, \quad 72, \quad 134, \quad 186, \quad 187, \quad \mathbf{2 0 3}$ Black 184, 186, 187, 280, 282, 284

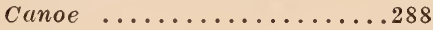
Cherry ..............280 European Paper .........290 European White .........290 Gray .................282 Gray .......72, 92, 2s6, 288 Key to Species ......... 203 Old Field .............286 Paper ...186, 282, 286, 2s8, 290 Poplar ..............286 Poverty ...............286 Red ...........282, 284 River ...........50, 284 Silver ..............282 Small White ............286 Sweet ...............280 White .......72, 92, 286, 288 Yellow ...186, 280, 2s2, 284, 288 Bird Cherry ............... 366 Bird's Eye Maple .........402 Bitternut .......264, 266, 274 Black :

Ash ........188, 422, 424, 426 Birch 184, 186, 187, 290, 2S2, 284 Cherry ................... 362 Gum .............183, 420 Knot ..................64 Larch ...............222 Locust . . .................388 Maple ..............402 Oak ......186, 312, 316, 318 Oak Group ....186, 191, 204, 318 Pine ................218 Scrub Oak ................320 Spruce ...........101, 166 $216,222,224,226, \mathbf{2 2 8}, 236,242$
Black (Continued)

Walnut ...49, 51, 264, 266, 390 Willow ..............250

Black-spot disease ........147 Block of Oak wood .......42, 43 Blue:

Beech ................278

Oak ...................... 304

Spruce .....166, 224, 226, 230

Bog Spruce ..............228

Bolting .................143

Borer ..... $80,150,151,170,176$ Maple ............150, 170 Maple Leaf-stem ........162 Box Elder . .48, 80, 157, 406, 412

Box White Oak ............300

Boxwood .................418

Bridge grafting ............. 138

Bristly Locust .............3ss

'Broom Hickory ..........272

Brown Ash .........424, 426

Brown-tail Moth 151, 154, 155, 156

Buckeye:

Fetid ................414

Ohio .................414

Sweet $\ldots \ldots \ldots \ldots \ldots \ldots \ldots$ 414

Budding .............. 58

Buds ................... 189

Bud-scales ............ 41

Bur Oak .........33, 302, 346

Bush Maple .........398, 418

Butternut .......7, 48, 49, 51 $187,189,190, \mathbf{2 6 4}, 266,274,390$

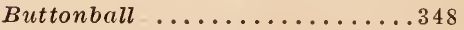

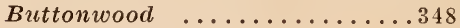

Cabinet Cherry .............. 362

Caliper ................ 21

Canada Plum ........372, 374

Canker Worm ........152, 157

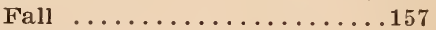

Spring $\ldots \ldots \ldots \ldots \ldots \ldots 157$

Canoe Birch ............288

Care of

Seedlings ............ 51

Trees ............31, 114

Carolina Poplar ............. $\ldots .9,41,46,79,80,96,153,188$ $189,190,193,254,256, \mathbf{2 6 0}, 262$

Carpinus caroliniana ........28s

Carya ................203 alba .................268

alba ...............270

amara ..............274

cordiformis .........274

glabra .............272

Key to Species ..........203

microcarpa ............272

ovata ...............26s

porcina ................272

tomentosa .............270 
Castanea :

dentata ...............296

sativa, var, americana ....296

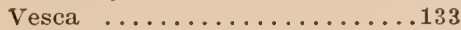
var. americana ........296

Cat spruce ............224

Catalpa ............. 9 $45,46,47,48,51,81,110,428$ bignonioides .........42s Common .............428 Hardy ..........79, 80, 428 speciosa .............4.28 Western .............428

Cavities:

Filling of ..............139

Cedar ....46, 52, 240, 242, 246

Coast White ..191, 240, 242, 246

Red .........240, 244, 246

White ...........240, 242

Celtis occidentalis .........330

Cercis canadensis ..........384

Chaining ...............143

Chamaecyparis :

sphaeroidea ...........240

thyoides ............240

Cherry ............. 46

$49,53,55,93,186,187, \mathbf{2 0 7}, 280$

Amarelles ...............370

Birch .................280

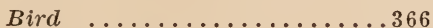

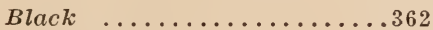

Black Tartarian ..........368

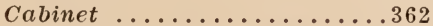

Choke .........362, 364, 370

Early Richmond .............. 370

European Bird ............368

Fire ..................366

Key to Species .........207

Louis Philippe ..........370

May Duke ................368

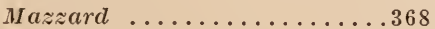

Montmorency ...........370

Morello ..................370

Napoleon ................368

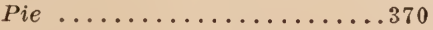

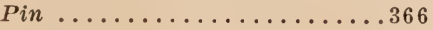

Pigeon ................366

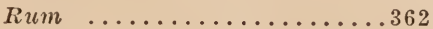

Sour ...184, 362, 364, 368, 370

Sweet $69,184,362,364, \mathbf{3 6 8}, 370$

Wild Black ...362, 364, 366, 370

Wild Red .......364, 366, 370

Windsor ...............368

Chestnut ............ 37

$41,48,66,69,81,133,147,148$

149, 157, 186, 188, 193, 296, 306

Bark disease ..699,147, 148, 149

oak ...................... 306

Oak $79,93,306,308,310,312$
Chinese:

Magnolia ...........336, 338

Sumach ................390

Chinquapin Oak ..9, 298, 306, 308

Chinquapin Oak .............30's

Choke Cherry ......362, 364, 370

Cigar Tree ..............428

City Homes:

Suggestions for ........ 89

Types of $\ldots \ldots \ldots \ldots \ldots \ldots 9$

Cladrastis lutea .............3si

Clammy Locust ............3s

Coast White Cedar ................ ........191, \$40, 242, 246

Cockspur Thorn .........360

Coffee :

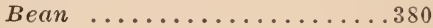

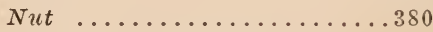

Coffee Tree, Kentucky .........

$\ldots \ldots \ldots 48,79,99,187, \mathbf{3 5 0}, 390$

Collecting seeds ..........4 47

Collections:

Of trees ..............24

Students' ............ 28

Colleges, tree study in ..... 25

Colorado Blue spruce .......230

Combatting insects, method of 150

Common :

Catalpa .............42s

Juniper ..........244, 246

Locust $48,79,81,190,382$, 3s.

Comparisons ................ 191

Conservation of scenery .....6 61

Control of Parasites .......146

Cork Elm ...99, 322, 326, 328, 346

Cornel, Flowering ........418

Cornus :

alternifolia ...........41s

florida ...............41s

Cottonwoód .............260

Cottony Maple-scale 167, 168, 169

Country Roads:

Location of ..........64

Problem of ...........6 64

Crataegus ..............360

Crus-galli ..............860

pruinosa .............360

Cucumber Tree ......81, 336t, 338

Large-leaved ...........207

Cultivated Plums ...........87

Cultivation .................. 115

Cupressus thyoides ........240

Curly Maple ............402

Cuttings, propagation by ..... 53

Cydonia vulgaris ...........3st;

Deerwood ..............276

Dehorning trees ..........134

Dimerosporium Collinsii .....358

Distribution ...............191 
Dogwood ............46, 418

Alternate-leaved ........418

Flowering ............418

Poison ..................394

Double spruce ...........228

Douglas :

Fir .........133, 234, 236

spruce ................234

Downy Poplar ..........202

Dracaena Draco ...........133

Dragon Tree ..............133

Dwarf :

Chinquapin Oak 298, 306, 308, 320

Juniper .............244

Pear ............... 55

Sumach .............392

Ecology of Tree .......... 19

Elder :

Box ........48, 80, 157, 412

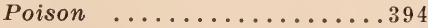

Elkwood ....................

Elm $\ldots \ldots \ldots \ldots 17,34,35,46,48$ $50,51,53,69,110,125,134,143$ $145,153,155,157,158,162,163$, $171,179,188, \mathbf{2 0 6}, 304,330,416$ American .....so, 96, 172, 326 Cork ....99, 322, 326, 328, 346

English .....184, 324, 326, 328

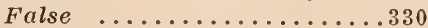

Hickory ................... 328

Key to Species .........206

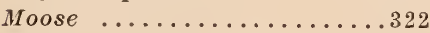

Northern Cork ............320

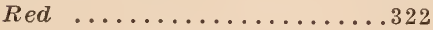

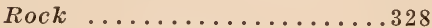

Scale ..............168

Slippery ........322, 326, 328

Water .................. 326

White ......66, 78, 80, 81 $96,172,184,322,324,326,328$

Winged ...............328

Elm-leaf Beetle .............

English :

Elm .......184. 324, 326, 328

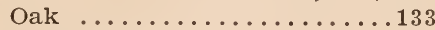

Eucalyptus $\ldots \ldots \ldots \ldots \ldots \ldots 133$

European :

Ash .............13, 424

Beech ..............294

Bird Cherry ..............368

Black Alder ............292

Holly ...............396;

Larch ...............222

Linden ...........80, 416

Mountain Ash ..........354

Paper Birch .............290

Plum ...............374

var. Lombard ..........374
European (Continued)

Weeping Willow ..........250

White Birch ..........290

White Willow .........250

Evergreens $36,41,47,48,49,72,88$ $92,103,132,155,163,184,195$

Fagus :

americana .............294

atropunicea ............294

ferruginia ............294

grandifolia ...........294

sylvatica $\ldots \ldots \ldots \ldots \ldots \ldots .294$

Fall :

Canker Worm ...........157

Web Worm .........151, 163

False Elm .......................

Fertilizers for Trees ........115

Fetid Buckeye ...........414

Field Work ............. 26

Filling Cavities ...........139

Fir ............ 99, 236

Balm of Gilead .........236

Balsam .....101, 234, 236, 238

Douglas .......133, 234, 236

Red ...................234

Scotch $\ldots \ldots \ldots \ldots \ldots \ldots 220$

White ................ 98

Fire Cherry .............366

Flowering :

Cornel ...................418

Dogwood ..............418

Forest :

Nursery .............4 47

Tent-caterpillar ..........163

Fraxinus ..............209

americana ..........193, 422

Darlingtonii .............424

excelsior .............424

Key to Species ..........209

nigra ..............426

pennsylvanica .........424

var. lanceolata ........424

pubescens ..............424

sambucifolia .............426

Fruit .................190

Trees, varieties for home plant-

ing ................101

Fungicides .........174, 176

Fungus troubles ..........146

Ginkgo .....79, 80, 103, 153, 248 biloba ..............248

Gleditsia triacanthus ......382

Golden Osier ...........250

Gopher Wood .............386

Graded Schools, tree study in .. 29

Grafting ............55, 56 Bridge ...................

Cleft ............... 56

Whip ............... 58 
Gray :

Birch ........72, 92, 286, 288

Birch ...............282

Pine ..................214

Green Ash .............424

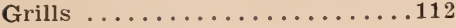

Growth of Tree .......... 31

Grubs ..................150

Guarding young trees ......110

Guards ..................112

Gum :

Black .............183, 420

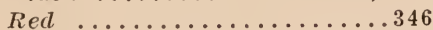

Sour .................... 4830

Sweet $\ldots \ldots \ldots 79,80,153, \mathbf{3 4 6}$

Gymnocladus :

canadensis ...............380

dioica ................350

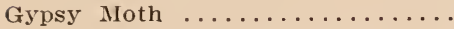

$\ldots \ldots 151,154,158,160,161,166$

Habit of Tree .............183

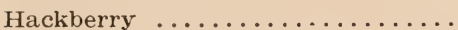
$\ldots .46,79,80,81,153,187,330$

Hackmatack .............222

Hamamelis virginiana .......344

Hard :

Maple ..............402

Pine ..................212

Hardy Catalpa ......79, 80, 428

Haw ..................... 360

Hawthorn 46, 49, 53, 170, 360, 382

Hazel, witch ............344

Heeling in ............... 102

Height measurer .....22, 23, 24

Hemlock .....36, 72, 236, 238

Spruce .............238

Hickoria :

alba ...................270

glabra ..............272

minima ..............274

ovata ................268

Hickory ............. 33,46

$48,49,51,66,{ }^{\prime} 110,157, \mathbf{2 0 3}, 328$

Big Bud .............270

Broom ...............272

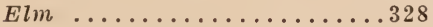

Key to Species ..........203

Pignut ..............272

Shag-bark ...186, 268s, 270, 272

Shell-bark .............268

Small-fruited ...........272

Swamp ...............274

White-heart ...........270

High Schools, Tree Study in .. 25

Hoary Alder ............292

Holly . ..........36, 46, 396

American ..................396

European ...............396

White ..................396
Home, location and adaptation 70

Honey Locust ............... $9,48,79,81,173,360, \mathbf{3 5 2}, 388$ Shucks ................... 382

Hoop Ash ...........330, 426

Hop Hornbeam ..46, 191, $\mathbf{2 7 6}, 278$

Hornbeam .............278

American 100, 186, 191, 276, 278

Hop .......46, 191, :276, 278

Seedling of $\ldots \ldots \ldots \ldots \ldots 33$

Horse Plum ...............372

Horse-chestnut $\ldots 38,39,41,45,79$

$80,81,96,110,153,187,188, \mathbf{4 1 4}$

Hypsometer ...........21, 22

Identification of Trees ....11, 183 Ilex :

Aquifolium ...........396

Opaca ................396

Imported Elm-tree Borer ....171

Indian Bean .............428

Injuries, care of $\ldots \ldots \ldots \ldots 136$

Caused by gas and smoke ..124

Common to shade trees ...124

from careless driving ....129

from horse bites ........129

from improper pruning ...128

from improper soil conditions 132

from overhead wires ......125

from regrading street $\ldots \ldots 127$

from wind and ice .......132

Sources of $\ldots \ldots \ldots \ldots \ldots 124$

Insects :

Combatting, method of $\ldots .150$

Control, preventive measures

for ................153

Enemies of ............154

Handpicking of ..........151

Leaf-eating ........155, 177

Shade tree ..............154

Spraying for ...........151

Sucking .........166, 178

Trapping .............151

Troubles ..............149

Insectícides $\ldots \ldots \ldots \ldots \ldots 174,177$

Contact ................ 175

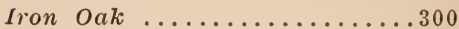

Ironwood .........276, 278

Ivy, Poison ................4

Jack Pine ...........191, 214

Japanese Plum ...........374

var. Red June ...........374

Judas Tree ...............384

Juglans :

cinerea ...............264

nigra ................266

Juneberry ...................

Juniper .........46, 54, 222

Common .........24, 246

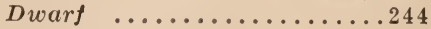

Red ................246 
Juniperus :

communis

var. alpina ............244

var. canadensis .........244

var. depressa .........244

nana ................244

virginiana ...........216

Kentucky Coffee Tree ......... $\ldots \ldots \ldots 48,79,99,187$, 3S0, 390

Key, use of ............... 192

to Genera and Species .....195

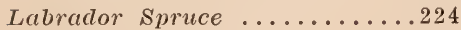

Lancewood ......................... 358

Landscape Picture ........ 74

Larch ......38, 48, 162, 201, 248 American .............222

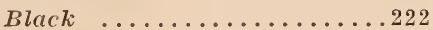

European .............222

Key to Species .........201

Large-leaved :

Magnolia .......207, 336, 338

Cucumber Tree .........207

Umbrella Tree ..........207

Large-toothed Aspen 252, 254, 256

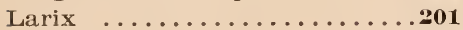

americuna ................222

decidua ..............222

europaea ................222

Key to Species ...........201

laricini ...............222

Laurel Magnolia .........207

Leaf Beetle .......69, 80, 163

Leaf, Function of ....... 35

Leaf-eating Insects . . . 155, 177

Leaf-scars ............. 187

Leopard Moth ............. $\ldots \ldots \ldots 153,154,171,172,173$

Leverwood $\ldots \ldots \ldots \ldots . \ldots 276$

Life of Tree ............ 31

Lime ............... 13, 416

Linden ...66, 79, 80, 81, 296, 416 European ...........8 $80, \mathbf{4 1 6}$

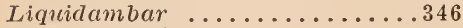
Styraciflua .............346

Liriodendron Tulipifera ......340

Location of the Home ...... 70

Locust $45,49,51,80,153,171,388$

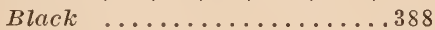

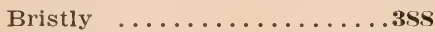

Clammy ............... 3ss

Common 48, 79, 81, 190, 382, $38 s$ Honey

$9,48,79,81,173,360, \mathbf{3 5 2}, 388$

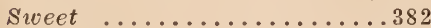

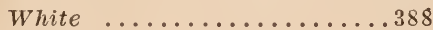

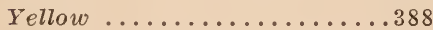

Lombardy Poplar ............ $\ldots 45,79,193,254,256,260, \mathbf{2 6 2}$

Maclura pomifera .........360
Magnolia $38,45,107,110, \mathbf{2 0 7}, 340$

acuminata ............336

Chinese .............336, 338

conspicua ..............336

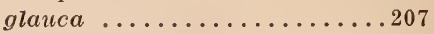

Key to Species .........207

Laurel ................207

Large-leaved .....207, 336, 338

macrophylla ............207

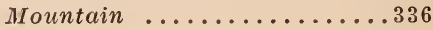

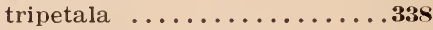

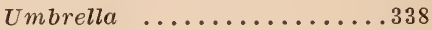

virginiana .............207

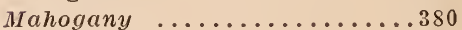

Maidenhair Tree ..........248

Malus Malus ................ 352

Maple .....27, 33, 46, 48, 66, 110

$147,153,155,158,169,171,208$

Ash-leaved ...........4412

Bird's Eye ..............402

Black ...............4402

borer ..............150, 170

Bush .............398, 418

Curly ...............4402

Hard ................402

Key to Species..........208

Leaf-stem Borer ........162

Mountain ...398, 400, 406, 418

Norway ................

$78,80,93,162,406,408,410$

Red .......27, 50, $78,80,81$

$93,189,190,191,402,404,406$

River ..............404

Rock .................402

Silver ......50, 78, $80,81,96$

$132,143,145,191,402, \mathbf{4 0 4}, 406$ Soft ...........51, 404, 406 Striped .....398, 400, 406, 418 Sugar ..............14, 15 $16,17,27,36,48,50,78,81,122$ $125,147,162,392,402,406,410$

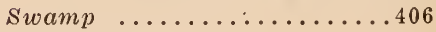
Sycamore ................ $78,80,81,162,406,408,410$ White ...........404, 406

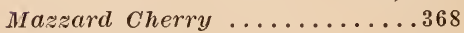

Measurement of Tree .......20

Mockernut ......268, 270, 272

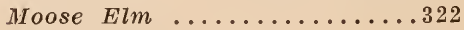

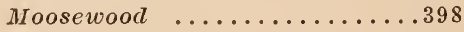

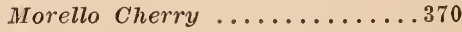

Morus ................206

alba $\ldots \ldots \ldots \ldots \ldots \ldots \ldots . . . . .334$

Key to Species .........206

rubra ..................332

Mossy-cup Oak ............302

Mountain :

Ash .........46, 53, 170, 354

Magnolia ................336

Manle .......398, 400, 406, 418 
Mourning Cloak Butterfly ...162

Moving Large Trees .........108

Mulberry ...............

$46,47,49,188,189,191, \mathbf{2 0 6}, 334$

Key to Species .........206

Red ..........9, 332, 334

Silkworm ...............334

White ............332, 334

Municipal Control of Shade Trees..

Name of Tree....................... 81

Necklace Poplar ...........260

Negundo:

aceroides .............4412

Negundo ...............412

Nettle Tree .................330

Nicker Tree ................. 380

Northern Cork Elm ..........328

Northern Scrub Pine .........214

Norway:

Maple

$.78,80,93,162,406,408,410$

Pine ...............216

Spruce .......166, 226, 232

Nursery, Forest .........4 47

Nyssa:

multiflora

420

sylvatica

420

Oak ..........36, 43, 48, 51

$66,110,134,153,155,161,173$

$186,187,191,193, \mathbf{2 0 4}, 294,296$

Bear ............. 308, 320

Black .....186, 312, 316, 318

Black Scrub ................ 320

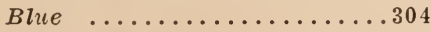

Box White ............... 300

Bur ............33, 302, 346

Chestnut ..............306

Chestnut $79,93,306,308, \mathbf{3 1 0}, 312$

Chinquapin ...............308

Chinquapin ...99, 298, 306, 308

Dwarf Chinquapin ..........

.........298, 306, 308, 320

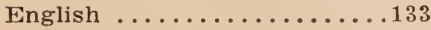

Iron ..................... 300

Key to Species .........204

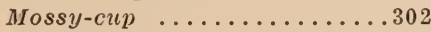

Over-cup ..................302

Pin $. .79,80,81,93,103,110, \mathbf{3 1 4}$

Post ..........36, 298, 300

Red ............79, 80

$81,146,296,310, \mathbf{3 1 2}, 316,318$

Rock ....................... 310

Rock Chestnut ............310

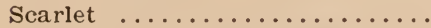

$78,80,81,312,314,316,318$

Scrub ......................

Scrub Chestnut ............308

Swamp ......................
Oak (Continued)

Swamp White

$\ldots \ldots \ldots \ldots 9, \mathbf{1 8 4}, 298, \mathbf{3 0 4}, 308$

White .........33, 48, 78,

$81,122,186, \mathbf{2 9 8}, 300,302,304$

Wood Block .........42, 43

Yellow ...........306, 318

Yellow-barked ...........318

Ohio Buckeye ............414

Oilnut ................264

Old-ficld Birch ..........286

Oriental Sycamore ......133, 34s

Osage Orange .............360

Osier :

Golden ...............250

Ostrya virginiana .........276

Over-cup Oak ......................

Oyster-shell Scale ......167, 168

Padus :

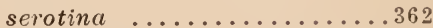

virginiana ................. 364

Paper Birch 186, 2\$2, 286, 2ss, 290

Parasites, control of .......146

Parking strips ........... 78

Parks ................ 87

Artificial style .......... 89

Natural type .......... 87

Peach ....55, 170, 177, 207, 37s

Pear ....53, 55, 58, 93, 157, 162

$170,184,187,188,336, \mathbf{3 5 0}, 352$

Dwarf .............. 55

Standard ............. 55

Pepperidge ...........1s3, 420

Permanent planting ........ 79

Photography ............. 18

Picea ..................201

Abies ................232

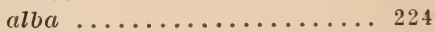

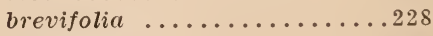

canadensis ...........2.

excelsa ...............232

Key to Species .........201

mariana ..............22s

var. semiprostrata ......22s

menziessii .............230

nigra ..................228

var. rubra .........226

Parryana ................230

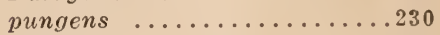

rubens ................226

rubra .............226

Pie Cherry ..............370

Pigeon Cherry ..............366

Pignut ...........26s, 272

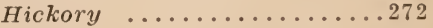

Pin Cherry ............... 366 Oak $79, \delta 0,81,93,103,110, \mathbf{3 1 4}$

Pine ........72, 191, 201, 248 Austrian ........216, 218 Black ...............218 


\section{Pine (Continued)}

Gray ................214

Hard ..................212

Jack .............. 2191

Key to Species ...........201

Northern Scrub .........214

Norway ..............216

Pitch ........210, 212, 216

Red ......210, 212, 216, 218

Scotch ...........214, 220

Soft .................210

Spruce ...............214

Weymouth ............210

White .....36, 45, 48, 66, 67,

$74,134, \mathbf{2 1 0}, 212,216,220,236$

Yellow ...............212

Pinus ...................201

Banksiana ............214

divaricata .............214

Key to Species .........201

Laricio, var. austriaca ....218 resinosa .............216

rigida $\ldots \ldots \ldots \ldots \ldots \ldots \ldots 212$

Strobus ..............210

sylvestris ............220

Pitch Pine .......210, 212, 216

Plane Tree ..................... 348

Planting of Trees ...31, 102, 105

Back yard ........... 93

Board ............107, 108

Conservaton of scenery ...661

Filling in .............. 107

For winter effect ....... 72

In cities ............. 75

In rural districts $\ldots \ldots \ldots \ldots 61$

In towns ............. 75

Making the hole .........107

Park system ..........6 62

Permanent ............ 79

Plan ...........72, 90, 94

Roadside .............6 68

Seeds ................ 50

Street trees .............105

Suggestions for city home ... 89

Temporary ............ 79

Time of .............106

Plant Lice .......150, 166, 175

Platanus:

occidentalis ...........348

orientalis ............348

Plowrightia morbosa .......364

Plum... 49, 53, 55, 170, 207, 364

American ..........372, 374

var. Gold ............374

Canada ...........372, 374

Cultivated ............374

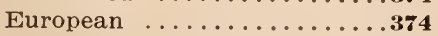

var. Lombard ...........374

Horse .................372
PlumContinued)

Japanese ..............374

var. Red June ...........374

Key to Species ...........207

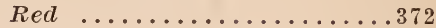

Wild .......................

Poetry, tree study in relation to 13

Poison:

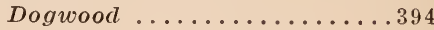

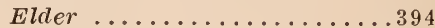

Ivy $\ldots \ldots \ldots \ldots \ldots \ldots \ldots . \ldots . \ldots . \ldots 4$

Sumach .......186, 392, 394

Poplar ...36, 41, 45, 47, 48, 50, 53 $103,110,122,132,134,162,171$ 184, 187, 188, 191, 202, 254, 256 Balsam ....100, 254, 256, 25s Birch ..............286

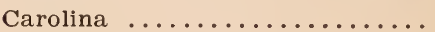
$\ldots .9,41,46,79,80,96,153,188$ $189,190,193,254,256,260,262$ Downy Poplar ..........202 Key to Species ..........202 Lombardy ................ $45,79,193,254,256,260, \mathbf{2 6 2}$ Necklace ............260 Silver ........252, 254, 256 Silver-leaf .............252 White .................252

Yellow .................340

Popple ............254, 256

Populus ...............202 alba ..............252

balsamifera ...........258

canadensis ............260

candicans ...........258

deltoides ..............260

dilatata ...............262

fastigiata ............262

grandidentata ..........256

heterophylla ...........202

Key to Species .........202

monilifera .............260

nigra, var. italica .......202

pyramidalis ............262

tremuloides ............254

Post Oak ....... 36, 298, 300

Poverty Birch ...........286

Propagation ............4 46

by budding $\ldots \ldots \ldots \ldots \ldots 58$

by cuttings $\ldots \ldots \ldots \ldots \ldots \ldots 5$

by graftage $\ldots \ldots \ldots \ldots \ldots 5,56$

from seeds ........... 46

nature's way $\ldots \ldots \ldots \ldots \ldots 46$

Pruning:

Before planting .........103

Shade trees ............ 116

Time of $\ldots \ldots \ldots \ldots \ldots \ldots \ldots \ldots$

Tools .................121

Prunus .........186, 207, 372

americana ...........374 
Prunus (Continued)

nar. nigra ..............372

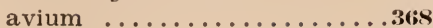

Cerasus ...............370

domestica ..............374

Key to Species .........207

nigra ...............372

pennsylvanica ..........366

Persica ..............37s

serotina .............362

triflora .............374

virginiana $\ldots \ldots \ldots \ldots \ldots \ldots .6 . \ldots 64$

Pseudotsuga :

Douglasii ..............234

mucronata ..............234

taxifolia .............234

Public Squares ........... 87

Artificial Style ......... 89

Puddling ...............102

Pyrus:

americana ...........354

Aucuparia ............354

communis ..............350

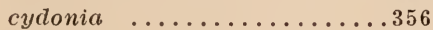

Malus .......................

sitchensis ............354

Quaking Aspen ..........254

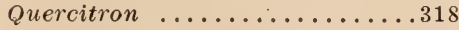

Quercus ................204

acuminata ............306

alba ...............298

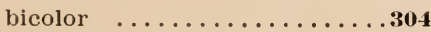

coccinea ...............316

var. tinctoria ............318

ilicifolia ..............320

Key to Species ..........204

macrocarpa ...........302

minor ....................

Muhlenbergii ...........306

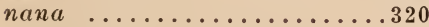

obtusiloba ..............................

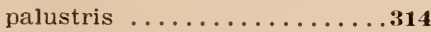

pedunculata .............133

platanoides ................304

prinoides ..............30s

var. rufescens ..........30s

Prinus ...............310

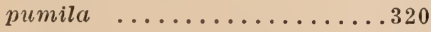

rubra ...............312

stellata ..............300

tinctoria .........................

velutina $\ldots \ldots \ldots \ldots \ldots \ldots \ldots$.

Quince ............55, 356

Red :

Ash ..............424

Birch ............282, 284

Cedar ..........240, 244, 246

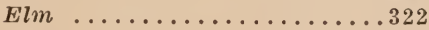

Fir ..................234

Gum .......................

Juniper ..............246
Red (Continued)

Maple $\ldots \ldots \ldots 27,50,78,80,81$ $93,189,190,191,402,404,406$ Mulberry ........9, 332, 334 Oak ............79, 80 $81,146,296,310, \mathbf{3 1 2}, 316,318$ Pine ......210, 212, 216, 218

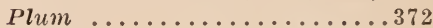
Spruce ....224, 2:6, 228, 236

Redbud .................44

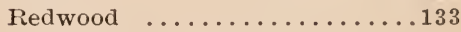

Renovation of trees .........133

Reproduction ........... 45

Rhus ...............20s copallina .............392 glabra ...............392

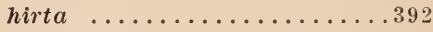

Key to Species .........208

Toxicodendron .........394

typhina ..............392

venenata ..............394

Vernix ..............394

River:

Ash ................424

Birch ............50, 284

Maple ..............404

Robinia:

hispida ...............3ss

Pseudo-Acacia .............3s8

viscosa .............3ss

Rock:

Chestnut Oak .............310

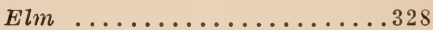

Maple ................402

oak ..................... 310

Root ................... 33

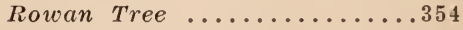

Rum Cherry .................

Salisburia adiantifolia ......248

Salix:

alba ...............250

var. vitellina .........250

babylonica .............250

nigra .............250

vitellina ...............250

San Jose Scale .............

$\ldots \ldots \ldots 150,154,167,168,170$

Sassafras ......9, 46, ${ }^{\circ} 186, \mathbf{3 4 2}$ officinale ............... 342

Sassafras ................. 342

variffolium ...........342

Savin ..................246

Saw-flies $\ldots \ldots \ldots \ldots \ldots \ldots 162$

Scale insects $150,167,168,176,177$

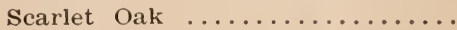

$\ldots .78,80,81,312,314, \mathbf{3 1 6}, 318$

Scenery, conservation of .....61

Scotch :

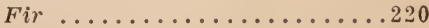

Pine $. . . \ldots \ldots \ldots \ldots 214,220$ 
Scrub:

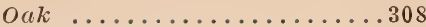

Chestnut Oak ..............30s

Scurfy scale ............167

Seed :

Collecting ........... 47

Planting ............... 50

Propagation from ....... 46

Storing ............ 48

Testing ............. 49

Vitality of ........... 49

Seedlings, care of $\ldots \ldots \ldots \ldots 51$

Sequoia gigantea ...........133 Service :

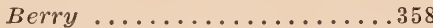

Tree ........................

Setting the tree $\ldots \ldots \ldots \ldots \ldots 106$

Shad Bush ..........46, 35s

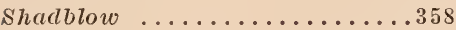

Shade Tree:

Insects ..............154

Municipal control of ......8 81

Shag-Bark Hickory ..........

$\ldots \ldots \ldots \ldots 186, \mathbf{2 6 8}, 270,272$

Shell-bark Hickory ........268

Shrubs ................ 71

Sign-boards ............6 63

Silkworm Mulberry ..........334

Silver:

Birch .................282

Maple .....50, 78, 80, 81, 96, $132,143,145,191,402,404,406$

Poplar .......252, 254, 256

Spruce ...............230

Silver-leaf Poplar .........252

Skunk Spruce .............224

Slippery Elm ......322, 326, 328

Slugs $\ldots \ldots \ldots \ldots \ldots \ldots \ldots 2$

Small White Birch ........286

Small-fruited Hickory .......272

Small-toothed Aspen ........... $\ldots \ldots \ldots 190,252,254,256,258$ Smooth:

Alder ................292

Sumach ...........390, 392 Soft:

Maple .......51, 404, 406

Pine ..................

Soil:

Improving condition of .....114

Injuries from improper condi-

tions ................132

Need of humus in .........114

Sorbus americana ..........354

Sour:

Cherry ..184, 362, 364, 368, 370

Gum ...........183, 420

Speckled Alder ..........292

Spiney Elm Caterpillar ......162
Spraying $\ldots \ldots \ldots \ldots \ldots 174,177$

for insects .............151

machinery .............178

Spring Canker Worm .......157

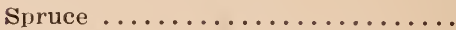
$33,54,72, \mathbf{2 0 1}, 214,236,238,248$

Black ...........101, 166 $216,222,224,226, \mathbf{2 2 8}, 236,242$

Blue ......166, 224, 226, 230

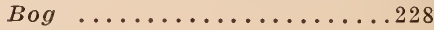

Cat .................224

Colorado Blue ...........230

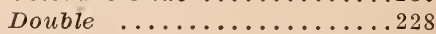

Douglas ...............234

Gall Louse .........166, 167

Hemlock ..............238

Key to Species ..........201

Labrador ...............224

Norway ........166, 226, 232

Pine .................214

Red .......224, 226, 228, 236

Silver ................230

Skunk ................224

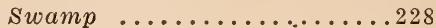

Water ................228

White .......166, 224, 226

Staghorn Sumach .......390, 392

Stakes ..................110

Staking the ground for trees ..106 young trees .............110

Standard Pear ........... 55

Stem of Tree ............ 38

Stomach poisons ..........174

Storing seeds ...........4 48

Street planting suggestions ... 76

Striped Maple ...398, 400, 406, 418

Structure of tree .......... 31

Study of tree ............ 11

Suburban lot ........... 92

Sucking-insects $\ldots \ldots \ldots \ldots 166,178$ Sugar:

Berry .................330

Maple .............14, 15

$16,17,27,36,48,50,78,81,122$

$125,147,162,392, \mathbf{4 0 2}, 406,410$

Sumach ........208, 392, 394

Chinese ................390

Dwarf ................392

Key to Species ........208

Poison .........186, $392 \mathbf{3 9 4}$

Smooth ...........390, 392

Staghorn ..........390, 392

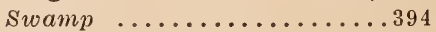

Surgery, Tree ........134, 140

Swamp:

Ash .................426

Bay .................207

Hickory ...........274

Maple ................406 
Swamp (Continued)

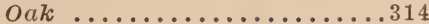

Spruce .................228

Sumach ..................394

White Oak 9, 184, 298, 304, 308 Sweet:

Bay .........207, 336, 338

Birch ...............280

Buckeye ..............414

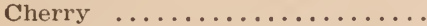
$\ldots .69,184,362,364, \mathbf{3 6 s}, 370$ Gum .......79, 80, 153, 346 Locust ................. 382

Sycamore ..46, 47, 48, 66, 78, s0, 81 133, 134, 153, 173, 186, 188, 34s

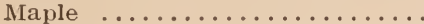
$78, \quad 80,81,162,406,408,410$ Oriental ............133, 34s

Tacamahac .............25s

Tamarack ...............222

Tar-spot disease ..........147

Taxodium mucronatum .......133

Temporary planting ....... 79

Tent-caterpillar .....151, 163, 164

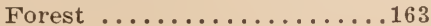

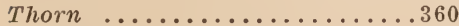

Apple ..................360

Cockspur ............360

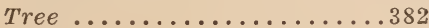

White ..................360

Three-thorned Acacia ........382

Thuja occidentalis .........242

Tilia:

americana .............416

Michauxii ............416

vulgaris .............416

Toothache Tree .............388

Transplanting ........... 52

Trapping insects ...........151

Tree of Heaven .............390

Trees:

Adaptation to home ...... 70

Age limit ...............133

Around the home ........ 70

Arrangement on street ..... 77

Avenue ................100

Bark of .............. 185

Care of $\ldots \ldots \ldots \ldots \ldots 31,114$

Collections ............24

Columnar ................ 99

Comparisons .............191

Cultivation for ...........115

Dehorning .............134

Distance between ........ 78

Distribution of $\ldots \ldots \ldots \ldots 191$

Ecology of ............ 19

Fertilizers for ...........115

For calcareous soils .......101

For dry conditions ........100

For limestone soils .........101
Trees (Continued)

For seaside planting ......100

For special purposes ...... 96

For wet soils ...........101

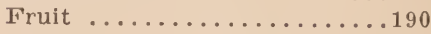

Function of $\ldots \ldots \ldots \ldots \ldots 71$

Growth of $\ldots \ldots \ldots \ldots \ldots . \ldots 31$

Guarding young .........110

Habit of $\ldots \ldots \ldots \ldots \ldots \ldots 183$

Heeling in .............102

Identification .........11, 183

In home decorātion ....... 71

Leaf-scars ..............187

Life of ................ 31

Measurement of $\ldots \ldots \ldots \ldots 20$

Moving of ...............

Names of ..............

Of rapid growth ........ so

Ordering of ............102

Parts, description of ...... 31

Photography .......... 18

Planting of $\ldots \ldots \ldots 31,102,105$

In cities $\ldots \ldots \ldots \ldots \ldots \ldots 75$

In rural districts $\ldots \ldots \ldots 61$

In towns $\ldots \ldots \ldots \ldots \ldots 75$

Making the holes for .....107

Parking strips ......... 78

Puddling ................102

Pyramidal .............. 99

Renovation of ..........133

Reproduction of ........4 45

Resistant to smoke .......100

Setting of $\ldots \ldots \ldots \ldots \ldots \ldots 106$

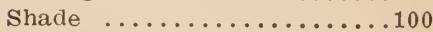

Species for city streets .... 80

Stem of $\ldots \ldots \ldots \ldots \ldots \ldots 38$

Structure of $\ldots \ldots \ldots \ldots \ldots 31$

Study ................ 11

Study in colleges ........25

Study in graded schools .... 29

Study in high schools .....2 25

Study in relation to art .... 13

Study in relation to poetry 13

Surgery ..........134, 140

Tall ................ 99

Twigs $\ldots \ldots \ldots \ldots \ldots \ldots \ldots 187$

Valued for winter effect .... 98

Weeping ............. 99

With brilliant autumnal tints $9 \mathrm{~s}$

With showy flowers ......92

With showy fruits ....... 97

With striking colored foliage 98

Wood of ................ 191

Tsuga canadensis ........238

Tulip Tree ..........27, 45

$66,79,81,110,133,153,338, \mathbf{3 1 0}$

Scale .........167, 168, 169

Tupelo ......183, 184, 187, 420

Tussock MIoth ........151, 163 
Twigs of Tree ............187

Ulmus ...............206

alata ................328

americana $\ldots \ldots \ldots \ldots \ldots .326$

campestris ...........324

fulva ................322

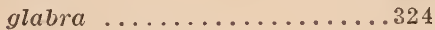

Key to Species .........206

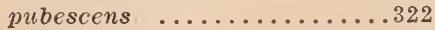

racemosa ..............32s

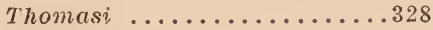

Umbrella Tree.........336, 338

Large-leaved ............207

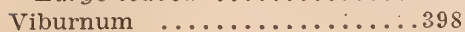

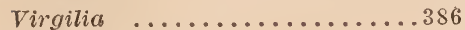

Vitality of seeds .......... 49

Walnut .............48, 268 Black ....49, 51, 264, 266, 390 White ................264

Water:

Beech ................278

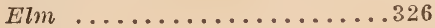

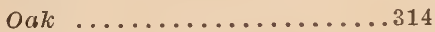

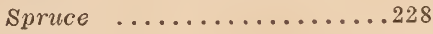

Western:

Catalpa ................428

Mountain Ash ............354

Weymouth Pine ...........210

Whistlewood ................398

White:

Ash $66,79,81,110,186,188192$, $193,272,340,408,422,424,426$ Birch ........72, 92, 286, 288 Cedar ..............240, 242 Elm .......666, 78, 80, 81 $96,172,184,322,324, \mathbf{3 2 6}, 328$

Fir ................ 98

Holly .................. 396

Locust ................388

Maple ...........404, 406

\section{White (Continued)}

Mulberry .........332, 334

Oak ......33, 48, $78,81,122$ $186, \mathbf{2 9 8}, 300,302,304,310,312$ Oak Group 186, 201, 298, 308, 310 Pine .......36, 45, 48, 66, 67 $74,134, \mathbf{2 1 0}, 212,216,220,236$ Poplar ................252 Spruce .......166, 224, 226 Thorn ................360

Walnut ...............264

White-heart Hickory .......270

White-marked Tussock Moth ...165 Whitewood ...........340, 416 Wild:

Black Cherry ..362, 364, 366, 370 Plum ...................... 376 Red Cherry .....364, 366, 370

Willow ......41, 45, 48, 50, 53 $110,122,131,132,134,162,250$ Black ..............250 European Weeping .......250

European White ..........250

Yellow ...............

Winged Elm .............32s

Witch Hazel ............34t

Witches' Brooms ............358

Wood of Trees .............191

Woolly Maple Scale .....167, 169

Work in Field ...........26

Wounds, eare of $\ldots \ldots \ldots \ldots 122$

Yellow :

Birch ....186, 280, 282, 284, 28s

Locust .....................

oak ...................306, 318

Pine .................212

Poplar .................340

Willow .............250

Yellow Wood ..............356

Yellow-barked Oak ..........318

Zanthoxylon americanum .....3ss

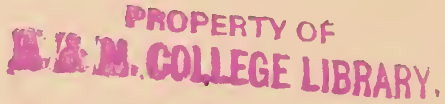







